THE

EVOLUTION OF MAN

ERNST HAECKEL 

1816

$v^{3} d v^{3}$

Lit $+2=$

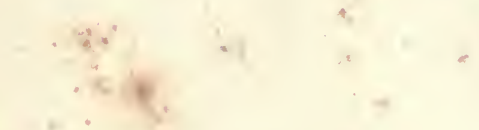




$$
+2+
$$

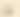

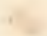

.

$y^{2}+$

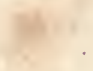

,
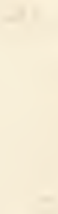

-

?" 


\section{THE EVOLUTION OF MAN.}


By the same Author.

THE HISTORY OF CREATION. Translation revised by Professor E. RAY Lankester, M.A., F.R.S. With Coloured Plates and Genealogical Trees of the various groups of both Plants and Animals. 2 vols. Second Edition. Post 8vo., cloth, 32s.

a VISIT TO CFYLON. Translated by Clara Bell. Post 8vo., cloth, 7s. 6d.

FREEDOM IN SCIENCE AND TEACHING. A Reply to Professor Virchow on the Freedom of Science in the Modern State. Authorised Translation, with Introduction by Professor Huxley. Crown 8vo., cloth, $5 s$.

London: Kegan Paul, Trench \& Co. 

DEVELopaENT OF 'THE FACE (Thirn Stage). IXILANATION OF CHAP, XXI.

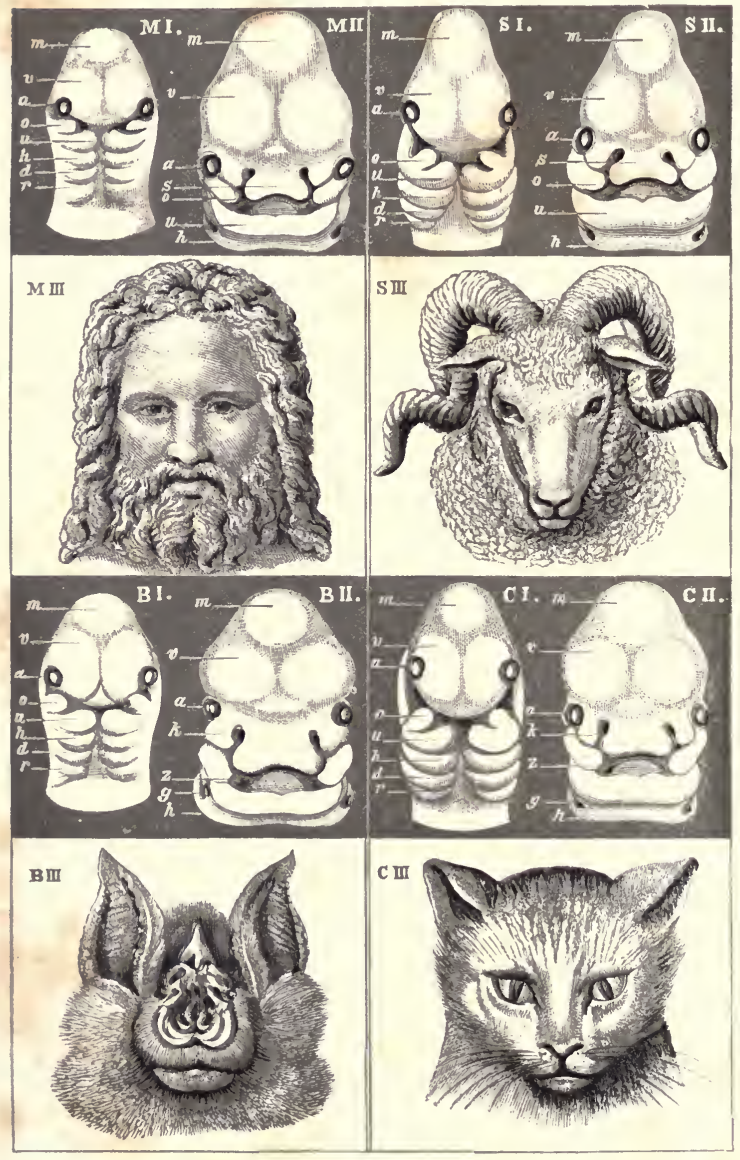

M. Man.

B. Bat.

S. Sheep.

c. Cat. 


\section{EVOLUTION OF MAN :}

A POPULAR EXPOSITION OF THE PRINCIPAL POINTS OF HUMAN ONTOGENY AND PHYLOGENY.

FROM THE GERMAN OF

ER N T H A E K E, PROFESSOR IN THE UNIVERSITY OF JENA, AUTHOR OF "THE HISTOEY OF CBEATION," ETO.

IN TWO VOLUMES.

VOL. I.

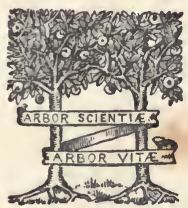

LONDON:

KEGAN PAUL, TRENCH \& CO., 1, PATERNOSTER SQUARE. 1883.

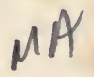


(The rights of translation and of reproduction are reserved.) 


\section{CONTENTS OF VOL. I.}

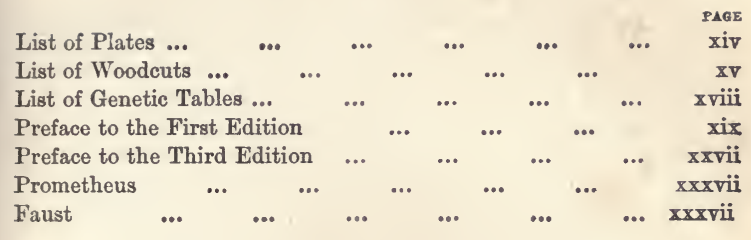

\section{CHAPTER I.}

\section{THE FUNDAMENTAL LAW OF THE EVOLUTION OF ORGANISMS.}

General Significance of the History of the Evolution of Man.-Ignorance of it among the so-called Educated Classes.-The Two Branches of the History of Evolution.-Ontogeny, or the History of Germs (Embryos), and Phylogeny, or the History of Descent (or of the Tribes).-Causal Connection between the Two Series of Evolution.-The Evolution of the Tribe determines the Evolution of the Germ.-Ontogeny as an Epitome or Recapitulation of Phy. logeny. The Incompleteness of this Epitome.-The Fundamental Law of Biogeny.-Heredity and Adaptation are the two Formative Functions, or the two Mechanical Causes, of Evolution.-Absence of Purposive Causes.-Validity of Mechanical Causes only.-Substitution of the Monistic or Unitary for the Dualistic or Binary Cosmology.-Radical Importance of the Facts of Embryology to Monistic Philosophy. - Palingenesis, or Derived History, and Kenogenesis, or Vitiated History.-History of the Evolution of Forms and Fanctions.-Necessary Connection between Physiogeny and 
Morphogeny.-The History of Evolution as yet almost entirely the Prodnct of Morphology, and not of Physiology.-The History of the Erolntion of the Central Nervous System (Brain and Spinal Marrow) is involved in that of the Psychic Activities, or the Mind

\section{CHAPTER II.}

\section{THE EARLIER HISTORY OF ONTOGENY.}

\section{Caspar friedrich Woltr.}

The Evolution of Animals as known to Aristotle.-His Knowledge of the Ontogeny of the Lower Animals.-Stationary Condition of the Scientifio Study of Natare dnring the Christian Middle AgesFirst Awakening of Ontogeny in the Beginning of the Seventeenth Century.-Fabricius ab Aquapendente.-Harvey.-Marcello Malpighi.-Importance of the Incubated Chick.-The Theories of Preformation and Encasement (Evolntion and Pre-delineation).Theories of :Male and Female Encasement.-Either the Spermanimal or the Egg as the Pre-forned Individual.-Animalculists : Leeuwenhoek, Hartsoeker, Spallanzani.-Orulists : Haller, Leibnitz, Bonnet.-Victory of the Theory of Erolution owing to the Authority of Haller and Leibnitz.-Caspar Friedrich Wolff.-His Fate and Works.-The Theoria Generationis.-Re-formation, or Epigenesis.-The History of the Evolution of the Intestinal Canal. -The Foundations of the Theory of Germ-layers (Four Layers, or Leaves).-The Metamorphosis of Plants.-The Germs of the Cellular Theory.-Wolff's Monistic Philosophy ...

\section{CHAPTER III.}

\section{MODERN ONTOGENY.}

\section{Karl Ernst Baer.}

Karl Ernst Baer, the Principal Disciple of Wolff.-The Würzbarg School of Embryologists : Döllinger, Pander, Baer.-Pander's Theory of Germ-layers. - Its Full Development by Baer.-The Disc-shaped first parts into Two Germ-layers, each of which again divides into Two Strata. The Skin or Flesh-stratum arises from the Outer or Animal Germ-layer. The Vascular or Mucous Stratum arises from the Inner or Vegetative Germ-layer. The Significance of the Germ-layers. - The Modification of the Layers into Tubes.-Baer's Discovery of the Human Egg, the Germ-vesicle, and Chorda Dor- 
salis.-The Four Types of Evolntion in the Four Main Groups of the Animal Kingdom.-Baer's Law of the Type of Evolution and the Degree of Perfection.-Explanation of this Law by the Theory of Selection.-Baer's Successors: Rathke, Johannes Müller, Bischoff, Kölliker.-The Cell Theory : Schleiden, Schwann.-Its Application to Ontogeny : Robert Remak.-Retrogressions in Ontogeny : Reichert and His.-Extension of the Domain of Ontogeny : Darwin

\section{CHAPTER IV.}

\section{THE EARLIER HISTORY OF PHYLOGENY.}

\section{Jean Lamarck.}

Phylogeny before Darwin.-Origin of Species.-Karl Linnæus' Idea of Species, and Assent to Moses' Biblical History of Creation.-The Delnge.-Palæontology.-George Cuvier's Theory of Catastrophes. -Repeated Terrestrial Revolutions, and New Creations.-Lyell's Theory of Continuity.-The Natural Canses of the Constant Modification of the Earth.-Supernatural Origin of Organisms.Immanuel Kant's Dualistic Philosophy of Nature.-Jean Lamarck. - Monistic Philosophy of Nature.-The Story of his Life.-His Philosophie Zoologique.-First Scientific Statement of the Doctrine of Descent.-Modification of Organs by Practice and Habit, in Conjunction with Heredity.-Application of the Theory to Man.Descent of Man from the Ape.-Wolfgang Goethe.-His Studies in Natural Science.-His Morphology.-His Studies of the "Formation and Transformation of Organisms."-Goethe's Theory of the Tendency to Specifio Differences (Heredity) and of Metamorphosis (Adaptation)

\section{CHAPTER V. \\ MODERN PHYLOGENY.}

\section{Charles Darwin.}

Relation of Modern to Earlier Phylogeny.-Charles Darwin's Work on the Origin of Species.-Causes of its Remarkable Success.-The Theory of Selection : the Interrelation of Hereditary Transmission and Adaptation in the Struggle for Existence.-Darwin's Life and Voyage Round the World-His Grandfather, Erasmus Darwin.Charles Darwin's Study of Domestic Animals and Plants.-Com. 
parison of Artificial with Natural Conditions of Breeding.-The Struggle for Existence.-Necessary Application of the Theory of Descent to Man.-Descent of Man from the Ape.- Thomas Haxley.- Karl Vogt.-Friedrich Rolle.-The Pedigrees in the Generelle Morphologie and the "History of Creation."-The Genealogical Alternative.-The Descent of Man from Apes deduced from the Theory of Descent.-The Theory of Descent as the Greatest Inductive Law of Biology.-Foundation of this Induction.-Palæontology.-Comparative Anatomy.-The Theory of Rudimentary Organs.-Purposelessness, or Dysteleology.-Genealogy of the Natural System.-Chorology.-Ekology.-Ontogeny.-Refutation of the Dogma of Species.-The "Monograph on the Chalk Sponges ; "Analytic Evidence for the Theory of Descent ...

\section{CHAPTER VI.}

\section{THE EGG-CELL AND THE AMEBA.}

The Egg of Man and of other Animals is a Simple Cell.-Import and Essential Principles of the Cell Theory.-Protoplasm (Cell-sub. stance), and the Nucleus (Cell-kernel), as the Two Essential Constitnent Parts of every Genuine Cell.-The Undifferentiated Egg. cell, compared with a highly Differentiated Mind-cell or Nerve-cell of the Brain.-The Cell as an Elementary Organism, or an Individual of the First Order.-The Phenomena of its Life.-The Special Constitution of the Egg-cell.-Yelk.-The Germ-vesicle.The Germ-spot.-The Egg-membrane, or Chorion.-Application of the Fundamental Principle of Biogeny to the Egg.cell.-One-celled Organisms.-The Amœbr.-Organization and Vital Phenomena.Their Movements.-Amcoboid Cells in Many-celled Organisms.Movements of such Cells, and Absorption of Solid Matter.-Absorbent Blood Corpuscles.-Comparison of Amœba with Egg-cell.Amœboid Egg-cells of Sponges.-The Amoba as the Common Ancestral Form of Many-celled Organisms

\section{CHAPTER VII.}

\section{THE PROCESSES OF EVOLUTION AND IMPREGNATION.}

Development of the Many-celled from the One-celled Organism.-The Cell-hermit and the Cell-state.-The Principles of the Formation of the State.-The Differentiation of the Individnals as the 
Standard of Measurement for the Grade of the State.-Parallel between the Processes of Individnal and of Race Development.The Functions of Evolution.-Growth.-Inorganic and Organic Growth.-Simple and Complex Growth.-Nourishment and Change of Substance.-Adaptation and Modification.-Reproduction.Asexual and Sexual Reproduction.-Heredity.-Division of Labonr, or Differentiation.-Atavism, or Reversion.-Coalescence.-The Functions of Evolution as yet very little studied by Physiology, and hence the Evolutionary Process has often been misjudged.The Evolution of Consciousness, and the Limits to the Knowledge of Nature.-Fitful and Gradual Evolntion.-Fertilization.-Sexnal Generation.-The Egg-cell and the Sperm-cell.-Theory of the Sperm-animals.-Sperm-cells a form of Whip-cell.-Union of the Male Sperm-cell with the Female Egg-cell. - The Product of this is the Parent-cell, or Cytula. -Nature of the Process of Fertilization. -Relation of the Kernel (Nucleus) to this Process.-Disappearance of the Germ-vesicle.-Monerula.-Reversion to the Moneraform.-The Cytula...

...

$\cdots$

... 148

\section{CHAPTER VIII.}

\section{EGG-CLEAVAGE AND THE FORMATION OF THE GERM-LAYERS.}

First Processes after the Fertilization of the Egg-cell is complete.Original or Palingenetio Form of Egg-cleavage.-Significance of the Cleavage-process.-Mulberry-germ, or Morula.Germ-vesicle, or Blastula Germ-membrane, or Blastoderm. - Inversion (Invagination) of the Germ-vesicle.-Formation of the Gastrula.Primitive Intestine and Primitive Mouth.-The Two Primary Germ-layers; Exoderm and Entoderm.-Kenogenetic Form of Eggcleavage.-Unequal Cleavage (segmentatio inequalis) and Hoodgastrnla (Amphigastrula) of Amphibia and Mammalia.-Total and Partial Cleavage.-Holoblastic and Meroblastio Eggs.-Discoidal Cleavage (segmentatio discoidalis) and Disc-gastrula (Discogastrula) of Fishes, Reptiles, Birds.-Superficial Cleavage (segmentatio superficialis) and Vesicular Gastrula (Peri-Gastrula) of Articulates (Arthropoda).-Permanent Two-layered Body-form of Lower Animals.-The Two-layered Primæval Parent-form; Gastræa.Homology of the Two Primary Germ-layers in all Intestinal Animals (Metazoa).-Significance of the Two Primary Germlayers.-Origin and Significance of the Four Secondary Gern. layers.-The Exoderm or Skin-layer gives rise to the Skin-sensory 
Layer and the Skin-fibrous Layer.-The Entoderm or Intestinal PAGR Layer gives rise to the Intestinal-fibrous Layer and the Intestinal-

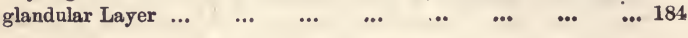

\section{CHAPTER IX.}

\section{THE VERTEBRATE NATURE OF MAN.}

Relation of Comparative Anatomy to Classification.-The Family-relationship of the Types of the Animal Kingdom.-Different Significance and Unequal Value of the Seven Animal Types.-The Gastroea Theory, and the Phylogenetio Classification of the Animal Kingdom.-Descent of the Gastræa from the Protozoa.-Descent of Plant-animals and Worms from the Gastræa.-Descent of the Four Higher Classes of Animals from Worms.-The Verte. brate Natare of Man.-Essential and Unessential Parts of the Vertebral Organism. - The Amphioxus, or Lancelet, and the Ideal Primitive Vertebrate in Longitndinal and Transverse Sections.The Notochord.-The Dorsal Half and the Ventral Half.-The Spinal Canal.-The Fleshy Covering of the Body.-The Leatherskin (corium).-The Outer-skin (epidermis).-Body-cavity (cceloma). -The Intestinal Tube.-The Gill-openings.-The Lymph-vessels. -The Blood-ressels.-The Primitive Kidneys and Organs of Re. production.-The Products of the Four Secondary Germ-layers ... 244

\section{CHAPTER X.}

\section{THE CONSTRUCTION OF THE BODY FROM THE GERM.} LAYERS.

The Original (Palingenetic) Development of the Vertebrate Body from the Gastrula.-Relation of this Process to the Later (Kenogenetic) Germination, as it occurs in Mammals.-The most important act in the Formation of the Vertebrate.-The Primary Germ-layers, and also the Secondary Germ-layers, which arise by Fission of the Primaries, originally form Closed Tubes.-Contemporaneously with the Completion of the Yelk-sac, the Germ-layers flatten, and only later again assume a Tabular Form.-Origin of the Disc-shaped Mammalian Germ-area. - Light Germ-area (area pellucida) and Dark Germ. area (area opaca).-The Oval Germ-shield, which afterwards assumes the Shape of the Sole of a Shoe, appears in the Centre of the Light Germ-area (a. pellucida).-The Primitive Streak 
separates the Germ-shield into a Right and Left Half.-Below the Dorsal Furrow the Central Germ-layer parts into the Notochord and the Two Side-layers.-The Side-layers split borizontally into Two Layers: The Skin-fibrous Layer and the Intestinal-fibrons Layer.-The Primary Vertebral Cords separate from the Sidelayers.-The Skin-sensory Layer separates into Three Parts: the Horny Layer, Spinal Canal, and Primitive Kidney.-Formation of the Cœlom and the First Arteries.-The Intestinal Canal proceeds from the Intestinal Furrow.-The Embryo separates from the Germ. vesicle.-Around it is formed the Amnion-fold, which coalesces over the back of the Embryo, so as to form a Closed Sac.-The Amnion.-The Amnion-water.-The Yelk-sac, or Navel-vesicle.The Closing of the Intestinal and Ventral Walls occasions the Formation of the Navel.-The Dorsal and Ventral Walls

\section{CHAPTER XI.}

\section{GENERAL STRUCTURE AND ARTICULATION OF THE INDIVIDUAL.}

Essential Agreement between the Chief Palingenetic Germ Processes in the case of Man and in that of other Vertebrates.-The Hnmar. Body, like that of all Higher Animals, develops from Two Primary and Four Secondary Germ-layers.-The Skin-sensory Layer forms the Horn-plate, the Medullary Tube, and the Primitive Kidneys.-The Middle Layer (Mesoderm) breaks up into the Central Notochord, the Two Primitive Vertebral Cords, and the Two Side-layers.The latter split up into the Skin-fibrous Layer and the Intestinalfibrons Layer.-The Intestinal-glandular Layer forms the Epithelium of the Intestinal Caral, and of all its Appendages.-Ontogenetio and Phylogenetic Fission of the Germ-layers.-Formation of the Intestinal Canal.-The Two-layered Globular Intestinal Germ-vesicle of Mammals represents the Primitive Intestine.Head Intestinal Cavity, and Pelvic Intestinal Cavity.-Month Groove and Anal Groove.-Secondary Formation of Month and Anus.-Intestinal Navel and Skin-navel--Movement of the Primitive Kidneys from the Outside to the Inside.-Separation of the Brain and Spinal Marrow.-Rudiments of the Brain-bladders. The Articulation or Metamerio Structure of the Body.-The Primitive Vertebræ (Trunk-Segments, or Metamera).-The Construction and Origin of the Vertebral Column.-Vertebral Bodies and Vertebral Arches.-Skeleton-plate and Mnscle-plate.-Forma- 
tion of the Skull from the Head-plates.-Gill-openings and Gillarches.-Sense-organs,-Limbs.-The Two Front Limbs and the

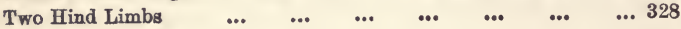

\section{CHAPTER XII.}

\section{THE GERM-MEMBRANES AND THE FIRST CIRCULATION OF THE BLOOD.}

The Mammalian Organization of Man.-Man has the same Bodily Structure as all other Mammals, and his Enibryo develops in exactly the same way.-In its Later Stages the Human Embryo is not essentially different from those of the Higher Mammals, and in its Earlier Stages not even from those of all Higher Vertebrates.The Law of the Ontogenetic Connection of Systematically Related Forms.-Application of this Law to Man.-Form and Size of the Human Embryo in the First Four Weeks.-The Human Embryo in the First Month of its Development is formed exactly like that of any other Mammal.-In the Second Month the First Noticeable Differences appear.-At first, the Human Embryo resembles those of all other Mammals ; later, it resembles only those of the Higher Mammals.-The Appendages and Membranes of the Human Embryo.-The Yelk-sac.-The Allantois and the Placenta.-The Amnion.-The Heart, the First Blood-vessels, and the First Blood, arise from the Intestinal-fibrous Layer.-The Heart separates itself from the Wall of the Anterior Intestine.-The First Circulation of the Blood in the Germ-area (a. germinativa) : Yelkarteries and Yelk-veins.-Second Embryonic Circulation of the Blood, in the Allantois : Navel-arteries and Navel-veins.-Divisions

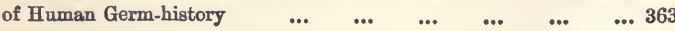

\section{CHAPTER XIII.}

\section{THE STRUCTURE OF THE BODY OF THE AMPHIOXUS AND OF THE ASCIDIAN.}

Causal Significance of the Fundamental Law of Biogeny.-Influence of Shortened and Vitiated Heredity.-Kenogenetic Modification of Palingenesis. - The Method of Phylogeny based on the Method of Geology.- Hypothetic Completion of the Connected Evolntionary Series by Apposition of the Actual Fragments.-Phylogenetic Hypotheses are Reliable and Justified.-Importance of the Amphi. 
oxns and the Ascidian.-Natural History and Anatomy of the

Amphioxus.-External Structure of the Body.-Skin-covering.Outer-skin (Epidermis) and Leather-skin (Corium).-Notochord.Medullary Tube.-Organs of Sense.-Intestine with an Anterior Respiratory Portion (Gill-intestine) and a Posterior Digestive Portion (Stomach-intestine).-Liver.-Pulsating Blood-vessels.Dorsal Vessel over the Intestine (Gill-vein and Aorta).-Ventral Vessel under the Intestine (Intestinal Vein and Gill-artery).Movement of the Blood.-Lymph-vessels.-Ventral Canals and Side Canals - Body-cavity and Gill-cavity. - Gill-covering. Kidneys. - Sexnal Organs.-Testes and Ovaries. - Vertebrate Nature of Amphioxus.-Comparison of Amphioxus and Young Lamprey (Petromyzon).-Comparison of Amphioxus and Ascidian. -Cellulose Tunic.-Gill-sac.-Intestine.-Nerve-centres.-Heart.

-Sexual Organs

\section{CHAPTER XIV.}

\section{GERM-HISTORY OF THE AMPHIOXUS AND OF THE ASCIDIAN.}

Relationship of the Vertebrates and Invertebrates.-Fertilization of the Amphioxus.-The Egg nndergoes Total Cleavage, and changes into a Spherical Germ-membrane Vesicle (Blastula).-From this the Intestinal Larva, or Gastrula, originates by Inversion.-The Gastrula of the Amphioxus forms a Medullary Tube from a Dorsal Furrow, and between, this and the Intestinal Tube, a Notochord: on both Sides the latter is a Series of Muscle-plates; the Matemera. -Fate of the Four Secondary Germ-layers.-The Intestinal Canal divides into an Anterior Gill-intestine, and a Posterior Stomachintestine.-Blood-vessels and an Intestinal-mnscle Wall originate from the Intestinal-fibrons Layer.-A Pair of Skin-folds (Gill. roofs) grow ont from the Side-wall of the Body, and, by Coalescence, form the Ventral Side of the Large Gill-cavity.-The Ontogeny of the Ascidian is, at first, identical with that of the Amphioxns.-The same Gastrula is Developed, which forms a Notochord between the Mednllary and Intestinal Tubes.Retrogressive Development of the same.-The Tail with the Notochord is shed.-The Ascidian attaches itself firmly, and envelops itself in its Cellulose Tunic.-Appendicularia, a Tunicate which remains thronghont Life in the Stage of the Larval Ascidian and retains the Tail-fin with the Chorda (Chordonia).-General Comparison and Significance of the Amphioxus and the Ascidian 


\section{LIST OF PLATES.}

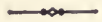

Plate I. (Frontispiece). Development of the face in Mammals (Man, Bat, Cat, Sheep) in three different stages

Explanation vol. $\ddot{i}$.

346

Plate II. (between p. 240 and p. 241). Total egg-cleavage. Gastrulation of holoblastic eggs (primordial and unequal cleavage) Explanation

Plate III. (between p. 240 and p. 241). Partial egg-cleavage. Gastrulation of meroblastic eggs (discoidal and superficial

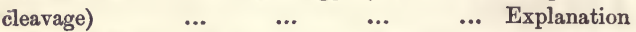

Plate IV. (between p. 320 and p. 321). Diagrammatic transverse section through various ontogenetic and phylogenetic stages in the development of the human body, showing the formation of this from the four secondary germ-layers ... Explanation 321

Plates V. (between p. 320 and p. 321). Diagrammatic longitudinal sections through various germ and tribal forms of Man, showing their formation from the four secondary germ-layers

Explanation

Plate VI. (between p. 362 and p. 363). Comparison of the embryos of a Fish, an Amphibian, a Reptile, and a Bird, in three different stages of evolution ... $\quad$... $\quad$ Explanation

Plate VII. (between p. 362 and p. 363). Comparison of the embryos of four different Mammals (Pig, Ox, Rabbit, and Man) in three different stages of evolution ... Explanation

Plate VIII. (between p. 404 and p. 405). Representation of two human embryos, the one of nine, the other of twelve weeks : the latter within the egg-membranes _.. Explanation

Plate IX. (between p. 404 and p. 405). Representation of a human embryo of five months, natural size, within the eggmembranes

... Explanation

Plate X. (between p. 438 and p. 439). Germ-history of Ascidian

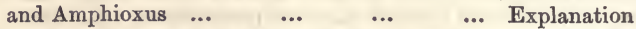

Plate XI. (between p. 438 and p. 439). Structure of the body of Ascidian, Amphioxus, and larva of Petromyzon 


\section{LIST OF WOODCUTS.}

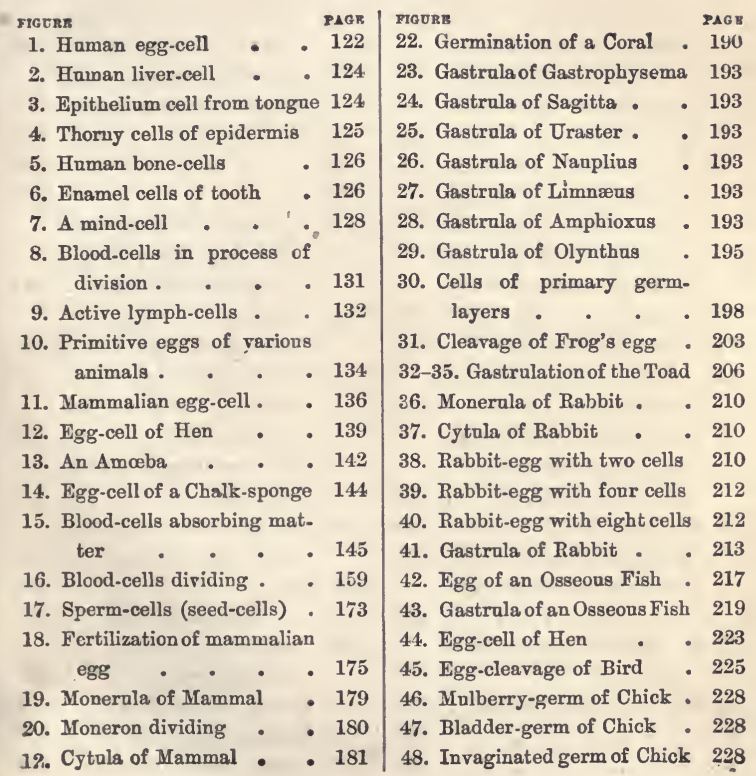


49. Gastrnla of Chick

50,51 . Four secondary germlayers . . .

52-56. Diagrammatic longita. dinal and transverse sections through the ideal Primitive Vertebrate .

\section{7, 58.}

59.

60.

61.

62-69. Diagrammatic transverse sections throngh the mostimportant germforms of the ideal Primitive Vertebrate . .

70. Diagrammatic transverse sections through various mammalian germs (explaining the separation of the intestine from the yelk-sac). . . . 283

71. Gastrula of Mammal . 288

72. Intestinal germ-vesicle of Mammal

73. Transverse section throngh the intestinal germ. vesicle of Mammal

74. Exoderm-cells of the above

75. Entoderm-cells of the above

76. Transverse section through germ-area . . . 293

77-81. Intestinal germ-vesicle

294

82, 83. Germ-area of Rabbit . 81.

85.

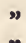

"

s

259

263

264

267

276
236

256

98.

99.

100. Separation of the intestine from the yelk-sac (diagrammatic) . 333

101. Longitudinal section

through embryo Chick . 336

102. Longitndinal section

through head of an embryo Chick . .

103-105. Lyre-shaped Chick embryo - . $\quad 342$

106,107 . Germ-diso or germarea of Rabbit . . 344 $108,109 . \quad$, " 345 110, 111. Skeleton of Man . 351 112. Transverse section throngh germ of Chick . 352 113. Human neck-vertebra . 354 297 114. Human chest-vertebra . 354 298 115. Human lumbar.vertebra. 354 


\begin{tabular}{lccc} 
& \multicolumn{2}{c}{ PAGE } \\
Chick - & - & - & 356
\end{tabular}

118. Head of embryo Dog 356

119. Rndiments of the limbs . 357

120.

$$
\text { " " }
$$

121. Lyre-shaped germ of Dog

122. Human germs from the second to the fifteenth week . . . . 368

123,124 . Anatomy of buman germs (four and five weeks). . . . 370

125. Head of Nose-ape . . 374 126. Head of Julia Pastrana . 374 127-131. Human eggs and germs from second to sixteenth weeks . $\quad 376$

132, 133. " $" \quad 377$ 134. " " $\quad 378$

135. Chick germ with allantois 380 136. Dog germ with allantois . 381 137. "

" 382

138. Pregnant human ateras with egg - membranes and navel-cord
FIकU KE

139. Development of egg-mem. branes . . . . 385

140. Development of amnion . 387 141. 388

142.

$$
\text { " }
$$
389

143, 144. Development of heart 392 $145,146$. 393 147.

148. First circulation of the

blood . • • . 396 150. " " $" 398$

151. Amphioxus lanceolatus . 420 152. Transverse section through Amphioxns - 424

153. An Ascidian . . . 431

154. Another Ascidian . . 434

155. Gastrula of Amphioxus . 444

156. Gastrula of Sponge - 445

157. Transverse section

through Amphioxus larva 4.17

158-160. " $\quad$ " 452

161. Transverse section through Vertebrate . 457

384 162. Appendicularia • . 459 


\section{LIST OF GENETIC TABLES.}

I. Systematic Survey of the main branches of Biogeny ...

II. Systematic Survey of the constituent parts of the onecelled germ-form before and after fertilization ...

III. Systematic Survey of the most important difierences in the egg-cleavage and gastrulation of animals

IV. Systematic Survey of the five first germinal stages of animals, with reference to the four main forms of

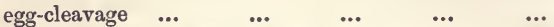

V. Systematic Survey of some of the most important observations in the rhythm of egg-cleavage $\quad \ldots \quad \quad \ldots$

VI. Systematic Survey of some of the most important organs of the ideal Primitive Vertebrates, and their development from the germ-layers ... ... ...

VII. Systematic Survey of the development of the human organ-systems from the germ-layers $\quad . . \quad \ldots$

VIII. Systematic Survey of the most important section of human germ-history $\quad \ldots \quad \quad \ldots \quad \quad \ldots \quad \quad \ldots$

IX. Systematic Survey of the most important homologies between the embryo of Man, and the embryo of the Ascidian and the Amphioxus in a corresponding stage of development, on the one hand, and the developed Man on the other ... ... ...

X. Systematic Survey of the relationship in form of the Ascidian and Amphioxus on the one hand, of the Fish and Man on the other, in a fully developed condition 


\section{PREFACE TO THE FIRST EDITION.}

These chapters on Anthropogeny are the first attempt to render the facts of human germ-history accessible to a wider circle of educated people, and to explain these facts by human tribal history. I have not overlooked the great difficulty and danger involved in thus entering for the first time on ground which is so especially full of risks. No other branch of natural science yet remains so exclusively confined to its own technical students; no other branch has been so wilfully obscured and mystified, by priestly influence, as has the germ-history of Man. If, even now, we say that each human individual develops from an egg, the only answer, even of most so-called educated men, will be an incredulous smile; if we show them the series of embryonic forms developed from this human egg, their doubt will, as a rule, change into disgust. Few educated men have any suspicion of the fact, that these human embryos conceal a greater wealth of important truths, and form a more abundant source of knowledge than is afforded by the whole mass of most other sciences and of all so-called "revelations." 
state has now at last begun in earnest the "struggle for culture." In this spiritual warfare, which now moves all thinking humanity, and which prepares the way for a future existence more worthy of man, spiritual freedom and truth, reason and culture, evolution and progress stand on the one side, marshalled under the bright banner of science; on the other side, marshalled under the black flag of hierarchy, stand spiritual servitude and falsehood, want of reason and barbarism, superstition and retrogression. The trumpet of this gigantic spiritual warfare marks the dawn of a new day and the end of the long darkness of the Middle Ages. For modern civilization, in spite of the progress of culture, lies bound in the fetters of the hierarchy of the Middle Ages; and social and civil life is ruled, not by the science of truth, but by the faith of the church. We need but mention the mighty influence which irrational dogmas still exercise on the elementary education of our youth; we need but mention that the state yet permits the existence of cloisters and of celibacy, the most immoral and baneful ordinances of the "onlysaving" church; we need but mention that the cirilized state yet divides the most important parts of the civil year in accordance with church festivals; that in many countries it allows public order to be disturbed by church processions, and so on. We do indeed now enjoy the unusual pleasure of seeing "most Christian bishops" and Jesuits exiled and imprisoned for their disobedience to the laws of the state. But this same state, till very recently, harboured and cherished these most dangerous enemies of reason.

In this mighty "war of culture," affecting as it does 
the whole history of the World, and in which we may well deem it an honour to take part, no better ally than Anthropogeny can, it seems to me, be brought to the assistance of struggling truth. The history of evolution is the heavy artillery in the struggle for truth. Whole ranks of dualistic sophisms fall before the monistic philosophy, as before the chain shot of artillery, and the proud structure of the Roman hierarchy, that mighty stronghold of infallible dogmatism, falls like a house of cards. Whole libraries of church wisdom and false philosophy melt away as soon as they are seen in the light afforded by the history of evolution. The church militant itself furnishes the most striking evidences of this, for it never ceases to give the lie to the plain facts of human germ-history, condemning them as "diabolical inventions of materialism." In so doing it gives the most brilliant witness that it recognizes as unaroidable the conclusions which we have drawn from these facts as to tribal history, as to the true causes of these facts.

In order to render these little known facts of germhistory and their causal explanation by tribal history accessible to as wide a circle of educated readers as possible, I have followed the same course as that which I adopted, six years ago, in my "Natural History of Creation," of which the "Anthropogeny" forms a second, more detailed part. In the summer of 1873 I had the academical lectures, on the outlines of the history of human evolution, which I have delivered during the last twelve years in Jena before a mixed audience of students of all faculties, taken down in shorthand by two of that audience, Messrs. Kiessling and Schlawe. The task I

VOL. $\mathrm{I}$. 
undertook in publishing these was indeed much harder than that incurred in the "Natural History of Creation;" for while the latter passed lightly through the widest circle of biological phenomena, and touched only on the most interesting points, I was obliged, in the "History of the Evolution of Man," to exhibit a much more limited series of phenomena in their proper connection, of which, indeed, each individual one is interesting in its proper place, although they are of very various degrees of interest. Moreover, the comprehension of form-phenomena, with which human germ-history deals, is among the most difficult of morphological tasks; the academical lectures on the bistory of human evolution are rightly considered even by medical men, who are previously acquainted with the anatomical features of the human body, as the most difficult to understand. I saw, therefore, that, if I desired to make the road into this dark region, entirely closed as yet to most men, really accessible to the educated laity, I must, on the one hand, limit myself as far as possible in my selection from the abundance of empiric matter, and yet, on the other hand, that I must be careful not to pass entirely over any essential part of this matter.

Although, therefore, I have throughout taken pains to present the scientific problem of Anthropogeny in as popular a form as possible, I do not imagine that I have completely accomplished this very difficult task. I shall, however, have gained my object if I succeed in affording educated persons an approximate conception of the most essential outlines of human germ-history, and in convincing them that the sole explanation and comprehension of the matter is afforded by the corresponding tribal 
history. Perhaps, at the same time, I may hope to convince some of those specialists, who deal indeed daily with the facts of germ-history, but who neither know nor wish to know anything about the true causes of these, which lie hid in tribal history. As this is quite the first attempt to present the Ontogeny and Phylogeny of man in their whole causal connection, I fear that, at best, the point at which I aim lies far beyond the point gained. But by this each thinking man will, it is to be hoped, be convinced that only by recognizing this connection does the history of human evolution become a science. Ontogeny can only be really understood through Phylogeny. The history of the tribe lays bare the true causes of the history of the germ.

Eravit Heinrich Haecket.

Jena, July 13, 1874. 



\section{PREFACE TO THE THIRD EDITION.}

When, two years ago, I published the first edition of the "History of the Evolution of Man," and this was followed, a few months later, by an unaltered second edition, I was fully conscious of the hazard involved in so doing, and was prepared to meet with numerous attacks. These were not slow to come; and if I were now obliged to answer all my opponents, this third edition might easily be doubled in size. I think, however, that I may satisfy myself with but a few remarks.

The great majority of my opponents are determined enemies of the Doctrine of Descent, who altogether deny a natural evolution of organic nature, and who can only explain both the origin of man and that of animal and plant species with the help of miracles, by supernatural creative acts. These adherents of the Creation Theory I need not answer; for Anthropogeny, as the special application of the Theory of Descent to Man, naturally starts from the recognition of this latter theory: ten years ago, in my Generelle Morphologie, and again in the "Natural History of Creation," I explained my own conception of this in sufficient detail. 
I cannot, however, refrain from defending my standpoint against those naturalists, who, taking their position indeed on the Theory of Descent and on Darwinism, yet combat my individual conception of this, and, especially, regard my application of the theory to Anthropogeny as erroneotis. Many of these naturalists, who were formerly determined opponents of the Theory of Descent, have recently passed over to Darwin's camp, merely in order not to stand entirely inactive at the barren standpoint offered by negation. Against two of these false Darwinists, Wilhelm His and Alexander Goette, I have defended myself in a special work on "The Aims and Methods of the Modern History of Evolution" ("Ziele und Wege der Heutigen Entwickelungsgeschichte." Jena, 1875). To that work I now refer. On the other hand, I have been forcibly attacked by naturalists who are really esteemed as wellknown and convinced adherents of the Theory of Evolution. Of these, Karl Vogt and Albert Kölliker require a few words of answer.

Vogt, whose many services in furthering Zoology I have always most readily acknowledged, ranked second to Huxley among those naturalists who, but a few years after the appearance of Darwin's "Origin of Species," attempted to apply the theory contained in that work to Man and represented this as necessary. He.afterwards, however, made no further progress in the same direction. While, as I am convinced, the mass of facts already accumulated in Comparative Anatomy, Ontogeny, Palæontology, and Systematic Zoology, is amply sufficient to afford the most general points on which to base the hypothetic human pedigree, Karl Vogt now holds opposed views, and entirely 
rejects the ancestral series as I have arranged it. He says: "We have been able to prove the assertion that Men and Apes must have originated from a common line;-more than this we have never asserted, and further back than this it is absolutely impossible to prove anything or even to show with any degree of probability more than that, at farthest, the higher Mammals may perhaps have developed from Pouched Animals (Marsupialia)." Against this view of Vogt's, I assert, that with the same logical "certainty or probability" the common descent of all Mammals from lower Vertebrates, primarily from Amphibia, less immediately from Fishes, may be "proved." With the same "certainty or probability"-I assert again -the descent of all these Skulled Animals (Craniota) from Skull-less forms (Acrania, allies of Amphioxus), the descent of these latter from Chorda Animals (Chordonia, forms allied to Ascidia), and the descent of these Chorda Animals from low Worms, "may be proved." With the same "certainty or probability"-I say finally-"we have been able to prove the assertion," that these Worms must, in their turn, have originated from a Gastræa (resembling the gastrula), and these Gastræads from a one-celled organism (resembling the undifferentiated Amœba). Proofs, as I believe, of these assertions are given in Chapters XIII.-XXV. of this edition.

The whole of this hypothetic pedigree Karl Vogt entirely rejects, without, however, substituting another. He especially denies our relationship with the Selachii and the Amphioxus, with the Ascidia and the Gastræa, although the. especially great phylogenetic significance of these instructive animal-forms is almost unanimously recognized by the 
first authorities in our science. Whilst Vogt completely opposes himself to these important views, which from day to day become more firmly established, he refers to Karl Semper, a "gifted" naturalist, who shares these views of Vogt's, and who derives Vertebrates from Ringed Worms (Annelida). I regret that I can make no use of this reference; nor do I find reason to answer Semper's polemic on "Haeckelism in Zoology" ("Haeckelismus in der Zoologie." Hamburg, 1876); for, apart from his defective education and his insufficient acquaintance with the whole subject of Zoology, this "gifted" zoologist is so much at variance with logic, as also with truth, that refutation seems superfluous. (Cf. vol. i. p. 91 and p. 426.) An example is sufficient to show this: In order to indicate the scientific value of "Haeckelism," and in order "to show that this tendency must continually diverge more and more widely from the really scientific study of nature," Semper brings forward the fact that, " according to Haeckel's own statement, Darwinism should be the religion of every naturalist." This last statement, which I consider absurd, is not mine, but that of my determined opponent, Professor Rütimeyer, and I quoted the sentence in the preface to the third edition of the "Natural History of Creation" merely to show the singular ground occupied by its author.

The wide cleft which separates my standpoint of the history of evolution and of natural science, as a whole, from that of Vogt and Semper cannot be better indicated than by our mutual position towards philosophy. Karl Vogt, like his friend Karl Semper, was a sworn contemner of all philosophy. The former seizes every opportunity to 
mock at philosophic tendencies and researches; and the latter knows no more severe charge to bring against me than that I seek to unite empiricism and philosophy, experience and idea, "observation and reflection." I am certainly firmly convinced that a really scientific study of nature can no more dispense with philosophic reflection, than can healthy philosophy ignore the results of natural scientific experience. "An exact empiricism," without those philosophic thoughts which combine and explain the raw material of facts, merely results in the accumulation of a lifeless store of knowledge; on the other hand, "speculative philosophy" which knows nothing of the firm basis afforded by natural scientific observation, can only produce transient cloud-pictures. The most intimate combination and blending of empiricism and philosophy can alone enable us to construct a permanent and sure scientific structure. I still hold as decidedly as ever the muchabused views which I expressed, ten years ago, about this matter in my Generelle Morphologie, and the fundamental ideas which $I$ have here reproduced.

Moreover, he must be very one-sided or short-sighted who does not recognize the natural approximation, which is now becoming more close in all branches of human knowledge, between experimental and reflective study. The enormous enlargement of the field of empiric knowledge which has been brought about by the progress of the last half-century, has resulted in a corresponding specialization of separate researches, and consequently in an isolation of diverging aims which cannot possibly continue to satisfy. All thoughtful observers feel, more acutely in consequence of this, that they must raise themselves from the wearisome 
task of accumulating dry details to wider views, and thus to gain sympathy with allied aims. On the other side, the sterility of such pure speculative philosophy as ignores all those enormous advances in empiric knowledge, has so forced its way into the consciousness of all sound thinkers, that they earnestly desire to fall back on the firm basis afforded by experimental science.

The ever-increasing flood of writings on natural philosophy, and essays on the relation of philosophy to natural science, plainly indicates the happy growth of this scientific unitary tendency. Nothing is more favourable to this, nothing better advances the combination of the various scientific lines, than the new theory of evolution. The extraordinary importance ascribed to this theory, rests especially on the fact that it supplies a philosophic central point, and just for this very reason it has in so short a time gained the active interest of all thoughtful minds. It raises us from a knowledge of facts to a knowledge of eauses, and thus affords a deeper satisfaction to the demand for causality innate in human reason than a mere experimental science could ever supply. When, therefore, Karl Vogt and many other naturalists entirely reject philosophy, and will not allow that it has any point of union with what is called "exact" natural science-they voluntarily renounce all the higher aims of investigation. (Cf. vol. ii. p. 387.)

Albert Kölliker occupies a similarly one-sided standpoint. This author, in the second edition of his "History of the Evolution of Man and the Higher Animals" ("Entwickelungsgeschichte des Menschen und der Höheren Thiere," 1876), in especially attacking the fundamental law 
of Biogeny, has impugned the very foundation on which Anthropogeny rests. Most of his objections are, it appears to me, refuted by the explanations which I have given in this third edition as to the very important relations of Palingenesis and Kenogenesis. (Compare especially Chapters I., VIII., and X.) Kölliker will not recognize the Gastræa Theory because he has been unable to discover a gastrula in Mammals and Birds. But his experiences are opposed to the most recent researches of Van Beneden and Rauber, of whom the former in the case of the Rabbit, the latter in the case of the Chick, describes a kenogenetic gastrula-form, which, in accordance with the Gastræa theory, may easily be referred to the palingenetic gastrula of the Amphioxus. Kölliker says finally: "As the last and most important argument, I bring forward the fact that Phylogeny as read by Darwin and Haeckel does not, it appears to me, represent the truth." This "most important argument" is a simple petitio principii. The sentence might as well be, "phylogeny is not true because it does not represent the truth."

How very different in other respects Kölliker's conception of the history of evolution is from mine is most clearly indicated in the "General Observations" (\$29) at the end of his book. The learned Würzburg anatomist there explains with reference to germ-history, his "essential agreement in fundamental conceptions" with the unlearned Leipzig anatomist Wilhelm His. I have explained the nature of these "mechanical fundamental conceptions" in Chapter XXIV. of this book (vol. ii. p. 352), and in greater detail in my work on "The Aims and Methods of the Modern History of Evolution" ("Ziele und Wege der 
Heutigen Entwickelungsgeschichte"). The celebrated theories of His, of which I have spoken as the "envelope theory," "gum-pouch theory," "waste-rag theory," etc., are the brilliant results of that "gifted" author's efforts and mathematical calculations. And yet many have allowed themselves to be dazzled by the "exact" appearance of his mathematical formulæ. The history of the evolution of organisms, equally with the history of human civilization, can never be the subject of "exact" investigation. The history of evolution is in its very nature an historic natural science, as is geology. To regard and treat these and other historic natural sciences as "exact" leads to the greatest errors. This is as true of germhistory (Ontogeny) as of tribal history (Phylogeny); for between the two there is the most intimate causal connection.

Many naturalists have especially blamed the diagrammatic figures given in the Anthropogeny. Certain technical embryologists have brought most severe accusations against me on this account, and have advised me to substitute a larger number of elaborated figures, as accurate as possible. I, however, consider that diagrams are much more instructive than such figures, especially in popular. scientific works. For each simple diagrammatic figure gives only those essential form-features which it is intended to explain, and omits all those unessential details which in finished, exact figures, generally rather disturb and confuse than instruct and explain. The more complex are the form-features, the more do simple diagrams help to make them intelligible. For this reason, the few diagrammatic figures, simple and rough as they were, with which Baer 
half a century ago accompanied his well-known "History of the Erolution of Animals," have been more serviceable in rendering the matter intelligible than all the numerous and very careful figures, elaborated with the aid of camera lucida, which now adorn the splendid and costly atlases of His, Goette, and others. If it is said that my diagrammatic figures are "inaccurate," and a charge of "falsifying science" is brought against me, this is equally true of all the very numerous diagrams which are daily used in teaching. All diagrammatic figures are "inaccurate."

The important advances in many different directions made during the last two years, both by germ-history and tribal history, especially the reconstruction of the germlayer theory and the development of the Gastræa theory, liave compelled me essentially to modify the second and third sections of the Anthropogeny. Chapters VIII., IX., XVI., and XIX. especially appear in a new form; but even in Sections I. and IX. I have been compelled to modify much and to improve many parts. At the same time I have exerted myself to the utmost, by improving the formal exposition, to render the extremely dry and unacceptable matter more interesting. This is, of course, an unusally hard task, and I am well aware how far even this third edition, in spite of all my efforts, is from affording a really popularly intelligible explanation of the Ontogeny and Phylogeny of Man. Because the defective natural scientific instruction in our schools, even in the present day, leaves educated men quite or nearly ignorant of the structure and arrangement of their bodies, the anatomical and physiological foundation is usually wanting, on which alone a true knowledge of human germ-history, and consequently 
of human tribal history, can be based. And yet, as Baer says, "no investigation is more worthy of a free and thoughtful man than the study of himself." (Cf. vol. i. p. 244.) Hoping, as I do, that I may have aided to some extent to bring about this true self-knowledge, I shall have gained my purpose if my labours arouse an active interest in wider circles in the historic evolution of our animal organism, and if they advance the knowledge of this most significant process.

Ensst Heinrich Haeckel.

Jena, October 6, 1876. 


\section{PROMETHEUS.}

EsveIL thine heaven, Zeus, with vaporous cloud, And practise, like a boy beheading thistles, On oaks and monntain summits;

Yet must thou let my earth alone to stand, And these my dwellings, which thon didst not build, And these my flocks, for whose bright glow

Thon enviest mc.

I know not aught more wretched

Beneath the sun than yon, ye Gods !

Who nourish piteously,

With tax of sacrifice and reek of prayer; your glory

Would starve, if children were not yet, and suppliants, So full of hope-and fools.

When I was young, and knew not whence nor whither,

I nsed to turn my dazzled eyes to the sun,

As if above me were

An ear to listen to my crying,

A heart, like mine, to pity those oppress'd.

Who aided me against the Titans' arrogance?

Who rescued me from death, from slavery ?

'Tis thon alone hast wronght it all, thou holy, glowing heart.

Thou didst glow young and fresh, thongh cheated; thanks for saving

That slumbering one above.

Why should I honour thee?

Hast thon e'er lighten'd the woes of the laden ones?

Hast thou e'er dried the tears of the sorrowful ?

It was not thou who welded me to manhood, But Time the almighty, Fate the crerlasting, My Lords and thine. 
Dost fondly fancy I shall hate my life, And hie me to the waste, because not all My blossom-dreams bear fruit?

Here sit I forming manhood in my image, A race resembling me, To sorrow, and to weep, To taste, to hold, to enjoy, And not take heed of thee, As I!

\section{FAUST.}

Earth's narrow circle is well known to me;

What is above the eye can never see.

Fool, who peers thither with his vision dim, And feigns a crowd of beings like to him!

Let him look round him, standing without fear; This world speaks plain for who has ears to hear: He need not stray within the vast to be, But clasp what he can feel and see.

So let him wander all his earthly day; Though ghosts should walk, still let him go his way: In every progress woe and joy betide, Though every moment be unsatisfied.

Yes, in this thought, I fix unswerving: Wisdom gives thus her judgment form; Those are of Freedom, Life, deserving, Who daily take them both by storm.

Gozthe. 


\section{THE EVOLUTION OF MAN.}

\section{CHAPTER I.}

\section{THE FUNDAMENTAL LAW OF THE EVOLUTION OF ORGANISMS.}

General Significance of the History of the Evolution of Man.-Ignorance of it among the so-called Educated Classes.-The Two Branches of the History of Evolution.-Ontogeny, or the History of Germs (Embryos), and Phylogeny, or the History of Descent (or of the Tribes).-Causal Connection between the Two Series of Evolution.-The Evolution of the Tribe determines the Evolution of the Germ.-Ontogeny as as Epitome or Recapitulation of Phylogeny. The Incompleteness of this Epitome.-The Fundamental Law of Biogeny.-Heredity and Adaptation are the two Formative Functions, or the two Mechanical Causes, of Evolution.-Absence of Purposive Causes.-Validity of Mechanical Causes only.-Substitntion of the Monistic or Unitary for the Dualistic, or Binary Cosmology.-Radical Importance of the Facts of Embryology to Monistic Philosophy.-Palingenesis, or Derived History, and Kenogenesis, or Vitiated History.-History of the Evolution of Forms and Functions.-Necessary Connection between Physiogeny and Morphogeny.-The History of Evolution as yet almost entirely the Product of Morphology, and not of Physiology.-The History of the Evolution of the Central Nervous System (Brain and Spinal Marrow) is involved in that of the Psychic Activities, or the Mind.

"The History of the Evolution of Organisms consists of two kindred and closely connected parts: ()ntogeny, which is the history of the evolution of individnal organisms, and Phylogeny, which is the history of the evolution of organic tribes. Ontogeny is a brief and rapid recapitnlation of Phylogeny, dependent on the physiological fanctions of Heredity (reproduc-

VOL. I. 
tion) and Adaptation (nutrition). The individnal organism reproduces in the rapid and short course of its own evolution the most important of the changes in form through which its ancestors, according to laws of Heredity and Adaptation, have passed in the slow and long course of their palæontological evolution."-HAEckes's Generelle Morphologie (1866).

THE natural phenomena of the evolutionary history of man claim an entirely peculiar place in the wide range of the scientific study of nature. There is surely no subject of scientific investigation touching man more closely, or in the knowledge of which he is more deeply concerned, than the human organism itself; and of all the various branches of the science of man, or anthropology, the history of his natural evolution should excite his highest interest. For it affords a key for the solution of the greatest of those problems at which human science is striving. The greatest problems with which human science is occupied-the inquiry into the true nature of man, or, as it is called. the question of "Man's Place in Nature," which deals with the past and primitive history, the present condition, and future of Man-are all most directly and intimately linked to this branch of scientific research, which is called The History of the Evolution of Man, or briefly, "Anthropogeny." 1 It is, however, a most astonishing but incontestable fact, that the history of the evolution of man as yet constitutes no part of general education. Indeed, our so-called "educated classes" are to this day in total ignorance of the most important circumstances and the most remarkable phenomena which Anthropogeny has brought to light.

In corroboration of this most astounding fact, I will ouly mention that most "educated people" do not even know that each human individual is developed from an egg, and that this egg is a simple cell, like that of any 
animal or plant. They are also ignorant of the fact that, in the development of this egg, an organism is first formed which is entirely different from the fully developed human body, to which it bears no trace of resemblance. The majority of "educated people" have never seen such a human germ, or embryo, in the early stages of development, ${ }^{2}$ nor are they aware that it is not at all different from those of other animals. They do not know that, at a certain period, this embryo has essentially the anatomical structure of a Lancelet, later of a Fish, and in subsequent stages those of Amphibian and Mammal forms; and that in the further evolution of these mammal forms those first appear which stand lowest in the series, namely, forms allied to the Beaked Animals (Ornithorhynchus); then those allied to Pouched Animals (Marsupialia), which are followed by forms most resembling Apes; till at last the peculiar human form is produced as the final result. These significant facts are so little known that, when incidentally mentioned, they are commonly doubted, or are even regarded as unfounded inventions. Every one knows that the butterfly proceeds from a pupa, the pupa from a caterpillar, to which it bears no resemblance, and again the caterpillar from the egg of the butterfly. But few, except those of the medical profession, are aware that man, in the course of his individual evolution, passes through a series of transformations no less astonishing and remarkable than the well-known metamorphoses of the butterfly. The mere tracing of this wonderful series of forms, through which the human embryo passes in the course of its development, is, of course, of great general interest. But our understanding will be satisfied in a far higher degree, if we refer these remarkable facts to their final causes, and recognize 
that these natural phenomena are of the utmost importance to the entire range of human knowledge. They are of special importance to the "History of Creation," and, in connection with this, to philosophy in general,--as we shall presently see. Further, as the general results of all human striving after knowledge are summed up in philosophy, it follows that every branch of scientific research comes more or less in contact with, and is influenced by, the History of the Evolution of Man.

In undertaking to describe the most important characteristics of these significant phenomena, and to trace them back to their final causes, I shall assign a much greater scope and aim to the History of the Evolution of Man than is usual. The lectures given on this subject in German universities during the past fifty years have been exclusively designed for medical students. It is true that the physician is most deeply interested in becoming acquainted with the development of the bodily organization of man, with which he deals, practically, from day to day, in his profession. I shall not here attempt to give a special account of the course of the evolution of the individual, such as has usually been given in embryological lectures, because few of my readers have studied human anatomy, or are acquainted with the physical structure of the developed man. Hence, I shall have to confine myself in many points to general outlines, neglecting many of the remarkable details, which would have to be discussed in treating of the evolution of special human organs, but which from their complicated nature, and because they are not easy to describe, can only be completely understood by the aid of an intimate acquaintance with human anatomy. I shall strive, however. 
to present this branch of the science in as popular a form as possible. A satisfactory general idea of the course of the evolution of the human cmbryo can, indeed, be given without going very deeply into anatomical details. As numerous successful attempts have recently been made to awaken the interest of larger classes of educated persons in other branches of Science, I also may hope to succeed in this department, though it is in many respects especially beset with difficulties.

The History of the Evolution of Man, as it has been usually treated in lectures for medical students at the universities, has only concerned itself with Embryology, so-called, or more correctly with Ontogeny, ${ }^{4}$ in other words, with the history of the evolution of individual human organisms. This, however, is only the first part of the task before us, only the first half of the History of the Evolution of Man in the wider sense which will here be attributed to the term. The second part, equal in importance and interest, is Phylogeny, ${ }^{5}$ which is the history of the evolution of the descent of man, that is, of the evolution of the various animal forms through which, in the course of countless ages, mankind has gradually passed into its present form. All my readers know of the very important scientific movement which Charles Darwin caused fifteen years ago, by his book on the Origin of Species. The most important direct consequence of this work, which marks a fresh epoch, has been to cause new inquiries to be made into the origin of the human race, which have proved the natural evolution of man through lower animal forms. The Science which treats of the development of the human race from the animal kingdom is called Phylogeny, or the tribal 
history of man. The most important source from which the science derives its material, is Ontogeny, or the history of germs, in other words, of the evolution of the individual. Palæontology, or the science of petrifactions, and, in a yet greater degree, Comparative Anatomy, also aftord most important aid to Phylogeny.

These two divisions of our science, Ontogeny, or the history of the germ, Phylogeny, or the history of the tribe, are most intimately connected, and the one cannot be understood without the other. The close intertwining of both branches, the increased proportions which germhistory and tribal history lend to each other, alone raise Biogeny ${ }^{6}$ (or the history of organic evolution, in the widest sense) to the rank of a philosophic natural science. The connection between the two is not external and superficial, but deeply internal and causal. Our knowledge of this connection has been but very recently obtained; it is most clearly and accurately expressed in the comprehensive statement which I call "the fundamental law of organic evolution," or more briefly, "the first principle of Biogeny." "

This fundamental law, to which we shall recur again and again, and on the recognition of which depends the thorough understanding of the history of evolution, is briefly expressed in the proposition : that the History of the Germ is an epitome of the History of the Descent; or, in other words : that Ontogeny is a recapitulation of Phylogeny; or, somewhat more explicitly: that the series of forms through which the Individual Organısm passes durıng its progress from the egg cell to its fully developed state, is a brief, compressed reproduction of the long series of forms through which the animal ancestors of that organism (or the ancestral forms 
of its species) have passed from the earliest periods of socalled organic creation down to the present time.

The causal nature of the relation which connects the History of the Germ (Embryology, or Ontogeny) with that of the tribe (Phylogeny) is dependent on the phenomena of Heredity and Adaptation. When these are properly understood, and their fundamental importance in determining the forms of organisms recognized, we may go a step further, and say: Phylogenesis is the mechanical cause of Ontogenesis. The Evolution of the Tribe, which is dependent on the laws of Heredity and Adaptation, effects all the events which take place in the course of the Evolution of the Germ or Embryo.

The chain of different animal forms which, according to the Theory of Descent, constitutes the series of ancestors, or chain of forefathers of every higher organism, and hence also of man, always forms a connected whole. This unbroken succession of forms may be represented by the letters of the Alphabet A, B, C, D, E, etc., down to Z, in their alphabetical order. In apparent contradiction to this, the history of the individual evolution, or the Ontogeny of most organisms show us only a fragment of this series of forms, so that the interrupted chain of embryonic forms would be represented by something like: A, B, F, H, I, K, L, etc.; or, in other cases, thus: B, D, H, L, M, N, etc. Several evolutionary forms have, therefore, usually dropped out of the originally unbroken chain of forms. In many cases also (retaining the figure of the repeated alphabet) one or more letters, representing ancestral forms, are replaced in the corresponding places among the embryonic forms by equivalent letters of another alphabet. Thus, for example, in 
place of the Latin B or D, a Greek B or $\Delta$ is often found. Here, therefore, the text of the biogenetic first principle is vitiated, while in the former case it was epitomized. This gives more importance to the fact that, notwithstanding this, the sequence remains the same, so that we are enabled to recognize its original order.

Indeed, there is always a complete parallelism between the two series of evolution. This is, however, vitiated by the fact that in most cases many forms which formerly existed and actually lived in the phylogenetic series are now wanting, and have been lost from the ontogenetic series of evolution. If the parallelism between the two series were perfect, and if this great fundamental law of the causal connection between Ontogeny and Phylogeny, in the strict sense of the word, had full and unconditional sway, we should only have to ascertain, with the aid of microscope and scalpel, the series of forms through which the fertilized human egg passes before it attains its complete development. Such an examination would at once give us a complete picture of the remarkable series of forms through which the animal ancestors of the human race have passed, from the beginning of organic creation to the first appearance of man. But this reproduction of the Phylogeny in the Ontogeny is complete only in rare instances, and seldom corresponds to the entire series of the letters of the alphabet. In fact, in most cases the epitome is very incomplete, and greatly altered and perverted by causes which we shall investigate hereafter. Hence we are seldom able to determine directly, by means of its Ontogeny, the different forms through which the ancestry of each organism has passed; on the contrary, we commonly find,- - and not less so in the Phylogeny of man,-a number 
of gaps. We are, however, able to bridge over the greater part of these gaps satisfactorily by the help of Comparative Anatomy, though not to fill them up directly by ontogenetic research. It is therefore all the more important that we are acquainted with a considerable number of lower animal forms which still find place in the history of the individual evolution of man. In such cases, from the nature of the transient individual form, we may quite safely infer the nature of the ancestral animal form.

For example, from the fact that the human egg is a simple cell, we may at once infer that there has been at a very remote time a unicellular ancestor of the human race resembling an Amœba. Again, from the fact that the human embryo originally consists merely of two simple germ-layers, we may at once safely infer that a very ancient ancestral form is represented by the two-layered Gastræa. A later embryonic form of the human being points with equal certainty to a primitive worm-like ancestral form which is related to the sea-squirts or Ascidians of the present day. But the low animal forms which constitute the ancestral line between the unicellular amœba and the gastræa, and further between the gastræa and the ascidian form, can only be approximately conjectured with the aid of Comparative Anatomy and Ontogeny. On account of a shortened process of Heredity, various ontogenetic intermediate forms, which must have existed phylogenetically, or in the ancestral lineage, have in the course of historic evolution gradually dropped out from these gaps. But notwithstanding these numerous and sometimes very considerable gaps, there is, on the whole, complete agreement between the two series of evolution. Indeed, it will be one of my principal objects to 
prove, the deep harmony, and original parallelism, between the two series. By adducing numerous facts, I hope to convince my readers that from the actually existing series of embryonic forms which can be shown at any time, we are able to draw the most important conclusions as to the genealogical tree of the human species. We shall thus be able to form a general picture of the series of animal forms which succeeded each other as the direct ancestors of man, in the long course of the history of the organic world.

In this phylogenetic significance of ontogenetic phenomena, it is of course most important to distinguish clearly and exactly between the original, palingenetic processes of evolution, and the later kenogenetic processes of the same. The term Palingenetic process ${ }^{8}$ (or reproduction of the history of the germ) is applied to all such phenomena in the history of evolution as are exactly reproduced, in consequence of conservative heredity, in each succeeding generation, and which, therefore, enables us directly to infer the corresponding processes in the tribal history of the developed ancestors. The term Kenogenetic process ${ }^{9}$ (or vitiation of the history of the germ) is applied to all such processes in the germ-history as are not to be explained by heredity from primæval parent-forms, but which have been acquired at a later time in consequence of the adaptation of the germ, or embryo form, to special conditions of evolution. These kenogenetic processes are recent additions, which do not allow of direct inference as to the corresponding processes in the tribal history of the ancestral line, but which rather falsify and conceal the latter.

This critical distinction between the primary palingenetic, and the secondary kenogenetic processes is of course 
of the greatest importance to scientific Phylogeny, which, from the available empiric material supplied by Ontogeny, by Comparative Anatomy, and by Palæontology, seeks to infer the long extinct historical processes of tribal evolution. It is of the same importance to the student of evolution as is the critical distinction between corrupt and genuine passages in the text of an old writer to the philologist; the separation of the original text from interpolations and corrupt readings. This distinction between Palingenesis or inherited evolution, and Kenogenesis or vitiated evolution, has not, however, yet been sufficiently appreciated by naturalists. But I believe that it is the first condition requisite, if the history of evolution is to be really understood, and I think that two separate main divisions, based on this distinction, must be made in germ-history; Palingenesis or inherited history, and Kenogenesis or vitiated history.

Let us illustrate this highly important distinction by a few examples taken from the evolution of man. In Man, as in all other higher Vertebrates, the following incidents of germhistory must be regarded as palingenetic processes: the formation of the two primary germ-layers, the appearance of a simple notochord (Chorda) between the spinal tube and the intestinal tube, the transitory formation of gill-arches and gill-openings, of primitive kidneys, of the primitive brain bladder, the hermaphrodite rudiment of the sexual organs, etc. All these, and many other important phenomena have evidently been accurately handed down, by constant heredity, from the primæval ancestors of Mammals, and must, therefore, be referred directly to corresponding palæontological evolutionary incidents in the history of the tribe. On the other hand, this is not the case with the following germinal 
incidents, which must be explained as kenogenetic processes; the formation of the yelk-sac, of the allantois and placenta, of the amnion and chorion, and, generally, of the different egg-membranes and the corresponding systems of blood-vessels; also the transitory separation of the primitive vertebrate plates and the side-plates, the secondary closing of the stomach wall and the intestinal wall, the formation of the navel, etc. All these, and many other phenomena are evidently not referable to corresponding conditions of an earlier, independent, and fully developed parent form, but must be explained as solely due to adaptation to the peculiar conditions of egg-life or embryo-life (within the egg-membranes). With reference to this fact we may now define our "first principle of Biogeny" more exactly as follows: "The evolution of the germ (Ontogeny) is a compressed and shortened reproduction of the evolution of the tribe (Phylogeny); and, moreover, this reproduction is more complete, in proportion as, in consequence of constant heredity, the original inherited evolution (Palingenesis) is more closely retained; on the other hand, the repetition is more incoruplete, in proportion as the later vitiated evolution (Kenogenesis) is introduced by changing adaptation." 10

The kenogenetic vitiations of the original, palingenetic incidents of evolution depend in great measure on a gradually occurring displacement of the phenomena, which is effected in the course of many thousands of years by adaption to the changed conditions of embryonic existence. This displacement may effect either the place or the time of the phenomena. If the former, it is called Heterotopy; if the latter, Hcterochrony. 
"Displacement in position," or "Heterotopy," especially affects the cells or elementary parts which compose the organs; but it also affects the organs themselves. For example, the sexual organs of the human embryo, as well as those of many higher animals, appear to originate from the middle germ-layer. But the comparative Ontogeny of the lower animals shows, on the other hand, that these organs did not originally arise from this layer, but from one of the primary germ-layers; the male sexual organs from the outer germ-layer, the female from the inner. Gradually, however, the germ-cells have altered their original site, and have made their way, at an early period, from their original position into the middle germ-layer, so that they now appear actually to originate in the latter. An analogous heterotopism affects the primitive kidneys in the higher Vertebrates. Even the appearance of the mesoderm itself is very greatly affected by a displacement in position, which is connected with the transition of embryo cells from one germ-layer into another.

The kenogenetic- "displacements in time," or "Heterochronisms," are equally significant. They are seen in the fact that in the germ-history (Ontogeny) the sequence in which the organs appears differs from that which, judging from the tribal history (Phylogeny), would be expected. By heterotopy the sequence in position is vitiated; similarly, by heterochrony the sequence in time is vitiated. This vitiation may effect either an acceleration or a retardation in the appearance of the organs. We must regard the following incidents in the germ-history of man as examples of ontogenctic acceleration: the early appearance of the heart, the gill-openings, the brain, the eyes, the chorda, 
etc. It is evident that these organs appear earlier in relation to others than was originaily the case in the history of the tribe. The reverse is true of the retarded completion of the intestinal canal, the body-cavity, and the sexual organs. It is evident that in these cases there is an ontogenetic postponement or retardation.

It is only by critically appreciating these kenogenetic incidents in relation to the palingenetic, and by constantly allowing for the changes in inherited evolution effected by vitiated evolution, that it is possible to recognize the fundamental significance of the first principle of Biogeny, which in this way attains its true value as the most important explanatory principle of the history of evolution. When it is thus critically appreciated, this first principle also proves to be the "red thread" on which we can string every one of the phenomena in this wonderful domain; this is the thread of Ariadne, with the aid of which alone we are able to find an intelligible course through this complicated labyrinth of forms. Even at an earlier period, when the history of the evolution of the human and the animal individual first became somewhat more accurately knownwhich is hardly half a century ago!-people were greatly surprised at the wonderful similarity existing in the ontogenetic forms, or the stages of the individual evolution, of very different animals. They noticed also the remarkable resemblance between these and certain developed animal forms of allied lower groups. Even the older natural philosophers recognized the fact that in a certain way these lower animals permanently represent in the system of the animal kingdom forms which appear transiently in the evolution of individuals of higher groups. But formerly 
it was impossible to understand and interpret aright this remarkable resemblance. Darwin's greatest merit is that he has now enabled us to understand this circumstance. This gifted naturalist was the first to place the phenomena of Heredity on the one hand, and of Adaptation on the other, in their true light, and to show the fundamental significance of their constant interaction in the production of organic forms. He was the first to point out the important part played by the continual Struggle for Existence in which all organisms take part, and how under its influence, through Natural Selection, new species of organisms have arisen, and still arise, entirely by the interaction of Heredity and Adaptation. Darwin thus enabled us properly to understand the immensely important relation existing between the two divisions of the History of Evolution: Ontogeny, and Phylogeny.

If the phenomena of Heredity and Adaptation are left unnoticed, if these two formative physiological functions of the organism are not taken into account, then it is entirely impossible thoroughly to understand the History of Evolution; so that bofore the time of Darwin we had no clear idea of the real nature and causes of the development of germs. It was utterly impossible to explain the strange series of forms through which a human being passes in its embryonic evolution; it was impossible to comprehend the reason of the curious series of various animal-like forms which appear in the Ontogeny of man. Previously it was even generally believed that the whole human being, with all its parts foreshadowed, existed even in the egg, and that his evolution was only an unfolding of the form, a simple process of growth. But this is not at all the case, On the contrary, 
the entire process of the evolution of the individual presents to the eye a connected series of diverse animal forms; and these various animal forms exhibit very diverse conditions of external and internal structure. The reason why every human individual must pass through this series of forms in the course of his embryonic evolution, was first explained to us by the Theory of Descent of Lamarck and Darwin. From this theory we first learn the efficient causes (causce efficientes) of individual evolution; by the aid of this theory we first perceive that such mechanical causes alone suffice to effect the evolution of the individual organism, and that the co-operation of designing, or teleological causes (causce finaies), which were formerly universally assumed, is unnecessary. Of course, these final causes still play an important part in the prevailing school-philosophy; but in our new natural philosophy we are enabled to replace them entirely by the efficient causes.

I allude to this matter at this early stage, in order to call attention to one of the most important advances made in any branch of human knowledge during the past ten years. The history of philosophy shows that in the cosmology of our day, as in that of antiquity, final causes are almost universally deemed to be the real ultimate causes of the phenomena of organic life, and especially those of the life of man. The prevailing Ductrine of Design, or Teleology, assumes that the phenomena of organic life, and in particular those of evolution, are explicable only by purposive causes, and that, on the contrary, they in no way admit of a mechanical explanation, that is, one entirely based on natural science. The most difficult problems in this respect which have been before us, and which seemed capable of 
solution only by means of Teleology, are, however, precisely those which have been mechanically solved in the Theory of Descent. The reconstruction of the history of the evolution of man, which this theory has effected, has actually removed the greatest difficulties. We shall see in the course of our inquiries how, through Darwin's reform of the Doctrine of Evolution, the most wonderful problems, hitherto deemed unapproachable, of the organization of man and animals have admitted of a natural solution, of a mechanical explanation, by non-purposive causes. It has enabled us to substitute everywhere unconscious causes acting from necessity, for conscious purposive causes.11

If the recent progress in the Doctrine of Evolution had accomplished only this, every thoughtful person must have admitted that even in this an immense advance had been made in knowledge. In consequence of it, the tendency called unitary or monistic, in contradistinction to the dualistic, or binary, which has heretofore prevailed in speculative philosophy, must ultimately prevail throughout philosophy. ${ }^{12}$ This is the point at which the history of the evolution of man at once penetrates deeply into the very foundations of philosophy. For this reason alone it is very much to be desired, in fact is indispensable, that any one who aspires to philosophic culture should learn the most important facts in this field of research.

The significance of the facts of Ontogeny is so great and so evident that the dualistic teleological philosophy, finding them extremely inconvenient, has of late endeavoured to meet them by simple denial. Such, for instance, has been the case with the fact that every human being develops from an egg, and that this egg is a simple cell, like the eggVol. I. 
cell of all other animals. When in my "History of Creation" I had discussed this fundamental fact, and had directed attention to its immense significance, several theological periodicals pronounced it a malicious invention of my own. The evident fact that at a certain stage of their cvolution the embryos of Man and of the Dog are entirely indistinguishable from one another was also denied.

The fact is that an examination of the human embryo in the third or fourth week of its evolution shows it to be altogether different from the fully developed Man, and that it exactly corresponds to the undeveloped embryo-form presented by the Ape, the Dog, the Rabbit, and other Mammals, at the same stage of their Ontogeny. At this stage it is a bean-shaped body of very simple structure, with a tail behind, and two pairs of paddles, resembling the fins of a fish, and totally dissimilar to the limbs of man and other mammals, at the sides. Nearly the whole of the front half of the body consists of a shapeless head without a face, on the sides of which are seen gill-fissures and gill-arches as in Fishes. (Cf. Plate VII. at the end of Chapter XI.) In this stage of evolution the human embryo differs in no essential way from the embryo of an Ape, Dog, Horse, Ox, etc., at a corresponding age. Even such facts as these, which can be easily and promptly demonstrated at any time by placing side by side the corresponding embryos of Man, a Dog, a Horse, etc., have been spoken of by theologians and teleological philosophers as inventions of materialism; and even naturalists, who were presumably acquainted with them, have tried to deny them. No stronger proof, surely, of the immense radical importance of these embryological facts in favour of the monistic philosophy can be given than 
these efforts on the part of the dualistic school to meet them by simple denial or utter silence. They are indeed extremely distasteful to that school, and are totally irreconcilable with their teleological cosmology. We must therefore take especial care to place them in their true light. We are entirely of the opinion of Huxley, who, in his able "Evidence as to Man's Place in Nature," says that these facts, "though ignored by many of the professed instructors of the public mind, are easy of demonstration, and are universally agreed to by men of science; while their significance is so great, that whoso has deeply pondered over them will, I think, find little to startle him in the other revelations of Biology."

Although our chief inquiry is primarily directed to the history of the evolution of the bodily form of Man and of his organs, and to their external and internal structural relations, I must here at once observe that the history of the evolution of the functions is inseparably connected with this. Everywhere in Anthropology, just as in Zoology, of which the former is but a part, and throughout the whole field of Biology, these two branches of research are thus inseparably connected. The peculiar form of the organism and its organs, both internal and external, is always closely related to the peculiar manifestations of life, of the organism and its organs, or, in other words, to the physiological functions performed by these. This intimate relation between form and function is also shown in the evolution of the organism and its various parts. The history of the evolution of forms, which primarily occupies us, is at the same time the history of the evolution of functions; and this is equally true of the human and of all other organisms. 
But I must here add at once, that our knowledge of the evolution of functions is as yet far from being so advanced as our knowledge of the evolution of forms. Indeed, properly speaking, the entire history of evolution, or Biogeny, including both Ontogeny and Phylogeny, has as yet been almost exclusively a history of the evolution of forms, while the Biogeny of functions hardly exists even in name. The fault lies solely with Physiology, which has as yet scarcely given a thought to the history of evolution, which it has left entirely to the care of Morphology.

The two chief divisions of biological research-Morphology and Physiology - have long travelled apart, taking different paths. This is perfectly natural, for the aims, as well as the methods, of the two divisions are different. Morphology, the science of forms, aims at a scientific understanding of organic structures, of their internal and external proportions of form. Physiology, the science of functions, on the other hand, aims at a knowledge of the functions of organs, or, in other words, of the manifestations of life. ${ }^{13}$ Physiology, however, has, especially during the last twenty years, been far more one-sided in its progress than Morphology. Not only has it entirely neglected to apply the comparative method, by which Morphology has gained its greatest results, but it has altogether disregarded the History of Evolution. Hence it has come to pass that, within the past few decades, Morphology has advanced far beyond Physiology, although the latter is pleased to look haughtily down upon the former. It is Morphology which has gained the greatest results in the fields of Comparative Anatomy and Biogeny, and almost everything stated in these pages as to the History of the Evolution of Man, is due to the 
exertions of morphologists, and not of physiologists. Indeed the direction at present taken by Physiology is so onesided that it has even neglected the recognition of the most important functions of Evolution, namely, Heredity and Adaptation, and has left this entirely physiological task to morphologists. We owe to morphologists, and not to physiologists, nearly all that we yet know of Heredity and Adaptation. The latter still works as little at the functions of evolution as at the evolution of the functions.

It will, therefore, be the task of a future Physiogeny to grasp the history of the evolution of the functions with the same earnestness, and with the same success, with which Morphogeny has long ago undertaken the study of the history of the evolution of forms. A few instances will show how closely the two are connected. The heart of the human embryo has at first a very simple structure, such as appears permanently only in Ascidians and other inferior Worms, and connected with it is a circulation of the blood of the most simple kind. When, on the other hand, we see that with the fully developed form of the human heart there is connected a function of the circulation of the blood totally different from the former one, and far more complicated, the study of the evolution of the heart necessarily enlarges from a task which was originally morphological to one which is physiological also. It is the same in the case of all other organs and their activities.

Thus, for instance, a careful comparative study of the history of the evolution of the form of the intestinal canal, the lungs, and the organs of generation, affords us also most important information as to the evolution of the respective functions of these organs. 
This important relation is most clearly seen in the history of the evolution of the nervous system. In the economy of the human body, this system performs the functions of sensation, of voluntary movement, volition, and finally the highest psychical functions, namely, those of thought; in a word, every one of the various activities which constitute the special subject of Psychology, or the science of the mind. Modern Anatomy and Physiology have demonstrated that these functions of the mind, or psychic activities, are immediately dependent upon the more delicate structure of the central nervous system, upon the internal conditions of the form of the brain and the spinal marrow. Here are placed the extremely complex mechanism of cells, whose physiological function constitutes the mind-life of Man. It is so complex that to most people its function appears to be something supernatural, and incapable of mechanical explanation. But the history of the evolution of the individual furnishes us with the most surprising and significant information as to the gradual origin and progressive formation of this most important system of organs. For the first rudiment of the central nervous system in the human embryo makes its appearance in the same most simple form in which Ascidians and other inferior Worms retain it throughout life. A perfectly simple spinal marrow, without brain, such as throughout its existence represents the organ of the mind of the Amphioxus, the lowest of Vertebrates, first develops from this rudiment. It is only at a later period that a brain develops from the anterior extremity of this spinal cord, and this brain is of the simplest form, similar to the permanent form of this organ in the lower Fishes. Step by step this simple brain develops still further, passing through forms corresponding to those of 
the Amphibia, Beaked Animals (Ornithostoma), Pouched Animals, or Marsupials, and Semi-apes (Prosimice), until the highly organized form is reached which distinguishes the Apes from all other Vertebrates, and which finally attains its highest development in the human brain. But step by step with this progressive evolution of the form of the brain, the evolution of its peculiar function, the psychical activities, moves on hand in hand, and it is therefore the history of the evolution of the central nervous system which for the first time enables us to understand the origin of life of the human mind from natural causes, and the gradual historic development of the psychic activities of man. It is impossible without the aid of Ontogeny to perceive how these highest and most brilliant functions of the animal organism have been historically developed. In a word, the history of the evolution of the spinal marrow and the brain of the human embryo at the same time directly leads us to understand the Phylogeny of the human mind, that most sublime activity of life which in the developed human being we are accustomed to regard as something wonderful and supernatural.

There is no doubt that this special result of the study of the history of evolution is among the greatest and most important. Happily, our knowledge of the Ontogeny of the central nervous system of Man is so satisfactory, and agrees so perfectly with the supplementary results of Comparative Anatomy and Physiology, that it affords us a perfectly clear insight into one of the highest problems of philosophy, namely, the Phylogeny of the psyche, the mind, or the history of the ancestral lineage of Man's psychic activities, and leads us into the only path by which we shall ever be able to solve this the highest of all problems. 


\section{T A B L E I.}

List of the principal branches of BIOGENY, or the History of Organic Evolution, with reference to the four chief stages of Organic Individnality-Cell, Organ, Person, and Race. ${ }^{14}$

I.

First branch of Biogeny, or of the history of the evolution of organisms: GerM-History, or Ontogeny (history of the development of the embryo of the individual organism).
1. Germ-history of Forms. (Morphogeny.)

(1. Germ-history of the cells (and cytods) and of the tissues composed of the cells. Histogeny.

2. Germ-history of the organs, and of the systems and apparatus composed of the organs, Organogeny.

3. Germ-history of the persons (called "the history of the evolution of bodily form "). Blastogeny.

4. Germ-history of races (or of social agrregates composed of persons: families, communities, states, etc. Cormogeny.

2. Germ-history of (The germ-history of the functions, or the Functions. (Physiogeny) been accurately and scientifically investigated.

II.

Second branch of Biogeny, or of the history of the evolution of organisms: TRIBAL HISTORY, or Phylogeny (history of the palæontological evolution of organic species).
3. Tribal history of Forms. (Morphophyly.)

\{

$\left\{\begin{array}{l}\text { 3. Tribal history of persons (an unrecog- } \\ \text { nized main object of the natural system }\end{array}\right.$ 4. Tribal history
of Functions.
(Physiophyly.) $\left\{\begin{array}{l}\text { The tribal history of the functions, or the } \\ \text { history of the palmontological develop- } \\ \text { ment of vital activities, has, in the case } \\ \text { of most organisms, not yet been ex- } \\ \text { amined. In the case of man, a large } \\ \text { nart of the history of culture falis under } \\ \text { this head. }\end{array}\right.$ of classification). Blastophyly.

4. 'Tribal history of races (or of social aggregates composed of persons : families, communities, states, etc. Coronophyly.

1. Tribal history of the cells (hardly attempted as yet). Histophyly.

2. Tribal history of organs (an unrecognized main object of comparative anatomy). Organophyly. 


\section{CHAPTER II.}

\section{THE EARLIER HISTORY OF ONTOGENY.}

\section{Caspar Friedrich Wolff.}

The Erolntion of Animals as known to Aristotle.-His Knowledge of the Ontogeny of the Lower Animals.-Stationary Condition of the Scien. tific Study of Nature during the Christian Middle Ages.-First Awakening of Ontogeny in the Beginning of the Seventeenth Century.-Fa. bricins ab Aquapendente.-Harvey.-Marcello Malpighi.-Importance of the Incubated Chick.-The Theories of Pre-formation and Encasement (Evolution and Pre-delineation).-Theories of Male and Female Encasement.-Either the Sperm-animal or the Egg as the Pre-formed Individual.-Animalculists.: Leenwenhoek, Hartsoeker, Spallanzani.Ovulists : Haller, Leibnitz, Bonnet.-Victory of the Theory of Evolution owing to the Authority of Haller and Leibnitz.-Caspar Friedrich Wolff. -His Fate and Works.-The Theoria Generationis.-Re-formation, or Epigenesis.-The History of the Evolution of the Intestinal Canal.The Foundations of the Theory of Germ-layers (Four Layers, or Leaves). -The Metamorphosis of Plants.-The Germs of the Cellular Theory. -Wolff's Monistio Philosophy.

"He who wishes to explain Generation must take for his theme the organio body and its constituent parts, and philosophize about them; he must show how these parts originated, and how they came to be in that relation in which they stand to each other. But he who learns to know a thing not only directly from its phenomena, but also its reasons and causes; and who, therefore, not by the phenomena merely, but by these also, is compelled to say : 'The thing must be so, and it cannot be otherwise; it is necessarily of such a character; it must have such qualities; and it is impossible for it to possess others'-understands the thing not only historically but traly philosophically, and he has a philosophic knowledge of it. Our own 
Theory of Generation is to be such a philosophic comprehension of an organic body, very different from one merely historical."-CASPAR FrIEDRICH WOLYF (1764).

Is approaching each science it is, in several respects, profitable to glance at the course of its evolution. The wellknown principle that "whatever has come into being can only be known from the process by which it came into being" is applicable to science. By tracing its gradual development, we shall most clearly perceive its tasks and aims. We shall also find that the present condition of the History of the Evolution of Man, with all its peculiar circumstances, can only be properly understood by taking into consideration the history of the evolution of the science itself. The examination will not detain us long; for the History of the Evolution of Man is one of the very youngest of the Natural Sciences. This is equally true of its two divisions: the History of the Germ, or Ontogeny, and the History of the Tribe, or Phylogeny.

Passing over such most ancient germs of the science as are found in classical antiquity, and which we shall have to discuss presently, the true History of the Evolution of Man, as a science, really begins in the year 1759 , when Caspar Friedrich Wolff, one of the most eminent of German naturalists, published his Theoria Generationis. This was the first foundation-stone for a true history of animal germs. In 1809, exactly fifty years later, Jean Lamarck published the Philosophie Zoologique, the first attempt at a History of Descent; and in 1859, another half century later; appeared Darwin's work, which must be regarded as the first to give a scientific basis to that attempt. But, before carefully examining this as the real foundation of the 
History of the Evolution of Man, we must rapidly glance at the great philosopher and naturalist of antiquity, who, in this as well as in all other branches of research in Natural Science, stands quite alone for a period of more than two thousand years. This was Aristotle, "the Father of Natural History."

Among the extant writings of Aristotle on Natural History, treating of various aspects of biological research, and the most important of which is the History of Animals, there occurs also a smaller work, specially confined to the History of Evolution. It is entitled Peri Zoon Geneseos ("On the Generation and Development of Animals")..5 This work is of great interest, if merely because it is the most ancient, and the only one of its kind, which has reached us from classical antiquity in a fairly complete condition. It is important also because, like others of Aristotle's writings on subjects of Natural History, it entirely controlled the science for two thousand years. The philosopher was a careful observer and an ingenious thinker; yet, while his importance as philosopher has never been doubted, his merits as an observant naturalist have only lately been duly appreciated. Those students of Nature who have lately more accurately examined his writings on Natural History, have been astonished at the mass of interesting statements, and the remarkable observar tions which abound in them. With regard to the History of Evolution, it is specially noticeable that Aristotle traced it in the most diverse classes of animals, and that he was acquainted, especially in connection with the lower animals, with several of the most remarkable facts which we have re-discovered only towards the middle of the present century. 
It is certain, for example, that he was thoroughly acquainted with the entirely peculiar method of propagation and development of the Cuttle-fishes, or Cephalapods, the embryo of which has a bag of yelk protruding from the mouth. He knew, also, that embryos of. Bees can be developed from the egg even when it has not been fertilized. The so-called parthenogenesis, or virginal generation, of Bees has been proved in our days only lately by the meritorious zoologist, Siebold, of Munich, who also showed that male Bees develop from unimpregnated, and female bees only from impregnated eggs. ${ }^{16}$ Aristotle further relates that some Fishes (of the species Serranus) are hermaphrodites, inasmuch as each individual has male and female organs, and impregnates itself. This fact, also, has only lately been established. He also knew that the embryos of several species of Sharks are connected with the mother's womb by a sort of placenta-an organ of nourishment, full of blood, which otherwise occurs only in Man and the higher Mammals. This placenta of the Shark was for a long time considered mythical, until, in 1839, Johannes Miuller; of Berlin, proved it to be a fact. We might quote many other remarkable observations from Aristotle's account of Evolution, which would prove the accuracy of this great naturalist's acquaintance with ontogenetic investigations, and the great degree in which he was in advance of subsequent times in this respect.

In most of his observations he was not satisfied with merely stating the facts, but he added reflections on their significance. Some of these theoretical thoughts are of special interest, because they indicate a right fundamental perception of the nature of the processes of evolution. $\mathrm{He}$ 
conceives the evolution of the individual to be a new formation, in which the several $\mathrm{P}$, arts of the body develop one after the other. According to him, when the human or animal individual develops, either within the mother's body or out of it in the egg, the heart is formed first, and is the beginning and the centre of the body. After the heart has been formed, the other organs appear; of these the interior precede the exterior, and the upper, or those above the diaphragm, precede the lower, or those below it. The brain is formed at a very early stage, and out of it grow the eyes. This assertion is, indeed, quite accurate. On trying to obtain from these statements of Aristotle an idea of his conception of the processes of evolution, we find that they indicate a faint presentiment of that theory of evolution which is now called Epigenesis, and which Wolff, some two thousand years later, first proved. It is especially remarkable that Aristotle altogether denied the eternity of the individual. He admitted that the kind or species, formed from individuals of the same kind, might possibly be eternal; but asserted that the individual itself was transient, that it came into being anew in the act of generation, and perished at death.

During the two thousand years after Aristotle no essential progress in Zoology in general, or in the History of Evolution in particular, is to be recorded. People were content to expound Aristotle's zoological writings, to copy them, to deface them greatly by additions, and to translate them into other languages. There was hardly any independent research during this long period. During the Middle Ages of Christianity, when insurmountable obstacles were laid in the way of independent researches in 
natural science by the development and diffusion of influential conceptions of faith, a re-commencement of biological researches was especially out of the question. Even when, in the sixteenth eentury, human Anatomy again began to be studied, and independent investigations of the structure of the body of the developed human being were again first made, anatomists dared not extend their investigations into the condition of the yet undeveloped human body, into the formation and development of the embryo.

The prevailing fear of such researches was due to several causes. This seems but natural when we remember that by the bull of Pope Boniface VIII. greater excommunication was pronounced against all who dared to dismember a human corpse. While anatomical investigation of the developed human body was a crime which drew down the curse of the Church, it is evident that the examination of the body of the child, hidden in the mother's womb, and which the Creator himself seemed, by its eoncealed position, to have intentionally withdrawn from the curious gaze of naturalists, would have appeared much more criminal and impious. The omnipotence of the Christian Church, which at that time caused many thousands to be executed and burned for heresy, and which even then with correct instinct foresaw danger threatened to itself from the deadly enemy which was then growing up in Natural Science, took care that the latter should not make too rapid strides.

It was only when the Reformation broke the allembracing power of the Only-Saving Church, and a new and fresh intellectual impulse began to release enslaved 
science from the iron chains of dogmatism, that human Anatomy and the History of the Evolution of Man could move again more freely, with the re-opening of research in other natural sciences. But Ontogeny remained far behind Anatomy, and it was only in the beginning of the seventeenth century that the first ontogenetic publications appeared. The first to begin was the Italian anatomist, Fabricius ab Aquapendente, Professor at Padua, who published two works-De Formato Foetu (1600), and De Formatione Foetus (1604),-which contain the oldest figures and descriptions of the embryo of Man and other Mammals, and also of the Chick. Similar imperfect representations were given soon after by Spigelius-De Formato Foetu (1631) - by the Englishman, Needham (1667), and his celebrated countryman, Harvey (1652). The latter discovered the circulation of the blood in the animal body, and made the important assertion: Omne vivum ex ovo ("Everything living comes from an egg"). The Dutch naturalist, Swammerdam, in his "Bible of Nature," published the results of the first investigations into the embryology of the Frog, and the so-called segmentation of its yelk. The most important ontogenetic researches of the seventeenth century, however, were those of the Italian, Marcello Malpighi of Bologna, who gave a fresh impetus both to Zoology and to Botany. His two dissertations, $D e$ Formatione Pulli, and De Ovo Incubato (1687), contain the first connected description of the history of the development of the chick in the incubated egg.

Here I must make some remarks on the great importance of the Chick in relation to our science. The history of the formation of a Chick, as well as of all birds, accurately 
corresponds in its essential characteristics with that of all other higher Vertebrates; and, therefore, also of Man. The three higher classes of Vertebrates, Mammals, Birds, and Reptiles (Lizards, Snakes, Turtles, etc.), are from the beginning of their individual development so surprisingly similar in all essential features of their bodily structure, especially in the earlier stages, that for a long while it is impossible to distinguish them. (Cf. Plates VI. and VII.) It has long been known that the accurate study of the evolution of the embryo of the Bird, which is most readily obtained as the subject of research, is all that is necessary in order to learn the essentially similar mode of evolution of Mammals, therefore also of Man. Even as early as the middle and the end of the seventeenth century, when human embryos, as well as those of all other Mammals, began to be examined in their earlier stages, this most important fact was soon recognized. It is of the greatest importance, both for theoretical and for practical purposes. Conclusions of the highest importance to the theory of evolution may be drawn from the similarity of structure of the embryos of widely differing animals. This similarity is invaluable in practical ontogenetic research, because the ontogeny of Birds, which is accurately known, most completely supplements and explains the embryology of Mammals, which has been but imperfectly studied. Hen's eggs can be obtained at all times and in any quantity, and by hatching them artificially the evolution of the embryo may be traced step by step. On the other hand, it is much more difficult to study the evolution of Mammals, because the embryo of these does not develop in a large egg that has been laid, or, in other words, in an 
independent and isolated body, but in a small egg, which, until maturity, remains enclosed and concealed in the body of the mother. For this reason it is very difficult to procure all the stages of development in any large number, for the purpose of making connected investigations, not to mention external reasons, such as the great cost, the technical difficulties, and the many other obstacles, which lie in the way of any extended series of researches into fecundated mammals. For this reason, from that time to the present day, the Chick during the process of incubation has been the subject oftenest and most closely investigated. The perfection of hatching-machines has made it yet easier to obtain embryo-chicks in any required stage of evolution and in any quantity, in order to examine the whole process of formation step by step.

About the end of the seventeenth century the history of the evolution of the incubated Chick had already been advanced as far, and its more essential, external, and less delicate conditions were as well known, owing to the labours of Malpighi, as investigations with the imperfect microscopes of that time rendered possible. Of course, the perfection of the microscope and of technical methods of research was a necessary condition for more accurate embryological research. For vertebrate embryos in their earlier stages are so small and delicate, that it is impossible to examine them without a good microscope, and without applying peculiar technical methods. But these means were not applied, and the microscope was not essentially perfected till the beginning of our century.

Throughout the whole of the first half of the eighteenth century, during which time the systematic Natural History

vol. I. 
of animals and plants received so great an impulse from Linnæus' famous Systema Naturce, the History of Evolution made scarcely any progress. It was in the year 1759 that Caspar Friedrich Wolff made his appearance, and his genius gave an entirely new direction to this science. Until then Embryology was almost exclusively occupied in unsuccessful attempts to construct various theories of evolution from the scanty material already acquired.

The theory which at that time gained almost universal acceptance, and which continued to be generally received during the entire eighteenth century, is in Germany commonly called the Theory of Unfolding (Auswickelung), or Evolution, but is better spoken of as the Theory of Preformation. ${ }^{17}$ Its main idea is the following: no really new formation takes place during the evolution of each individual organism, animal or plant, including therefore Man; there is only a growth and an unfolding of parts, all of which have, from eternity, been present, pre-formed, and complete, though only very minute, and wrapped together. Every organic germ, therefore, contains all the parts and organs of the body pre-formed and represented in their subsequent form, position, and connection, and the entire course of the evolution of the individual, the entire ontogenetic process, is nothing but an evolution in the most exact meaning of the word; namely, an unwrapping of wrapped-up parts already formed. Hence, for example, in a hen's egg we do not find a simple cell which undergoes division, and the generation of cells of which form layers of germs, and by various changes, separations, and new formations, ultimately bring into being the body of the Bird; but every hen's egg contains from the beginning a complete 
Chick, with all its parts pre-formed and wrapped together, and during the development of the incubated egg these parts are merely drawn out and grow.

As soon as this theory was carried out logically, it necessarily led to the Theory of Encasement. According to this, every species of animal or plant was originally created only as a pair or as a single individual; but this one individual already contained, encased within itself, the germs of all the other individuals of its species which have ever lived or will live. As at that time the age of the earth was calculated, according to the Biblical history of creation, at five or six thousand years, people thought they could approximately calculate the number of germs of every species of organism which had lived during that period, and consequently the number which had existed encased in the first " created" individual of the species. The theory was logically extended to mankind, and it was accordingly maintained that our first common mother Eve held in her ovary the germs of all the children of men, one encased in the other.

This Theory of Encasement was then developed so that the female individuals were considered to be the created beings which were encased one in another. It was believed that only a single pair of each species was originally created; but the ovary of the female individual contained, encased within it, all the germs of all the individuals of the kind, of both sexes, which were ever to develop. But the Theory of Pre-formation took quite another shape when, in 1690, Leeuwenhoek, the Dutch microscopist, discoverer the human spermatozoids, or seminal threads, and proved that a large number of extremely delicate and actively 
moving threads exist in the sperm or seminal fluid of the male. (Cf. Fig. 17 in Chap. VII.) This astonishing discovery was at once interpreted to the effect that these minute living bodies, briskly swimming about in the seminal fluid, were genuine animals, the pre-formed germs of future generations. When at the time of fecundation the two generative substances, male and female, came in contact with each other, these thread-like seminal animalcules were to penetrate into the fruitful soil of the ovary and there to attain their development like vegetable seeds in the fruitful soil of the earth. According to this theory every single seminal animalcule of Man is a complete human being; all the separate parts of the body would be entirely pre-formed in it, and subject only to a mere unwrapping and enlargement as soon as they reached the favourable matrix of the female egg. This theory also was logically carried out to the effect that in every single thread-like body were contained all the subsequent generations of its descendents, one encased in the other, each in the most extreme degree of fineness, and of the minutest size. The seminal gland of Adam, therefore, contained the germs of all the children of men who have ever peopled our planet, who inhabit it at present, or will occupy it in the future " until the end of the world."

Of course, this Doctrine of Encasement in the Male was utterly opposed to the Doctrine of Encasement in the Female, which had previously prevailed. The only ground common to both was the false idea that the germs of innumerable generations, previously formed and encased one in another, existed in every organism ; a conception on which was also founded the curious Prolepsis Theory of Linnæus.

The two opposite theories of encasement soon began a 
vigorous contest, which resulted in the division of the physiologists of the eighteenth century into two large bodies of combatants, entirely opposed and contending vehemently. These were the Animalculists, and the Ovulists. The dispute between these two parties appears laughable to us now, for the theory of the one is just as unfounded as that of the other. As Alfred Kirchhoff says, in an excellent biographical sketch of Wolff, "this dispute was as little capable of settlement, as the inquiry whether the angels lived in the East or in the West of the heavenly regions." 18

The Animalculists, or the Believers in Sperm, looked upon the moving seminal threads as the real animal germs, and they found support on the one hand in the lively movement, and on the other in the form of these seminal animalcules. For in the case of man, as well as of a large majority of other animals, they appear to have a somewhat oblong, egg-like, or pear-like head, a thin intermediate segment, and a very thin tail, narrowing to a hair-like form (Fig. 17). In reality, the whole formation is but a simple whip-shaped eell. The head is the cellular nucleus, surrounded by cell-matter, which is protracted into the thinner portions in the middle, and to the hair-like, moveable tail; the latter is the whip, or thread-like appendage of other whip-shaped cells. The Animalculists, however, considered the head to be a real animal head, and the rest of the body to be a complete animal body. Leeuwenhoek, Hartsoeker, and Spallanzani were the chief defenders of this theory of Pre-delineation.

The opposite party, the Ovulists (Ovists), or Believers in Eggs, who adhered to the older Theory of Evolution, 
maintained that the egg was the real animal germ, and that the seminal animalcules, at the time of fecundation, only gave the impulse which caused the unfolding of the egg in which all generations were encased one in the other. This opinion prevailed with the majority of biologists during the whole of the last century, though Wolff, in 1759, demonstrated its utter want of foundation. Its acceptance was specially due to the fact that the most celebrated biological and philosophical authorities of that time had pronounced in its favour,-among them principally Haller, Bonnet, and Leibnitz.

Albrecht Haller, Professor at Göttingen, who has often been called "the Father of Physiology," was a very learned and comprehensively educated man, but, as an interpreter of the more profound natural phenomena, occupied no very high position. He has best described himself in the celebrated and often-cited saying, that "Into the inner side of Nature no created mind ever penetrates; happy he to whom she shows only her outer husk!" The best answer to this "husk" view of nature was given by Goethe, in his splendid poem which ends with the lines:

\footnotetext{
"Nor hask nor kernel Nature brings-

For all one only type of things ;

Yet prove thyself, and seek to know

If husk or kernel thou dost show."
}

Attempts have, however, been recently made to justify Haller's "husk" view. Wilhelm His has made himself the special defender of this strange conception. Haller, in his well-known work, Elementa Physiologioe, adopted the Theory of Evolution (Theory of Pre-formation) in a most decided manner, in these words: "There is no coming into being ! 
(Nulla est epigenesis). No part of the animal body was made previous to another, and all were created simultaneously (Nulla in corpore animali pars ante aliam facta est, et omnes simul creatce existunt)." In reality, therefore, he denied any actual evolution in the natural sense, and in this went so far as to maintain even the existence of a beard in the new-born boy, and the existence of the horns in the hornless fawn; all the parts were already present in a complete state, but hidden for a while from the human eye. Haller even calculated the number of human beings which God, on the sixth day of His work of creation, at once created and encased in the ovary of Eve, the Mother of all. $\mathrm{He}$ estimated them at two hundred thousand millions, by assuming the creation of the world to have been six thousand years ago, the average human life thirty years, and the number of human beings alive at the same time one thousand million. And the celebrated Haller advocated all this rampant nonsense, and the inferences drawn from it, most successfully, even after Wolff had discovered the true Epigenesis, and proved it by investigation.

Leibnitz was the most important of the philosophers who adopted the Theory of Evolution (Pre-formation), and by his great authority, as well as by his talented exposition, gained numerous followers for it. Based upon his Theory of Monads, according to which soul and body are in an eternally inseparable union, and in their bi-unity constitute the individual (the Monad), Leibnitz quite logically applied the Theory of Encasement to the soul also, and denied all real development for it, equally with the body. In his Theodica, for instance, he says: "I think that souls, which will some day be human souls, as in the case of those of 
other species, pre-existed in the semen; that they existed in the ancestors as far back as Adam, therefore since the beginning of things, always in the form of organized bodies."

The Theory of Encasement seemed to receive its most important experimental support in the researches of Bonnet, one of its most zealous adherents. He observed, for the first time, in Plant-lice, the so-called "virginal generation," or parthenogenesis, which is an interesting form of propagation lately proved by Siebold and others, in many other articulated animals, such as various Crabs and Insects. ${ }^{16}$ The females of these and other lower animals of certain groups propagate for several generations without having been impregnated by a male. Such eggs, which for their evolution do not require to be impregnated, are called "false eggs," Pseudova, or Spores. Bonnet, in 1745, for the first time observed that a female Plant-louse, which he had completely shut off, as in a nunnery, and shielded from all contact with males, after shedding its skin four times, gave birth on the eleventh day to a living female, and within the next twenty days produced as many as ninety-four other females; and that soon all of these, without having come in contact with a male, multiplied again in the same virgin manner. Thereupon, of course, it seemed that a tangible proof of the truth of the Theory of Encasement, according to the interpretation of Ovulists, had been abundantly furnished, and it naturally became almost universally accepted in this sense.

The case stood thus, when suddenly, in the year 1759 , Caspar Friedrich Wolff, then a young man, appeared, and with his new Theory of Epigenesis gave the death-blow to the entire Theory of Pre-formation. Wolff was born at 
Berlin, in 1733. He was the son of a tailor, and studied natural science and medicine at first in Berlin, at the Medico-surgical College, under the celebrated anatomist Meckel, and subsequently in Halle. Here, in the twentysixth year of his age, he passed his examination for his doctor's degree; and on the 28th of November, 1759, in his dissertation as doctor, he defended the new doctrine of true evolution, the Theoria Generationis, founded on Epigenesis. This dissertation, in spite of its small limits and difficult language, ranks among the most important essays ever written in the whole range of biological literature. It is equally distinguished by its abundance of new and most careful researches, and by its far-reaching and very suggestive ideas given in connection with the observations, which latter he developed into a brilliant Theory of Evolution entirely true to nature. Yet this remarkable publication had at first no results whatever. Although the study of Natural Science was then flourishing in consequence of the impetus given by Linnæus; although botanists and zoologists soon numbered, not dozens, but hundreds; yet hardly anybody took any interest in Wolff's Theory of Generation. And the few who had read it, foremost among whom was Haller, considered it totally false.

Although Wolff proved the truth of Epigenesis by means of the most accurate research, and refuted the unfounded hypotheses of the Theory of Pre-formation, yet the "exact" physiologist Haller continued to be the most zealous adherent of the latter, and rejected the correct doctrine of Wolff with his dictatorial decree: Nulla est epigenesis! It is not surprising that the entire body of physiological scholars of the second half of the eighteenth 
century submitted to the dictum of this physiological pope, and opposed Epigenesis as a dangerous innovation. More than half a century elapsed before Wolff's labours met with their deserved acknowledgment. Only after Meckel, in the year 1812, had translated into German another most important publication of Wolff"s, "On the Formation of the Intestinal Canal" (published 1764), and had drawn attention to its extraordinary significance, people began to reoccupy themselves with this almost forgotten author, who, of all the naturalists of the preceding century, had made the deepest progress into the knowledge of the living organism.

Thus, as so often happens in the history of human knowledge, new-born truth succumbed to all-powerful error, upheld by the weight of authority. The knowledge of Epigenesis, clear as the sun, was not able to pierce through the thick fog of the Dogma of Pre-formation, and its ingenious discoverer was vanquished in the fight for the truth by the overwhelming power of the enemy.

The result was that all progress in the History of Evolution was for a while arrested. This is all the more to be regretted because Wolff was finally compelled, by untoward circumstances, to quit his German Fatherland. From the first without means, he had only been able to finish his classical work in the face of great difficulties, and was then compelled to earn his bread as a practising physician. During the Seven Years' War he was busy in the Silesian hospitals, and gave excellent lectures on Anatomy in the field hospital of Breslau, attracting the attention of Cothenius, the eminent Director of Hospitals. When peace had been concluded, this distinguished patron tried to procure a chair in Berlin for Wolff, but failed on account of the narrow- 
mindedness of the professors of the Berlin Medico-surgical College, who were averse to all scientific progress. This most learned faculty persecuted the Theory of Epigenesis as one of the most dangerous heresies; just as is the case now with the Theory of Descent. Although Cothenius, and other patrons in Berlin, took a warm interest in Wolff, it was impossible even to procure permission for him to give public lectures on Physiology in Berlin. The consoquence was, that Wolff was obliged to accept a summons with which the Empress Catherine of Russia honoured him in 1766. He went to St. Petersburg, where he remained for twenty-seven years, devoting himself in undisturbed quiet to his deep researches, and enriching the publications of the St. Petersburg Academy with the productions of his brilliant talents. He died there in $1794 .^{19}$

The progress which Wolff made in the entire science of Biology was so great that the naturalists of that time could not grasp it. The mass of important new researches, and of fruitful and great ideas accumulated in his publications, is so enormous that their full value has only been gradually appreciated, and their bearing properly understood during the present century. Wolff opened up the right path into the most various branches of biological investigations. Firstly, and above all, by the Theory of Epigenesis, he first made the real nature of organic evolution intelligible. He proved satisfactorily that the evolution of every organism consists of a series of new formations, and that no trace of the form of the developed organism exists either in the egg or in the semen of the male. These are simple bodies of an entirely different significance. The germ, or embryo which develops from the egg, shows in the various 
phases of its evolution an internal structure and an external form totally different from those of the developed organism. In none of these phases do we find any pre-formed parts; nowhere any encasement. In these days we can scarcely continue to call this Theory of Epigenesis a theory, for we have been thoroughly convinced of its correctness in fact, and we are able to demonstrate it in any moment under the microscope. Nor, during the last decade, has any doubt of the truth of Epigenesis been expressed.

Wolff supplied detailed proof of his Theory of Epigenesis in his scholarly treatise "On the Formation of the Intestinal Canal (1768)." In its complete condition the intestinal canal of the Chick is a very complex, long tube, to which the lungs, the liver, the salivary, and many smaller glands are attached. Wolff showed that there is no trace of this complex tube, with all its various parts, in the embryo Chick during the first period of incubation, but that in its place there is a flat, leaf-shaped body; and that the whole embryo-body in the earliest period is also of a flat, oblong, leaf-like form. Considering the difficulty of accurately examining conditions so extremely minute and delicate as the first leaf-shaped beginnings of the body of the bird with the indifferent microscopes of the last century, we cannot but admire the rare talent for observation possessed by Wolff; who actually proved the most important facts known in this the darkest portion of Embryology. From this very difficult investigation he even drew the correct conclusion that the entire embryonic body of all higher animals, as well as of birds; is for a while a flat, thin, leaf-shaped plate, which at first appears simple, but subsequently as if composed of several layers. The lowest of all these 
layers, or leaves, is the intestinal canal, the development of which Wolff examined thoroughly, from its beginning to its completion. He showed that the leaf-like rudiment first forms a groove, the edges of which curve towards each other, thus growing into a closed tube, and that, finally, at the ends of this tube the two openings, mouth and anus, arise. .

Nor did Wolff overlook the fact that the other organic systems of the body originate, in an entirely similar way from leaf-shaped rudiments, which afterwards assume the form of tubes. Like the intestinal canal, the nerve, muscle, and vascular systems, with all the various organs belonging to the last, develop from a simple layer-like or leaf-like rudiment. Thus in 1768 Wolff learned the very significant fact, which, half a century later, was first formulated by Pander, in the fundamental "germ-layer theory." The sentence in which Wolff expressed the main idea of this theory is so remarkable, that I quote it. "This very wonderful analogy between parts which in Nature are so widely separated, an analogy which is not imaginary, but is founded on the -most reliable observations, is in the highest degree worthy of the attention of physiologists; for it will be granted that it has a deep significance and that it is most intimately connected with the generation, and with the nature of animals. The different systems which compose the whole animal seem to be successively formed, at different times but on one plan; and these systems are therefore like one another, even though in their nature they are distinct. The system which is first produced, which first assumes a peculiar definite form, is the nerve-system. When this is completed the flesh-mass, which properly speaking constitutes the embryo, is formed 
on the same plan. A third, the vascular system, now appears, which is certainly sufficiently similar to the two earlier structures to allow of its form being easily recognized as that which has been described as approximately common to all the systems. The fourth system, the intestinal canal, now follows ; this, again, is formed on the same plan, and, when completed and closed, resembles the three earlier systems." In this most important discovery Wolff laid the first foundations of the fundamental "germ-layer theory" which was not completely developed till long afterwards, by Pander (1817) and by Baer (1828). It is true that Wolff's propositions are verbally incorrect, but in them he reached the truth as nearly as was then possible, and as was to be expected. We shall presently see how nearly he approached to the real state of the case.

Wolff owes much of his comprehensive conception of nature to the fact, that he was as good a botanist as a zoologist. He studied the history of the development of plants also, and in the field of botany first founded the theory which Goethe afterwards developed in his brilliant treatise on the "Metamorphosis of Plants." Wolff was the first to show that all the various parts of plants may be traced back to the leaf as their common rudiment, or "fundamental organ." Flower and fruit, with all their parts, consist only of modified leaves. This discovery must have seemed all the more surprising to Wolff, from the fact that he had discovered a simple leaf-like rudiment to be the first form of the embryonic body of animals, as it is of plants.

We therefore find in Wolff distinct traces of those theories of which, at a much later period, other gifted 
naturalists were to construct the foundation of the knowledge of the morphology of the animal and vegetable body. But our admiration for this eminent genius is still greater when we discover that he also first indicated the famous cellular theory. Indeed, Wolff had, as Huxley first pointed out, an evident presentiment of this fundamental theory, for he considered minute microscopical vesicles to be the real elementary parts constituting the germ-layers.

Finally, particular attention must be directed to the monistic character of the profound philosophical reflections which Wolff published in connection with all his admirable investigations. Wolff was a great monistic Natural Philosopher, in the best and most correct sense of the word. It is true that his philosophical researches, like his experimental ones, were ignored for more than half a century, and have not even yet met with the recognition which they deserve; but we therefore emphasize yet more strongly the fact that their tendency was strictly in that line of philosophy which we call monistic, and which alone can be considered correct. 


\section{CHAPTER III.}

\section{MIODERN ONTOGENY.}

\section{Karl Erast Baer.}

Karl Ernst Baer, the Principal Disciple of Wolff.-The Würzburg School c Embryologists : Döllinger, Pander, Baer.-Pander's Theory of Germ. layers.-Its Full Development by Baer.-The Disc-shaped first parts into two Germ-layers, each of which again divides into Two Strata. The Skin or Flesh-stratum arises from the Outer or Animal Germ-layer. The Vascular or Mucous Stratum arises from the Inner or Vegetative Germ-layer. The Significance of the Germ-layers. - The Modification of the Layers into Tubes.-Baer's Discovery of the Human Egg, the Germ-vesicle, and Chorda Dorsalis.-The Four Types of Evolution in the Four Main Groups of the Animal Kingdom.-Baer's Law of the Type of Evolution and the Degree of Perfection.-Explanation of this Law by the Theory of Selection.-Baer's Successors: Rathke, Johannes Müller, Bischoff, Kölliker.-The Cell Theory : Schleiden, Schwann.-Its Application to Ontogeny: Robert Remak.-Retrogressions in Ontogeny: Reichert and His.-Extension of the Domain of Ontogeny : Darwin.

* The History of Evolution is the real sonrce of light in the investigation of organio bodies. It is applicable at every step, and all our ideas of the correlation of organio bodies will be swayed by our knowledge of the history of evolution. To carry the proof of it into all branches of research would be an almost endless task." -KARL ERnST BAER (1828).

IF we wish to separate our historic survey of the course of the development of the Science of Human Ontogeny into parts, it is most convenient to make three. The first of these occupied the last chapter, and includes the whole preparatory period of embryological researches; it extends 
from Aristotle to Caspar Friedrich Wolff, to the year 1759, when the Theoria Generationis appeared and laid the foundation for future work. The second, to which we now turn our attention, comprises exactly a century; that is, to the year 1859, in which appeared Darwin's work on "The Origin of Species," which reformed the whole basis of the science of Biology, and especially of Ontogeny. The beginning of the third division is as recent as the time of Darwin.

As Wolff's labours remained entirely unnoticed during half a century-till the year 1812-we are not quite accurate in assigning the exact duration of a century to the second division. During fifty-three years not one book appeared which followed in the lines laid down by Wolff, and carried on his Theory of Evolution. His opinions, which were perfectly correct and founded directly on actual observations, were only occasionally mentioned, and then only to be rejected as erroneous. His opponents, followers of the prevalent and mistaken theory of Pre-formation, did not even deign to refute him. This was owing, as I have said before, to the extraordinary authority possessed by Albrecht Haller, Wolff's distinguished opponent, and the circumstance furnishes one of the most remarkable examples of the influence which a great authority may, as such, long exert against the clear recognition of facts. The neglect of Wolff's labours was so universal that in the beginning of this century two naturalists, Oken (1806) and Kieser (1810), undertook independent investigations into the development of the intestinal canal in the Chick, and obtained a correct insight into Ontogeny, without being aware of the existence of Wolff's important work in the

VOI. I.

E. 
same field, and trod in his very footsteps unconsciously. That they really did not know his works is proved by the fact that they did not advance as far as Wolff had done. In the year 1812 when Meckel translated Wolf's book on the Evolution of the Intestinal Canal into German, and called attention to its great importance, the eyes of anatomists and physiologists were for the first time suddenly opened, and a great number of Biologists soon after undertook new embryological investigations, following out and corroborating Wolff's theory step by step.

This revival of Ontogeny, and the first confirmation and further development of the only true theory of Epigenesis, started from the university of Würzburg. The distinguished biologist, Döllinger, was then lecturing there. He was the father of the famous theologian of Munich, who has done such good service in our day by his opposition to the new dogma of papal infallibility. Döllinger was both a thoughtful natural philosopher, and an accurate biological observer. He felt the greatest interest in the History of Evolution, and was much occupied with it. Yet he himself was unable to produce any very important work in this department, from want of means. But in the year 1816, a young doctor of medicine, who had just graduated, and whom we shall soon learn to know as the most important follower of Wolff; came to Wuirzburg. This was Karl Ernst Baer. His conversations with Döllinger on the History of Evolution resulted in a renewal of the investigations. Döllinger expressed a wish that, under his direction, some young naturalist should undertake a series of independent researches into the evolution of the Chick during the hatching of the egg. But neither he nor Baer possessed the con- 
siderable pecuniary means then necessary to provide a hatching-apparatus, such as would afford uninterrupted observations of the process, or to pay a skilled artist to depict in a reliable form the successive stages of development. They, therefore, confided the execution of the plan to Christian Pander, a wealthy, early friend of Baer's, by whom he had been induced to come to Würzburg. Dalton, a skilful artist, was engaged to prepare the necessary copperplates.

Thus was formed, as Baer says, "that combination, ever" memorable in the history of science, in which a veteran, grown gray in physiological researches (Döllinger), a youth glowing with zeal for science (Pander), and an artist without a peer (Dalton), united their powers to lay a firm foundation for the History of the Evolution of the Animal Organism." In a short time the history of the evolution of the Chick, in which Baer took, though indirectly, a most active part, was so far advanced that Pander, in his dissertation ${ }^{20}$ for the degree of doctor, published in 1817, was able to give the first complete sketch of the history of the evolution of the Chick on the basis of Wolff's theory. He was able to define clearly Wolff"s Theory of Germ-leaves, and to prove from observation the evolution of the complex system of organs from simple leaf-shaped primitive organs, as anticipated by Wolff. According to Pander, the leaf-shaped germinal appendage of the hen's egg separates before the twelfth hour of incubation into two distinct layers-an outer serous layer, and an inner mucous layer. Between the two, a third, vascular layer, subsequently develops.

Baer, who was one of those most active in inducing Pander to make his investigations, and who retained the 
liveliest interest in them after his departure from Würzburg, began his own much more comprehensive researches in 1819, and nine years later published, as the fruit of these researches, a work on "The History of the Evolution of Animals," which even now is generally and rightly considered the most important and valuable contribution to embryological literature. This book, a true model of careful, experimental investigation, combined with ingenious philosophical speculation, appeared in two parts; the first in the year 1828, the second in $1837 .{ }^{21}$ It is the firm foundation on which the whole history of the evolution of the individual rests to this day, and so far surpasses its predecessors, including Pander's outline, that, next to the labours of Wolff, it must be regarded as the most important basis of modern Ontogeny. As Baer, who died at Dorpat in November, 1876, was one of the greatest naturalists of our century, and has exerted a most important influence on other branches of Biology also, it may be of interest to give some account of the life of this extraordinary man.

Karl Ernst Baer was born in 1792, in Esthonia, on the little estate of Piep, which his father owned. He studied at Dorpat from 1810 to 1814, and then went to Wuirzburg, where Döllinger not only initiated him into Comparative Anatomy and Ontogeny, but also exercised over him, by his own interest in philosophical studies, a highly stimulating influence. From Würzburg Baer went to Berlin, and then, accepting a call from the physiologist Burdach, to Königsberg. There he delivered lectures on Zoology and Evolution, with some interruptions, until 1834, and complejed his most important works. In. 1834 he went to St. Petersburg as a member of the Academy of that place. 
There, however, he forsook almost entirely his former field of labour, and occupied himself with researches of a totally different nature, in various branches of Natural Science, especially in Geography, Geology, Ethnography, and Anthropology. His works on the History of the Evolution of Animals are far the most important; nearly all of these were completed while he was in Königsberg, though some of them were not published until later. Their merits, like those of Wolff's writings, are many-sided, and extend over the whole domain of Ontogeny in very various directions.

Baer especially perfected the fundamental Theory of Germ-layers, as a whole as well as in detail, so clearly and completely, that his idea of it yet forms the safest basis of. our knowledge of Ontogeny. He showed that in Man and the other Mammals, as in the Chick-in short, as in all Vertebrates-first two, and then four germ-layers are formed, always in the same manner, and that the modification of these into tubes gives rise to the first fundamental organs of the body. According to Baer, the first rudiment of the body of a Vertebrate, as it appears on the globular yelk of the fertilized egg, is an oblong disc, which first separates into two leaves or layers. From the upper or animal layer evolve all the organs which produce the phenomena of animal life: the functions of sensation, of motion, and the covering of the body. From the lower or vegetative layer proceed all the organs which bring about the growth of the body: the vital functions of nutrition, digestion, bloodmaking, breathing, secretion, reproduction, and the like. Each of these two original germ-layers separates again into two thinner layers, or lamellæ, one lying above the other. First, the animal layer separates into two, which Baer calls 
the skin, or dermal layer, and the flesh, or muscular layer. From the uppermost of these two lamellæ, the skin-layer, are formed the outer skin, the covering of the body, and the central nervous system, the spinal cord, the brain, and the organs of sensation. From the lower, or flesh-layer, the muscles, or fleshy parts, the internal or bony skeleton,in short, the organs of motion, arise. Secondly, the lower, or vegetative germ-layer, parts in the same way into two lamellæ, which Baer distinguishes as the vascular and the mucous layer. From the outer of the two, the vascular layer, proceed the heart and the blood-vessels, the spleen, and the other so-called blood-vessel glands, the kidneys, and the sexual glands. Finally, from the lowest, and fourth or mucous layer, arises the inner alimentary membrane of the intestinal canal, with all its appendages, liver, lungs, salivary glands. Baer traced the transformation of these four secondary germ-layers into tube-shaped fundamental organs as ingeniously as he had successfully determined their import and their formation in pairs by the segmentation of the two primary germ-layers. He was the first to solve the difficult problem as to the process by which the entirely different body of the vertebrate develops from this flat, leaf-shaped, four-layered original germ; the process was the transformation of the layers into tubes.

In accordance with certain laws of growth, the flat layers bend, and become arched; the edges grow towards each other so that the distance between them is continually decreased; finally they unite at the point of contact. By this process the flat intestinal layer changes into a hollow intestinal tube; the flat spinal layor becomes a hollow spinal tube, the skin-layer becomes a skin-tube, etc. 
Amorig the many and great services which Baer rendered in detail to Ontogeny, especially to that of Vertebrates, his discovery of the human egg must be especially mentioned here. Most, even of the earlier naturalists, had assumed that man proceeds, like other animals, from an egg. The Theory of Evolution (pre-formation) had, moreover, assumed that all past, present, and future generations of the human race existed encased in the ova of Eve, the common mother. Yet the ova of Man and other Mammals were not actually known till the year 1827. For the egg is exceedingly small, a spherical vesicle or bladder of only one-tenth of a line in diameter, which can be seen with the naked eye only under very favourable circumstances. This spherical vesicle, when in the ovary of the mother, is enclosed in a number of peculiar spherical vesicles of much larger size, called Graafian follicles, after their discoverer Graaf, and these were formerly universally regarded as the actual eggs. It was not until the year 1827-not fifty years ago-that Baer proved that these Graafian follicles are not the actual eggs, which are much smaller, and only imbedded in the Graafian follicles. (Cf. end of Chapter XXV.)

Baer was also the first to observe the so-called germinal vesicle of Mammals, that is, the little spherical bladder which is first developed from the impregnated egg, and the thin wall of which consists of a single layer of uniform polygonal cells. (See Chapter VIII.) Another discovery of Baer's, of great importance in understanding the types of the lineage of the Vertebrates, and the characteristic organization of this group of animals in which Man is included, was that of the Chorda Dorsalis. This is a long, thin, cylindrical cartilaginous cord, which in all Vertebrates 
passes lengthwise through the whole body of the embryo. It is developed at a very early stage, and is the first formation of the spine, the firm axis of Vertebrates. In the Lancelet (Amphioxus), the lowest of all Vertebrates, the entire inner skeleton is limited to this Chorda throughout life. But in Man and all the higher Vertebrates, first the spine, and later the skull, are developed round this cord.

Important as these and many other discoveries of Baer's were in the Ontogeny of Vertebrates, yet the great importance of his researches rested especially on the fact that he was the first to apply the comparative method to the study of the evolution. It was, of course, the Ontogeny of Vertebrates, and principally of Birds and Fishes, that Baer first and especially investigated. Yet he by no means limited himself to these; for he included various Invertebrates in his investigations. The most general result of these comparative embryological researches was that Baer assumed four totally different courses of evolution for the four principal groups of the animal kingdom. These four chief groups, or types, which at that time had just begun to be distinguished, in consequence of George Cuvier's researches in Comparative Anatomy, are: (1) Vertebrates (Vertebrata); (2) Articulated animals (Arthropoda); (3) Soft-bodied animals (Mollusca); and (4) the lower animals, which at that time were all erroneously grouped under the term Radiata. Cuvier, in the year 1816, demonstrated for the first time that these four groups of the animal kingdom show very essential and typical distinctions in their whole inner structure, and in the arrangement and position of the organic systems; that, on the other hand, the internal structure of all animals of one type, for example, of all Ver- 
tebrates, is essentially similar, notwithstanding the great variety of outward forms. Baer, however, independently and almost simultaneously, furnished proof that the four groups develop from the egg by entirely different processes, and further, that the order of the series of embryonic forms in the course of evolution is from the very beginning identical in all animals of the same type, but, on the other hand, different in those of different types. Up to that time, in making a classification of the animal kingdom, an endeavour had always been made to arrange all animals, from the lowest to the highest, from the infusoria to man, in a single connected series of forms; and the false idea had always been maintained, that there was a single unbroken gradation of development from the lowest animal to the highest. Cuvier and Baer proved that this conception is totally erroneous, - and that, on the contrary, there are four wholly distinct types of animals, which must be distinguished not only as to their anatomical structure, but also as to their embryonic evolution.

As a result of this discovery, Baer succeeded in establishing a very important law, which we shall name in his honour Baer's Law, and which he expresses as follows: "The evolution of an individual of a certain animal form is determined by two conditions: firstly, by a continuous perfection of the animal body by means of an increasing histological and morphological differentiation, or an increasing number and diversity of tissues and organic forms; secondly, and at the same time, by the continual transition from a more general form of the type to one more specific." The degree of perfection of the animal body depends on the greater or less amount of heterogeneity there is in its 
elementary parts, and in the segments of its composite organs,-in a word, in the degree of histological and morphological differentiation. The type, on the other hand, is the order of the arrangement of the organic elements and of the organs. The type is quite distinct from the degree of perfection; the same type may exist in several degrees of perfection; and, conversely, the same grade of perfection. may be reached in several types. This explains the phenomenon that the most perfect animals of any type,-for example, the highest Arthropods and Molluses,-are much more perfectly organized, or more highly differentiated, than the most imperfect animals of other types,-for example, than the lowest Vertebrates and Star-animals.

Baer's Law has been of the greatest importance in advancing our knowledge of animal organization; though it was not until a later period that Darwin enabled us to perceive and value its real significance. Here we may at once remark that it can only be really understood by means of the Theory of Descent, by the recognition of the very important part played by Heredity and Adaptation in the construction of organic form. As I have shown in my Generelle Morphologie (vol. ii. p. 10), the type of evolution is the mechanical result of Heredity; the degree of perfection is the mechanical result of Adaptation. Heredity and Adaptation are the mechanical factors in the production of organic forms, which were first brought to bear on Ontogeny by Darwin's Theory of Selection, and which have enabled us for the first time to understand Baer's Law.

Baer's labours marked the beginning of a new epoch, and aroused an extraordinary interest in embryological 
research throughout a very wide circle. We find, therefore, that a large number of investigators occupied the newly found field of research, and, with praiseworthy industry, made a great number of distinct new facts in a short time. The majority of these new embryologists are industrious specialists, who have been very useful in collecting fresh materials, but who have, as a rule, done but little to advance the general problem of the History of Germs. I can, therefore, limit myself to the mention of a few names. Of special importance are the investigations of Heinrich Rathke, of Königsberg (died 1861), who did much to advance the History of the Evolution of Invertebrates (Crabs, Insects, Molluscs), as well as of Vertebrates (Fishes, Turtles, Snakes, Crocodiles). In the subject of the Embryology of Mammals, the widest conclusions are due to the careful experiments of Wilhelm Bischoff, of Munich. His History of the Evolution of the Rabbit (1840), of the Dog (1842), of the Guinea-Pig (1852), and of the Roe-Deer (1854), are as yet the most important basis of study in this department. Among the numerous works on the Eistory of the Evolution of Invertebrates, those of the well-known zoologist, Johannes Müller, of Berlin, on Star-animals (Echinoderma), are especially noteworthy; also those of Albert Kölliker, of Würzburg, on Cuttle-fishes (Cephalopoda); of Siebold and Huxley, on Worms and Plant-animals ; of Fritz Müller (Desterro), on the Crustacea ; of Weismann, on Insects, etc. The number of labourers in this field has of late greatly increased, although not very much of special importance has been accomplished. It is evident, from the majority of recent publications on Ontogeny, that their authors are not familiar enough with Comparative Anatomy. The most important of the latest 
ontogenetic works are those of Kowalevsky, E. Ray Lankester, and Eduard van Beneden, to which we shall presently again refer. ${ }^{22}$

A more decided advance in general knowledge than was effected by all these separate investigations, dates from the year 1838, when the proof of the Cellular Theory suddenly opened a new field of research in the History of Evolution. The distinguished botanist, Schleiden, of Jena, having proved by means of the microscope that every vegetable body is composed of innumerable elementary parts, the socalled cells, Theodor Schwann, of Berlin, a pupil of Johannes Müller, applied this discovery directly to the animal body. ${ }^{23}$ He showed, that not only in plants, but also in the bodies of the most dissimilar animals, these same cells are distinguishable, under the microscope, in all the tissues, and that they form the actual building material of organisms. All the numerous tissues of the animal body, such as the entirely dissimilar tissues of the nerves, muscles, bones, outer skin, mucous skin, and of other similar parts, are originally composed of cells; and the same is true of all the various tissues of the vegetable body. These cells, which we shall hereafter consider more closely, are independent living beings, the citizens of the state, which constitute the entire multi-cellular organism. The knowledge of this most important fact was, of course, of direct service to the History of Evolution also, in that it raised many new questions, chiefly these: What relation have the cells to the germ-layers? Are the germ-layers already composed of cells, and how are they related to the cells of the tissues which afterwards appear? What place does the egg hold in the Cell Theory? Is it itself a cell, or is it 
composed of cells? These were the important questions which the Cell Theory at once raised in the study of Embryology.

Several naturalists attempted in different ways to furnish the right answers, but the excellent "Investigations into the Evolution of Vertebrates," by Robert Remak, of Berlin (1851), became conclusive. By somewhat remoulding the Cellular Theory of Schleiden and Schwann, this gifted naturalist was able to overcome the great obstacles which this theory, in its first form, had placed in the way of Embryology. It is true that the anatomist, Karl Boguslaus Reichert, of Berlin, had previously attempted to explain the origin of the tissues. But this attempt was necessarily a total failure, owing to the fact that the extraordinarily confused mind of the author was equally destitute of every correct idea of the History of Evolution, of the Cellular Theory as a whole, and of a sound view of the structure and development of tissues in particular. The inaccuracy of Reichert's observations, and the falsity of the conclusions drawn from them, is shown by every accurate test applied to his so-called discoveries. By way of illustration, it may be said that he declared the whole of the upper germ-layer, from which the most important parts of the body-brain, spinal cord, outer skin, and the like-proceed, to be merely a transient "enveloping-skin" of the embryo, and that it had nothing to do with the formation of the body; that many of the first formations of the separate organs did not proceed from the primary germ-layers, but came one by one from the yelk of the egg, and joined the layers afterward. Reichert's preposterous embryological labours succeeded in gaining a passing attention, only because they 
were put forward with unusual presumption, and professed to disprove Baer's Theory of Germ-layers. They are written in so clumsy and confused a style, that no one could quite understand them; but for this very reason they won the admiration of many readers, who supposed that a nucleus of profound wisdom was hidden somewhere behind these obscure oracular and mysterious sayings.

Remak was the first to throw full light on the great confusion which Reichert had caused, by explaining, in the simplest possible manner, the evolution of the tissues. According to him, the egg of animals is always a simple cell, and the germ-layers, which proceed from the egg, are also composed only of cells, and those cells, which alone constitute the egg, are produced in a very simple manner by the continuous and repeated segmentation or dividing up of the original simple egg-cell. This cell divides, or parts, first into two, and then into four; from these four arise eight, then sixteen, and then thirty-two, and so on. Hence, in the individual evolution of every animal, as well as of every plant, from the one simple cell, constituting the egg, is formed, by repeated segmentation, an aggregate of cells, as Kölliker had already maintained, in 1844. The cells of such a mass spread themselves out flatly, and so form into layers, so that every one of these layers is originally composed of but one kind of cell. The cells of the layers differentiate themselves, or assume various forms ; and then there is a further differentiation, or, in other words, a division of labour of the cells within the layers themselves, and this latter differentiation produces all the various tissues of the body.

These are the very simple principles of Histogeny, or 
the Science of the Evolution of Tissues, as first elaborated by Remak and by Kölliker in this comprehensive sense. By thus proving more definitely the part which the germlayers take in the formation of the various tissues and systems of organs, and applying the Theory of Epigenesis to the cells and the tissues formed from them, Remak raised the Germ-layer Theory; at least as regards Vertebrates, to that degree of perfection in which we shall find it hereafter when we examine it in detail. According to him, the two germ-layers, of which the so-called germinal disc, the first simple leaf-shaped formation of the body of a Vertebrate, is composed, are soon increased by another layer, produced by the lower layer separating into two. These three have entirely distinct relations to the various tissues. First, from the upper layer proceed those cells which compose the outer skin (epidermis) of the body, together with the parts belonging and necessary to it (hair, nails, and the like)that is, the external covering which envelops the whole body; and, remarkable as it is, it produces also the cells which constitute the central nervous system,-the brain and spinal marrow. Secondly, from the lower germ-layer spring the cells which form the intestinal epithelium,-that is the whole inner coating of the intestinal canal and its appendages (liver, lungs, salivary glands, and the like); in other words, the tissues which take up the food of the animal body and attend to its digestion. Finally, from the middle layer, lying between these two, arise all the other tissues of the body of the Vertebrate; flesh and blood, bones and ligaments, and the like. Remak also proved that the middle layer, which he calls the "motor-germinative" Jayer, again separates, secondarily, into two layers. In this way we get 
the same four layers which Baer had previously assumed. The upper part of the middle layer after its cleavage (Baer's "Flesh-stratum"), Remak calls the skin-lamella (Hautplatte, or better, Hautfaserplatte); it forms the outer wall of the body (the true skin, cutis vena, the muscles, bones, and the like). The lower part (Baer's "Vascular stratum"), he calls the intestinal-fibrous lamella (Darmfaserplatte); it forms the outer covering of the intestinal canal, and of the heart, the blood-vessels, and so on.

Based on the firm foundation which Remak thus supplied to the History of the Evolution of the Tissues, or the science called Histogeny, numerous investigations of special points which have considerably extended our information have been made. Of course many attempts have been made to give much narrower limitations to Remak's doctrines, or to remodel them altogether. Reichert, of Berlin, and Wilhelm His, of Leipsic, have specially busied themselves to establish, in comprehensive works, an entirely new view of the evolution of the body of Vertebrates, according to which the rudiments of the body of the Vertebrate does not consist solely of the two primary germ-layers. But these works, owing to their total lack of the necessary knowledge of Comparative Anatomy, and clear knowledge of Ontogeny, and to the fact that they do not even glance at Phylogeny, could exert but a very transient influence. Only the total want of critical ability and comprehension of the real problems of the History of Evolution can explain the fact that many people for a time regarded the strange fancies of Reichert and His as a great gain.

His, in 1868, in a large book, on "The Early Evolution of the Chick in the Egg," detailed his entirely erroneous 
views in a very learned form, and under the banner of a new and very exact mathematical and physical method, he has recently expressed the same views in a general form in his book on "Our Body and the Physiological Problem of its Origin" (Leipsic, 1875). As His, in order to increase the circulation of the latter book, has allowed it to be publicly advertised as "important to readers of Haeckel's Anthropogenie," I shall only remark that my treatise on "The Aims and Methods of the History of Evolution" (Jena, 1875) frees me from the necessity of further answer. To the most important points in his false theories I shall refer again. (See Chapter XXIV.)

Quite recently, however, His, and Reichert's books on Ontogeny, which had previously ranked as the most perverted and unfortunate of the larger works on this science, have been far eclipsed, in that respect, by a ponderous work by Alexander Goette, of Strasburg, on the "History of the Evolution of Bombinator igneus, as the Basis of a Comparative Morphology of Vertebrates " (Leipsic, 1875). This monograph is the biggest existing contribution to the literature of Ontogeny-a thick volume of 964 pages, accompanied by a very beautiful folio atlas of 22 plates. These splendid plates, containing as many as 382 accurate and very carefully executed drawings, representing the history of the development of the Bombinator, are the result of years of incessant labour, and excite a most favourable interest in the huge work. Unfortunately, however, the reader who is induced by this splendid picture-book to expect a corresponding degree of excellence in the voluminous text, will be sadly disappointed. Not only is the whole account most obseure, confused, and VOL, I. 
contradictory, but, further, the entire treatment shows that, by his whole scientific education, the author is incapable of the heavy task. I should not pronounce this harsh judgment, but that Goette flatters himself that, as the reformer of the science, he is about to place it on an entirely new basis; and but that, consequently, he treats the great leaders of the science-Baer, Remak, Gegenbaur, and others-in the most insolent manner, as narrow-minded labourers who, "by reason of their lack of knowledge of the history of evolution, have missed their aim." The following samples seem to show the mode in which the new science is constituted by Goette: "Perfect life renders evolution impossible. The capacity of evolution in the mature egg excludes real life. Egg-cleavage is not a living process of evolution. The egg neither as a whole nor as to its parts, neither in its origin nor in its complete state, is a cell. The cells of the various tissues are not organisms, are not organic individuals. The individuality of an organism is only a peculiar expression of the end of its evolution," and so on.

In these and many other statements Goette abruptly upsets the whole science, as at present constituted. The Cell Theory and the Protoplasmic Theory are rejected as worthless; even Comparative Anatomy is, according to this writer, of no scientific value; Phylogeny is no science, and so on. I have explained the most incredible of Goette's assertions and his most unexampled errors in my work on "The Aims and Methods of the History of Evolution" (Leipsic, 1875); in which book I have also criticized the views held by His and Agassiz. Errors of this sort are no longer possible in other sciences. Their occurrence in the History of Evolution is explained partly by the great 
difficulty of the very complex task which lies before this science, and partly by the insufficient general preparation possessed by most of the more recent students.

All valuable modern investigations into Animal Ontogenesis have only tended to confirm and add to the Theory of Germ-layers as established by Baer and Remak. As the most important advance made in this direction, it is deserving of mention, that the same two primary germ-layers, from which the body of Vertebrates, including Man, develops, have recently been shown to exist in all invertebrate animals also, with the single exception of the lowest group, that of the Primæval animals (Protozoa.) The distinguished English naturalist, Huxley, in the year 1849, had already shown that this is also true of Plant-animals ( $(N e d u s c e)$. He drew attention to the fact that the two cell-layers, from which the body of this Plant-animal develops, correspond, morphologically as well as physiologically, to the two primary germ-layers of Vertebrates. The upper germ-layer, from which the outer skin and the tlesh proceed, he namerl Ectoderm, or Outer layer; the lower, which forms the organs of digestion and reproduction, he called the Entoderm, or Inner layer. But during the past ten years, the two germ-layers have been found to exist among many other Invertebrates. The indefatigable Russian zoölogist, Kowalevsky, has found them among widely differing groups of Invertebrates, in Worms, Star-animals (Echinoderma), Soft-bodied animals (Mollusca), Articulates (Arthropoda), and the like.

In my Monograph on the Calcareous Sponges, which appeared in 1872, I have shown that this same pair of primary germ-layers forms the basis of the body of the Sponges, and 
that they are to be regarded as occupying the same relative place, or as being homologous, throughout all the various classes of animals, from the Sponges to Man. This homology of the two primary germ-layers, which is of extraordinary significance, extends throughout the animal kingdom, with only a few exceptions in the lowest class, the Primæval animals (Protozoa). These animals are of an exceedingly low organization, and do not advance to the stage of forming germ-layers, and consequently never form real tissues. The whole body merely consists, either of a single cell, as in Amœbæ and Infusoria, or of a loose mass of but slightly differentiated cells, or, as in Monera, it does not even attain a form as high as that of a cell. But from the egg-cell of all other animals two primitive germ-layers first proceed, the outer, animal layer (Ectoderm or Exoderm), and the inner, or vegetative layer (Entoderm), and from these the various tissues and organs arise. This is equally true of Sponges, of the other Plant-animals, and of Worms ; it is as. true of Soft-bodied animals (Mollusca), Star-animals (Echinoderma), and Articulates (Arthropoda), as of Vertebratesi All these animals may be comprised under the head of Intestinal Animals (Metazoa), in distinction from the Primæval Animals (Protozoa), which have no intestine.

It is perhaps more correct not to place the Protozoa among the true animals at all, but to class them in the neutral kingdom of the Protista, those humblest primæval beings which are neither true animals nor true plants. According to this view the Metazoa can alone be considered as true animals, and the origin from two primary germlayers may be held to form the primary character of the animal kingdom. 
In the lowest forms of Metazoa, the body consists throughout life of these two primary germ-layers. But in all higher Intestinal Animals, each of these forms by cleavage two other layers, so that the body is thenceforward composed of four secondary germ-layers. In my "Gastræa Theory" (1873), I have tried to show the general homology of these four layers in all Metazoa, and I have pointed out the important bearing of this fact on the natural system of the animal kingdom. ${ }^{24}$

But though the most important facts in the individual evolution of the human and animal body had been sufficiently established by these advances in Animal Ontogeny, yet the most difficult task remained,-namely, the discovery of the causes by which the evolution of organisms and the production of their forms is effected. The real mechanical causes of individual evolution were first explained in 1859, in Darwin's work, in which the facts of Heredity and Adaptation were for the first time scientifically discussed, and their bearing on Ontogeny correctly interpreted. Only by the Theory of Descent, and by the aid of the laws of Heredity and Adaptation, are we really able to understand the facts of individual evolution, and to explain them by efficient causes. This is the point in which the Darwinian Fheory is so important to the History of the Evolution of Man and to the immediate connection of the first part of our science, Germ-history, or Ontogeny, with the second part, Tribal-history, or Phylogeny 


\section{CHAPTER IV.}

\section{THE EARLIER HISTORY OF PHYLOGENY.}

\section{Jean Lamarck.}

Phylogeny before Darwin.-Origin of Species.-Karl Linnæus' Idca of Species, and Assent to Moses' Biblical History of Creation.-The Deluge.-Palæontology.-George Cuvier's Theory of Catastrophes.Repeated Terrestrial Revolutions, and New Creations.-Lyell's Theory of Continuity.-The Natural Causes of the Constant Modification of the Earth.-Snpernatural Origin of Organisms.-Immannel Kant's Dualistic Philosophy of Nature.-Jean Lamarck.-Monistic Philosophy of Nature.-The Story of his Life.-His Philosophie Zoologique:-First Scientific Statement of the Doctrine of Descent. - Modification of Organs by Practice and Habit, in Conjunction with Heredity.-Application of the Theory to Man.-Descent of Man from the Ape.-Wolfgang Goethe.-His Stndies in Natural Science.-His Morphology.-His Stndies of the "Formation and Transformation of Organisms."Goethe's Theory of the Tendency to Specific Differences (Heredity and of Metamorphosis (Adaptation).

"It wonld be an easy task to show that the characteristics in the organization of man, on account of which the human species and races are gronped as a distinct family, are all results of former changes of occupation, and of acquired habits, which have come to be distinctive of individuals of his kind. When, compelled by circumstances, the most highly developed apes accustomed themselves to walking erect, they gained the ascendant over the other animals. The absolnte advantage they 
enjoyed, and the new requirements imposed on them, made thom change their mode of life, which resulted in the gradual modification of their organization, and in their acquiring many new qualities, and among them the wonderful power of speech."-JEAN LaMarck (1809).

THose researches into the history of the individual evolution of man and animals, the history of which we surveyed in the last two chapters, had until recently hardly any other object than that of practically determining the changes of form undergone by the organism in the course of its growth. But until within the past fifteen years, no one dared to seek for the causes of these phenomena. During the entire century, from the year 1759 , the date of the publication of Wolff's Theoria Generationis, until the year 1859, when Darwin published his "Origin of Species," the causes of the evolution of the germ remained entirely hidden. During the whole century noboly thought of seriously examining the real causes of the changes of form which take place in the evolution of the animal organism. Indeed, the task was looked upon as so difficult that it entirely surpassed the powers of human comprehension. It was reserved for Charles Darwin to declare all these causes. We may therefore point to this gifted naturalist, who, in other respects, has effected a complete revolution throughout the whole range of Biology, as the founder of a new era in the field of Ontogeny also. It is true that Darwin himself has not really entered very deeply into embryological investigations, and even in his well-known chief work on the phenomena of individual evolution has but casually touched upon these, yet, by his reform - of the Theory of Descent, and by constructing what he has named the Theory of Selection, he has placed in our hands the 
means of tracing the causes of the Evolution of Forms. It seems to me that it is in this respect that this great naturalist has had such an extraordinary effect on the entire subject of the History of Evolution.

In glancing, as we must now do, at the last period, but just begun, of ontogenetic research, we enter at the same time into the second division of the History of Evolution, namely, the History of the Descent, or Tribe (Phylogeny). In the first chapter I drew attention to the exceedingly important and intimate causal connection which exists between these two main branches of the History of Evolution,- - that of the individual, and that of his ancestors. We stated this connection in the fundamental Law of Biogeny: the brief Ontogeny, or the Evolution of the Individual, is a swift and contracted reproduction, a compressed recapitulation, of the Phylogeny, or the Evolution of the Species. This proposition in reality comprises everything essentially relating to the causes of evolution, and we shall try everywhere, in the course of these chapters, to establish it, and to uphold its truth, by adducing actual facts in proof. The meaning of this fundamental Law of Biogeny, in relation to this causal significance, is perhaps yet better expressed as follows: "The evolution of the species, or tribes (phyla), contains, in the functions of heredity and adaptation, the determining cause of the evolution of individual organisms;" or, quite briefly: "Phylogeny is the mechanical cause of Ontogeny."

It is owing to Darwin that we are now able to trace the causes of individual evolution, which were previously deemed quite unapproachable, and to understand their real 
nature; we therefore give his name to the new era of the History of Evolution. But before considering the grand discovery by means of which Darwin enabled us to understand the causes of evolution, we must glance rapidly at the efforts made by earlier naturalists in the same direction. The historical survey of these endeavours will be much shorter even than that of the labours in the field of Ontogeny. There are really but few names to be mentioned. At the head stands the great French naturalist, Jean Lamarck, who, in 1809, for the first time gave a scientific value to the so-called Theory of Descent. But even before this, the most important German philosopher, Kant, and the greatest German poet, Goethe, had both entertained the idea. During the previous half-century, however, their statements on this matter remained almost unnoticed. It was only in the commencement of our century that "Natural Philosophy" took up the question. Previously no one even dared to inquire seriously into the Origin of Species, which, properly speaking, is the culminating point of the History of Descent, or Phylogeny.

The entire Phylogeny of Man, and also of other animals, is most intimately connected with the question as to the nature of species, and with the problem, how the distinct kinds of animals, which in systems are called species, really originated. The idea of species occupies the foreground. This idea was first presented by Linnæus, who, in 1735, in his Systema Naturce, attempted the first accurate discrimination and nomenclature of animal and vegetable species, and made a systematic list of the species then known. Since that time species has retained its place in descriptive Natural History, in systematic Zoology and 
Botany, as the most important collective term, although incessant strife has been waged as to the particular meaning of the term. Linnæus himself gave no clear, scientific definition of the real nature of organic kind, or species. On the contrary, he took as a basis the mythological views of this subject, which the prevailing religicus "faith," grounded on the Mosaic History of Creation, had introduced, and which are even now very generally maintained. He even adhered directly to the Mosaic History of Creation, and assumed that, as it is written in Genesis "male and female created he them," there had originally been but one pair of each animal and vegetable kind, or species. He supposed that all the individuals of a kind were descendants of the original pair created on the sixth day of Creation. Linnæus held that only a single individual was created of those organisms which are hermaphrodite, that is, which unite in their bodies both sexual organs, for these already possessed in themselves the qualifications for propagating their own species. In further developing these mythological ideas, Linnæus adhered to the Mosaic account and utilized the so-called "Deluge," and the myth of the ark of Noah connected with it, to explain the chorology of organisms, the doctrine, that is, of the geographical and topographical distribution of animal and vegetable species. In harmony with Moses he assumed that all plants, animals, and human beings had been destroyed by the Deluge, with the exception of a single pair, which was saved in the ark to perpetuate the species, and which was put on land on Mount Ararat after the waters had subsided. Mount Ararat seemed to him specially adapted for this disembarkation, because it is in a warm climate and rises to a height 
of more than sixteen thousand feet, so that in its several zones of elevation it possessed all the climates necessary for the preservation of the various species of animals. The animals used to a cold climate could climb to the highest parts of the mountain; those accustomed to a warm climate could descend to the foot; and those from temperate zones could occupy the intermediate portions. From this mountain the animal and vegetable species could spread anew over the face of the earth. ${ }^{25}$

A scientific development of the History of Creation was impossible in the time of Linnæus, because, among other reasons, the science of petrifactions, or Palæontology, one of its principal bases, did not as yet exist. This science of petrifactions, or of the remains of extinct animals and plants, is most intimately connected with the whole History of Creation. Without reference to it, it is impossible to answer the question as to the manner in which the animals and plants now in existence came into being. But the knowledge of these petrifactions arose in much later times, and the real founder of Palæontology, as a science, was the eminent zoologist, George Cuvier, who followed Linnæus in constructing a System of Animals, and who, in the beginning of this century, brought about a complete reform of Systematic Zoology. The influence of this celebrated naturalist, who displayed an especially great power with extraordinary results during the first thirty years of this century, was so great that he opened new paths in almost every branch of Zoology, but especially in Classification, Comparative Anatomy, and Palæontology. It is, therefore, important to glance at his views of the nature of species. In this respect he followed Linnæus and 
the Mosaic account of Creation, though it was very difficult - for him to do so, on account of the knowledge which he had of fossil animal forms. He was the first to show clearly that a number of totally different series of inhabitants had lived on our globe. He also showed that we must distinguish at least ten or fifteen different main periods in the history of the earth, each of which exhibits a series of animals and plants of its own, peculiar to itself.

Of course, Cuvier was at once confronted with the question, whence these various series of inhabitants had come, and whether they had any connection with each other. $\mathrm{He}$ answered this question negatively, and maintained that these several "creations" were totally independent of each other; hence, that the supernatural act of creation by which, according to the received account of creation, the animal and vegetable species came into being, was repeated several times. Consequently, a series of quite distinct periods of creation must have followed one another, and in connection with them there must have occurred several vast alterations of the whole surface of the earth,--revolutions and cataclysms similar to the mythical Flood. These catastrophes and upheavals were favourite subjects with Cuvier; especially as at that time the science of geology was also beginning to move greatly, and made rapid progress towards a knowledge of the structure and origin of the earth. Others, especially the geologist Werner and his school, were occupied in carefully examining the various layers of the crust of the earth, and systematically investigating the fossils found in these. The result of their researches also was the recognition of several periods of creation. The inorganic crust of the earth, the stratified surface, bore evidence of having 
been just as different at every period as were the animals and plants then inhabiting it. Combining this view with the results of his own palæontological and zoological researches, and striving to understand clearly the whole course of the evolution of Creation, Cuvier arrived at the hypothesis usually called the Theory of Cataclysms or Catastrophes, or the Doctrine of Violent Upheavals. According to it several revolutions occurred on our earth at certain times, suddenly destroying every living inhabitant; and at the end of each of these catastrophes an entirely new creation of organisms took place. But as the latter cannot be conceived as having been effected wholly by natural means, we must suppose, in explanation, that the Creator supernaturally interfered in the natural course of things. This Doctrine of Revolutions, treated by Cuvier in a separate work, which has been translated into several modern languages, was soon generally accepted, and for half a century continued to prevail among biologists; there are even yet a few prominent naturedists who advocate it.

It is true that more than forty years ago Cuvier's Doctrine of Catastrophes was altogether renounced by geologists; and first of all by the English geologist, Charles Lyell, the most important authority in this branch of natural science. As early as the year 1830, in his famous "Principles of Geology," he proved that that doctrine is utterly false so far as the crust of the earth itself is concerned; and he showed that in order to explain the structure and evolution of mountains, there is no need of having recourse to supernatural causes or universal catastrophes. On the contrary, the ordinary causes which eve $\mathrm{a}$ now unceasingly effect the transformation and reconstruction of the earth, are 
amply sufficient to explain these phenomena. These causes are: atmospheric influences; water in its various formssuch as snow and ice, fog and rain, the running stream and the surging sea; and finally, the volcanic phenomena contributed by the hot liquid mass in the interior of the earth. The most convincing proof was furnished by Lyell, that these natural causes are quite sufficient to explain all the phenomena of the structure and development of the crust of the earth. The geological teaching of Cuvier as to the revolutions and new creations was, therefore, soon totally abandoned, but in Biology the doctrine prevailed unopposed for thirty years longer. Zoologists and botanists, as far as they at all permitted themselves to think on the origin of organisms, adhered to Cuvier's false doctrine of repeated new creations and re-formations of the earth. This is certainly one of the most curious examples of two closely related sciences long pursuing utterly divergent courses. One-Biology-remains far behind in the dualistic path, and even denies the possibility of solving "questions of creation" by the study of natural phenomena. The otherGeology-moves far ahead in the monistic path, and solves those very questions by the discovery of the actual causes.

As an instance how utterly biologists refrained from inquiries into the origin of organisms, and the creation of the animal and vegetable species, during this period from 1830 to 1859 , I mention, from my own experience, the fact that during all the whole course of my studies at the university, I never heard a single word on these most important and fundamental questions of biology. During this time, from 1852 to 1857 , I had the good fortune to listen to the most distinguished teachers in all branches of the science of 
organic nature; but not one of them ever spoke of this fundamental point, or even once alluded to the question of the origin of species. Not a word was ever spoken in reference to the earlier attempts toward understanding the origin of the animal and vegetable species; it was never thought worth while to allude to Lamarck's valuable Philosophie Zoologique, in which that attempt had been made in the year 1809. The enormous opposition which Darwin met with when he first took up this question again may, therefore, be understood. His attempt seemed at first to be unsubstantial and unsupported by previous labours. Even in 1859 the entire problem of creation, the whole question of the origin of organisms, was considered by biologists as supernatural and transcendental. Even in speculative philosophy, in which this question should necessarily be approached from various sides, no one dared to take it seriously in hand.

The dualistic position taken by Immanuel Kant, and the extraordinary importance attached, during the whole of this century, to this most influential of modern philosophers, probably offer the best explanation of the last-mentioned fact. For while this great genius, equally excellent as a naturalist and a philosopher, in the field of inorganic nature aided essentially in constructing a "Natural History of Creation," he for the most part adopted the supernatural view of the origin of organisms. On the one hand, Kant, in his "Universal History of Nature and Theory of the Heavens," made a most successful and important "attempt to treat the constitution and the mechanical origin of the entire universe according to Newtonian principles," or, in other words, to treat it mechanically, to conceive 
it monistically: and this attempt of his to explain the origin of the entire world by means of naturally working causes (causce efficientes), forms to this day the basis of all our natural cosmogony. But, on the other hand, Kant maintained that the "principle of the mechanism of nature here applied, without which, after all, there could be no science of nature," was wholly inadequate to explain the phenomena of organic nature, and especially the origin of organisms; that it was necessary to assume supernatural causes effecting a design (causce finales) for the origin of these natural bodies constructed with design. Indeed, he even went so far as to assert that "it is quite certain we cannot become adequately acquainted with organized beings, and their inner possibilities, by purely mechanical principles of nature, much less are we able to explain them; and that this is so much the case that we may boldly assert that it is not rational for man even to enter upon such speculations, or to expect that a Newton will ever arise who, by natural laws not ordered by design, can render the production of a blade of grass intelligible; in fact, we are compelled utterly to deny that it is possible for man ever to reach such knowledge." In these words Kant most definitely declared the dualistic and teleological standpoint which he adopted in the science of organic nature.

Kant sometimes, however, departed from this standpoint, especially in some very remarkable passages which I have discussed at some length in the fifth chapter of my "History of Creation," in which he has expressed himself in quite the opposite, or monistic sense. With reference to these passages, as I there showed, he might even be declared. 
an adherent of the Theory of Descent. Several very significant expressions, to which Fritz Schultze, in his interesting work on "Kant and Darwin, ${ }^{26}$ has lately again called attention, actually enable us to recognize Kant ${ }^{27}$ as the earliest prophet of Darwinism. He expresses with perfect clearness the great idea of an all-embracing, uniform evolution; he assumes " a variation from the primitive type of the tribe as the result of natural wandering." He even declares that man originally moved on four feet, and that it was only gradually that the human race raised their heads proudly over those of their old comrades, the beasts. But all these evidently monistic utterances are but stray rays of light; as a rule Kant adhered in Biology to those obscure dualistic notions according to which the powers which operate in organic nature are entirely different from those which prevail in the inorganic world. This dualistic, or two-sided conception of nature is still dominant in school-philosophy; most philosophers still consider these two domains of natural phenomena as entirely different. On one side is the field of inorganic nature, the so-called "inanimate" world, where only mechanical laws (causce efficientes) are supposed to operate, of necessity and without purpose. On the other side is the field of "animated" organic nature, all the phenomena of which in their profoundest essence and first origin can be made intelligible only by assuming pre-ordained purposes, or so-called (causce finales) causes fulfilling a design.

Although the question of the origin of animal and vegetable species, and the allied question as to the creation of man, remained until the year 1859 under the sway of these false dualistic prejudices, and were very generally

voL. I. 
declared to be a subject beyond the reach of scientific knowledge, yet even in the beginning of our century there were independent eminent minds, who, undeterred by the prevailing doctrines, took these questions quite seriously in hand. The so-called earlier school of Natural Philosophy, which has so often been abused, deserves the highest praise in this respect. It was represented in France by Jean Lamarck, Buffon, Geoffroy St. Hilaire, and Ducrotay Blainville; in Germany, by Wolfgang Goethe, Reinhold Treviranus, Schelling, and Lorenz Oken.

The gifted naturalist and philosopher who must here be mentioned first, is Jean Lamarck. He was born at Bazentin, in Picardy, August 1, 1744, and was the son of a clergyman who destined him for the Church. He, however, first joined the army, and as a boy of sixteen distinguished himself by his bravery in the battle of Lippstadt in Westphalia, which resulted unfavourably for the French. He was then stationed for several years in a garrison in the south of France. Here he became acquainted with the interesting flora on the Mediterranean coast, which soon won him over to the study of botany. He resigned his commission, and published, as early as the year 1778, his valuable Flore Francaise. For years he could gain no scientific position. It was only in his fiftieth year, in 1794, that he obtained a poor professorship of zoology at the museum of the Jardin de Plantes in Paris. His position caused him to enter more deeply into the study of zoology, towards the classification of which his labours were as valuable and important as those which he had dedicated to systematic botany. In 1802 he published his Considérations sur les corps vivants, which contains the first germs of 
his Theory of Descent. In 1809 appeared the important Philosophie Zoologique, the principal work in which he elaborated this theory. In $\mathbf{1 8 1 5}$ he gave to the world his comprehensive treatise on the Natural History of Invertebrates (Histoire naturelle des animaux sans vertèbres), in the Introduction to which the same theory is again developed. About this time Lamarck entirely lost his eyesight. Grudging fate never favoured him. While his principal opponent, Cuvier, was lucky enough to gain an influential position and the highest rank of scientific fame in Paris, Lamarck, who far surpassed Cuvier in clear and high-minded conception of nature, was obliged to struggle in lonely seclusion for the very necessaries of life, and could obtain no recognition. In 1829 his laborious life closed in the midst of the most needy circumstances. ${ }^{28}$

Lamarck's Philosophie Zoologique was the first scientific outline of a real history of the evolution of Species, a natural history of the creation of plants, animals, and men. The effect produced by this remarkable and important book was, like that of Wolff's, none: neither was understood. No naturalist felt called upon to interest himself seriously in this book, and to forward the development of the rudiments of the most valuable progress in Biology which it laid down. The most eminent botanists and zoologists threw the book entirely aside, and did not consider it worth refuting. Cuvier, who taught and laboureci in Paris as a contemporary of Lamarck, in his account of the progress made in Natural Science, in which the most insignificant observations were mentioned, did not deem it worth while to devote a syllable to this the greatest advance. In short, Lamarck's Zoological Philosophy shared the fate 
of Wolff's Theory of Evolution, and was ignored for half a century. Even Oken and Goethe, the German natural philosophers, who were simultaneously employed in similar speculations, do not appear to have been aware of Lamarck's work. Had they known it, it would have been a great help to them, and they would have worked out the Theory of Evolution to a point beyond that which was otherwise possible to them.

To enable my readers to judge of the great value of the Philosophie Zoologique, I shall here briefly mention some of the most important of Lamarck's ideas. According to him, there is no essential difference between animate and inanimate nature; all nature is a single world of connected phenomena, and the same causes which form and transform inanimate natural bodies are alone those which are at work in animate nature. Hence, we must apply the same methods of investigation and explanation to both. Life is only a physical phenomenon. The conditions of internal and external form of all organisms-plants and animals, with man at their head-are to be explained, like those of minerals and other inanimate natural bodies, only by natural causes (causce efficientes), without the addition of purposive causes (causce finales). The same is true of the origin of the various species. Without contradicting nature, we can neither assume for them one original act of creation, nor repeated new creations as implied in Cuvier's Doctrine of Catastrophes,-but only a natural, uninterrupted, and necessary evolution. The entire course of the evolution of the earth and its inhabitants is continuous and connected. All the various species of animals and plants which we now see around us, or which ever existed, have 
developed in a natural manner from previously existing, different species; all are descendants of a single ancestral form, or at least of a few common forms. The most ancient ancestral forms must have been very simple organisms of the lowest grade, and must have originated from inorganic matter by means of spontaneous generation. Adaptation through practice and habit, to the changing external conditions of life, has ever been the cause of changes in the nature of organic species, and Heredity caused the transmission of these modifications to their descendants.

These are the principal outlines of the theory of Lamarck, now called the Theory of Descent or Transmutation, and to which, fifty years later, attention was again called by Darwin, who firmly supported it with new proofs. Lamarck, therefore, is the real founder of this Theory of Descent or Transmutation, and it is a mistake to attribute its origin to Darwin. Lamarck was the first to formulate the scientific theory of the natural origin of all organisms, including man, and at the same time to draw the two ultimate inferences from this theory: firstly, the doctrine of the origin of the most ancient organisms through spontaneous generation; and secondly, the descent of Man from the Mammal most closely resembling Man-the Ape.

Lamarck attempted to explain the latter process, a most important one, and of special interest to us here, by the same efficient causes to which he had also referred the natural origin of animal and vegetable species. He considered that, on the one hand, practice and habit (Adaptation), and, on the other, Heredity, are the most important of these causes. The chief modifications of the organs of animals and plants result, according to him, from the 
functions or actions of the organs themselves, from the exercise or absence of exercise, the use or disuse of these organs. To mention examples, the Woodpecker and the Humming-bird owe their peculiarly long tongue to their habit of using these organs to take their food out of narrow and deep crevices; the Frog acquired a web between its toes from the motions of swimming; the Giraffe gained its long neck by stretching it up to the branches of trees. Habits, the use and disuse of organs, are certainly of the greatest importance as efficient causes of organic form; but they are insufficient to explain the modification of species. As a second and equally important cause, Lamarck fully perceived that Heredity must necessarily co-operate with Adaptation. He maintained that the variations of organs arising from habit or use are in themselves at first but insignificant in each separate individual; but that by the accumulation of the effects produced in each individual, transmitted from generation to generation in an ever increasing number, they become very significant. This was quite a correct fundamental idea; but Lamarck did not reach the principle which Darwin subsequently introduced as the most important factor in the Theory of Transmutation, namely, the principle of Natural Selection in the Struggle for Existence. Lamarck failed to discover this most important causal relation, and this, together with the low condition of all biological sciences at that time, prevented him from more firmly establishing his theory of the common descent of animals and man.

Lamarck also attempted to explain the evolution of Man from the Ape, as principally due to the progress made by the Ape in its habits of life, the further development and 
increased use of its organs, and to the fact that it transmitted the improvements thus acquired to its descendants. Lamarck considered the most important of these advantageous variations to be the erect gait of Man, the differing form of the hands and feet, the growth of language, and the correlative higher development of the brain. He assumed that the Apes most closely akin to Man, those which became the ancestors of mankind, made the first step toward becoming human when they gave up the habit of climbing and living on trees, and accustomed themselves to an upright gait. This resulted in the carriage peculiar to Man and in the reconstruction of the spinal column and pelvis, as well as in the specialization of the two pairs of limbs -the fore pair developing into hands for the purpose of grasping and touching, while the hind pair were used only for walking, and thus developed into true feet. In consequence of the totally changed mode of life and of the correlation and interrelation of the various parts of the body and their functions, important changes occurred also in other organs and their functions. The change of food, for example, caused a change in the jaws and teeth, and, consequently, in the entire formation of the face. The tail, no longer used, gradually disappeared. As these Apes lived together in societies and acquired regulated family relations, such as are still found among the higher classes of Apes, the social habits, or so-called "social instincts," were especially developed. The Ape's language of mere sounds grew into the word-language of Man, and abstract ideas were accumulated from concrete impressions. The brain gradually developed in correlation with the larynx; the organ of the mind in interrelation with that of speech. These important 
ideas of Lamarck contain the first and oldest germs of a real history of the human tribe.

Toward the end of the preceding and the beginning of this century, the great poet Goethe, whose genius was of the highest order, busied himself, independently of Lamarck, with the problem of creation, and his thoughts on this subject are of special interest. It is well known that Goethe's ready recognition of all the beauties of Nature, and his deep insight into her workings, early attracted him to natural scientific studies of the most various kinds. Throughout his life these formed the favourite occupation of his leisure hours. The theory of colours especially resulted in his well-known and comprehensive work on this subject; but the most valuable and important of Goethe's natural scientific studies are those in connection with organic bodies, with "Life, that splendid, priceless thing." In Morphology, the doctrine of forms, he made most unusually deep researches. Aided by Comparative Anatomy, he obtained most brilliant results in this, and went far in advance of his time. His cranial theory, his discovery of the temporal jawbone in man, and his doctrine of the metamorphosis of plants, must be especially mentioned here. ${ }^{29}$ These morphological studies led Goethe to make those researches into the formation and transformation of organisms which we must rank, after those of Lamarck, among the oldest and profoundest rudiments of phylogenetical science. He came so near the Theory of Descent that he must be classed with Lamarck among the founders of it. It is true that Goethe has nowhere given a connected scientific exposition of his theory of evolution; but his brilliant miscellaneous writings, "Zur Morphologie," 
abound in most excellent ideas. Some of them may indeed be called the rudiments of the Theory of Descent. In proof of this it is sufficient to adduce some of his most remarkable propositions. He says: "This, then, is what we have gained, fearlessly to assert that the more perfect natural organisms, such as Fishes, Amphibia, Birds, Mammals, and Man at the head of the last, have been formed after one primordial type, the very permanent parts of which only vary a little one way or another, and which in the course of reproduction is still being remoulded and perfected" (1796). This "primordial type " of Vertebrates, after which Man also has been shaped, answers to what we call "the common ancestral form of the vertebrate tribe," and from which all the various species of Vertebrates have arisen by constant "development, variation, and reproduction." In another passage Goethe says (1807): "Plants and animals, regarded in their most imperfect condition, are hardly distinguishable. This much, however, we may say, that from a condition in which plant is hardly to be distinguished from animal, creatures have appeared, gradually perfecting themselves in two opposite directions,- the plant is finally glorified into the tree, enduring and motionless, the animal into the human being, of the highest mobility and freedom."

That Goethe, in these and other utterances, did not speak merely figuratively, that he grasped the internal relation and connection of organic forms in a genealogical sense, is yet more evident in remarkable separate passages in which he declares himself as to the causes of the external multiplicity of species, on the one hand, and of the internal anity of their structure on the other. He assumed that 
every organism is the product of the co-operation of two contrary constructive forces, or formative tendencies. One, the internal formative tendency, "the centripetal force," is that of the type, or "the tendency toward specification," which constantly aims at maintaining uniform the organic forms of the species in the series of generations. This is Heredity. The other, the external formative tendency, "the centrifugal force," is variation, or "the tendency toward metamorphosis," which acts, through the continual changes made in the external conditions of their existence, so as continually to vary the species. This is Adaptation.

In this significant conception, Goethe very nearly conceived the two great mechanical factors, Heredity and Adaptation, which are, we assert, the most important efficient causes of the formation of species. For example, he says, that "at the foundation of all organization there is an original intrinsic kinship" (which is Heredity); "the variety of forms, however, is due to the conditions of relation. necessarily held to the external world, on account of which we may properly assume, for the purpose of explaining the present forms, which are both varied and unvaried, that there was diversity, originally and simultaneously, and that a progressive transformation is continually going on". (which is Adaptation).

In order rightly to appreciate Goethe's morphological views it is, however, necessary to grasp the connection between the whole peculiar course of his monistic study of nature and his pantheistic conception of the world. Most significant in this respect is the lively and warm interest with which he followed the efforts which the French 
natural philosophers were making in the same direction, and especially the contest between Cuvier and Geoffroy St: Hilaire. (See Chapter IV. in "History of Creation.") It is also necessary to be in some degree master of Goethe's language and his process of thought, before it is possible rightly to understand the many expressions, often incidental, which refer to the doctrine of descent. He who does not know the great poet and thinker as. a whole, may possibly even construe these very expressions in a contrary sense.

In proof of this I adduce the strange fact that two second-rate German zoologists have recently discovered that Goethe was an extremely narrow-minded naturalist and a "willing adherent of the doctrine of constancy of species." Karl Semper, the gifted discoverer of "Haeckelism in Zoology," and Robby Kossman, the ingenious "Solver of the Rhizo-cephalic Problem," have extracted from Goethe's morphological writings that the latter needy Frankfort geniuses had neither a clear conception of the whole significance of organic forms, nor the faintest idea of the natural evolution of these forms, and of their connection by common descent. All who know the poor and narrowminded literary productions of Semper and Kossman must smile at the sentence of annihilation thus pronounced on Goethe's conception of nature.

Notwithstanding the condemnation by these great students of animal life, the rest of the world may continue to admire Goethe as a true prophet of the theory of descent. The numerous sentences which I have prefixed, as mottos to the chapters of the Generelle Morphologie, clearly show how far Goethe had advanced in his conception of the innate genealogical connection of the diverse organic 
forms. At the end of the last century he so nearly grasped the principles of natural tribal history, that we are justified in regarding him as one of the earliest forerunners of Darwin, although, unlike Lamarck, he did not formulate the Theory of Descent in a scientific system. 


\section{CHAPTER V.}

\section{MODERN PHYLOGENY.}

\section{Charles Darwin.}

Relation of Modern to Earlier Phylogeny.-Charles Darwin's Work on the Origin of Species.-Causes of its Remarkable Success.-The Theory of Selection : the Interrelation of Hereditary Transmission and Adaptation in the Struggle for Existence.-Darwin's Life and Voyage Round the World.-His Grandfather, Erasmus Darwin.-Charles Darwin's Study of Domestic Animals and Plants.-Comparison of Artificial with Natural Conditions of Breeding.-The Struggle for Existence.-Necessary Application of the Theory of Descent to Man.-Descent of Man from the Ape. - Thomas Hnxley.-Karl Vogt. - Friedrich Rolle.The Pedigrees in the Generelle Morphologie and the "History of Creation."-The Genealogical Alternative.-The Descent of Man from Apes deduced from the Theory of Descent.-The Theory of Descent as the Greatest Inductive Law of Biology.-Foundation of this Induction.-Palæontology.-Comparative Anatomy.-The Theory of Rudimentary Organs.-Purposelessness, or Dysteleology.-Genealogy of the Natural System.-Chorology.-CEkology.-Ontogeny.-Refatation of the Dogma of Species.-The "Monograph on the Chalk Sponges;" Analytic Evidence for the Theory of Descent.

"By considering the embryological structure of man-the homologies which he presents with the lower animals - the rudiments which he retainsand the reversions to which he is liable, we can partly recall in imagination the former condition of our early progenitors; and can approximately place them in their proper position in the zoological series. We thus learn that man is descended from a hairy quadruped, furnished with a tail and pointed ears, probably arboreal in its habits, and an inhabitant of the Old World. 
This creature, if its whole structure had been examined by a naturalist, would have been classed among the Quadrumana, as surely as would the common and still more ancient progenitor of the Old and New World monkeys."-CharLis Darwin (1871).

In the short time that has passed since the appearance of Charles Darwin's book "On the Origin of Species in the Animal and Vegetable Kingdom," the History of Evolution has advanced so greatly that it is scarcely possible to point to an equally great advance throughout the whole record of the Natural Sciences. The literature of Darwinism is increasing day by day, not only in connection with Zoology and Botany-which are the special sciences most affected and reformed by the Darwinian Theory-but far beyond. It is applied in much wider circles with a zeal and interest which no other scientific theory has ever aroused. There are two distinct circumstances which principally explain this extraordinary success. In the first place, all the natural sciences, and especially Biology, made unusually rapid progress during the preceding half century, and from actual experience many new data for the theory of natural evolution were amassed. When compared with the failure of Lamarck, and the earlier naturalists to obtain recognition for their first attempts to explain the origin of organisms and of man, the success of the second attempt, made by Darwin, who had at his command such vast accumulations of well-attested facts, was all the more thorough. In availing himself of recent progress, the latter was able to employ quite other scientific evidence than Lamarck and Geoffroy, Goethe and Treviranus, could command. But, in the second place, we must give due weight to the fact that Darwin has the especial merit of having approached the 
question from an entirely new direction, and of having worked out that independent theory in explanation of the Doctrine of Descent which we properly call the Darwinian Theory, or Darwinism.

While Lamarck explained the variation of organisms descended from common ancestral forms, as especially the effect of habit and the use of the organs, but also by the aid of the phenomena of Heredity, Darwin independently, and on an entirely new basis, unfolded the actual causes which mechanically accomplish the modification of the various animal and vegetable forms by the aid of Adaptation and Heredity. Darwin deduced his "Theory of Selection" from the following considerations. He compared the origin of the various breeds of animals and plants which man is able to produce artificially,--the conditions of "Selection" in horticulture, and in the breeding of domestic animals, - with the origin of wild species of plants and animals in a natural state. He thus found that causes similar to those which, in artificially breeding domestic animals, and raising cultivated plants, we apply to alter the forms, are also at work in Nature. He named the most effective of all the co-operating causes the Struggle for Existence. The gist of Darwin's theory, properly so called, is this simple idea: that the Struggle for Existence in Nature evolves new Species without design, just as the Will of Man produces new Varieties in Cultivation with design. Just as the gardener and the farmer breed for their own advantage, and according to their own will, making judicious use of the productive effects of Heredity and Adaptation, so does the Struggle for Existence constantly modify the forms of vegetables and 
animals in an undomesticated state. This Struggle for Existence, or the universal efforts of organisms to secure the necessary means of existence, works without design, but yet in the same way modifies the organisms. But as under its influence Heredity and Adaptation enter into most intimate reciprocal relations, there necessarily arise new forms, or variations, which are of advantage to the organism, and which have, therefore, an object, although in reality not originating from a preconceived design.

This simple fundamental idea is the real gist of Darwinism, or the "Theory of Selection." Its author conceived the idea long ago, but with admirable industry he employed twenty years in collecting data from actual experience for proving his theory before declaring it. In the "History of Creation" (Chapter VI.), I gave a full account of the method by which he reached his results, as well as of his most important writings, and his life. I shall, therefore, now only allude very briefly to some of the most important points. ${ }^{30}$

Charles Darwin was born on the 12th of February, 1809, at Shrewsbury, where his father, Robert Darwin, practised as a physician. His grandfather, Erasmus Darwin, was a thoughtful naturalist, who laboured in the line of the earlier natural philosophy, and who, toward the end of the eighteenth century, published several works on that subject. The most important of these is his "Zoonomy," which appeared in 1794, and in which he expressed views like those of Goethe and Lamarck, though he knew nothing of the similar efforts of these contemporaries. Erasmus Darwin transmitted to his grandson Charles, according to the law of latent transmission (Atavism), certain mole- 
cular movements of the cells in the ganglia of his powerful brain, which had not made their appearance in his son Robert. This fact is of great interest in relation to the remarkable law of Atavism which Charles Darwin himself has so well discussed. But in the writings of Erasmus Darwin, formative imagination too greatly outweighs critical judgment, while in his grandson, the two are evenly balanced. As, at present, many naturalists of limited genius regard imagination as superfluous in Biology, and their own lack of it as a great and "exact" advantage, I take this opportunity of calling attention to a striking remark of an able naturalist, who was himself one of the leaders of the school called "exact," confining itself strictly to experience. Johannes Müller, the German Cuvier, whose works will always be regarded as models of exact investigation, declared that continuous interaction and harmonious balance of imagination and reason, are the indispensable conditions of the most important discoveries. This passage is given in full as a motto at the beginning of the eighteenth chapter.

After completing his university studies in his twentysecond year, Charles Darwin was fortunate enough to accompany an expedition which sailed round the world for scientific purposes. This lasted for five years, thus affording him an abundance of most instructive suggestions and of opportunities for the contemplation of Nature in its grandest forms. In the very beginning of the voyage, when he first landed in South America, he noticed a variety of phenomena, which suggested to him the great problem of his life-long work, the question of the "Origin of Species." On the one hand, the instructive phenomena of the geogra-

vOL. I. 
phical distribution of species, and on the other, the relation between the living and extinct species of the same continent, suggested to him the idea that nearly allied species might have descended from a common ancestral form. On his return from his five years' voyage, he devoted himself for years most zealously to the systematic study of domestic animals and garden-plants, and he recognized the evident analogies between the formation and transmutations of these, and those of wild species in a state of nature. He had, however, no conception of natural selection through the struggle for existence, which is the most important feature in the construction of his theory, until after he had read the celebrated book of Malthus, the political economist, on the "Principles of Population." This gave him a clear conception of the analogy between the changing relations of population and over-population in civilized countries and the social relations of animals and plants in a wild state. He continued for many years to collect materials in order to accumulate a great mass of evidence for the support of this theory. At the same time, as a practical breeder, he instituted many important experiments in breeding, and gave special attention to the instructive breeding of domestic pigeons. Ample leisure was afforded him by the quiet retirement in which, after his return from his journey round the world, he has lived on his property of Down, near Beckenham.

It was not until the year 1858 , that Darwin was induced, by the work of another naturalist, Alfred Russell Wallace, who had conceived the same Theory of Selection, to publish the outlines of his theory. In 1859 appeared his principal work, "On the Origin of Species," in which the theory is 
exhaustively discussed, and is established by the weightiest evidence. Having fully expressed my opinion of this book in my Generelle Morphologie, and in the "History of Creation," it will here be sufficient to recapitulate briefly the gist of the Darwinian theory, on the right understanding of which everything depends. The whole is based on the simple fundamental idea that the Struggle for Existence in Nature modifies organisms, and produces new species by the aid of the same means by which man produces new domesticated varieties of animals and plants. These means consist in the constant preference or selection of the individuals most suitable for propagation, so that the interaction of Heredity and Adaptation acts as a modifying cause. ${ }^{31}$

The celebrated traveller Wallace had independently formed the same conclusions. He had, however, by no means determined the influence of Natural Selection in forming species as clearly and thoroughly as had been done by Darwin. But the writings of Wallace (especially those on Mimicry, etc.) 'contain many admirable, original contributions to the Theory of Selection. It is most unfortunate that the imagination of this gifted naturalist has since become diseased, and that he now only plays the part of a spiritualist in the spiritualistic society of London.

The effect produced by Darwin's book on "The Origin of Species by Natural Selection" in the animal and vegetable kingdom, was extraordinarily great, though not at first in the special branch of science to which it most directly applied. Several years passed before botanists and zoologists recovered from their surprise at the new views of nature advanced by this great reconstructive work. The 
effect of the book on the special sciences with which zoologists and botanists are concerned, has become really prominent only during the past few years, during which the Theory of Descent has been applied in Anatomy and Ontogeny, and in zoological and botanical classification. In some ways it has already caused extraordinary progress and a great reform in the prevailing views.

But in Darwin's first work of 1859, the point which most interests us here-the application of the Theory of Descent to Man-was not touched at all. For many years it was even asserted that Darwin had no intention of applying his theory to Man, but that he shared the prevalent opinion, that an entirely peculiar place in creation must be assigned to Man. Not only men unversed in science, including very many theologians, but even educated naturalists, asserted with the greatest ingenuousness, that the Darwinian Theory in itself was not to be combated, and was entirely correct, for it afforded an excellent means of explaining the origin of the various species of animals and plants; but that the theory was in no way applicable to Man.

In the mean time, however, many thoughtful people, naturalists as well as others, expressed the opposite opinion, that it necessarily follows as the logical conclusion from the Theory of Descent, as formulated by Darwin, that Man must have descended from other animal organisms, and, immediately, from Mammals resembling Apes. The truth of this conclusion was early recognized by many thoughtful opponents of the theory. Just because they regarded this as a necessary consequence, many felt that the whole theory must be rejected. The first scientific application of this 
theory to Man was made by Huxley, who now holds the first place among English zoologists. ${ }^{32}$ This able and learned philosopher, to whom much progress in zoological science is due, published a little work entitled "Evidences of Man's Place in Nature," in the year 1863, containing three essays: 1. On the Natural History of Manlike Apes; 2. On the Relations of Man to the Lower Animals; 3. On Some Fossil Remains of Man. In these three very important and interesting essays, it is clearly shown that the much-disputed descent of Man from the Ape is the necessary consequence of the Theory of Descent. If the Theory of Descent is correct as a whole, it is impossible not to regard the Apes most resembling Man as the animals from which the human race has been immediately evolved.

Almost simultaneously Karl Vogt, a most acute zoologist, published.a larger work on the same subject, entitled "Lectures on Man, his Place in Creation and in the History of the Earth." This author has since partly retracted his views, and has, indeed, quite recently adopted the strange assumption that the descent of Man can only be traced from the Apes, and not from the yet lower animals. This, however, only shows that Vogt has not followed the recent progress of Zoology, and that he has long ceased to sympathize with the most important parts of the History of Evolution.

Gustav Jaeger ${ }^{33}$ and Friedrich Rolle ${ }^{34}$ must be mentioned among zoologists who, after the publication of Darwin's work, took up the Theory of Descent, advanced it, and drew the right logical conclusion, that Man is descended from the lower animals. Friedrich Rolle, in $\mathbf{1 8 6 6}$ 
published a work on "Man, his Descent and Ci-ilization, in the light of the Darwinian Theory."

At the same time, in the second volume of my Generelle Morphologie der Organismen, which appeared in 1866, I made the first attempt to apply the Theory of Evolution to the entire classification of organisms, including $\mathrm{Man}^{35}$ I tried to sketch the hypothetical genealogies of the different classes of the animal kingdom, of the kingdom of Protista, and of the vegetable kingdom, not only as they must be according to the principles of the Darwinian Theory, but also, as it is already really possible to do, with a certain degree of probability. For, if the Theory of Descent, as first definitely stated by Lamarck, and afterwards firmly established by Darwin, is correct in its general principles, then it mist also be possible to interpret the natural system of plants and animals genealogically, and to place the smaller and larger divisions recognized in the system, as limbs and branches of a genealogical tree. The eight genealogical tables which I appended to the second volume of the Generelle Morphologie, are the first attempts to accomplish this. In the twenty-seventh chapter of the same work are given the most important stages in the ancestral line of the human race, as far as they can be traced in the descent of Vertebrates. I there attempted especially to determine the place in the mammalian class assigned to Man by the system, and, as far as seems possible at present, the genealogical significance of the latter. In the twenty-second and twenty-third chapters of my "History of Creation," I materially improved on this attempt and explained it in a more popular form.

At last, in 1871, Darwin himself published a very in- 
teresting work, which contains the much-disputed application of his theory to Man, and which, therefore, completes his great doctrine. In this work, entitled "The Descent of Man, and Selection in Relation to Sex," ${ }^{36}$ Darwin has openly and most logically drawn the inference, about which he had before purposely maintained silence, that Man also must have been evolved from lower animals. In a most masterly manner he discussed especially the very important part paid by Sexual Selection in the progressive exaltation of Man, and of all other higher animals. According to this theory, the careful selection which the two sexes exercise on each other, in relation to their sexual connection and reproduction, and the resthetic taste evinced by the higher animals in this matter, has a most important influence on the progressive evolution of forms and in the distinction of the sexes. The male animals seek out the most beautiful females, and, on the other hand, the females choose the finest males, so that the specific, and at the same time the sexual character is continuously ennobled. In this respect many of the higher animals exercise a better taste and a more impartial judgment than does man. But even among men sexual selection has given rise to a noble form of family life, which is the chief foundation on which civilization and social states have been built. The human race certainly owes its origin in great measure to the perfected Sexual Selection which our ancestors exercised in the choice of wives. (Cf. Chapter XI. of the "History of Creation," and pp. 244-247 in the second volume of the Generelle Morphologie.)

In all essential points Darwin approves of the general outline of the genealogical tree given in the Generelle Mor- 
phologie and the "History of Creation," and he expressly states that his experience points to the same conclusions. It is impossible not to appreciate his great wisdom in not himself applying the Theory of Descent to Man, in his first work; for the inference was of a sort to raise the strongest prejudices against the entire doctrine. It was at first only necessary to establish the theory in relation to the species of animals and plants. Its application to Man then inevitably followed sooner or later.

It is most important to understand this connection rightly. If all organisms have sprung from a common root, Man is also included in this common descent. But if, on the contrary, each separate kind or species of organism has been separately created, then Man was also "created, not evolved." Between these two opposite views lies our choice; and this decisive alternative cannot be often enough and prominently enough placed in the foreground. Either all the various species of the vegetable and animal kingdoms are of supernatural origin, created, not evolvedin which case Man is also the product of a supernatural act of creation, as is assumed in all the various systems of religious belief; or, the various species and classes of the animal and vegetable kingdoms have evolved from a few common and most simple ancestral forms; and if this is the case, man himself is the latest product of the evolution of the genealogical tree of animals.

The connection between the two may be concisely stated as follows: the Descent of Man from lower animals is a special deductive law, necessarily following from the general inductive law of the entire Doctrine of Descent. This sentence formulates the relation most clearly and simply. 
The Doctrine of Descent is really nothing but a great inductive law, to which we are led by grouping and comparing the most important empirical laws of Morphology and Physiology. We are obliged to draw our conclusions according to the laws of induction in every case in which we are unable to establish the truths of nature immediately by the infallible method of direct measurement, or mathematical calculation. In the study of animated nature, we are seldom able entirely to ascertain the significance of phenomena immediately, and by infallible mathematical means, as is possible in the much simpler study of inorganic bodies, in Chemistry, Physics, Mineralogy, and Astronomy. In the last especially, we can always employ the very simple and absolutely sure method of mathematical calculation. But in Biology, this is for many reasons entirely impossible, and especially because the phenomena in it are far too complex to admit of immediate solution by mathematical analysis. We are therefore compelled to proceed inductively; in other words, from the mass of separate observation we must gradually draw general conclusions, which must be more and more approximately correct. These inductive conclusions, it is true, cannot claim the absolute certainty of mathematical propositions; but they are more and more approximately true in proportion with the increase in extent of the experiences on which they are based. The importance of such inductive laws is in no way lessened by the circumstance that they must only be regarded as provisional scientific achievements, which may possibly be improved, or perfected, by the further progress of knowledge. This is equally true of the greater part of knowledge in other sciences; for example, in Geology and 
Archæology. However much particular items of such inductive knowledge may in time be improved and modified; their general significance, as a whole, remains quite untouched.

The Theory of Descent, according to Lamarck and Darwin, as a great inductive law, and indeed the greatest of all inductive biological laws, is in the first place based on the facts of Palæontology, on the modification of species brought to light by the science of Petrifactions. From the conditions under which these fossils, or petrifactions, are found buried in the rock-layers of our earth, we draw the first sure conclusion, that the organic population of the earth, as well as the crust of the earth itself, has been slowly and gradually evolved, and that series of diverse populations have successively appeared at different periods of the earth's history. Modern geology shows us that the evolution of the earth has been gradual, and without total and violent revolutions. Comparing the various plant and animal creations that have successively appeared during the course of the earth's history, we find, in the first place, that an increase in the number of species has been constant and gradual from the earliest to the most recent times; and, in the second place, we perceive that the increase in the perfection of the forms belonging to each of the larger groups of animals and plants is also constant. For example, the only Vertebrates existing in the earliest times are the lower Fishes; then the higher kinds of Fishes; later Amphibia appear; still later, the three higher classes of Vertebrates, Reptiles first, then Birds, and Mammals; of these only the most imperfect and lowest forms appear first; it is only at a very late period that the higher placental Mammals 
appear, and among the latest and youngest forms of the latter is Man. Both the perfection of forms and their variety originate, therefore, only gradually, and in a period extending from the oldest time to the present day. This fact is of great importance, and can be explained only by the Doctrine of Descent, with which it perfectly agrees. If the various groups of plants and animals really descended one from another, then such an increase in number and degree of perfection, as the series of fossils actually exhibits, must necessarily have occurred.

A second series of phenomena of great importance for the inductive law with which we are dealing, is contributed by Comparative Anatomy. This latter is that part of Morphology, or the Science of Forms, which compares the developed organic forms, and seeks, in their great variety, to find the one common law of their organization, or, as it was formerly called, the "general plan of structure." Since Cuvier first formed this science, at the beginning of this century, it has always been a favourite study of the most eminent naturalists. Goethe, even before him, had been greatly attracted by the charm of the mysteries which it solved, and had been drawn into the study of Morphology. It was especially Comparative Osteology, the philosophical observation and comparison of the bony skeletons of Vertebrates, which is really one of the most interesting branches of the science, that riveted his attention and led him to form his Theory of the Skull, which has already been mentioned. Comparative Anatomy teaches that in each line of descent in the animal kingdom, and in each class in the vegetable kingdom, the inner structures of all the animals belonging to the one, and of the plants belonging to the other, are in 
all essential points in the highest degree similar, even though the outward forms are extremely unlike. Man, accordingly, in all essential features of internal organization so closely resembles other Mammals, that no comparative anatomist has ever doubted that he belongs to that class. The whole inner structure of the human body, - the disposition of its various systems of organs,- the arrangement of the bones, muscles, blood-vessels, and the like,-the coarser and more minute structure of all these organs, corresponds so well with that of all other Mammals,-such as Apes, Gnawing animals (Rodentia), Hoofed animals (Ungulata), Whales, and Oppossums,- that the complete dissimilarity of the outward form is as nothing in the balance against it. We learn also from Comparative Anatomy that the fundamental characteristics of animal organization are so much alike, even within the various classes, numbering from thirty to forty in all, that they may fittingly be arranged in from six to eight principal groups. But even in these few groups, which represent the lineages or types of the animal kingdom, it can be shown that certain organs, especially the intestinal canal, were originally uniform.

We can only explain this most essential uniformity in all these various animals, notwithstanding their great external dissimilarity, by the aid of the Theory of Descent. Only by considering the internal correspondence as the result of Heredity from common ancestral forms, and the external dissimilarity as the result of Adaptation to varied conditions of life, can this wonderful fact be thoroughly understood.

The recognition of this truth raised Comparative Anatomy itself to a higher rank, so that Gegenbaur, ${ }^{37}$ the 
ablest living representative of this science, could say with perfect justice, that the Theory of Descent opened a new period in Comparative Anatomy, and that the former is the touchstone of the latter. "So far, no experience in Comparative Anatomy is contradictory to the theory of Descent; all rather lead to it. So that the theory will receive back from the science that which it has imparted to its methods; namely, clearness and certainty." Formerly, the remarkable internal similarity of structure in organisms had been a source of wonder, incapable of explanation. Now, however, we can understand the causes of these facts, and can prove that this wonderful uniformity is simply the necessary consequence of Heredity from common ancestral forms, and that the striking dissimilarity of the external form is the necessary consequence of Adaptation to the outward conditions of existence.

There is a special branch of Comparative Anatomy which is peculiarly interesting in this respect, and at the same time of the most extended philosophical significance. This is the science of Rudimentary Organs, which we may call, in reference to their philosophical consequences, the Doctrine of Purposelessness, or Dysteleology. Almost every organism, with the exception of the lowest and most imperfect, and especially every highly developed vegetable or animal body, man as well as others, possesses one or more structures which are useless to its organism, valueless for its life-purposes, worthless for its functions. Thus all of us have in our bodies various muscles which we never use; for example, the muscles in the external ear and the parts immediately surrounding it. These outer and inner ear muscles are of great use to most Mammals, especially such 
as have the power of erecting the ears, because the form and position of the ear may thus be materially altered, in order to take in the various waves of sound in the best possible manner. In Man, however, and in other animals not possessing the power of pricking up the ears, the muscles, though present, are useless. As our ancestors long ago discontinued to make use of them, we have lost the power of moving them. Again, there is in the inner corner of our eye a small crescent-shaped or semi-lunar fold of skin; the last remnant of a third inner eyelid, the so-called nictitating membrane. In our primitive relatives, the Sharks, and in many other Vertebrates, this membrane is highly developed, and of great use to the eye; but with us it is abortive and entirely useless. On the intestinal canal we have an appendage, which is not only useless, but may become very injurious, the so-called vermiform appendage of the cæcum. This little appendage of the intestine not infrequently causes fatal disease. If in the process of digestion, by an unlucky accident, a cherry-stone or some similar hard body is pressed into its narrow passage, a violent inflammation ensues, which usually causes death. This vermiform appendage is not of the slightest use in our organism; it is the last and dangerous remnant of an organ, which was much larger in our vegetarian ancestors, and was of great use to them in digestion; as it is still in many herbivorous animals, such as Apes and Rodents, in which it is of considerable size, and of great physiological importance.

Other similar rudimentary organs exist in us, as in all higher animals, in different parts of the body. They are among the most interesting phenomena with which Com- 
parative Anatomy acquaints us ; firstly, because they afford the most obvious proof of the Theory of Descent, and secondly, because they most forcibly refute the customary teleological philosophy of the schools. The Doctrine of Descent renders the explanation of these remarkable phenomena very simple. They must be regarded as parts which in the course of many generations have gradually been disused and withdrawn from active service. Owing to disuse and consequent loss of function, the organs gradually waste away, and finally entirely disappear. The existence of rudimentary organs admits of no other explanation. Hence, they are of the greatest philosophical importance; they clearly prove that the mechanical, or monistic conception of the nature of organisms is alone correct, and that the prevailing teleological, or dualistic method of accounting for them, is entirely false. The very ancient fable of the all-wise plan according to which "the Creator's hand has ordained all things with wisdom and understanding," the empty phrase about the purposive "plan of structure" of organisms is in this way completely disproved. Stronger arguments can hardly be furnished against the customary teleology or Doctrine of Design, than the fact that all more highly developed organisms possess such rudimentary organs.

The favourite phrase, "the moral ordering of the world," is also shown in its true light by these dysteleological facts. Thus viewed, the "moral ordering of the world" is evidently a beautiful poem which is proved to be false by the actual facts. None but the idealist scholar, who closes his eyes to the real truth, or the priest, who tries to keep his spiritual flock in ecclesiastical leading-strings, can 
any longer tell the fable of "the moral ordering of the world." It exists neither in nature nor in human life, neither in natural history, nor in the history of civilization. The terrible and ceaseless "Struggle for Existence" gives the real impulse to the blind course of the world. A "moral ordering," and "a purposive plan" of the world can only be visible, if the prevalence of an immoral rule of the strongest and undesigned organization is entirely ignored.

The Natural System of Organisms, which classifies all the various forms in larger and smaller groups, according to the degree of similarity or dissimilarity of these forms, is the widest inductive basis of the Theory of Descent. These groups or categories of the system, the varieties species, genera, families, orders, classes, and so on, always show such relative eo-ordination and subordination that they can be explained only genealogically, and the whole system can but be represented figuratively under the form of a tree with many branches. This tree is the genealogical tree of the groups related in form, and their relation in form really is their relation in blood. As no other explanation can be given of the fact that the system naturally assumes a tree-like form, we may regard this as an immediate and powerful proof of the truth of the Doctrine of Descent.

Among the most important of the phenomena, testifying to the inductive law of the Theory of Descent, is the geographical distribution of animal and vegetable species over the surface of the earth, and their topographical distribution on the heights of mountains and in the depths of oceans. Alexander Humboldt gave a fresh impulse to the 
scientific investigation of these conditions, to the Science of Distribution, or Chorology; but until Darwin, people were satisfied to observe the phenomena of Chorology, and tried principally to establish the demarcations of the distributions of existing organic groups of greater or less extent. But the causes of the remarkable phenomena of distribution, the reasons why some groups exist only here, others only there, and why there are such numerous divisions of the various species of plants and animals, it was impossible to explain. The Doctrine of Descent, for the first time, furnishes the key to the solution of this problem also; it alone puts us in the right way to obtain an explanation, by showing us that the various species and groups of species spring from common ancestral species, the widely diverging posterity of which gradually spread over the whole earth. Yet for every group of species there must be assumed a socalled "centre of creation"- - that is, a common cradle, or original habitat, in which the common ancestral species of a group first evolved, and from which their immediate descendants dispersed in different directions. Individuals of these migrated species became in their turn the ancestral species of new groups, which again, by active and passive migration, dispersed; and so on. As every form after its migration adapted itself to new conditions of existence in its new home, it underwent modification, and gave rise to new series of forms.

Darwin, by the Theory of Descent, was the first to establish this highly important doctrine of active and passive migrations. At the same time he correctly pointed out the significance of the important chorological relations between the living population of each region and their fossil vol. I. 
ancestors and allied forms. Moritz Wagner worked out this point most excellently under the name of "The Theory of Migration." 38 But, in our opinion, this famous traveller has over-estimated the importance of his "Theory of Migration," in so far as he declares it to be a condition necessary to the rise of new species, and holds the "Theory of Selection" to be incorrect. The two theories are, however, in no way opposed. On the contrary, migration, by which the ancestral species of a new kind becomes isolated, is only a special form of selection. The great and interesting series of chorological phenomena, since they can only be explained by the Theory of Descent, must also be considered as important inductive data of the latter.

Exactly the same is true of all the remarkable phenomena which, in the "Household of Nature," we observe in the economy of the organisms. All the various relations of animals and plants, to one another and to the outer world, with which the CEkology of organisms has to do, and especially such interesting phenomena as those of parasitism, of family life, of the care of young, and of socialism,-all admit of simple and natural explanation only by the Doctrine of Adaptation and Heredity. While it was formerly usual to marvel at the beneficent plans of an omniscient and benevolent Creator, exhibited especially in these phenomena, we now find in them excellent support for the Theory of Descent; without which they are, in fact, incomprehensible.

Finally, the whole of Ontogeny, the history of the individual evolution of all organisms, is an important inductive foundation of the Theory of Descent. But as this subject will be especially treated in later chapters, nothing further need be said of it here. Step by step, I shall endeavour. 
to show that the whole of the phenomena of Ontogeny forms a connected chain of evidence in favour of the truth of the Theory of Descent, and that they can be explained only by Phylogeny. With the aid of this close causal connection between Ontogeny and Phylogeny, and by constantly appealing to our fundamental law of Biogeny, we shall be gradually able to prove from the facts of Ontogeny that Man is descended from the lower animals.

In conclusion, it must be mentioned that very recently the important theoretical question as to the nature and idea of "kind," or "species," which is the point on which really hang all the disputes about the Theory of Descent, has been definitely settled. For more than a century this question was discussed from the most varied points of view, without resulting in a satisfactory settlement. During that time thousands of zoologists and botanists have occupied themselves in systematically distinguishing and describing species, without, however, any clear idea of the meaning of "species." Many hundred thousand vegetable and animal forms were set up and marked as good species, though even those who declared them such were unable to justify the proceeding, or to give logical reasons for thus distinguishing them. Endless disputes arose among the "pure systematizers," on the empty question, whether the form called a species was "a good or a bad species, a species or a variety, a sub-species or a group," without the question being even put as to what these terms really contained and comprised. If they had earnestly endeavoured to gain a clear conception of the terms, they would long ago have perceived that they have no absolute meaning, but are merely stages in the classification, or systematic categories, and of relative importance only. 
It is true that in the year 1857 a celebrated and able, but very untrustworthy and dogmatic naturalist, Louis Agassiz, attempted to give an absolute signification to these categories. He attempted this in an "Essay on Classification," in which the phenomena of organic nature were inverted, and in which, instead of explaining these by natural causes, he examined them through the seven-sided prism of theological dreams. Every "good species, or bona species," is, according to him, "an embodiment of a creative thought of God." But this fine phrase is as little able to hold its ground against the criticism of natural science, as all other attempts to preserve an absolute conception of species. I think I have demonstrated this sufficiently in my Generelle Morphologie (vol. ii. pp. 323-402), in the exhaustive critique there given of the morphological and physiological idea of species and of systematic categories.

Moreover, Agassiz can himself hardly have believed his theosophic phrases. This great American, who, as Carus Sterne rightly said, laid the foundation of much natural science, ${ }^{39}$ was, in reality, gifted with too much genius actually to believe in the truth of the mystic nonsense which he preached. Crafty calculation, and well-judged reliance on the want of understanding of his credulous followers, can alone have given him courage to pass the juggler's pieces of his anthropomorphic Creator as true coin. The divine Creator, as represented by Agassiz, is but an idealized man, a highly imaginative architect, who is always preparing new building plans and elaborating new species. (Cf. Chap. III. of the "History of Creation," and also "The Aims and Methods of the History of Evolution." Jena, 1875.) 
When, in 1873, the grave closed over Louis Agassiz, the last great upholder of the constancy of species and of miraculous creation, the dogma of the constancy of species eame to an end, and the contrary assumption - the assertion that all the various species descend from common ancestral forms-now no longer encounters serious difficulties. All the elaborate inquiries as to the real nature of species, and how it is possible that various species can proceed from a single ancestral species, have now been brought to a perfectly satisfactory close by the fact that the sharp demarcations between species and variety on the one side, between species and genus on the other, have been entirely set aside. I have given the analytical evidence of this in my "Monograph on Chalk Sponges," 40 which appeared in 1872. In it I closely examined the variations of all the species of this small, but highly instructive group of animals, and demonstrated in every instance the impossibility of dogmatic distinctions of species. Just in proportion as the systematizer takes the ideas of Genus, Species, and Varieties in a wider or narrower sense, he distinguishes in the little group of Chalk Sponges, either only a single genus with 3 species, or 3 genera with 21 species, or 21 genera with 111 species, or 39 genera with 289 species, or even 113 genera with 591 species. But all these diverse forms are so intimately connected by numerous transitions and intermediate forms that the common descent of all the Chalk Sponges from a single ancestral form, the Olynthus, can be proved with certainty.

I think I have thus given the analytical solution of the problem of the Origin of Species, and have thus satisfied the demands of those opponents of the Theory of Descent who 
wished to see the origin of allied species from a single ancestral form proved "in special instances." Those who are not satisfied with the synthetic proofs of the truth of the Doctrine of Descent, as afforded by Comparative Anatomy and Ontogeny, Palæontology and Dysteleology, Chorology and Classification, may try to overthrow the analytic proofs in the "Monograph on Chalk Sponges," which was the product of five years of the closest observa tion. I repeat: if any one still asserts, in opposition to the, Theory of Descent, that the derivation of all the species of a group has hitherto never been convincingly shown in a special instance, the assertion is now completely without foundation. The "Monograph on the Chalk Sponges" furnishes this analytic proof in detail, entirely from facts, and, as I am convinced, also with incontrovertible certainty. Every naturalist who will examine the extensive material used in my investigations, and follow my statements, will find that in the Chalk Sponges, the various species can be traced step by step through the course of their evolution in statu nascenti. But, if this is really the case, if, in a single class or family, the derivation of all the species from a common ancestral form can be shown, then the problem of the Descent of Man has been definitely solved; and we are able to demonstrate the derivation of man also from lower animals.

The demand which has been so often made, and which has recently been repeated even by well-known naturalists, that the derivation of Man from the lower animals, and immediately from Apes, yet requires "sure proof," has thus been satisfied. These "sure proofs" have been for some time available to all who would open their eyes to see them. 
Quite vainly, many so-called "Anthropologists" demand as proof, that direct transitional forms between Men and Apes should be found, or even that a living Ape should be deliberately cultivated into a Man. Convincing and "sure" proofs are evident in the abundant material which has already been accumulated. The invaluable sources of Comparative Anatomy and Ontogeny afford the surest proof of Phylogeny. It is, therefore, unnecessary to search out fresh proofs of the descent of the human race, though it is necessary to recognize and to learn to understand the "sure proofs" which have been obtained. 


\section{CHAPTER VI.}

\section{THE EGG-CELL AND THE AMCEBA.}

The Egg of Man and of other Animals is a Simple Cell.-Import and Essential Principles of the Cell Theory.-Protoplasm (Cell-substance), and the Nucleus (Cell-kernel), as the Two Essential Constitnent Parts of every Genuine Cell.-The Undifferentiated Egg-cell, compared with a highly Differentiated Mind-cell or Nerve-cell of the Brain.-The Cell as an Elementary Organism, or an Individual of the First Order.-The Phenomena of its Life.-The Special Constitution of the Egg-cell.Yelk.-The Germ-vesicle.-The Germ-spot.-The Egg-membrane, or Chorion.-Application of the Fundamental Principle of Biogeny to the Egg.cell.-One-celled organisms.-The Amœbæ.-Organization and Vital Phenomena. - Their Movements.-Amcoboid Cells in Many.celled Organisms.-Movements of such Cells, and Absorption of Solid Matter.Absorbent Blood Corpuscles.-Comparison of Amœba with Egg-cell.Amoeboid Egg-cells of Sponges.-The Amoeba as the Common Ancestral Form of Many-celled Organisms.

"The ancestors of the higher animals must be regarded as one-celled beings, similar to the Amœbæ which at the present day occur in our rivers, pools, and lakes. The incontrovertible fact that each hnman individual develops from an egg, which, in common with those of all animals, is a simple cell, most clearly proves that the most remote ancestors of man were primordial animals of this sort, of a form equivalent to a simple cell. When, therefore, the theory of the animal descent of man is condemned as a 'horrible, shocking, and immoral' doctrine, the unalterable fact, which can be proved at any moment under the microscope, that the human egg 
is a simple cell, which is in no way different to those of other mammals, must equally be pronounced 'horrible, shocking, and immoral." "-STAMYBAUM DES MENSChengeschlechts (1870.)

IN order clearly to understand Ontogeny, or the evolution of the individual Man, the most significant of the many wonderful and varied facts which meet us must first be brought into prominence, and then from the important points of view thus gained, the innumerable less weighty and important phenomena must be explained. The first and most important point of view, and, therefore, the starting-point of our ontogenetic studies, is the fact that every human individual is developed from an entirely simple cellular egg. The human egg-cell is, in its whole form and constitution, not essentially different from those of other Mammals, though there is some difference between the egg-cells of Mammals and those of other animals.

This most important fact, the fundamental significance of which is hardly surpassed by any other, is of recent discovery. It was only in 1827 that Baer, by practical observation, discovered the human and mammalian egg. Before that, the larger vesicles, which in reality contain the true and much smaller egg, had been erroneously regarded as the eggs. Of course the important discovery that the mammalian egg is a simple cell like that of other animals could only be made after the establishment of the Cell Theory, which was first laid down, with respect to plants, by Schleiden, and extended to the animal kingdom by Schwann in 1838. The reader is already aware of the great importance of the Cell Theory in the complete explanation of the human organism and its evolution. It therefore seems desirable to say a few words as to the 
present position of the cell theory, and as to the views commonly held in connection with it.

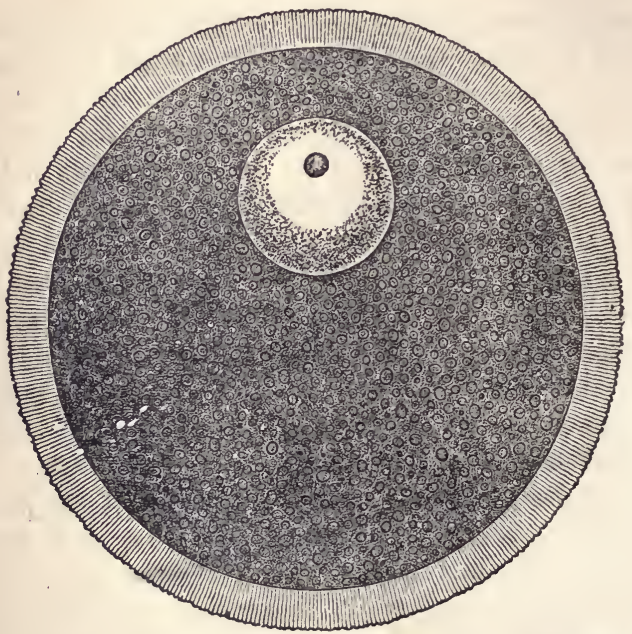

Fig. 1. The human egg from the ovary of the female; much enlarged The entire egg is a simple, globular cell. The greater part of the spherical egg-cell is formed by the egg-yelk, or the granular cell-substance (proto. plasm), which is composed of innnmerable, delicate yelk-granules, with a little intervening substance. The germ-vesicle, answering to the cellkernel (nucleus) lies in the upper part of the yelk. It contains a dark nucleolns or germ-spot. The globular mass of yelk is surrounded by a thick transparent egg-membrane (zona pellucida, or ehorion). This is penetrated by the pore-canals, in the form of very numerous hair-like lines, which run radially towards the centre of the globe; through these the thread-shaped, moving sperm-cells pass, in the process of impregnation, into the egg-yelk.

In order rightly to appreciate the Cell Theory, which 
has been regarded during the last thirty-five years as the true basis of all morphological and physiological knowledge in Zoology and Botany, it is especially necessary to conceive the cell as an integral organism, or, in other words, an independent living being. When by dissection we have separated the developed body of a Man, or of any other animal or plant, into its organs, and when we then proceed further to examine by means of the microscope the more minute constituents of these larger organs, which give the form to the whole organism, we are surprised to find that all these various parts are made up of the same fundamental constituents or structural elements; and these are cells. Whether we examine anatomically and by means of the microscope, a leaf, a flower, or a fruit; or again, a bone, a muscle, a gland, or a piece of skin, etc., we everywhere find one and the same form-element, which has been called the Cell, since Schleiden gave it that name. Very different views are held as to the real nature of this cell ; but whatever we think of it, it must be regarded as an independent life-unit. The tiny cell is, as Brücke says, "an elementary organism," or, as Virchow expresses it, a "seat of life" (Lebensheerd). It is, perhaps, most accurately described as. the organic unit of form of the lowest grade, as an individual of the first order (Generelle Morphologie, vol. i. p. 269). This unit is such both in anatomical form, and in physiological function. In the Protista, in the one-celled plants and primitive animals, the whole organism permanently consists only of a single cell. On the contrary, in most animals and plants, it is only in the earliest period of individual existence that the organism is a simple cell; it afterwards forms a cell-society, or, more correctly, an 
organized cell-state. The human body is not in reality a' simple life-unit, as is at first the universally current, simple belief of men.. It is, rather, an extremely complex social community of innumerable microscopic organisms, a colony or: a state, consisting of countless independent life-units, of different kinds of cells. ${ }^{43}$

The term cell is, in reality, not well chosen. Schleiden, who first introduced it as a scientific term in the sense in which it is used in the cell theory, named the little elementary organisms "cells," because in a cross-section of most parts of plants, they look like chambers, which, like the cells of a honeycomb, are massed together, are separated by solid walls, and are filled with liquid or a soft pulpy substance. This conception of the cell, as held by Schwann, namely, that it was a small closed sac, or bladder, filled with a fluid, and surrounded by a solid envelope, or wall, continued prevalent for a long time; but in the case of most of the cells in the animal body, it is altogether inapplicable. The further the investigation of the cells of the animal body was carried, the more evident it became that the cell must be
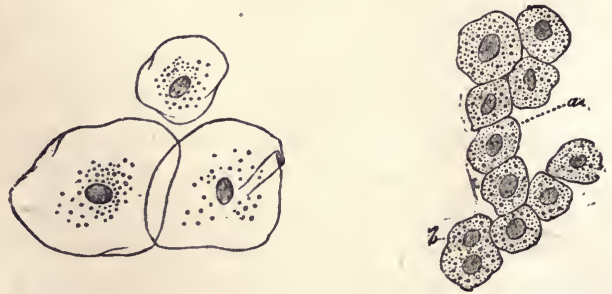

Frg. 2.-Ten cells from the liver; one (b) has two kernels.

Fig. 3.-Three epithelial cells from the mucous membrano of the tongue. 
entirely differently conceived. The cell is now usually defined as a small semi-solid or semi-fluid (i.e. neither solid nor fluid) dense body, the chemical nature of which is albuminous, and in which another small roundish body, generally more solid, and also albuminous, is enclosed. An envelope or membrane may exist, as is the case with most plantcells; but it may be wanting, as in most animal-cells. Originally it is never present. The young cells are usually roundish in form, but they afterwards vary very greatly. The cells from different parts of the human body, represented in Figures 2-6, may be compared as examples.
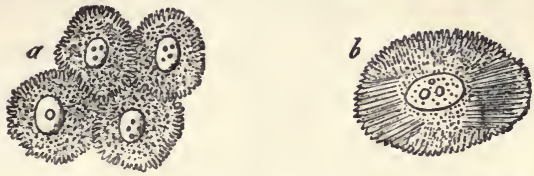

FrG.4.-Five thorny, or heckle-cells, the edges of which fit into each other, from the epidermis; one $(b)$ is separated from the rest.

The most essential feature in the modem conception of the cells is, therefore, that the cell-body is composed of two distinct parts. The one constituent part is the inner, and is called the nucleus (cytoblastus); this is generally of a round, oval, or spherical form, usually more solid, seldom softer than the protoplasm, and consists of a peculiar albuminous substance, the nuclein or kernel-substance; the second essential constituent part of every cell is the cellslime or cell-substance-the protoplasm, or primitive slime (Urschleim of the older natural philosophers). This protoplasm, which surrounds the nucleus, also belongs, in point of chemical composition, to the class of albuminous substances, and is a compound of carbon, containing some 
atoms of nitrogen. It remains throughout life in a soft condition of density, or aggregation, neither solid nor fluid. The albuminous composition of the protoplasm is similar to that of the nucleus, but is yet essentially and constantly diverse.

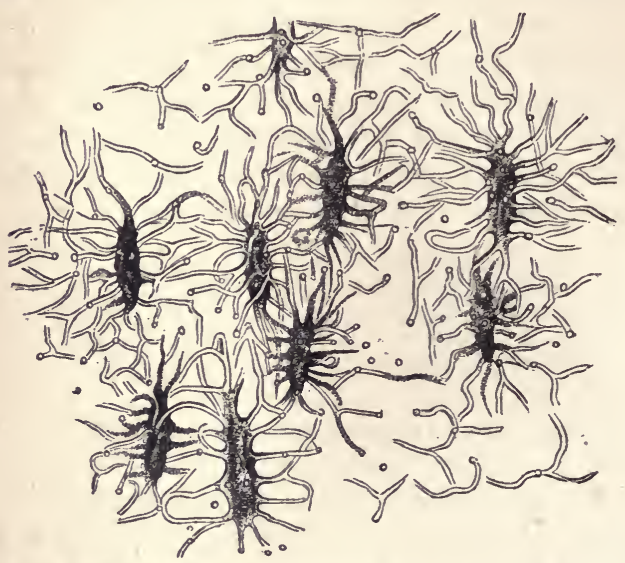

FIG. 5.-Nine star-shaped bone-cells with branched processes.
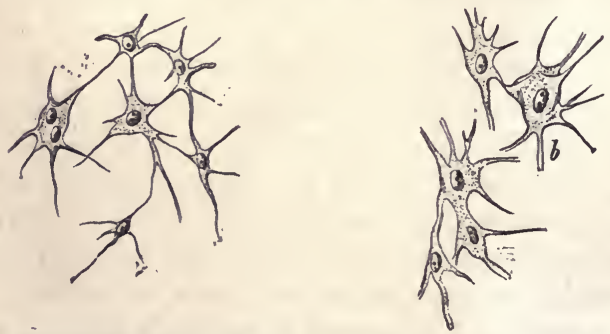

Fig. 6.-Eleven star-shaped enamel-cells from a tooth; they are connected by their branched processes. 
Nucleus and protoplasm, the inner cell-kernel and the outer cell-slime, are the only two essential constituents of every genuine cell. Everything else which occurs in and on the cell, is of secondary importance, as it develops afterwards; the membrane, which may be variously constituted, and is often very thick ; the intermediate cell-mass, or intercellular substance, which is secreted between the contiguous cells; and also the bodies of various kinds contained in the cell, such as fatty particles, crystals, grains of colouring matter, water-vesicles, etc. All these are subordinate and passive parts, which are formed by the activity of the protoplasm or are taken up from without, and are of no interest to us at present. The nucleus and the protoplasm are the only two active, essential, and always present parts of the cell-organism.

In contrast to the simple cell (Fig. 1, p. 122), let us compare with it a large nerve-cell, or ganglion-cell of the brain. The egg-cell potentially represents the whole animal-that is, it possesses the capacity to develop from itself the entire multi-cellular animal body; it is the common mother of all the generations of innumerable cells, which form the various tissues of the animal body: in a certain sense it unites in itself their various powers, but only potentially, only in design. In direct contrast to this, the nerve-cell of the brain (Fig. 7) is an extremely onesided formation. It cannot, like the egg-cell, develop from itself numerous generations of cells, of which some transform themselves into skin-cells, some into flesh-cells, and others into bone-cells, etc. But instead, the nerve-cell which is formed for the highest activities of life, possesses the capacity to feel, to will, to think. It is a true mind- 


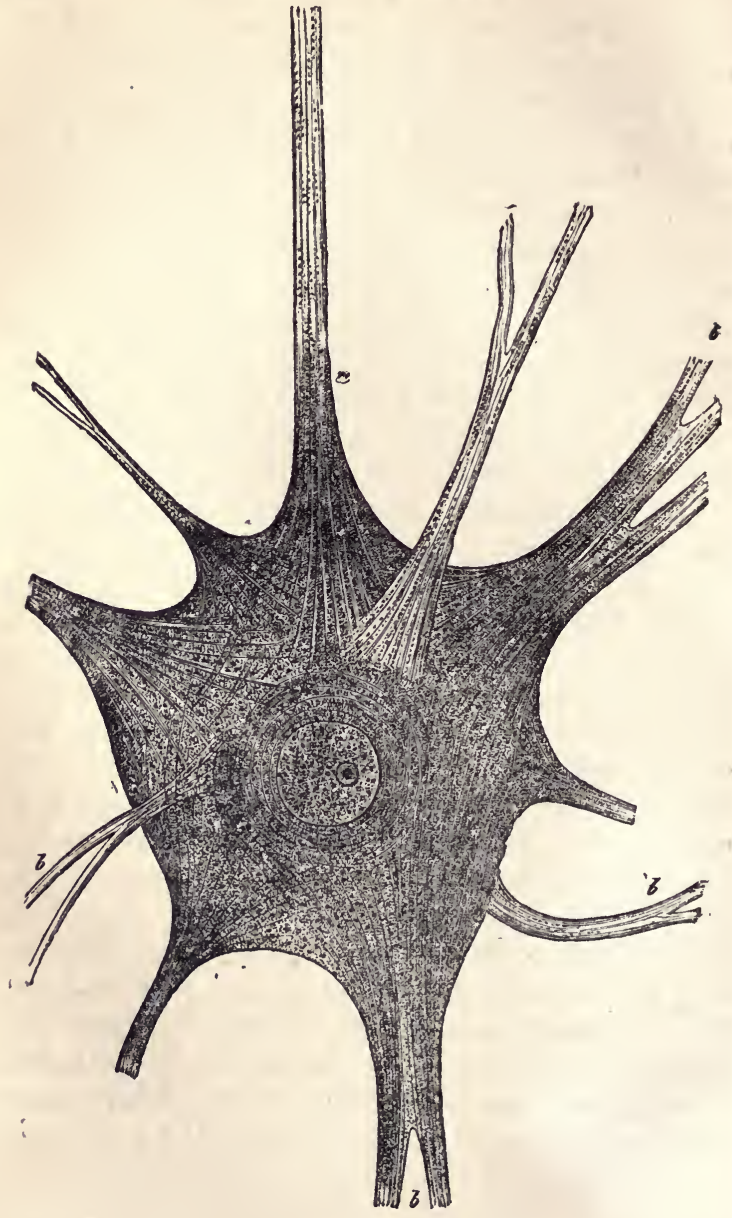


Fig. 7.-A large branched nerve-cell, or " mind-cell," from the brain of an Electric Fish (Torpedo); 600 times the natural size. The large, bright, globular kernel (nucleus) lies in the centre of the cell ; this nuclens contains a nucleolus, and in that, again, there is a nucleolinus. The protoplasm of the cell has separated into innumerable fine threads (or fibrillø), which are embedded in the inter-cellular substance, and which pass out into the branched processes of the cell. An unbranched process (a) passes over into a nerve vessel. (After Max Schultze.)

cell, an elementary organ of mental activity. Correspondingly, it has an extremely complex minute structure. Innumerable filaments of exceeding fineness, which may be compared to the numerous electric wires of a great central telegraph station, traverse, crossing each other again and again, the finely granulated protoplasm of the nerve-cell and pass into branched processes, which proceed from this mind-cell, and connect it with other nerve-cells and nervefibres $(a, b)$. It is scarcely possible to trace, even approximately, the tangled paths of these filaments in the fine substance of the protoplasmic body.

We thus have before us a highly complex apparatus, the more minute structure of which we have hardly begun to know, even with the help of our strongest microscope, and the significance of which we rather guess than know. Its complex mechanism is capable of the most intricate psychical functions. But even this elementary organ of mental activity, of which there are thousands in our brain, is only a single cell. Our whole intellectual life is but the sum of the results of the activity of all such nerve-cells or mind-cells. In the centre of each cell lies a large transparent ball, which encloses a smaller dark body. This is the nucleus which contains the nucleolus. Here, as everywhere, the nucleus determines the individuality of the cell, and shows that the entire formation, notwithstanding VOL. I. 
its minute and complex structure, is in form only a single cell.

In contrast to this highly complex specialized mindcell (Fig. 7) is the egg-cell (Fig. 1), which is in no way specialized. Yet here, also, we are obliged to infer from its active properties a highly complex chemical composition of its protoplasmic substance, and a minute molecular structure, which are completely hidden from our eyes.

The description of these cells as elementary organisms, or individuals of the first order, must be somewhat qualified. For cells by no means represent quite the lowest grade of organic individuality, as that is usually understood. There are yet more simple elementary organisms at which we will now give a passing glance, in order to return to them hereafter. These are cytods: living, independent existences which consist merely of an atom of plasson; in other words, of an entirely homogeneous atom of an albuminous substance, which is not yet differentiated into nucleus and protoplasm, but exercises the properties of both united. For example, the remarkable Monera are cytods of this kind. (Cf. Chapter XVI.) Strictly speaking, we should say : the elementary organism, or the individual of the first order, occurs in two different grades. The first and lowest is the cytod, which consists merely of an atom of simple plasson. The second and higher grade is the cell, which has been differentiated into nucleus and protoplasm. Both grades, cytods and cells, are grouped together under the idea of sculptors or builders, because they alone in reality build the organism. ${ }^{42}$ But in higher animals and plants, such cytods do not, as a rule, appear, so that only actual nucleated cells occur. Here, therefore, the elementary 
individual always consists of two different parts, the outer protoplasm and the inner nucleus.

In order to be thoroughly convinced that every cell is an independent organism, it is only necessary to trace the active phenomena and the development of one of these tiny bodies. We then see that it performs all the essential lifefunctions which the entire organism accomplishes. Every one of these little beings grows and feeds itself independently. It assimilates juices from without, absorbing them from the surrounding fluid; the naked cells can even take up solid particles at any point of their surface, and therefore eat without using any mouth or stomach. (Cf. Fig. 15.) Each separate cell is also able to reproduce itself and to increase (Fig. 8). This increase generally takes place by simple division, the nucleus parting first, by a contraction round its circumference, into two parts; after which the protoplasm likewise separates into two divisions. The single ceil is also able to move and

Fig. 8. - Blood-cells, which increase by division, from the embryo of a young stag. Each blood-cell has originally a kernel, and is globular (a). When they are about to in. crease, the cell-kernel, or nucleus, first separates into two kernels $(b, c, d)$. The protoplasmic body then becomes pinched in at a point between the two kernels, which become more widely separated from each other (e). Finally a complete separation between the two parts is effected at the point where the original cell was pinched in, so that there are now trro cells $(f)$. (After Frey.)

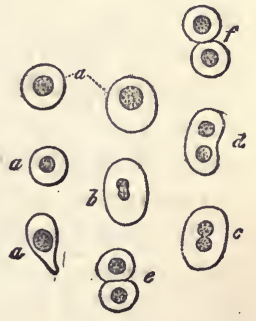

creep about, if it has room for free motion, and is not prevented by a solid covering; from its outer surface, it sends 
out and draws back again, finger-like processes, thereby modifying its form (Fig. 9). Finally, the young cell has

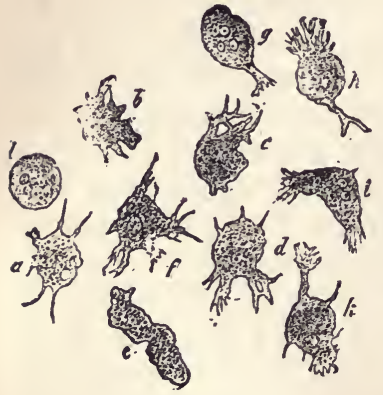

Fig. 9.-Active cells from the inflamed eye of a Frog (from the watery moisture of the eye, the humor aqueus). The naked cells move freely and creep about; like Amœbr and Rhizopods they accomplish this by extending delicate processes from their naked protoplasmic bodies. These pro. cesses continually alter in number, form, and size. The kernel of these amoboid lymph-cells is not visible, being covered by the numerous deli. cate granules which are scattered in the protoplasm. (After Frey.)

feeling, and is more or less sensitive. It performs certain movements on the application of chemical and mechanical irritants. Thus we can trace in every single cell all the essential functions, the sum of which constitute the idea of life: feeling, motion, nutrition, reproduction. All these properties which the multi-cellular, highly developed animal possesses, appear in each separate cell, at least in its youth. There is no longer any doubt about this fact, and we may therefore regard it as the basis of our physiological idea of the elementary organism.

Without lingering here over the extremely interesting phenomena of cell-life, we will at once attempt to apply the Cell Theory to the egg. The comparison which we have made leads to the important result that we must regard every egg as originally a simple cell. This is of the highest significance, because the whole Science of 
Ontogeny can be demonstrated in answer to the problem: "How does a many-celled organism arise from a one-celled organism?" Every individual organism is originally a simple cell, and as such, an elementary organism, or an individual of the first order. It is only at a later period that this cell gives rise, by division, to a multitude of cells, from which the many-celled organism, an individual of a higher order, is developed.

If we next observe somewhat more closely the original composition of the egg-cell, we notice the very remarkable fact, that in its original condition it is so exactly the same in Man as in all other animals, that it is impossible to discover any essential difference. At a later period, the eggs, even when they remain one-celled, are very different in size and form, have different coverings, etc. But, if they are sought in the place where they originate, in the ovary of the female animal, these primitive eggs, in the first stages of their life, are found to be always of the same formation-every primitive egg being originally an entirely simple, somewhat round, moving, naked cell, possessing no membrane, and consisting only of the nucleus and protoplasm (Fig. 10). These two parts have long borne distinctive names; the protoplasm being called the vitellus, or yelk, and the nucleus the germinal vesicle, (vesicula germinativa). As a rule, the nucleus of the egg is of a soft, often vesicular texture. Within this nucleus, as in many other cells, is enclosed a third body, which in ordinary cells is called the nucleolus. In the egg-cell it is called the germinal spot (macula germinativa). Lastly, in many, but not in all eggs, within this germinal spot, is found yet another little point, a nucleolinus, which may be called 

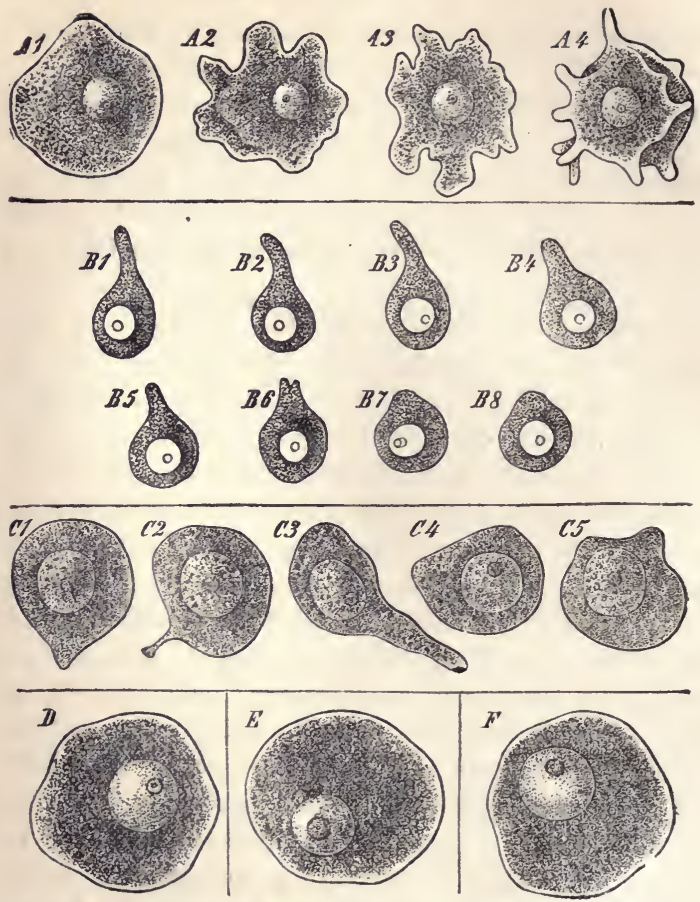

FIG. 10.-Primitive eggs of varions animals, performing amœboid movements (very much enlarged). All primitive eggs are naked cells, capable of change of form. Within the dark, finely granulated protoplasm (egg-yelk) lies a large vesicular kernel (the germ-vesicle), and in the latter is a nucleolus (germ-spot); in the nucleolus a germ-point (nucleolinus) is often visible. Fig. $A 1-A$ 4. The primitive egg of a Chalk Sponge (Leuculmis echinus), in four consecutive conditions of motion. Fig. $B 1-B$. The primitive egg of a Hermit-crab (Chondracanthus cornutus), in eight consecutive conditions of motion (after $\mathrm{E}$. $\operatorname{van}$ Beneden). Fig. $C 1-C 5$. Primitive egg of a Cat, in four different conditions of motion (after Pfluger). Fig. D. Primitive egg of a Tront. Fig. $E$. Primitive egg of a Hen. Fig. F. Primitive human egg. 
the germinal point (punctum germinativum). But these last two parts, the germinal spot and the germinal point, are only of subordinate importance; only the first two parts are of primary importance, the protoplasm (Vitellus) and the nucleus (vesicula germinativa).

In many lower animals, for example, in Sponges and Medusce, the egg-cells retain their entirely simple original nature until fertilization. But in most animals they undergo certain changes before that time; they sometimes acquire certain additional Protoplasm, which serves for the nourishment of the egg (food-yelk), sometimes outer envelopes or membranes, which serve for its protection (egg-membranes). An envelope of this sort appears on all mammalian eggs in the course of their further development. The little sphere is surrounded by a thick covering of a perfectly transparent, glass-like nature, which is distinguished as the zona pellucida, or chorion (Fig. 11). When this is very closely examined under the microscope, very fine radial lines may be distinguished, traversing the zona; these are very fine canals. The human egg cannot be distinguished from that of most other Mammals either in its immature or in its more complete condition. Its form, its size, its composition, are approximately the same in all. In its fully developed condition, it has an average diameter of $\frac{1}{10}$ of a line, or 0.2 millimetres. If the mammalian egg is properly isolated and held on a glass plate toward the light, it appears to the naked eye as a very fine point. The eggs of most of the higher Mammals are of exactly the same size. The diameter of the spherical eggcell almost always measures from $\frac{1}{10}$ to $\frac{1}{20}$ of a line $\left(\frac{1}{5}-\frac{1}{10}\right.$ of a millimetre). It has always the same spherical form, 
always the same characteristic thick covering; always the same clear, round germinal vesicle with its dark germinal spot. Even under the highest magnifying power of the

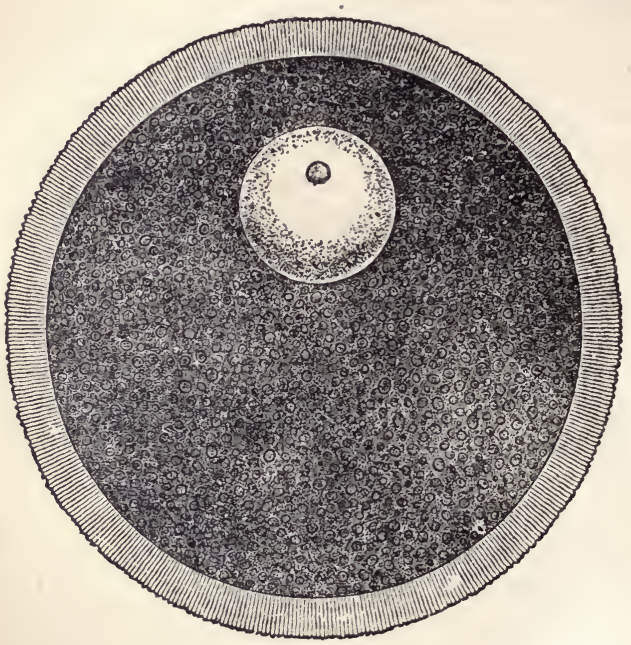

FiG. 11. - A human egg (much enlarged) from the ovary of a female. The whole egg is a simple spherical cell. The greater part of this cell is formed by the egg-yelk, by the granular cell-substance (protoplasm), consisting of innumerable yelk-granules with a little inter.granular substance. In the upper part of the yelk lies the bright, globular, germ-vesicle, corresponding with the cell-kernel (nucleus). This contains a darker germ-spot, answering to the nucleolus. The globular yelk mass is surrounded by a thick, light-coloured egg-membrane (zona pellucida, or chorion). This is traversed by very numerous hair-like lines, radiating towards the central point of the mass; these are the porous canals, throngh which, in the course of fertilization. the thread-shaped, active sperm-cells penetrate into the egg-yelk. 
best microscope, there appears to be no essential difference between the eggs of Man, of the Ape, of the Dog, etc. This does not mean that they are not really different in these different Mammals. On the contrary, we must assume that such differences, at least in point of chemical composition, exist universally. Even of human eggs, each differs from the other. In accordance with the law of individual variation, we must assume that "all individual organisms are, from the very beginning of their individual existence, different, though often very similar." (Gen. Morph. vol. ii. p. 202). But with our rough and incomplete apparatus we are not in a position actually to perceive these delicate individual differences, which must often be sought only in the molecular structure. Yet in spite of this, the remarkable morphological similarity of human and mammalian eggs, which has the appearance of absolute similarity, remains a strong argument in favour of the common descent of Man and the other Mammals. The similar embryo-form bears witness to the common parent-form. On the other hand, there are striking peculiarities by which the ripe mammalian egg may be very easily distinguished from the ripe eggs of Birds and other Vertebrates. (Cf. the end of Chapter XXV.)

The ripe egg of the Bird is especially different, although as a primitive egg (Fig. 10, $E$ ) it was entirely similar to that of Mammals. But the egg-cell of the Bird at a later period, though while still within the oviduct, absorbs a mass of food which it elaborates into the large and well-known yellow yelk. If a very young egg from the ovary of a hen is examined, it is found to be exactly like the young ergcells of Mammals and other animals (Fig. 10). But it 
afterwards grows so considerably that it expands to the well-known yellow ball of yelk. The nucleus, or the germinal vesicle, of the egg-cell, is thus pressed on to the surface of the spherical cell, and is there embedded in a small mass of clear, so-called white yelk. This then forms a circular white spot, which is called the tread, or cicatricle (cicatricula, Fig. 12, b). From the tread a thin cord of white yelk passes through the yellow to the middle of the round cell, where it swells to a little central ball, the falsely-called yelk-cavity (latebra, Fig. 12, d). The yellow yelk, which surrounds this white yelk, appears in the hardened egg in concentric layers (c). The yellow yelk is encircled by a delicate structureless yelk-skin (membrana vitellina, $a$ ).

Of late it has been widely believed that the large yellow egg-cell of the Bird, which in the case of the largest birds reaches a diameter of several inches, cannot be regarded as a simple cell. But, with Gegenbaur, we believe this vicw to be erroneous. The unimpregnated and unsegmented eggcell of the Bird, with its simple nucleus, remains a simple cell, even though its yellow yelk-substance increases very greatly. Every animal which consists of a single cell, every Amœba, every Gregarina, every Infusorial animal, is onecelled, and remains so, however much food of various kinds it absorbs. In the same way the egg-cell remains a simple cell, however much food-yelk it may afterwards collect within its protoplasm. Gegenbaur has proved this clearly in his excellent work on the embryos of Vertebrates. ${ }^{43}$

The Bird's egg, of course, assumes a different form as soon as it is fertilized. Its germinal vesicle, or nucleus, then separates by repeated division into many parts, and the protoplasm of the tread, which surrounds it, is corre- 
spondingly divided. At this stage the egg consists of as many cells as there are nuclei in the tread. Hence, the yellow ball of yelk of the impregnated egg, as it is laid, and as we eat it every day, is already a many-celled body. Its tread is composed of many cells, and is now distinguished as the germ-disc (discus blastodermicus). In the eighth chapter we shall refer to this again.

Fig. 12.-A ripe egg-cell from the ovary of a hen. The yellow nutritive yelk (c) is composed of many concentric strata $(d)$ and is surronnded by a thin yelk-membrane (a). The cell-kernel, or germ-vesicle, lies in the npper part, in the tread (b). From this the white yelk passes into the centre of the yelk-cavity $\left(d^{\prime}\right)$. The two kinds of yelk are not, howerer, distinctly separated.

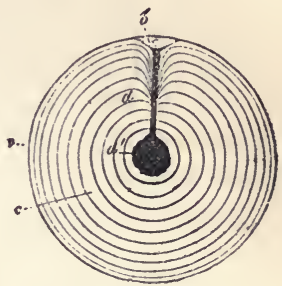

After the ripe egg of the Bird (Fig. 12) has left the ovary and has been fertilized in the oviduct, it surrounds itself with various coverings which are secreted from the inner surface of the oviduct. The thick layer of transparent albumen first forms round the yellow yelk; this is followed by the formation of the outer calcareous shell, within which lies another envelope of skin. All these coverings and additions which are gradually formed around the egg, are of no importance to the development of the embryo; they are parts that have nothing to do with the original simple eggcell. Even in the case of other animals we often find very large eggs with thick coverings,-for example, in that of the Shark. In this case also the egg is originally exactly similar to those of Mammals, that is, it is a simple naked cell. But, as in the case of Birds, a considerable quantity 
of food-yelk is collected within the original yelk, as provision for the growing embryo: various coverings are formed around the egg. The egg-cells of many other animals receive similar internal and external additions. But as these are always of subordinate importance in the formation of the embryo itself, serving either as food, or as a protecting covering for the embryo, we may disregard them entirely, and turn our attention to the most important point,-the essential similarity of the original egg-cells of Man and other animals (Fig 10).

Let us here make use for the first time of our fundamental biogenetic law, and apply this causal law of development directly to the human egg-cell. This results in an extremely simple, but highly important conclusion. From the one-celled organization of the human egg and of the eggs of the other animals, the conclusion directly follows, according to this fundamental law of Biogeny, that all animals, including Man, descend originally from a onecelled organism. If that fundamental principle is really true, if germ-history or the development of the individual is an epitome or a brief reproduction of the tribal history or the development of the race (and it is impossible to doubt this), then, from the fact that all eggs are originally simple cells, we must necessarily conclude, that all many-celled organisms are descended from a one-celled organism. As, however, the original egg-cell has the same structure in the case of Man as in that of all other animals, we may reasonably assume that this one-celled original form was probably the common one-celled ancestral organism of the whole animal kingdom, including Man. But this last hypothesis is by no means as certain as the former conclusion. 
The inference from the one-celled germ-form to the one-celled parent-form is so simple, and yet so full of significance, that it is impossible to lay too much stress upon. it. Naturally the first question arising is, whether there exist at the present day any one-celled organisms, from the form of which we may draw an approximately correct. conclusion as to the one-celled ancestors of many-celled organisms? The answer to this question is undoubtedly affirmative. There are most certainly one-celled organisms now in existence, the whole organization of which is but that of a permanent egg-cell; there are independent one-celled organisms, which never undergo any further development, which pass their whole lives as simple cells, and as such reproduce themselves without attaining to any higher development. We now know a great number of such one-celled organisms, - for example, the Gregarina, Flagellata, Acineta, Infusoria, etc. But one among them is especially interesting to us, because it affords the most complete answer to our question, and must be regarded as the onecelled primary organism which most nearly approaches the type-form of the race. This organism is the Amœba.

The name Amœbæ has long been applied to a number of microscopic one-celled organisms, which are by no means rare, and are indeed widely distributed, principally in fresh water, but also in the ocean; lately they have been found inhabiting moist earth. When one of these living Amœbæ is placed in a drop of water under the microscope and greatly magnified, it appears to be a roundish body of very irregular and varying form (Fig. 13). Enclosed in the soft, slimy, half-fluid body, which consists of protoplasm, we can only see a small solid or vesicular substance, which is the 
nucleus. This unicellular body now begins to move, and crawls about in various directions on the glass, on which we are observing it. The shapeless body accomplishes these

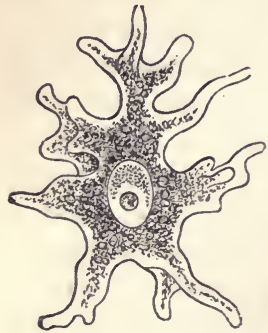

Frg. 13.-A creeping Amœba (mnch en. larged). The form-value of the whole organism is that of a simple naked cell, which moves about by means of variable processes, sometimes extended from the protoplasm of its body, sometimes drawn in. In the centre is the round kernel, or nacleas, with its nucleolus.

movements by extending finger-like processes from various points of its surface, which are moved in slow but constant alternations, and draw the rest of the body after them. After a time something new is seen; the Amœba suddenly stands still, draws in its processes, and assumes a spherical form. But soon the little slimy ball begins to spread out again, and stretches its processes in different directions, and moves forward again. These variable processes are called false-feet (Pseudopodia), because they perform the office of feet, and yet are no special organs, in a morphological sense; for they vanish as quickly as they appear, and are only variable extensions of the semi-fluid, homogeneous, and structureless substance of the body.

If one of these creeping Amnbæ is touched with a needle, or if a drop of acid is added to the water, the whole body at once contracts in consequence of this mechanical or chemical irritation. Usually it reassumes its spherical form. Under certain circumstances, for example, if the impurity is retained in the water, the Amœba begins to encase itself. It exudes a homogeneous envelope, or cap- 
sule, which immediately hardens, and in a state of repose assumes the form of a spherical cell surrounded by a protecting membrane. The one-celled Amœba obtains its food, either by absorbing dissolved substances directly from the water by imbibition, or by pressing into itself solid particles of foreign matter with which it comes into contact. The latter operation can be observed at any time if it is made to eat. If finely pulverized colouring matter, such as carmine or indigo, is placed in the water in very small quantities, the soft body of the Amœba can be seen to assimilate these particles of colouring matter, over which the soft substance of the cell flows together. The Amœba can take food in this way at any point of the surface of its body, althcugh it possesses no special organs for taking in and digesting nutritive matter, no true mouth or stomach. By means of this assimilation of nutriment and dissolving the particles in its protoplasm, the Amœba grows; and, after it has reached a certain size by this process, it begins to reproduce. This occurs in the simplest way, by division. The enclosed nucleus first separates into two pieces. Then the protoplasm distributes itself between the two new nuclei, and the whole cell parts into two similar cells, in consequence of the growth of the protoplasm round the two nuclei. This is the usual method of propagation; the nucleus first divides into two halves, which separate from each other, and act as centres of attraction to the surrounding cell-substance or protoplasm (Fig. 8).

Though the Amoba is, therefore, only a simple cell, it shows itself capable of performing all the functions of a many-celled organism. It moves itself by creeping, it feels, it feeds, it reproduces its kind. Some species of Amœbæ 
are quite visible to the naked eye; but the greater number are microscopic. Our reasons for regarding the Amœbæ as the particular one-celled organisms, the phylogenetic relations of which to the egg-cell are of peculiar importance, will be evident from the following facts. In many lower animals, the egg-cell remains in its original, naked condition till it is fertilized; it acquires no covering, and is often indistinguishable from an Amœba. Like the latter, these naked egg-cells can extend processes and move about. In the Sponges, these active egg-cells creep freely about, as though they were independent Amœbæ (Fig. 14), even

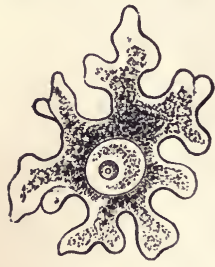

Fig. 14.-Egg-cell of a Chalk Sponge (Olynthus). The egg-cell moves and creeps about within the Sponge, by means of variable processes which it extends. It is not distinguishable from the common Amœba.

within the parent organism. In this condition they were observed by earlier naturalists, and were mistaken for Amœbæ, living as parasitical intruders in the body of the Sponge. It was only afterwards that it was discovered that these supposed one-celled parasites were in reality the egg-cells of the Sponge itself. This remarkable phenomenon is also found in other lower animals, for example, in those pretty bell-shaped Plant-animals (Medusae); the eggs of these also remain as naked, uncovered cells, which stretch out amoboid processes, feed themselves, move, and from which, after fertilization, the many-celled Medusa-organism is indirectly or directly developed by repeated division.

It is, therefore, certainly no wild hypothesis, but an 
entirely sober conclusion, which regards the Amœba as the particular one-celled organism which gives us an approximate representation of the ancient one-celled ancestral form common to all many-celled organisms. The naked, simple Amoba possesses a less differentiated and more primary character than most other cells. To this may be added the circumstance, that similar amœboid cells can be shown in the full-grown bodies of all many-celled animals. For example, they occur as the so-called white blood-corpuscles among the red blood-cells (corpuscles) in human blood, and in that of all other Vertebrates. They also occur in many Invertebrate animals ; for instance, in the blood of the Snail; and in 1859 I showed that these colourless bloodcorpuscles, like independent Amœbæ, can assimilate solid particles, can, therefore, eat (Fig. 15). Lately, it has been found that very many different cells, if they have room,

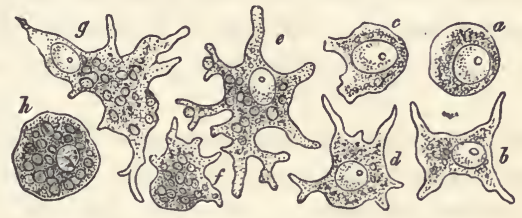

Fig. 15.-Devouring blood-cells of a Naked Sea-snail (Thetis) very much magnified. In connection with the blood-cells of this snail, I was the first to observe the important fact that " the blood.cells of invertebrate animals are uncovered lumps of protoplasm, and, like the Amœbæ, by means of their peculiar movements can absorb matter," can, therefore, "eat." When at Naples (on the 10th of May, 1859) I had injected the blood-vessels of one of these Snails with pulverized indigo dissolved in water, I was much astonished to find after a few hours that the blood cells themselves were more or less filled with fine particles of indigo. By repeated experimental injections, I was able to watch the absorption of the colouring matter into the blood-cells, which was accomplished exactly as by Amcbæ. (See "Monograph of Radiolaria," 1862, pp. 104, 105.)

VOL. I. 
are able to move, to eat, and to act entirely like Amœbæ (Fig. 9).

The capacity of the naked cell to make these characteristic amœboid movements depends on the contractility (or automatic movableness) of the protoplasm. This seems to be the universal property of all young cells. Where they are not surrounded by a strong membrane, or shut up in a "cell prison," they are all capable of amœboid movements. This is as true of the uncovered egg-cell as of other uncovered cells, of the moving cells of various kinds, lymphcells, mucous cells, etc.

Our examination of the egg-cell and comparison of it with the Amœba, has afforded us the best and surest basis for the history of the germ as well as for the history of the tribe. From it we have drawn the conclusions that the human egg is a simple cell; that this egg-cell is not essentially different from those of other Mammals, and that we must therefore infer the existence of a primeval one-celled ancestral form, which in all essential points was of amœboid form.

The assertion that the first ancestors of the human race were simple cells of this sort, which, like the Amœba, led an independent one-celled life, has not only been ridiculed as an empty scientific chimera, but has also been indignantly rejected in theological periodicals as "horrible, shocking, and immoral." But, as I have already remarked in my lectures "On the Origin and Genealogy of the Human Race," the same righteous indignation must fall with equal justice on the "horrible, shocking, and immoral " fact, that every human individual develops from a single cell, and that this human egg-cell cannot be distinguished from 
those of other Mammals. This fact can be demonstrated at any moment under the microscope, and it is useless to close our eyes to this "immoral" fact. It remains as incontrovertible as the important conclusions which we have linked with it.

The very important bearing which the Cell Theory has on the whole conception of organic nature is thus very clearly seen. The "place of man in nature" is radically explained by it. Without this theory, Man is an unintelligible puzzle. Philosophers, therefore, and certainly psychologists, ought especially to acquaint themselves thoroughly with the Cell Theory. The human mind can only be really understood by means of this theory, and its simplest form is illustrated in the Amœba.

The extant Amœbæ and the kindred one-celled organisms, Arcellæ, Gregarinæ, etc., are therefore of great interest, because they show us the simple cell in a permanently independent form. The human organism and that of other higher animals, on the contrary, is only onecelled in its earliest, immature condition. As soon as the egg-cell is fertilized, it multiplies by division and forms a community, or colony of many social cells. These differentiate themselves, and by their specialization, by various modifications of these cells, the various tissues which compose the various organs are developed. The developed many-celled organisms of $\mathrm{Man}$ and of all higher animals resembles, therefore, a social, civil community, the numerous single individuals of which are, indeed, developed in various ways, but were originally only simple cells of one common structure. 


\section{CHAPTER VII.}

\section{THE PROCESSES OF EVOLUTION AND IMPREGNATION.}

Development of the Many-celled from the One-celled Organism.-The Cellhermit and the Cell-state.-The Principles of the Formation of the State.-The Differentiation of the Individuals as the Standard of Measurement for the Grade of the State.-Parallel between the Processes of Individual and of Race Development.-The Functions of Evolution.Growth.-Inorganic and Organic Growth.-Simple and Complex Growth. -Nourishment and Change of Substance.-Adaptation and Modification. -Reproduction.-Asexual and Sexual Reproduction.-Heredity.-Division of Labour, or Differentiation.-Atavism, or Reversion.-Coalescence. -The Functions of Evolution as yet very little studied by Physiology, and hence the Evolntionary Process has often been misjndged.-The Evolution of Conscionsness, and the Limits to the Knowledge of Natare. -Fitful and Gradual Evolution.-Fertilization.-Sexual Generation.The Egg-cell and the Sperm-cell.-Theory of the Sperm-animals.Sperm-cells a form of Whip.cell.-Union of the Male Sperm-cell with The Female Egg-cell.-The Product of this is the Parent.cell, or Cytula.-Nature of the Process of Fertilization.-Relation of the Kernel (Nucleus) to this Process.-Disappearance of the Germ-vesicle.-Mone. rula.-Reversion to the Monera-form.-The Cytula.

"If the man of science chose to follow the example of historians and pulpit-orators, and to obsenre strange and peculiar phenomena by employing a hollow pomp of big and sounding words, this would be his opportunity; for we have approached one of the greatest of the mysteries which surround the problem of animated nature and distinguish it above all other problems of science. To discover the relations of man and woman to the egg-cell would be almost equivalent to solving all those mysteries. The origin and development of the egg-cell in the body of the mother, the transfer to it 
by means of the seed, of the physical and mental characteristics of the father, affect all the questions which the human mind has ever raised in regard to existence."-RUDOLPB ViRCHOW (1848).

THE discovery that every human being at the beginning of his existence is a simple cell, that this egg-cell is essentially similar to those of other Mammals, and that the forms arising during the evolution of this cell in Man and in the other higher Mammals, are at first similar,-supplies a basis from which we may trace the further processes of evolution. In the first place we have convinced ourselves of a fact which is of great importance to the empiric side of the history of development, relating to those ontogenetic facts which can be directly traced by means of the microscope; and this fact is that in Man as well as in other animals the dereloped many-celled organism with all its various organs proceeds from a simple cell. Secondly, as regards the phylogenetic side of the question, the speculative part of the History of Human Development, which is based on those facts, we have reached the conclusion that the original ancestral form of Man as of the other animals was a one-celled organism. The whole difficult problem of the History of Evolution is thus now reduced to the simple question: "How has the complex many-celled organism arisen from the simple one-celled form? By what natural process has the simple cell been transformed into that complex life-apparatus with all its various organs, the apparently rational and purposive construction of which we admire in the developed body?"

Turning now to answer this question, we must bear in mind the view to which we have already alluded, that the many-celled organism is ordered and constituted on the 
same principles as a civilized state, in which the several citizens have devoted themselves to various services directed towards common ends. This comparison is of the greatest service in enabling us thoroughly to understand the construction of Man from many cells of various kinds, and to understand also the harmonious co-operation of these various cells for an apparently pre-conceived purpose. If we bear this comparison in mind, and apply this significant idea of the developed many-celled organism as a civil union of many individuals, to the history of the evolution of this organism, we shall obtain a correct view of the real nature of the first and most important processes of evolution. We can even, on deeper reflection, guess the first stages of development, and establish them d priori, before we call observation, a posteriori knowledge, to our aid.

For once we will reverse the process, and will not, as will be the case hereafter, first observe the facts of Ontogeny and then attach their phylogenetical significance to them. Beginning at the other end, let us here try to guess the course which evolution must have taken, if the comparison is well founded. Then if, afterwards, the facts of Ontogeny confirm our preconception, we shall be yet more firmly convinced of the truth of our views on Phylogeny. This agreement will afford us a more striking justification of our views than can be gained in almost any other way.

Let us therefore first answer this question: "Granting the correctness of the fundamental law of Biogeny, how would the original one-celled organism which founded the first cell-state, and thus became the ancestor of the higher, many celled animals,- -how must that organism have acted at the beginning of organic life on the earth, or at the 
beginning of creation, as it is usually expressed?" The answer is very simple. It must have acted just as a man who founds a state or a colony for a given purpose. Let us trace this process in its simplest form, as, for example, may have easily taken place when any of the remote islands in the Pacific Ocean were first peopled. Two South Sea Islanders, a man and a woman, have gone in a boat to fish; they are overtaken by a storm, carried far away, and at length driven on to a remote island, as yet uninhabited. This "first human pair," remaining isolated, play the parts of Adam and Eve, and produce a numerous posterity, thus becoming the parents of the future inhabitants of the island. As they are entirely devoid of all resources, without the many means of support possessed by the founders of states of advanced civilization, the posterity of this uncivilized and isolated pair have first developed as genuine savages. Their only purpose in life for centuries has remained as simple as that of the lower animals and plants; the simple aim of self-preservation and of the production of descendants; they have been contented with the simplest organic functions, nutrition and reproduction. Hunger and love are their only motives of action.

For a very long period, these savages, scattered over the whole island, must have aimed at the one single object of self-preservation. Gradually, however, several families collected at certain places, larger communities arose, and now many reciprocal relations began to arise between individuals ; in consequence, a rude division of labour took place. Certain savages continued to fish and hunt, others began to eultivate the ground, others devoted themselves to religion and medicine, which now began to develop, 
and so on. In short, the ever-increasing division of laiour specializes the people into various ranks or castes, which always tend to become more sharply defined in proportion as the state becomes more highly developed: all follow diverse occupations, and yet work for a common end. In this way, from the descendants of a single human pair, a simple community of individuals, originally alike, first gradually arises, and this is followed by a more or less well-organized confederation. In this community, we may regard the more or less complete division of labour among individuals, or the so-called specialization, as the standard by which the grade of development of its culture may be measured.

A process similar to this, and the details of which each can easily fill up for himself, took place millions of years ago, when, at the beginning of organic life on the earth, one-celled organisms at first developed, and were afterwards followed by many-celled forms.

The single cells which arose by reproduction from the oldest parent-cells must at first have lived in an isolated condition; each one performed the same simple offices as all the others; they were satisfied with self-preservation, nutrition, and reproduction. At a later period isolated cells gathered into communities. Groups of simple cells, which had arisen by the continued division of a single cell, remained together, and now began gradually to perform different offices in life. The first traces of specialization, or division of labour, soon occurred, as one cell assumed one office, another another. One set of cells may have devoted themselves especially to the absorption of food, or nutrition; other cells may have busied themselves only with repro. 
duction; and others, again, have formed themselves into protecting organs for the little community, and so on. In short, various classes or castes must have arisen in the cell-state, following diverse occupations and yet working together for the common end. In proportion as this division of labour progressed, the many-celled organism, or the specialized cell-community, became more perfect or civilized.

We may follow the comparison further. It may be asserted $a$ priori, that in consequence of the reciprocity of relations which was occasioned by the struggle for existence and the gathering of many organic individuals in a common dwelling-place, when organic life first began on the earth, a community of many similar individuals arose from a onecelled organism; that a division of labour afterwards took place among these similar cells, and that finally, in consequence of continuous specialization, a developed manycelled organism with many different organs, all working for a common end, arose. In order fully to realize the value of this significant comparison, it would be necessary to enter in detail into the theory of the division of labour, or specialization, which now plays a very important part in Biology, especially since Darwin's Theory of Selection has enabled us to understand the true causes of these phenomena. At present I must refer for the more detailed elaboration, which would carry us too far to be entered into here, to Darwin's Doctrine of the Divergence of Character, and to my lecture on the Division of Labour. We shall hereafter return to this subject. ${ }^{44}$

At present we will rather examine whether the $d$ priori views on Phylogeny which we preconceived, are in accord- 
ance with the facts which Ontogeny places before us; whether in the evolution of the individual organism from the egg-cell, the same phenomena appear, which we have presupposed as necessary in this comparison. The ontogenetic structural process proves to be in very close harmony with our conclusions, and we find that the facts of the evolution of the individual which can be seen under the microscope, do in fact correspond perfectly with the picture of the process of phylogenetic evolution which we have sketched a priori. The first processes which occur in the evolution of the individual from the egg-cell, and also the succeeding simple processes which first come under observation, really correspond to the events which we have just traced in the development of a colony of savages, and have assumed as the first phylogenetic processes in the origin of a many-celled organism.

In the first stage of the evolution of the individual, many homogeneous cells first arise, from the simple egg-cell, by continuous division. These are exactly comparable to a community of human beings as yet uncivilized. These homogeneous cells increase still more, so that the accumulation of cells ever increases. As in making our comparison we found that an entire colony of savages proceeded from the descendants of a single isolated human pair, so likewise all the homogeneous cells of this multitude (which we shall hereafter learn to know better under the name of cleavage-globules), are inter-related as the descendants of a single pair of cells. Their common father is the male sperm-cell, and their common mother the female egg-cell.

At first, all these numerous cells which arise by the con- 
tinuous division of the fertilized egg-cell, are exactly alike, and cannot be distinguished from each other. But gradually a division of labour occurs among them by their assuming different offices. Some accomplish nutrition, others reproduction, others protection, others locomotion, and so on. We may translate this into the language of the theory of the tissues and say: some of these cells become intestinal cells, others muscle-cells, others, again, bone-cells, nerve-cells; cells of the sense-organs, of the reproductive organs, etc. Thus we see that the whole course of the evolution of the individual corresponds in its essential features to that presupposed course of phylogenetic development, and thus affords a striking confirmation of our fundamental law of Biogeny.

This observation naturally leads to a brief examination of the physiological functions, or vital activities, which are concerned in the evolution of the individual as in that of the race. At first sight a great number of complex processes seem to blend and co-operate here; all of these can, however, in reality be reduced to a few simple organic functions. These vital activities are: (1) Growth; (2) Nutrition; (3) Adaptation; (4) Reproduction; (5) Heredity; (6) Division of Labour, or Specialization; (7) Atavism; (8) Coalescence. Heredity, Adaptation, and Growth are of especial importance in the evolution of the organic body; these must, therefore, be regarded as especially formative functions.

Of all vital phenomena, growth may be regarded as the one which plays the chief part in the evolution of the individual organism, and as the really fundamental function of evolution. The bearing of this function on the evolu- 
tion of the germ is so great, that Baer expressed the most general result of his researches in the following proposition: "The history of the evolution of an individual is the history of the growth of individuality in every relation." Whenever a unit, an individual, develops in nature, growth is the first condition. This is equally true of inorganic (inanimate) and of organic (animate) natural bodies. In the former, in minerals, growth is often the only function of evolution. Growth is, therefore, especially interesting, because both in the inorganic individual, the crystal, and in the simplest organic individual, it is the necessary preliminary to all further evolution. Growth, the addition of homogeneous body-substance, is absolutely universal. The inorganic crystal grows by absorbing homogeneous matter from the surrounding fluid medium, which then passes from a fluid into a solid condition. Similarly, the cell, the simplest organic individual, grows by attracting to itself particles from the surrounding medium, which is usually fluid, and by then transforming these particles into a semi-fluid, and more or less homogeneous condition (assimilation). The only difference between the growth of the crystal, and that of the simplest organic individual, the cell, is that the former adds the new substance externally, while the latter absorbs it internally. This essential difference depends on the different conditions of density, or of aggregation, of the two different groups of bodies. The inorganic bodies may be either in a solid, fluid, or gaseous condition. They grow by apposition. Organic bodies, on the contrary, are in the fourth, the soft or semi-fluid condition of aggregation. They grow by intussusception.

Each individual or trophic growth is, however, only the 
simple or direct form of growth common to crystal and to simple organic individuals of the first order. This simple form of growth is secondarily opposed to compound or numerical growth, which is scen in the course of the evolution of all many-celled organisms, in all individuals of the second, or higher order. In this case, the simple cell does not continually increase, as might be supposed, until the whole large organic individual, with all its parts, is formed; but after the cell has attained a certain, very limited size, it does not increase further, but parts by self-division into two cells. Owing to the frequent repetition of this process of compound growth, a many-celled organism, which is far larger than the largest cell, at last arises. In this case, the growth of the ever-increasing organism is no longer the mere addition of homogeneous parts, but depends really on generation, i.e., the multiplication of the originally simple individual.

A further distinction between organic and inorganic growth depends on the fact that the former, unlike the latter, is connected with nutrition. Nutrition is necessary to the existence of every living organism, for loss of substance of body-material is implied in all life-energies; and this loss of substance must be replaced by the addition of new substance or food. This continual change of substance, the absorption and assimilation of new matter, the expulsion of used-up particles, and briefly, all the processes included by the term nutrition, are conditions as necessary to the accomplishment of evolution as for all the other activities of life: they are as indispensable to the evolution of the single cell as to that of the entire manycelled organism. The usual method of nutrition in the 
case of the single cells is by the absorption by their soft semi-fluid cell-substance of food-material from the surrounding fluid; less frequently solid particles are pressed into the cell-substance. Similarly, the worn-out material is discharged, usually in a fluid, seldom in a solid form.'

Adaptation, the most important vital function, is directly connected with nutrition, and plays the most important part in the progressive development of the organism. It is, in reality, the most influential cause of every advance and of all perfection of the organism. Adaptation effects all the modifications or variations which organic forms undergo under the influence of the external conditions of existence; it is the true cause of every modification. As I have very fully discussed the importance of modification and the various laws of Adaptation in my Generelle Morphologie, and in the "History of Creation," I may here dispense with any further reference to it. I shall only call attention to the fact, that all these various laws of Adaptation can appropriately be brought into the two classes that I have there distinguished; on the one side indirect, or Potential Adaptation, on the other direct, or Actual Adaptation. I have shown in my Generelle Morphologie (vol. ii. pp. 193-226), that all these varied and important phenomena, if regarded from a physiological point of view, can be reduced to the mechanical function of nutrition, and, indeed, to the elementary conditions of cell-nutrition.

Just as progressive Adaptation is linked with nutrition, so is conservative Heredity linked with reproduction. This latter activity of the organism may also be referred to the former functions. For radically "reproduction is a form of nutrition and a growth of the organism to a size beyond 
that belonging to it as an individual, so that a part is thus elevated into a (new) whole" (Generelle Morphologie, vol. ii. p. 16). The functions of growth and reproduction are therefore very intimately connected. Reproduction is only a continuation of the growth of the individual. But the latter, again, depends in its compound form, on generation, that is, on the multiplication of the simple constituent individuals. While, on the one hand, reproduction appears to be only a growth of the individual to a size exceeding that of the individual,- compound growth, on the other hand, is the result of the reproduction of simple individuals of the first order. This view enables us clearly to understand reproduction and, consequently, Heredity, which otherwise appears to be an obscure and mysterious process.

To prove the correctness of this view, we must start from the simplest form of reproduction, that is, division, as it occurs in the case of almost every cell. When the cell,

Fig. 16.-Blood-cells (corpuscles), increasing by self-division, from the blood of the young embryo of a stag. Each has originally a kernel (nuclens), and is globular (a). When the cells are about to mnltiply; the kernel first separates into two $(b, c, d)$. The protoplasmio body then becomes pinched in between the two kernels, which separate more and more from each other $(e)$. Finally the cell parts into two, at the point where it was pinched in $(f)$. (After Frey.)

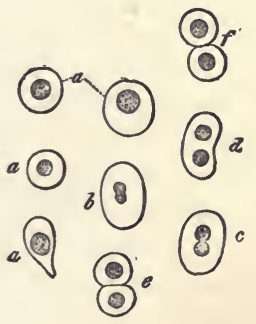

having, by the absorption of nutrition, already reached its usual size, exceeds that measure, it divides into two cells (Fig. 16). Just in the same way in many-celled animals (for example, Corals), when the individual grows beyond the 
definite size proper to it, a separation into two new individuals necessarily takes place. Starting from this simplest form of reproduction, we can learn to understand the many complex forms with which we meet, especially in the lower animals and plants. Division is first followed by propagation by buds, then that by the formation of germbuds, and propagation by germ-cells, or spores. All these forms of multiplication are classed under the name of asexual reproduction, or Monogeny; in these cases it does not require the union of different individuals to effect the production of new, independent individuals. ${ }^{45}$

The conditions of sexual reproduction, or Amphigony, are quite different.' Its nature consists in this; that two distinct cells must unite in a particular way and blend in order to cause the production of a new individual. As we shall soon return to the subject of sexual reproduction, when we consider the fertilization of the egg, we need not here linger over it. We must only emphasize the fact, that this process of sexual reproduction, in spite of its peculiarity, is yet nearly related to the higher forms of asexual reproduction, and especially to that by the formation of germcells. But while in the latter case a single cell separates from the confederacy of the many-celled organism and forms the foundation of a new individual,-in the former, two different elementary individuals, a female egg-cell and a male sperm-cell, must unite and blend into a single body to effect that purpose. The double cell formed in this way is alone capable of forming by division an aggregate of cells, from which a new many-celled organism then develops. ${ }^{46}$ (Cf. Chap. XXV.)

Immediately connected with reproduction is a fifth 
highly important evolutionary. function, Heredity. Just as we were able to trace Adaptation back to nutrition, we can also show that Heredity is a necessary phenomenon of reproduction; and this is equally true of both kinds of Heredity-of conservative, as well as of progressive Heredity. As I have also fully explained these highly important Laws of Heredity, which maintain constant reciprocal relations with the Laws of Adaptation, in my "History of Creation," vol. i. Chapter VIII. p. 175, we will not stop to examine them here. (See also Generelle Morphologie, vol. ii. pp. 170-191.)

Division of labour, or differentiation, which has but recently begun to be correctly valued, forms a sixth evolutionary function of especial importance. We have already seen that division of labour is the strongest impulse towards progressive evolution, not only in civic and social life, but also in the social cell-confederacy of every manycelled organism. A glance at any community or state organization shows that the first condition of all higher development and civilization, is, on the one hand, the division of the various duties among the various classes of the citizens; and, on the other hand, the co-operation of these single individuals for the common purposes of the state. This is exactly the case also in every many-celled organism. Every multicellular individual in the plant or animal kingdom is more perfectly developed, and ranks higher in proportion as the division of labour among its constituent cells, the differentiation of its cell-individuals, is more perfect. Therefore in the various classes of organisms we find this differentiation, sometimes in a more, sometimes in a less perfect condition. The simplest form of division of VOL. I. 
labour occurs in those lower animals in the bodies of which only two kinds of cells have become differentiated. This is the case, for example, in the lowest Plant-animals, in Sponges, and the simplest Polyps, as well as in their common parent-form, the Gastræa. Throughout the entire many-celled bodies of these, there are only two different kinds of cells; the one kind effect the nutrition and reproduction of the animal, the other kind are its organs of feeling and motion. These two kinds of cells are identical with those which first come to perfection in the first process of differentiation of the germ-layers in the human embryo. But in most higher animals the differentiation of the cells proceeds much further. Some take merely the office of nutrition; others that of reproduction; a third group constitute the outward covering of the body and form the skin; a fourth group, the muscle-cells, form the flesh; a fifth group, the nerve-cells, develop into the organs of sensation, of will, of thought, etc. All these different kinds of cells originally proceeded by differentiation or specialization from the simple egg-cell, and from the homogeneous descendants of that egg-cell, owing to division of labour. This differentiation of the cells, or this division of labour, originally arose in tribal history, from causes similar to the division of labour in the civilized states of men. Afterwards it appears in the germ-history, and by that time it has been made over to Heredity, and is merely repeated in accordance with the fundamental law of Biogeny. Now, although Differentiation usually leads to the progress of the whole organism as well as of its various constituent individuals, the single cells, yet it is also in many cases the occasion of retrogression, or atzvism. Not only progressive, but also 
retrograde modifications take place in consequence of division of labour.

Atavism, or reversion, must be regarded as a seventh function of evolution, and, as such, plays no unimportant part. In the evolution of almost every higher organism we observe that the progressive completion of most organs is accompanied by retrograde processes of evolution in single parts. In the cell this retrograde metamorphosis usually first occurs in consequence of the formation of fat-particles in the protoplasm. The cell is destroyed by the fatty degeneration of the protoplasm. During the course of phylogenetic, as of ontogenetic evolution, whole organs may thus retrograde by the dissolution of the cells which form them. Thus, for example, during the evolution of the germ of Man and of other Mammals, cartilages, muscles, etc., disappear which were of great importance in our primitive ancestors, the Fishes. This ontogenetic reversion reproduces, owing to Heredity, a corresponding phylogenetic process. The very interesting " rudimentary organs" are arrestedbodily growths of this kind, traces of which still remain in various stages of development (see p. 110). They are found in nearly every higher many-celled organism attaining to any considerable stage of evolution; in this case the general progress of the whole is scarcely ever conditional on the equally progressive development of the cells; on the contrary, certain cells perish during Ontogeny, while others go on growing at their expense. This same phenomenon is met with in human society. In this it is always the case that many individuals perish without effecting anything; while the majority constantly develop more or less steadily. The comparison is perfectly apt. For the 
conditions of aggregation are the same in states as in many-celled organisms.

Finally, we must mention an eighth and last function of organic development, viz. coalescence, or concrescence. As yet, this has been but little noticed, nor is it very striking; yet it is of real importance in certain processes. Coalescence consists in this, that two or more individuals which were originally separate afterwards combine and blend into one individual. We may regard the process of sexual generation as a coalescence of two cells. We also often find a similar coalescence of cells in other processes of evolution. Those tissues of the animal body which discharge the highest functions, viz. the muscular tissue, or flesh, which is concerned in locomotion, and the nervous tissue which performs the functions of sensation, will, and thought, consist in great part of coalescent cells. But not only cells, or individuals of the first order, but also organs, or individuals of the second order, coalesce very freely in the process of Ontogeny into a compound formation. Even independent organisms may coalesce, as is very often the case, e.g. in the Sponges. The process of coalescence (often also called conjugation or copulation), is in a certain sense the opposite process to that of propagation. In the latter two or more new individuals arise from one, while in the former one individual results from several. As a general rule, this individual possesses a higher function than that of the two units from the coalescence of which it sprang.

- In reviewing for a moment the different vital activities. of the organism which we have here enumerated as the essential functions of evolution-as the true formative forces. 
of the nascent organism-it will easily be seen that they all admit of purely physiological investigation. And yet till very recently many of them were never closely studied, and consequently the processes of evolution have very often been regarded as something altogether enigmatical and peculiar, and even in some respects miraculous and supernatural. So that even yet many distinguished naturalists hold that the phenomena of evolution are beyond the limits of human knowledge, and are only explicable by the assumption of supernatural forces.

This curious situation, reflecting as it does a somewhat unpleasant light upon the present status of our science, must be laid to the charge of modern Physiology. As I have already had occasion to remark, the Physiology of our day pays no attention either to the functions of evolution or to the evolution of the functions. With praiseworthy energy it has, it is true, exerted itself to perfect as far as possible the knowledge of certain groups of functions, to which an exact mathematical and physical treatment is directly applicable (e.g. the Physiology of the sense-organs, of muscular movement, of the circulation of the blood, etc.). But, on the other hand, it has paid but little attention to many important groups of functions, to which this exact method is not applicable. Among the latter are the chorological and ocological functions, many psychological phenomena and correlations of growth, and especially the most important of those functions of evolution which we have just enumerated-that of Heredity and Adaptation. Our present knowledge of these two most influential physiological functions of evolution has been almost entirely acquired by means of morphological, not physiological research, 
though Physiology had in the pursuit of its own objects occasion enough to devote itself earnestly to the study of these functions. In the same way the important functions of growth and coalescence, as also those of differentiation and atavism, have as yet been very little studied from a physiological point of view.

This neglect of the history of evolution explains the little interest and the lack of insight exhibited by the physiologists of our time with regard to the theory of descent. When Darwin, in his Theory of Natural Selection, gave a new basis to the theory of evolution, and so pointed out the way to a physiological explanation of the formation of species, a new and most interesting field of research was thrown open to Physiology. But Physiology has hardly yet entered this; and it has done as little to advance our knowledge of the processes of evolution in their ontogenetic as in their phylogenetic aspect. In fact, with a few illustrious exceptions, most physiologists have paid very little attention to the theory of descent, and to this day some of their most renowned leaders look on this most important biological theory as "an unproved and baseless hypothesis."

This want of comprehension of the history and significance of evolution can alone explain, for instance, the fact that the famous Berlin physiologist, Du Bois-Reymond, in his well-known address "On the limits of Natural Science," delivered at Leipsic in 1872, before the meeting of German naturalists, declared human consciousness to be a phenomenon absolutely and unconditionally transcending the bounds of human comprehension. It never occurred to him that consciousness, in common with every other cerebral activity, 
is in actual process of evolution. He overlooked the obvious consideration that even the consciousness of the human race must have arisen gradually by evolution through many phylogenetic stages precisely in the same way that even yet the individual consciousness of every child is gradually completed in the course of many ontogenetic stages.

Again, this same want of insight into the functions and the physiological process of evolution accounts for the fact that even at the present day esteemed and learned naturalists are earnestly discussing the question whether the creation of species, or, in other words, the phyletic evolution of forms, took place suddenly or gradually. This dispute is as irrational as would be a dispute as to whether the mouse is a great or a small animal. The elephant will of course declare the mouse to be a tiny creature, while the louse, living on the skin of the mouse, must regard the latter as an animal of gigantic size. Just as in the one case the estimate of extension in space is purely relative, and only to be taken in a relative sense, so in the other case is the estimate of extension in time:

Every process of evolution as such is always continuous, and real leaps or interruptions never occur. Natura non facit saltus-nature never leaps. This is true both of ontogenetic and of phylogenetic processes: of the evolution of the individual as well as of that of the species. It is true that in Ontogeny leaps sometimes appear to occur, e.g. when the butterfly is developed from the pupa into which the caterpillar has been transformed, or when a Medusa is developed from an entirely dissimilar hydra-form Polyp. But the morphologist who step by step studies the exact course of these processes of evolution, finds that, 
though certain stages seem omitted, the continuity is really unbroken, and that each new form arises directly from that which preceded it. Throughout there is a causal and unbroken connection; nowhere a sudden leap. ${ }^{47}$ But when the rapidity of the process of evolution is at one time retarded and again suddenly accelerated, or when heredity is curtailed, the result of the process appears to be a sudden leap.

This unbroken causal connection of the processes of evolution exists equally in germ-history, and in tribal history. For as Ontogeny is but a brief reproduction of Phylogeny, conditional on Heredity and modified by Adaptation, in the latter, therefore, as in the former, no leap or open gap can ever really exist between two consecutive evolutionary forms. As in the evolution of the individual so in that of the species, each new form arises directly from that which preceded it; and here also the physiological process of development always preserves its continuity. Even in those extreme cases where a new form does indeed seem to come into existence quite suddenly, as in what is called "sudden or monstrous adaptation," there is always, under the surface, an unbroken physiological evolutionary process which has the appearance of being a "sudden leap" only because of its comparative rapidity, or of the magnitude of its result.

As a striking instance, let us consider a frequently observed case of such "sudden variation." A common twohorned he-goat, the consort of which is also a common twohorned goat, begets a kid, from the skull of which grow four horns, in place of the two horns previously hereditary in this family of goats. In this case a new variety of goats bearing four horns has "suddenly" arisen, and under favourable 
conditions this young he-goat may become the founder of an entirely new four-horned race, or (by correlative adaptation and constant heredity) of a new fixed species.

But if we now search for the plysiological functions of evolution which have "suddenly" formed this new race or species, we find that a change in the hereditary nutrition at two points in the frontal bone and in the skin covering the same is the prime cause. Owing to the excessive local nutrition of the osseous tissue, and the consequent proportionate multiplication of cells, a bony protuberance gradually appears at each of these points; and in consequence of correlative adaptation, the hairy skin covering both these protuberances, changes into a hard, bare horny sheath, analogous to the other two horns which have long been hereditary. As these bony protuberances grow, and their horny sheaths become correspondingly larger, a new, second pair of horns appears behind the old ones. All these functions of evolution which "suddenly and by a leap" produce this four-horned form of goat are in reality perfectly "gradual and continuous" changes in the evolution of those masses of cells of which we have spoken : they depend on a change in the nutrition of the tissue at these two points in the frontal bone and skin. In this instance, therefore, an accurate examination of the physiological function of evolution affords a perfectly natural explanation of an apparently miraculous process. This is equally true of individual and of phyletic evolution.

This is also the explanation of a process of evolution which above all others is usually put under mystical veil as though it were a supernatural wonder; this is the process of fertilization, or sexual generation. In all the 
higher plants and animals this constitutes the first act in which the evolution of the new individual begins. But it must be noted here that this important process is by no means as universally distributed throughout the animal and vegetable world as is commonly supposed. On the contrary, there are very many low organisms which always multiply asexually, e.g. the Amœbæ, Gregarinæ, Flagellata, Foraminiferæ, Radiolaria, Myxomycetæ, etc. In these cases there is no form of impregnation: the multiplication of individuals, and the preservation of the species depend here simply on asexual generation, under the forms of fission, propagation by buds or by germ-cells. On the other hand, in the case of all higher plant and animal organisms, sexual propagation is the general law, and asexual generation never or but seldom occurs. Among Vertebrates in particular "virginal generation" (Parthenogenesis) never occurs. This we must explicitly affirm in the face of the celebrated dogma of the "immaculate conception." "Immaculate conception" has never been observed either in Man, or in any other Vertebrate. ${ }^{48}$

Sexual propagation in the various classes of animals. and plants exhibits an especially large number of interesting correlations, especially those relating to fertilization and the transmission of the male sperm to the female egg. These correlations are of the utmost significance not only in regard to propagation, but also in the production of organic bodily forms, and especially of sexual differences. Very remarkable instances of interaction take place between plants and animals. The recent admirable researches of Darwin and Hermann Müller on the fertilization of flowers by insect agency, are especially interesting from this point 
of view. ${ }^{49}$ As a result of this interaction we find a sexual apparatus of very complex anatomy. But in spite of the great interest of these phenomena, we cannot discuss them now, as they are only of subordinate importance in studying the essential nature of the process of fertilization. On the other hand, the nature of this process itself-the meaning of sexual generation, must be closely studied.

In every process of fertilization, as has already been said, two different kinds of cell, male and female, are concerned. In animals generally the female cell is called the egg, or egg-cell (ovulum), and the male is called the spermcell, or seed-cell (zoospermium, spermatozoon). The female. egg-cell, the form and structure of which we have already considered, is in all animals originally of the same simple structure. At first it is simply a globular, naked cell, consisting of protoplasm and cell-nucleus (Fig. 10, p. 134). When this cell lies free, and is capable of motion, it performs a number of slow, amœboid movements, as we have seen in the case of the egg of the Sponges (Fig. 14, p. 144). But commonly at a later period it is enclosed in peculiar envelopes and coatings of a very heterogeneous ana frequently very complex structure. On the whole, the eggcell is one of the largest of cells. In nearly all animals it is larger than any of the other cells.

On the other hand, the other cell which plays a part in impregnation, the male sperm-cell, is one of the smallest cells of the animal body. As a rule, fertilization results from a mucous fluid, secreted by the male, coming into contact with the egg-cell, either within or without the body of the female. This fluid is called the sperm, or male seed. The sperm, like the saliva and the blood, is not a simple 
clear fluid, but a dense mass of exceedingly numerous cells, floating about in a comparatively small quantity of fluid. It is not this fluid, but the cells suspended in it, which produce fertilization. In most animals, these sperm-cells are possessed of two special properties. In the first place, they are extraordinarily small, usually the smallest cells in the organism; and secondly, they are possessed of a very peculiar quick motion called the spermatozoid movements. The form of the cells is in correlation with this movement. In most animals, as also in many of the lower plants (but not in the higher), each of these cells consists of a very small naked cellular body, enclosing an oblong nucleus, and of a long vibrating filament attached to the body of the cell (Fig. 17). It was a very long time before it was discovered that these structures are simple cells. In former times they were universally regarded as actual animals, and were called sperm-animals (Spermatozoa). It is only through the searching investigations of the past few years that we have acquired positive evidence of the fact that each of these so-called spermatozoa is really a simple cell. It is, therefore, best to call them simply seed-cells or spermcells. In Man these possess the same form as in many other Vertebrates, and in the majority of Invertebrates. In many of the lower animals, however, the form of the seed-cells is very different. Thus, for example, in the Crayfish, they are fixed, round cells, motionless, and furnished with peculiar stiff, bristly processes. So, too, in certain Worms, e.g. the Thread-worms, the sperm-cells possess a very anomalous form. Some of these are amœboid, resembling very small egg-cells. Yet even in most of the lower animals, e.g. the Sponges and the Polyps, they possess 
the "pin-shaped form" which occurs in Man and other Mammals (Fig. 17).

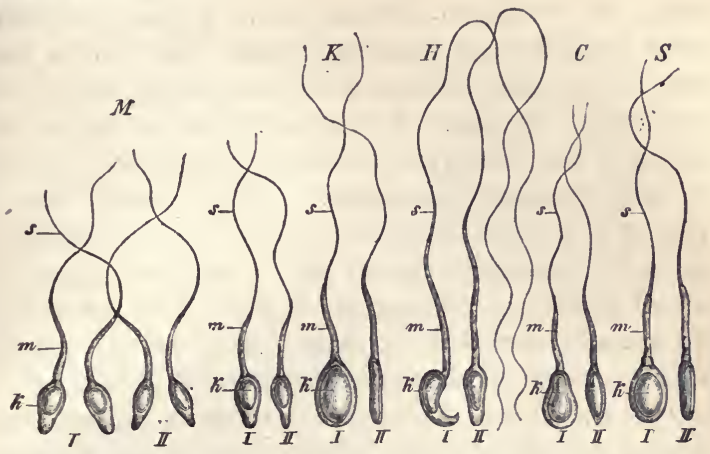

Fig. 17.-Seed-cells or sperm-cells from the semen of varions Mammals. The broad side of the flattened, pear-shaped nucleus portion of the sperm. cell (the so-called "head of the sperm-animalcule") is represented in the drawings marked $I$; the narrow side in those marked $I I: k$, kernel of the sperm-cell; $m$, central portion (protoplasm); $s$, active tail-like process (whip) ; $M$, four human sperm.cells; $A$, two sperm-cells of the ape; $K$, of the rabbit; $H$, of the common monse; $C$, of the dog; $S$, of the pig.

In 1677, when the Dutch naturalist, Leeuwenhoek, first discovered these filamentous and very active tiny bodies in the human semen, they were generally supposed to be distinct, independent animalcules, resembling Infusoria, and they were at once named "seminal animalcules." As we have already observed, they played an important part in the erroneous theory of preformation which was then prevalent, according to which the whole of the developed organism with all its parts exists preformed, though very small and as yet unexpanded, in each seminal animalcule. (See p. 36.) These animalcules had only to penetrate 
into the fruitful soil of the female egg-cell in order that the preformed human body might unfold and grow in all its parts. This radically erroneous view is now completely refuted, and the most accurate researches have shown that these active small seminal bodies are genuine cells, of the form called flagellate. In the earlier expositions of the subject a head, trunk, and tail were distinguished in each of these "seminal animalcules." The so-called "head" (Fig. $17 k$ ) is only the longish round or oval cell-nucleus; the body, the central portion $(m)$, is only an aggregation of cell material, a prolongation of which forms the tail (s). We now also know that the form of these seminal animalcules is not even peculiar and unrepresented in other cells; for entirely similar vibratory cells occur in various other parts of the animal body. When these cells are possessed of many processes they are called ciliate cells; but if they have only one process, they are said to be flagellate. The ciliated sponge particles afford instances of flagellate cells resembling those of the sperm-cells.

Thus the process of fertilization in sexual generation depends essentially on the fact that two dissimilar cells meet and blend. In former times the strangest views prevailed with regard to this act. Men have always been disposed to regard it as thoroughly mystical, and the most widely different hypotheses have been framed to account for it. It is only within the last few years that closer study has shown that the whole process of fertilization is extremely simple, and entirely without any special mystery. Essentially it consists merely in the fact that the male sperm-cell coalesces with the female egg-cell. Owing to its sinuous movements, the very mobile sperm-cell finds its way 
to the female egg-cell, penetrates the membrane of the latter by a perforating motion and coalesces with its cell-material.

FrG. 18.-Fertilization of the egg. cell by the sperm-cells. The threadshaped, lively sperm.cells penetrate throngh the porons canals of the eggmembrane into the granular mass of yelk, with which they amalgamate. The kernel (nucleas) of the egg-cell has disappeared.

A poet might find in this circumstance a capital opportunity for painting in glowing

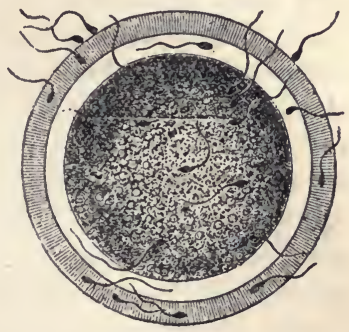
colours the wonderful mystery of the process of fertilization; he might describe the struggles of the living "seedanimalcules" eagerly dancing round the egg-cell shut up in its many coverings, disputing the passage through the minute pore-canals of the chorion, and then "of purpose" burying themselves in the protoplasm of the yelk-mass, where, in a spirit of self-sacrifice, they completely efface themselves in the better "ego." Or a teleologist might here find occasion to admire the peculiar wisdom of the Creator, who made many fine pore-canals in the eggmembrane in order that the seed-animalcules might pass through them. But the critical naturalist very prosaically conceives this poetical incident, this " crown of love," as the mere coalescence of two cells. The result of this is that, in the first place, the egg-cell is rendered capable of further evolution; and, secondly, that the hereditary qualities of both parents are transmitted to the child.

The fertilized egg-eell is, therefore, of a nature entirely different from that of the unfertilized egg-cell. For since 
we regard the sperm-cell as well as the egg-cell as true cells, and since fertilization essentially consists in the amalgamation of the former with the latter, therefore the cell which results from this amalgamation must be regarded as an entirely new independent organism. It contains, in the protoplasm of the sperm-cell, a portion of the paternal, male body, and on the other hand, in the protoplasm of the original egg-cell, a portion of the maternal, female body. This is equally shown by the fact that the child inherits many qualities from both parents. Heredity from the father is transmitted through the sperm-cells, Heredity from the mother through the egg-cell. The new cell, which is the rudiment of the child, the newly generated organism, originates in an actual amalgamation or coalescence of the two cells.

In order to gain a correct and clear knowledge of fertilization, I think it is absolutely necessary to emphasize as quite fundamental this simple but most important process, which as yet is not sufficiently appreciated. I therefore assign a peculiar name to the new cell, from which the child really proceeds, and which is usually inaptly called "the fertilized egg-cell" or "the first cleavage globule;" I shall call it the parent-cell (cytula), and its kernel (nucleus) the parent-kernel (cytococcus). The name "parent-cell" seems to me the simplest and most apt, because all the other cells of the organism descend from it, and because it is in the most real sense both the male ancestor and the female ancestor of all the numerous generations of cells, which are afterwards employed in the formation of the many-celled organism. The very complex molecular movement of the protoplasm in this parent-cell, 
summed up in the word "life," is naturally entirely different from that of the two distinct ancestral cells, the amalgamation of which gave rise to the parent-cell. The life of the parent-cell (CyTuLA) is the product or resultant of the paternal activities, transmitted through the spermcell, together with the maternal activities, transmitted through the egg-cell.

All good recent observations agree in showing that the individual evolution of man and of other animals begins with the formation of such a parent-cell, and that in the course of further evolution this then separates by self-division, or cleavage, into a number of cells, the so-called cleavage-globules or cleavage-cells (segmentella). But the most active strife is still waged over the question of the mode in which the parent-cell (cytula) originates, and of the relative parts played by the sperm-cell and the egg-cell in the formation of the parent-cell and in the act of fertilization. Formerly it was usually assumed-and many well-known naturalists still adhere to this-that the, original kernel (nucleus) of the egg-cell (p. 136, Fig. 11), the so-called germ-vesicle, is retained unaltered during fertilization, and that it directly transforms itself into the parent-kernel, "the kernel of the first cleavage-globule." But most more recent observers (with whom I agree) have become convinced that the germ-vesicle, the original eggkernel, sooner or later disappears, and that the parentkernel (cytococcus) forms itself anew. Here again, even the question as to the time and mode in which the new kernel of the parent-cell forms is at present still much debated. Some assume that the germ-vesicle disappears before fertilization, others say that this happens after fertivoL. I. 
lization. One party affirms that it is expelled from the egg-cell, the other that it dissolves in the yelk. Some are of opinion that it disappears entirely, others, that it only does so partially.

We cannot here enter into the various views which have recently been formed as to this remarkable incident in fertilization, the examination of which presents great difficulties. Those who are particularly interested in it may be referred to valuable works on this subject by Auerbach, Bütschli, Hertwig, Strasburger, and others. ${ }^{50}$ Here we can only briefly indicate the view which at present appears most probable. Most students of this point now assume as a universal incident in fertilization that the germ-vesicle, the original kernel of the egg-cell, disappears before fertilization, being either expelled from the egg or dissolved in the yelk. Either no part of the egg-cell, or only the germ-spot (nucleolus), remains as a defined part in the yelk. According to Hertwig and others, this germ-spot amalgamates with the sperm-kernel, or the kernel of the intruding sperm-cell, and this amalgamation gives rise to the kernel of the parent-cell. On the contrary, according to other observers, the parent-kernel (cytococcus) is an entirely new formation in the protoplasm of the parent-cell (cytula, Fig. 21).

At present, therefore, the majority of observers assume that between the original nucleated egg-cell and the known nucleated parent-cell there is a stage in which there is no real cell-kernel or nucleus, and in which, therefore, the form-value of the whole organic individual is no longer that of a true nucleated cell, but that of a non-nucleated cytod, i.e. a simple protoplasmic body in which no true cell-kernel (nucleus) is to be found. (Cf. p. 129.) Even if, with Hert- 
wig, we assume that the germ-vesicle does not completely disappear, but that the germ-spot (nucleolus) remains and amalgamates at the moment of fertilization with the nucleus (or nucleolus?) of the sperm-cell, we may say that the kernel of the parent-cell arises anew in that act, and that; therefore, a non-nucleated germ-stage, in which the form-value of the germ is only that of a cytod, precedes the one-celled germ-stage (the parent-cell). For reasons which we shall presently recognize, we shall call this simplest. (non-nucleated) stage, the Monerula. ${ }^{51} \quad$ (Fig. 19.)

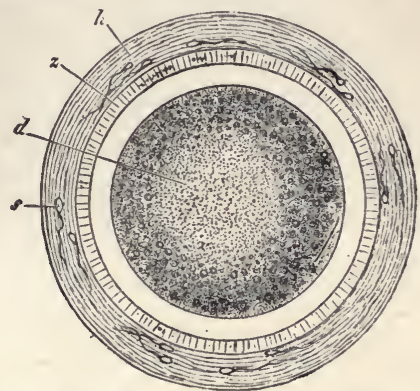

Fig. 19.-Monerula of a Mammal (Rabbit). The fertilized egg-cell, after the disappearance of the germ-vesicle, is a simple globe of protoplasm $(d)$. The outer membrane is formed by the modified zona pellucida (z), together with a mucons layer $(h)$ secreted on the ontside of the zona. A few single sperm-cells $(8)$ are still visible in the membrane.

We regard it as a fact of the greatest interest that the human child, like that of every other animal, is, in this first stage of its individual existence, a non-nucleated ball of protoplasm, a true cytod, a homogeneous, structureless body, without different constituent parts. For in this "Monerula-form" the structure of the animal, and thus of 
the human organism, is of the simplest conceivable nature. The simplest actually known organisms, and at the same time the simplest conceivable organisms, are the Monera, most of which are minute, microscopic, and formless bodies, consisting of a homogeneous substance, of an albuminous or mucous, soft mass, and which, though they are not composed of diverse organs, are yet endowed with all the vital qualities of an organism. They move, feed, and reproduce themselves by division (Fig. 20). These Monera

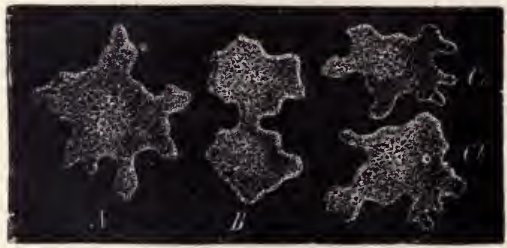

Fig. 20.-A Moneron (Protamoba) in the act of reproduction. A. The whole Moneron, which, like the Amœba (Fig. 13), moves by means of changeable processes. $B$. The Moneron is pinched in at a central point, so that it is divided into two halves. C. The two halves have separated and each now forms an independent individual. (Much enlarged.)

are of great importance, owing to the fact that they afford the surest starting-point for the theory of the origin of life on our earth. We shall presently have further occasion to point out their significance. (Cf. Chapter XVI.) Here we need only give due weight to the very remarkable fact that, both in germ-history and in tribal history, the animal organism begins its evolution as a structureless mucous ball. The human organism, like that of the higher animals, exists for a short time in this simplest conceivable form, and its individual evolution commences from this simplest form. The entire human child, with all its great 
fature possibilities, is in this stage only a small, simple ball of primitive slime (protoplasm, Fig. 19). The membrane is still there, but seems to be an entirely passive part of the egg, and takes no real share in the active processes of the evolution of this egg. We may, therefore, for a time pass over this membrane, for we shall afterwards enter into the changes which it undergoes in a later stage; as regards the actual process of evolution, it is entirely without significance. At present we need only concern ourselves with the contents

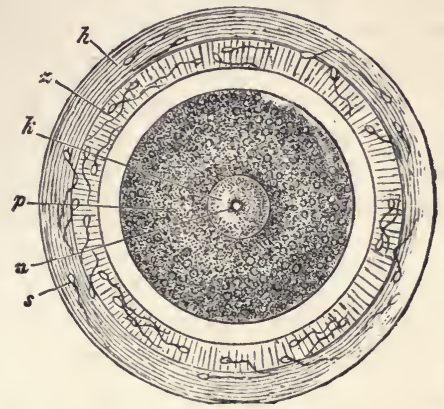

FIG. 21.-Parent-cell or cytula of a Mammal (Rabbit): $k$, parentkernel; $n$, nucleolus of the latter; $p$, protoplasm of the parent-cell; $z$ modified zona pellucida; $s$, sperm-cells; $h$, external albuminous membrane.

of the globular egg, the homogeneous yelk, which when in this condition we call the Monerula, in allusion to the Monera-form.

Although morphologically we can see no defined constituent parts in the Monerula, yet chemically we must regard the latter as the complex product of at least four different constituents; these are : (1) the protoplasm of the maternal egg-cell; (2) the protoplasm of the paternal 
sperm-cell; (3) the substance of the maternal germ-vesicle (kernel-substance or nuclein of the egg-cell); and (4) the substance of the paternal sperm-kernel (kernel-substance or nuclein of the sperm-cell). From the mixture of the two former substances $(1,2)$ the protoplasm of the parent-cell (Fig. 21, $p$ ) seems to originate; from the mixture of the two forms $(3,4)$ the parent-kernel (cytococcus) seems to originate (Fig. 21, k). ${ }^{52}$

The parent-cell (cytula, Fig. 21), which was formerly regarded as merely the "fertilized egg-cell," differs very essentially, therefore, from the original egg-cell, both in point of form (morphologically), and in point of composition (chemically, and lastly, also in point of vital qualities (physiologically). Its origin is partly paternal, partly maternal; we need not, therefore, be surprised, when we see that the child, which develops from this parent-cell, inherits individual qualities from both parents. ${ }^{53}$

The vital activities of each cell form a sum of mechanical processes, which depend radically on movements of the smallest "life particles," the molecules of the living substance. If we call this active substance the Plasson, and the molecules the Plastidules, we may say that the individual physiological character of each cell depends on the molecular movements of its plastidules. The plastidule movements of the cytula are therefore the resultant of the united plastidule movements of the female egg-cell and of the mate sperm-cell. If we regard the two latter as the sides of the parallelogram of forces, then the plastidule movement of the cytula is the diagonal. In my work on the "Perigenesis of Plastidules" (1876), I have explained the inportant bearing of this conception in explanation of the elementary processes of evolution. 


\section{TABLE II.}

Review of the Constituent Parts of the One-celled Germ-organism, before and after fertilization.

Cf. the works of Eduard Strasburger ("Ueber Zellbildung, Zelltheilung und Befruchtung," 2nd Edition; Jena, 1876); of Oscar Hertwig ("Beiträge zur Kentniss der Bildung, Befruchtung, nnd Theilung des Thierischen Eies;" 1875); of Leopold Auerbach ("Organologische Studien;" 1874); and of Otto Bütscbli ("Studien über die ersten Entwickelungs-Vorgänge der Eizelle," etc.; 1876). ${ }^{\text {st }}$

I. The Fertilizing Male,
or Paternal Sexual
Cell. The Fertilized Female,
or Maternal Sexual
Cell.

The sperm-cell. Spermule.

Syn. Thread - cell. Seed-animalcule. Spermatozoa. Zoosperm.

Fig. 17, p. 173.

Constituent Parts.

I. A. Protoplasm of the Sperm-cell.

\section{(Spermoplasma.)}

The central portion and the tail of the seedthread, together with the outer sheath of the "head."

\section{B. Kernel (nucleus)} of the Sperm-cell.

(Spermococcus.)

Sperm-kernel (Hertwig). "Head of the sperm-animal" (with the exception of the thin outer sheath). Syn. The nnfertilized egg.

Fig. 1, p. 122.

Fig. 10, p. 134 .

Constituent Parts.

II. A. Protoplasm of the Egg-cell.

(Ovoplasma.)

Yelk, egg-yelk, Lecythus, vitellus.

II. B. Kernel (nucleus) of the Egg-cell.

(Ovococcus.)

Germ-vesicle, or Purkinje's vesicle (Vesicula Germinativa), containing the germ-spot (Macula Germinativa),
III. The New Cell, the product of the Concrescence of I. and II.

\section{The Parent-cell. Cytula.}

Syn. The fertilized or the nucleolus, which, according to Hertwig, becomes the egg-kernel. egg. The first cleavageglobule. The oldest cleavage-cell. Segmen. tella prima.

Fig. 21, p. 181.

Constituent Parts.

III. A. Protoplasm of Parent-cell : Cleavagejelk.

(Cytuloplasma.)

Protoplasm of the first cleavage-globule (the product of the amalgamation of I. A. and II. A.

III. B. Kernel (nucleus) of the Parent-cell.

(Cytulococcus.)

Cleavage-kernel(Hertwig). Germ - kernel (Strasburger). Kerncl of the first cleavageglobule (product of the amalgamation of the sperm-kernel and the egg-kernel ?). ${ }^{.54}$ 


\section{CHAPTER VIII.}

\section{EGG-CLEATAGE AND THE FORMATION OF THE GERM- LAYERS.}

First Processes after the Fertilization of the Egg-cell is complete.-Original or Palingenetic Form of Egg-cleavage.-Significance of the Cleavageprocess.-Mulberry-germ, or Morula.-Germ-vesicle, or Blastula. Germmembrane, or Blastoderm.-Inversion (Invagination) of the Germ-vesicle. -Formation of the Gastrula.-Primitive Intestine and Primitive Month.-The Two Primary Germ-layers; Exoderm and Entoderm.Kenogenetic Form of Egg-clearage.-Unequal Clearage (segmentatio inequalis) and Hood-gastrula (Amphigastrula) of Amphibia and Mammalia.-Total and Partial Cleavage.-Holoblastic and Meroblastic Eggs.-Discoidal Cleavage (segmentatio discoidalis) and Disc-gastrula (Discogastrula) of Fishes, Reptiles, Birds.-Superficial Cleavage (segmentatio superficialis) and Vesicular Gastrula (Peri-Gastrula) of Articulates (Arthropoda). - Permanent Two-layered Body-form of Lower Animals. - The Two-layered Primæral Parent-form; Gastræa. Homology of the Two Primary Germ-layers in all Intestinal Animals (Metazoa).-Significance of the Two Primary Germ-layers--Origin and Significance of the Four Secondary Germ.layers.-The Exoderm or Skin-layer gives rise to the Skin-sensory Layer and the Skinfibrous Layer.-The Entoderm or Intestinal Layer gives rise to the Intestinal-fibrous Layer and the Intestinal-glandular Layer.

"The distinguishing of the strata, or layers, in the embryonic membrane was a turning-point in the study of the history of evolution, and placed later researches in their proper light. A division of the (disc-shaped) embryo into an animal and a plastic part first takes place. When this division is complete, each part has two layers. In the lower part (the plastic or vegetative layer) are a serons and a vascular layer, each of pecu- 
liar organization. In the upper part also (the animal or serous germ-layer) two layers are clearly distinguishable, a flesh-layer and a skin-layer."-KARL Ersst Baer (1828).

THE first processes which occur in the evolution of the individual, after the impregnation of the egg-cell is complete, and after the formation of the parent-cell, are essentially similar throughout the whole animal kingdom, and always begin with the so-called yelk-cleavage, and the formation of the germ-layers. Only the lowest and simplest animals, the Primæeval Animals, or Protozoa, are peculiar in this respect. These latter include the Monera, Amœbæ, Gregarinæ, Flagellata, Rhizopoda, Infusoria, and others. All these Primæval Animals reproduce themselves, as far as we yet know, only asexually, by division, the formation of buds, spores, germ-cells, and so on. On the other hand, they never have true eggs, i.e. germ-cells, to the evolution of which fertilization is necessary. Nor do they ever form true germ-layers. All other animals, on the contrary, all true animals, or Metazoa (as we may call them, in contradistinction from the Protozoa) have true eggs, and, from their impregnated eggs, form true germ-layers. This is as true of the low Plant-animals and Worms, as of the higher developed Soft-bodied animals (Mollusca,) Star-animals (Echinoderma), Articulated animals (Arthropoda), and Vertebrates. ${ }^{55}$

The most important processes of germination are essentially similar in all these true Animals (the Primæeval animals being excluded). In all, the parent-cell, which arose from the fertilized egg-cell, separates, by repeated cleavage, into a large number of simple cells. All these cells are direct followers or descendants of the parent-cell, and, for reasons 
which will be explained later, are called Cleavage-cells or Cleavage-globules (segmentella). The repeated process of division of the parent-cell, which gives rise to the cleavagecells, has long been known as egg-cleavage, or, inaccurately, as cleavage (segmentation). At an earlier or later stage, the entire mass of cleavage-cells divides into two essentially different groups, which range themselves in two separated cell-strata; the two primary germ-layers. This formation of the germ-layers is a process of the greatest significance, and the real beginning of the formation of the true animal body.

It is only quite recently that the fundamental germinal processes of egg-cleavage and the formation of the germlayers have been thoroughly understood, and their real significance rightly estimated. In the various animal groups these processes exhibit various striking differenees, and it was no easy task to show their essential similarity or identity throughout the whole animal kingdom (always excepting, of course, the Primæval Animals, or Protozoc). It was only after I had established the Gastræa Theory, ${ }^{40}$ in 1872, and afterwards, in 1875, had traced back individual forms of egg-cleavage and of the formation of the gastrula to one and the same type-form, that this important identity could be regarded as really proved. This furnished a single law which conditions the earliest germinal processes of all animals. ${ }^{56}$

The relation of Man to these earliest and most important processes is entirely similar to that of other higher Mammals, and especially to that of Apes. As the human germ or embryo, even in a much later stage of its formation, when the brain-bladders, the eyes, the organs of hearing, the gill-arches, etc. are also present, does not essentially 
differ from the correspondingly developed embryos of other higher Mammals (Plate VII., 1st row), we may quite safely assume that the earliest germinal-processes, the cleavage of the egg and the formation of the germ-layers, also coirespond. As yet, however, these processes have not been actually observed; for there has never been an opportunity of dissecting a female of the human species immediately after fertilization is completed, and of seeking the parentcell, or the cleavage-cells, in the oviduct. As, however, the youngest human embryo (in the form of germ-vesicles), which have yet been really observed, as well as the subsequently developed germ-forms, correspond in all essential points with those of the Rabbit, the Dog, and other higher Mammals, no reasonable man can doubt that egg-cleavage and the formation of the germ-layers proceeds, in the one case as in the other, in the way represented in Plate II. Fig. $12-17^{57}$

The particular form which egg-cleavage and the formation of the germ-layers assume in the case of Mammals, is, however, by no meanis the original, simple, and palingenetic form of germination. On the contrary, it has been very much changed, vitiated, and kenogenetically modified in consequence of numerous embryonic adaptations. (Cf.p. 12.) It is, therefore, impossible from a mere study of it to learn its nature. On the contrary, in order to obtain this knowledge, it is necessary to study and compare the various forms of egg-cleavage, and of the formation of the germlayers, which occur in the animal kingdom; and it is especially necessary to search for the original, palingenetic form, from which the modified, kenogenetic form of germination of Mammals gradually arose at a much later time. 
This original, palingenetic form of egg-cleavage, and of the formation of the germ-layers is altogether unrepresented in the present day in the Vertebrate tribe, to which Man belongs, except in the lowest and oldest member of this tribe, the remarkable Lancelet or Amphioxus (Cf. Chapters XIII. and XIV., and Plates X. and XI.). But it is still found in exactly this form in many low invertebrate animals-for example, in the remarkable Sea-squirts (Ascidia), in the Pond-snail (Limnceus), in the Arrow-worm (Sagitta); also in many Star-animals (Echinoderma) and Plant-animals,-for example, in the common Star-fish and Sea-urchin, in many Medusæ and Corals, and in the simplest Chalk Sponges (Olynthus). As an example, let us examine the palingenetic egg-cleavage and formation of the germ-layers of an eight-rayed single Coral, which I found in the Red Sea, and described in my Arabischen Korallen under the name of Monoxenia Darwinii. ${ }^{58}$

After the Monerula (Fig. 22, $A$ ) has changed into the parent-cell, or cytula $(B)$, the latter divides into two similar cells $(C)$. The kernel of the parent-cell first parts into two similar halves; these part asunder, shrink from each other, and then act as centres of attraction to the surrounding protoplasm; after this the protoplasm becomes contracted by a circular groove running round its circumference, and then separates into two similar halves. Each of the two cleavage-cells, which are thus produced, again separates in the same way into two similar cells, the plane of division between these two latter lying at right angles to that between the two former (Fig. 22, D). The four similar cleavage-cells, the descendants in the second generation of the parent-cell, lie in one plane. Each of these now again 
divides into two similar halves, the division of the cellkernel again preeding that of the surrounding protoplasm. The eight cleavage-cells thus produced bisect in the same way into sixteen. Thirty-two cleavage cells are formed from these by further division. As each of these again bisects, sixty-four of these cells are produced; afterwards one hundred and twenty-eight, and so on. ${ }^{59}$ These repeated and similar bisections finally result in the production of a globular mass of similar cleavage-cells; we call this mass the mulberry-germ (morula). The cells lie as close together as the drupes of a mulberry or blackberry; so that the entire surface of the round mass appears rugged (Fig. 22, E). . (Cf. Plate II. Fig. 3. ${ }^{60}$ )

After this egg-cleavage is completed, the solid mulberrygerm changes into a hollow globular vesicle. A watery liquid or jelly collects in the centre of the solid ball; the cleavage-cells part asunder, and all seek the surface of the ball. Here by mutual pressure they become multilaterally flattened, assume the form of truncated pyramids, and range themselves in order; side by side, in a single stratum (Fig. 22, $F, G$ ). This cell-stratum is called the germ-membrane (blastoderma); the cells (all of one kind), a simple stratum of which forms the germ-membrane, are called the germ-membrane-cells (cellulce blastodermica); and the entire hollow ball, the walls of which are composed of these cells, is called the germ-membrane-vesicle, or, briefly, the germvesicle, or vesicular-germ (blastula; formerly called the vesicula blastodermica). ${ }^{61}$ The inner cavity of the ball, which is filled with clear liquid or jelly, is called the cleavage-cavity (cavum segmentarium), or the germ-cavity (blastocoeloma). 

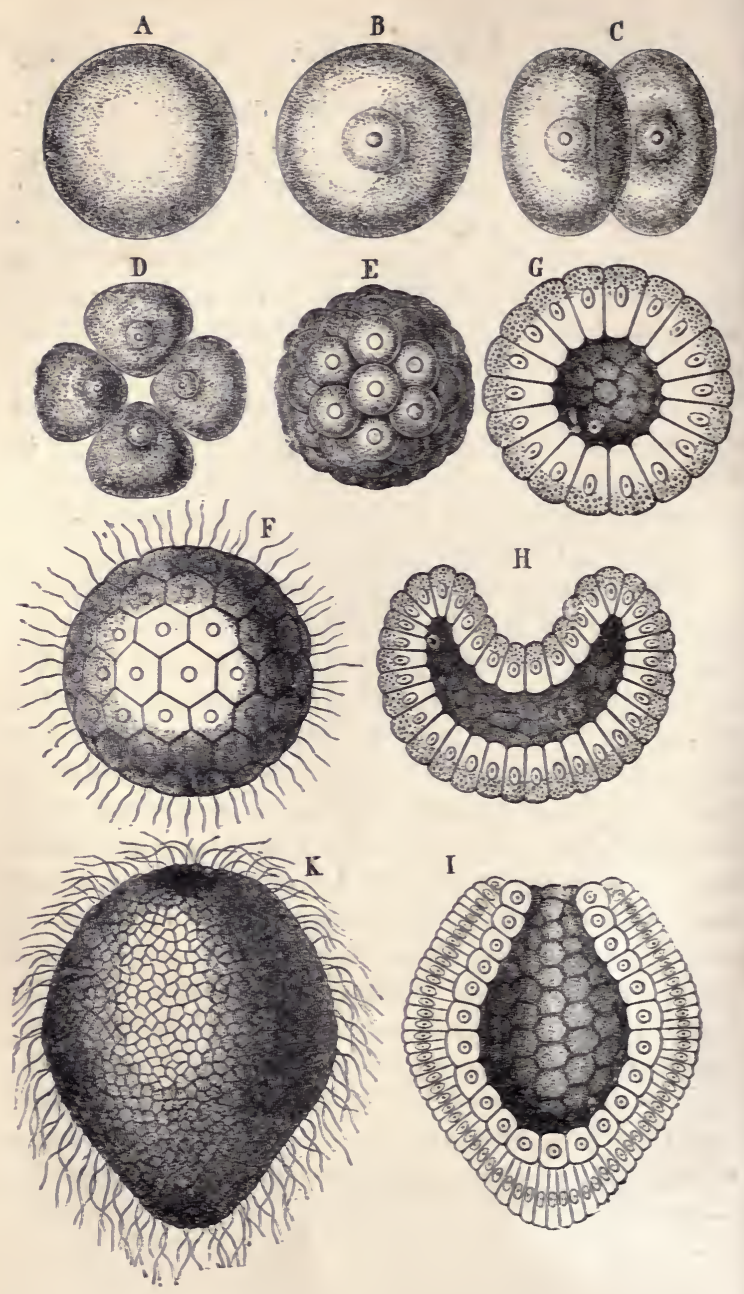
Fro. 22.-Germination of a Coral (Monoxenia Darucinii): A, Moperala ; $B$, Parent-cell (Cytula); $C$, two clearage-cells; $D$, four clearage-cells; $E$, Mnlberry-germ (Morula); $F$, the Germinal vesicle (Blastula); $G$, Germinal vesicle in section; $H$, Germinal vesicle (inverted) in section; $I$, Gastrula in longitudinal section; $K$, Gastrula, or Germ.cup, seen from outside.

In this Coral, as in many other low animals, the young animal-germ begins to move even in this stage, and swims about independently in the water. A long, thin, thread-like process, a whip or thong, grows out from each of the cells of the germ-membrane; and these independently exert slow vibrations, which afterwards become quicker (Fig. 22, $F^{\prime}$ ). Each cell of the germ-membrane is thus transformed into a vibrating whip-cell. The whole globular germ-vesicle revolves or turns, and is driven about in the water by the united force of all these vibrating whipprocesses. In many other animals, especially in those in which the germ is developed within closed egg-membranes, the vibrating whip-threads on the cells of the germ-membrane are not developed till a later period, or, even, are not formed at all. The germ-vesicle is capable of growing and extending, for the cells of the germ-membrane increase by repeated division, which occurs within the surface of the ball, and more liquid is secreted in the centre cavity.

A most important and remarkable process now occurs; this is the inversion of the germ-vesicle (invaginatio blastuloe, Fig. 22, $H$ ). The ball, the wall of which is cellular, consisting of a single layer, changes into a cup with a twolayered cellular wall. (Cf. Fig. 22, $G, H, I$.) The outer surface of the ball becomes flattened at a particular point; and this flattening deepens into a groove. The groove becomes deeper and deeper, growing at the expense of the central 
germ-cavity, or cleavage-cavity. The latter decreases in proportion as the former extends. At last the central germcavity entirely disappears, while the inner, inverted portion of the germ-membrane, the wall of the groove, attaches its inner surface to the inner surface of the outer, uninverted portion of the germ-membrane. At the same time, the cells of the two parts assume a different form and size; the inner cells become rounder; the outer become longer (Fig. 22, I). The germ thus acquires the form of a cup or gobletshaped body, the wall of which consists of two different cell-layers, while the cavity in its centre : grows outward at one end, at the place where the inversion originated. This highly important and interesting germ-form is called the germ-cup or the intestinal larva (Gastrula, Fig. 22, $I$, in longitudinal section; $K$, surface view) ${ }^{62}$

The Gastrula seems to me the most important and significant germ-form of the animal kingdom. For in all true animals, the Protozoa excepted, the egg-cleavage results either in a genuine, original, palingenetic gastrula (Fig. 22, $I, K$ ), or in an equivalent kenogenetic germform, which has arisen secondarily out of the earlier form, and which may be referred directly back to that form. It is certainly a most highly interesting and significant fact, that animals of the most diverse tribes, Vertebrates, Softbodied Animals (Mollusca), Articulated animals (Arthropoda), Star-animals (Echinoderma), Worms, and Plantanimals (Zoophyta) develop from one common germ-form. In most striking illustration of this, I place side by side several genuine Gastrula forms, taken from tribes of animals (Fig. 23-28, with the description).

This extraordinary importance of the Gastrula makes 
it necessary that we should most carefully examine the structure of its body. Ordinarily it is invisible to the

FIg. 24.

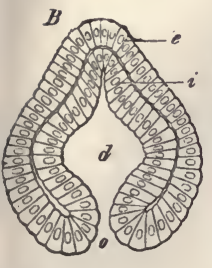

Fig. 25.

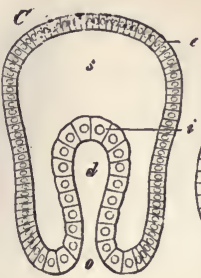

Fig. 26.
Fig. 27.

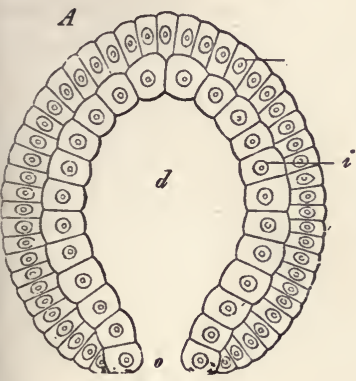

FIg. 23.

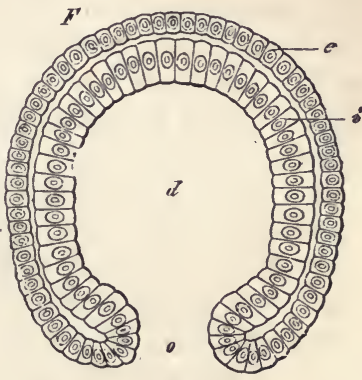

Fig. 28.

Fig. 23.-(A) Gastrula of a Zoophyte (Gastrophysema). (Haeckel.)

Fig. 24.-(B) Gastrula of a Worm (Sagitta). (After Kowalevsky.)

Fig. 25.-(C) Gastrula of an Echinoderm (Starfish, Uraster). (After Alexander Agassiz.)

Fig. 26.-(D) Gastrula of an Arthropod (Nauplius).

Frg. 27.-(E) Gastrula of a Molluso (Pond-snail, Limnous). (After Karl Rabl.)

Fig. 28.-( $F$ ) Gastrula of a Vertebrate (Lancelet, Amphioxus). (After Kowalevsky.)

In all, $d$ indicates the prinitive intestinal cavity; 0 , the primitive month; $s$, the cleavage-cavity ; $i$, the entoderm, or intestinal layer; $e$, the exoderm, or skin-layer.

VOL. I. 
naked eye, or, at most, under favourable circumstances, it is seen as a tiny speck, usually $\frac{1}{20}-\frac{1}{10}$, or at most $\frac{1}{5}-\frac{1}{2}$ millimetre in diameter; it is hardly ever more. In form the body of the Gastrula is usually cup-like; sometimes it is rather egg-shaped, sometimes rather ellipsoid or fusiform ; in other cases it is more hemispherical, or almost spherical; and again in others, longer or almost cylindrical. The geometric outline of the body is highly characteristic; it is marked by a single axis with two differing poles. This axis is the main, or longitudinal axis of the future animal body; one pole is the mouth, or oral pole; the opposite is the aboral pole. This outline with one axis distinguishes the Gastrula very essentially from the globular Blastula and Morula, in which all the axes of the body are similar. ${ }^{63}$

I shall call the central cavity of the Gastrula-body the primitive intestine (protogaster), and its opening the primitive mouth (protostoma). For this cavity is the original nutritive, or intestinal cavity of the body, and this opening originally served to admit food into the body. It is true that at a later period the primitive intestine and the primitive mouth appear very different in the different tribes of animals. This is especially true of Vertebrates, in which only the middle portion of the later-formed intestinal canal proceeds from the primitive intestine; and in which the later mouth-opening is a formation entirely independent of the primitive mouth, which closes. It is, therefore, necessary to distinguish clearly between the primitive mouth and intestine of the Gastrula on the one hand, and the later-formed intestine and mouth of the developed Vertebrate on the other. ${ }^{64}$

The two cellular layers which surround the cavity of 
the primitive intestine, and alone constitute the wall of the latter, are of very great significance. For these two which alone constitute the whole body, are, in fact, the two primary germ-layers, or primitive germ-layers (blastophylla). Their fundamental significance has already been pointed out in the historical introduction (Chapter III.). The outer cell-layer is the skin-layer, or exoderm (Fig. 29, e); the inner cell-layer is the intestinal layer, or entoderm (Fig. 29,e). The whole body of all true animals proceeds solely from these two primary germ-layers. The skinlayer furnishes the outer body-wall; the intestinal layer forms the inner wall of the intestine, and directly surrounds the intestinal cavity. At a later period a cavity forms

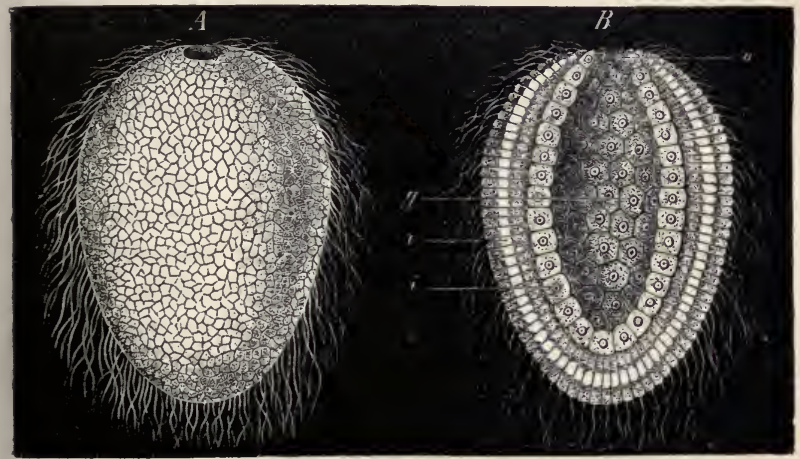

Fig. 29.-The Gastrula of a Chalk Sponge (Olynthus) : A, external view. $B$, in longitndinal section through the axis ; $g$, primitive intestine (primitive intestinal cavity); $o$, primitive mouth (primitive month-opening); $i$, the inner cell-layer of the body-wall (the inner germ-layer, entoderm or intestinal layer); $e$, the outer cell-layer (the outer germ-layer, exoderm or skin. layer). 
between the two germ-layers; this cavity, filled with blood or lymph, is the body-cavity (coloma) ${ }^{65}$

The two primary germ-layers, the outer or serous, and the inner or mucous layer, were first clearly distinguished, in 1817 , by Pander, in the incubated Chick (p. 51). But their full significance was first thoroughly recognized by Baer, who, in his "History of Evolution" (1828), gave the name of animal layer to the outer layer, that of vegetative layer to the inner. These names are very apt, because it is the outer layer which especially (if not exclusively) gives rise to the animal organs of sensation and movement, the skin, the nerves, and the muscles; while, on the other hand, it is especially from the inner layer that the vegetative organs of nourishment and reproduction, the intestine and bloodvessel system in particular, arise. Twenty years afterwards (in 1849) Huxley pointed out that in many low Plant-animals (Zoophyta), such as the Medusæ, the whole body permanently consists only of these two primary germ-layers. The outer of these he called the ectoderm, or exoderm; the inner he named the endoderm, or entoderm. Recently Kowalevsky and Ray Lankester especially have tried to show that other Invertebrate animals of the most diverse classes, in Worms, Soft-bodied Animals (Mollusca), Star-animals (Echinoderma), and Articulated animals (Arthropoda), form from the same two primary germlayers. Lastly, I have myself shown that this is the case also in the lowest Plant-animals, in Sponges; and at the same time I tried to prove in my Gastræa Theory that these two primary germ-layers must be considered as of the same significance, or as homologous, in all cases, from Sponges. and Corals to Insects and Vertebrates, including Man. 
Ordinarily the cells of the Gastrula-germ, which compose the two primary germ-layers, already present recognizable differences. In most cases, if not in all, the cells of the skin-layer, or exoderm (Fig. 29, e), are smaller, more numerous, and brighter coloured; on the other hand, the cells of the intestinal layer, or entoderm (Fig. 29, $i$ ), are larger, less numerous, and darker. The protoplasm of the exoderm cells is clearer and firmer than the darker and softer cell-substance of the entoderm cells; the latter are generally much richer than the former in fatty particles. The cells of the intestinal layer usually also have a much greater affinity for colouring matter, and take up carmine, aniline, and so on, from solution much more quickly and vigorously than do the cells of the skin-layer.

These physical, chemical, and morphological differences in the two germ-layers correspond to their physiological differences, and are of great interest, because in them we see the first and earliest process of division or differentiation of the animal body. The germ-membrane (blastoderma), which forms the wall of the globular germ-vesicle, or Blastula (Fig. 22, $F, G$ ), consisted solely of a single layer of similar cells. These cells of the germ-membrane, or blastoderm, are usually formed in a very regular and even way, and are of entirely similar size, form, and qualities. Generally they are flattened by pressing against each other, and are often uniformly six-sided. This uniformity of the cells disappears, at an earlier or later period, during the inversion (invaginatio) of the germ-vesicle. The cells, composing the inverted, inner part of the germ-vesicle (which afterwards form the entoderm) usually assume, even during the process of inversion (Fig. 22, $H$ ), a nature differing from 
that of the cells which constitute the outer, uninverted part (the future exoderm). When the process is completed, the histological differences in the cells of the two primary germ-layers are usually very strongly marked (Fig. 30). The small, bright-coloured cells of the exoderm $(e)$ are clearly distinguishable from the larger, darker cells of the entoderm (i).

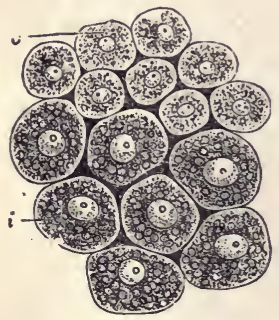

Fig. 30.-Cells from the two primary germ. layers of a Mammal (from the two strata of the germ-membrane): $i$, the larger, darker cells of the inner stratum, the vegetative germ-layer, or entoderm; $e$, the small, brightercoloured cells of the onter stratum, the animal germ-layer, or exoderm.

At present we have only considered that form of egg-cleavage, of germ-layer and gastrulation, which on many and important grounds we are justified in regarding as the original, primary, and palingenetic form. We call this the primordial, or original, form of egg-cleavage; and the Gastrula, resulting from this, we call the Bell-gastrula (Archigastrula). In a form exactly similar to that of our Coral (Monoxenia, Fig. 22), we meet with this Bell-gastrula in the lowest Plant-animals, in the Gastrophysema (Fig. 23), also in the simplest Chalk Sponges (Olynthus, Fig. 29), in many Medusæ and Hydra-polyps; in low Worms of different classes (Sagitta, Fig. 24; Ascidia, Plate X. Fig. 1-4); gain, in many Star-animals (Eclinoderma, Fig. 25); in low Articulated-animals (Artliropocla, Fig. 26), and Softbodied Animals (Mollusca, Fig. 27); lastly, in the lowest Vertebrate (Amphioxus, Fig. 28 - Plate X. Fig. 7-10). 
Although the animals which we have named belong to the most diverse classes, they all have this in common with each other and with many other animals, that, owing to constant heredity, they have retained the palingenetic form of egg-cleavage and Gastrula-formation, which they received from their oldest common ancestors, up to the present day. This is, however, not true of the large majority of animals. On the contrary, in them the original process of germination has, in the course of many million years, gradually changed in a greater or less degree, and has become vitiated owing to adaptation to new conditions of evolution. . Both the egg-cleavage, or segmentation, and the formation of the Gastrula, or gastrulation, which succeeds the segmentation, have in consequence of this acquired an aspect which is in many ways different. In the course of time the differences have even become so marked that the cleavage process of most animals was wrongly interpreted, and the Gastrula of these animals was altogether unknown. It is only owing to the extensive comparative reseárches which I instituted in late years among animals of the most diverse classes, that I have been enabled to indicate the one common process which underlies those processes of germination, apparently so different, and have traced back all the diverse forms of germination to the one original form, the form which has already been described. To distinguish them from this primary palingenetic form of germination, I shall call all the secondary forms, varying from the primary, vitiated, or kenogenetic processes. The more or less varying Gastrula-form, which results from this kenogenetic egg-cleavage, may be called, generally, the secondary, modified Gastrula, or Metagastrula. 
Among the many and various kenogenetic or vitiated forms of egg-cleavage and gastrulation, I again distinguish three different chief forms: 1 . Unequal cleavage (segmentatio incoqualis, Plate II. Fig. 7-17); 2. Discoidal cleavage (segmentatio discoidalis, Plate III. Fig. 18-24); and 3. Surface cleavage (segmentatio superficialis, Plate III. Fig. 25-30). Unequal cleavage results in a Hood-gastrula (Amphigastrula, Plate II. Fig. 11 and 17); discoidal cleavage results in a Disc-gastrula (Discogastrula, Plate III. Fig. 24); surface cleavage results in a Bladder-gastrula (Perigastrula, Plate III. Fig. 29). The last form does not occur among Vertebrates, with which we are now specially concerned; it is, on the contrary, the usual form among Articulated Animals (Spiders, Crabs, Insects, etc.). In Mammals and Amphibia the cleavage is unequal, and the Gastrula is a Hood-gastrula; this is equally true of the Ganoid fish and the Round-mouths (Lampreys and Hagfishes). On the other hand, in most Fishes, and in all Reptiles and Birds, we find the discoid form of cleavage, and a Disc-gastrula.

(Cf. Table III.)

As Man is a true Mammal, and as human germination is entirely similar to that of other Mammals, the cleavage in his case also is unequal, and results in the formation of a Hood-gastrula (Amphigastrula, Plate II. Fig. 12-17). But it is peculiarly difficult to investigate the first incidents in the egg-cleavage and gastrulation of Mammals. It is true that more than thirty years ago the anatomist Bischoff, of Munich, laid a foundation for this work in two books, which he published, on the germ-history of the Rabbit (1842), and on that of the Dog (1845); and that these were afterwards followed by two equally careful studies of the germination 
of the Guinea-pig (1852), and of the Roe-deer (1854). But it was only quite recently that Eduard van Beneden, an eminent Belgian zoologist, was able, owing to the elaborated methods of preparation of the present day, to throw full light on the obscurity which surrounded the germination of Vertebrates, and to give a right explanation of its details. It still, however, remains so difficult to understand these details, that it is desirable to glance first at the germination of Amphibia. In common with Mammals, these animals exhibit unequal cleavage, and form a Hood-gastrula. But the details of germination are simpler and more evident in Amphibia than in Mammals, and they are more nearly akin to the original, palingenetic form of germination.

The eggs of the common, tailless Amphibia, of the Frog and the Toad, afford the best and most convenient objects for this examination. Masses of them are easily obtainable in the spring from all ponds and pools; and a careful examination of the eggs with a magnifying glass is suffcient to show at least the external features of the eggcleavage. In order, however, to obtain a correct idea of the intricate details of the whole process, and to understand the formation of the germ-layers and of the gastrula, the egg of the Frog must be carefully hardened, and, the thinnest possible sections having been cut with a razor from the hardened egg, these must be most minutely examined under a powerful microscope. ${ }^{66}$

The eggs of the Frog and of the Toad are globular in form, and have a diameter of about two millimetres; they are laid in great numbers in masses of jelly, which, in the case of the Frog, form thick lumps, while those of the Toad form long strings. When the opaque, brown, grey, 
or black-coloured egg is minutely examined, the upperhalf appears darker than the lower. In some kinds, the centre of the upper half is blacker, while the corresponding centre of the lower half is of a whiter colour. ${ }^{67}$ This marks a distinct axis of the egg with two different poles. In order to give a clear conception of the cleavage of this egg, it is best to compare it to a globe, on the surface of which different meridian and parallel circles are marked. For the superficial boundary lines between the different cells, which result from repeated division of the egg-cell, have the appearance of deep furrows on the surface, for which reason the whole process has received the name of "the furrowing" (i.e. cleavage) ${ }^{59}$ But this so-called cleavage, which was formerly regarded with astonishment as a very wonderful process, is, in reality, only an ordinary and oftenrepeated division of the cells. Therefore the "cleavageglobules," which result from it, are really true cells.

Unequal cleavage, as we see it in the amphibian egg, is especially marked by the fact that it begins at the upper, darker pole-the north pole of the globe, according to our simile-and proceeds slowly downwards towards the lower, lighter pole, the south pole. During the egg-cleavage the upper, darker hemisphere is in advance, and its cells divide more vigorously and quickly; the cells of the lower hemisphere, therefore, appear larger and less numerous. ${ }^{67}$ The cleavage of the parent-cell (Fig. 31, $A$ ) begins with the formation of an entire meridian-furrow, which starts at the north pole and ends at the south pole $(B)$. An hour later, a second meridian-furrow arises in the same way, and cuts the first at right angles (Fig. 31, C). The sphere of the egg is thus divided into four similar segments. 
Each of these four first cleavage-cells consists of an upper, darker, and of a lower, brighter half. A few hours afterwards a third furrow appears, perpendicularly to the two
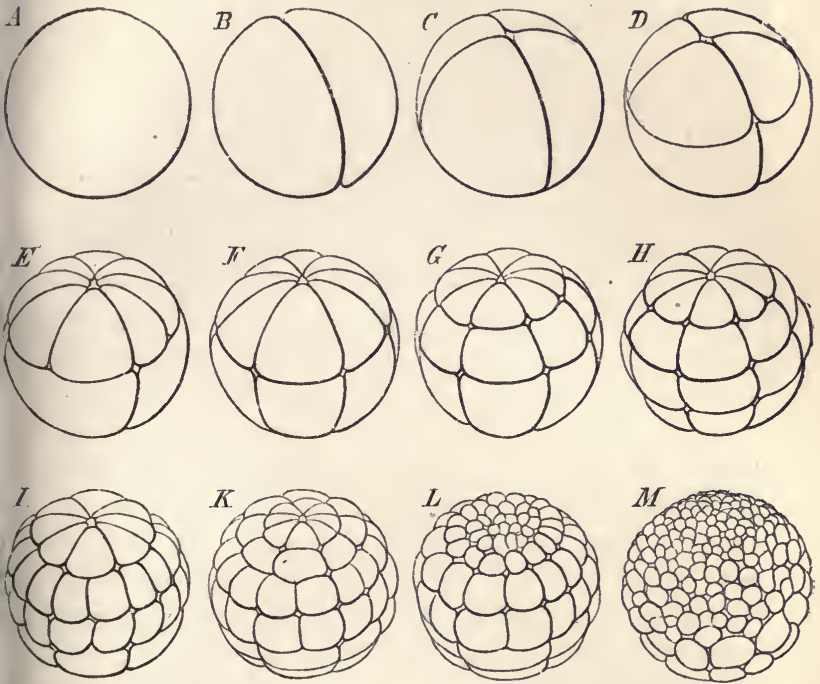

FiG. 31. -The cleavage of a Frog's egg (10 times enlarged): $A$, the parent-cell ; $B$, the two first cleavage-cells; $C, 4$ cells; $D, 8$ cells (4 animal and 4 vegetative); $E, 12$ cells (8 animal and 4 vegetative); $F$, 16 cells ( 8 animal and 8 vegetative); $G, 24$ cells ( 16 animal and 8 vegetative); $H, 32$ cells; $I, 48$ cells ; $K, 64$ cells ; $L, 96$ cleavage-cells ; $M$, 160 cleavage.cells (128 animal and 32 vegetative).

former (Fig. 31, D). This ring-furrow is generally, but wrongly, called the "equatorial furrow;" it lies north from the equator, and should, therefore, rather be compared to the 
northern tropical line. The spherical egg now consists of 8 cells, 4 smaller, upper, or northern, and 4 larger, lower, or southern. A meridian-furrow, starting from the northern pole, now appears in each of the first four cells, each of which falls into two similar halves, so that 8 upper cells lie on 4 lower cells (Fig. 31, $E$ ). It is only later that the four new meridian cells place themselves slowly on the lower cells, so that the number mounts from 12 to $16\left(k^{\prime}\right)$. Parallel to the first, horizontal ring-furrow, a new ringfurrow now appears, nearer the northern pole; this, therefore, we may compare to the arctic circle. The result of this is that we find 24 cleavage-cells: 16 upper, smaller and darker, and 8 lower, larger and brighter $(G)$. The latter, however, soon separate into 16 , for a third parallel circle appears in the southern hemisphere ; there are, therefore, 32 cells in all (Fig. 31, $H$ ). Eight new meridianfurrows now arise at the northern pole, and, first cutting the upper, darker, cellular circle, afterwards intersect the lower, southern circle, and finally reach the southern pole. We thus find stages in which there are successively $40,48,56$, and finally, 64 cells $(I, K)$. The inequality between the two hemispheres constantly becomes greater. While the inert southern hemisphere, for a long time, does not add to its 32 cells, the vigorous northern half of the globe furrows itself twice successively, and thus parts into 64, and then into 128 cells (Fig. 31, $L, M$ ). In the stage in which we now see the egg, there are, therefore, 128 :small cells on the surface of the upper, darker half of the egg-sphere, and only 32 cells in the lower, brighter half: 160 cleavage-cells in all. The inequality between the two hemispheres increases yet further; and while the northern 
hemisphere parts into a very large number of small cells, the southern hemisphere consists of a much smaller number of larger cells. Finally, they almost entirely overgrow the surface of the spherical egg; and it is only at a small circular point in the middle of the lower hemisphere, at the south pole, that the inner, larger, and brighter cells are visible. This white space at the southern pole corresponds, as we shall presently see, to the primitive mouth of the Gastrula. The whole mass of inner, larger, and brighter cells (together with this white space at the pole) belongs to the entoderm, or intestinal layer. The outer envelope of dark, smaller cells forms the exoderm, or skin-layer.

The often repeated division of the cells, which as cleavage or segmentation is plainly traceable on the surface of the egg-sphere, is not confined to this surface, but extends to the whole interior of the ball of the egg. The cells also segment in strata, which approximately correspond to concentric strata of the sphere; this process advances more quickly in the upper than in the lower half. A large cavity, filled with liquid forms, has in the mean time arisen, in the interior of the egg-sphere; this is the cleavage-cavity ( 8 , drawings of sections in Plate II. Fig. 8-11). The first trace of this cavity makes its appearance in the middle of the upper hemisphere, at the point at which the three first cleavage-planes, which are at right angles to one another, intersect (Plate II. Fig. $8 \mathrm{~s}$ ). During the progress of cleavage, this hollow extends significantly, and afterwards assumes an almost hemispherical form (Fig. $32 F$; Plate II. Fig. $9 s, 10 s$ ). The arched roof of this hemispherical cleavage-cavity is formed by the smaller, darker-coloured cells of the skin-layer, or exoderm (Fig. 
$32, D)$; on the other hand, the flat floor of the cavity is composed of the larger, whiter-coloured cells of the intestinal layer, or entoderm (Fig. $32 z$ ).
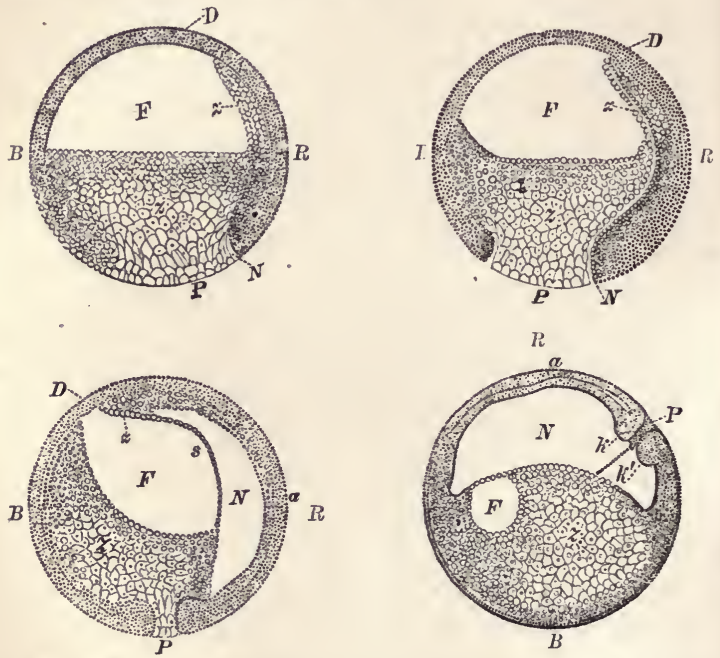

F1G. 32-35.-Fonr longitudinal sections of the segmented egg of a Toad, in four successive stages of evolution. In all, the letters indicate the same parts: $F$, cleavage-cavity; $D$, the roof of this cavity; $R$, dorsal half of the germ; $B$, intestinal half; $P$, the yelk-plug (white circular space at the lower pole); $z$, yelk-cells of the entoderm (the gland-germ of Remak); $N$, primitive intestinal cavity (protogaster, or Rusconi's nutritive cavity). The primitive mouth is filled up by the yelk-plug $(P)$; $s$, boundary between the primitive intestinal cavity $(N)$ and the cleavage-cavity $(F) ; k, k$, section through the swollen circular lip or edge of the primitive mouth (the socalled anus of Rusconi). The dotted line between $k$ and $k^{\prime}$ indicates the former connection between the yelk-plng $(P)$ and the central mass of yelkcells (z). In Fig. 35 the egg has tarned round $90^{\circ}$, so that the dorsal half of the germ $(R)$ is seen above; the intestinal half $(B)$ is now turned downward. (After Stricker.) 
A second cavity, narrower but larger, now arises, owing to an inversion of the lower pole, and to a separation in the white entoderm-cells next to the cleavage-cavity (Fig. $32-35, N)$. This is the primitive intestinal cavity or stomach-cavity of the Gastrula, the Protogaster. It was first observed by Rusconi in the eggs of Amphibia, and is accordingly called Rusconi's "nutritive cavity." In the longitudinal section (Fig. 33) it appears bent and sickleshaped, and extends from the south pole nearly to the north, for it folds a portion of the inner intestinal cells inward and upward-between the cleavage-cavity $\left(F^{\prime}\right)$ and the dorsal skin $(R)$. The primitive intestinal cavity is so narrow at first because the greater part of it is filled up with the yelk-cells of the entoderm. The latter also plug up the entire wide opening of the primitive mouth, and there form the so-called yelk-plug, which appears from the outside as the white, circular spot at the south pole $(P)$. Round this yelk-plug the skin-layer thickens, swells, and forms the lip of the primitive mouth (the properistoma, Fig. $\left.35 k, k^{\prime}\right)$. Presently the primitive intestinal cavity $(N)$ extends gradually at the cost of the cleavage-cavity $\left(F^{\prime}\right)$; and, finally, the latter entirely disappears. A thin partition (Fig. 34, s) alone separates the two cavities. That portion of the germ in which the primitive intestinal cavity develops, afterwards becomes the dorsal surface $(R)$. The cleavage-cavity lies in the anterior, the yelk-plug in the posterior part of the body. ${ }^{68}$

When the primitive intestine is complete, the Frogembryo has reached the Gastrula stage (Plate II. Fig. 11). But it is evident that this kenogenetic amphibian Gastrula differs greatly from the genuine palingenetic Gastrula, which 
we saw before (Fig. 23-29). In the latter, the Bell-gastrula (Archigastrula), the body has but one axis. The primitive intestine is empty, and the opening of the primitive mouth is wide. The skin-layer and the intestinal layer consist each of a single cell stratum. The two lie close together, for the cleavage-cavity has entirely disappeared during the process of unfolding. The amphibian Hood-gastrula ( $\mathrm{Am}$ phigastrula) is entirely different (Fig. 32-35; Plate II. Fig. 11). In this the cleavage-cavity $\left(F^{\prime}\right)$ continues for a considerable time side by side with the primitive intestinal cavity $(N)$. Yelk-cells fill the greater part of the latter; and they also fill the primitive mouth (yelk-plug, $P$ ). Both the intestinal layer $(z)$ and the skin-layer $(a)$ consist of several strata of cells. Finally, the general outline of the entire Gastrula, instead of having only one axis, has three; for the three axes which characterize the bilateral body of the higher animals, are indicated by the eccentric evolution of the primitive intestinal cavity.

In the evolution of the Hood-gastrula (Amphigastrula) we are unable to distinguish sharply between the different epochs, which, marked by the mulberry-germ and the germvesicle, we saw followed each other in the case of the Bellgastrula (Archigastrula). The Morula-stage (Plate II. Fig. 9 ) is as indistinctly separated from the Blastula-stage (Fig. 10), as the latter is from the Gastrula (Fig. 11). But in spite of this, we shall not have much difficulty in retracing the whole kenogenetic or vitiated course of evolution of this amphibian Amphigastrula to the genuine, palingenetic origin of the Archigastrula of the Amphioxus.

It is far harder to do this in the case of Mammals, although the course of egg-cleavage and gastrulation in 
these is, on the whole, very similar to that of Amphibia. Until recently the growth of the mammalian embryo was entirely wrongly explained; and it is only lately (1875) that Van Beneden, whose views we adopt here, pointed out its real significance. ${ }^{69}$ His studies were directed towards the embryo of the Rabbit, an animal in connection with which Bischoff first discovered the history of the mammalian germ. As the Rabbit in common with Man belongs to the group of disco-placental Mammals, as this Rodent develops entirely in the same way as does Man, and as even at a later stage of evolution the embryos of Man and of the Rabbit are hardly distinguishable (cf. Plate VII. Fig. $K, M$ ), there is not the slightest reason to doubt that the egg-cleavage and gastrulation of the two are similar.

When the fertilization of the egg of the Rabbit is complete, and the elaboration of the parent-kernel has transformed the Monerula (Fig. 36) into the parent-cell, or cytula (Fig. 37), the latter (the cytula) separates into the two first cleavage-cells (Fig. 38). In this process the parent-kernel first becomes fusiform and divides into two kernels (the two first cleavage-kernels). These repel each other and the two move apart. After this the protoplasm of the parentcell, attracted by the two kernels, parts into two halves, each of which assumes a globular form. They afterwards change from this globular to an ellipsoid form (Fig. 38). These two cleavage-cells are not, as was formerly believed, of the same size and significance. The one is larger, brighter, and more transparent than the other. Again, the smaller cleavage-cell takes a much deeper colour from carmine, osmium, etc., than does the larger. The two cells thus already betray their relations to the two primitive VOL. I. 

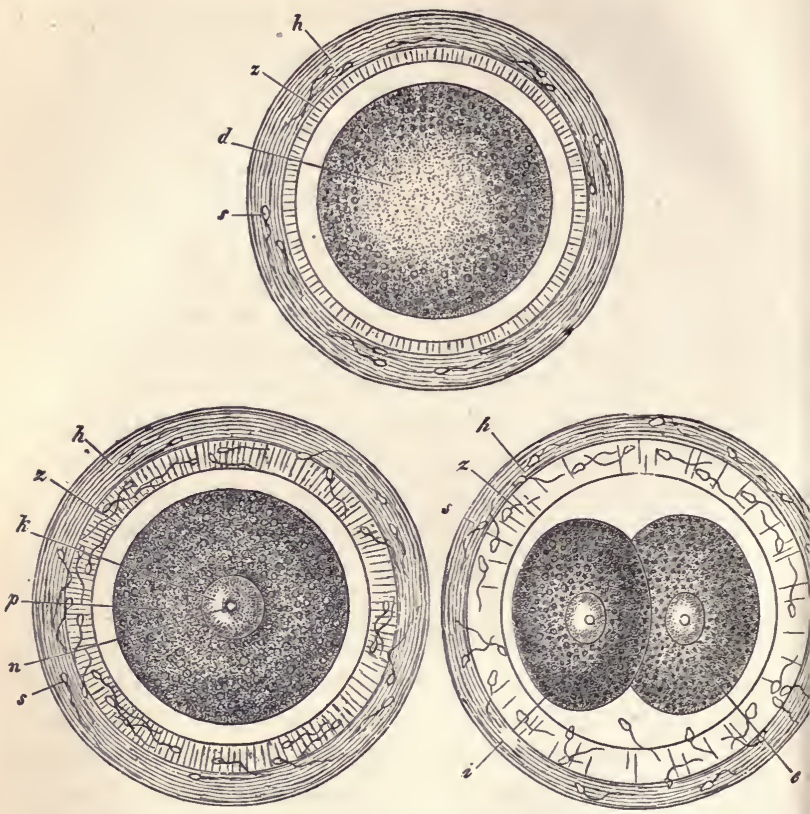

Fig. 36.-Monerula of a Mammal (Rabbit). The fertilized egg-cell after loss of the germ-resicle is a simple ball of protoplasm (d). The outer envelope of this is formed by the modified zona pellucida $(z)$ and by a mucous layer $(h)$, which is deposited on the outside of the zona. A few sperm-cells are still visible in this mucons layer $(s)$.

Fig. 37.-Parent-cell, or cytula, of a Mammal (Rabbit): $k$, parent-kernel, or nucleus; $n$, nucleolus; $p$, protoplasm of the parent-cell; $z$, modified zona pellucida; $h$, external albuminous envelope; 8 , sperm-cells.

Fig. 38.-Commencement of cleavage in the mammalian egg (Rabbit).

The parent-cell has separated into two differing cells; the brighter, mother-cell of the skin-layer $(e)$, and the darker, mother-cell of the intestinal layer $(i): z$, zona pellucida; $h$, external albuminons envelope; $s$, dcad sperm-cells. 
germ-layers. The brighter and harder cleavage-cell (Fig. $38, e)$ is the mother-cell of the exoderm; the darker and softer cleavage-cell (Fig. 38, $i$ ) is the mother-cell of the entoderm. All the cells of the outer germ-layer, the skinlayer, are produced from the exoderm mother-cell (Fig. 38, e; Plate II. Fig. 13,e). In the same way the whole of the cells of the inner germ-layer, the intestinal layer, descend from the entoderm mother-cell (Fig. 38, $i$; Plate II. Fig. 13, i). This interesting relation, which we thus see in the mammalian germ, is yet more pronounced in the germs of many lower animals. In many Worms, for example, at the beginning of cleavage, the parent-cell parts into two cleavage-cells of very dissimilar size and chemical qualities. In such cases the mother-cell of the exoderm is often very many times smaller than the entoderm mother-cell, which contains a large store of nutritive yelk.

The two first cleavage-cells of the Mammal, which are to be regarded as the mother-cells of the two primary germlayers, now contemporaneously separate into two cells (Fig. 39; Plate II. Fig. 14). These four cleavage-cells usually lie in two different planes, perpendicular to each other; more rarely in one plane. The two larger and brighter cells (Fig. 39, e), the descendants in the first generation of the exoderm mother-cell, if placed in carmine, colour much more deeply than do the two smaller and darker cells, the descendants of the entoderm mother-cells (Fig. 39, $i$ ). The line which connects the central points of the two latter cleavage-globules is usually perpendicular to that which connects the central points of the two latter. Presently each of these four cells again divides into two similar cells; 
we therefore find that there are now eight cleavage-cells, the descendants in the third generation of the parent-cell (Fig. 40). Four larger, brighter, and firmer cells lie in one plane; the descendants in the second generation of the exoderm mother-cell. Four smaller, darker, and softer cells lie in a second plane, perpendicular to the former; the descendants in the second generation of the entoderm mother-cell. If we connect the central points of the opposite cleavage-cells of one plane, two and two, by straight lines, these lines meet each other at right angles. But the four connecting lines of the two parallel planes together intersect at an angle of forty-five degrees (Fig. 40).
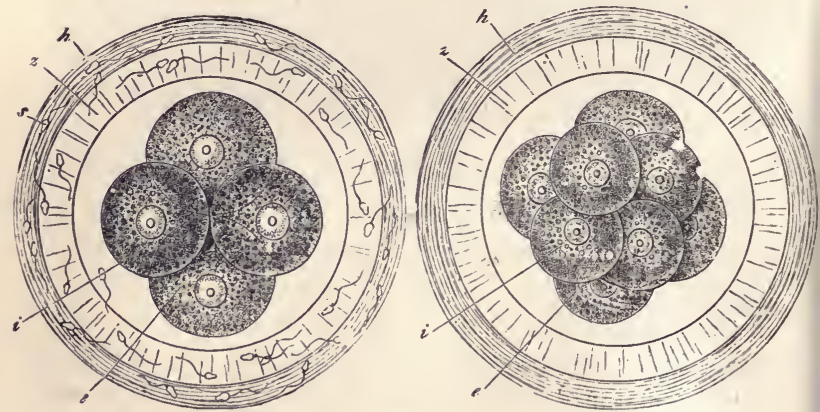

Fig. 39.-The four first cleavage-cells of a Mammal (Kabbit) : $e$, the two exoderm-cells (larger and brighter); $i$, the two entoderm-cells (smaller and darker); z, zona pellucida; $h$, onter albuminous envelope.

F1G. 40.-Egg of Mammal (Rabbit), with eight cleavage-cells : $e$, four exoderm-cells (larger and brighter); $i$, four entoderm-cells (smaller and darker); $z$, zona pellucida; $h$, outer albuminous covering.

Now, however, the eight cleavage-cells alter their original position, and lose their globular form. One of the 
four exoderm-cells makes its way into the middle of the cell-mass, and, together with its three fellows, forms a pyramid (or tetrahedron). The four exoderm-cells arrange themselves in the form of a cap over the point of this pyramid (Plate II. Fig. 15). This is the beginning of a germinal process which must be regarded as a shortened and vitiated repetition of the inversion of the germ-membrane vesicle, and which results in the formation of a Gastrula. From this time the further cleavage of the mam malian egg adheres to a rhythm which is most essentially similar to that of the Frog's egg. While in the original (ar primordial) egg-cleavage, the rhythm advances in regular geometrical progression $(2,4,8,16,32,64,128$, and so on); in the modified progression of the mammalian egg, the sequence of numbers is the same as that of the amphibian egg: $2,4,8,12,16,24,32,48,64,96,160$, etc. (Cf. Table V.)

Fig. 41. - Gastrula of a Mammal (Amphigastrula of a Rabbit), in longitudinal-section through the axis: $e$, exodermcells (64 brighter and smaller); $i$, entoderm-cells ( 32 darker and larger); $d$, central entodermcells, filling up the primitive intestinal cavity ; 0 , external entoderm-cells, plngging the primitive mouth-opening (yelk-plng in the "anns of Rasconi").

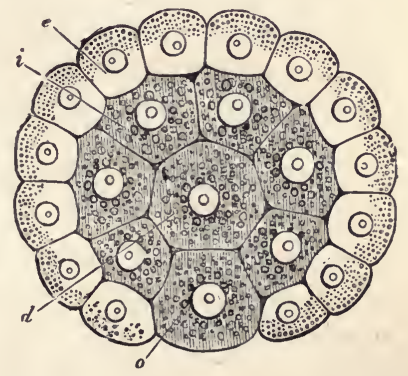

This depends on the fact that from this time the more vigorous exoderm-cells increase at a quicker rate than the more inert entoderm-cells. The latter always remain behind the former, and are overgrown by them. This pro- 
cess in which the inner intestinal layer cells are overgrown, is really nothing but the inversion of the vegetative hemisphere into the animal hemisphere of the germ-vesicle; i.e. the formation of a Gastrula (Fig. 41). ${ }^{69}$

Next, therefore, follows a stage in which the mammalian germ consists of 12 cleavage-cells; 4 darker entodermcells form a three-sided pyramid which is covered by a cap of 12 lighter exoderm-cells (Plate II. Fig. 15 in section). The next stage, in which there are 16 cleavage-cells, is seen to consist of 4 entoderm-cells in the interior, 4 other outer and lower entoderm-cells; while the 8 exoderm-cells, in the form of a hemispherical cap, cover the upper half of the germ. This cap of exoderm-cells, which increase in number from 8 to 16, continues to overgrow the inner cell mass; of the 8 entoderm-cells, 3 , 4, or 5 lie in the centre of the germ, and the rest at the base of the globular germ (Plate II. Fig. 16). This 24-celled stage is followed by one in which there are 32, for the 8 entoderm-cells also double their number. This is afterwards succeeded by germ-forms in which there are 48 cleavage-cells ( 32 exoderm and 16 entoderm); 64 cleavage-cells (32 skin-layer and 32 intestinal layer); 96 cleavage-cells (64 exoderm and 32 entoderm), and so on.

When the mammalian embryo has acquired 96 cleavagecells, a stage which, in the case of the Rabbit, is reached in about the 70th hour after fertilization, the characteristic form of the Hood-gastrula (Amphigastrula) becomes plainly visible (Fig. 41; cf. Plate II. Fig. 17 in section). The globular embryo consists of a central mass of 32 soft, roundish, dark granular entoderm-cells, which, by mutual pressure, are flattened multilaterally, and which assume 
a dark brown colour when treated with osmic acid (Fig. $41, i$ ). This dark central cellular mass is surrounded by a brighter globular membrane, composed of 64 smaller cubeshaped and finely granulated exoderm-cells, which lie side by side in a single layer, and take up very little colour from osmic acid (Fig. 41, e). The exoderm-membrane is broken only at one single point, when 1,2 , or 3 entoderm-cells pierce to the surface. The latter form the yelk-plug which entirely occupies the primitive mouth of the Gastrula (o). The central primitive intestinal cavity is filled by entoderm-cells (Plate II. Fig. 17). The single axis of the outline of the mammalian Gastrula is thus clearly indicated. ${ }^{\text {c9 }}$

Although the unequal egg-cleavage and gastrulation of Mammals and Amphibia present various peculiarities, it is comparatively easy to trace these processes back to the egg-cleavage and gastrulation of the lowest Vertebrate, the Amphioxus, which is entirely similar to the form of cleavage carefully examined by us in the case of the Coral. (Cf. Fig. 22 and 28.) All these and many other classes of animals agree in that, in their egg-cleavage, the whole egg parts, by repeated division, into a large number of cells. All such animal eggs have long been called holoblastic, a name given them by Remak, because in them the cleavage into cells extends to the whole mass; or, in other words, is total (Plate II.).

In very many other classes of animals this is, however, not the case; for instance, among Vertebrates, in Birds, Reptiles, and most Fishes; among Articulated animals (Arthropoda), in Insects, most Spiders and Crabs; among Softbodied animals (Mollusca), in Cephalopods or Cuttle-fishes. 
In all these animals, both the ripe egg-cell, and the parentcell, into which fertilization transforms this egg-cell, consist of two quite distinct and separate parts, which are distinguished respectively as the formative yelk and the nutritive yelk. The formative yelk (vitellus formativus, or morpholecithus) is the nucleated egg-cell, capable of evolution, which divides in the process of cleavage, and produces the numerous cells which constitute the embryo. The nutritive yelk (vitellus nutritivus, or tropholecithus), on the other hand, is a mere appendage of the true egg-cell, and contains hoarded food-substance (albumen, fat, etc.); so that it forms a sort of storehouse for the embryo in the course of its evolution. The embryo absorbs a quantity of nutritive matter from this storehouse, and finally entirely consumes it. Indirectly, therefore, the nutritive yelk is of great importance in germination. Directly, however, it takes no share in the process, for it is not concerned in the cleavage, and is not cellular. Sometimes the nutritive yelk is smaller, sometimes larger; generally many times larger than the formative yelk; for which reason, greater importance was formerly attached to the nutritive than to the formative yelk. All eggs which have this independent nutritive yelk, and of which, therefore, only a portion undergoes cleavage, are called meroblastic, the name given them by Remak; their cleava'ge is incomplete or partial (Plate III.).

It is not easy correctly to apprehend this partial eggcleavage, and the peculiar form of Gastrula which results from it; and it was only quite recently that comparative research enabled me to remove this difficulty, and to retrace this kenogenetic form of cleavage and gastrulation to the original, palingenetic form. The sea eggs of one of the 
Osseous Fishes (Teleostei), the evolution of which I studied at Ajaccio, in Corsica, in 1875, were of the greatest service to me in this respect (Plate III. Fig. 18-24). I found these, massed together in lumps of jelly, floating on the surface of the sea; and as the tiny eggs were quite transparent, I was easily able to watch each stage in the evolution of the germ. ${ }^{70}$ These eggs, probably those of a cod-fish of the Gaddoid family, but perhaps of a Cottoid, are colourless globules, as transparent as glass, and of rather more than half a millimetre in diameter $(0.64-0.66 \mathrm{~mm}$.). Within a thin, structureless but firm egg-membrane (chorion, Fig. 42, c) lies

F1G. 42.-Egg of an oceanic Osseons Fish : $p$, protoplasm of the parent.cell ; $k$, kernel of parent-cell; $n$, clear albuminous ball of nutritive yelk; $f$, fat-globule of the latter; c, external egg-membrane, or chorion.

a large albuminous ball, which is quite transparent and as clear as water $(n)$. At both poles of the axis of this ball there is a

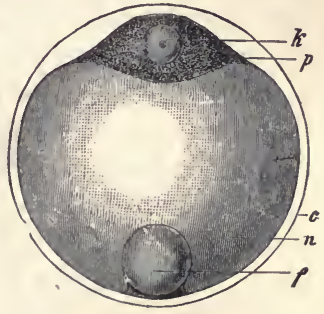
groove-like indentation. In the groove at the upper pole, which, in the floating egg, is turned downwards, lies a simple, lentil-shaped cell, containing a kernel (Fig. 42, p). In the unfertilized egg, this is the original egg-cell; after fertilization it is the parent-cell. In the interval between these two nucleated stages there is probably a nonnucleated condition, representing the Monerula. At the opposite pole of the egg, in the lower groove, lies a simple, clear fat-globule $(f)$. This small fat-globule and the large albuminous globule together form the nutritive yelk. The 
small cell alone is the formative yelk, and is the only part concerned in the cleavage process, which does not extend to the nutritive yelk. ${ }^{70}$

The cleavage of the parent-cell, or the formative yelk, proceeds entirely independently of the nutritive yelk, and in quiet, regular, geometric progression. (Cf. Plate III. Fig. 18-24.) Only the formative yelk, with the contiguous portion of the nutritive yelk $(n)$, is represented in the perpendicular section (through a meridian-plane); the greater part of the nutritive yelk and the egg-membrane is therefore omitted. The parent-cell (Fig. 18), first separates into two similar cleavage-cells (Fig. 19). By repeated division, this gives rise to 4 , then 8 , then 16 cells (Fig. 20). By continued contemporaneous division, 32 , and then 64 cells originate from these; and so the process goes on. All these cleavage-cells are alike in size and character. At last they form a lentil-shaped mass of closely layered cells (Plate III. Fig. 21). This entirely corresponds to the globular mulberry-germ of the primordial cleavage-process (Morula, Plate II. Fig. 3). The cells of this lentil-shaped mulberrygerm now move off in a peculiar centrifugal direction, so that the mulberry-germ changes into a vesicular germ (Blastula, Plate III. Fig. 22). The ordinary lentil becomes a disc, in the shape of a watch-glass, with thickened edges. Just as a watch-glass lies upon a watch, this convex cellular disc lies on the upper, more slightly arched, pole surface of the nutritive yelk. Meanwhile, liquid has collected between the disc and the surface of the nutritive yelk, so that a low circular cavity has been formed (Fig. 22, s). This is the cleavage-cavity, and corresponds to the cleavagecavity in the centre of the palingentic Blastula (Plate II. 
Fig. 4). The slightly arched floor of this low cleavagecavity is formed of nutritive yelk $(n)$; the more arched roof is of Blastula-cells. In fact, the embryonic Fish is now a vesicle with an eccentric cavity, as was the Blastula of the Frog (Plate II. Fig. 10).

The important process of inversion, resulting in gastrulation, now takes place. In consequence of a further removal, or wandering, of the blastula-cells, and of a further increase in their number, the thickened edges of the cellular disc, which lie on the nutritive yelk, grow toward each other in a centripetal direction, and toward the centre of the cleavage-cavity (Fig. 23), at which point they finally unite. The whole cell-mass now forms a small flat sac lying on the top of the nutritive yelk. The cavity of this sac, the cleavage-cavity, soon, however, disappears, because the whole upper surface of the lower wall of the sac attaches itself closely to the whole lower surface of the upper wall (Fig. 24). This completes the gastrulation of this Fish.

Frg. 43.-Disc-gastrulá (Disco-gastrula) of an Osseons Fish : e, exoderm; $i$, entoderm ; $w$, swollen edge, or primitive month-edge; $n$, albnminons ball of nutritive yelk; $f$, fat-globnle within the latter; $c$, onter egg-membrane (chorion); $d$, boundary between entoderm and exoderm (former site of the cleavage-cavity).

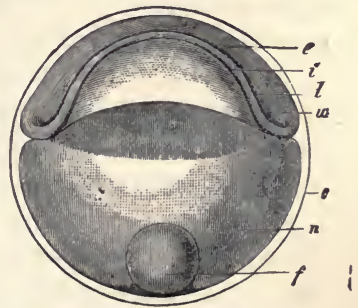

In order to distinguish this third important form of Gastrula from the two previously mentioned, we will call it the Disc-gastrula (Disco-gastrula, Fig. 43). The cell-mass of this Gastrula forms a thin, circular disc. The lower concave, 
surface of this disc lies immediately on the upper, convex surface of the nutritive yelk $(n)$. On the other hand, the outer surface of the disc is convex as in a Shark. If we make a perpendicular section through a meridian-plane of the globe-shaped egg, we shall find that it is composed of several layers of cells (in this particular case there are four) (Plate III. Fig. 24). Immediately above the nutritive yelk lies a single layer of larger cells (Fig. 24, $i$ ), which are characterized by a softer, less transparent, and more coarsely granulated protoplasm, and which take up a dark red colour from carmine. These form the intestinal layer, or entoderm, which arises by the ingrowth of the edges of the disc (infolded germ-layer). The three outer layers, lying on top of this lower layer, form the skin-layer, or exoderm (Fig. 24,e). They consist of smaller cells which take only a slight colour from carmine; their protoplasm is firmer, more transparent, and more finely granulated. At the thickened edges of the gastrula, the primitive mouth-edge (properistoma), the entoderm, and the exoderm pass into each other without clear limits (Fig. 43, w).

It is evident that the most important peculiarities which distinguish the Disc-gastrula from the two typical Gastrulaforms which we before examined, are due to the large nutritive yelk. This takes no part in the cleavage, and from the first occupies the whole primitive intestinal cavity, while at the same time it extends far beyond the mouth-opening of the latter. If we imagine the original Bell-gastrula (Archigastrula, Fig. 23-29) attempting to swallow a globe of nutritive matter far larger than itself, in the attempt the Gastrula will be spread out in the form of a disc on the nutritive matter, much in the same way as in the Disc- 
gastrula (Disco-gastrula, Fig. 43). We may therefore infer that the latter is directly, or through the intermediate stage of the Hood-gastrula, descended from the original Bellgastrula. It arose phylogenetically owing to the fact that a store of nutritive matter collected at one pole of the egg, and thus formed a nutritive yelk distinct from the formative yelk. Yet, notwithstanding this, the Gastrula in this, as in the former cases, was origiriated by an inversion or invagination of the Blastula. We may, therefore, also refer this kenogenetic form of discoidal cleavage (segmentatio discoidalis) to the original and palingenetic form.

Although it is thus tolerably easy and safe to trace back the descent of the small egg of this oceanic Osseous Fish, yet, on the other hand, it seems hard to do this with certainty in the case of larger eggs, such as occur in the case of most other Fishes, and in the case of all Reptiles and Birds. In the first place, the nutritive yelk of these is quite disproportionately large; so large; indeed, that it almost causes the formative yelk to disappear. And, in the second place, the nutritive yelk contains a number of variously formed constituent parts, which are known as the yelk-granules, yelk-globules, yelk-vesicles, and so on. These definite yelkelements have often even been explained as true cells, and it has been quite wrongly assumed that a portion of the body of the embryo is found in them. ${ }^{71}$ This is by no means the case. The nutritive yelk, whatever its size, always remains a lifeless store of nutritive matter, which, in the process of germination, is taken into the intestine during its development, and is consumed by the embryo. The latter develops solely from the living formative yelk, from the parent-cell. This is equally true 
of the small Osseous-fish which we have been examining, and of the huge eggs of the Primitive Fishes (Selachii), of Reptiles, and of Birds.

The egg of the Bird is specially important to us, for most of the important researches into the evolution of Vertebrates have been founded on study of incubated hen's eggs. It is much harder to procure and to examine mammalian eggs; for which very practical and incidental reason the latter has been more rarely accurately studied. On the other hand, hen's eggs can always be obtained in any quantity, and artificial hatching enables us accurately to follow every stage in the changes undergone by the embryo in the course of its evolution. As we have seen, the chief difference which distinguishes the egg of the Bird from the minute egg of the Mammal is the very considerable size of the former, which is due to the accumulation of a very large mass of fatty nutritive yelk. This is the yellow mass which, daily consumed under the name of yelk of egg, is collected within the original yelk or protoplasm of the egg-cell. In order to obtain a correct conception of the Bird's egg, the nature of which has very frequently been misrepresented, we must search for it in its earliest condition, and follow its evolution from its beginning in the ovary. In this stage, we find that the original egg is a very small, naked, and simple cell with a nucleus, and that it differs neither in size or shape from the original egg-cell of Mammalia and other animals. (Cf. Fig. 10 E, p. 134.) As in all Skulled-animals (Craniota) the original egg-cell or primitive egg (protovum) is completely covered by a continuous layer of smaller cells, as though by an epithelium. This skin-coat, or epithelium, is 
the so-called Graafian follicle; immediately under this the structureless yelk-membrane is secreted by the egg-yelk.

At a very early period the small protovim of the Bird begins to imbibe a mass of food-substance through the yelk-membrane, and to elaborate this matter into the socalled "yellow yelk." The protovum is thus transformed into the metovum (after-egg), which is many times larger than the protovum, but which, nevertheless, is only a single, enormously enlarged cell. ${ }^{72}$ The accumulation of the large yellow-yelk mass within the ball of protoplasm forces the kernel (vesicula germinativa), which is contained in the latter, quite to the upper surface of the yelk-mass. Here the kernel (vesicula germinativa) is surrounded by a small quantity of protoplasm; and these two together form the lentil-shaped "formative yelk" (Fig. 44, b). This appears on the outside of the yellow yelk-mass, at a particular point of the upper surface, in the form of a small, white, circular point; the so-called "tread," or icatricula. A

Fig. 44.-A mature egg-cell from the ovary of a Hen (in section). The yellow nutritive yelk is composed of concentrio layers (c), and is surronnded by a thin yelkmembrane (a). The cell-kernel(vesicula germinativa), together with the protoplasm of the egg-cell, forms the formative yelk (b), or the tread. The white yelk (here represented as black) passes from the tread to the yelkcavity $\left(d^{\prime}\right)$. The two kinds of yelk are, however, not sharply distinguished.

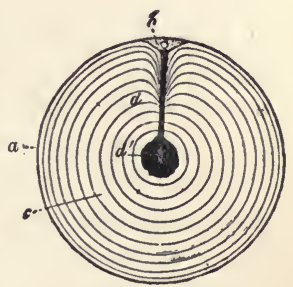

thread-like cord of white nutritive yelk $(d)$, which contains no particles of yellow yelk, and is softer than the yellow nutritive yelk, passes from the tread directly to the 
centre of the yellow yelk-mass, and there forms a small central ball of white yelk (Fig. 44, $d$ ). The whole mass of this white yelk is, however, not sharply divided from the yellow yelk, which in hardened eggs shows a slight trace of concentric stratification (Fig. 44,c). Just as in this globular egg in the ovary, so also in the hen's egg after it has been laid; when the egg-shell is opened and the yelk taken out, a small, circular, white disc is seen on the upper surface of the latter. This disc represents the cicatricula, or tread. This small white germ-disc is, however, far advanced in development, and is, in fact, the Gastrula of the hen. The body of the latter proceeds entirely from this Gastrula. The whole nuass of white and yellow yelk is entirely without share in the formation of the Chick, for it is only used up as nutritive matter and consumed as food by the embryo in the course of its evolution. The transparent, tough, and voluminous mass of albumen, surrounding the yellow yelk of the Bird's egg, and the hard chalky shell of the egg, are formed round the egg, in the oviduct, after it is already fertilized.

After the fertilization of the egg within the body of the parent Bird is complete, the germ-vesicle (vesicula germinativa) probably, as in other cases, first disappears; and the reconstruction of a kernel results in a parent-cell (cytula). This lentil-shaped parent-cell now undergoes a discoidal cleavage (segmentatio discoidalis, Fig. 45) entirely similar to that of the egg of the Fish (Plate III. Fig. 18-24). Two similar cleavage-cells $(A)$ first arise from the parentcell. These part into $4(B)$, into $8,16(C), 32,64$ cells, and so on. As before, the division of the kernel always precedes the division of the cells. The planes of division between 
the cleavage-cells appear at the free surface of the "tread" as "furrows." The two first furrows are at right angles to each other, in the form of a cross $(B)$. Two new furrows then originate, which cut the former two at an angle of $45^{\circ}$. The tread, which is changing into the germ-dise, now forms
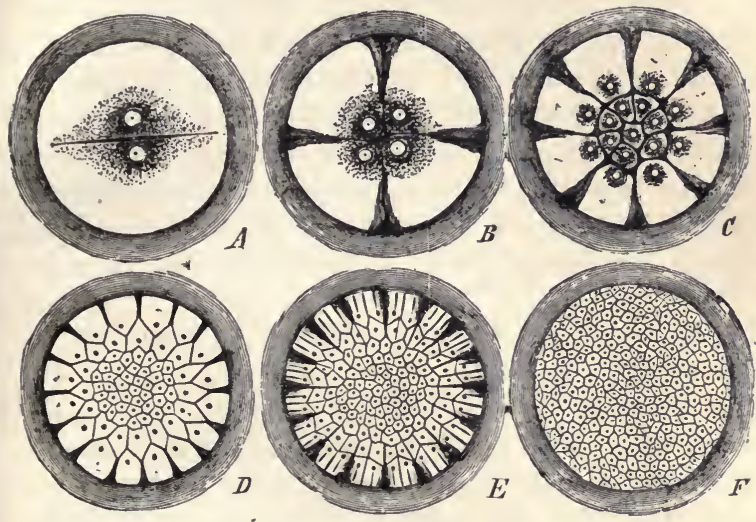

Fig. 45.-Discoidal cleavage of a Bird's egg (diagrammatic, about ten times enlarged). Only the formative yelk (the tread, or cicatricula, is represented in these 6 figures $(A-F)$, because it alone is affected by cleavage. The much larger nutritive yelk, which does not share in the cleavage, is omitted, and only indicated by the dark, outer ring. A. The first furrow separates the parent-cell into two parts. $B$. These two first cleavage-cells are parted by a second furrow (perpendicular to the first) into four cells. C. 16 cells have originated from the 4 cleavage-cells, owing to the fact that between the first two bisecting furrows, two other, radial furrows have appeared, and that the central portions of these 8 radial segments by a furrow running rond the centre. $D$. A stage with 16 radial furrows and about 4 concentrio ring-furrows. $E$. A stage with 64 radial furrows and abont 6 ring-furrows. $F$. The whole tread has been broken up into a heap of small cells by the further formation of radial and ring furrows; the whole now forms the lentil-shaped mulberry-germ (Morula). The separation of the kernel always precedes the formation of the furrows.

vOL. I. 
an eight-rayed star. A circular furrow now forms round the centre, so that the 8 three-cornered cleavage-cells become 16, of which 8 lie in the middle, surrounded by 8 others (C). After this, new furrows, some circular and others radiating from the central point, succeed each other more or less irregularly $(D, E)$. Finally this cleavageprocess, like the others, results in the formation of small cells of like character. ${ }^{73}$ In this case also, the cleavagecells form a circular lentil-shaped disc, which represents the mulberry-germ, and lies embedded in a slight deepening in the white yelk (Fig. 46, in perpendicular section). The Morula in the case of the Hen's egg is, however, thinner and flatter than that of the egg of the Osseous Fish (Plate III. Fig. 21).

In the Hen's egg, just as in that of the Osseous Fish, a kenogenetic germ-vesicle, or Blastula, now arises (Fig. 47). The cleavage-cells of the Morula increase in number and move away from the nutritive-yelk, so that a disc, in the form of a watch-glass, with thickened edges ( $w)$, is again formed; and a cleavage-cavity $(s)$ is formed between this germ-membrane (Blastoderma, Fig. $47, b$ ) and the nutritive yelk. After this the thickened, swollen edge turns inward, and a simple layer of larger, darker-coloured cells grows from the edge, centripetally towards the middle of the cleavage-cavity (Fig. 48). The meeting of these two edges at a central point gives rise to the intestinal layer, or entoderm (Fig. 48, $i$ ). This attaches itself immediately to the roof of the cleavage-cavity, the cells of which form the skin-layer, or exoderm (Fig. 49, i). This completes the Gastrula of the Chick, a flatly extended, disc-shaped Gastrula (Discogastrula), resembling that of the Osseous Fish 
(Plate III. Fig. 24). While, however, in the latter case the nutritive yelk is attached directly to the lower surface of the entoderm, filling the whole primitive intestinal cavity, a low germ-cavity remains between the entoderm and the nutritive yelk in the Disc-gastrula of the Chick; this is a part of the primitive intestinal cavity (Fig. 49, $d$ ), and must not be confused with the cleavage-cavity (Fig. 47, $s, 48, s$ ). The latter lies between the nutritive yelk and the blastoderm, the former between the nutritive yelk and the entoderm. The inversion (invagination) of the Gastrula is complete when the primitive intestinal cavity has taken the place of the cleavage-cavity, the entoderm at the same time attaching its inner surface to the inner surface of the exoderm.

The germ-disc (Blastodiscus), which in an unincubated, freshly-laid Hen's egg lies at the tread, or cicatricula, is thus already a complete Disc-gastrula (Discogastrula, Fig. 49). It is plainly visible to the naked eye, and appears like a small, circular, white spot, 4-5 $\mathrm{mm}$. in diameter, in the middle of the-upper surface of the yellow yelk-mass. It is separated from the latter by the primitive intestinal cavity, and its thickened edges alone touch the latter. It is possible to lift up the entire Gastrula. The two primary germ-layers are plainly visible in the perpendicular section; an upper or outer layer of smaller, brighter cells forming the skin-layer (exoderm, Fig. 49,e); and a lower or inner layer of larger, darker cells forming the intestinal layer (entoderm, Fig. 49 i). ${ }^{74}$

In order to complete our survey of the important processes of egg-cleavage and gastrulation, we will now finally glance quickly at the fourth type-form of these processes 
superficial cleavage (segmentatio superficialis, Plate III. Fig. 25-30). This form is entirely unrepresented among Vertebrates. It, however, plays the most important part
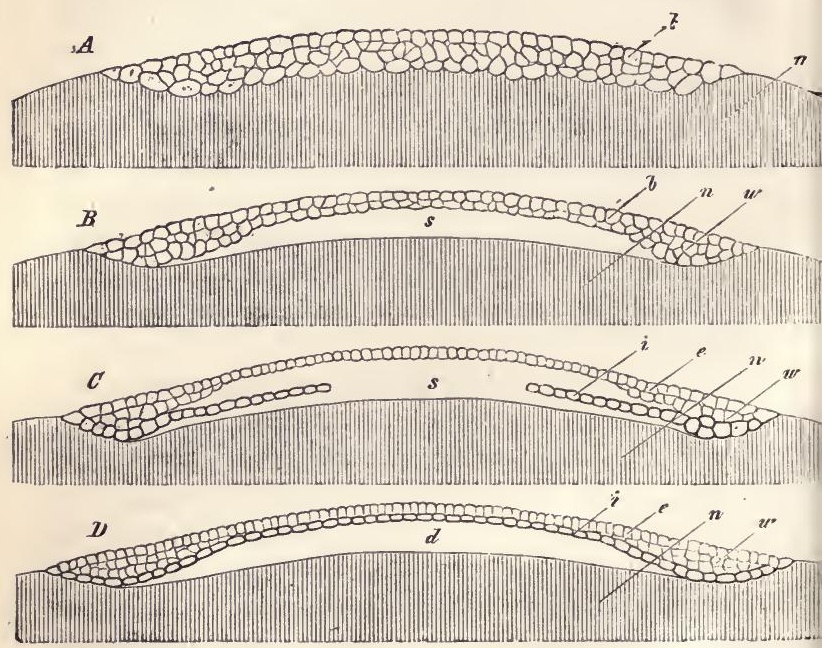

Frg. 46-49.-Gastrulation of a Hen's egg. All four figures represent perpendicular, half-diagrammatic sections through the middle of the thin, circular tread, or germ-disc. Of the nutritive yelk $(n)$ only the contignous part (perpendicnlarly shaded) is represented.

Fig. 46.-(A) Mulberry-germ (Morula); $b$, cleavage-cells.

FiG. 47.-(B) Germ-vesicle (Blastula); $s$, cleavage-cavity; b, blastoderm-cells; $w$, thickened or swollen edge of the germ-disc.

Fig. 48.-(C) Germ.resicle in the process of inversion (Blastula in. raginata); $e$, exoderm; $i$, entoderm; $n$, nutritive yelk; $w$, thickened edge ; $s$, cleavage-cells. carity.

FrG. 49.-(D) Gastrula (Discogastrula) of Chick: $d$, primitire intestinal 
in the very extensive articulated tribe (Arthropoda), in Insects, Spiders, Centipedes, and Crabs. The Gastrula which results from this form of cleavage is the Bladdergastrula (Peri-gastrula, Plate III. Fig. 29).

In eggs which undergo this superficial cleavage, just as in the eggs which have been mentioned, those of Birds, Reptiles, Fishes, and other animals, the formative yelk is quite distinct from the nutritive; and the former is alone concerned in the cleavage, which does not touch the latter. But while in those eggs, the cleavage of which is discoidal, the formative yelk is eccentric, and lies at one pole of the single axis of the egg, while the nutritive-yelk is massed together at the other pole; in those eggs, on the contrary, which undergo a superficial cleavage, we find that the formative yelk is spread over the whole surface of the egg, surrounding the nutritive yelk in the form of a bladder, which is central, and situated in the middle of the egg. The cleavage, as it affects only the former, not the latter, is naturally entirely superficial; the provision, which is massed in the centre, is entirely untouched by it. Otherwise, this superficial cleavage proceeds quite regularly, like the original cleavage, in geometrical progression. (Plate III. Fig. 25-30 represents several stages of this process in perpendicular meridian section through the ellipsoid egg of a Crab, Peneus.) The parent-cell, or cytula (Plate III. Fig. 25), first parts into two similar cells; from these, by repeated simultaneous division, arise first 4 (Fig. 26), then S, then 16 (Fig. 27), 64, 128, and so on. Finally, the whole formative yelk parts into numerous, small, similar cells, which lie side by side in a single layer over the whole surface of the egg, forming a superficial germ-membrane 
(Blastoderma, Fig. 28, $b$ ). This germ-membrane is a simple, completely closed vesicle, the space within being wholly filled with nutritive yelk. The chemical quality of the contents of this true germ-vesicle, or Blastula (Fig. 28) alone distinguishes it from the Blastula of the primordial cleavage-process (Plate II. Fig. 4). The latter contains water, or jelly as transparent as water; the former contains a dense mixture of albuminous and fatty substances, in which there is much nutritive matter. As this extensive nutritive yelk occupies the centre of the egg from the very beginning of the cleavage, there is naturally no difference in this case between the mulberry-germ and the vesicular germ.

When the germ-vesicle (Fig. 28) is quite complete, the important process of inversion (invaginatio), which produces the Gastrula, follows (Fig. 29). A circular, groove-like deepening first arises at a point on the surface, and this enlarges into a cavity, the primitive intestinal cavity of the Gastrula (Fig. 29, d); the point at which the inversion takes place forming the primitive mouth of this cavity (o). The inverted portion of the germ-membrane, the cells of which enlarge and assume a slender cylindrical form, constitutes the intestinal layer and surrounds the cavity of the primitive intestine. The superficial, uninverted portion of the germ-membrane forms the skin-layer; the cells of this, owing to continual self-division, become smaller and more flattened. The space between the skin-layer and the intestinal layer (the remnant of the cleavage-cavity) continues full of nutritive yelk, which is now gradually consumed. This is the only essential point in which the Bladdergastrula (Peri-gastrula, Fig. 29) differs from the original 
form, that of the Bell-gastrula (Archi-gastrula, Fig. 6). It is evident that the former has gradually originated from the latter, in the course of a long period of time, by the accumulation of nutritive-yelk in the centre of the egg. ${ }^{75}$

The fact that we have been thus enabled to retrace all the numerous and multiform phenomena in the germination of different animals to these four type-forms of egg-cleavage and gastrulation, may be regarded as an advance of the widest significance. Of these four type-forms we have been able to declare that one is the original, palingenetic form, and that the other three are kenogenetic forms descended from the first. The unequal, discoidal, and the superficial forms of cleavage have evidently all originated, in consequence of secondary adaptation, from the primary, original cleavage; and we must consider that the most important cause of their origin was the gradual formation of a nutritive-yelk, and the distinction, which is always appearing in an earlier stage, between the animal and the vegetative parts of the egg, between the skin-layer and the intestinal layer. The inter-relation of the four cleavage-forms, with regard to the ordinary distinction between total and partial egg-cleavage is as follows :-

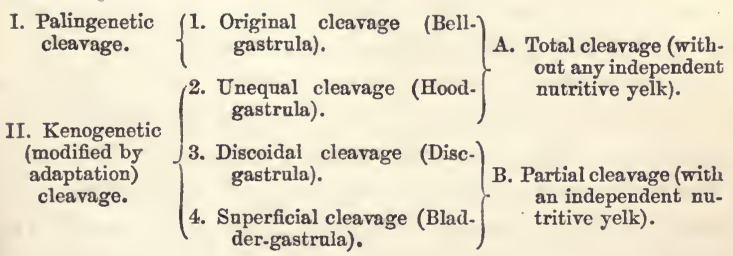

The lowest known intestinal animals (Metazoa), that is to 
say, the low Plant-animals (Sponges, simplest Polyps, etc.), remain throughout their life stationary in a structural stage which differs very little from the Gastrula; their whole body being composed of only two cell-strata or layers. This fact is of the very greatest significance. For we see that Man, and indeed all Vertebrates, pass quickly through a transitory two-layered structural stage, which is persistently retained throughout life by these lowest Plant-animals. By now again applying our first principle of Biogeny, we immediately obtain the following very important conclusion: Man and all those other animals, which in the first stages of their individual evolution pass through a two-layered structural stage or a Gastrula-form, must have descended from a primavial, simple parent-form, the whole body of which consisted throughout life, as now in the case of the lowest Plant-animals, only of two different cell-strata or germlayers. To this most important primæval parent-form, to which we shall presently refer in detail, we will now provisionally give the name of the Gastræa (i.e. primitive intestinal animal). ${ }^{24}$

According to the Gastræa theory, there is in all animals one organ which is originally of the same morphological and physiological significance; this is the primitive intestine; the two primary germ-layers, which form the wall of this intestine, must therefore in all cases be regarded as also of the same significance, or as "homologous." This important "homology of the two primary germ-layers" is, on the one hand, demonstrated by the fact that the Gastrula in all cases originates in one way, that is, by the inversion (invagination) of the Blastula; and, on the other hand, by the fact that in all cases the same fundamental organs arise 
from the two germ-layers. The outer or animal germ-layer, the skin-layer, or exoderm, always forms the outer bodywall with the most important organs of animal life; the skin-covering, nerve-system, organs of the senses, etc. On the other hand, the inner or vegetative germ-layer, the intestinal layer, or entoderm, gives rise to the inner intestinal wall with the most important organs of vegetative life; the organs of nutrition, of digestion, those which form the blood, etc.

In these low Plant-animals, especially in Sponges, the whole body of which remains permanently stationary in the same structural stage, these two functional groups (the animal and the vegetative acts) also continue strictly distributed between the two simple, primary germ-layers. Throughout life the outer or animal germ-layer retains the simple significance of a covering (an outer skin), and, at the same time, accomplishes the movements and sensations of the body. On the other hand, the inner cell-stratum, or the vegetative germ-layer, always retains the simple significance of an intestinal epithelium, a nutritive intestinal cell-stratum, and in addition to this appears only to produce the reproductive cells. ${ }^{40}$

In all other animals, and especially in all Vertebrates, the Gastrula appears only as a very transitory germ-stage. The two-layered stage of their germ-rudiment changes quickly, first into a three-layered, and then into a fourlayered stage. On the completion of the germ-layers, which lie one over the other, we have again provisionally attained a fixed and definite point of view; and one from which we may trace and explain the incidents in the construction, which are much more obscure and intricate. Trustworthy 
researches by many observers, embracing the Ontogeny of the most diverse higher animals, have now established the important fact that the germ in a certain stage is composed of four secondary germ-layers. It is most important to notice that this is quite as true of Man as of other Mammals.

In many cases there is a three-layered stage intermediate between the two and the four-layered condition. ${ }^{76}$ But in proportion to the certainty of this conclusion, that there are at first two, and afterwards four layers, it is difficult to understand the way in which these four secondary layers arose from the two primary layers. In this respect the opinions of the many observers who have studied the question are so contradictory that comparison of them fails to enable us to reach the truth. There is, however, no doubt of the one fact, that these four layers result solely from the two original germ-layers, and that they are not partly independent of the latter, as Reichert, His, and other confused observers have asserted..$^{71}$ But the question yet remains undecided whether the two middle layers both originate from one of the two primary layers. (from the outer or the inner), or whether one of the two middle layers must be referred to the upper, the other to. the lower of the primary germ-layers.

In order to show the importance of this question to. the whole history of evolution, I will now briefly indicate the significance of the two middle layers. We must call these two middle layers the second and the third, numbering the four secondary germ-layers in order from the outer to the inner. The outer skin, the muscular mass or flesh of the trunk, the muscles, which move the body 
and limbs, as well as the inner skeleton, or bony framework of the body, arise from the second germ-layer, or the outer middle layer, which is called the skin-muscular layer, or the skin-fibrous layer. The muscles and vascular membranes, which first surround the inner cellular canal of the intestine and its glands, and which accomplish the digestive movements of the throat (pharynx), œsophagus, the stomach, and the various other parts of the intestinal canal, are all produced from the third germ-layer, the inner middle layer, which is called the intestinal-muscular layer, or the intestinal-fibrous layer; the heart and the most important blood-vessels also originate in this. The two middle layers, therefore, especially provide those cellstrata which are employed in the formation of the fibrous coverings, and of the flesh or muscles. The cells of the second layer change into the flesh and the bony framework of the trunk; the cells of the third layer change into the muscles and the fibrous coverings of the intestinal canal. Both middle or fibrous layers are therefore called muscular, or flesh-layers; the outer is called the skin-muscular layer, because it lies on the first secondary layer, the skin-sensory layer; the inner is called the intestinal-muscular layer, as it lies next to the fourth secondary layer, the intestinalglandular layer (Fig. 50).

Baer was the first naturalist who recognized and clearly distinguished the four secondary germ-layers of the higher animals. He did not, however, fully understand their origin and their wider significance, nor was he quite right in his explanation of the details of their respective purposes. But in the main, their significance did not escape him, and he even expressed that view of the origin 
of the two middle layers, which I, in opposition to most other authors, still hold to be correct. That is to say, he derived each middle layer separately from a primary germlayer (by fission), and said, that the outer or animal germ-
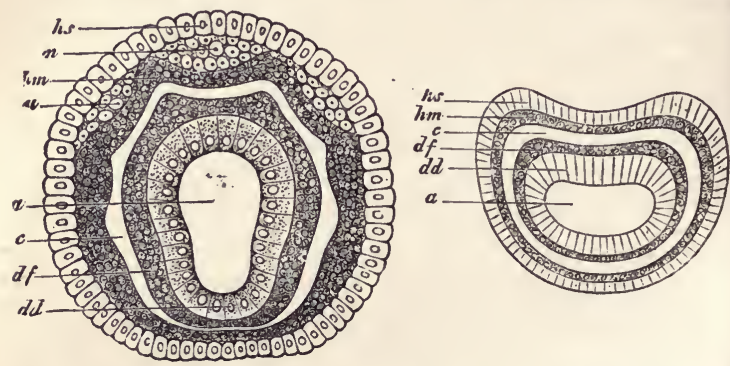

Frg. 50.-Transverse section through the embryo of an Earth-worm: $h s$, skin-sensory layer; $h m$, skin-fibrous layer; $d f$, intestinal-fibrous layer; $d d$, intestinal-glandular layer; $a$, intestinal cavity; $c$, body-cavity, or Colona $n$, nerve-centres; $u$, primitive kidneys.

FiG. 51.-Corresponding section of the larva of Amphioxus (after Kowalersky). The letters indicate the same parts as in Fig. 50.

layer separates into two strata, a skin-stratum and a fleshstratum; similarly the inner or vegetative germ-layer separates into two strata; the vascular stratum and the mucous stratum. In the following table this view of Baer, which I believe to be right in regard to the phylogenetic origin of the middle layers, is compared with the newer nomenclature, which is now in vogue:-
A. The two primary germ-layers.
B. The four secondary germ.layeis.

I. The outer or animal germ. layer (the skin-layer, or exoderm).

1. Skin-gensory layer (skin-stratum, Baer).

2. Skin-fibrons layer (flesh-stratum, Baer).

II. The inner or vegetative germ-layer (the intesti. nal layer, or entoderm).

3. Intestinal.fibrous layer (vascular stra tum, Baer).

4. Intestinal-glandular layer (mucous stratum, Baer). 
Much recent research by Kowalevsky, Ray-Lankester, Van Beneden, and others has justified this "Four-layer Theory" of Baer. For instance, it can be plainly shown that in the Earth-worm (Fig. 50), in the Amphioxus (Fig. 51 ), and in some other animals each of the two primary germ-layers parts into two secondary germ-layers; the skin, or outer-layer parts into the skin-sensory layer (hs), and the skin-fibrous layer $(\mathrm{hm})$ : similarly the intestinal or inner layer separates into the intestinal-fibrous layer $(d f)$, and the intestinal-glandular layer $(d d)$. The body, cavity, or cœloma (c), forms between the two fibrous layers.

Contrary to this view, most recent observers assume that the two middle layers proceed from plane-division of a single, middle germ-layer (mesoderma). According to this, a third originates between the two primary layers, and by a secondary process of fission splits into two layers along the plane of its surface. Some observers, however, as certainly derive this third layer from the lower primary layer, as do the others from the upper primary layer. It is exactly this suspicious circumstance, together with manyother grounds (based especially on Comparative Anatomy) that lead us to the conjecture, which I believe to be correct, that neither party is right, but that the outer middle layer rather proceeds from the animal, the inner middle layer from the vegetative germ-layer. It is true, as we shall presently find, that only a single middle layer (Remak's "motor-germinative germ-layer") usually arises between the two primary germ-layers of mammals, and that by the fission of this, the two different middle layers, the skin-fibrous layer and the intestinal-fibrous layer, originate only secondarily. There are, however, strong 
grounds for the assumption that this process is the effect of vitiated Heredity. The simple middle germ-layer of Vertebrates has most probably originated only secondarily by the coalescence of two distinct primary middle layers, and, therefore, the fission of the former into the two latter must be regarded as a tertiary process.

However this may be, we have now reached the important, definite point in the History of Evolution, in which the whole Vertebrate body, in common with that of most higher animals, forms a tube, the wall of which is composed of four layers, lying one over the other. This is not a figurative comparison; these constituent parts of the tube-wall are actually layers, or thin plates, which lie fixed one over the other. They can even be mechanically parted or split off from each other. This separability is connected with the fact that the cells in each one of the four layers are alike, while those of each are already in some degree distinct or differentiated from those of the other three layers. The first, the skin-sensory layer, consists of cells differing from those of the second, or skinfibrous layer; the cells of the latter are again different from those of the third, the intestinal-fibrous layer; and these latter are of a somewhat different nature from the cells of the fourth, the intestinal-glandular layer. We find the same four germ-layers as in Man and other Vertebrates (Fig. 51), also in Soft-bodied Animals (Mollusca), Articulates (Arthropoda), Star-animals (Echinoderma), and again in the higher Worms (Fig. 50). This fact in Comparative Ontogeny is of the greatest phylogenetic significance. In all cases, these four secondary germ-layers develop from the two primary germ-layers; it is only in the lower Plant- 
animals (Zoophytes), especially in Sponges, that the latter retain their original simplicity.

Finally, as a special proof of the prophetic genius of Caspar Friedrich Wolff, due emphasis must be given to the remarkable fact that that naturalist assumed the existence of these four secondary germ-layers under the name of "four systems formed on one type," the proof of which was not furnished till half a century later by Baer: ${ }^{77}$ (Cf. p. 46.)

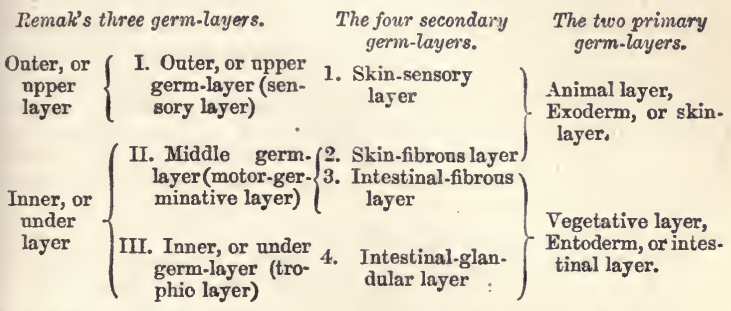

Modified ontogenetic process. | Original phylogenetic proces:- 


\section{EXPLANATION OF PLATES II. AND III.}

\section{Egg-cleatage and Gastrutation.is}

These two plates are intended to illustrate, by means of diagrammatic sections, the most important differences in animal egg-cleavage and gastrulation. Plate II. represents holoblastic eggs (with total cleavage); Plate III. meroblastic eggs (with partial cleavage). The animal halves of the eggs (exoderm) are coloured gray; the vegetative halves (entoderm with nutritive yelk) red. The nutritive yelk is perpendicularly shaded. All the sections are perpendicular meridian sections through the axis of the primitive intestine. In all, the letters indicate the same parts : $c$, parent.cell (Cytula); $f$, cleavage-cells (Segmentella); $m$, mulberry-germ (Morula); $b$, germ-resicle (Blastula); $g$, cnp-germ (Gastrula); $s$, cleavage-carity; $d$, primitive intestinal cavity; 0 , primitive month; $n$, nutritive yelk; $i$, intestinal layer (Entoderm); e, skin-layer (Exoderm).

FIG. 1-6. - Original or primordial egg-cleavage of the lowest Vertebrate (Amphioxus). Fig. 1, parent-cell (Cytula); Fig. 2, cleavage-stage with 4 cleavage-cells; Fig. 3, mulberry-germ (Morula); Fig. 4, germ-vesicle (Blastula) ; Fig. 5, the same, in process of inversion (Invaginatio); Fig. 6, Bell-gastrula (Archigastrula).

Fig. 7-11.-Unequal egg-cleavage of an amphibian (Frog). Fig. 7 , parent-cell (Cytula); Fig. 8, cleavage-stage with 4 cleavage-cells; Fig. 9, mnlberry-germ (Morula); Fig. 10, germ-vesicle (Blastula); Fig. 11, Hoodgastrula (Amphigastrula).

Fig. 12-17.- Unequal egg-cleavage of a Mammal (Man). Fig. 12, parent-cell (Cytula); Fig. 13, cleavage-stage with 2 cleavage-cells $(e$, mother-cell of the exoderm; $i$, mother-cell of the entoderm); Fig. 14, cleavage stage with 4 cleavage-cells; Fig. 15, beginning of the inversion of the germ-vesicle; Fig. 16, further advanced inversion; Fig. 17, Hoodgastrula (Amphigastrula).

Fig. 18-24.-Discoidal egg-cleavage of an Osseous fish (Motella? Cottus?). The greater part of the nutritive yelk $(n)$ is omitted. (Cf. Fig. 42, 43, pp. 217, 219.) Fig. 18, parent-cell (Cytula); Fig. 19, clearage stage with 2 cells; Fig. 20, cleavage-stage with 32 cells; Fig. 21, mnlberry.germ (Morula) ; Fig. 22, germ-vesicle (Blastula) ; Fig. 23, the same, in process of inversion; Fig. 24, Disc-gastrula (Discogastrula).

Fig. 25-30.-Snperficial egg-cleavage of a Crab (Peneus). Fig. 25, parent-cell (Cytula); Fig. 26, cleavage-stage with 4 cells ; Fig. 27, clearagestage with 32 cells; Fig. 28, mnlberry-germ (Morula), and at the same time the germ-resicle (Blastula) ; Fig. 29, Bladder-gastrula (Perigastrula); Fig. 30, Nauplins-germ; the pharynx-cavity has formed in front of the primitive mouth $(d)$, owing to an inversion from without. 



\section{GASTRULA'TION.}
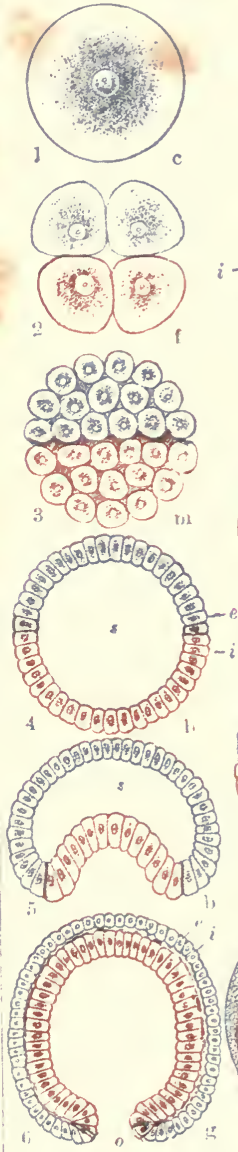

Amphioxus.

F:o,

Non. 


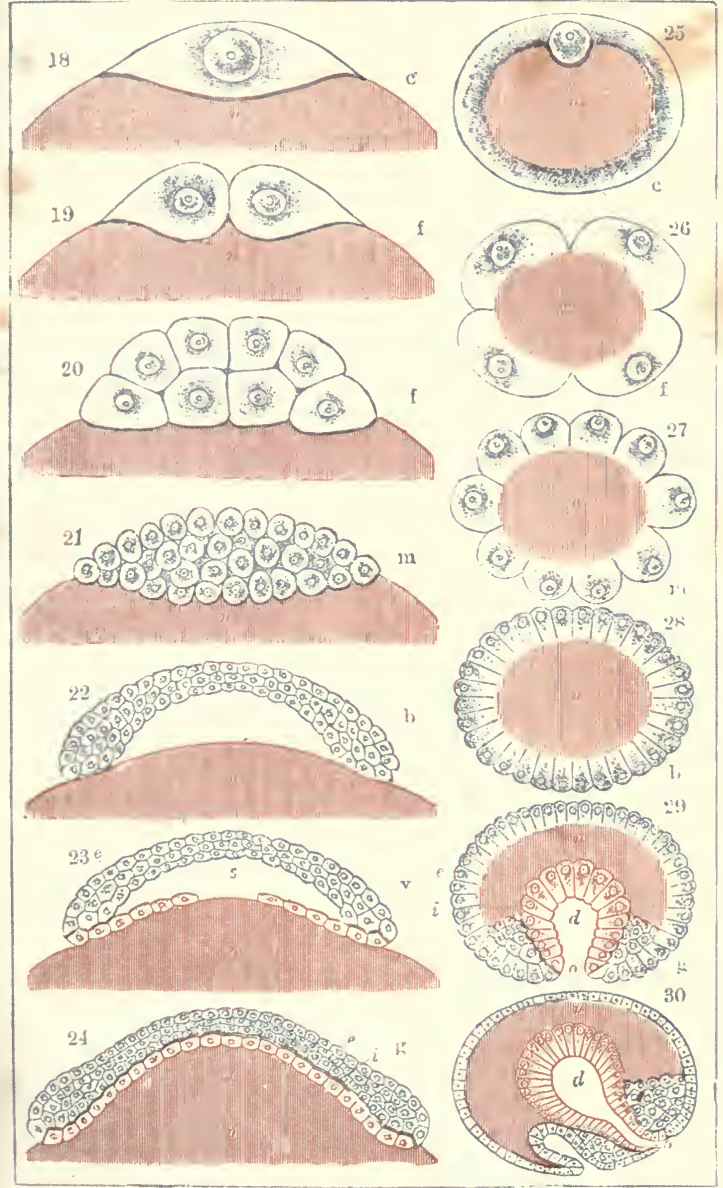

Fis?t. Crab. 



\section{T A B L E I I I.}

List of the most important differences in Animal Egg-cleavage and : Gastrulation. ${ }^{79}$

The letters $a-f$ indicate the 6 animal tribes (the primitive animals being excluded) : $a$, Plant-animals ; $b$, Worms ; $c$, Soft-bodied animals (Mollusca); $d$, Star-animals (Echinoderma) ; e, Articulates (Arthropoda); $f$, Vertebrates.

\section{I.}

Total Cleavage. Segmentatio totalis. Holoblastic Eggs.

\section{Gastrula with- out} nutritive jelk. Hologastrula.
I. Original Cleavage. (Segmentatio primordialis.)

Archiblastic eggs.

Bell-gastrula. (Archigastrula.)

(Plate II. Fig. 1-6.)

II. Unequal Cleavage. (Segmentatio inaqualis.)

Amphiblastic eggs.

Hood-gastrula. (Amphigastrula.)

(Plate II. Fig. 7-17.) a. Most low Plant-animals (low Sponges, Hydrapolyps, Meduse, Corals).

b. Many low Worms (Sagitts, Phoronis, Ascidia, many Nematodes, etc.).

c. A few low Soft-bodied animals (Mollusca) - Terebratula, Argiope, Pisidium.

d. Most Star - animals (Echinoderma).

e. A few low Articulates (some Branchiopods, Copepods, Tardigrades).

$f$. The Sknll-less Vertebrate (Amphioxus).

a. Numerous Plant-animais (many Sponges, Medusæe, Corals, Siphonophores, Ctenophoræ).

b. Most Worms.

c. Most Soft-bodied Animals (Motlusca).

d. Individual Star-animals (viviparous species and a few others).

e. A few low Articulates (Arthropoda)-both Crustaceans and Tracheates.

f. Cyclostoma, Ganoids, Amphibia, Mammals (all ?).
II.

Partial Cleavage. Segmentatio partialis. Meroblastic eggs.

Gastrula with nutritive yelk. Merogastrula.
III. Discoidal Cleavage. (Segmentatio discoidalis.)

Discoblastic eggs.

Disc-gastrula. (Disco-gastrula.)

(Plate III. Fig. 18-24.) c. Cuttle-fish, or Cephalopods.

e. Some Articulates (Arthropóda), Millepedes, Scorpions, and others.

f. Primitive Fishes (Selachii), Osseons Fishes, Reptiles, Birds (and Monotremes ?).

IV. Superflcial Cleavage. (a. A few Sponges (?).

(Segmentatio superficialis.)

Periblastic eggs.

Bladder-gastru'a.

(Perigastrula.)

(Plate III. Fig. 25-30.)

VOL. I. Alcyonium (?).

b. Individual Worms (?).

e. The great majority of Articulates (Arthropoda) - Crustaceans, Myriopods, Spiders. Insects. 


\section{TABLE IV.}

Systematic Survey of the five earliest germinal stages of Animals with reference to the four different type-forms of Egg-cleavage.

A. Total
(Segmenta
a. Original or primor-
dial cleavage.
I. a. Archi-
monerula.
(Fig. 22 A, p. 191.)
A cytod in which
formative and
nutritive yelk are not
distinct.
II. a. Archi-
cytula.
(Plate II. Fig. 1.)
Parent-cell which
nas arisen out of the
archi-monernla by the
formation of the pa-
rent-kernel.
III. a. Archi-
morula.
(Plate II. Fig. 3.)
A solid (generally
globular) beap of
similar cells.

\section{IV. a. Archi- blastula.}

(Plate II. Fig. 4.)

A hollow (nsually globular) vesicle, the wall of which consists of a single layer of similar cells.

\section{V. a. Archi- gastrula. \\ Bell-gastrula.}

(Plate II. Fig. 6.)

Fig. 23-28, p. 193 .

Primitlve intestine empty, without nutritive Jelk. Primary germ-layers one-layered. b. Unequal cleavage.

\section{I. b. Amphi-} monerula.

A cytod which includes formative yelk at the animal pole, nutritive yelk at the vegetative pole: the two are not very distinct.

\section{II. b. Amphi-} cytula.

(Plate II. Fig. 7, 12.)

Parent-cell which has arisen out of the amphi-monerula by the formation of the parent-kernel.

III. b. Amphimorula.

(Plate II. Fig. 9.)

A roundish hesp formed of two klnds of cells, the animal cells at one, the vegetative cells at the other pole.

\section{IV. b. Amphi.} blastula.

(Plate II. Fig. 10.)

A roundish vesicle, the wall of which at the animal pole consists of smaller cells, at the vegetative pole of larger celis.

\section{v. b. Amphi- gastrula.}

Hood-gastrula.

(Plate II. Fig. 11, 17.)

Fig. 32-35, p. 206, Fig. 41.

Primitive intestine partly filled with segmented nutritive yelk. Germ-layers often many-layered.

\section{B. Partial Cleavage.}

(Segmentatio partialis.)

\begin{tabular}{c|c} 
c. Discoidal cleavage. & d. Superficial cleavage. \\
\hline $\begin{array}{c}\text { I. c. Disco- } \\
\text { monerula. }\end{array}$ & $\begin{array}{c}\text { I. } d \text {. Peri- } \\
\text { monerula. }\end{array}$
\end{tabular}

A cytod which A cytod which inincludes formative cludes formative yelk yelk at the animal in the outer wall, pole, nutritive yelk nutritive yelk in the at the vegetative centre.

pole: the two are quite distinct.

\section{II. c. Disco- cytula.}

(Plate III. Fig. 18.)

Parent-cell which has arisen out of the disco-monerula by the formation of the parent-kernel.

\section{III. c. Disco-} morula.

(Plate III. Fig. 21.)

A flat disc, composed of aimilar cells on the animal pole of nutritive yelk.

\section{IV. c. Disco- blastula.}

\section{(Plate III. Fig. 22.)}

A roundish vesicle, the small bemisphere of which consists of cleavage - cells, the larger of nutritive yelk.

\section{V. c. Disco-} gastrula.

Disc-gastrula.

(Plate III. Fig. 24.)

sig. 43, p. 219 .

Fig. 49, p. 228.

Primitive intestine filled with unsegmented nutritive yelk. Flat germ-disc.

\section{II. d. Peri-} cytula.

(Plate III. Fig. 25.)

Parent-cell which has arisen out of the peri-monerula by the formation of the parent-kernel.

III. $d$. Perimorula.

(Plate III. Fig. 27.)

A closed vesicle: a cellnlar stratnm surronnds the whole central nutritive yelk.

\section{IV. d. Peri- blastula.} (Plate III. Fig. 28.)

A closed vesicle : a cell layer surrounds the whole nutritive yelk (= Peri-morula).

\section{V. d. Peri-} gastrula.

Bladder-gastrula.

(Plate III. Fig. 29.)

Cleavagt-cavity filled with unsegmented nutritive yelk. Priferent. mitive intestine dif- 


\section{T A B L E V.}

Systematic Survey of some of the most important rhythmical variations in Egg-cleavage. ${ }^{80}$

Only the first colnmn (Amphioxus) presents the original, palingenetic cleavage- hythm, in regular geometrical progression. All the other colnmns show the descended kenogenetic modifications.

$$
c=\text { parent-cells. } \quad \begin{aligned}
& s=\text { cleavage-cells. } \quad e=\text { exoderm-cells. } \\
& i=\text { entoderm-cells. }
\end{aligned}
$$

\begin{tabular}{|c|c|c|c|c|c|}
\hline $\begin{array}{l}\text { I. } \\
\text { Iancelet } \\
\text { (Amphi- } \\
\text { oxns). }\end{array}$ & $\begin{array}{c}\text { II. } \\
\text { Amphivian } \\
\text { (Frog). }\end{array}$ & $\begin{array}{c}\text { Ir. } \\
\text { (Rammal } \\
\text { (Rabbit). }\end{array}$ & $\begin{array}{c}\text { Iv. } \\
\text { Snail } \\
\text { (Trochus). }\end{array}$ & $\begin{array}{c}\text { v. } \\
\text { Worm } \\
\text { (Fabricia). }\end{array}$ & $\begin{array}{c}\text { vi. } \\
\text { Worm } \\
\text { (Cyclogena). }\end{array}$ \\
\hline $1 c$ & $1 c$ & $1 c$ & $1 c$ & $1 c$ & $1 c$ \\
\hline $2 s$ & $2 s$ & $\begin{array}{c}2 s \\
(1 s+1 i)\end{array}$ & $2 s$ & $\left(1 e^{28}+1 i\right)$ & $\left(\begin{array}{l}28 \\
(1 e+1 i)\end{array}\right.$ \\
\hline $4 s$ & $4 s$ & $\begin{array}{c}4 s \\
(2 e+2 i)\end{array}$ & $4 s$ & $\begin{array}{c}3 s \\
(2 e+1 i)\end{array}$ & $\begin{array}{c}3 s \\
(2 e+1 i)\end{array}$ \\
\hline \multirow[t]{2}{*}{$8 s$} & $\begin{array}{c}8 s \\
\left(4 e^{+}+4 i\right)\end{array}$ & $\begin{array}{c}8 s \\
(4 e+4 i)\end{array}$ & $\begin{array}{c}8 s \\
\left(4 e^{8}+4 i\right)\end{array}$ & $\begin{array}{c}5 s \\
(4 e+1 i)\end{array}$ & $(3 e+1 i)$ \\
\hline & $\left(8 e^{12 s}+4 i\right)$ & $\begin{array}{c}12 s \\
\left(8 e^{+}+4 i\right)\end{array}$ & $\begin{array}{c}12 s \\
\left(8 e^{2}+4 i\right)\end{array}$ & $\begin{array}{c}6 s \\
4 e+2 i)\end{array}$ & $\begin{array}{c}5 s \\
(4 e+1 i)\end{array}$ \\
\hline \multirow[t]{2}{*}{$16 s$} & $\begin{array}{c}16 s \\
\left(8 e^{+}+8 i\right)\end{array}$ & $\left(8 e^{16 s}+8 i\right)$ & $\begin{array}{c}20 s \\
(16 e+4 i)\end{array}$ & $\begin{array}{c}10 s \\
\left(8 e^{+}+2 i\right)\end{array}$ & $\begin{array}{c}68 \\
(5 e+1 i)\end{array}$ \\
\hline & $\begin{array}{c}24 s \\
(16 e+8 i)\end{array}$ & $\begin{array}{c}24 s \\
(16 e+8 i)\end{array}$ & $\begin{array}{c}24 s \\
(16 e+8 i)\end{array}$ & $\begin{array}{c}11 s \\
\left(8 e^{+}+3 i\right)\end{array}$ & $\begin{array}{c}7 s \\
\left(6 e^{7}+1 i\right)\end{array}$ \\
\hline \multirow[t]{2}{*}{$32 s$} & $\begin{array}{c}32 s \\
(16 e+16 i)\end{array}$ & $\begin{array}{c}32 s \\
(16 e+16 i)\end{array}$ & $\begin{array}{c}40 s \\
\left(32 e^{2}+8 i\right)\end{array}$ & $\begin{array}{c}19 s \\
(16 e+3 i)\end{array}$ & $\left(7 e^{8 s}+1 i\right)$ \\
\hline & $\begin{array}{c}48 s \\
(32 e+16 i)\end{array}$ & $\begin{array}{c}48 s \\
\left(32 e^{4}+16 i\right)\end{array}$ & $\begin{array}{c}44 s \\
(32 e+12 i)\end{array}$ & $\begin{array}{c}21 s \\
(16 e+5 i)\end{array}$ & $\begin{array}{c}9 s \\
\left(8 e^{+}+1 i\right)\end{array}$ \\
\hline \multirow[t]{2}{*}{$64 s$} & $\begin{array}{c}64 s \\
(32 e+32 i)\end{array}$ & $\begin{array}{c}64 s \\
(32 e+32 i)\end{array}$ & $\begin{array}{c}76 s \\
(64 e+12 i)\end{array}$ & $\begin{array}{c}37 s \\
(32 e+5 i)\end{array}$ & $\left(9 e^{10 s}+1 i\right)$ \\
\hline & $\begin{array}{c}96 s \\
(64 e+32 i)\end{array}$ & $\begin{array}{c}96 s \\
(64 e+32 i)\end{array}$ & $\begin{array}{c}84 s \\
(64 e+20 i)\end{array}$ & $\begin{array}{c}38 s \\
\left(32 e^{+6 i}\right)\end{array}$ & \\
\hline $128 \mathrm{~s}$ & $\begin{array}{c}160 s \\
(128 e+32 i)\end{array}$ & & $\begin{array}{c}148 s \\
(128 e+20 i)\end{array}$ & $\begin{array}{c}70 s \\
(64 e+6 i)\end{array}$ & 1 \\
\hline
\end{tabular}




\section{CHAPTER IX.}

\section{THE VERTEBRATE NATURE OF MAN.}

Relation of Comparative Anatomy to Classification.-The Family-relationship of the Types of the Animal Kingdom.-Different Significance and Unequal Value of the Seven Animal Types.-The Gastrcea Theory, and the Phylogenetic Classification of the Animal Kingdom.-Descent of the Gastræa from the Protozoa.-Descent of Plant-animals and Worms from the Gastræa.-Descent of the Fonr Higher Classes of Animals from Worms.-The Vertebrate Nature of Man.-Essential and Unessential Parts of the Vertebral Organism.-The Amphioxas, or Lancelet, and the Ideal Primitive Vertebrate in Longitudinal and Transverse Sections.-The Notochord.-The Dorsal Half and the Ventral Half.-The Spinal Canal.-The Fleshy Covering of the Body.The Leather-skin (corium).-The Outer-skin (epidermis).-Bodycarity (cceloma). - The Intestinal Tube--The Gill-openings. - The Lymph-vessels. - The Blood-vessels. - The Primitive Kidneys and Organs of Reproduction.-The Products of the Four Secondary Germ. layers.

"Know thyself! This is the source of all wisdom, said the great thinkers of the past, and the sentence was written in golden letters on the temple of the gods. To know himself, Linnæus declared to be the essential indisputable distinction of man above all other creatures. I know, indeed, in study nothing more worthy of free and thonghtful man than the study of himself. For if we look for the purpose of our existence, we cannot possibly find it outside ourselves. We are here for our own sake."-KARL ERsst BaEr (1824).

A DIFFICULT task now lies immediately before us in this history of our individual development; we must trace the complex human body with all its various parts,-organs, 
limbs, etc. from the simple Gastrula. The two primary germ-layers which form the entire body of the Gastrula fall by fission into the four secondary germ-layers, which have already been named; and of these four the whole complex form of the perfected human and animal body constructs itself. It is so difficult to understand this process of construction, that we will first look around us for an ally capable of helping us over many obstacles.

This powerful ally is the science of Comparative Anatomy. Its object is, by comparison of the perfected bodily forms of the various groups of animals, to discover the universal structural laws, in accordance with which the animal body develops; and at the same time, by critically determining the degrees of difference between the various classes, and the larger groups of animals, to establish their relations to each other and to the whole system. There was a time when this task was attempted from a teleological point of view, and in the actually existing apt organization of animals proof was sought of a pre-arranged "plan of construction" by the Creator; but, recently, the establishment of the Theory of Descent has enabled Comparative Anatomy to go deeper, and its philosophical task has developed into the explanation of the variety of organic forms by Adaptation, and their similarity by Heredity; it has also to seek to discover the various degrees of bloodrelationship in the graduated and various form-relationships, and to prove as nearly as possible the genealogy of the animal kingdom. In this way Comparative Anatomy is most closely allied to the classification of organic bodies, which, starting from the opposite direction, aims at the same result. 
In asking ourselves what place the most recent discoveries of Comparative Anatomy and the Science of Classification, among other organisms, assign to Man, what light is thrown by a comparison of developed bodily forms on the position of Man in the whole animal system, we receive a very simple and significant answer; " and this answer affords conclusions of extreme importance in explanation of the evolution of the embryo, and as to the phylogenetic interpretation of this evolution.

Since the time of Cuvier and Baer, since the great progress originated by these two great zoologists in the first decades of this century, the whole animal kingdom has been universally held to be divisible into a small number of main divisions, or Types. They are called types, because a certain typical or characteristic structure of body is invariably maintained within each one of these main divisions. ${ }^{81}$ Of late, since the Development Theory has been applied to this celebrated Doctrine of Types, it has been discovered that all animals of the same type stand in direct blood-relationship "to each other, and can be traced from a common parent-form. Cuvier and Baer assumed four of these types; more recent research has raised the number to seven. These seven types, or tribes $(P h y l a),{ }^{82}$ of the animal kingdom, are: (1) the Protozoa ; (2) the Plant-animals (Zoophytes); (3) the Worms (Vermes); (4) the Soft-bodied animals (Mollusca); (5) the Star-animals (Echinoderma); (6) the Articulated-animals (Arthropoda); (7) the Vertebrata.

- I may at once introduce the reader to the genealogical inter-relations of these seven types as I am fully convinced they are phylogenetically constituted. For this purpose I will give as briefly as possible the outlines of 
my Gastræa Theory, ${ }^{24}$ on which I base the monophyletic genealogy of the animal kingdom, and which I am convinced must supersede the Theory of Types which now prevails. According to this Gastrea Theory, which I enunciated in the "Monograph on the Chalk Sponges" (vol. ii. pp. 465-467), the seven types or tribes of the animal kingdom possess an entirely different significance and an entirely unequal value. Only the four higher tribes -Vertebrates, Arthropods, Molluses, and Echinodermsare types in the sense of Cuvier and Baer, and even these only in a limited sense, not as originally meant by the authors of the theory. On the other hand, the lowest type, that of the Primitive-animals, is not really a "type," but the sum of all the lowest animals; it was from a branch of the Primitive-animals that the Gastræa developed. The two remaining types, the Plant-animals and the Worms, stand between the Primitive-animals and the four higher types. They are more specialized and typical than the Primitive-animals, and less typically organized and characterized than the four higher tribes.

The Gastræa Theory is founded on the fact that we have proved the two primary germ-layers to be the rudimentary bodily-structure common to the six higher groups of animals. But it is also proved that a single original organ is of the same use, or homologous, in all these animals; this is the intestine (protogaster), the primitive intestinal or stomach cavity, in its most simple form. In the Gastrea itself, and in the extant Gastreads (Haliphysema, Gastrophysema), the entire, simple, spherical or oval body consists only of this simple primitive cavity, open at one pole of the axis (the primitive intestine and primitive 
mouth), and of the two primary germ-layers which surround it in their simplest original form (Entoderm and Exoderm). But in none of the Protozoa are there germlayers, and therefore no primitive intestine. The entire protozoan body is formed either of a very simple cytod, a little shapeless mass of protoplasm, as in the Monera, or a very simple cell, as in Amcebæ and Gregarinæ, or a colony of simple cytods or cells (as in most Protozoa). But in the last case the cells of this cell-community are either entirely homogeneous, or but slightly differentiated, and never separated into true germ-layers. A real intestine never appears in the Protozoa. The Infusoria, which reach the highest degree of physiological perfection among Protozoa, do indeed appear to have an intestine with a mouth and vent. But as the entire body, notwithstanding the considerable differentiation of its individual parts, retains only the form-value of a simple cell, we cannot compare this physiological food-canal with its openings, with the true many-celled intestine, which in other animals are morphologically characterized by their covering of germ-layers. ${ }^{83}$

We must therefore primarily divide the whole animal kingdom into two main divisions; on the one side the Protozoa, without a primitive intestine or germ-layers, without yelk-cleavage or differentiated many-celled tissues; on the other side, the Intestinal animals (Metazoa) with intestines, with two primary germ-layers, with yelk-cleavage, with differentiated many-celled tissues. The Intestinal animals, or Metazoa, in which we include the six higher groups of animals, have all descended from the Gastræa, the previous existence of which may be, even at this day, proved with certainty by means of the Gastrula. This 
Gastrula, or intestinal larva, which recurs in a remarkably similar form in the history of the individual development of the several groups of animals, is of the greatest significance. From this Gastrula the lowest Vertebrate develops, just as the lower forms of Worms, Soft-bodied Animals, Star-animals, Plant-animals, etc. (Cf. Plates II., III., and Fig. 22-28, pp. 191, 193.) The Gastrula at the present day presents a correct picture of the primitive Gastræa, which must have developed from the Protozoa in the Laurentian period.

Comparative Anatomy and Ontogeny teach us, further, that from this Gastræa the animal kingdom at first developed in two diverging directions or lines. In the one direction proceeded the low group of the Plant-animals (Zoophytes), to which the Sponges, Polyps, Corals, Medusæ, and many other marine animals belong; and among freshwater animals the well-known Hydra, or fresh-water Polyp, and the Spongilla, or fresh-water Sponge. In the other direction, the very important group of the Worms, in the narrower sense in which the present zoological classification limits this group, developed from the Gastræa. In the Linnæan system, and generally in earlier times, all the lower animals, Infusoria, Worms, Soft-bodied Animals, Plant-animals, Star-animals, etc., were included under the name of Worms; the name is now, however, much more narrowly restricted to the true Worms. Under it are included Earth-worms, Leeches, Ascidians, and also the various parasitic Worms, Tape-worms, Round-worms, Trichinæ, etc. Different as all these worms appear, in their perfect state, they can all be traced back to the Gastruea. (Cf. Table XVIII. in Chap. XVII.) 
We must look for the original parent-form of the four higher tribes of animals among the numerous branch-forms of the Worm Tribe. The comparative Anatomy and Ontogeny of these four tribes certainly teach that all originated from four different branches of Worms. This tribe is the common ancestral group of the four higher animal tribes. These last are: (1) the Star-animals (Echinoderma-Starfishes, Sea-urchins, Sea-lilies, Sea-cucumbers); (2) the important class of the Articulated-animals (ArthropodaCrabs, Spiders, Centipedes, Insects); (3) the Soft-bodiedanimals (Mollusca-Lamp-shells, Mussels, Snails, etc.); and finally (4) the Vertebrata, the most highly developed tribe of animals, to which Man belongs.

These are the principles of the unified or monophyletic genealogy of the animal kingdom, as they present themselves, provisionally, according to the Gastræa Theory, at the present stage of zoological classification and of embryological knowledge. If $\mathrm{I}$ am right in asserting the original similarity or homology of the primitive intestine and the two primary germ-layers enclosing it in all intestinal animals, this phylogenetic classification of the animal kingdom may supersede the systems hitherto based on the Type Theory. According to this, therefore, the seven types of that theory acquire a wholly different significance. Of these seven tribes (Phyla), (1) that of the Protozoa remains at the foot of the scale; from it springs (2) the Gastræa, which branches into the two lines of the Plantanimals and Worms; and from the Worms develop (3) the four higher groups of animals ; these last are four diverging lines, which are only connected together at the base, among the lowest Worms, but are not otherwise comparable. 
In specially observing the position of Man in the animal system, it cannot be doubted for a moment that the entire bodily structure of Man is that of a Vertebrate, and that Man possesses in the characteristic position and combination of his organs all those peculiarities which appear only in the Vertebrate class, and are totally wanting in all other animals. The Vertebrates are either in no way related to the three other higher groups of animals, or they are so only in their common descent from the Worms and from the Gastræa ; on the contrary, a relationship really exists, and may be clearly proved between Vertebrates and some forms of Worms. I may now enunciate the proposition, which we shall hereafter prove, that the entire Vertebrate tribe has developed from the Worm tribe. On the other hand, the Vertebrates have certainly not descended from the Articulated-animals (Arthropoda), the Soft-bodied Animals (Mollusca), or Star-animals (Echinoderma). Therefore by far the greater part of the animal kingdom may be entirely overlooked in our future investigations, whether Ontogenetic or Phylogenetic. We have nothing further to do with these. The three groups which alone interest us, are the Primitive Animals (Protozoa), the Worms, and the Vertebrates.

Those people who regard the descent of Man from the animal kingdom as a more or less degrading stigma, and are ashamed of it, may take such consolation as they can from the fact that the greater part of the animal kingdom is not akin to them. The Vertebrates have no connection with the great group of Articulated-animals (Arthropoda); but to the latter belong not only the Crabs, but also the Spiders and Insects, which last form a single class, com- 
prising probably as many, if not more, distinct species than all the other classes of animals together. Unfortunately, we lose by this the relationship which might otherwise connect us with Termites, Ants, Bees, and other virtuous members of the Articulate class. Among these insects are many well-known patterns of virtue, which the fable writers of old classic times held up as examples for men. In the civil and social arrangements of the Ants especially, we meet with highly developed institutions which we may even yet regard as instructive examples. But unfortunately these highly civilized animals are not related to us.

Our next task must now be, to enter in greater detail into the vertebrate nature of Man, and to determine the special position which he holds in the system of Vertebrates. Here it is necessary to point out the most essential facts in the particular structure of the vertebrate body; for, otherwise, we shall be quite unable to enter rightly into the difficult question of Ontogeny. The evolution of even the simplest and lowest Vertebrate from the simple Gastrula is so complex a process, and is so difficult to trace, that it is necessary to understand the principles of the organization of the perfect Vertebrate, in order to comprehend the principles of its evolution. But it is equally important that in this brief anatomical description of the vertebrate organism, we should stop only at the essential facts, and leave all others untouched. Therefore, in giving an ideal anatomical sketch of the main form of the Vertebrate and its inner organization, I leave out all secondary and non-essential circumstances, and confine myself to those most essential.

Many particulars, which will probably appear highly 
important and essential to the reader, are shown by the History of Evolution and Comparative Anatomy to be of secondary and subordinate importance, or even entirely nonessential. For example, from this point of view the head with the skull and the brain are non-essential, as are also the extremities, or limbs. It is true that these parts of the body possess a very high-even the very highest physiological importance; but for a morphological conception of the Vertebrate, they are non-essential, because they appear only in the higher Vertebrata, and are wanting in the lower. The lowest Vertebrates possess neither a clearly marked head with a brain and skull, nor extremities, nor limbs. The human embryo also passes through a stage in which it possesses no head, no brain, no skull, in which the trunk is still entirely simple and undivided into head, neck, breast, and abdomen, in which there is no trace of limbs, arms, or legs. In this stage of evolution, Man, as well as every other higher Vertebrate, essentially resembles that simplest Vertebrate form, which is represented only by a single existing Vertebrate, retaining the form throughout life. This single lowest Vertebrate, which deserves the closest consideration, and, next to Man, must undoubtedly be called the most interesting of all Vertebrates, is the wellknown Lancelet, or Amphioxus (Plates X. and XI.). As we shall afterwards examine this animal minutely (in Chapters XIII. and XIV.), I shall say but little about it now.

The Amphioxus lives buried in sea-sand; it attains a length of 5-7 centimetres, and in its adult condition is shaped exactly like a long, lanceloate leaf. It is, therefore, called the Lancelet. The narrow body is compressed on both sides, is similarly pointed in front and at the back, 
without any trace of external appendages, without any division of the body into head, neck, breast, abdomen, etc. Its whole form is so simple, that its first discoverer declared it to be a naked Snail. Not until much later (about forty years ago) was the remarkable little being more closely examined, and it then became evident that it is a true Vertebrate. Later investigations have shown that its bearing on Comparative Anatomy and human Embryology and Phylogeny is of the highest importance. For the Lancelet enables us to solve the weighty question as to the descent of Vertebrates from Worms, with certain lower forms (Ascidia) of which it is immediately connected in its development and bodily structure.

Now, if we make several sections through the body of the Amphioxus,-first, perpendicular longitudinal sections through the whole body from front to back, and secondly, a perpendicular cross-section through it from right to left, we shall obtain two instructive anatomical pictures. (Cf. Plates $\mathrm{X}$. and XI.) In all essential points they correspond to the abstract ideal, which, aided by Comparative Anatomy and Ontogeny, we are able to conceive as the primitive type, as the picture of the Primitive Vertebrate; of that long extinct parent-form, to which the whole Vertebrate tribe owes its origin. We need only make very slight and immaterial alterations in the actual sections of the Amphioxus, in order to obtain such an ideal anatomical picture or diagram of the primitive form of the Vertebrate, as it is represented in Fig. 52-56. The Amphioxus differs so little from this primitive form that it may be accurately described as a Primitive Vertebrate. (Cf. Plates X. and XI. with Fig. 52-56. ${ }^{85}$ 
In the longitudinal section of the type of the Vertebrate, a thin but firm rod, of cylindrical form, and pointed at the posterior and anterior ends (Fig. 52, $x$ ), is seen in the middle of the body. This passes through the whole length of the centre of the body, and represents the original rudiments of the spine or vertebral column. This is the notochord, the chorda dorsalis, or chorda vertebralis, which is also called the vertebral chord or spinal axis, or, briefly, the chorda. This firm, but flexible and elastic chord, consists of a cartilaginous mass of cells, and forms the central inner axis of the skeleton or main support of the body; it occurs exclusively in Vertebrates, and is entirely wanting in all other animals. As the first rudiment of the spine, it possesses the same significance in all Vertebrates, from the Amphioxus to Man. But in the Amphioxus alone the notochord is retained, throughout life, in its simplest form. In Man and all the other higher Vertebrates, on the contrary, it is found in this form only in the earliest embryonic stages, and afterwards develops into the articulated vertebral column.

The spinal axis, or notochord, is the fixed main axis of the Vertebrate body, corresponding with the ideal axis of length, and at the same time serving as a sure guide by which we learn the true bearing of the typical relative positions of the most important organs of the Vertebrate body. By means of it we can picture the body of the Vertebrate in its original natural arrangement, in which the axis of length lies horizontally; the dorsal side lies above, and the ventral side below (Fig. 52). If we make a vertical section through the whole length of this axis, the whole body separates into two similar and symmetrical parts, the right and left halves. In both halves exactly the same organs originally lie, in the 

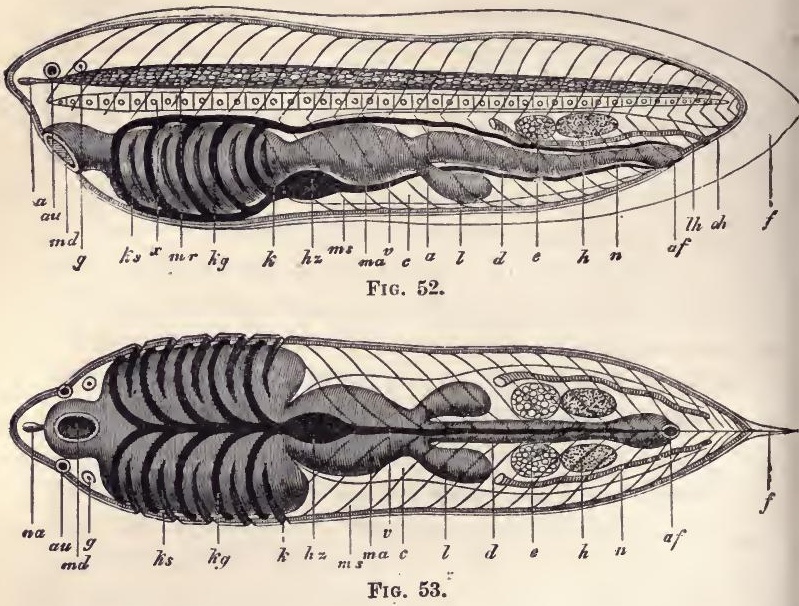

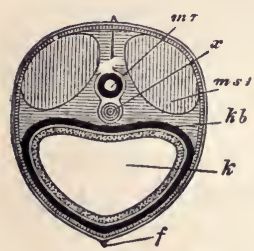

FIG. 54 .

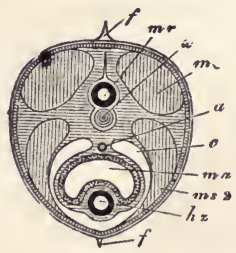

Fig. 55.

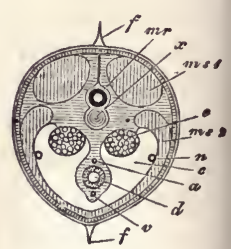

Fig. 56.

Fig. 52.-The ideal Primitive Vertebrate type, seen from the left side : $m r$, mednllary tube; $x$, chorda; na, nose; au, eyes; $g$, ear-vesicle; $m d$, month; $k$, gill.body; $k s$, gill-openings; $k g$, gill-arches; ma, stomach; $l$, liver; $d$, small intestine; $a f$, anns; $v$, intestinal vein; $h z$, heart; $a$, bodyartery; $n$, primitive kidney canal; $e$, ovary; $h$, testicles; $c$, body-cavity (visceral cavity); ms, muscles; th, leather-skin (corium); oh, outer-skin (epidermis); $f$, skin-fold, acting as fin.

Fig. 53.- Same as above, viewed from the ventral side. 
FrG. 54.-Transverse section of the same in the anterior part (throngh the gill-body, at $\mathrm{kg}$, Fig. 53).

Fig. 55.-Transverse section of the same in the central part (in the neighbourhood of the heart, at $h z$, Fig. 53).

Fig. 56.-Transverse section of the same in the posterior part (through the ovary, at $e$, Fig. 53). The letters indicate the same parts in all the sections.

same relative position and connection; but their positions in relation to the central plane of section are exactly reversed; the left half resembles the right, as though reflected in a mirror. The two halves are called counterparts, or antimera. The perpendicular line of section which divides the two halves, passes from the back to the abdomen, and is called the sagittal or dorso-ventral axis. If, on the other lıand, we make a horizontal section lengthwise through the chord, the whole body falls into a dorsal and a ventral half. The line of section which passes through the body from the right to the left side is called the cross or lateral axis. (Cf. Plates IV. and V. ${ }^{84}$ )

The two halves of the Vertebrate body which are separated by this horizontal, transverse axis, have an entirely different significance. The dorsal half is especially the animal part of the body, and contains the greater part of the so-called animal organs, of the nerve-system, musclesystem, bone-system, etc. The ventral half, on the other hand, is essentially the vegetative part of the body, and contains the greater part of the vegetative organs of the vertebrate, the digestive system, the reproductive system, etc. The two outer secondary germ-layers are, therefore, specially employed in the formation of the dorsal half, and the two inner in the formation of the ventral half. Each of the two halves develops in the form of a tube, and surrounds a cavity in which anotherr tube is enclosed. VOL. I. 
The dorsal half encloses the spinal cavity, which lies above the notochord, and contains the tube-shaped central nerve system, the spinal marrow or spinal tube. The ventral half, on the other hand, encloses the much larger intestinal or ventral cavity, which lies below the notochord, and contains the intestinal canal with all its appendages.

The spinal, or medullary tube, as the central nerve system or mental organ of Vertebrates is called in its primitive condition, consists in Man, as in all higher Vertebrates, of two very different parts: the large brain lying within the skull, and the long spinal cord which extends from the brain along the whole back (Plate V. Fig. 16, $m$ ). But no part of this structure is seen in our primitive vertebral type. In this the highly important mental organ, which occasions the feeling, willing, and thinking of the Vertebrate, appears in an extremely simple form. It is composed of a long cylindrical tube which passes lengthwise through the body immediately above the notochord, and encloses a narrow central canal filled with fluid (Fig. 52-57, mr). We find that the Amphioxus at the present day retains throughout life this simplest form of the spinal canal, just as it existed in all the older and lower Vertebrates (Plate XI. Fig. 15, $m$ ). It is enclosed in a tube of skin which proceeds from the immediate surrounding of the notochord, the so-called notochord sheath, and in which, at a later period, the bony vertebræ of the higher Vertebrates are developed.

Of organs of sense, the parent-form of Vertebrates probably possessed an olfactory groove, as the simplest rudiment of a nose (Fig. 52, 53, na), a pair of eyes (au), and a pair of auditory vesicles $(g)$ of the most simple character. ${ }^{86}$ Some of these organs of sense are not represented 
in the Amphioxus, probably in consequence of secondary reversion. (Cf. Chap. XIII.)

Fig. 57.-Transverse section through the anterior part of the primitive vertebrate type: $m r$, spinal tnbe; $x$, chorda (notochord); $m s 1$, dorsal muscles; $k b$, gill-vent; $k$, gill-intestine.

On both sides of the spinal tube of all Vertebrates, and the notochord which underlies it, great masses of flesh are seen, which form the muscular

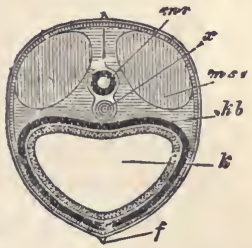
parts of the trunk and accomplish its movements. Although in developed Vertebrates these masses are differentiated and combined in various ways (corresponding to the variously differentiated parts of the bony skeleton) yet in our ideal primitive Vertebrate we can distinguish only two pairs of main muscles which traverse the whole length of the body parallel to the notochord. These are the upper, or dorsal, and the lower, or ventral, side-muscles of the trunk. The upper (dorsal) side-muscles of the trunk, the primitive back-muscles (Fig. 58, ms1) form the thick mass of the flesh of the back. The lower (ventral) side-muscles, the primitive abdominal muscles, on the other hand, form the fleshy wall of the abdomen (Fig. 58, ms2).

Fig. 58.-Transverse section through the sentral portion of the ideal Primitive Vertebrate $: f$, skin-fold, forming fin; $m r$, spinal tnbe; $\tau$, chorda; $m s_{1}$, dorsal muscles; $m s_{2}$, ventral xusscles; $a$, aorta (in the mesentery); $m a$, stomach-cavity; $c$, body-cavity (visceral carity); $i z$, heart.

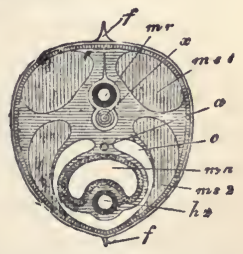

Outside this wall we find the outer firm covering of the whole body, called the leather-skin (corium, or 
cutis, $(h)$. The lower layers of this tough and thick covering consist principally of fat and loose connective tissue; the outer layers of skin-muscles and firmer connective tissues. It covers the whole surface of the fleshy body, with which it is connected, and it lies immediately below the thin outer skin (epidermis, oh). In the case of the higher Vertebrates, hairs, nails, feathers, claws, scales etc., arise from this outer skin. With all its appendages and products, it consists entirely of simple cells, and contains no blood-vessels. Its cells are connected with the ends of the sensory nerves. Originally the outer skin (epidermis) is an entirely simple covering for the outer surface of the body, and consists of but one kind of cell. In higher Vertebrates, it afterwards separates into two strata, an outer, firmer horn-stratum, and an inner, softer mucous stratum; many external and internal appendages arise from it at a later period; the hair, nails, etc., externally, and the sweat and sebaceous glands internally.

In the primitive Vertebrate the skin probably arose along the middle line of the body in the form of an erect, perpendicular seam used for floating purposes $(f)$. The Amphioxus and the Cyclostomi yet retain a similar seam, which passes almost entirely round their bodies; one is also found on the tail of the larval Frog, or Tadpole (Fig. 194).

From these external parts of the vertebrate body we will now turn to the inner organs, which we find beneath the notochord, in the large body, or intestinal cavity. To avoid confusion, we will in future call this cavity the coeloma. In Anatomy it is usually called the pleuro-peritoneal cavity (Fig. 58, c). In Man and all other Mammals, but in no other animals, this cœlom, when developed, is 
separated into two distinct cavities, which are completely divided by a transverse partition, the muscular midriff, or diaphragm. The first, or chest-cavity, contains the œsophagus, the heart, and the lungs; the other, the ventral cavity, contains the stomach, small intestine, large intestine, liver, spleen, kidneys, etc. But in mammalian embryos, these two form a single connected cavity, a simple cœlom, before the diaphragm is developed, and this we find to be the case in all lower Vertebrates throughout life. This cœlom is covered by a delicate layer of cells, the intestinal epithelium.

The most important of the viscera within the bodycavity (coloma), is the nutritive intestinal tube, the organ which forms the whole body of the Gastrula. This is a long tube, more or less differentiated, enclosed in the cœlom, and having two openings; a mouth-opening for taking in food (Fig. 59, 60, md), and an anal opening for discharging waste-matter or excrement ( $a f$ ). Numerous glands, all of which proceed from the intestine, are attached to the intestinal canal, which are of great importance in the vertebrate body. These are the salivary glands, lungs, liver, and numerous smaller glands. A pair of simple liverpouches (Fig. $59,60, l$ ) were probably present even in the parent-form of Vertebrates. The walls of the intestinal canal and of all these appendages, consist of two very different parts or layers; the inner cellular covering is the intestinal-glandular layer, or the fourth germ-layer; the outer fibrous envelope, on the other hand, proceeds from the third germ-layer, the intestinal-fibrous layer; it is mainly composed of muscle-fibres, which effect the digestive movements of the intestine, and of a tissue of connective fibres forming a firm covering. The mesentery, a thin, 
ribbon-like layer, by which the intestinal canal is attached to the ventral side of the notochord, is a continuation of this. In addition to this, the most important parts of the blood-vessel system, especially the heart, and the greater arteries, also develop from this intestinal-fibrous covering. In Vertebrates the intestinal canal, as a whole as well as in its separate parts, is modified in various ways, although its original very simple form is always the same. As a rule, the intestinal canal is longer, often many times longer, than the body, and therefore lies, in many convolutions, enclosed in the cœloma, especially in the back part. In higher Vertebrates it is also often divided by valves into various separate parts; the parts being distinguished as the mouth, throat, œsophagus, stomach, small intestine, large intestine, and rectum. All these parts arise from a very simple formation, which originally (and, in the Amphioxus, permanently) is a straight, cylindrical canal running from front to rear below the notochord.

As the intestinal canal, in a morphological sense, may be regarded as the most important organ of the animal body, it is interesting to get a clear conception of its essential nature in Vertebrates, setting aside all non-essential parts. In this respect, it is especially necessary to give due weight to the fact that the intestinal canal in all Vertebrates shows a very characteristic division into two parts, a front half (Fig. 59, $k$ ) which serves especially for respiration, and a hind half which serves entirely for digestion (d). In all Vertebrates peculiar clefts appear, at a very early period, on the right and left sides of the front division of the intestinal canal; these, the so-called gill-openings ( $k s)$, are most closely connected to the primitive 
THE INTESTINAL CANAL IN PRIMITIVE VERTEBRATES. 263

respiration of Vertebrates. All lower Vertebrates, the Amphioxus, Lampreys, and Fishes, continually take in water through the mouth, and let it pass out through

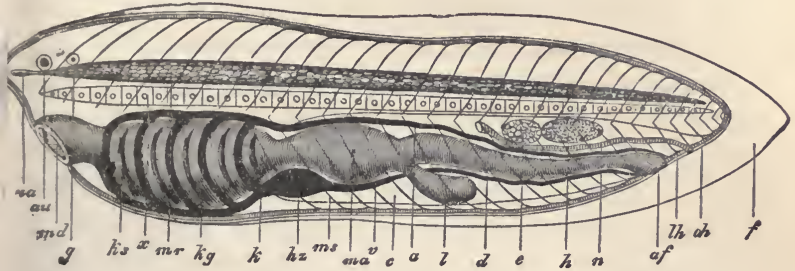

FIG. 59.-The ideal Primitive Vertebrate, seen from the left side: na, nose ; $a u$, eye; $g$, ear; $m d$, mouth; $l s$, gill-openings; $x$, chorda; $m r$, spinal tabe; $k g$, gill-vessels; $k$, gill-intestine; $h z$, heart; $m s$, muscles; ma, stomach ; $v$, intestinal rein ; $c$, body-cavity ; $a$, aorta ; $l$, liver ; $d$, small intestine; $e$, ovary; $h$, testes ; $n$, kidney canal; $a f$, anus; $l h$, leather skin; oh, outer skin (epidermis) ; $f$, skin-fold, acting as fin.

the lateral openings of the neck. The water that passes through the mouth serves for breathing. The oxygen contained in it is inhaled by the blood-channels which extend along the "gill-arches" ( $k g)$, situated between the gill-openings. These very characteristic gill-openings and gill-arches are found in the human embryo, and in the embryos of all higher Vertebrates, at an early period of their development, in that form in which they are retained throughout life by the lower Vertebrates. In Mammals, Birds, and Reptiles they never act as true organs of respiration, but gradually develop into very different organs. The fact that they originally actually exist in the same form as in Fishes, is, however, one of the most interesting proofs of the descent of these three higher classes of Vertebrates from the Fishes. 
Not less interesting and significant is the circumstance that the later respiratory organs of Mammals, Birds, and Reptiles develop from the front, or respiratory portion of the intestinal canal. A bladder-like fold develops at an early period from the throat of the embryo, and soon takes the form of two large sacs, which are afterwards filled with air. These sacs are the two air-breathing lungs which take the place of the water-breathing gills. But this bladderlike fold, from which the lungs arise, is simply the wellknown air-filled bladder which is called the swimmingbladder in Fishes, and serves throughout life as a hydrostatic organ, a swimming-apparatus lightening the specific gravity of the Fish. Human lungs are a modification of the swimming-bladder of Fishes.

The vascular system of Vertebrates stands in the closest morphological and physiological relation to the intestinal canal, its most important parts being developed from the intestinal-fibrous layer. It consists of two distinct parts, which are, however, immediately dependent on each other,

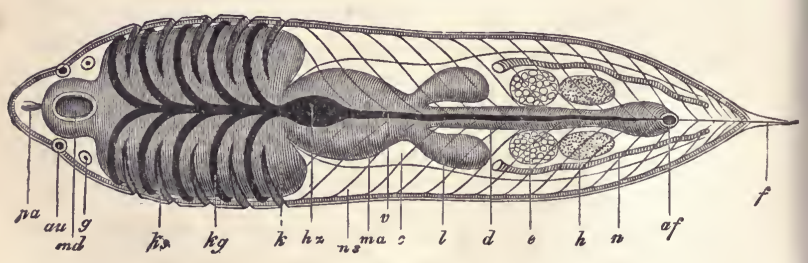

Frg. 60.-Ideal Primitive Vertebrate, ventral view : na, nose; $a u$, eyes; $g$, ear; $m d$, month; $k$, gill-body; $k s$, gill-openings; $k g$, vascular gill-arches; $h z$, heart; $v$, intestinal vein; $m a$, stomach; $l$, liver; $d$, small intestine; af, anus; $n$, primitive kidneys; $e$, ovary; $h$, testicles; $c$, bodycavity; $m s$, muscles; $f$, skin-fold, acting as float. 
the system of blood-vessels and the system of lymphatic vessels. The cavities of the former contain the red blood; those of the latter, the colourless lymph. To the lymphatic system belongs the cœlom (the so-called pleuro-peritoneal cavity); and also numerous lymphatic ducts which extend through all the organs, absorbing the juices which have been consumed from the tissues, and conveying them into the venous blood. Finally, the chyle-vessels, which absorb the white chyle or milky nutritive juice prepared by the intestines, carry it into the blood.

The blood-vessel system of Vertebrates is developed in various ways, but seems originally to have existed, in the Primitive Vertebrate, in the simple form in which it now permanently exists in the Ringed-worms (Annelida)-for example, the common Earth-worm-and in the Amphioxus. Two large unequal blood-channels, which are originally situated in the fibrous wall of the intestine, and which run along the intestinal canal in the central plane of the body (one underneath the intestinal canal, and the other above), must especially be regarded as essentially and originally the most important part of the blood-vessel system. These two principal channels give rise to many branches which traverse all parts of the body, and pass into each other in curves at the anterior and posterior ends of the body; we will call them the primitive artery and primitive vein. The former represents the dorsal vessels, the latter the ventral vessels of the Worms. The primitive artery or primordial aorta (Fig. 59, a) lies on the top of the intestine, along the central line of the dorsal side, and conveys oxygenated or arterial blood from the gills into the body. The primitive or primordial principal vein (Fig. $60, v$ ) lies below the intes- 
tine, along the central line on the side toward the abdomen, and conveys carbonated, or venous blood, from the body back to the gills. In the front part of the gill-division of the intestine, these two main channels are connected by several connecting branches, which rise in the form of arches between the gill-openings. These "vascular gillarches" ( $\mathrm{kg}$ ) pass along the gill-openings, and directly accomplish respiration. Immediately behind their base the front end of the primitive vein enlarges into a spindle-shaped bladder $(h z)$. This is the simplest rudiment of the heart, which, in higher Vertebrates and in Man, afterwards assumes the form of a four-chambered, pulsating organ.

In the lowest part of the body-cavity of Vertebrates, on the under side of the dorsal wall, near and on both sides of the notochord and the mesentery, lie the sexual glands, which form the reproductive cells ; in the female the ovary, in the male the testis. Recent study of the development of these parts seems to show that the original formation of the sexual glands in mankind and in all other Vertebrates, is hermaphroditic, or sexless. The embryonic glands of the Vertebrate contain the rudiments of both kinds of reproductive organs-the ovary of the female, which forms the ovule; and the testis of the male, which forms the sperm. These two kinds of sexual glands, each of which at a later stage of development is distributed to one only of the two sexes, are originally united in the embryo. This fact leads us to the conviction, which appears probable on other grounds also, that Vertebrates, in common with lower animals, were originally hermaphrodite, that each individual was capable of reproducing itself independently, and that the separation of the sexual organs took place at a 
SEXUAL ORGANS IN THE PRIMITIVE VERTEBRATE. 267

later period. We may, therefore, assume that the primitive Vertebrate possessed both ovaries (Fig. 60, 61, e) and testes $(h)$.

Fic. 61.-Transverse section through the posterior part of the ideal Primitive Vertebrate : $f$, float; $m r$; spinal tube; $x$, notochord; $m s$, muscles; $e$, ovaries; $n$, primitive kidney ducts; $a$, body-arteries; $d$, intestine; $v$, intestinal vein.

The sexual organs of Vertebrates are most intimately connected with the primitive kidneys, two glands running

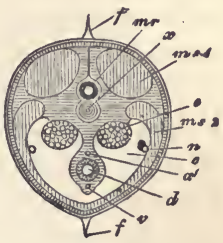
along near the notochord, which, in the embryo, secrete the urine, and in Fishes and Amphibia, remain permanently as urinary organs. ${ }^{87}$ In higher Vertebrates, their place is taken at a later period by the permanent kidneys, which arise from the posterior portion of the primitive kidney ducts. In their earliest and simplest form, the primitive kidneys appear to be a pair of simple ducts, running along either side of the notochord within the body-cavity, and having openings at their posterior ends (Fig. $60, n$ ). In this form they yet appear transiently in the embryo of higher Vertebrates, and permanently in the Worms.

The organs which we have thus enumerated in a general survey of the primitive Vertebrate, and have examined in relation to their characteristic positions, are those parts of the organism which are repeated in all Vertebrates without exception, in the same mutual relations, though they are modified in very various ways. We have turned our attention principally to the transverse section of the body (Fig. 54-56), because it shows most distinctly the peculiar relative positions of these organs. 
But, in order to perfect our picture, we must turn for a moment to pay special attention to their articulation or metameric structure, which is best seen in the longitudinal section (Fig. 52, 53). The body of Man, as of all developed Vertebrates, appears to be composed of a string or chain of like members lying one behind the other along the longitudinal axis of the body. In Man the number of these like segments or metamera is about forty; in many Vertebrates, for example, in Snakes and Eels, it is several hundred. As this inner articulation corresponds essentially with the vertebral column and the muscles surrounding it, these members, segments or metamera, are called primitive vertebræ. Now, this structure of these primitive vertebræ, or internal metamera, is correctly regarded as a prominent characteristic of Vertebrates, and the various forms into which it is differentiated bear greatly on the different groups of Vertebrates. But in our present task, that of tracing the development of the simple body of the primitive Vertebrate from the Gastrula, the segments or metamera are of subordinate significance, and we need not deal with them till later.

Putting these metamera temporarily aside, I think that, in the above brief description of the essential parts, I have said everything necessary as to the fundamental structure of Vertebrates. The chief organs which have been mentioned are the original and most important parts, nearly all of which are to be found, in a similar form, in the adult Amphioxus, and which re-occur in the original rudimentary germ of all members of this tribe. Many very important parts, which appear to be entirely essential, will, it is true, be missed in this review. As I have already remarked, the 
specialized head of the Vertebrate with skull and brain is a non-essential, secondary formation; and the same may be said of the limbs or extremities. Important as these parts of Man and the higher vertebrates are physiologically, they are morphologically unimportant, for originally they were absent, and they develop only at a later period. The older Vertebrates of the Silurian Period had neither skull nor brain, and were entirely without limbs.

If we pay no attention to those parts which are secondarily formed, and are therefore unimportant, and if we provisionally examine only the essential, primary parts, we shall greatly simplify our task. This task is essentially to trace the described organism of the "primitive Vertebrate" from the simple germ-form of the Gastrula. That simplest Vertebrate body is, as is usually said, composed of two symmetrical, double tubes; of a lower tube, the bodywall, which surrounds the intestinal tube, and of an upper tube, spinal canal, which surrounds the spinal marrow. Between the spinal tube and the intestinal tube, lies the notochord, the most essential part of the inner axis of the skeleton which characterizes the Vertebrate. This characteristic arrangement of the most important organs re-occurs in all Vertebrates from the Amphioxuis to Man. (Cf. Plate IV., with explanation.) We must, therefore, now examine the way in which these organs develop from the two primary germ-layers of the Gastrula, and from the four secondary germ-layers which arise by fission of the two primaries.

In order to solve this difficult problem it seems desirable to begin with a statement of the most important conclusions of ontogenetic study. The distant goal will be more easily 
reached if we see it clearly before us. I will now, therefore, mention as briefly as possible the relations which these particular organs of the vertebrate organism bear to the four different germ-layers.

The first of the secondary germ-layers, the skin-sensorylayer, produces,-firstly, the outer covering of the whole body; the outer skin, or epidermis, and, in higher Vertebrates, the hair, nails, sweat and sebaceous glands, and all other parts developing secondarily from the originally simple outer skin (epidermis). In the second place, from this layer arises also the central nerve-system, the medullary or spinal canal. It is remarkable that this mental organ develops from the outer surface of the epidermis, and, only afterwards, during the coinrse of the development of the individual, gradually moves inward, so that, at a later period, it is situated internally, surrounded by muscles, bones, and other parts. Thirdly, the primitive kidney of the Vertebrate which secretes the urine, probably develops from the outer germ-layer. It may be presumed that this primitive kidney was originally a secretory gland of the skin, like the sweat-glands, and, like them, developed from the outer skin (epidermis); at a later period it lies deep within the body.

From the second of the secondary germ-layers, the skinfibrous layer, arises the principal mass of the vertebrate body, namely, all those parts lying between the epidermis and the inner colom, and forming the firm body-wall. To these belong, firstly, the leather-skin (corium), which lies at the surface directly under the epidermis,- the firm, fibrous covering which contains the nerves and blood-vessels of the skin; secondly, the great masses of muscle of the 
whole trunk, or the flesh, surrounding the vertebral column, and consisting of two main groups of muscles; the dorsal, or upper side-muscles of the trunk, and the ventral, or lower side-muscles of the trunk. To these must be added, in the third place, the inner skeleton, which is especially characteristic of Vertebrates, the central formation of which is the spinal axis or notochord, developing at a later period into the articulated vertebral column; also all the bones, cartilages, ligaments, etc., which form the vertebral skeleton in all more highly developed Vertebrates, and are connected by the sinews and muscles belonging to it. Fourthly and finally, from the innermost layer of cells of this secondary germ-layer develops the exocolar, that is, the outer, or parietal cœlom-epithelium, the cell-layer which forms the inner covering of the body-wall, and which is also probably the original site of the male sexual cells.

The third secondary germ-layer is the intestinal-fibrous layer. From this is developed, firstly, the endocoelar, that is, the inner, or visceral cœlom-epithelium, the layer of cells, covering the outer surface of the whole intestine, probably also the site of the female sexual cells. Secondly, from this layer originates the heart, and the great blood-vessels of the body, as well as the blood itself, so that it has been called, in a peculiar sense, the vascular layer. The great blood-channels, or arteries, going from the heart and the great veins passing to the heart, as well as the chyle-vessels, which open into the latter, are formed, like the heart, the the lymph, and the blood itself, from this third germlayer. Thirdly, arises the muscular tube of the intestines, or the mesenteric tube, that is, the whole of those fibrous and fleshy parts which form the outer wall of the 
intestinal canal, as well as the mesentery, the thin, fibrous membrane by which the intestinal canal is connected with the ventral side of the vertebral column.

The history of the fourth secondary germ-layer, or the intestinal-glandular layer, is very simple and clear. Its only product is the intestinal cellular covering, or the Epithelium of the intestinal canal with all its appendages, the large and small intestinal glands, among which are the lungs, liver, salivary glands. (Cf. Plates IV., V.) 


\section{TABLE VI.}

Systematic Survey of the principal organs of the ideal Primitive Vertebrate, the hypothetical parent-form of Vertebrates, and of their development from the germ-layers.

\begin{tabular}{|c|c|c|}
\hline $\begin{array}{l}\text { Primary Germ- } \\
\text { layers. }\end{array}$ & $\begin{array}{l}\text { Secondary Germ- } \\
\text { layers. }\end{array}$ & $\begin{array}{l}\text { Most important Organs of } \\
\text { the Primitive Vertebrato. }\end{array}$ \\
\hline $\begin{array}{c}\text { I. } \\
\text { Skin-layer } \\
\text { (Animal germ-layer, } \\
\text { Baer). }\end{array}$ & $\begin{array}{c}\text { I. } \\
\text { Skin-sensory layer } \\
\text { (Skin-stratum, Baer), } \\
\text { or } \\
\text { Sensory layer. } \\
\text { Lamina neurodermalis, } \boldsymbol{n} \text {. }\end{array}$ & $\begin{array}{l}\text { 1. Outer skin (Epidermis). A } \\
\text { simple cell-covering of the } \\
\text { onter surface. } \\
\text { 2. Spinal tube (Tubus medul- } \\
\text { laris) (with the organs of } \\
\text { sence: the nose, eyes, organs } \\
\text { of hearing). } \\
\text { 3. Primitive Kidneys (Protone- } \\
\text { phra) (a pair of simple ducts, } \\
\text { primitive kldney ducts). }\end{array}$ \\
\hline $\begin{array}{l}\text { Lamina dermalis, } H \text {. } \\
\text { Exoderma. }\end{array}$ & $\begin{array}{c}\text { II. } \\
\text { Skin-fibrous layer } \\
\text { (Flesh-stratum, Baer), } \\
\text { or } \\
\text { Flesh-layer. } \\
\text { Lamina inodermalis, } n .\end{array}$ & $\begin{array}{l}\text { 4. True skin (Corium) (Cutis and } \\
\text { subcutis). } \\
\text { 5. Mnscies of the trunk (dorsal } \\
\text { and ventral munscles). } \\
\text { 6. Notochord (Chorda dorsalis). } \\
\text { 7. Exoccelar, or l'arietal Coelon- } \\
\text { epitlieliun (the inner cell- } \\
\text { covering of the body-wall). } \\
\text { 8. Male sexual glands (Testes) }\end{array}$ \\
\hline
\end{tabular}

Coeloma, or Body-cavity. A space between the body-wall and the intestinal wall, between the exoderm and the entoderm, filled with lymph (colourless blood).

9. Female sexuul glands (Ovary).

10. Endoccelar, or Visceral Coe lom-epithellum (the outer cell-covering of the intestinal tube).

III.

Intestinal-fibrous layer

(Vascular stratnm, Baer),

or

II.

Intestinal layer

(Vegetative germlayer, Baer).

Lamina gastralis, $\boldsymbol{H}$. Entoderma.

\section{Vascular layer.} Iamina inogastralis, $\boldsymbol{H}$.

IV.

Intestinal-glandular layer (Mucous stratum, Baer),

or

Mucous layer. Lamina mycogastralis, $\boldsymbol{H}$.
11. Principal blood-vessels (primltive artery or dorsal vessel. and the primitive vein or ventral vessei).

12. Mesentery.

13. Muscular intestine wall (ftbrous intestinal wail).

14. Intestinal epithelium (Inner cell-covering of the intestlnal tube).

15 Intestinal glandnlar epithelium (IIver-cells and other intestinal glandular cells). 


\section{CHAPTER $\mathrm{X}$.}

\section{THE CONSTRUCTION OF THE BODY FROM THE GERM-}

\section{LAYERS.}

The Original (Palingenetic) Development of the Vertebrate Body from the Gastrula.-Relation of this Process to the Later (Kenogenetic) Germination, as it occurs in Mammals.-The most important act in the Formation of the Vertebrate.-The Primary Germ-layers, and also the Secondary Germ-layers, which arise by Fission of the Primaries, originally form Closed Tubes.-Contemporaneonsly with the Completion of the Yelk-sac, the Germ-layers flatten, and only later again assume a Tubnlar Form.-Origin of the Disc-shaped Mammalian Germ-area. - Light Germ-area (area pellucida) and Dark Germ-area (area opaca).-The Oval Germ-shield, which afterwards assumes the Shape of the Sole of a Shoe, appears in the Centre of the Light Germ-area (a. pellucida).-The Primitive Streak separates the Germ-shield into a Right and Left Half.-Below the Dorsal Furrow the Central Germlayer parts into the Notochord and the Two Side-layers.-The Sidelayers split horizontally into Two Layers: the Skin-fibrous layer and the Intestinal-fibronslayer.-The Primary Vertebral Cords separatefrom the Side-layers.-The Skin-sensory Layer separates into Three Parts: the Horny Layer, Spinal Canal, and Primitive Kidney.-Formation of the Cœlom and the First Arteries.-The Intestinal Canal proceeds from the Intestinal Furrow. The Embryo separates from the Germ-vesicle. -Around it is formed the Amnion-fold, which coalesces over the back of the Embryo, so as to form a Closed Sac.-The Amnion.-The Amnion-water.-The Yelk-sac, or Navel-vesicle.-The Closing of the Intestinal and Ventral Walls occasions the Formation of the Navel.The Dorsal and Ventral Walls.

"The development of the Vertebrate proceeds from an axis npward, in two layers, which coalesce at the edges, and also downward, in two layers, 
which likewise coalesce at the edges. Thus two main tabes are formed, one above the other. Doring the formation of these, the embryo separates into strata, so that the two main tubes are composed of subordinate tubes which enclose each other as fundamental organs, and are capable of developing into ali the organs." - KARL ERNST BAER (1828).

THE mammalian egg, in the stage of development in which we left it, presented an extremely important and remarkable germ-form, the Gastrula (Fig. 41, p. 213, and Plate II. Fig. 17). The whole body of this globular Gastrula consists solely of the two kinds of cells which compose the two primary germ-layers. A single stratum of lightercoloured and firmer cells forms the outer germ-layer, and constitutes an outer covering over the whole surface of the body of the Gastrula. The whole interior of the latter is filled by the darker and softer cells of the inner germ-layer: it is only at a single point that these latter cells appear at the outer surface of the spherical body; this point is the mouth of the Gastrula, the primitive mouth (protostoma, Fig. 41,o).

It is no easy task to explain how the complex mammalian organism originates from this simple Gastrula. In order to lighten the task, we have, as a preliminary, made ourselves acquainted with the typical structure of the simple primitive Vertebrate (Fig. 52-56, p. 256). We chiefly based our study of that directly on the real conditions which may yet be actually seen in the structure of the body of the lowest extant Vertebrate, the Amphioxus. In most important points of internal organization we may regard the Amphioxus as a correct, palingenetic picture of the long-extinct parent-form of all Vertebrates, the form to which the origin of Man must also be referred. It is only in a few unimportant points that the Amphioxus appears to 

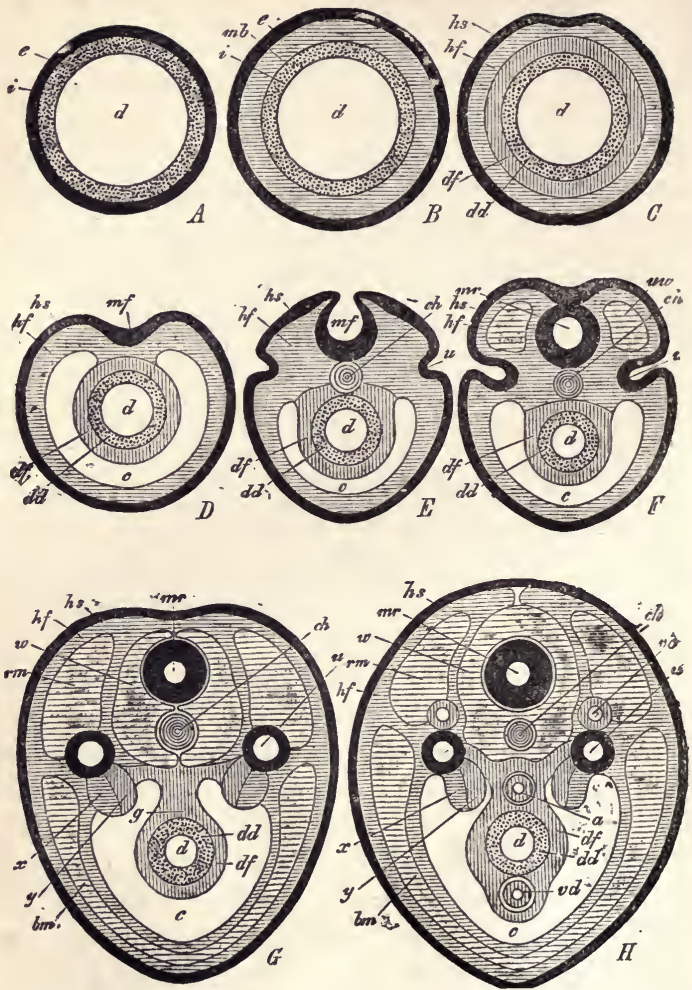

Fig. 62-69.-Diagrammatic transverse sections through the most important germ-forms of the ideal Primitive Vertebrate (Fig. 52-61). ${ }^{89}$

FiG. 62.-A. Transverse section through the Gastrula; two-layered germ.

Fig. 63.-B. Three-layered germ.

Fig. 64.-C. Four-layered germ (four secondary germ-layers). 
FIG. 65.-D. The body-cavity appears between the skin-layer and the intestinal layer.

Fig. 66.-E. The notochord appears between the spinal furrow and the intestine.

Frg. 67. $-F$. The primitive kidneys and primitive vertebræ appear; the spinal tube is closed.

FIG. 68.- $G$. The rudiments of the sexual organs appear near the primitive kidneys. The primitive vertebræ surround the notochord and the spinal tube.

Fig. 69.-H. The main blood-vessels appear above and below the intestine.

The letters indicate the same parts in all : $d$, the intestinal cavity; $d d$, the intestinal-glandnlar layer; $d f$, the intestinal-fibrous layer; $g$, mesentery; $y$, female germ-glands (rudimentary ovary); $x$, male germ-glands (rudimentary testes); $a$, aorta (primitive artery); $v d$, intestinal vein (primitive vein); $v c$, cardinal vein; $c h$, notochord; $u w$, primitive vertebræ; $w$, vcrtebræ; $v u$, dorsal muscles; $b m$, ventral muscles; $u$, primitive kidneys; $m f$, spinal furrow; $m r$, spinal tnbe; $h s$, horn-plate. In all, the four secondary germ-layers are indicated by shading: the intestinal. glandnlar layer $(d d)$ is dotted. The intestinal-fibrous layer $(d f)$ is perpendicnlarly shaded. The skin-fibrous layer $(h f)$ is horizontally shaded. The skin-sensory layer $(h s)$ is black.

be kenogenetically altered, and we must suppose that the conditions were originally different. This is equally true of the very important germ-history of this lowest Vertebrate. In a later chapter (XIV.) we shall enter into the details of this. Here, however, we may base our argument on this germ-history so far as we are able, from a comparative study of the germination of the various Vertebrates, to form an approximate conception of the course of individual evolution, as it originally occurred in the oldest and simplest Vertebrates. Only after we have gained a general view of this, can we turn to the far harder task of tracing the construction of the mammalian organism, and especially that of Man, from the Gastrula.

The palingenetic Bell-gastrula of the Amphioxus (Fig. 28 , p. 193) affords a safe starting-point. A series of dia- 
grammatic transverse sections through those germ-forms which first develop from the Gastrula, will best and most easily afford us the desired view. (Cf. Fig. 62-69, and Plates IV., V.) In the first place, a third layer, the middle layer, or fibrous layer (mesoderma, Fig. $63 \mathrm{mb}$ ), arises between the two primary germ-layers of the Gastrula (Fig. 62). Then, this three-layered stage is followed by one in which there are four layers (Fig. 64). As we have already stated, each of the two primary germ-layers probably originally contributed to the formation of the middle layer (mesoderma), although it is usually asserted that the latter originates from one only of the former. It is probable that the exoderm, or skin-layer (e), separated into the skinsensory layer $(h s)$ and the skin-fibrous layer ( $h f$ ), and correspondingly, the entoderm, or intestinal layer, into the intestinal-fibrous layer $(d f)$ and the intestinal-glandular layer $(d d)$.

When the four germ-layers are completed, the form of the Gastrula, which had but one axis, has become symmetrically bilateral (cf. p. 257). In consequence of the body becoming flat, a distinction is formed between the dorsal and ventral sides, between the right and the left. Parallel with the axis of length, a delicate streak, the indication of a furrow, appears in the centre of the dorsal side. The side walls of this furrow, which is called the "spinal furrow" $(\mathrm{mf})$, rise in the form of two parallel ledges (Fig. $65 \mathrm{mf}$ ); these are the spinal swellings (medullary or dorsal swellings). Their two parallel edges bend toward each other (Fig. $66 \mathrm{mf}$ ) and finally coalesce, so that the trench becomes a tube; this is the spinal tube (Fig. $67 \mathrm{mr}$ ). Along the longitudinal axis of the body, a solid cylindrical 
cord arises between the spinal tube and the intestinal tube; this is the notochord, or chorda (ch). It originates from the central portion of the skin-fibrous layer, while the side portions of the latter supply the true skin and the great part of the flesh. This flesh-mass separates into the dorsal muscles (Fig. 68, $69 \mathrm{rm}$ ) and the ventral muscles $(\mathrm{bm})$.

The separation of the four secondary germ-layers is followed by a separation between the skin-fibrous layer ( $h f$ ) and the intestinal-fibrous layer $(d f)$. Between the two, a chink-like cavity, filled with fluid, arises; this is the true body-cavity (coloma, Fig. 65-69 c). The intestinal tube lies freely in this, being only supported along the length of the notochord by a band of the intestinal-fibrous layer, which afterwards extends into the mesentery (Fig. $68 \mathrm{~g}$ ). Two narrow canals, filled with blood, form within the intestinalfibrous layer, and traverse the whole length of the intestine, one passing underneath, and the other above; these are the first blood-vessels. The upper of the two is the dorsal vessel (Fig. $69 a$ ), the latter is the ventral vessel $(v d)$; the one afterwards gives rise to the aorta, the other to the intestinal vein and the heart.

Finally, the first rudiments of the urinary and sexual glands make their appearance on either side of the intestinal tube and the notochord attached to the dorsal wall of the body-cavity. The primitive kidneys $(u)$ resemble two narrow canals, traversing the body, parallel to the notochord, opening at the anterior end into the body-cavity, and at the posterior end through the outer skin (or in the last chamber of the intestine). They probably originally arose as skin-glands, formed by an inversion of the skin-sensory layer (Fig. 66-68u). In 
their immediate neighbourhood are the sexual organs, in the form of simple heaps of cells, which are attached to the body-wall, near the mesentery. Presumably, they originated as hermaphrodite glands, the female gland $(y)$ from the inner, the male gland $(x)$ from the outer germ-layer. The former becomes the ovary, the latter the testes. Simultaneously with these changes, the spinal tube has completely detached itself from its original site, the skin-sensory layer, and has made its way far into the body. A sheath has formed round the notochord, and processes from this "notochord sheath " grow round the spinal tube, imbedding it in a vertebral canal (Fig. 68, $69 w$ ).

If, for a moment, we leave the transverse sections, and trace the evolution of the primitive Vertebrate in longitudinal sections, we see that at a very early period the intestinal tube is divided into a gill-intestine and a stomachintestine, in consequence of the appearance of gills in the anterior portion. The primitive mouth of the Gastrula closes; the two permanent openings of the future intestine arise as new formations from the exterior; the mouth in front, the anus behind. Moreover, the outer body-wall becomes articulated, owing to the fact that the fleshy mass of the trunk-muscles assumes the form of a number of similar, consecutive portions, segments, or metamera. In correspondence with these, each of the respective portions of the nerve and vascular systems becomes distinct.

The following processes must, therefore, be emphasized as the chief acts by which the simple Gastrula changes into the typical vertebrate organism : 1. The two primary germlayers part by fission into four secondary germ-layers. 2. The Gastrula becomes flattened, so that, instead of a form 
with a single axis, it assumes the bilateral vertebrate form. 3. The body-cavity (coloma) arises, in consequence of the disconnection of the skin-fibrous layer and the intestinalfibrous layer. 4. Along the central line of the dorsal surface the nerve-centre appears in the form of a trenchshaped furrow; it then changes into the spinal-tube and completely detaches itself from the skin-sensory layer. 5. Immediately below the spinal tube, the notochord originates from the central part of the skin-fibrous layer, while the side parts of the same layer form the true skin and the trunk-muscles; the latter articulate themselves into metamera. 6. In the outer stratum of the intestinal wall, in the intestinal-fibrous layer, originate the main blood-vessels, a dorsal vessel (arta) above the intestinal tube, and a ventral vessel (primitive vein) below the latter. 7. The intestinal tube separates into two main parts; the gill-intestine in front, the stomach-intestine behind. Several gill-openings form on either side of the gill-intestine. 8. The intestinal tube acquires two new openings, a mouth in front, an anus behind; the original primitive mouth of the Gastrula closes. 9. Close by the intestine and notochord, and on either side of them, arises a tube which separates urine, and which opens into the body-cavity in front, outside the body in the rear; this is the primitive kidney canal. 10. Close by this canal, between it and the notochord, develop the rudiments of the sexual glands (the testes and ovary), in the form of roundish cellular masses, which penetrate from the wall of the body-cavity to this position (the undefined boundary of the skin-fibrous layer and the intestinalfibrous layer). ${ }^{90}$

These chief, fundamental, and palingenetic acts in the 
evolution of the individual, the assumption of which is justified by the comparative germ-history of Vertebrates, re-occur essentially in all branches of this tribe, though in single cases they are more or less changed, or kenogenetically modified. In their simplest and earliest form, which is certainly mainly palingenetic, we yet find them in the Amphioxus ; in the Round-mouths (Cyclostomi), Fishes, and Amphibia they have already become 'much changed and vitiated, kenogenetically transformed; and this is true in a much greater degree of the three higher vertebrate classes, Reptiles, Birds, and Mammals. In these the gradual formation of a very large nutritive yelk and of peculiar egg-membranes has introduced so many changes, or secondary kenogenetic modifications, that at first sight it is hardly possible to recognize the primary palingenetic incidents of evolution.

In these, the kenogenetic relation of the germ to the nutritive yelk is especially prominent, and till quite recently caused an entirely false conception of the first and most important conditions of the germ of the higher Vertebrates, introducing many false views as to the Ontogeny of these. Previously, the germ-history of the higher Vertebrates was universally based on the view that the first rudiment of the germ is a flat layer-shaped disc; and for this reason the cell strata which compose the germ-disc (also called the germ-area) were called "germ-layers." This flat germ-dise which is at first circular, afterwards oval, and which in the hen's egg we have learned to call the tread (cicatricula), lies at a particular point on the outer surface of the large globular nutritive yelk. When germination begins, the flat germ-disc arches outwards and detaches its outer surface 
from the large yelk-ball which lies beneath it. The flat layers become tubes, in consequence of their edges inclining

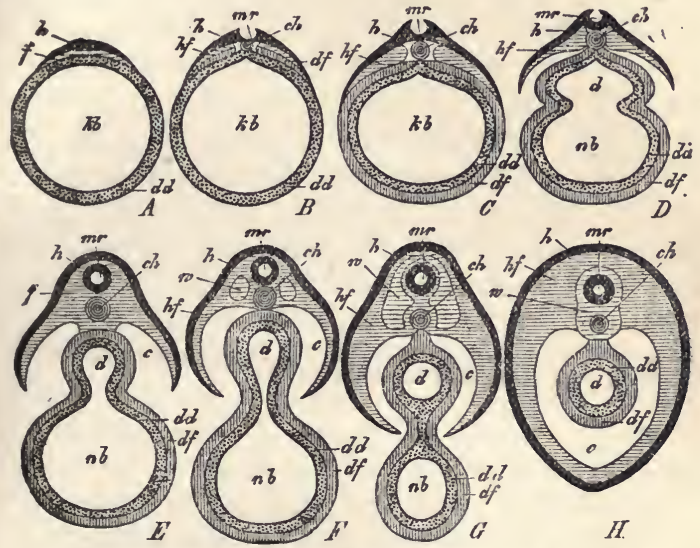

Fic. 70.-Separation of the disc-shaped mammalian germ from the yelk-sac; in transverse section (diagrammatic). A. The germ-disc $(h, h f)$ lies flat on one side of the intestinal germ-vesicle $(k b)$. $B$. The spinal tube ( $m r)$ appears in the centre of the germ-disc, and underneath this the notochord (ch). C. The intestinal-fibrons layer (df) has grown round the intestinal-glandular layer $(d d)$. D. The skin-fibrons layer $(h f)$ and the intestinal-fibrons layer $(d f)$ separate in the outer wall; the intestine $(d)$ begins to separate itself from the navel-vesicle $(n b)$. $E$. The intestinal tube $(m r)$ is closed; the body-cavity $(c)$ begins to form. $F$. The primitive vertebræ $(w)$ separate; the intestine $(d)$ is almost entirely closed. $G$. Tho primitive vertebræ $(w)$ begin to grow round the spinal tube $(m r)$ and tho notochord $(c h)$; the intestine $(d)$ is separate from the navel-vesicle $(n b)$. $H$. The vertebræ $(u)$ have grown rond the spinal tube $(m r)$ and the notochord; the body-eavity $(c)$ is closed, the navel-resicle has disappeared. The amnion and serous membrane are omitted.

In all, the letters indicate the same parts: $h$, horn-plate; $m r$, spinal tube; $h f$, skin-fibrous layer; $w$, primitivo vertebræ; $c h$, notochord ; $c$, bodycavity (cœloma); $d f$, intestinal-fihrous layer; $d d$, intestinal-glandular layer: $d$, intestinal carity ; $n b$, narel-vesicle. 
towards each other and coalescing (Fig. 70). The germ growing at the expense of the nutritive yelk, the latter continually becomes smaller; it is completely surrounded by the growth of the germ-layers. At a later period the remnant of the nutritive yelk forms only a small globular sac, the yelk-sac, or navel-sac (saccus vittelinus, or vesicula umbilicalis, Fig. $70 \mathrm{nb}$ ). This is surrounded by the intestinal layer, and connected with the central portion of the intestinal tube by a thin stalk, the yelk-duct (ductus vitellinus), and, in most Vertebrates, is at last completely absorbed by the intestinal tube (Fig. $70 \mathrm{H}$ ). The point at which this happens, and at which the intestine finally closes, is the intestinal navel. In Mammals, in which the remnant of the yelk-sac remains outside and gradually dwindles, the yelk-duct pierces the outer ventral wall to the last. The navel cord parts at birth at this point, which permanently remains as the navel (umbilicus) in the outer skin.

As in the germ-history of the higher Vertebrates, based chiefly on that of the Chick, the distinction between the germ (or formative yelk) and the nutritive yelk (or yelk sac) has up to the present time been regarded as original, the flat, leaf-shaped rudiment of the germ-disc has also necessarily been regarded as the original germ-form, and the greatest weight has been laid on the fact that these flat germ-layers curve, and thus become hollow trenches; and that, by the concrescence of their edges, they become closed tubes.

This view, which has governed all past expositions of the germ-history of the higher Vertebrates, is, I am convinced, entirely false. For the Gastræa Theory, the full significance of which now becomes evident, teaches us that 
the real state of the case is originally just the opposite. The Gastrula, in the body-wall of which the two primary germ-layers appear from the first as closed tubes, is the original germ-form of all Vertebrates, as of all Invertebrate animals; and the flat germ-disc, with its flatly extended germ-layers, is a later, secondary germ-form, which arose in eonsequence of the kenogenetic formation of the large nutritive yelk, and the consequent extension of the germlayers over the surface of the latter. ${ }^{91}$ The curving of these germ-layers, which actually occurs, and their coalescence into tubes is, therefore, not original and primary, but a much later, tertiary incident of evolution. Accordingly, the three following stages of germ-formation must be distinguished in the Phylogeny of Vertebrates:

\begin{tabular}{|c|c|c|}
\hline $\begin{array}{l}\text { A. First Stage : } \\
\text { Primary } \\
\text { (Palingenetic) } \\
\text { Process of Germ- } \\
\text { formation. }\end{array}$ & $\begin{array}{l}\text { B. Second Stage: } \\
\text { Secondary } \\
\text { (Kenogenetic) } \\
\text { Process of Germ. } \\
\text { formation. }\end{array}$ & $\begin{array}{l}\text { C. Third Stage: } \\
\text { Tertiary } \\
\text { (Kenogenetic) } \\
\text { Process of Germ. } \\
\text { formation. }\end{array}$ \\
\hline $\begin{array}{l}\text { From the first, the } \\
\text { germ-layersform closed } \\
\text { tubes. } \\
\text { No nutritive yelk. }\end{array}$ & $\begin{array}{l}\text { The germ.layers } \\
\text { spread themselves ont } \\
\text { in the form of a leaf, } \\
\text { in consequence of the } \\
\text { formation of a large } \\
\text { yelk-sac from the cen- } \\
\text { tre of the intestinal } \\
\text { tube. }\end{array}$ & $\begin{array}{l}\text { The germ-layers form } \\
\text { a flat germ-disc, the } \\
\text { edges of which incline } \\
\text { toward each other, and } \\
\text { coalesce into a closed } \\
\text { tube. }\end{array}$ \\
\hline
\end{tabular}

If this view is correct, and, as the logical conclusion from the Gastræa Theory, I am obliged to believe it is so, then the explanation of the process as at present accepted must be exactly reversed. The yelk-sac must no longer be treated as though it were originally distinct from the 
germ or embryo, but as essentially a part of the latter, a part of its intestinal tube. According to this view, the primitive intestine (protogaster) of the Gastrula of the higher animals has separated, in consequence of the kenogenetic formation of the nutritive yelk, into two different parts: the after-intestine (metagaster) or the permanent intestinal canal, and the yelk-sac or navel-vesicle.

If the germ-histories of the Amphioxus, the Frog, the Chick, and the Rabbit are comparatively studied (Plates II., III.), I am convinced that there can be no doubt as to the correctness of this view, which I have thus explained. In the light afforded by the Gastræa Theory we shall regard the structural proportions of the Amphioxus alone of all Vertebrates, as original and but slightly varied from the palingenetic germ-forms. In the Frog these proportions are on the whole but slightly kenogenetically altered. In the Chick, on the contrary, they are very much altered, and most of all in the Rabbit. Both in the Bell-gastrula of the Amphioxus and in the Hood-gastrula of the Frog, the germlayers are visible from the first in the form of closed tubes (Plate II. Fig. 6, 11). But, on the other hand, the embryonic Chick (in the freshly-laid, unincubated egg) appears in the form of a flat, circular dise; it was only quite recently that the true gastrula-character of this germ-disc was recognized by Rauber and Goette. ${ }^{74}$ This Disc-gastrula grows and surrounds the huge globular yelk, and the afterintestine (metagaster) parts off from the external yelk-sac; in these two processes all that is diagrammatically represented in Fig. 70 is accomplished; and these are the processes which have been regarded as main acts, though they are in reality only secondary acts. 
In Mammals the corresponding germinal processes are very complex and peculiar. Till quite recently they were entirely wrongly explained; the recently published researches of Eduard van Beneden ${ }^{6}$ which placed them, for the first time, in a true light, enabled us to bring them into agreement with the principles of the Gastrea Theory, and to trace their relation to the germination of the lower Vertebrates. Although there is no independent nutritive yelk, distinct from the formative yelk, in the mammalian egg, and although the cleavage is therefore total, a large yelk-sac arises from the embryo which is produced by this cleavage, and the true germ spreads itself in a layer-like form on the surface of this yelk-sac, as in the case of Reptiles and Birds, the eggs of which have a large nutritive yelk and undergo partial cleavage. As in the latter, the flat, leaf-shaped germ-dise of Mammals detaches itself from the yelk-sac, its walls incline towards each other and coalesce into tubes.

This striking contradiction can only be explained as a consequence of very peculiar, strange, kenogenetic modifications of the germ, the causes of which are not yet fully explained. They are evidently connected with the fact that the ancestors of the viviparous Mammals were Amnionanimals, which laid eggs, and which only gradually became viviparous. When the Hood-gastrula (Amphigastrula) of the Mammal is complete (Fig. 71), it changes into a large globular vesicle, filled with fluid. According to Van Beneden, this happens in the following way: The Gastrulamouth disappears in consequence of the entoderm-cell (o), which formed the yelk-plug, disappearing into the interior, to the other cells of the intestinal layer $(d)$. The mammalian germ now forms a solid ball, consisting of a quantity 
of dark, multilateral entuderm-cells (i), and covered by a light-coloured globular membrane, which is composed of a single stratum of exoderm-cells (e). A transparent brightcoloured liquid now collects at a point between the two germ-layers; and this increases so greatly that it expands the exoderm cellular membrane into a large globular vesicle. The mass of entoderm-cells, forming a ball of smaller diameter, remains attached to one point of the exoderm; (according to Van Beneden, this point is that of the yelkplug, $o$ ). The entoderm mass now becomes flattened, first assuming a hemispherical, then a lentil-shaped, and finally a discoidal form: this is accomplished by a movement among the cells, which spread themselves out in a onelayered circular disc.

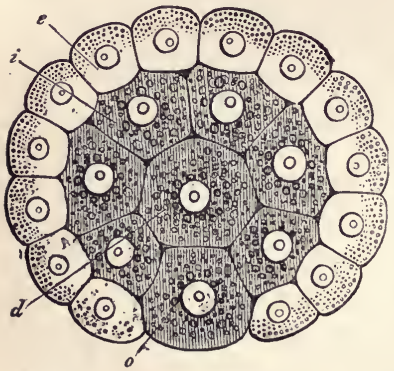

Fig. 71.-Gastrula of a Mam. mal (Amphigastrula of a Rabbit) in longitudinal section through the axis : $e$, exoderm-cells (64, lighter-coloured and smaller); $i$, entoderm-cells (32, darker and larger); $d$, central entoderm-cells, occupying the primitive intestinal cavity; 0 , peripheric entoderm-cells, plugging the primitive mouth-opening (the yelkplng in the "anus of Rusconi").

This vesicular condition of the mammalian germ was detected two centuries ago (1677) by Regner de Graaf. He discovered small, globular, transparent vesicles, with a double membrane, lying free in the uterus of a Rabbit four days after impregnation. But Graaf's statement was not accepted. It was not till 1827 that these vesicles were 
re-discovered by Baer; those of the Rabbit were afterwards more minutely described by Bischoff, in 1842. They may be found in the uterus (matrix) of the Rabbit, the Dog, and other small Mammals within a few days after impregnation. The ripe mammalian eggs, having left the ovary, are fertilized, either here or in the oviduct, by the active spermcells which make their way in. ${ }^{92}$ (On the uterus and oviduct cf. Chapter XXV.) Cleavage and gastrulation take place within the oviduct. Either while the mammalian Gastrula is still in the oviduct, or after it has entered the uterus, it changes into the globular vesicle which is represented in Fig. 72 (the surface) and in Fig. 73 (in
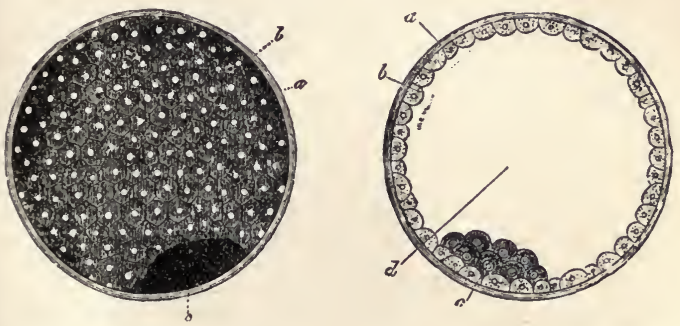

Fic. 72.-Intestinal germ-vesicle (Gastrocystis) of a Rabbit (the so-called "Germ-vesicle," or vesicula blastodermica, of other writers) : a, external egg-membrane (chorion); $b$, skin-layer (exoderma), forming the whole wall of the germ-yelk vesicle; $c$, heap of dark cells, forming the intestinal layer (entoderma).

Frg. 73.-The same in section. The letters as in Fig. 72: $d$, hollow space within the intestinal germ-vesicle.

section). The thick, external, structureless membrane which surrounds this is a modification of the original egg-membrane (zona pellucida, p. 135), with the addition of an

VOL. I. 
albuminous stratum, which has been externally deposited. In future we shall call this membrane the outer egg-membrane, the primary chorion (prochorion, $a$ ). The real wall of the vesicle, surrounded by this outer egg-membrane, consists of a simple layer of exoderm-cells $(b)$, which have been regularly flattened by mutual pressure, and most of which are hexagonal; a "light-coloured kernel is visible through their finely granulated protoplasm (Fig. 74). On a

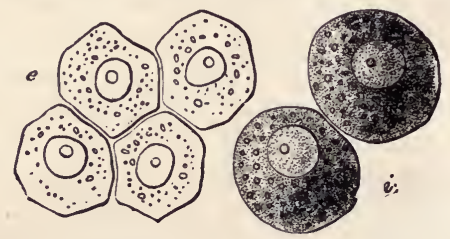

FiG. 74.-Four exoderm-cells from the intestinal germ-vesicle of a rabbit.

Fig. 75.-Two entoderm-cells from the same.

point on the inside of this hollow sphere lies a circular disc, formed of darker, softer, and rounder cells, of the dark granulated entoderm-cells (Fig. 75).

The characteristic germ-form in which the developing Mammal now is has usually been called the "germ-vesicle" (Keimblase, Bischoff); the "sac-germ" (Baer); the "vesicular embryo," or the "germ-membrane vesicle" (vesicula blastodermica, or, briefly, blastosphara). The wall of the hollow sphere, consisting of a single cell-stratum, was called the "germ-membrane," or blastoderm, and it was supposed to be equivalent to the cell-stratum, called by the same name, which forms the wall of the true germ-membrane vesicle (Blastula) of the Amphioxus (Plate II. Fig. 4), and 
of many Invertebrate Animals (e.g. of the Monoxenia, Fig. $22, F, G)$. This true germ-membrane vesicle has, up to the present time, been universally regarded as homologous with the germ-vesicle of Mammals. It is not so, however. 'The so-called "germ-vesicle" of Mammals and the true germmembrane vesicle of the Amphioxus and of many Invertebrates are entirely different germ-forms. The latter (the Blastula) precedes gastrulation. The former (vesicula blastodermica) follows gastrulation. The globular wall of the blastula is a true germ-membrane (Blastoderma), and consists entirely of cells of one sort (blastoderm-cells); it is not yet specialized into the two primary germ-layers. On the other hand, the globular wall of the mammalian "germ-vesicle" is the specialized skin-layer (exoderma), and a circular dise of entirely different cells lies at a point on the inside of this; this disc is the intestinal layer (entoderma). The spherical cavity, filled with clear liquid, in the interior of the blastula, is the cleavage-cavity. On the other hand, the similar cavity in the interior of the mammalian germ-vesicle is the yelk-sac cavity, which is joined on to the developing intestinal cavity.

On all these grounds, which have been very recently brought to light by the researches of Van Beneden, it is very necessary to recognize the secondary "intestinal germvesicle" of Mammals (Gastrocystis) as a peculiar germ-form, occurring only in this class of animals, and as quite distinct from the "germ-membrane vesicle" (Blastula) of the Amphioxus and of the Invertebrates. The wall of this mammalian "intestinal germ-vesicle" consists of two distinct parts. Far the larger part is one-layered, and is formed by the exoderm. For the smaller part, the circular disc, which 
is formed of both primary germ-layers, we will adopt Van Beneden's name, and call it the intestinal germ-disc (Gastrodiscus).

The small, circular, dull whitish spot which lies at a particular point on the outer surface of the bright-coloured, transparent, and spherical "intestinal germ-vesicle," and which is the "intestinal germ-disc" (Gastrodiscus), has long been known to naturalists, and was compared with the "germ-disc" of Reptiles and Birds. Sometimes, therefore, it was called the "germ-dise" (discus blastodermicus), sometimes the "embryonic spot" (tache embryonnaire), but more usually the germ-area (area germinativa). The further evolution of the germ proceeds especially from this germ-area. On the other hand, the greater part of the intestinal-germ-vesicle of Mammals is not directly employed in the formation of the future body, but in the formation of the transitory "navel-vesicle." The embryo-body pinches itself off from the latter more and more, in proportion as it grows and develops at the expense of the latter; the two become no longer connected except by the yelk-duct (the stalk of the yelk-sac); and the latter forms the indirect communication between the cavity of the navel-vesicle and the intestinal cavity in the course of development (Fig. 70).

The germ-area, or the intestinal germ-disc of Mammals, originally consists, like the germ-disc of Birds, merely of the two primary germ-layers, each of which is formed of a single cell-stratum. Soon, however, a third cell-stratum, the rudiment of the middle fibrous layer (mesoderma), appears in the middle of the circular disc, between the two earlier strata. According to most observers, the mesoderm arises trom the inner primary germ-layer; according to others, on 
the contrary, it arises from the outer of the two $;^{93}$ both are probably concerned in the process. The middle of the germ-area, or germ-disc, now consists of three germ-layers, while the circular rim consists of two; the rest of the wall of the intestinal germ-vesicle consists only of a single germlayer, the outer. But this wall also now becomes two-layered.

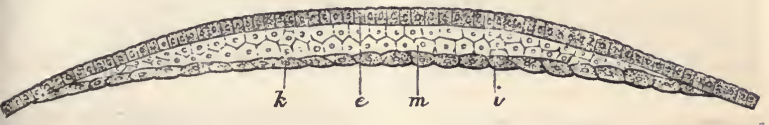

F1G. 76.-Section throngh the germ-area of a Mammal, at right angles to the surface (diagrammatic) : $e$, exoderm (the simple cell-stratum of the skin-layer); $m$, mesoderm (the several cell-stratum of the middle layer); $i$, entoderm (the simple cell-stratum of the intestinal layer); $k$, hollow cavity in the intestinal germ.vesicle.

While, in the centre of the germ-area, the fibrous layer becomes greatly thickened, in consequence of cell-growth, the inner germ-layer simultaneously extends and grows in all directions from the edge of the disc. Everywhere closely applied to the outer germ-layer, it completely overgrows the inner surface of the latter; it covers first the upper, and then the lower hemisphere of the inner surface, and finally closes in the centre of the latter. (Cf. Fig. 77-81.) The whole wall of the intestinal germ-vesicle now, therefore, consists of two cell-strata: the exoderm without, the entoderm within. In the centre only of the circular germ-disc, which, in consequence of the excessive growth of the middle layer, continually increases in thickness, this germ-dise consists of all three germ-layers. Simultaneously, small structureless knots, or warts, secrete themselves on the surface of the outer egg-membrane (prochorion), which 

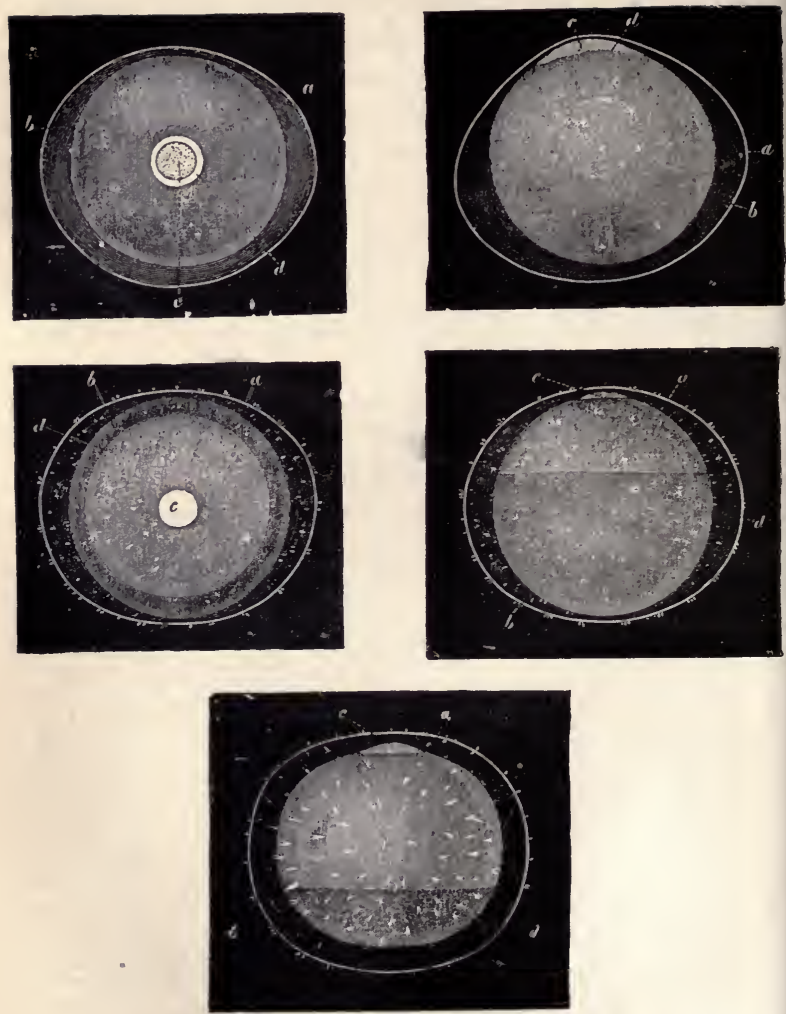

Fic. 77.-Egg from the aterus of a Rabbit (4 mm. in diameter). The germ-membrane vesicle $(b)$ has sliglitly retreated from the smooth outer egg-membrane (prochorion, $a$ ). The circular germ-area $(c)$ is visible in the certre of the germ-membrane, and at the edge of the former (at $d$ ) the inner 
stratum of the germ-vesicle is already beginning to extend. (Fig. 77-81, after Bischoff.)

Fig. 78. - The same, seen from one side. The letters as in Fig. 77.

Frg. 79.-Egg from the nterus of a Rabbit $(6 \mathrm{~mm}$. in diameter). The germ-membrane is already to a great extent donble-layered $(b)$. The onter egg-membrane (prochorion) becomes knotty, or warty $(a)$.

Fig. 80.-The same, seen from one side. The letters as in Fig. 79.

Fig. 81. - Egg from the uterus oi a Rabbit $(8 \mathrm{~mm}$. in diameter). Nearly the whole of the germ-membrane vesicle is already double-layered (b); only below (at $d$ ) there is still only one layer.

has raised itself from the intestinal germ-vesicle (Fig. $79-81$ a).

We need not at present pay any attention either to this outer egg-membrane (prochorion) or to the larger portion of the germ-vesicle, and may turn our full attention to the germ-area (or germ-dise). For it is in this part alone that the important modifications which result in the specialization of the earliest organs first appear. In this respect it is quite immaterial whether we examine the germ-area of a Mammal (e.g. a Rabbit), the germ-disc of a Bird or a Reptile (e.g. a Lizard or a Tortoise). For in all members of the three higher vertebrate classes, all called Amnion-animals, the germinal processes which immediately follow are essentially alike. In this respect Man is like the Rabbit, the Dog, the Ox, etc.; and in all these Mammals the germ-area undergoes essentially the same modifications as in Birds and Reptiles. It is in the Chick that these have been chiefly and most accurately traced, for any requisite number of incubated hen's eggs, in all stages, can always be obtained. Within a few hours from the beginning of incubation the circular germ-dise of the Chick also passes from a twolayered to a three-layered stage, in consequence of the development of the mesoderm between the exoderm and the entoderm. 
The first modification of the discoidal, three-layered germ-area consists in the fact that the cells round its edge increase more rapidly, and accumulate dark granules in their protoplasm. In this way a darker ring is formed, which is
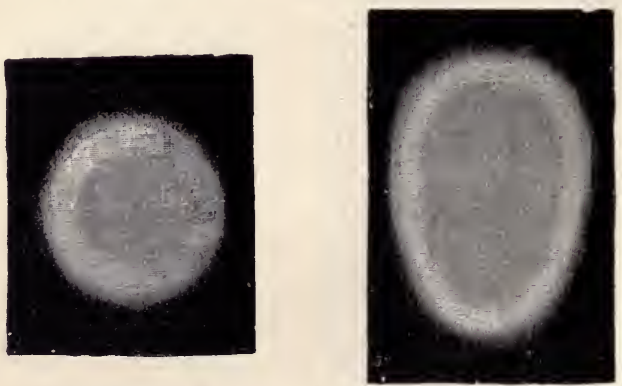

Frg. 82.-Circular germ-area of a Rabbit, distinguished into the central, light-coloured germ-area (area pellucida), and the peripheric dark germ-area (a. opaca). As it makes itself visible through the dark part, the area pellucida appears the darker.

FIG. 83.-Oval germ-area (a. germinativa). The dull whitish area opaca appears on the outside.

more or less distinctly marked off from the lighter centre of the germ-disc (Fig. 82). The latter we shall in future call the light germ-area (area pellucida); the darker ring we shall call the dark germ-area (area opaca). (In reflected light, as in Fig. 82-84, it appears reversed ; the light germarea appears dark, because the dark ground makes itself seen from below; the dark germ-area appears lighter in comparison.) The circular form of the germ-area changes to an elliptic, and immediately afterwards to an oval form (Fig. 83). One end appears broader and more abruptly 
rounded off, the other is smaller and more pointed; thie former represents the hinder portion of the future body. The characteristic bilateral form of the body, the distinction between anterior and posterior, between right and left, is thus already indicated.

In the centre of the light germ-area a dull-coloured, large, oval spot now appears; at first it is very delicate and hardly noticeable, it soon however becomes more sharply distinguished, and presently appears as an oval shield, surrounded by two rings (Fig. 84). The inner, lighter ring

FIG. 84. - Germ-area or germ-dise of a Rabbit (about ten times magnified). As the delicate, half-transparent germ-diso lies on black ground, the light germ-area appears as a darker ring, the dark germ-area (situated on the outside), on the contrary, as a white ring. The oval germ-shield, situated in the centre, also appears whitish; along its axis the dark spinal furrow is already visible. (After Bischoff.)

is the remnant of the light germ-area; the outer, darker ring is

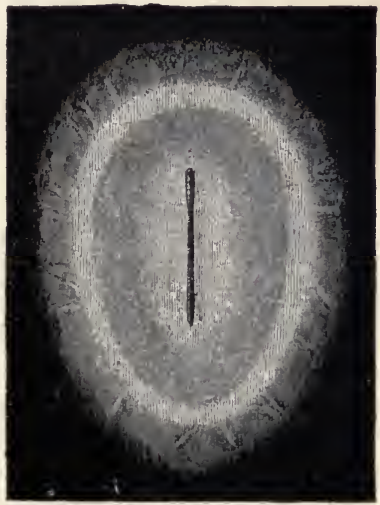
the dark germ-area; but the dull-coloured shield-shaped spot itself is the first rudiment of the dorsal portion of the embryo. We will call it briefly the "germ-shield" (notaspis). ${ }^{94}$ Remak called it the "double shield," because it arises from a shield-shaped thickening of the outer and the middle germ-layers. In most books this germ-shield is 
spoken of as the "first germ-rudiment or embryoric rudiment," as the "primitive germ," or "the first trace of the emioryo." But these designations, which are based on the authority of Baer and Bischoff, are incorrect. For in reality the germ or embryo already exists in the parent-cell, in the Gastrula, and in all the subsequent germ-stages. The germshield is merely the earliest rudiment of that dorsal part which first becomes defined.
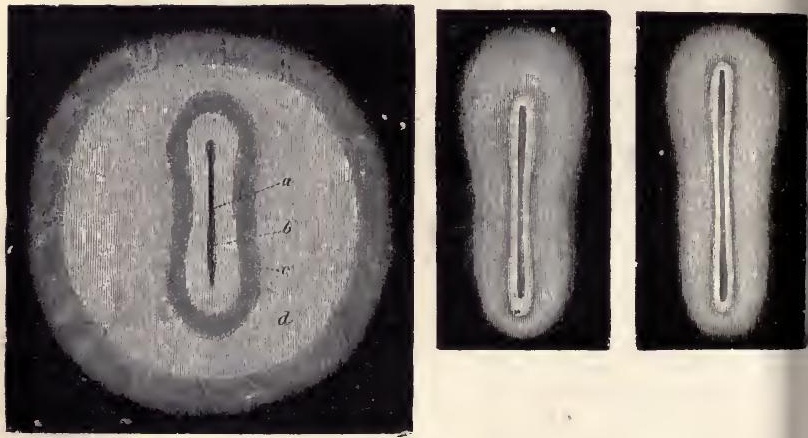

Fig. 85.-Germ-area or germ-lise of a labbit, with a sole-shaped germ. shield (about ten times enlarged). The light, circular tract $(d)$ is the dark area (a. opaca). The light area (a. pellucida) (c) is lyre-shaped, as is the germ-shield itself $(b)$. Along its axis the dorsal furrow or spinal furrow $(a)$ is seen. (After Bischoff.)

Fig. 86-Dole-shaped germ-shield of a Dog ("double shield" of Remak, "embryo-rudiment" of other anthors). In the centre is the dorsal furrow, on either side are the spinal swellings, or medullary swellings.

Fig. 37.-Sole-shaped germ-shield of Chick.

After the oval germ-shield has become distinctly defined, in the centre of the light germ-area, along its central line a delicate, white streak appears, which soon becomes pro- 
miment; this is the "primitive streak" of Baer, the "axial plate" of Remak. This phenomenon is due to the fact that the upper and middle germ-layers coalesce along their central lines, thus forming the axis-band at this point. (Cf. Fig. 88, 89.) In the centre of the primitive streak an even, dark line, the so-called primitive groove, becomes defined (Fig. 84, 85, a). This separates the germ-shield into two symmetrical halves, a right and a left half. While the primitive groove deepens, the oval germ-area (a. germinativa) resumes its earlier circular form.

The germ-shield, on the other hand, leaves its oval form and assumes the so-called lyre-shape, or sole-shape. Its elliptical leaf-shaped body becomes somewhat pinched in the middle, while its anterior and posterior ends become somewhat enlarged (Fig. 85). This very characteristic shape, which is most aptly compared to the sole of a shoe, a violin, or a lyre, is retained for some time by the embryo of the Mammal (Fig. 86, 87), and also by that of the Bird and the Reptile. The human germ-shield assumes this soleform as early as the second week of its development. Towards the end of that week its length is about two millimetres.

We will now leave the peripheric part of the germarea, for its changes are only interesting to us at a much later period, and we will give our whole attention to the sole-shaped germ-shield, from which the further evolution of the body directly proceeds. In order correctly to understand this, we must employ a method which was first turned to full account by Remak, viz, that of viewing seetions made from right to left perpendicularly through the thin disc of the germ-shield. It is only by very carefully 
studying these sections, one by one, in every stage of the evolution, that it is possible fully to understand the processes by which the exceedingly complex structure of the vertebrate body is developed from the simple leaf-shaped germ-shield.

If we now make a perpendicular section through the sole-shaped germ-shield (Fig. 86, 87), the first thing we notice is the difference between the three germ-layers, as they lie one over the other (Fig. 88). The germ-shield.consists, as it were, of three shoe-soles overlying each other. The undermost, or innermost, of these (the intestinal-glandular layer) is the thinnest stratum, and consists of a single layer of cells (Fig. $88 d$ ). The middle of these shoe-shaped bodies (the mesoderm) is considerably thicker and more or less evidently appears to be composed of two closely connected layers. The third and uppermost, or outermost sole-

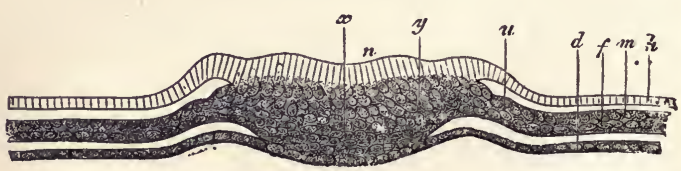

Fig. 88.-Transverse section throngh the germ-disc of a Chick (a few hours after the beginning of incubation): $h$, skin-sensory layer; $m$, skinfibrons layer; $f$, intestinal-fibrous layer (the two latter are united into the middle-layer, or mesoderm); $d$, intestinal-glandnlar layer. All the fonr secondary germ-layers have coalesced in the middle and from the thick axis-band $(x y)$; $n$, first trace of the primitive groove; $u$, region of the future primitive kidney rudiment. (After Waldeyer.)

shaped body (h), is the skin-sensory layer, and consists of smaller and lighter-coloured cells. In the middle of the transverse section, along a considerable part of the longi- 
tudinal axis of the sole, all three soles coalesce, and here form the thick axial band (Fig. 88, xy). This coalescence is very significant. It causes an exchange of cells between the primary germ-layers. These cells move, alter their position, and multiply, so that exoderm-cells penetrate among the entoderm-cells, and entoderm-cells among those of the exoderm. The middle layer, or mesoderm, therefore, contains cells from both of the two primary germ-layers. Even if Remak's explanation, according to which the mesoderm is originally split off from the entoderm, is correct, in consequence of the coalescence at the central point, exoderm cells may also afterwards make their way into the mesoderm. The fibrous layer indeed soon plainly shows that it is composed of two different strata; the outer, which, phylogenetically, must be referred to the skin-layer, and the inner, which must be referred to the intestinal layer. The outer is the rudiment of the skin-fibrous layer (Fig. $88, m, 89, m$ ); the inner becomes the intestinal-fibrous layer (Fig. $88, f, 89, f$ ). Soon after the coalescence of the germ-layers in the axial portion of the germ-shield has taken place, and the cells have been exchanged, the small rectilineal primitive groove (Fig. $89, n$ ) becomes visible in

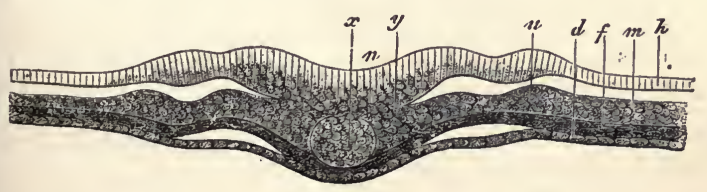

FIG. 89.-Transverse section throngh the germ-shield of a Chick (in a stage rather later than in Fig. 88). The letters indicate the same parts as in Fig. 88. In the middle of the axis-band $(y)$ the chorda dorsalis, or notochord, becomes defined (x). (After Waldeyer.) 
the central line of the outer surface. On each side of this, the dorsal swellings rise in the form of low ridges. In the centre of the lower side of the primitive groove a cylindrical band separates itself from the cell-mass of the thick axis-band; this, which in transverse section appears roundish, is the first rudiment of the notochord (chorda dorsalis, $x$ ). The four secondary layers separate more and more distinctly. The intestinal-fibrous layer $(f)$ appears as the product of the intestinal-glandular layer $(d)$, and distinct from the skin-fibrous layer $(m)$, which arises from the skin-sensory layer $(h)$.

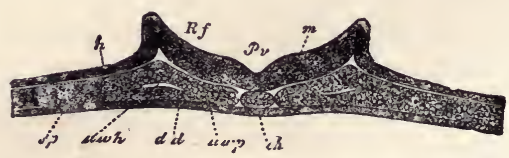

FIG. 90.-Transverse section through the germ-shield of an incubated Chick (about the end of the first day); about 100 times the natural size. The skin-sensory layer (the outer germ-layer) separates into two different parts : (1) the thinner, peripheric horn-plate $(h)$, from which the outer skin with its appendages arises; (2) the thicker, axial spinal plate $(m)$, which gives rise to the spinal tube (tubus medullaris); this originates from the dorsal furrow $(R f)$, the deepest part of which forms the primitive groove $(P v)$. The boundaries between the spinal plate $(m)$ and the horn-plate $(h)$ form the prominent, parallel dorsal swellings. The middle germ-layer, the componnd fibrous layer (the " motor-germinative "), is already distinguished into the notochord $(c h)$ and the two side-layers $(s p)$. The inner portion of these side-plates soon becomes defined as the primitive vertebral band $(u w p)$. The tiny fissure in the side-plates is the first rudiment of the future body-cavity $(u w h)$. The inner germ-layer (the intestinal-glandnlar layer) $(d d)$ is not yet modified. (After Kölliker.)

The primitive groove (Fig. $90 P v$ ) soon becomes considerably deeper and so fashioned as to constitute the bed of the broader spinal furrow (medullary or dorsal furrow) 
$(R f)$. On both sides of this rise the two parallel dorsal swellings, or spinal swellings $(m)$. At the same time the central notochord, or chorda dorsalis (Fig. $90 \mathrm{ch}$ ), separates entirely and definitely from the two lateral portions of the mesoderm. These we will henceforth regard as side-layers $(s p)$ in reference to the axial chord. They are usually called side-plates. In the middle of each of these sidelayers a horizontal fissure appears, where the upper or outer skin-fibrous layer separates from the lower or inner intestinalfibrous layer. This fissure (Fig. $90 u w h$ ) is very significant, for it represents the first rudiment of the future bodycavity (coloma). (Cf. Plate IV. Fig. 2, $c$ and 3, c.)

In speaking of these side-layers, which are usually called "side-plates," I would say a word or two about those figurative expressions "layers" and "plates," which have been universally employed since Baer's time. The "layers" (lamince), as well as the "plates" (lamelloe), are leaf-like or plate-shaped bodies originally consisting of a single homogeneous cellular stratum, or of several lying one above the other, and constituting the first basis of the organic systems and of the organs of the body. But the language of Ontogeny distinguishes considerably between a layer, or leaf (lamina), and a plate (lamella). The first and oldest cell-layers of the germ, which overspread the whole germ, and form the first basis of whole organ-systems, are layers, or leaves (lamince). On the other hand, the term plates (lamellas) is applied to separate portions of the layers, or leaves, and to the cellular strata produced from the latter, which only belong to a part of the germ and serve to form single organs of variable size.

Of course this distinction is by no means sharply 
drawn : thus, for instance, the two middle, secondary germlayers are usually called the skin-fibre plate and the intestinal-fibre plate (instead of layers, or leaves). Conversely, the horn-plate (which is a portion of the skin-sensory layer) is usually called the horn-layer, or leaf. As far as possible we shall, however, maintain this important distinction: we shall only use the term layers, or leaves, of the two primary, and the four secondary germ-layers; naturally, however, we must speak of the side-plates as side-layers, or leaves, as they first originate by a coalescence of the two primary germ-layers. On the other hand, we shall speak of the so-called horn-layer and of all the layer-like rudimentary organs, which are split off or differentiated from the four layers, or leaves, as plates; e.g. the muscle-plate. etc.

After the chorda has entirely separated from the two side-layers, a portion, in the shape of a long, thick cord, breaks off, in the posterior portion of the germ-shield, from the inner edge of each of the side-layers (Fig. 90, uwp, 91, u). We will call this the primitive vertebral plate, or better, the primitive vertebral cord, for it afterwards develops into

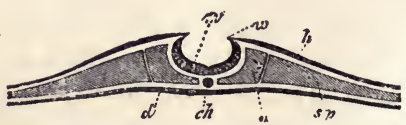

Fig. 91.-Transverse section through the germ-shield of a Chick (at the end of the first day), rather more developed than in Fig. 90; abont twenty times the natnral size. The two edges of the spinal plate $(m)$, which, as spinal swellings $(w)$, separate the latter plate from the horn-plate $(h)$, incline towards each other. On both sides of the notochord $(c h)$ the inner portion of the side-layers $(u)$ has separated itself as a primitive vertebral band fron the onter portion. The intestinal-glandular layer $(d)$ is not yet modified. (After Remak.) 
the primitive vertebræ and the neighbouring parts. It forms the first rudiment of the individual segments of the vertebral column, the primitive vertebræ. At a later period these primitive vertebræ become very closely connected with the chorda dorsalis which they surround, and this whole axismass then develops into the vertebral column, which is afterwards articulated in so many complex ways. The peripheral parts of the two side-layers, which remain after the separation of the primitive vertebral cord, are henceforth called the side-plates (lamelloc), the term being thus used in its restricted sense. They develop into the two fibrous layers, which have already been mentioned. In the anterior half of the germ-shield, representing the future head, there is no separation between the inner primitive vertebral mass and the outer side-layers.

During these processes, this intestinal-glandular layer, the inner germ-layer, remains quite unaltered; no separations are to be seen in it (Figs. 90, $d d, 91, d$ ). The changes, therefore, which take place at this period in the skin-sensory layer, the outer germ-layer, are all the more remarkable. The eontinuous elevation and growth of the dorsal swellings tends to make the upper, free margins of these prominent ridges incline towards each other, and as they continually approach each other (Fig. 91, w), they finally coalesce. Thus the open dorsal furrow, the separation at the top of which grows narrower and narrower, is transformed into a closed cylindrical tube (Fig. 92, $\mathrm{mr}$ ). This tube is of the greatest importance, for it is the first basis of the central nervous system-the brain and spinal cord. This rudiment is called the medullary tube (tubus medullaris). Formerly this fact was regarded with wonder as an inexplicable enigma, but VOL. J. 
the Theory of Descent explains it as but a perfectly natural process. It is quite natural that the central nervous system, the organ by which all intercourse with the outer world, all mental activities, and all sensory perception are aceomplished, should be developed by detachment from the outer skin (epidermis). At a later stage the medullary tube separates entirely from the outer germ-layer, is surrounded by the primitive vertebræ, and is forced inwards. . From this time, the remaining portion of the skin-sensory layer (Fig. $92, h$ ), is called the horn-plate or "horn-layer," because the

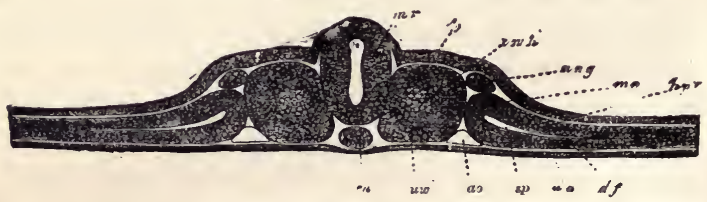

Fic. 92.-Transverse scetion through tho germ-shield of a Chick (second day of incubation); about 100 times the natural size. In the outer germ. layer, the axial dorsal furrow, having completely closed, forms the spinal tube $(m r)$, and has pinehed itself off from the horn.plate $(h)$. In the middle germ-layer, the axial notochord $(c h)$ is entirely separated from the primitive vertebral bands $(u w)$, in the interior of which a transitory cavity ( $u w h$ ) afterwards forms. The side-layers have split into the outer skin-fibrouslayer $(h p l)$ and the inner intestinal-fibrous layer ( $d f)$, the two boing still connected by the middle plates $(m p)$. The fissure $(s p)$ between the two is the first rudiment of the body-cavity (cocloma). In the gap between the primitive vertebral bands and the side-layers, on either side, is the primitive kidney $(u n g)$, and on the inside the primitive artery (ao). (After Kölliker.)

outer skin (epidermis), with its horny appendages-nails, hair, etc.-develops from it. (Cf. Plates IV. and V.)

At a very early period, in addition to the central nervous system another or wholly different organ is seen to arise from the outer skin; this is the primitive kidney, which 
accomplishes the excretory functions of the body, and secretes the urine of the embryo. The primitive kidney originally consists of an entirely simple, tubular, elongated passage, a straight duct situated on each side of the ventral aspect of the primitive vertebral cord, running from an anterior to a posterior direction (Fig. 92, ung). It apparently arises from the horn-plate, and at the side of the medullary tube (spinal tube), in the space between the primitive vertebral cord and the side-plates. Even while the medullary tube is separating from the horn-layer, the primitive kidney is visible in this gap. Some authors, however, hold that the first rudiment of the primitive kidney is not furnished by the skin-sensory layer, but by the skin-fibrous layer.

While the skin-sensory layer is thus splitting up into the horn-plate, the spinal tube, and the primitive kidneys, the mesoderm, or fibrous layer, also separates into three portions, viz.: (1) the notochord in the central line of the germshield (Fig. 92, ch); (2) the primitive vertebral bands on each side of the notochord ( $u v v$ ); and (3) the side-layers which separate from the exterior of primitive vertebral bands. These side-layers still show the original separation of the middle germ-layer into the outer skin-muscle layer (or skinfibrous layer, $h p l$ ), and the inner intestinal-muscle layer (or intestinal-fibrous layer, $d f$ ). The point of union of the two fibrous layers is called the middle plate, or mesenteryplate $(m p)$. The narrow fissure $(s p)$, or empty space which arises between the two fibrous layers, is the first rudiment of the body-cavity (coloma), the great visceral cavity, in which the heart, lungs, intestines, etc., are afterwards situated. In Mammals this is separated, at a later 
period, into two distinct cavities by the formation of the diaphragm ; these are the chest, or thoracic cavity, and the abdominal cavity. Immediately below the mesentery-plate, in the gap between the intestinal-glandular layer, the intestinal-fibrous layer, and the primitive vertebral bands, another organ appears at an early stage, in the form of a tube with a thin wall (Fig. 92, ao). This is the first rudiment of a large blood-vessel, the primitive artery, or aorta. It arises by fission from the intestinal-fibrous layer.

During these processes the inner germ-layer, the intestinal-glandular layer (Fig. 92, $d f$ ), remains quite unaltered, and it is only somewhat later that it begins to show a very shallow, channel-like depression along the central line of the germ-shield, immediately below the notochord. This is the intestinal channel, or intestinal furrow, and it already indicates the future destination of this germ-layer. For as the intestinal channel gradually deepens, and its lower edges bend towards one another, it assumes the form of a closed tube, the intestinal tube, precisely as the dorsal furrow became the spinal or medullary tube (Fig. 92). The intestinal-fibrous layer $(f)$, which lies on the intestinal-glandular layer $(d)$, naturally follows the curve of the latter. Thus from the time when it first begins to develop, the intestinal wall is composed of two strata, internally of the intestinal-glandular layer, externally of the intestinalfibrous layer.

The formation of the intestinal tube is so far similar to that of the spinal tube, that in both cases a rectilineal trench, or furrow, first appears along the central line of a flat germlayer. The edges of this furrow then incline towards each other, and by coalescence form a tube (Fig. 93). But the 
two processes are in reality quite different. For the spinal tube closes along throughout its entire length into a cylin-

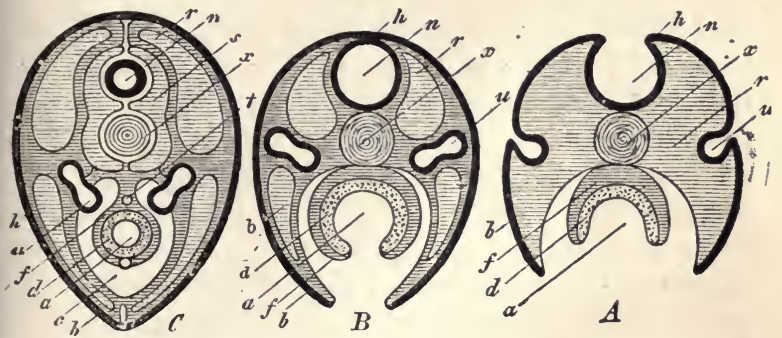

Fig. 93.-Three diagrammatic transrerse sections through the germshield of a higher Vertebrate, showing the origin of the tnbular rudimentary organs from the bent germ-layers. In Fig. $A$ the spinal tube $(n)$ and tho intestinal tnbe $(a)$ are still open trenches; the primitive kidneys $(u)$ are still simple skin-glands. In Fig. $B$ the spinal tube $(n)$ and the dorsal wall have already closed, while the intestinal tnbe $(a)$ and the ventral wall are still open; the primitive kidneys are pinched off. In Fig. $C$ both the spinal tube with the dorsal wall above, and the intestinal tube with the ventral wall below, are closed. All the open trenches have become closed tubes; the primitive kidneys have penetrated into the interior. In all three figures the letters indicate the same parts: $h$, skin-sensory layer; $n$, spinal tube, or medullary tnbe; $u$, primitive kidneys; $x$, notochord; 8 , vertebral rudiments; $r$, dorsal wall; $b$, ventral wall ; $c$, body-cavity (ccloma); $f$, intestinal-fibrons layer; $t$, primitive artery (acrta); $v$, primitive vein (intestinal vein); $d$, intestinal-glandular layer; $a$, intestinal tube. (Cf. Plates IV. and V.)

drical tube, while the intestinal tube remains open in the middle, and, till a much later stage, this cavity remains connected with the cavity of the intestinal germ-vesicle. The connection between these two cavities is closed only at a very late period, by the formation of the navel. The closing of the medullary tube proceeds from both sides, the right and left edges of the dorsal furrow coalescing. The 
closing of the intestinal tube, on the other hand, takes place not only from the right and left, but by a concrescence of the walls on all sides of the intestinal groove towards the navel, as a central point. Moreover, the whole process of the secondary formation of the intestine in the three higher classes of Vertebrates is most closely connected with the formation of the navel, with the "pinching in" of the embryo from the yelk-sac (navel-vesicle). (Cf. Fig. 70, p. 283, and Plate V. Figs. 14 and 15.)

In order to be quite clear about these points, it is necessary to bear in mind the relation of the germ-shield to the germ-area and to the intestinal germ-vesicle. This is best accomplished by comparing the five stages which are represented in longitudinal section in Fig. 94. The germ-shield $(e)$, which at first protruded only slightly from the surface of the germ-area, soon begins to raise itself from the latter, and to pinch itself off the intestinal germ-vesicle. During this the germ-shield, seen from the dorsal side, still retains its original simple sole-shape (Figs. 86,87, p. 298). There is as yet no appearance of any distinction into head, neck, trunk, or limbs. But the germ-shield has grown much thicker, especially in the anterior portion. It now, therefore, protrudes from the surface of the germ-area like a thick, much arched, oval swelling, and begins to separate and free itself completely from the intestinal germ-vesicle, to which it is attached by its ventral surface. The progress of this separation renders the back continually more curved; in proportion as the embryo grows and becomes larger, the germ-vesicle decreases and becomes smaller, till at last it hangs, in the form of a small bladder, from the abdomen of the embryo (Fig. 94, $5 d s$ ). In consequence of the processes of growth 
which effect this separation, a furrow-like depression is first formed round the embryo-body on the upper surface of the germ-vesicle, surrounding it like a trench; round the outside of this trench a circular wall, or dike, is formed by the elevation of the adjoining parts of the germ-vesicle (Fig. 94, ${ }_{2} k s$ ).

In order to get a clear and connected view of this important process, we may compare the embryo to a fortress surrounded by a moat and a wall. This moat, or trench, consists of the outer part of the germ-area, and ceases where the germ-area passes into the intestinal germvesicle. The important process of fission in the middle germ-layer which occasions the formation of the large body-cavity, extends over the whole germ-area along the periphery of the embryo. At first the extent of this middle germ-layer is co-extensive with that of the germarea; the whole remaining part of the intestinal germvesicle originally consisting only of the two original germlayers, the outer and the inner. Thus, over the extent of the germ-area, the middle germ-layer splits into the two layers which we knew as the outer skin-fibrous layer, and the inner intestinal-fibrous layer. These two layers separate widely, a clear fluid collecting between them (Fig. 94, ${ }_{3} \mathrm{am}$ ). The inner layer, the intestinal-fibrous layer, remains lying on the inner layer of the intestinal germvesicle (on the intestinal-glandular layer). The outer layer the skin-fibrous layer, on the contrary, attaches itself closely to the outer layer of the germ-area, to the skin-sensory layer, and the two together rise up from the intestinal germ-vesicle. From these two united outer layers, a connected membrane now arises. This is the circular wall, which continues to 

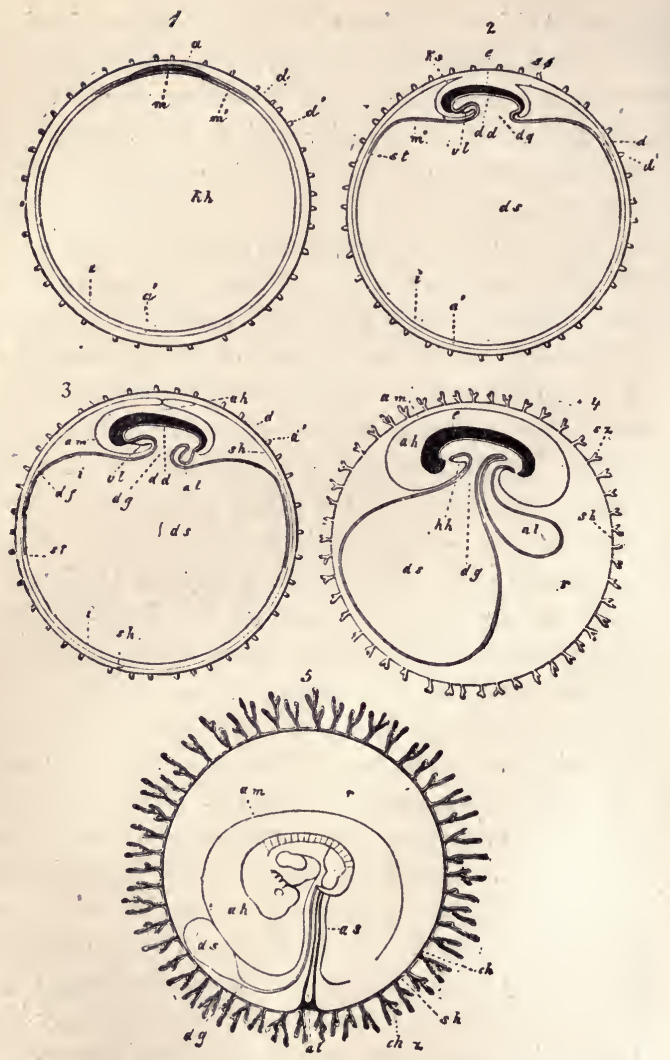

Frg. 94.-Five diagrammatic longitudinal sections through the maturing mammalian germ and its egg-membranes. In Fig. 1-4, the longitndinal section passes throngh the sagittal plane, or the central plane of the bods, 
which separates the right and left halves; in Fig. 5, the germ is seen from the left sido. In Fig. 1, the tufted $(d)$ chorion encloses the germ.vesicle, the wall of which consists of the two primary germ-layers. Between the outer $(a)$ and inner $(i)$ germ-layers, the middle germ-layer $(m)$ has developed, co-extensively with the germ-area. In Fig. 2, the embryo (e) is beginning to separate from the germ-vesicle $(d s)$, while the wall of the amnion-fold is developing round it (in front as the head-sheath, $k s$, in rear as tail-sheath, ss). In Fig. 3, the edges of the amnion.fold (am) meet above the back of the embryo and thus form the amnion-cavity $(a h)$; while the embryo (e) separates still more from the germ-resicle, the intestinal canal $(d d)$ is developed, and from the posterior end of this, the allantois (al) grows ont. In Fig. 4, the allantois $(a l)$ becomes larger; the yelk-sac $(d s)$ smaller. In Fig. 5, the embryo shows the gill-openings and the rudiments of the two pairs of limbs; the chorion has formed branching tufts. In all the five figures $e$ signifies embryo; $a$, outer germ.layer; $m$, middle germ-layer; $i_{\text {, }}$ inner germ-layer; $a m$, amnion ( $k s$, head-sheath; ss, tail-sheath); $a h$, amnion.cavity; as, amnion-sheath of the nmbilical cord; $k h=d s$, intestinal germ-vesicle; $d s$, yelk-sac (navel-vesicle); $d g$, yelk-duct; $d f$, intestinalfibrous layer; $d d$, intestinal-glandular layer; $a l$, allantois; $v l=h h$, region of the heart; $d$, yelk-membrane (prochorion); $d^{\prime}$, tufts on prochorion; $s h$, serons membrane; sz, tufts of the foregoing; ch, tufted membrane or ehorion; $r$, the space between the amnion and chorion, filled with fluid. (According to Kölliker.) Compare Table V. Fig. 14 and 15.

raise itself higher and higher around the entire embryo, and at last coalesces above it (Fig. 94, 2, 3, 4, 5, am). To keep up the simile of a fortress imagine that the surrounding wall of the fortress becomes extraordinarily high, and towers far above the fortress. Its edges arch like the crests of a jutting cliff which is about to enclose the fortress; they form a deep cavern, and at last grow together above. At last the fortress lies entirely within the cavern formed by the concrescence of the edges of this mighty wall. (Cf. Figs. 95-98, p. 319, and Plate V. Fig. 14.)

These two outer strata of the germ-area, rising in this way in the form of folds around the embryo and coalescing above it, at last form a spacious sac-like envelope around it. This envelope bears the name of germ-membrane, 
water-membrane, or amnion (Fig. 94, am). The embryo swims in a watery fluid, which fills the space between it and the amnion, and is called the amnion-water, or germwater (Fig. 94, $4,5 a h$ ). We shall return hereafter to the significance of this remarkable formation. It is of no interest to us at present, because it bears no direct relation to the formation of the body.

Among the various appendages, the significance of which we shall presently recognize, we will mention, in passing, the allantois and the yelk-sac. The allantois, or urinary sac (Fig. $94,{ }_{3}, 4 a l$ ), is a pear-shaped bladder, which grows out from the hindmost part of the intestinal canal: the innermost portion of it afterwards changes into the urinary bladder; the outer part, with its vessels, forms the foundation of the placenta. In front of the allantois, the yelk-sac, or navel vesicle (Fig. 94, $3,4 d s$ ), the remnant of the original intestinal germ-vesicle (Fig. $94,{ }_{1} k h$ ), protrudes from the open abdomen of the embryo (Fig. $94,{ }_{3}, 4 d s$ ). In a later stage of development of the embryo, in which the intestinal and ventral walls are nearly closed, this hangs out from the navel-opening in the form of a little stalked bladder (Fig. 94, 4,5 ) $d 8$. Its wall consists of two layers, the inner of which is the intestinal-glandular layer, the outer the intestinal-fibrous layer. It is, therefore, a direct continuation of the intestinal wall. In proportion as the embryo grows larger, this yelk-sac becomes smaller. At first the embryo looks merely like a small appendage on the large intestinal germ-vesicle. But, on the contrary, at a later period, the yelk-sac, or the remnant of the intestinal germ-vesicle, looks like a little purse-shaped appendage of the embryo (Fig. 70). Finally, it loses all importance. The 
very wide opening by which the intestinal cavity at first communicates with the navel bladder, afterwards grows continually narrower, and at last altogether disappears. The navel, the little pit-like depression which appears in the middle of the ventral wall of the developed Man, is the place at which the remains of the germinal vesicle, the navel bladder, once entered the intestinal cavity, and by which it was connected with the intestine in the course of its evolution. (Cf. Figs. 14 and 15 on Plate V.)

The formation of the navel takes place at the same time as the closing of the outer ventral wall. The ventral wall originates in exactly the same way as the dorsal wall; iboth are formed essentially from the skin-fibrous layer, and are eovered outwardly by the horn-plate, the peripheric part of the skin-sensory layer. Both are formed by the modification of the animal germ-layer into a double tube; above, at the back, the vertebral canal, which encloses the spinal tube,--below, at the abdomen, the wall of the bodyeavity, which encloses the intestinal tube (Fig. 93, p. 309).

We will first notice the formation of the dorsal wall, and then that of the ventral wall (Figs. 95-98). In the centre of the dorsal surface of the embryo the spinal tube $(m r)$ lies, originally immediately below the horn-plate $(h)$, from the central part of which it has separated. But, at a later period, the primitive vertebral plates (uw) grow from the right and the left so as to penetrate between these two originally connected parts (Figs. 97, 98). The upper inner edges of the two primitive vertebral plates wedge themselves in between the horn-plate and the spinal tube, press these two apart, and finally coalesee between them in a suture corresponding with the central line of 
the back. The closing is effected in exactly the same way as that of the spinal tube, which is now entirely enclosed by the vertebral canal. In this way the dorsal wall is formed, and the spinal tube lies quite in the interior (Fig. 98). In the same way the primitive vertebral mass grows lower down round the notochord (chorda dorsalis), there forming the vertebral column. In this lower part the inner under edge of the primitive vertebral plates on each side splits into two laminæ, the upper of which passes in between the notochord and the spinal tube, while the under, on the contrary, penetrates between the notochord and the intestinal tube. These two laminæ, by meeting from each side above and below the notochord, completely enclose the latter, and thus form the tubular outer notochord-sheath, the skeleton-forming layer, from which the vertebral column arises (Figs. 97, 98). (Cf. Figs. 3-6 on Plate IV., and the following chapter.)

Processes similar to these which take place above, on the back, during the formation of the dorsal wall, are observed below, on the abdomen, during the formation of the ventral wall (Fig. 98, $h h$ ). Here the side-plates grow together round the intestine in a similar way to that in which the intestine itself closed. The outer part of the side-plates forms the ventral wall, or the lower body-wall, while on the inner side of the amnion-fold, which has been mentioned, the two side-plates curve more and grow toward each other from right and left. While the intestinal canal is closing, the closing of the ventral wall is also taking place from all sides. Thus the ventral wall, which encloses the whole ventral cavity below, also originates from two halves, from the two side-plates, which incline toward each other; 
these grow toward each other from all sides, and at last unite in the navel at the centre. We must, therefore, distinguish between two navels, an inner and an outer. The inner or intestinal navel is the point at which the intestinal wall finally closes, at which the communication between the intestinal cavity and the cavity of the yelksac was cut off (Fig. 70). The outer or skin-navel is the point at which the ventral wall finally closes, and which even in adults is visible as a depression. In each concrescence two secondary germ-layers are concerned; at that of the intestinal wall, the intestinal-glandular layer and the intestinal-fibrous layer; at that of the ventral wall, the skinfibrous layer and the skin-sensory layer. The intestinal wall, as a whole, arises, therefore, from the entoderm, and the ventral wall (and, indeed, the entire body-wall) from the exoderm. ${ }^{95}$

The processes by which the double tubular rudiment of the body originates from the four-layered germ-dise are, therefore, really very simple. They are not, however, at once easily understood, nor is it easy to describe them. Very much, doubtless, yet remains obscure to the reader,

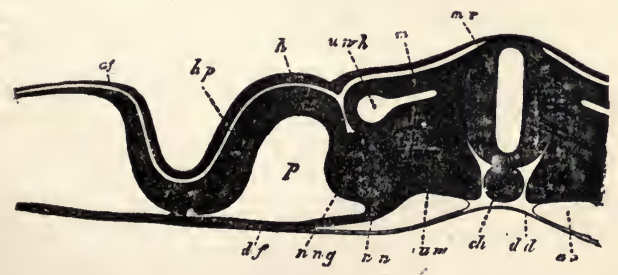

Fig. 95, 


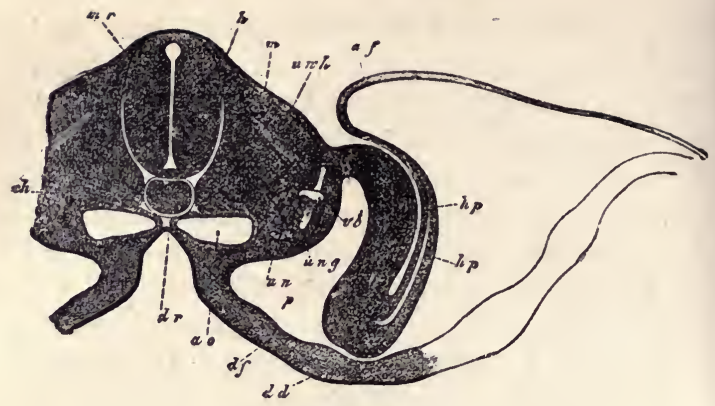

ㅍig. 96.

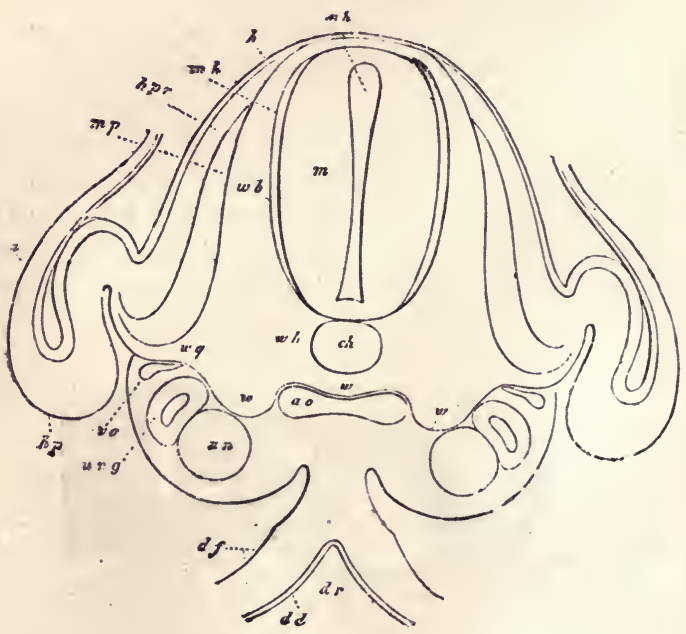

Fig. 9\%. 


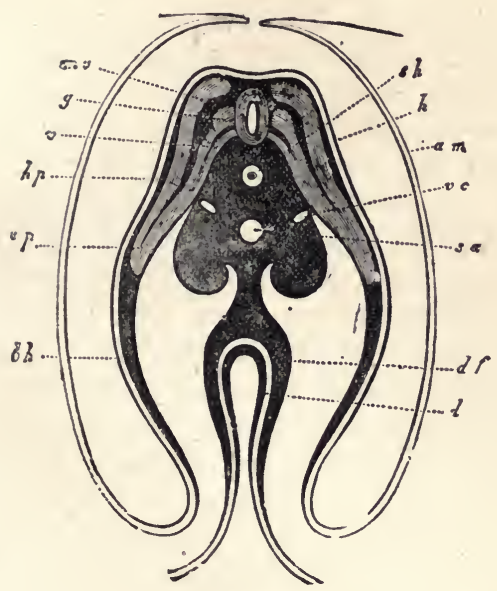

Fig. 98.

Figs. 95-98.-Transverse sections through embryo Chick: Fig. 95, the second day of incubation; Fig. 96, the third; Fig. 97, the fourth; and Fig. 98, the fifth. Figures 95-97 are after Kölliker (magnified abont 100 times); Fig. 98, after Remak (magnified about 20 times).

$h$, horn-plate; $m r$, spinal tube; $u n g$, primitive kidney duct; $u n$, primitivo kidney vesicle; $h p$, skin-fibrons layer; $m=m u=m p$, muscleplate; $u w$, primitive vertebral plate $(w h$, membranons formation of the vertebral body; $w b$, of the vertebral arch; $w q$, of the rib, or transverse apophysis); uwh, primitive vertebral cavity; ch, spinal axis, or notochord; $s h$, notochord-sheath; $b h$, ventral wall; $g$, posterior; $v$, anterior nerre roots of the spinal marrow; $a=a f=a m$, amnion-fold; $p$, bodycavity, or cœlom; $d f$, intestinal-fibrous layer; $a 0$, primitive aortas; $s a$, secondary aorta; $v c$, principal veins; $d=d d$, intestinal-glandular layer; $d r$, intestinal groore. In Fig. 95, the greater part of the right half of the cross-section is omitted, and in Fig. 96 the greater part of the left half. Only a small part of the wall of the yelk-sac, the remnant of the germvesicle, which lies below, is shown.

especially to those who are not at all familiar with the 
anatomical features. If, however, the subsequent stages of development, which throw light on their predecessors, are accurately noted, and especially, if the transverse sections in the preceding figures and in Plate IV., representing the complete vertebrate body and its germ, are carefully compared, the reader will probably obtain a clear conception of the main features of mammalian Ontogeny. A close and thoughtful comparison of the transverse sections is of the greatest importance in this respect.

It is true, however, that a deeper, phylogenetic knowledge of these complex processes can only be gained with the aid of Comparative Anatomy and Ontogeny. These teach us that the ontogenetic process which we have described as resulting in the formation of the Vertebrate must be explained as kenogenetic, and that, in consequence of continual embryonic adaptation, these processes have departed very widely from the original palingenetic form. The Amphioxus alone of all living Vertebrates has, in consequence of tenacious heredity, approximately retained the palingenetic form. ${ }^{96}$ (Cf. Chapters XIII. and XIV.)

As yet we have paid no attention to the various sections which are distinguishable in the length of the body: the head, neck, breast, abdomen, tail, etc. The transverse sections do not help us in this respect, and we must, therefore, closely observe the articulation in the longitudinal axis of the mammalian body. 


$$
\text { . }
$$


TR.INGERE SECHIONS.

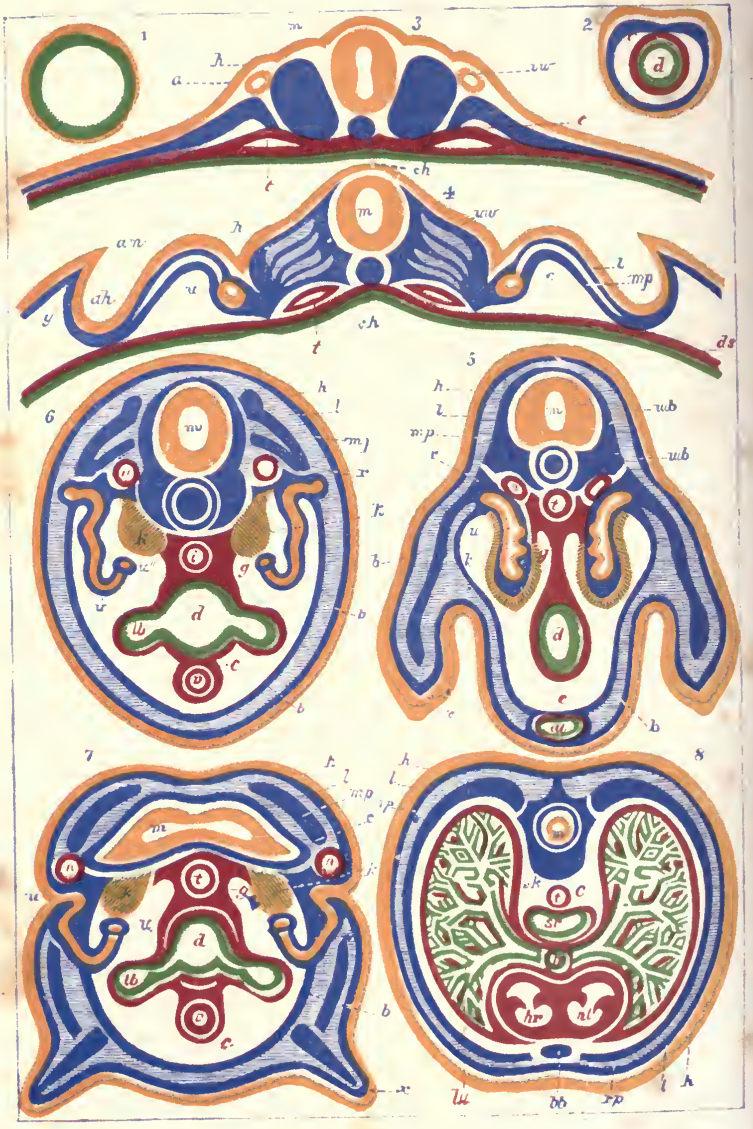




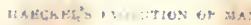

LONGITUDINAL, SECTIONS.

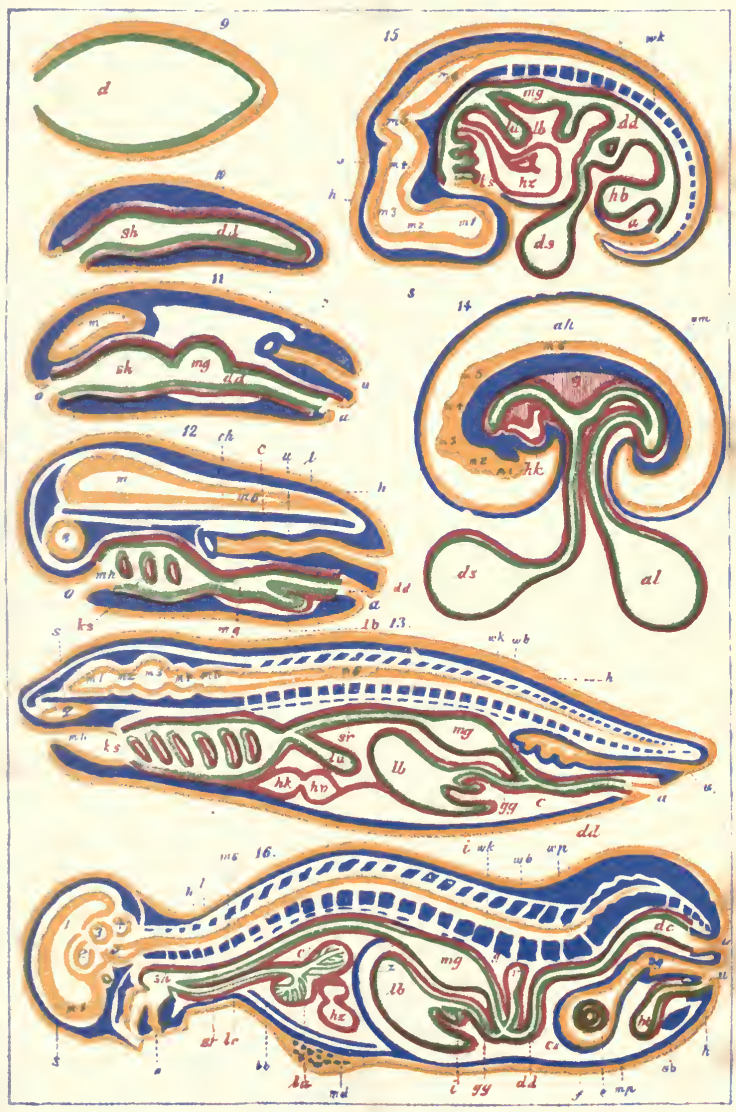





\section{EXPLANATION OF PLATES IV. AND V.}

The two Plates IV. and V. exhibit, partly ontogenetically and partly phylogenetically, the mode in which the human body arises from the germlayers. Plate IV. contains only diagrammatic transverse sections (through the sagittal and transverse axes); Plate V.contains only diagrammatic longitndinal sections (throngh the sagittal and longitndinal axes), seen from the left side. The four secondary germ-layers and their products are distinguished throughont by the same four colours, namely: (1) the skin-sensory layer is orange; (2) the skin-fibrous layer, blue; (3) the intestinal-fibrons layer, red; and (4) the intestinal-glandular layer, green. In all, the letters indicate the same parts. In Fig. 1 and 9 alone the two primary germlayers are represented-the outer, or skin-layer, orange; the inner, or intestinal layer, green. In all the figures the dorsal surface of the body is uppermost, the ventral surface underneath. All organs proceeding from the skin-layer are marked with blue letters; all those proceeding from the intestinal layer, with red letters. ${ }^{97}$

\section{Plate IV.-Diagrammatic Traxsverse Sectoos.}

Fig. 1.-Transverse section through the Gastrula. (Compare Fig. 9, longitudinal section, and Figs. 22-28, p. 193.) The whole body is formed by the intestinal-tube $(d)$; the wall of this consists solely of the two primary germ-layers.

Fig. 2.-Transverse section through the larva of the Amphioxus, in that early stage in which the body consists merely of the four secondary germlayers. The intestinal tube $(d)$, formed of the intestinal layer, is separated from the body-wall by the cœlom (c), which is formed of the skin-layer.

Fig. 3.-Transverse section through the germ-disc of a higher Vertebrate, with the rudiments of the earliest organs. (Compare the transverse section of the embryo Chick at the second day of incubation, Fig. 92.) The spinal tube $(m)$ and the primitive kidneys $(u)$ are separated from the horn-plate $(h)$. On both sides of the notochord $(c h)$ the primitive vertebræ $(u v)$ and the side-layers are differentiated. Between the skin-fibrous layer and the intes-

VOL. I. 
tinal-fibrous layer, the first rudiment of the body-cavity, or the coelom (c), is visible; under it are the two primitive aortas $(t)$.

Frg. 4.-Transverse section throngh the germ-disc of a higher Vertebrate, somewhat further developed than in Fig. 3. (Compare the transverse section of the embryo Chick at the third day of incubation, Fig. 95 and 96 , p. 317.) The spinal tube $(m)$ and the notochord $(c h)$ are already beginning to be enclosed by the primitive vertebræ $(u w)$, in which the muscle-plates, bone-plates, and nerve-roots are becoming distinct. The primitive kidneys $(u)$ are already completely separated from the horn-plate $(h)$ by the leatherplate $(l) ; c$, the cœlom; $t$, the aortas. The skin-layer, rising around the embryo, forms the amnion-fold $(\mathrm{am})$; this gives rise to a hollow space $(g)$ between the amnion-fold and the wall of the yelk-sac $(d s)$.

Fig. 5. - Transverse section throngh the pelvio region and the postarior limbs of the embryo of a higher Vertebrate. (Compare the transverse section through Chick at the fifth day of incubation, Fig. 120.) The spinal tube $(m)$ is already entirely enclosed by the two curving halves of the vertebræ $(w b)$, and similarly the notochord and its sheath by the two halves of the vertebral body $(w k)$. The leather-plate $(l)$ has entirely separated from the muscle-plate $(m p)$. The horn-plate $(h)$ has thickened very much at the head of the posterior limbs $(x)$. The primitive kidneys $(u)$ are prominent in the coelom $(c)$, and lie very near the germ-epithelinm, or the radimentary sexnal glands $(k)$. The intestinal tube $(d)$ is attached to the dorsal surface of the body by the mesentery $(g)$, beneath the main artery $(t)$, and the two principal veins $(n)$. Below, in the centre of the ventral wall, the stalk of the allantois $(a l)$ is visible.

Fig. 6.-Transverse section throngh a developed Primitive Fish, or some other Vertebrate of a low order. The parts, on the whole, bear the same relation to each other as in the preceding transverse seotion, Fig. 5, and are marked in the same way. But the sexual glands $(k)$ have developed into ovaries, and the primitive kidneys are transferred into oviducts, which open into the coelom. The two side protuberances $(l b)$ of the intestinal tube $(d)$ indicate the intestinal glands, for example, the liver. Below the intestinal tube, in the intestinal wall, lies the intestinal vein $(v)$; above the intestinal trbe lies the aorta $(t)$, and above this, again, the two principal veins $(n)$.

Fig. 7.-Transverse section through one of the higher Worms (through the head of an Annelid), showing its essential agreement with the Vertebrates in the construction of the body from the four secondary germ. layers. It should be carefnlly compared with the diagrammatic transverse section through the low Vertebrate, Fig. 6: $m$, the "brain," or " apper throat ganglion." The leather-plate $(l)$ and the mnscle-plate, which lies below the former, have differentiated from the skin-fibrous layer. The muscle-layer has separated into an outer circular muscle-stratnm and a long inner stratnm, and the muscle of the latter has distributed itself into dorsal mascles $(r)$ and ventral muscles $(b)$. The two are scparated by the primitive kidneys $(u)$, 
which extend from the horn-plate $(h)$ to the coelom $(c)$. Here the primitive kidneys have a funnel-shaped opening, through which they carry out the ovules, which fall from the ovaries $(k)$ into the cœlom. The intestinal tube (d) has glands on its surface (liver-vesicles, $l b$ ). Below it lies the ventral vessel (the intestinal rein, $v$ ), above it the dorsal vessel (the aorta, $t$ ). The position and origin of all these primitive organs is entirely the same in Man and every other Vertebrate, as in the Worms. The only essential difference is that in the Vertebrates a notochord is developed between the spinal tube and the intestinal tube.

FIG. 8. - Transverse section through the hnman thorax. The spinal tnbe $(m)$ is entirely enclosed by the developed circular vertebræ $(w)$. A curved rib proceeds right and left from the vertebra, supporting the wall of the breast $(r p)$. Below, on the ventral surface, between the right and left rib, lies the breast-bone, or sternum (bb). Without, above the ribs, and the muscles between the ribs, lies the outer skin, formed from the leather-plate $(l)$ and the horn-plate $(h)$. The greater part of the breast-cavity (or the anterior part of the cœlom, $c$ ) is occupied by the two lungs $(l u)$, in which the branches of the trachea ramify like a tree. These all open together into the unequal branches of the trachea $(l r)$, which opens further up at the neck into the osophagus $(8 r)$. Between the intestinal tube and the vertebral column, lies the aorta $(t)$. Between the trachea and the sternum lies the heart divided by a partition wall into two halves. The left heart $(h l)$ contains only arterial, the right $(h r)$ only venous blood. Each half of the heart is divided by a valved opening into an auricle and a ventricle. The heart is here represented diagrammatically in its (phylogenetic) original symmetrical position (in the centre of the ventral side). In the developed human being, and in apes, the heart lies in an unsymmetrical and oblique position, inclined to the left.

\section{Plate V.-Dingrammatic Longitudinal Sections.}

Fic. 9.-Longitudinal section through a Gastrula. (Compare Fig. 1, transverse section.) The intestinal cavity $(d)$ opens in front throngh the mouth $(0)$. The body consists merely of the two primary germ-layers.

Frg. 10.-Longitudinal section through an hypothetical Primitive Worm (Prothelmis), the entire body of which consists of the four secondary germ. layers. The intestinal tube $(d)$ is still very simple; but the anterior and posterior intestines begin to grow distinct. The mouth $(0)$ is still the anus also.

Fig. 11.-Longitudinal section through a low Colomate Worm. The primitive brain $(m)$, or the first nerve-centre overlying the throat, has separated from the horn-plate $(h)$. The intestinal tube has acquired a second posterior anal opening $(a)$ in addition to the mouth-opening $(a)$ in front. A skingland has developed into primitive kidneys $(u)$ and opens into the body- 
cavity (c), which has formed between the skin-fibrons layer and the intestinal-fibrous layer.

FIG. 12.-Longitndinal section throngh an hypothetical Worm (Chordoninm), which was among the common parent-forms of Vertebrates and Ascidians. The primitive brain $(m)$ has lengthened into an elongated spinal tabe. Between this spinal tube and the intestinal tube $(d)$, the notochord (ch) has developed. The intestinal tube has differentiated into two divisions, an anterior gill-intestine (with three pairs of gill-openings, $k s$ ) which scrves for breathing, and a posterior stomach-intestine (with a liverappendage, $l b)$ which serves for digestion. In front, at the head-extremity, an organ of scnse $(q)$ has developed. The primitive kidncy $(u)$ opens into the body-cavity $(c)$.

Fra. 13.-Longitndinal section through a Primitive Fish (Proselachius), closely related to the existing Sharks, and hypothetical ancestors of Man (the fins are omitted). The spinal tube has differentiated into the five primitive brain-bladders $\left(m_{1}-m_{5}\right)$ and the spinal marrow $\left(m_{0}\right)$. (Comparo Figs. 15 and 16.) The brain is cnclosed in the skull (8), the spinal marrowin the vertebral canal (above the spinal marrow, the vertebral arches $(w b)$; nnder it the vertebral bodies $(w k)$; under the latter the origin of the ribs is indicated). In front an organ of sense ( $q$, nose or eye) has developed from the horn-layer, - at the back, the primitive kidney $(u)$. The intestinal tube (d) has differentiated into the following parts, lying one behind another: the month-cavity $(\mathrm{mh})$, the throat-cavity with six pairs of gill-openings $(k s)$, the swimming-bladder (=lungs, $l u$ ), the cesophagus $(8 r)$, the stomach $(m g)$, the liver $(l b)$ with the gall-bladder $(i)$, the smak intestine $(d d)$, and the rectum with the anns (a). Below the throat-cavity lies the heart, with the auricle $(h v)$ and the ventricle $(h k)$.

Fig. 14.-Longitudinal section throngh a human embryo of three weeks, showing tine relation of the intestinal tube to its appendages. In the centre the long-stalked yelk-sac (or the navel-vesicle, $d s$ ) projects from the intestinal tube $(d s)$; similarly the long-stalked allautois (al) projects from the intestine at the back. The heart $(h z)$ is visible beneath the anterior intestine. Amnion-cavity (ah).

FIG. 15.-Longitndinal section throngh a human embryo of five weeks. (Compare Fig. 14.) The amnion and the placenta, with the urachns, are omitted. The spinal tube has differentiated into the five primitive brain-bladders $\left(m_{1}-m_{s}\right)$, and the spinal marrow $\left(m_{0}\right)$. (Compare Figs. 13 and 16.) The skull $(s)$ is formed around the brain; below the spinal marrow the series of vertebral bodies $(w k)$. The intestinal tube has differentiated into the following divisions, lying one behind another: the throat-cavity with three pairs of gill-openings $(k s)$, the lnng $(l u)$, the cesophagus $(s r)$, the stomach $(m g)$, the liver $(l b)$, the coil of the small intestine $(d d)$, into which the yelk-sac $(d s)$ opens, the urinary bladder $(h b)$, and tre rectum. Heart $(h z)$.

FIG. 16.-Longitndinal section through developed human fcmale. All 
the parts are perfectly developed, but diagrammatically reduced and sim plified, in order to exhibit clearly their relative positions and their relations to the four secondary germ-layers. In the brain, the five original brainbladders (Fig. 15, $m_{1}-m_{5}$ ) have been differentiated and transformed in the manner peculiar to the higher mammals: $m_{1}$, fore brain (cerebrum), ontweighing and covering all the other four brain bladders; $m_{2}$, twixt brain (" the centre of sight "); $m_{3}$, mid brain ("the four bulbs"); $m_{4}$, hind brain (cerebellum); $m_{s}$, after brain, or prolonged marrow (medulla oblongata), passing into the spinal marrow $\left(m_{0}\right)$. The brain is enclosed in the sknll (8), the spinal marrow by the vertebral canal: above the spinal marrow the vertebral arches and spinal processes, under it the vertebral bodies $(w k)$. The intestinal tnbe has differentiated into the following parts lying one behind another: the mouth-cavity, the throat-cavity (in which at an earlier period the gill-openings, $k 8$, were sitnated), the trachea $(l r)$ with the lungs $(l u)$, the cosophagus $(8 r)$, the stomach $(m g)$, the liver $(l b)$, with the gall-bladder $(i)$, the ventral salivary gland, or pancreas $(p)$, the small intestine $(d d)$, the large intestine $(d c)$, and the rectnm with the anus $(a)$. The body-cavity, or coolom $(c)$, is divided by the diaphragm $(z)$ into two distinct cavities; the breast-cavity $(c)$, in which the heart $(h z)$ lies in front of the lungs, and the ventral cavity in which most of the intestines lie. In front of the rectnm lies the sheath (vagina, $v g$ ), which leads into the nterns $(f)$; in this the embryo, indicated here by a small germ-membrane vesicle (e), is developed. Between the uteras and the os pubis lies the vesica urince $(h b)$, the remains of the stalk of the allantois. The horn-plate $(h)$ as the onter skin, covers the whole body, and also forms the coating of the cavities of the mouth, the anus, the vagina, and the uterus. The milk glands, or n:amme $(m i d)$, are also originally formed from the horn-plate. 


\section{ALPHABETICAL LIST \\ Of the Meaning of the Letters in Plates IV. and $V$.}

N.B.-The skin-sensory lajer is indicated by orange, the skin-fibrous layer by blue, the intestinal-fibrons layer by red, and the intestinal-glandular layer by green.

$a$, anal opening

$a h$, amnion-cavity

$a l$, allantois (urine sac)

am, amnion

$b$, ventral muscles

$b b$, breast-bone (sternum)

c, body-cavity (cceloma)

$c$, breast-cavity (cavitas pleurce)

$c_{\mu}$, ventral cavity (cavitas peritonei)

$c h$, notochord (chorda)

$d$, intestinal tube (tractus)

$d c$, large intestine (colon)

$d d$, small intestine (ileum)

$d s$, yelk-sac (navel-vesicle)

$e$ embryo or germ

$f$, matrix (uterus)

$g$, mesentery (mesenterium)

$h$, horn-plate (ceratina)

$h b$, urinary vesicle (vesica urince)

$h k$, ventricle of heart

$h l$, left (arterial) heart

$h r$, right (venons) heart

$h v$, auricle (atrium)

$h z$, heart (cor)

$i$, gall-bladder (vesica fellea)

$k$, germ-glands (sexual glands)

$k s$, gill-openings (throat-openings)

$l$, leather-plate (corium)

$\imath b$, liver (hepar)

$\imath r$, windpipe (trachea)

$l u$, lung (pulmo)

in, medullary tube (tubus medullaris) $m_{1}-m_{5}$, the five brain-bladders

$m_{1}$, fore-brain

$m_{2}$, twixt.brain

$m_{3}$, mid-brain

$m_{4}$, hind-brain

$m_{5}$, after-brain

$m_{e}$, spinal cord (medulla spinalis)

$m d$, milk-glands (mammos)

$m g$, stomach

$m h$, mouth-cavity

$m p$, muscle-plate (muscularis)

$n$, principal veins

$o$, month-opening (osculum)

$p$, ventral salivary gland (pancreas)

$q$, organ of sense

$r$, muscles of the back

$r p$, ribs (costce)

$s$, skull (cranium)

$s b$, os pubis

$s h$, throat-cavity (pharynx)

$s r$, gullet (cesophagus)

$t$, aorta (main artery)

$u$, primitive kidney (protonephron)

$u w$, embryonic vertebra (metameron)

$v$, intestinal vein (primitive vein)

$v g$, vagina

$w$, vertebra

$w b$, vertebral arches

$w k$, vertebral bodies

$x$, legs, or limbs

$y$, space between the amnion and the yelk-sac

$z$, midriff (diaphragma) 


\section{$327)$ \\ 1 TABLE VII.}

Systematic Survey of the Development of the Organic Systems of Man from the Germ-layers. (Cf. Plates IV. and V.)

\begin{tabular}{|c|c|c|c|}
\hline $\begin{array}{c}\text { A. } \\
\text { Outer Primary } \\
\text { Germ-layer. } \\
\text { Skin-layer. } \\
\text { (Animal } \\
\text { Germ-layer, } \\
\text { Baer.) }\end{array}$ & $\begin{array}{c}a . \\
\text { First } \\
\text { secondary } \\
\text { germ-layer. } \\
\text { Skin-sensory } \\
\text { layer. } \\
\text { (Skin-stratum, } \\
\text { Baer.) } \\
\text { Lamina } \\
\text { neurodermalis, } \\
\boldsymbol{H} .\end{array}$ & $\begin{array}{c}\text { I. } \\
\text { Horn-plate. } \\
\text { Lamella ceratina. } \\
\text { II. } \\
\text { Marrow-plate. } \\
\text { Iamella medullaris. } \\
\text { III. } \\
\text { Primitive kidney } \\
\text { plate. } \\
\text { Lamella renalis. }\end{array}$ & $\begin{array}{l}\left\{\begin{array}{l}\text { 1. Onter-skin (epidermis). } \\
\text { 2. Appendsges of the epi- } \\
\text { dermis (hair, nails, etc.). } \\
\text { 3. Glands of the epidermis } \\
\text { (perspiratory, sebaceous, } \\
\text { lacteal glands). }\end{array}\right. \\
\left\{\begin{array}{l}\text { 4. Spinal marrow }\}^{\text {medullsry }} \text { tube. } \\
\text { 5. Brain } \\
\text { 6. Organs of the senses (es- } \\
\text { sential part). }\end{array}\right. \\
\left\{\begin{array}{l}\text { 7. Primitive kidneys (?) and } \\
\text { the outlets, which arise } \\
\text { from them for the sexusl } \\
\text { products (perhaps from } \\
\text { the skin-fibrons layer??) }\end{array}\right.\end{array}$ \\
\hline $\begin{array}{c}\text { Exoderma. } \\
\text { Lamina } \\
\text { dermalis, } I .\end{array}$ & $\begin{array}{c}\text { b. } \\
\text { Second } \\
\text { secondary } \\
\text { germ-layer. } \\
\text { Skin-fibrous } \\
\text { layer } \\
\text { (Flesh-stratum, } \\
\text { Baer.) } \\
\text { Lamina } \\
\text { inodermalis, } H .\end{array}$ & $\begin{array}{l}\text { IV. } \\
\text { Leather-plate. } \\
\text { Lamella coriaria. }\end{array}$ & $\begin{array}{l}\left\{\begin{array}{c}\text { 8. True skin (corium) and } \\
\text { skin-muscle stratum? }\end{array}\right. \\
\text { 9. Trunk- muscle stratum } \\
\text { (side muscles of the } \\
\text { trunk, etc.). } \\
\text { 10. Inner skeleton (chord, ver- } \\
\text { tebral column, etc.) } \\
\text { 11. Exocolsr?(parietal colom- } \\
\text { epithelium) } \\
\text { 12. Male germ-epithelium (ru- } \\
\text { dimentary testes)?? }\end{array}$ \\
\hline
\end{tabular}

Body-Cavity (Coeloma): A space between the skin-layer and the intestinal layer, between the body-wall and the intestinal wall, filled with lymph (colourless blood).

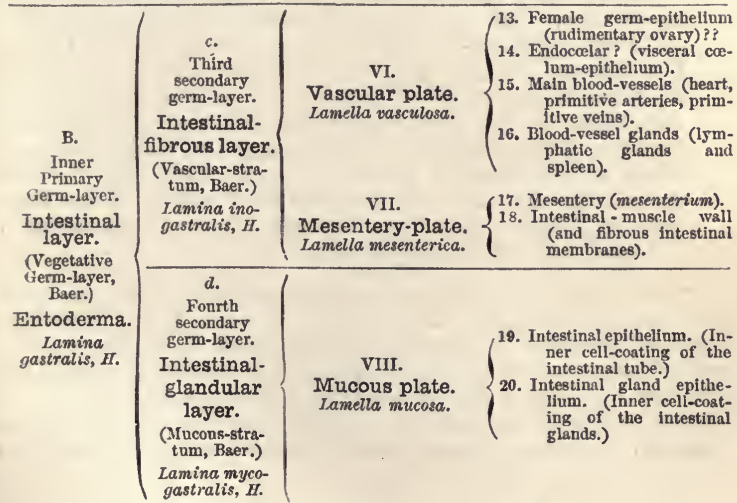




\section{CHAPTER XI.}

\section{GENERAL STRUCTURE AND ARTICULATION OF THE INDIVIDUAL.}

Essential Agreement between the Chief Palingenetic Germ Processes in the case of Man and in that of other Vertebrates.-The Human Body, like that of all Higher Animals, develops from Two Primary and Four Secondary Germ-layers. - The Skin-sensory Layer forms the Horn-plate, the Medullary Tube, and the Primitive Kidneys.-The Middle Layer (Mesoderm) breaks up into the Central Notochord, the Two Primitive Vertebral Cords, and the Two Side-layers.-The latter split up into the Skin-fibrous Layer and the Intestinal-fibrons Layer.-The Intestinalglandnlar Layer forms the Epithelium of the Intestinal Canal, and of all its Appendages.-Ontogenetic and Phylogenetic Fission of the Germ-layers.-Formation of the Intestinal Canal.-The Two-layered Globular Intestinal Germ-vesicle of Mammals represents the Primitive Intestine.-Head Intestinal Cavity, and Pelvic Intestinal Cavity.Month Groove and Anal Groove.-Secondary Formation of Mouth and Anus.-Intestinal Navel and Skin-navel.-Movement of the Primitive Kidneys from the Outside to the Inside.-Separation of the Brain and Spinal Marrow.-Rndiments of the Brain-bladders.-The Articnlation or Metameric Structure of the Body.-The Primitive Vertebræ (Trunk-Segments, or Metamera).-The Construction and Origin of the Vertebral Colnmn.-Vertebral Bodies and Vertebral Arches.-Skeleton-plate and Mnscle-plate--Formation of the Skull from the Head-plates.-Gill-openings and Gill-arches.-Sense-organs. -Limbs.-The Two Front Limbs and the Two Hind Limbs.

"The occurrence of an internal skeleton in definite local relations to the other organ-systems, and the articulation of the body into homologous segments, are points in the general organization of Vertebrates to which especial weight must be giren. This metameric structure is more or less definitely expressed in most of the organs, and as it extends to the axial skeleton, the latter also gradually articulates into separate segments, the vertebræ. The latter, however, must be regarded only as the partial ex- 
pression of a general articulation of the body, which is all the more important in consequence of its appearing prior to the articulation of the originally inarticulate axial skeleton. Hence this general articulation may be considered as a primitive vertebral structure, to which the articnlation of the axial skeleton is related as a secondary process of the same sort."Kari Gegenbaur (1870).

THE most important processes, which we have just noticed in the construction of the body from the germ-layers, are essentially similar in all Vertebrates. In these points Man entirely resembles the other Mammals; nor do the latter essentially differ from other Vertebrates. It is true that a more exact study of germ-history brings various differences to light, some of which are very striking: among these may be mentioned the formation of a large yelk-sac in most Fishes, in all Reptiles, Birds, and Mammals; also the formation of the amnion and allantois in the three higher vertebrate classes. But all these remarkable structural conditions, which react on the diversified development of other parts, were only kenogenetically acquired at a later stage, in consequence of Adaptation to the conditions of egg-life ; on the contrary, the most important conditions of the original body-structure, which must be regarded as palingenetic, as transmitted by Heredity from the common parent-form of all Vertebrates, are, on the whole and in the main, everywhere the same.

As such essential main acts in the germ-history of all Vertebrates, the following must be especially noted:-1. The formation of a Gastrula (in the most original form in the Amphioxus, in a form which is modified from the latter in all other Vertebrates). 2. The fission of the four primary germ-layers into four secondary germ-layers (often with a three-layered stage intermediate between the two 
and the four-layered stages). 3. The axial soldering, or the coalescence of the germ-layers along the longitudinal axis (giving rise to the axis-band). 4. The early separation of the medullary tube from the skin-sensory layer. (by the formation of the dorsal furrow and the spinal swellings). 5. The early origin of the primitive kidney ducts (probably from the skin-sensory layer). 6. The early division of the skin-fibrous layer into the chorda, the primitive vertebral cords, and the trunk-muscle plates. 7 . The separation of the skin-fibrous layer from the intestinalfibrous layer (giving rise to the body-cavity, or coloma). 8. The rudimentary primitive vessels, or aortæ (from the intestinal-fibrous layer). These important germ-processes result in the formation of ten different parts of the body, which we may call "the primitive organs," and which, in the following list, are represented in their relation to the germ-layers. (Cf. Fig. 99, and Plate IV. Fig. 3.)

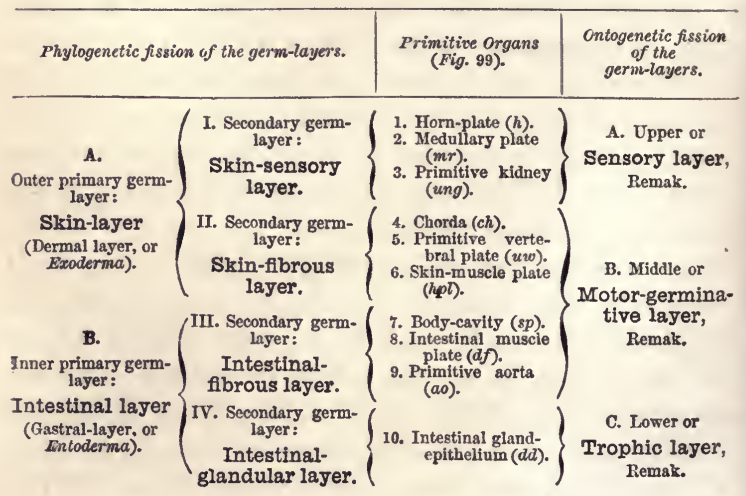


In the important transverse section through the germshield of a Chick (Fig. 99), which represents these primitive organs in their original relative positions, they are seen to be flattened and spread out; and they are found in this same condition in a corresponding transverse section through the germ-shield of a Mammal. In order rightly to appreciate these instructive sections (with which Figs. 3 and 4 on Plate IV. should be compared), it must be remembered that the layer-like extension of the flat germ-layers over the surface of the large yelk-sac represents a derived, kenogenetic condition, which has arisen in consequence of the gradual acquisition of a large nutritive yelk. In those low Vertebrates in which there is no such yelk-sac, and in which the original, palingenetic condition is more or less

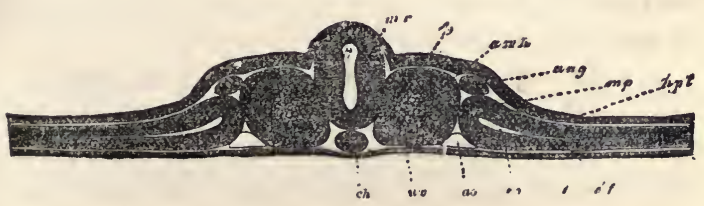

Fig. 99.-Transverse section through the germ-shield of a Chick (on the second day of incubation, about 100 times enlarged). In the outer germ. layer the axial dorsal furrow has completely closed and forms the medullary tube $(m r)$, which has separated itself from the horn-plate $(h)$. In the middle germ-layer the axial notochord $(c h)$ has entirely separated itself from the two primitive vertebral cords $(u w)$, in the interior of which a transitory cavity (uwh) afterwards forms. The side-layers have split into the outer skin-fibrous layer $(h p l)$ and the inner intestinal-fibrous layer $(d f)$, which are still connected by the middle plates $(m p)$. The fissure $(s p)$ between the two is the rudiment of the body-cavity. In the gap between the primitive vertebral cords and the side-layers on either side are, attached on the outer side, the primitive kidney (ung), on the inside the primitive artery $\left(a_{0}\right)$. (After Kölliker.) 
retained, the germ-layers, even in the earliest stage, form closed tubes, which may be immediately referred to the tubular shape of an elongated Gastrula. (Cf. Figs. 62-69.)

When, therefore, it was generally thought that the main object of the germ-history of Vertebrates was to derive the later organization of these from a primitive, flat, discoid form, the two-layered germ-disc (or the threelayered germ-shield), a grave error was committed. ${ }^{91}$ For this flat, circular germ-dise, and the flat, sole-shaped germshield which arose from the former, are phylogenetic formations, which arose only secondarily, in consequence of the accumulation of a large mass of nutritive yelk in the primitive intestine of the primary Gastrula ; and so when, at a later period, the dorsal side of the flat germ-shield arches, and its edges bend towards each other and coalesce into tubes on the ventral side, the process is neither primary nor secondary, but tertiary.

A right conception of the formation of the intestine is evidently the real point on which a thorough knowledge of these important germinal processes depends. The greatest difficulties are solved when a clear and correct conception of the formation of the intestinal canal has been acquired. For the primitive intestine is, according to the Gastræa Theory, the earliest and the most important organ of the animal body. In order to gain this clear idea of the formation of the intestinal tube and the parts attached to it, it is especially necessary to note accurately the important modification undergone by the intestinal-glandular layer of the mammalian germ. This, as has been said, is at first a simple layer of cells (an epithelium), which lines the inner surface of the globular intestinal germ-vesicle. It is a 
simple globule, the wall of which consists of a simple layer of homogeneous cells (Fig. 100, $A d d$ ). The first change in
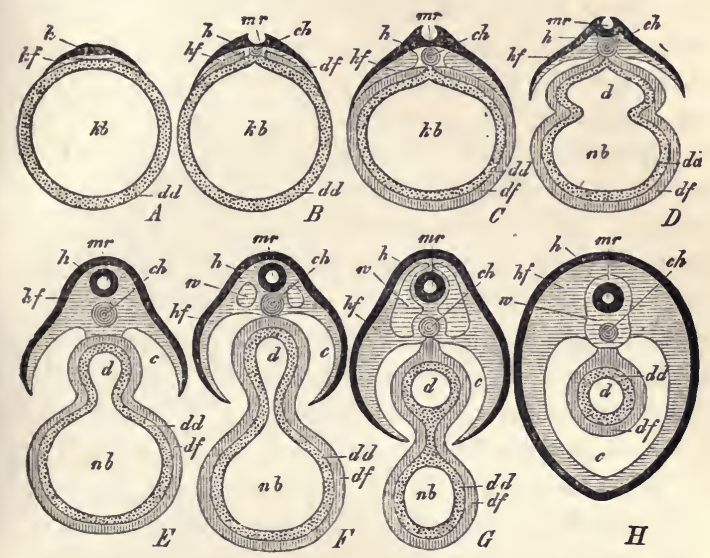

Frg. 100.-The separation of the discoidal mammalian germ from the yelk-sac, seen in section (diagrammatic). A. The germ-disc $(h, h f)$ lies extended on one side of the intestinalgerm-vesicle $(k b)$. B. In the centre of the germ-disc the medullary furrow $(m r)$, and under that the notochord $(c h)$ appear. C. The intestinal-fibrous layer $(d f)$ has grown ronnd the intestinalglandular layer $(d d)$. D. Skin-fibrous layer $(h f)$ and intestinal-fibrous layer (df) part round the circumference of the germ-disc; the intestine (d) begins to separate itself from the yelk-sac or navel-vesicle $(n b)$. $E$. The intestinal tube $(m r)$ is closed; the body-cavity $(c)$ begins to form. $F$. The primitive vertebræ $(v)$ appear; the intestine $(d)$ is almost completely closed. $G$. The primitive vertebræ $(w)$ begin to grow round the medullary tube (mr) and the notochord $(c h)$; the intestine $(d)$ is separated from the navel. vesicle $(n b)$. H. The vertebræ $(w)$ have enclosed the medullary tube $(m r)$ and the notochord (ch); the body-cavity $(c)$ is closed; the navel-vesicle has disappeared. The amnion and serous membranes are omitted.

In all, the letters indicate the same parts : $h$, horn-plate; $m r$, mednllary tabe; $h f$, skin-fibrous layer; $w$, primitive rertebræ; $c h$, notochord ; $c$, bodycavity; $d f$, intestinal-fibrons layer; $d d$, intestinal-glandular layer; $d$, in. testinal cavity ; $n b$, navel-resicle. 
this globular formation is that at one point in the germ disc, immediately below the notochord, and, therefore, below the axis of the developing body, a furrow-like depression arises. This is the primitive groove (Fig. 100, B). It gradually becomes deeper and broader, assumes the form of a canal, and completely separates from the germ-vesicle, of which it originally formed a part (Fig. 100, $D-H$ ). At first the whole intestinal germ-vesicle is, in a certain sense, the intestinal cavity. We may, therefore, compare the entire intestinal germ vesicle of the Mammal, the wall of which, closed on all sides, is formed by the intestinal layer, with the primitive intestine of a Gastrula, the primitive mouth of which has closed. This primitive intestine separates into two parts, the permanent after-intestine $(d)$, and the transient navel-vesicle $(n b)$.

This is also true of the formation of the intestine in Birds and Reptiles. For in these, the large yelk-sac, filled with nutritive yelk, represents the smaller mammalian navel-vesicle, filled with clear liquid. In Birds and Reptiles again, the later, permanent intestine also separates itself from the yelk-sac by the intestinal groove changing into a canal, into the intestinal tube. This tube is formed from the intestinal-furrow in the same way as the medullary tube originates from the dorsal furrow. The groove grows deeper and deeper; its edges grow downwards towards each other, and coalesce at the point at which they meet. But the difference between the structure of the intestinal tube and that of the medullary tube consists, as we have shown, in the fact that the medullary tube is closed equally along its whole length in a suture, while the intestinal tube grows together more concentrically, not only from the two 
edges, but the ends also come together with the edges which close, and form a navel.

With this concentric closing of the intestinal tube is connected the formation of two cavities, which are called the head intestinal cavity and the pelvic intestinal cavity. When the embryo gradually becomes detached from the wall of the germ-vesicle, on which it at first lies flat, the anterior and posterior ends are the first to be released, while the central portion of the ventral surface continues attached to the yelk-sac by the yelk-duct, or navel-duct (Fig. 101, $m$ ). In the mean time the dorsal surface of the body becomes much arched; the head end, on the other hand, bends downward and against the breast, while the tail end, in the same way, presses against the abdomen; the embryo tries to roll itself together, as a hedgehog makes itself into a ball to ward off its enemies. This arching of the back is caused by the quicker growth of the dorsal surface, and is directly connected with the detachment of the embryo from the yelk-sac (Fig. 101). In the head there is no separation between the skin-fibrous layer and the intestinal-fibrous layer, as is the case in the trunk, but the two layers remain attached and form the so-called "head-plates." Now as these head-plates free themselves at a very early period from the surface of the germ-area, and grow, first downward toward the surface of the intestinal germ-vesicle, and then backwards toward the point, at which the latter passes into the intestinal groove; a small cavity is thus formed within the head portion, which represents the foremost blind end of the intestine. This is the small head intestinal cavity (Fig. 102, to the left of $d$ ); its opening into the middle intestine is called the 
anterior "intestinal gate" (Fig. 102, at $d$ ). Just in the same way the tail curves back against the ventral surface; the intestinal wall then encloses posteriorly a similar small

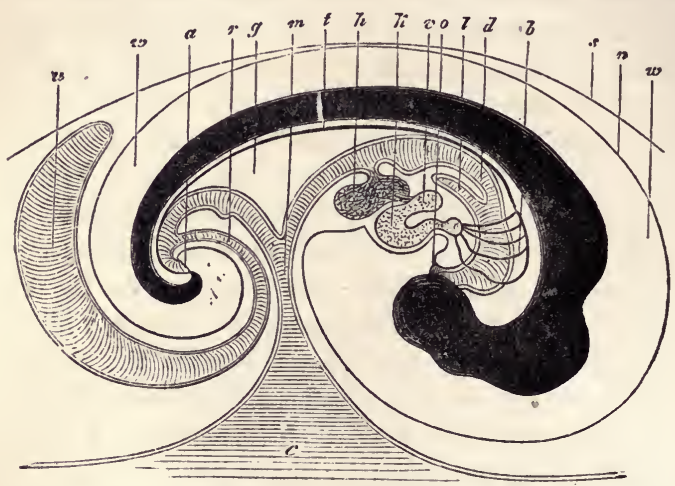

Fig. 101.-Longitndinal section through the embryo of a Chick (fifteenth day of incubation). Embryo with arched dorsal surface (black) : $d$, intestine; 0 , mouth; $a$, anus; $l$, lungs; $h$, liver; $g$, mesentery; $v$, auricle of heart; $k$, ventricle of heart; $b$, arterial arches; $t$, aorta; $c$, yelk-sac; $m$, yelk-duct; $u$, allantois; $r$, stalk of allantois ; $n$, amnion; $v$, amnioncavity; $s$, serous membrane. (After Baer.)

eavity, the hind end of which is blind; this is the pelvic intestinal cavity. Its opening into the middle intestine is the "hind intestinal gate."

In consequence of these processes the embryo assumes a form resembling a canoe lying bottom upward. Imagine a canoe with rounded ends, and fitted with a little deck fore and aft; then turn this canoe upside down, so that its arched bottom is uppermost: this affords an approximate representation of this canoe-shaped embryo (Fig. 101, e). 
The reversed convex keel represents the middle line of the back; the little chamber under the fore-deck represents the head intestinal cavity, and that under the after-deck the pelvic intestinal cavity. (Cf. Fig. 94, p. 312.)

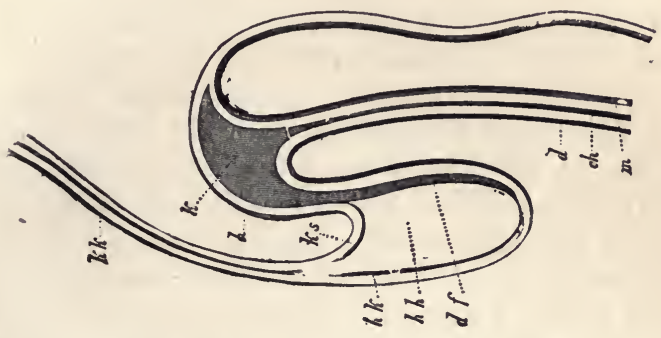

Fic. 102.-Longitudinal section through the front half of a chick (at the end of the first day of incubation), seen from the left side: $k$, headplates; ch, notochord; above the latter, the blind front end of the medullary tube $(\mathrm{mr})$; below it the head intestinal cavity, the blind front end of the intestinal tube; $d$, intestinal-glandular layer; $d f$, intestinalfibrous layer; $h$, horn-plate; $h h$, heart-carity; $h k$, heart-cap; $k s$, headsheath; $k k$, head-cap. (After Remak.)

With its two free ends the embryo now presses somewhat into the external surface of the germ-vesicle, and at the same time lifts the middle portion away from the germ-vesicle. The consequence is that the germ-vesicle soon appears to be merely a pouch-shaped appendage protruding from the middle of the body. This appendage, which continues to decrease in size, is afterwards called the yelksac, or navel-vesicle. (Cf. Fig. 94, ${ }_{4}, 5, d s$; Fig. 100, and Plate V. Fig. 14.) The cavity of this yelk-sac, or cavity of the germ-vesicle, communicates with the growing intestinal cavity through a wide connecting aperture, which after-

VOL. I. 
wards extends into a long narrow canal, the yelk-duct. Let us suppose we are within the cavity of the yelk-sac; we may then pass from it, through the yelk-duct (Fig. 101, $m$ ), directly into the middle part of the intestinal canal, which is still wide open. If from there we pass on into the head portion of the embyro, we reach the head intestinal cavity, the anterior end of which is blind. If, on the other hand, we pass from the middle of the intestine backwards into the tail portion, we reach the pelvic intestinal cavity, the hind end of which is blind (Fig. 94, 3 ). The first rudiment of the intestinal tube now consists, therefore, strictly speaking, of three distinct sections: (1) the head intestinal cavity, the hind end of which opens, through the front intestinal gate, into the middle intestine; (2) the middle intestinal cavity which opens downwards, through the yelk-duct, into the yelk-sac; and (3) the pelvic intestinal cavity, the front of which opens, through the posterior intestinal gate, into the middle intestine.

At first the mouth and anal openings are wanting. The whole primitive intestinal cavity is entirely closed, and is only connected in the middle by the yelk-duct with the cavity of the intestinal germ-vesicle, which is also closed (Fig. 94, 3). The two future openings of the intestinal canal, the anal opening and the mouth-opening, form only secondarily, on the outside, and from the outer skin; that is to say, a groove-like depression arises in the hornplate at the point where the mouth is afterwards situated, and this grows deeper and deeper, growing towards the blind front-end of the head intestinal cavity: this is the mouth-groove. A similar groove-like depression appears posteriorly on the outer skin, at the point where the anus 
is afterwards found, and this also grows continually deeper and towards the blind anterior end of the pelvic intestinal cavity; this is the anal groove. At length the innermost and deepest parts of these grooves touch the two blind ends of the primitive intestinal canal, from which they are now only separated by a thin membranous partition wall. Finally, this thin skin is broken through, and the intestinal tube now opens outward in front through the mouthopening, and in the rear through the anal opening (Fig. $94,4 ; 101)$. At first, then, we really have before us, if we look into these grooves, a partition wall separating them from the cavity of the intestinal canal, and it is only later that these partitions disappear. The mouth and anal openings develop secondarily.

The remnant of the intestinal germ-vesicle, which we have called the navel-vesicle, or yelk-sac, grows smaller and smaller as the intestine develops, and finally hangs like a small pouch from the middle of the intestine by a slender stalk, by the yelk-duct (Fig. $94,5 d s$ ). This yelk-duct is of no permanent importance, and, like the yelk-sac itself, is completely degraded and absorbed. Its contents are absorbed by the intestine, and the yelk-duct itself closes. The place at which it attaches itself to the navel is the intestinal navel. The complete closing of the intestine finally takes place at this spot. (Cf. Chap. XII., and Plate V. Fig. 14, 15.)

Just as the intestinal tube arose from the vegetative germ-layer, so from the animal germ-layer arises the outer ventral wall, which surrounds the entire body-cavity (coeloma), and includes the intestine. It develops from the outer portions of the side-layers. As has been already 
observed, these side-layers, which for a time were separated from the primitive vertebral cords, afterwards again adhere to the latter. While the inner portion of the side-layers (belonging to the intestinal-fibrous layer) is thus forming the external wall of the intestine, the outer portion of the same layers (belonging to the skin-fibrous layer) grows in a circle round the intestine, thus closing the body-cavity (Fig. 100, p. 333). The edges of the ventral plates, as these portions of the side-layers are called, grow toward each other from all sides, continually narrowing the slit-like ventral opening, from which the yelk-sac depends. Finally, the latter is, in Mammals, completely separated from the intestine by the closing of the ventral plates, while in Birds and Reptiles it is taken into the intestine. This point at which the ventral wall finally closes-the last point of coalescence-is the ventral navel, the externally visible skinnavel, which is commonly briefly called the navel. This must be distinguished from the inner, or intestinal navel, which is the point at which the intestinal eanal closes, and of which no trace can afterwards be found. With the closing. of the intestinal tube and of the ventral wall, the double tubular form of the vertebrate body is complete.

A few words must still be said concerning the modifications which, while these processes are going on, take place in the primitive kidneys and in the blood-vessels. The primitive kidneys, which at first lie quite superficially just below the outer skin (epidermis, Fig. 99, ung), soon penetrate far into the interior in consequence of peculiar conditions of growth (Figs. 95, 96, ung, pp. 317, 318); at last they lie very far within, underneath the chorda dorsalis (Fig. 97, un, p. 318). 
Similarly the two primitive aortæ penetrate within, below the notochord, and there eventually amalgamate and form a single secondary aorta, which is situated under the rudimentary vertebral column. (Cf. Figs. 95-98, ao.) So, too, the cardinal veins, the first rudiments of the venous blood-vessels, penetrate further inwards, and afterwards lie directly over the primitive kidneys (Fig. 97, vc). In the same locality, at the inner side of the primitive kidneys, the first rudiments of the sexual organs soon become visible. The chief portion of this apparatus, apart from all its appendages, is, in the female, the ovary-in the male, the testes. Originally both these appear in the form of a simple hermaphrodite gland, formed from a small portion of the cœlom-epithelium, the cellular lining of the bodycavity, at the point of contact between the skin-fibrous layer and the intestinal-fibrous layer. It is only secondarily that this hermaphrodite gland seems to connect itself with the primitive kidney ducts, which lie very close to them, and which are very importantly related to the sexual glands. (Cf. Chap. XXV., and Plate IV. Figs. 5-7.)

We will now leave the transverse sections of the vertebrate body, the comparison of which has been so extremely instructive and important, and by means of which we have solved the hardest problem of germ-history, the problem as to the part taken by the germ-layers in the formation of the body. In place of those, we will now examine the longitudinal form of the rudimentary embryo of the mammalian body, partly superficially, and partly in various longitudinal sections.

Let us now examine the surface, from the dorsal side, of that very simple embryonic form which we called the sole- 

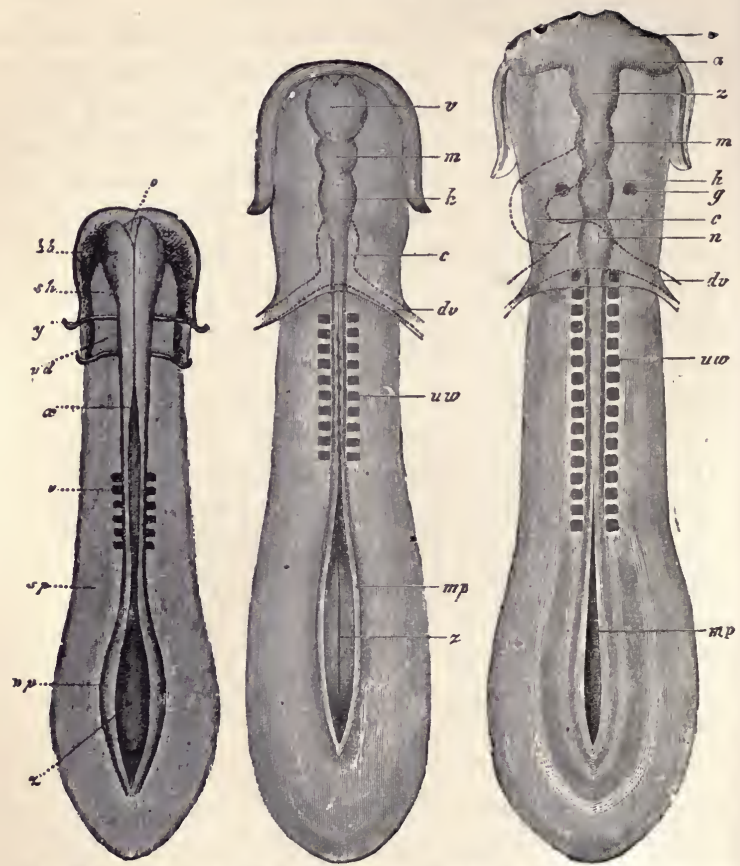

Frgs. 103-5. - Lyre-shaped germ-shield of a Chick, in three consecutive stages of development, seen from the dorsal surface (about 20 times the natural size). Fig, 103, with six pairs of primitive vertebræ. Brain is a simple bladder $(h b)$. The spinal farrow is open behind $x$; at the posterior end it is very wide open at $z$; $m p$, medullary plates; $s p$, side-plates; $y$, limit between throat-cavity $(s h)$ and head-intestine $(v d)$.-Fig. 104, with 10 pairs of primitive vertebræ. The brain has parted into three bladders : $v$, fore-brain ; $m$, mid-brain ; $h$, hind-brain ; $c$, heart ; $d v$, yelk-veins. The medullary furrow continues wide open at the posterior end $(z)$; $m p$, medullary plates.-Fig. 105, with 16 pairs of primit ${ }_{\text {ve }}$ vertebræ. The brain has parted into five bladders : $v$, fore-brain; $z$, twixt-brain; $m$, mid-brain; $h$, hind-brain; $n$, after-brain; $a$, eye-bladders; $g$, ear-vesicles; $c$, heart; $d v$, yelk-rcins; $m p$, medullary plates; $u r v$, primitive vertebræ. 
shaped or lyre-shaped germ-shield (Figs. 86, 87, p. 298). In the middle line of its dorsal surface the primitive groove first made its appearance, enclosed by the two parallel dorsal, or medullary swellings. The coalescence of these formed the medullary tube. When we examine the further modifications of this, we very soon perceive a difference between the formation of the anterior and that of the posterior ends. At the anterior end in Man, as in all the higher Vertebrates, the brain very soon begins to separate or differentiate from the medullary tube. The first rudiment of the brain is merely a roundish, bladder-like protuberance of the vertebral canal (Fig. 103, $h b$ ). Very soon, however, this bladder is divided by two circular contractions of its circumference, into three consecutive vesicles, the so-called primitive brain-bladders (Fig. 104, $v m h$ ). Two other similar contractions then appcar, so that we now find five brain-bladders in a row (Fig. 105). This is the mode of development of the brain in all Mammals, from the simplest Fishes to Man. In all, we find a simple vesicle as the first rudiment of the brain, which is afterwards parted, by contractions in its circumference, into five smaller bladders. Though the brain, as the organ of the soul and the mental activities, afterwards develops in various Vertebrates in such very various ways, yet the first rudiment is of this simple and homogeneous form. This is a fact of the highest importance.

Directly below the medullary tube, in the lyre-shaped germ-shield, we found the notochord. Right and left of the notochord the two parallel primitive vertebral cords had split away from the side-layers. But while the five brain. bladders are becoming distinct at the anterior end of the 
medullary tube, the two primitive vertebral cords in the centre of the primitive germ break up into a number of pieces, lying one behind another, and resembling small cubes on each side of the medullary tube. Two pairs usually first make their appearance simultaneously. Then

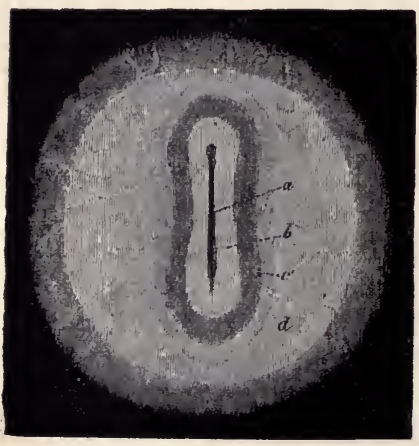

Frg.106-109.-The Germdisc of a Rabbit (the circular germ-area with the lyreshaped germ-shield), seen from the dorsal snrface, in four consecntive stages of evolution (about ten times the natural size). (After Bischoff.)

In Fig. 106 the embryo (b) is as yet without primitive vertebræ; the open dorsal furrow (a) surrounded by a narrow light germ-area (a. pellucida, a), in the middle of the dark germ. area $(a$. opaca, $d)$.

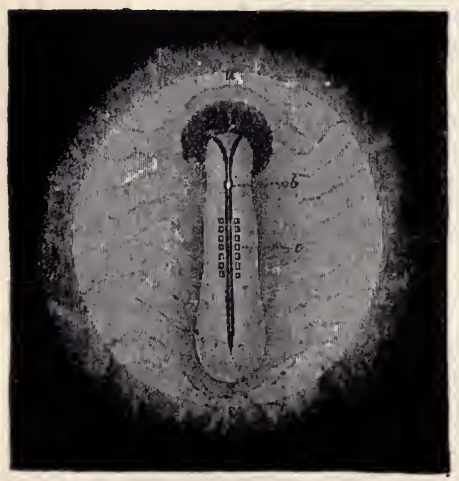

In Fig. 107 seren primitive vertebræ (c) may already be seen; the dorsal furrow is closed; the first rudiment of the brain $(a)$, a brain-bladder, behind which a second $(b)$ is form. ing, is arising; the light germ-area is now only visible at the anterior end, in the form of a dark sickleshaped body on a black ground. 
appear three, four, and five pairs, and finally a larger number of these pieces, which are called the primitive vertebræ.

In Fig. 108 the em. bryo has eight primitive vertebræ and three brain-bladders; the first brain-bladder (b) shows two lateral protuberances, the first rudiments of the eye-bladders $(c)$; the second $(d)$ and the third (e) brain-bladders are much smaller; $a$ indicates the edge of the headsheath of the amnion.

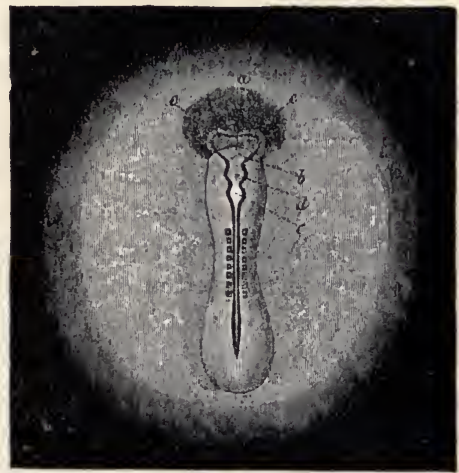

- In Fig. 109 the embryo has ten primitive vertebræ; in the germarea the first traces of the net of blood-vessels appear, bounded by the vena termi. nalis $(a): b$, tailsheath, $b b$, headsheath of the amnion; the folds in the latter indi. cate the serous membrane.

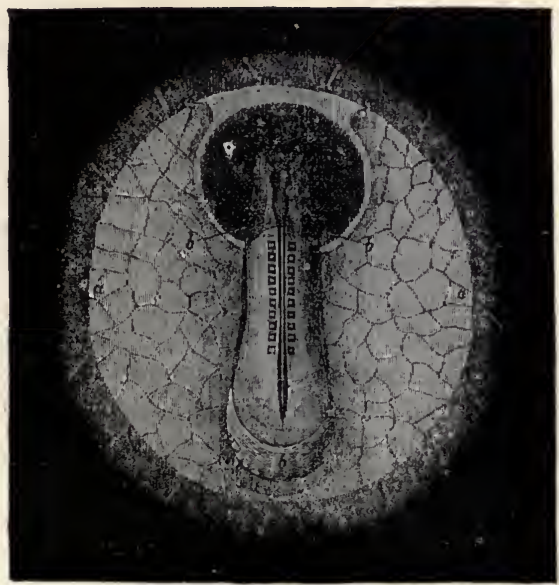


In Fig. 107 there are seven, in Fig. 108 there are eight, and in Fig. 109 ten pairs of primitive vertebræ. Their number afterwards increases considerably, amounting in Man to upwards of thirty. As we shall presently see, out of each pair of these primitive vertebral segments an individual section of the trunk, a metameron, develops. Each pair of primitive vertebræ is not, as the name seems to. indicate, merely the rudiment of a future vertebra, but, in addition to the vertebra, the appropriate muscles also develop from it, as does a pair of nerve-roots, etc. It is only the innermost portion of the primitive vertebra, the part lying next to the notochord, that gives rise to the rudiment of the articulated vertebral column, extending: from the cranium to the tail, and composed of a number of bony vertebral rings. ${ }^{98}$

The breaking up of the vertebral cord into a doublechain of primitive vertebral segments, or, briefly, the forming of the metamera, is of the greatest importance, because it is in this process that the body of the Vertebrate passes from its originally inarticulate to its permanent articulate conditions. The developed Vertebrate is composed of a chain of homogeneous parts, lying one behind another precisely as are the Articulated Animals (Arthropoda). In the latter class, in Crabs, Spiders, Millipedes, and insects, this articulation is very clearly marked externally, the skin between each two members (metamera) having a ringshaped contraction or dent round the circumference of the body. In Vertebrates the articulation of the body is equally complete, but it does not appear externally, though internally it is fundamental. Every Vertebrate, in its perfect state, is an articulated person. Its personality forms a chain of 
members, metamera, or trunk-segments. In the same way in which the articulate and the externally articulated Worms developed from an inarticulate condition, so the internally articulated Vertebrate proceeded from an originally inarticulate condition. We shall presently examine more closely the living representative of this condition, the Ascidia, a remarkable class of inarticulate Worm forms. (Chapters XIII. and XIV.)

This process of articulation or metameric formation is, I repeat, of the highest importance in enabling us to understand each higher animal form, not only in its morphological, but.also in its physiological relations. This articulation is one of the most important conditions necessary to perfection: it is one of the principal causes of the complex body-functions of higher animals. The inarticulate animal can never attain so high a degree of perfection in form or in function as the articulated. And the reason is plain. These members, or metamera, are, in a certain sense, independent individuals. By division of labour, these originally homogeneous individuals develop into the different parts of the composite body-person, just as the embryonic cells fashion themselves, in consequence of division of labour, into the various tissues. The body of articulated animals. may be likened to a railway train, in which the individual carriages, held together by the couplings, represent the metamera. The engine is the head of this articulated organism. Then come tender, mail-van, luggage-vans, passenger-carriages, cattle-trucks, etc. Each separate waggon or carriage is morphologically an individual, and' physiologically, yet the entire chain presents only a single individual, the railway train. As in this instance the- 
various functions are distributed among the various kinds of carriages-functions which each separate carriage cannot discharge simultaneously-so in the articulated animal body the division of labour among the metamera of the trunk must be regarded as a material advance.

The best explanation of the nature of metameric formation is afforded by the articulated Worms, especially the Tape-worms and the Ringed-worms (Annelida). In these the members, or metamera, composing the ringed body, are all of the same structure and of the same form-value. The first member, the head, alone seems to be differently formed and more or less differentiated. In many Tapeworms the various members are so independent, that many zoologists regard each separate metameron as an individual animal, and the whole chain of members as a colony of animals. In a certain sense this is quite correct, in so far as each separate metameron is an individual of a lower order, while the chain, composed of many metamera, is an individual of a higher order. But in proportion as the separate members relinquish their independence; in proportion as they become differentiated in consequence of division of labour, and become dependent on each other and on the whole body, and in proportion as the latter becomes centralized, the more perfect does the entire unitary organism become. In most Articulated Animals (Arthropoda), and in all Vertebrates, centralization has so far progressed that the individual metamera are no longer of any importance in themselves alone, and are to be considered merely as the necessary component parts of the entire chain.

When we investigate the origin of the metameric chain 
in the Worms, we find that it results, in consequence of repeated asexual generative processes, in consequence of what is called terminal budding, from an originally inarticulate Worm-body, which is equivalent to a single metameron. Thus the Tape-worm embryo is at first all head; and on this head, which is only equivalent to a single metameron, repeated budding gives rise to one metameron after another; all, however, remain connected. So, too, in the Ringed Worms (Annelida) the originally inarticulate body puts out numerous buds from its posterior extremity, thus giving rise to the long articulated chain. Such is the nature of this process, which, however, in the germ-history of Articulated Animals and Vertebrates appears much compressed and secondarily modified. Originally, however, every vertebrate animal is just such a metameric chain, which has arisen, in consequence of terminal budding, from an inarticulated germ. ${ }^{99}$

As the metamera arise in this way, it will readily be understood that the anterior primitive vertebræ are earliest found. Such is indeed the case. The earliest primitive vertebræ, which are situated about the centre of the germ, are the first and second neck-vertebræ. Then come the third and fourth neck-vertebræ, and so on. Each primitive vertebral segment in its turn soon produces, by the process of budding, a new metameron at its posterior extremity, till the chain is complete. The entire jointed body grows, therefore, in a direction from front to rear. In this way the articulated vertebral column of Man is at length produced (Figs. 110, 111). In the developed Man it is composed of the cranium, with a chain of thirty-three or thirty-four different vertebræ: viz., seven neck-vertebræ, twelve chest- 
vertebræ, to which the ribs are attached, five lumbarvertebræ, five cross-vertebræ (inserted into the pelvis), and four or five tail-vertebræ. Each of these represents a corresponding section of the nervous, muscular, and vascular systems, etc.

A further consequence of the mode of development of the metamera is, that nearly the whole front half of the lyre-shaped germ-shield (Figs. 103, 107) mustre present the future head. The seven primitive vertebræ which occupy the third quarter of the whole length, form the neck, so that all the rest of the body originates from only the fourth and last quarter. This proportion seems strange at first, but its phylogenetic explanation, as the result of the terminal budding, is simple. The head portion of the vertebrate animal must accordingly be regarded phylogenetically and originally as the oldest portion of the bodyas a group of a few (six to ten) closely coalescent metamera, which, by continued budding at the posterior extremity, have produced the remainder of the body. The tail, on the other hand, is the most recent part, the latest in order of development.

As has been already observed, the articulation affects the entire body of the Vertebrate, although the skin shows no external signs of articulation. The primitive vertebral pieces are, therefore, not merely rudiments of future vertebre; they are real metamera, or trunk-segments. Each metameron first appears as a nearly cube-shaped, solid, roundly-hexagonal body, entirely composed of cells.

Fig. 110.--Hnman skeleton, from the front.

Fig. 111.-Human skeleton, from the right side. The arms have been removed. (Both figures after $\mathrm{H}$. Meyer.) 

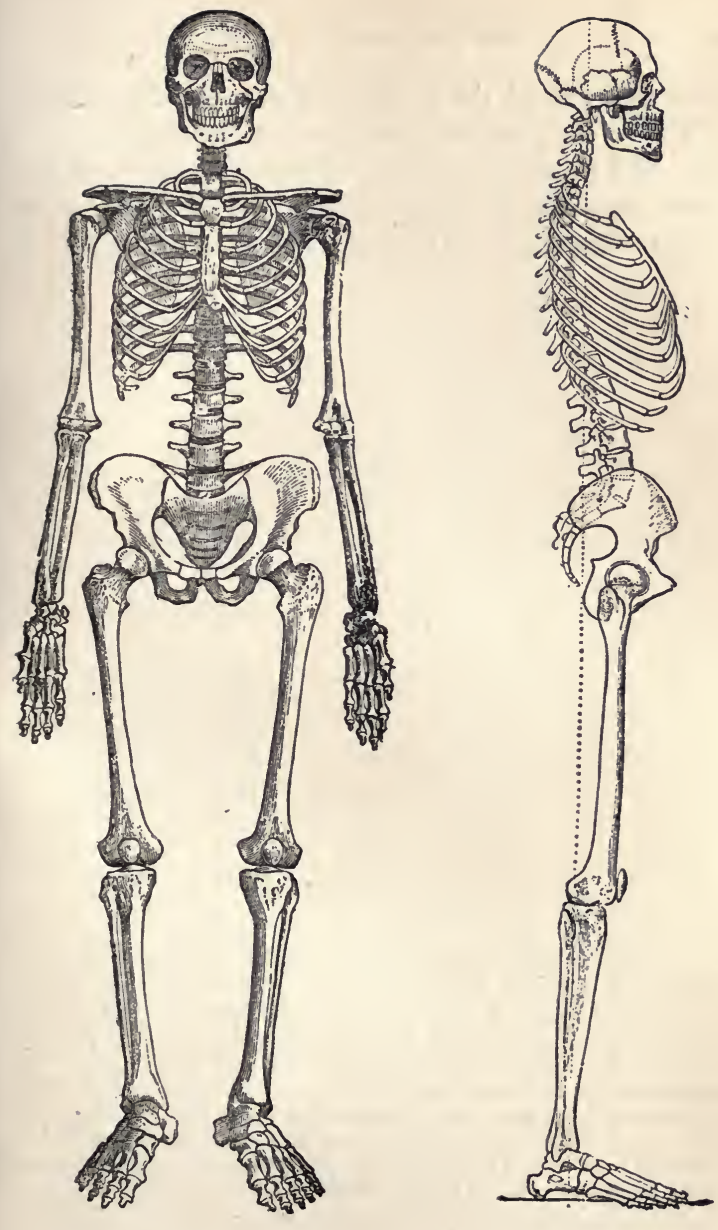
These cells are all the products of the skin-fibrous layer. At a very early period, a small cavity appears in each of these solid primitive vertebræ, which cavity, however, soon again disappears. This "primitive vertebral cavity" (Figs. $95,96, u w h, p p .317,318$ ) is worthy of note only in so far as it

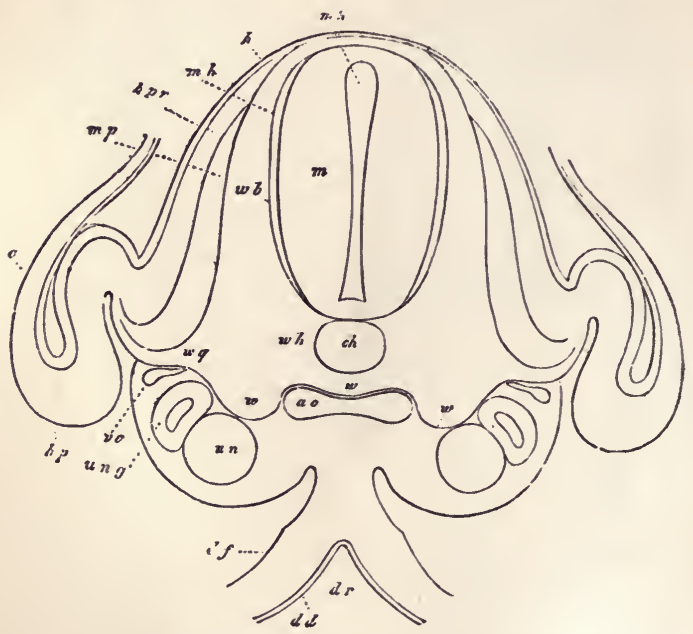

Fig. 112.-Transverse section throngh the embryo of a Chick oi the fourth day of incubation (about 100 times the natural size). The primitive vertebræ have separated into the outer muscle-plate $(\mathrm{mp})$ and the inner skeleton-plate. The latter below, as the vertebral bodies $(w h)$, begins to surround the notochord $(c h)$; above, as the vertebral arches $(w b)$, begins to surround the medullary tube $(\mathrm{m})$, the cavity of which $(\mathrm{mh})$, is already very narrow. At $w q$ the primitive vertebra passes into the skin-muscle plate of the ventral wall $(h p) ; h p r$, leather-plate of the dorsal wall; $h$, horn-plate; $a$, amnion; ung, primitive kidney dact; un, primitive urinary canal; $a o$, primitive artery; $v c$, cardinal rein; $d f$, intestinal-fibrous layer; $d d$, intestinal-glandular layer; $d r$, intestinal groove. 
indicates an internal separation of the primitive vertebra into two entirely distinet parts : an inner part, which forms the skeleton-the skeleton-plate (Fig. 95, uw, Fig. 112, wb), and an outer part, which forms the muscle-the muscleplate (Figs. 95, 96, $m$, Fig. 112, $m p$ ).

The skeleton-plate is formed of the entire inner half of each primitive vertebra, immediately adjoining the medullary tube (Fig. 112, wh, wb). Its lower part, the inner lower corner of the cube-shaped primitive vertebra, splits up into two lamellæ, which grow round the chord, thus forming the basis of the vertebral bodies $(w h)$. The upper lamella forces its way between the chorda and the medullary tube, the lower lamella between the chorda and the intestinal tube (Figs. 68, 69, p. 276; Fig. 93). As the lamellæ of two opposite primitive vertebral pieces come together from right and left and unite, a ring-like sheath is formed round that particular part of the notochord. From this afterwards arises a vertebral body, i.e., the massive, lower, or ventral portion of the bony ring, which, as a vertebra in the strict sense, surrounds the medullary tube (Figs. 113-115). The upper or dorsal half of this bony ring, the vertebral arch (Fig. 112, wb) arises in just the same way from the upper portion of the skeleton-plate; i.e., from the inner, upper corner of the cube-shaped primitive vertebra. The two inner, upper corners of two opposite primitive vertebræ coalesce, from right to left, over the medullary tube, resulting in the closing of the vertebral arch. Between each pair of vertebral arches appear, at a later period, the roots of the spinal nerves, which arise from the same portion of the skeleton-plate (Fig. 98, $g, v$, p. 318).

The whole secondary vertebra, which thus results from VOL. I. 
the coalescence of the skeleton-plates of a pair of primitive vertebræ, and which encloses within itself a part of the chorda, consists originally of a somewhat soft cell-mass, which afterwards passes into a second firmer, cartilaginous state, and finally into a third, permanent, bony state. These three different conditions are generally distinguishable in the greater part of the skeleton of the higher Vertebrates; at
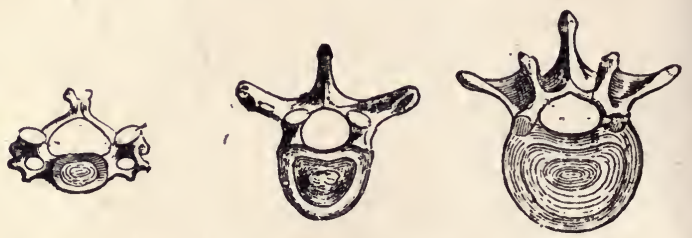

Fig. 113.-Third human neck-vertebra.

Fig. 114.-Sixth human chest-vertebra.

Fig. 115.-Second human lumbar-vertebra.

first, most parts of the skeleton are quite tender, soft, and membranous; then, in the course of development, they become cartilaginous, and finally they ossify.

All the bony vertebræ which afterwards compose the backbone, or vertebral column, arise, as we have already observed, entirely from the inner portion of the primitive vertebræ, from the skeleton-plate. The outer portion, on the other hand, which we have called the "muscle-plate" (Fig. 112, $m p$ ), produces the great mass of the dorsal muscles (the dorsal "side muscles of the trunk"), as well as the leather skin, which covers the flesh of the back. This muscle-plate is in direct communication with that portion of the side-plates which develops into the ventral skin and the ventral muscles. 
In front, at the head end of the embryo, the middle layer (mesoderma) does not split into primitive vertebræ and side-plates, and the original fibrous layer here remains undivided, forming the so-called "head-plates" (Fig. 102, $k$, p. 337). From these arise the skull-the bony covering of the brain-as well as the muscles and leather-skin of the head. The skull develops precisely in the same way as the membranous vertebral column. The right and left head-plates arch towards each other over the brain-bladder, enclose the anterior extremity of the chorda, and thus eventually form a simple soft, membranous capsule round the brain. This afterwards changes into a cartilaginous primitive skull, similar to that which is retained throughout life by many fishes. It is only much later that the permanent bony skull, with all its different parts, is formed from this cartilaginous primitive skull.

In the embryo of Man, as in that of all other Vertebrates, the very remarkable and important structures, which are called the gill-arches and gill-openings, appear, at a very early period, on each side of the head (Plate I. Fig. 1, and Figs. 116, 118, $f$ ). . These are among the characteristic and never-failing organs of the Vertebrates, for which reason we mentioned them in considering the typical primitive Vertebrate (Figs. 52, 53, p. 256). On the right and left walls of the intestinal head-cavity, in the anterior portion, first one, and then several pairs of sac-like protuberances are formed, which break through the entire thickness of the side wall of the head. They thus become slits through which there is a free passage from without into the throatcavity: these are the gill-openings, or throat-openings. Between each pair of gill-openings the wall of the throat- 
cavity grows thicker, and is changed into a bow-shaped or sickle-shaped ridge: these are the gill-arches; on their inner side a vascular arch afterwards arises (Fig. 101, p. 336).
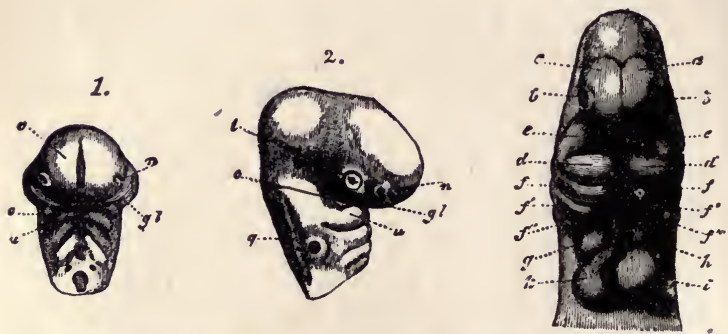

Figs.116,117.-Head of a Chick, on the third day of incubation: 116 is a front view; 117 from the right side; $n$, nose-rudiments ; $l$, eye-rudiments ; $g$, ear-rudiments; $v$, front-brain; $g l$, eye-fissures. The first of the three pairs of gill-openings is separated into an upper jaw process $(c)$ and a lower jaw process ( $u$. . (After Kölliker.)

Fig. 118.-Head of embryo of a dog, from the front: $a$, the two side halves of the front brain-bladder; $b$, eye-rudiments; $c$, middle brain-bladder; $d e$, the first pair of gill-arches ( $c$, upper jaw process; $d$, lower jaw process) ; $f, f^{\prime}, f^{\prime \prime}$, the second, third, and fourth pair of gill-arches; $g h i k$, heart ( $g$, right, $h$, left auricle; $i$, left, $k$, right ventricle); $l$, origin of the aorta, with three pairs of aorta-arches, which pass on to the gill-arches. (After Bischoff.)

The number of the gill-arches, and of the gill-openings, which alternate with the former, amounts in the higher Vertebrates to four or five on each side (Fig. 118, $e, d, f, f, f^{\prime}$ ). The lower Vertebrates have a yet larger number. Originally these remarkable formations discharged the function of a breathing-apparatus-were gills. Even yet in the Fishes generally, water, serving for respiration, and which is taken in through the mouth, passes out through the gill slits on 
the side of the gullet. In the higher Vertebrates they afterwards close. The gill-arches are transformed partly into the jaws, partly into the tongue-bone and the bonelets of the ear (ossicula auditus). (Cf. Plates I., VI., and VII.)

Almost simultaneously with the development of the gillarches, and immediately behind these, the heart with its four compartments is formed (Fig. 118, $g h i k$ ), and above, on the sides of the head, the rudiments of the higher sense-organs appear : nose, eye, and ear. These highly important organs

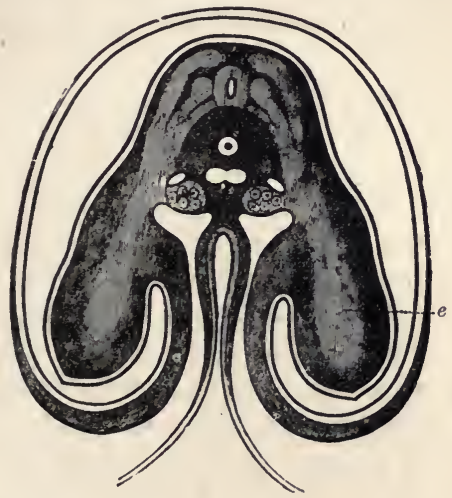

Fig. 119.-Transverse section through the shoulder region and the front limbs (wing-rudiments) of a Chick, on the fourth day of incubation (about 20 times the natural size). Near the intestinal tube three lighter cords are visible on each side in the dark dorsal wall, which pass into the rudiments of the fore limbs or wings (e). The upper of these is the muscle-plate, the middle is the hind, and the lower is the front root of a spinal nerve. In the middle, below the chorda, is the aorta, and on each side of this a cardinal vein; below the latter are the primitive kidneys. The intestine is almost closed. The ventral wall extends into the amnion, which forms a closed covering round the embryo. (After Remak.) 
originate in the very simplest form. The organ of smell, or the nose, appears quite in the front of the head, in the shape of two little pits above the mouth-opening (Fig. $117, n)$. The organ of sight, or eye, also in the form of a pit (Fig. 117, $l, 118, b$ ), comes next, behind the organ of smell, towards which a considerable vesicular outgrowth of the fore-brain grows on both sides of the head (Fig. 105, $a$ ). Further back appears a third pit on each side of the head, the first rudiment of the organ of hearing (Fig. 117, g). No trace of the very marvellous future structure of these organs, or of the characteristic form of the face, is yet to be seen.

The human embryo, having reached this stage of development, is yet hardly distinguishable from the germ of any of the higher Vertebrates. (Cf. Plates I., VI., and VII.) All the essential portions of the body are now begun: the head with its primitive skull, the rudiments of the three higher sense-organs, and the five brain-bladders, and the gill-arches and gill-openings; the trunk with the medulla, the rudiments of the vertebral column, the chain of metamera, the heart and principal blood-vessels, and, finally, the primitive kidneys. Man, in this germ-stage, is a higher Vertebrate, and yet there is no essential, morphological difference between the human embryo and that of Mammals, Birds, Reptiles, etc. (Plates VI. and VII., upper line of sections). This is an ontogenetic fact of the highest significance; from it are drawn the most important phylogenetic conclusions.

There is, however, as yet no trace of limbs. Though the head and the trunk are already separated, though all the important inner organs are begun, there is as yet no trace of the limbs, or extremities, in this stage. These do 
not appear till later. This also is a fact of the profoundest interest; for it tells us that the older Vertebrates were footless, as the lowest living Vertebrates (Amphioxus and

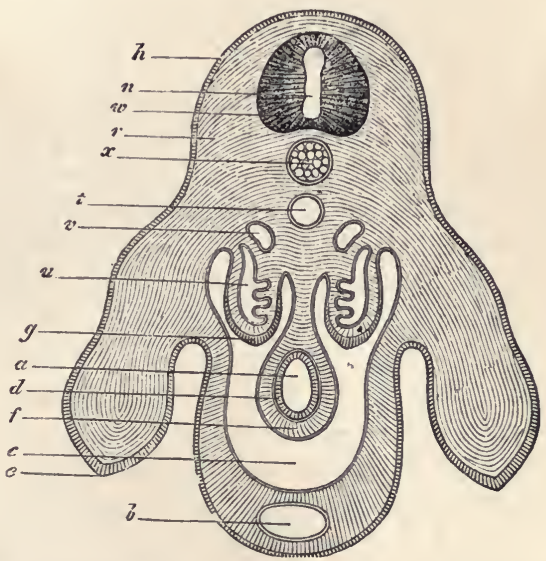

Fig. 120.-Transverse section through the pelvic region and the hind limbs of a Chick, on the fonrth day of incubation (about 40 times the natnral size) : $h$, horn-plate; $w$, medullary tube; $n$, spinal canal; $u$, primitive kidneys; $x$, chorda; $e$, hind limbs; $b$, allantois canal in the ventral wall; $t$, aorta; $v$, cardinal veins; $a$, intestine ; $d$, intestinal-glandular layer; $f$, intestinal-fibrous layer; $g$, germ-epithelium ; $r$,dorsal muscles; $c$, body-cavity (ccloma). (After Waldeyer.)

the Cyclostoma) are at the present time. The descendants of these primæval, footless Vertebrates did not acquire limbs till a much later period in the course of their development, when they acquired four limbs - a front pair and a hind pair. These limbs are all originally formed after one model, though they afterwards develop very differently: in Fishes they 
become fins (pectoral and ventral); in Birds, wings and legs; in creeping animals, fore and hind legs; in Apes and in Man, arms and legs. All these parts arise from a first rudiment of the same perfectly simple form, which grows secondarily from the skin-layer (Figs. 119, 120). They always make their appearance in the form of two small buds, which at first resemble mere round knobs or plates. Gradually each of these plates increases into a more considerable projection, in which there is a more slender part, nearer the body of the embryo and distinct from the outer, broader, thicker part. This later portion is the rudiment of foot or of hand, while the former is the rudiment of arm or of leg. Plates VI. and VII. show how similar are the rudimentary limbs in very different Vertebrates.

A careful study and thoughtful comparison of the embryos of - Man and other Vertebrates in this stage of development is very instructive, and reveals to the thoughtful many profounder mysteries and weightier truths than are to be found in the so-called "revelations" of all the ecclesiastical religions of the earth. Compare, for instance, carefully and attentively the three consecutive stages of development, represented in Plate VI. of the Fish $(F)$, Salamander $(S)$, Tortoise $(T)$, and Chick $(C)$, and in Plate VII. the corresponding embryos of the Hog $(H)$, Calf $(C)$, Rabbit $(R)$, and of Man $(M)$. In the first stage (upper row of Section I.), in which the head with the five brain-bladders, and the gill-arches are indeed begun, though the limbs are still entirely wanting, the embryos of all Vertebrates from Fish to Man differ not at all, or only in non-essential points. In the second stage (middle row of Section II.), in which the limbs are indicated, differences begin to appear between the 
embryos of the lower and the higher Vertebrates; as yet, however, the embryo of Man is hardly distinguishable from that of the higher Mammals. Finally, in the third stage (lower row of Section III.), in which the gill-arches have already disappeared and the face is formed, the differences become more evident, and grow, henceforth, more and more striking. The significance of such facts as these cannot be over-estimated. ${ }^{100}$

If there exists an inner, causal connection between the incidents of germ-history and those of tribe-history, as in accordance with the law of heredity, we must assume then these ontogenetic facts immediately afford most important phylogenetic conclusions. For the wonderful and comprehensive harmony between the individual evolution of Man and that of other Vertebrates is only explicable by assuming the descent of these from a common parent-form. Indeed, this common descent is now granted by all able naturalists, who in place of a supernatural creation assume a nonmiraculous evolution of organisms. 


\section{EXPLANATION OF PLATES VI. AND VII.}

Plates VI. and VII. are meant to represent the more or less complete agrecment, as regards the most important relations of form, between the embryo of Man and that of other Vertebrates in early stages of indiridual development. This agreement is the more complete, the earlier the period at which the human embryo is compared with those of other Vertebrates. It is retained longer, the more nearly related in descent the respective matured animals are-corresponding to the "law of the ontogenetic connection of systematically related forms." (Cf. Chapter XII., p. 366.)

Plate VI. represents the embryos of two of the lower, and two of the higher Vertebrates in three different stages : of a Fish (Osseous-fish, $F$ ); of an Amphibian (Land-salamander, $S$ ); of a Reptile (Tortoise, $T$ ) ; and of a Bird (Chick, $C$ ).

Plate VIII. shows the embryos of four Mammals in the three corresponding stages : of a $\operatorname{Hog}(H)$, Calf $(C)$, Rabbit $(R)$, and a Man $(M)$. The conditions of the three different stages of development, which the three crossrows (I., II., III.) represent, are selected to correspond as exactly as possible.

The first, or npper cross-row, I., represents a very early stage, with gillopenings, and withont limbs. The second (middle) cross-row, II., shows a somewhat later stage, with the first rudiments of limbs, while the gillopenings are yet retained. The third (lowest) cross-row, III., shows a still later stage, with the limbs more developed and the gill-openings lost. The membranes and appendages of the embryonic body (the amnion, yelk-sac, allantois) are omitted. The whole twenty-four figures are slightly magnified, the upper ones more than the lower. To facilitate the comparison, they are all reduced to nearly the same size in the cnts. All the embryos are seen from the left side; the head extremity is above, the tail extremity below; the arched back turned to the right. The letters indicate the same parts, in all the twenty-four figures, namely : $v$, fore-brain; $z$, twixt-brain; $m$, midbrain; $h$, hind-brain; $n$, after-brain ; $r$, spinal marrow; $e$, nose; $a$, eye; $o$, ear; $k$, gill-arches; $g$, heart ; $w$, vertebral column; $f$, fore-limbs; $b$, hindlimbs; $s$, tail..$^{100}$. 



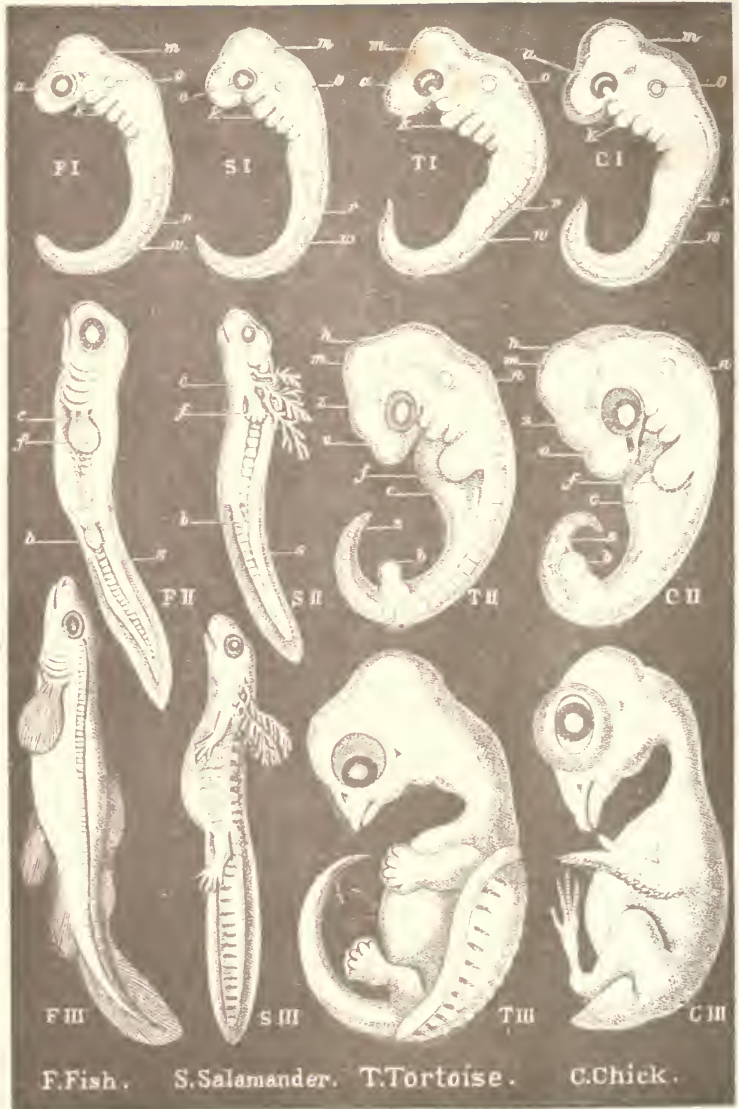




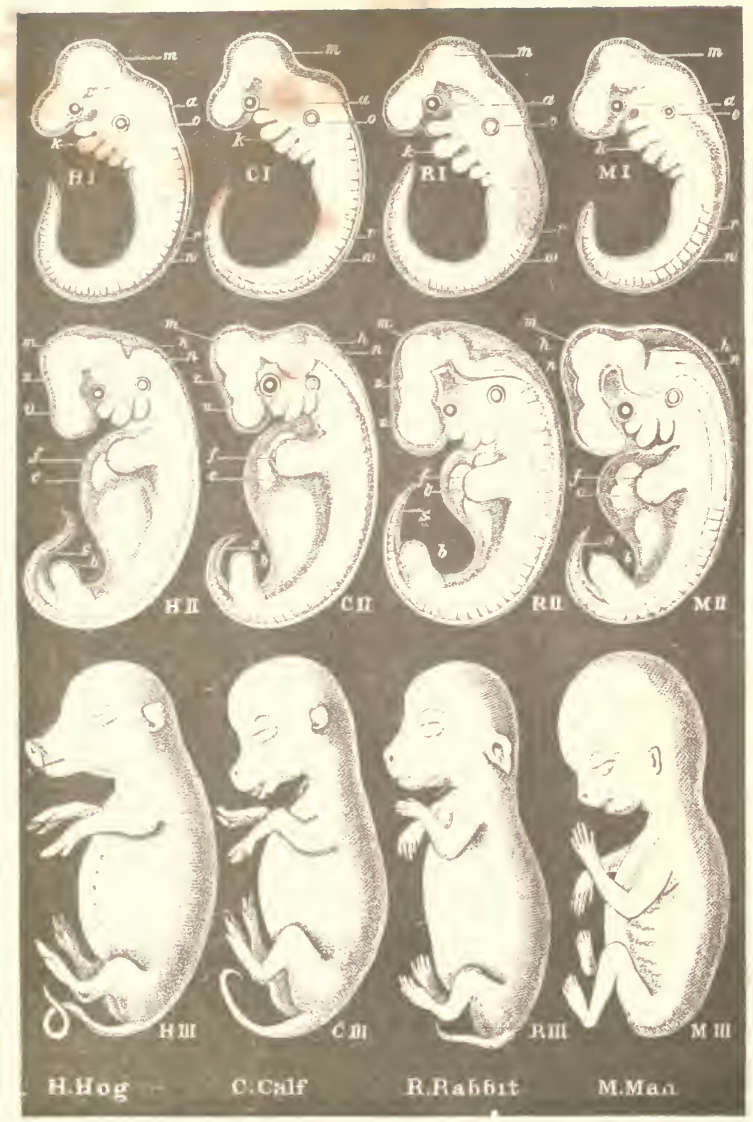





\section{CHAPTER XII.}

\section{THE GERM-MEMBRANES AND THE FIRST CIRCULATION OF THE BLOOD.}

The Mammalian Organization of Man.-Man has the same Bodily Structure as all other Mammals, and his Embryo develops in exactly the same way.-In its Later Stages the Human Embryo is not essentially different from those of the Higher Mammels, and in its Earlier Stages not even from those of all Higher Vertebrates.-The Law of the Ontogenetic Connection of Systematically Related Forms.-Application of this Law to Man.-Form and Size of the Human Embryo in the First Fonr Weeks. - The Hnman Embryo in the First Month of its Development is formed exactly like that of any other Mammal.-In the Second Month the First Noticeable Differences appear.-At first, the Hnman Embryo resembles those of all other Mammals; later, it resembles only those of the Higher Mammals.-The Appendages and Membranes of the Human Embryo.-The Yelk-sac.-The Allantois and the Placenta.-The Amnion.-The Heart, the First Blood-vessels, and the First Blood, arise from the Intestinal-fibrons Layer.-The Heart separates itself from the Wall of the Anterior Intestine.-The First Circulation of the Blood in the Germ-area (a. germinativa) : Yelk-arteries and Yelk-veins.-Second Embryonic Circulation of the Blood, in the Allantois: Navel-arteries and Navel-veins.-Divisions of Hnman Germ-history.

"Is man a pecnliar organism? Does he originate in a wholly different way from a dog, bird, frog, or fish? and does he thereby justify those who assert that he has no place in nature, and no real relationship with the lower world of animal life? Or does he develop from a similar embryo, and undergo the same slow and gradual progressive modifications? The answer is not for an instant doubtful, and has not been donbtful for the last. thirty years. The mode of man's origin and the earlier stages of his 
development are undoubtedly identical with those of the animals standing directly below him in the scale; without the slightest doubt, he stands in this respect nearer the apo than the ape does to the dog."-Thomas HUXLEY (1863).

THE most important phenomenon, having a general bearing, that we have so far met with in the process of human germhistory, is surely the fact that the development of the human body proceeds from the beginning in exactly the same way as that of other Mammals. All the special peculiarities of individual development which distinguish Mammals from all other animals are found also in Man. Long ago, from the physical structure of the perfect Man the conclusion was drawn that his natural position in the system of the animal world can only be in the mammalian class. In 1735 Linnæus, in his Systema Natura, placed Man in one and the same class with the Apes. This position is fully corroborated by comparative germ-history. We have evidence that, no less in embryonic development than in anatomical structure, Man closely resembles the higher Mammals, and especially the Apes. If we now seek, by applying the fundamental biogenetic law, to understand this ontogenetic agreement, the perfectly simple and necessary conclusion is that Man is descended from other mammalian forms. Hence we can no longer doubt the common descent of Man and the other Mammals from a single primreval parent-form, or hesitate to believe that the blood-relationship is closest between Men and Apes.

This essential harmony between the embryo of Man and of the other Mammals, in their whole bodily form and internal structure, exists even in that latest age of development, in which the mammalian body, as such, is already 
unmistakable. (Cf. Plates VI. and VII., the second row.) But in a somewhat earlier stage, in which the rudiments of the limbs, the gill-arches, the sense-organs, etc., are already present, we cannot yet recognize mammalian embryos as such, nor can we distinguish them from the embryos of Birds and Reptiles. If we go back to still earlier stages of development, we are unable even to discover any distinction between the embryos of these higher Vertebrates and those of the lower, such as the Amphibia and Fishes (Plates VI., VII., upper row). Finally, if we go still further back, to the construction of the body from the four secondary germ-layers, we make the surprising discovery that these same four germ-layers exist, not only in all Vertebrates, but also in all the higher Invertebrates, and that they are everywhere concerned in the same way in forming the fundamental organs of the body. And if then we inquire into the origin of these four secondary germlayers, we find that they develop from the two primary germ-layers, which are identical in all animals, with the exception of the lowest division, the Protista. (Cf. Figs. 23-28, p. 93.) Finally, we see that the cells, which compose the two primary germ-layers, universally originate by fission, from a single simple cell, from the egg-cell.

It is impossible to lay too much stress on this remarkable parallelism of the most important germ-conditions of man and animals. We shall afterwards turn the fact to account in support of the hypothesis of monophyletic descent, i.e., the assumption of the common, single line of descent of man and the higher animal tribes. It declares itself in the very beginning of the individual development; in the cleavage of the egg-cell, in the formation of the 
germ-layers, in the fission of these, in the construction of the most important fundamental orǵans from these germ-layers, etc. The first rudiments of the principal parts of the body. and, above all, of the oldest main organ, the intestinal canal, are everywhere originally identical; they always appear in the same simplest form. But all the peculiarities by which the various larger and smaller groups of the animal kingdorn are differentiated from one another only make their appearance gradually, and secondarily, in the course of the evolution of the germ; and those which distinguish the animals most elosely allied in the system of the animal kingdom are the latest to appear. This latter phenomenon can be formulated as a definite law, which may be regarded as, in some sense, an addition or appendage to the fundamental law of Biogeny. It is the law of the ontogenetic connection between systematically allied animal forms. The meaning of this is that the nearer two full-grown perfect animals are to each other in point of general body-structure, and hence the more closely they are allied in the system of the animal kingdom, the longer do their embryonic forms remain the same, and the longer are their embryos, and their young forms in general, either altogether indistinguishable, or distinguishable only by subordinate characters. This law holds good of all animals in which the original form of evolution has been correctly inherited palingenetically, or by "inherited evolution". Where, on the other hand, this original form has been altered kenogenetically, or by "vitiated evolution," the law is less true in proportion as a greater number of new evolutionary conditions have been introduced by adaptation (cf. pp. 10-14).101

If we apply this law of the ontogenetic connection 
between systematically (and hence also phylogenetically) allied forms to Man, and if, with reference to this law, we rapidly run through the earliest human conditions, the first striking thing noticeable in the early history of the germ is the morphological identity of the egg-cells of Man and of other Mammals (Fig. 1). All the properties that characterize the mammalian egg, are also observable in the human egg; especially that characteristic structure of its coating (the zonc pellucida) which clearly distinguishes the mammalian egg from that of all other animals. When

Fig. 121.-Lyre-shaped germ-shield of a dog. "Double shield" of Remak, "embryonic rudiment" of other authors.) The dorsal furrow is visible in the centre; on either side are the mednllary swellings.

the human embryo is fourteen days old, it, like all other mammalian embryos, is in the form of an entirely simple, lyreshaped germ-shield. Along the middle line of the dorsal side of this, there appears the rectilineal, groove-shaped medullary furrow, bordered by the two parallel

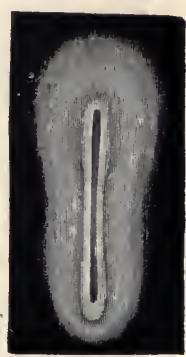
dorsal, or medullary swellings. The ventral side is attached to the wall of the globular intestinal germ-vesicle. In this stage the human embryo is one line, or two millimetres in length. It is not distinguishable from that of other Mammals, e.g., of the Dog (Fig. 121). ${ }^{102}$

A week later, or at the end of the twenty-first day, the human embryo has already attained twice this length: it is now two lines or about five millimetres in length, and already shows, when seen from the side, the characteristic curvature of the back, the swelling of the head end, the earliest rudi- 
ments of the higher sense-organs, and the rudiments of the gill-openings, piercing the sides of the neck (Fig. 122, III.; Plate VII. Fig. $M$ I.). The allantois has grown out from the

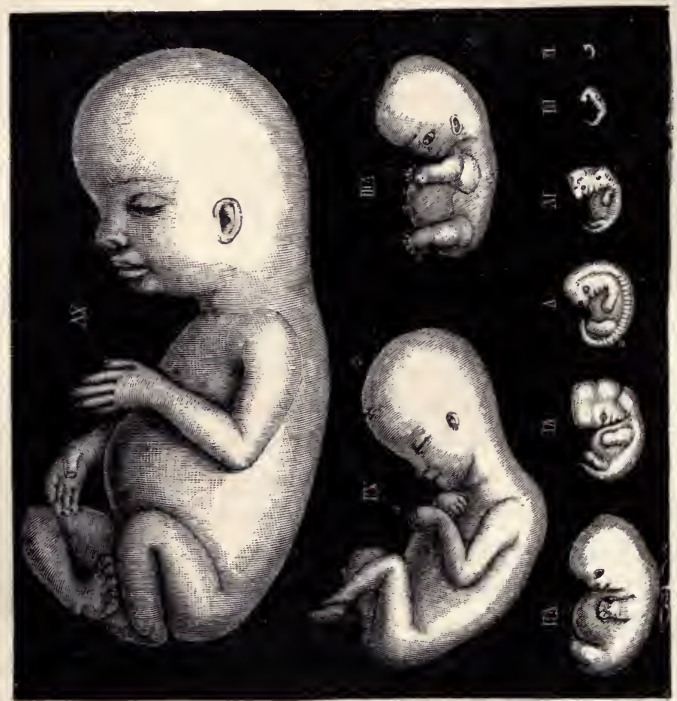

Fig. 122.-Human germs or embryos from the second to the fifteenth week (natural size), seen from the left side, the arched back turned towards the right. (Principally after Ecker.) II., human embryo of 14 days; III., of 3 weeks; IV., of 4 weeks; V., of 5 weeks; VI., of 6 weeks; VII., of 7 weeks; VIII., of 8 weeks; XII., of 12 weeks ; XV., of 15 weeks.

hind end of the intestine. The embryo is already entirely enveloped by the amnion, and is now only connected with the germ-vesicle, which is changing into the yelk-sac, by means of the yelk-duct, in the centre of the abdomen. 
In this stage of development, the extremities, or limbs, are still entirely wanting; there is as yet no trace either of arms or legs. The head end, however, has already become markedly distinct or differentiated from the tail end ; moreover, the first rudiments of the brain-bladders appear in front, and the heart appears more or less distinctly on the anterior intestine. A real face is, however, not yet formed. We may also search in vain for any character distinguishing the human embryo, in this stage, from that of other Mammals. (Cf. Fig. $M$ I., $R$ I., $C$ I., and $H \mathrm{I}$. on Plate VII. $)^{103}$

Another week later, at the end of the fourth week, between the twenty-eighth and the thirtieth day of development, the human embryo is four or five lines in length, or about one centimetre (Fig. 122, IV.; Plate VII. Fig. $M$ II.). The hearl with its various parts is now plainly distinguishable: within, the five primitive brain-bladders (fore-brain, mid-brain, twixt-brain, hind-brain, and after-brain); at the lower end of the head, the gill-arches, which divide the gill-openings; on the sides of the head the rudiments of the eyes, two indentations of the outer skin, towards which grow two simple bladders from the side-wall of the forebrain. Far behind the eyes, above the last gill-arch, the bladder-like rudiment of the organ of hearing is visible. The head, which is very large, is attached to the trunk at a very considerable angle, almost a right angle. The trunk itself is still attached at the centre of its ventral side to the intestinal germ-vesicle; but the embryo is already still further separated from the latter, which, therefore, protrudes and forms the yelk-sac. Like the front part, the hind part of the body is very much curved, so that the pointed tail end is turned towards the head. The head rests, face down-

voL. I. 

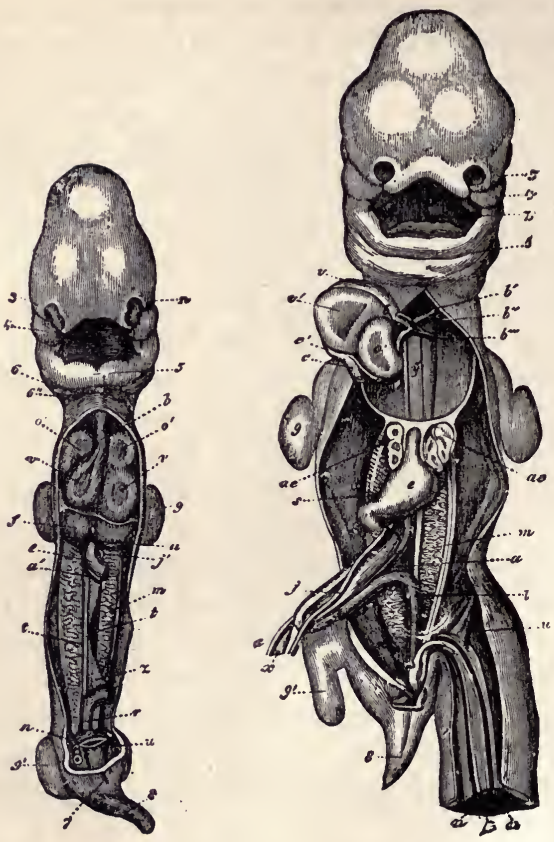

FIG. 123.-Human embryo of four weeks old, opened on the ventral side. The walls of the chest and abdomen have been cut away, so that the contents of the chest and ventral cavities are visible. All the appendages (amnion, allantois, and yelk-sac) have been removed, and also the middle portion of the intestine : $n$, eye ; 3 , nose ; 4 , upper jaw ; 5 , lower jaw ; 6 , the second gill-arch, and $6^{\prime \prime}$ the third; $o v$, heart ( $o$, right, $o$, left auricle; $v$, right, $v^{\prime}$, left ventricle); $b$, origin of the aorta; $f$, liver ( $u$, navel-vein); $e$, intestine (with the yelk-artery, cut away at $a^{\prime}$ ); $j^{\prime}$, yelk-vein; $m$, primitive kidney; $t$, rudiments of the sexual glands; $r$, terminal intestine (with mesentery, $z$, cut away) ; $n$, navel-artery ; $u$, navel-vein; 7 , anus; 8 , tail ; 9 , front limb; $9^{\prime}$, hind limb. (After Coste.) 
Fig. 124. - Human embryo of five weeks old, opened on the ventral side (as in Fig. 123). The chest and ventral walls, with the liver, have been removed; 3, outer nasal process ; 4, npper jaw ; 5 , lower jaw ; $z$, tongue; $v$, right, $v^{\prime}$, left ventricle of heart; $o^{\prime}$, left auricle; $b$, origin of the aorta ; $b^{\prime} b^{\prime \prime} b^{\prime \prime \prime}$, first, second, third arterial arches; $c, c^{\prime}, c^{\prime \prime}$, hollow veins (vence cavce); ae, lungs ( $y$, arteries of lungs); $e$, stomach; $m$, primitive kidneys; ( $j$, left yelk-veins; $s$, vena portce; $a$, right yelk-artery ; $n$, navel-artery ; $u$, navel.vein); $x$, yelk-duct; $i$, large intestine; 8 , tail ; 9 , front limb; 9', hind limb. (After Coste.)

ward, on the yet open chest. The curvature presently becomes so great that the tail almost touches the forehead (Fig. 122, V.; Fig. 137). Three or four distinct curves of the arched dorsal side are now distinguishable; a skull-curve or "front head-curve" near the second brain-bladder, a neckeurve or "hind head-curve" at the beginning of the spinal marrow, and a tail-curve at the hind end of the body. This marked curvature is shared by Man with the three higher classes of Vertebrates (the Amnion-animals), while in the lower classes it is either much less pronounced, or altogether absent. In this stage, when four weeks old, Man has a true tail, double the length of the legs. The rudiments of the limbs are now plainly marked: four entirely simple buds in the form of roundish plates, two fore limbs and two hind limbs, the former being a little larger than the latter. ${ }^{104}$

On opening the human embryo of the age of one month (Fig. 123), we find the intestinal canal already formed in the body-cavity, and that it is nearly completely separated from the germ-vesicle. The mouth-opening and anus already exist. The cavity of the mouth is, however, not yet separated from that of the nose, nor is the face in general yet formed. The heart, on the other hand, already shows all the four compartments; it is very large, filling 
almost the entire chest-cavity (Fig. 123,ov). Behind it the very small rudiments of the lungs lie concealed. The primitive kidneys are very large (Fig. 123, $m$ ), occupying the greater part of the ventral cavity, and extending from the liver $(f)$ to the pelvic intestine. Thus at the end of the first month, all the essential parts of the body are already begun; and yet, in this stage, we are still unable to discern any characters essentially distinguishing the human embryo from those of the Dog, the Rabbit, the Ox, the Horse, or, indeed, of any of the higher Mammals. All these embryos are still of the same form, and at best differ from the embryo of Man only in the general dimensions of the body, or in the size of the individual organsdifferences of no moment. Thus, for example, the head, relatively to the trunk, is a little larger in Man than in the Sheep; in the Dog the tail is somewhat longer than in Man. But these are all, evidently, very trifling differences indeed, and of no importance. On the other hand, the whole internal and external organization, the form, the disposition, and the connection of the separate parts of the body of the germ are essentially the same in the human embryo of four weeks, and in the embryos of other. Mammals in a corresponding stage of development.

But the case is different even in the second month of human development. Fig. 122 represents a human germ, VI., of six weeks, VII., of seven weeks, VIII., of eight weeks, in the natural size. The differences which distinguish the human embryo from those of the Dog and the lower Mammals, now gradually begin to become more prominent. Even after the sixth, and yet more after the eighth week, considerable differences are visible, especially 
in the structure of the head (Plate VII. Fig. $M$ III., etc.). The size of the various divisions of the brain in Man is now greater, while, on the contrary, the tail appears shorter. Other differences between Man and the lower Mammals are to be seen in the relative dimensions of the interior parts. Yet even now the human embryo is hardly distinguishable from that of the nearest allied Mammals, the Apes, and especially the anthropomorphic Apes. The characters which distinguish the human embryo from those of Apes make their appearance much later; even in a very advanced stage of development, in which the human embryo is instantly distinguishable from that of hoofed animals (Ungulata), the former is still very similar to the embryo of the higher Apes. At length, in the fourth or fifth month these characters make their appearance, and during the four last months of the embryonic life of the human being, from the sixth to the ninth month of pregnancy, the human embryo is readily distinguishable from those of all other Vertebrates; then the characters which distinguish the various races of mankind also make their appearance, especially those in the structure of the skull.

The striking resemblance which exists for a long time between the embryos of Man and of the higher Apes disappears, moreover, at a much earlier period in the lower Apes. It is naturally retained longest in the large anthropomorphic Apes (the Gorilla, Chimpanzee, Orang-outang, and Gibbon; Plate XIV.). The facial resemblance, which strikes us in these man-like Apes, continually decreases with age. On the other hand, it is retained throughout life by the remarkable Nose-apes (Semnopithecus nasicus) of Borneo (Fig. 125), the well-shaped nose of which might well be coveted by men 
in whom this organ is too short. On comparing the face of this nosed monkey with that of specially ape-like human beings (e.g., the noted Julia Pastrana, Fig. 126), the
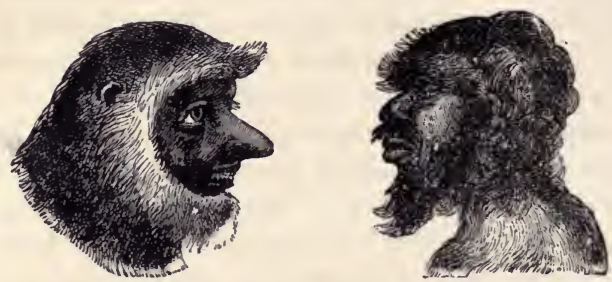

Frg. 125.-Head of a nose-ape (Semnopithecus nasicus) from Borneo. (After Brehm.)

Fig. 126.-Head of Julia Pastrana. (From a photograph by Hintze.)

former will appear a higher form of development than. the latter. There are very many persons who believe that the "image of God" is unmistakably reflected in their own features. If the Nosed-ape shared in this singular opinion, he would hold it with a better right than some snub-nosed people. ${ }^{105}$

This gradually progressive separation, this increasing divergence of the human from the animal form, which depends on the law of the ontogentic connection between systematically allied forms, is seen not only in the external structure of the body, but also in the formation of the internal organs. It is even expressed in the formation of the coverings and appendages that are found round the outside of the embryo, and which we are now about to consider somewhat more in detail. Two of these appendages, the amnion and the allantois, belong only to the 
three higher vertebrate classes, while the third, the yelksac, occurs in most Vertebrates. This circumstance is very significant, and we shall afterwards find that it affords material assistance towards the construction of the genealogical tree of Man.

The nature of the outer egg-membrane, which surrounds the entire egg embedded in the uterus of the Mammal, is the same in Man as in the higher Mammals. At first the egg is surrounded, as we have already stated, by the transparent, structureless zona pellucida (Fig. 1, p. 122, and Fig. $36-40$, pp. 210-212). Very soon, however, even in the first week of development, its place is taken by the permanent tufted membrane (chorion). This originates from the outer fold of the amnion, from the so-ealled serous membrane, the formation of which we shall presently examine. It is formed of a single stratum of cells from the outer germlayer, the skin-sensory layer. At its first appearance the serous membrane is an entirely simple, flat, closed vesicle; like a wide sac, elosed in all directions, it surrounds the embryo with its appendages; the intermediate space between the two is filled with clear watery fluid. At an early period, however, the smooth outer surface of the sac becomes covered with numerous small tufts or knots, which are really hollow processes, resembling the fingers of a glove (Fig. 127; 139, ${ }_{4} s z,{ }_{5} c h z$ ). These branch and grow into the corresponding depressions formed by the bag-like glands of the mucous membrane of the maternal uterus; the egg thus acquires its permanent, fixed position (Figs. 130, 132, 134).

In the human egg, even between the thirteenth and fourteenth day, this outer egg-membrane, which we shall 


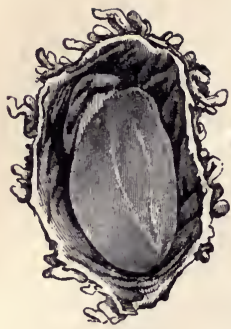

Fic. 127.

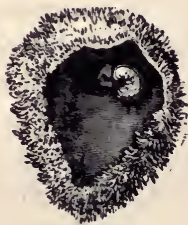

Fig. 130.
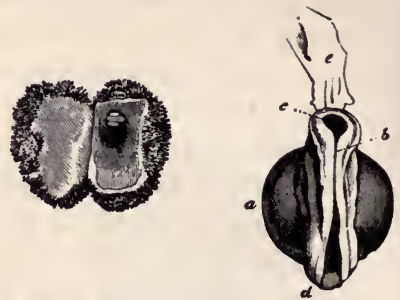

FE. 120 .

TIG. 128.

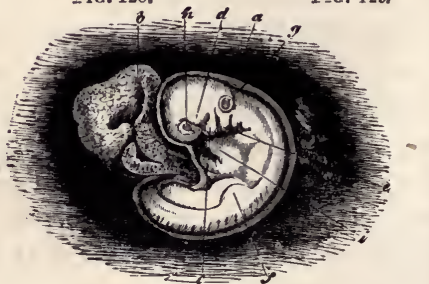

Fig. 127.-Human egg between the twelfth and thirteenth day. After Allen Thomson. 1. Not opened; natural size. 2. Opened, and enlarged. Within the outer tufted membrane (chorion) the small curved germ lies upon the left of the upper side of the large intestinal germ-vesicle.

Fig. 128.-Human egg on the fifteenth day. After Allen Thomson. Natural size, and opened. The small germ lies in the upper right-hand part of the right half.

FiG. 129.-Human germ on the fifteenth day, taken from the egg; enlarged : $a$, yelk-sac; $b$, region of the neck (where the medullary furrow is already closed); $c$, head part (with open medullary furrow); $d$, hind part (with open medullary furrow); $e$, a shred of the amnion.

- Fig. 130.-Hnman egg between the twentieth and twenty-second day. After Allen Thomson. Natnral size; opened. The outer tufted membrane (chorion) forms a capacious vesicle, to the inner wall of which the small germ (above, on the right) is attached by a short navel.cord.

Fig. 131.-Human germ between the twentieth and twenty-second day, taken out of the egg; enlarged : $a$, amnion; $b$, yelk-sac ; $c$, lower jaw process of the first gill-arch; $d$, upper jaw process of the same; $e$, second gill-arch (behind it are two other small arches). Three gill-openings are very plainly seen; $f$, rndiments of the fore-limbs; $g$, ear-vesicle ; $h$, eye; $i$, heart. 
brietly call the tufted membrane (chorion), is completely covered with small knots or tufts, and forms a globe or sphere of 6-8 millimetres in diameter (Figs. 127-129.) In consequence of the accumulation of a large mass of liquid in the inside, the tufted membrane (cloorion) continually increases in size, so that the embryo occupies only a small part of the space within the egg-bladder. At the same time the tufts on the chorion increase in number and size, and
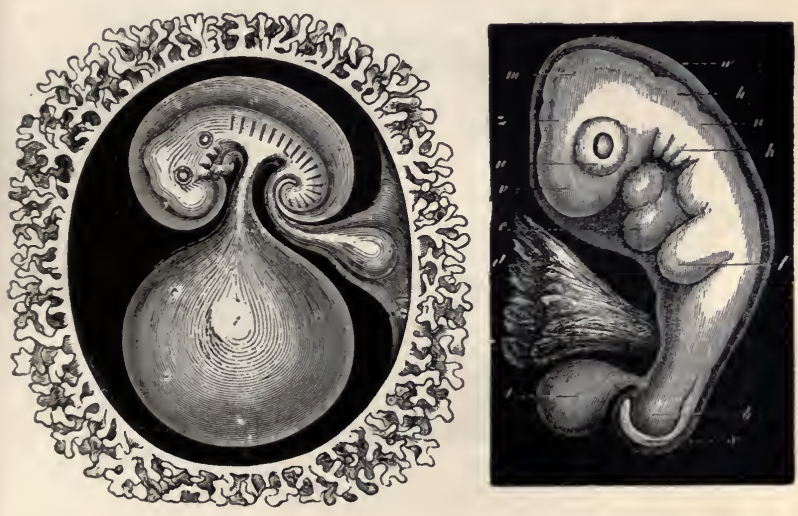

Fig. 132.-Human embryo, with amnion and allantois, in the third week; with a large globular yelk-sac (below) and a bladder-like allantois (right); there are as yet no limbs. The germ and its appendages are surrounded by the tufted membrane (chorion).

Fig. 133.- Hnman embryo, with amnion and allantois, in the fourth week. (After Krause.) The amnion (w) lies pretty close to the body. The greater part of the yelk-sac $(d)$ has been torn away. Behind this the allantois $(l)$ is visible, as a pear-shaped vesicle of considerable size. Arms $(f)$ and legs $(b)$ are just beginning; $v$, fore-brain; $z$, twixt-brain; $m$, mid-brain; $h$, hind-brain; $n$, after-brain; $a$, eye; $k$, three gill-arches; $c$, heart; $s$, tail. 
become more branched. Though these tufts at first covered the whole surface, they afterwards degenerate over a great part of this; they develop in consequence all the more vigorously at a particular point, at the place where the allantois forms the placenta.

On opening the chorion of a human embryo of three

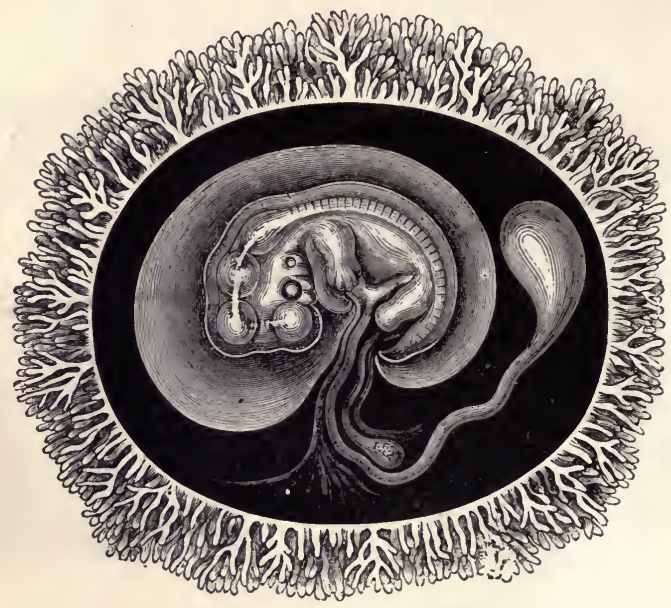

FIG. 134.-Human embryo with its membranes, six weeksold. The outer covering of the embryo forms the chorion, which is covered with numerous branching tufts, and is lined internally by the serous membrane. The embryo is surrounded by the delicate membrane of the amnion-sac. The yelk-sac is reduced to a little pear-shaped navel-vesicle; its thin stalk, the long yelkduct, is enclosed in the navel-cord. In this cord, behind the yelk-duct, lies the much shorter stalk of the allantois, the inner layer of which (intestinalglandalar layer) in Figs. 132 and 133 presented a bladder of considerable size; while the onter layer attaches itself to the inner wall of the outer egg-membrane, and at this point forms the placenta. 
weeks old, we find a large, round sac, filled with liquid, on the ventral side of the germ. This is the yelk-sac, the so-called navel-vesicle, the origin of which we have already examined (Figs. 132, 133). In proportion as the embryo grows larger, the yelk-sac grows smaller. At a later period it hangs, as a small pear-shaped vesicle, at the end of a long stalk (the yelk-duct), from the abdomen of the embryo (Fig. 139, ${ }_{5} d s$ ), and is finally detached from the body by the closing of the navel. The wall of this navel-vesicle consists, as we have seen, of an inner layer, the intestinal-glandular layer, and an outer layer, the intestinal-fibrous layer. It is therefore composed of the same constituents as the intestinal wall itself, of which it forms, in fact, a direct continuation. In Birds and Reptiles the yelk-sac is much larger, and contains a considerable quantity of albuminous and fatty nutritive matter. This penetrates through the yelk-duct into the intestinal cavity and serves as food. In Mammals the yelksac plays a much smaller part in the nourishment of the germ, and degenerates at an early period. The relation of the intestine to the yelk sac has very often been entirely mistaken. According to the Gastræa Theory the two form one whole. We may say that the primitive intestine of those Vertebrates which are without a skull afterwards separated in their descendants (in conséquence of the accumulation of nutritive yelk) into two parts, a transitory embryonic organ (the yelk-sac), and a permanent intestine (the after-intestine).

Behind the yelk-sac, a second and much more significant appendage forms, at an early period, on the abdomen of the vertebrate embryo. This is the allantois, or primitive urinary sac, an important embryonic organ, which occurs 
only in the three higher classes of Vertebrates. It grows from the hind end of the intestinal canal, from the pelvic intestinal cavity (Figs. 133, $l, 135, r, u, 136, p, 139, a l$ ). Its

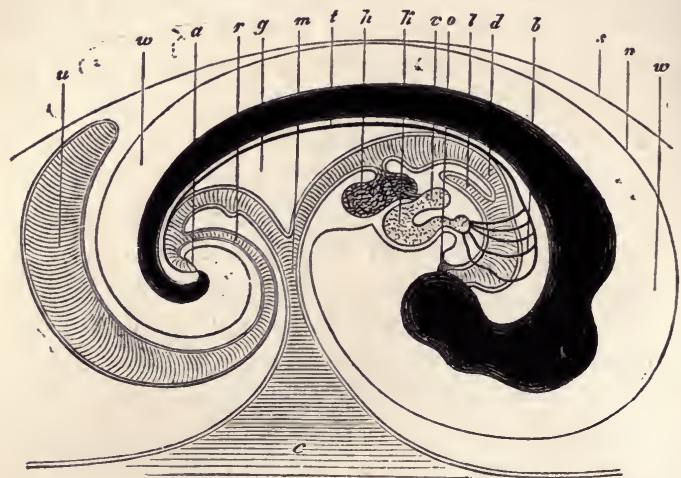

FrG. 135.-Longitudinal section throngh the embryo of a Chick (in the fifth day of incubation). The embryo with curved dorsal surface (black): $d$, intestine; 0 , mouth; $a$, anus; $l$, lungs ; $h$, liver; $g$, mesentery; $v$, anricle; $k$, ventricle; $b$, arterial arches; $t$, aorta; $c$, yelk-sac; $m$, yelk-duct; $w$, allantois; $r$, stalk of allantois-; $n$, amnion; $v$, amnion-cavity; 8 , serous membrane. (After Baer.)

first rudiment appears as a small vesicle on the edge of the pelvic intestinal cavity, representing an extension of the intestine, and therefore (like the yelk-sac) has a two-layered wall. The cavity of the vesicle is coated by the intestinalglandular layer, and the outer lamella of the wall is formed by the thickened intestinal-fibrous layer. The small vesicle grows larger and larger, and forms a sac of considerable size, filled with liquid, and in the wall of which large bloodvessels form. It soon reaches the inner wall of the egg- 
cavity, and spreads itself out on the inner surface of the chorion. In many Mammals the allantois becomes so large that it finally surrounds the whole embryo with its other appendages, as a great covering, and extends over the whole inner surface of the egg-membrane. On cutting such an egg, the first thing met with is a large space filled with

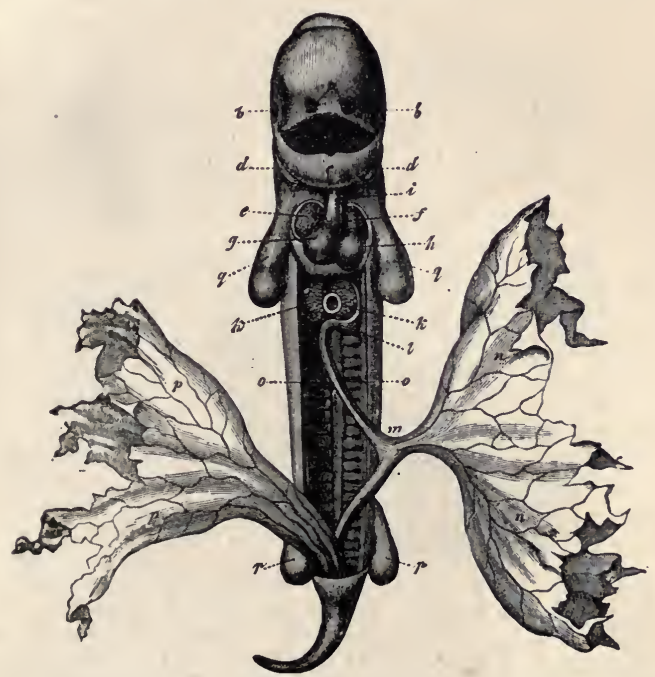

Fig. 136.-Embryo of Dog, twenty -five days old, opened on the ventral side (as in Figs. 134 and 135). Chest and ventral walls hare been removed: $a$, nose-pits; $b$, eyes ; $c$, under-jaw (first gill-arch); $d$, second gill-arch; ef $g h$, heart ( $e$, right, $f$, left anricle; $g$, right, $h$, left ventricle); $i$, aorta (origin of); $k k$, liver (in the middle between the two lobes is the cnt yelk-vein); $l$, stomach; $m$, intestine; $n$, yelk-sac ; 0 , primitive kidneys : $p$, allantois ; $q$, fore-limbs; $h$, hind-limbs. The crooked embryo has been stretched straight. (After Bischoff.) 
fluid; this is the allantois cavity, and it is only after the removal of this membrane that the real embryonic body, which is enclosed in the amnion, is found.

In Man, the allantois does not attain so great a size, but losing its vesicular form, changes into the placenta soon after it has reached the inner wall of the chorion.

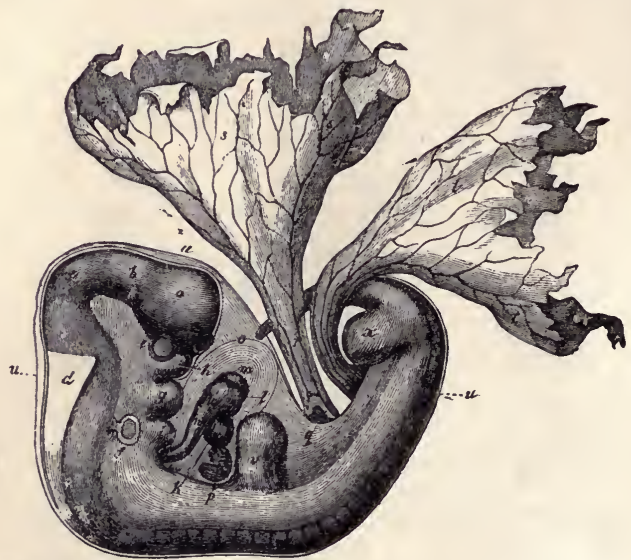

FIG. 137.-Embryo of a Dog, from the right side: $a$, the first brain. bladder; $b$, second; $c$, third; $d$, fourth; $e$, the eye; $f$, the ear-vesicle; $g h$, first gill-arch ( $g$, lower jaw, $h$, upper jaw); $i$, second gill-arch; $k l m$, heart ( $k$, right auricle; $l$, right ventricle; $m$, left ventricle); $n$, beginning of the aorta ; 0 , heart pouch; $p$, liver; $q$, intestine ; $r$, yelk-duct; $s$, yelk-sac (torn away); $t$, allantois (torn away); $u$, amnion; $v$, fore-limb; $x$, hind-limb. (Afier Bischoff.)

Yet even in Man the first rudiment of the allantois is a stalked pear-shaped bladder (Fig. 133, l), just as in other Mammals. I stated this in 1874 , in the first and second 
editions of this book, and explained it in the drawing now given in Fig. 137. I based the statement on a very apt deduction. For as the general form and the finer structure of the placenta is entirely similar in Man and in Apes, the origin of the organ could not be different in the two cases. As, however, the bladder-like form of the allantois of the human being had never been directly observed, I was gravely accused by Wilhelm His of falsifying science. His stated that "it is known that the allantois in the human being is never seen in the bladder-like form" (!). Luckily for me, this "never visible" bladder form was actually seen by Professor Krause of Göttingen in the following year (1875), and a drawing of it, reproduced in Fig. 133, was given. $^{106}$

When the bladder-shaped human allantois has reached the inner wall of the tufted membrane (chorion), spreading itsclf flatly over the latter, it forms the placenta, which is very important to the nourishment of the germ. The stalk of the allantois, which connects the embryo with the placenta, and carries the large blood-vessels of the navel from the former to the latter, is enveloped by the amnion, and, together with the amnion-sheatli, forms the so-called navel-cord (Fig. 138, as). The large network of bloodfilled vessels of the embryonic allantois attaches itself closely to the mucous membrane of the maternal uterus, and the partition wall between the blood-vessels of the mother and those of the child grows very much thinner, thus giving rise to the remarkable apparatus for nourishing the embryonic budy which we call the placenta, and to which we shall refer hereafter. (Cf. Chapter XIX.) At present, I will speak of it only in connection with the fact 
that it appears exclusively in the higher Mammals, not in. the lower. Of the three sub-classes or principal groups of the Mammals, the two lower groups, the Beaked Animals

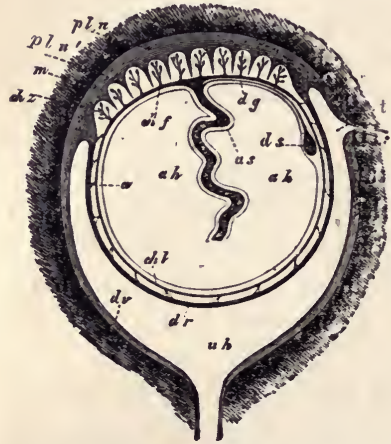

Fig. 138.-Egg-membránes of the human embryo (diagrammatic) : $m$, the thick, fleshy wall of the aterus; $p l u$, placenta (of which the inner layer ( $\left.p l u^{\prime}\right)$ sends processes in between the tufts of the chorion (chz); chf, tufted chorion; $c h l$, smooth chorion; $a$, amnion; $a h$, amnioncavity; as, amnion-sheath of the navel-cord (which passes below into the navel of the embryo, not represented here); $d g$, yelk-duct; $d s$, yelk-sac; $d v, d r$, decidua ( $d v$, true, $d r$, false decidua). The cavity of the uterus $(u h)$ opens below into the sheath (vagina), above, on the right, into the oviduct $(t)$. (After Kölliker.)

(Ornithostoma) and Pouched Animals (Marsupialia), have no placenta, the allantois remaining a simple bladder, filled with fluid, as in Birds and Reptiles. Only in the third and most highly developed mammalian sub-class, the Placental Animals, is a true placenta developed from the allantois. To the placental sub-class belong the Hoofed Animals, Whales, Beasts of Prey, Insect-eating Animals, Rodents, Bats, Apes, and Men. This circumstance is direct evidence that man has developed from this group of Mammals.

In connection with the line of descent of the human race, the allantois is, therefore, of twofold interest: firstly; because this appendage is entirely wanting in the lower classes of Vertebrates, and is developed only in the three 

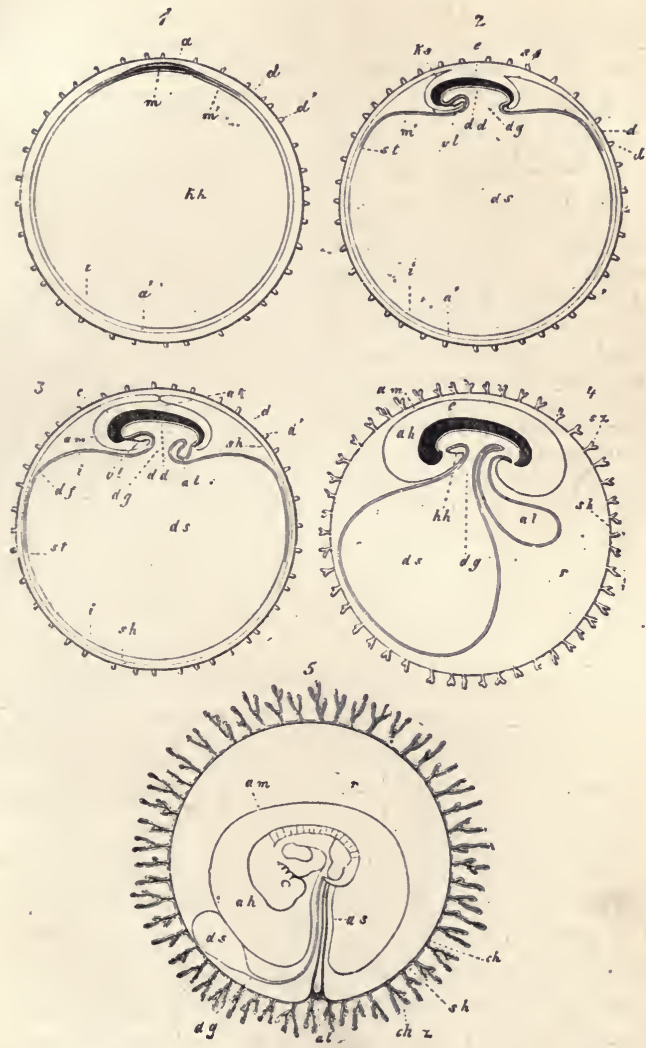

FIG. 139.-Five diagrammatic longitudinal sections through the developing mammalian germ with its egg-coverings. In Fig. 1-4 the longitudinal section is through the sagittal plane or the middle plane of the body, which 
separates the right and left halves; in Fig. 5 the germ is seen from the left side. In Fig. 1 , the prochorion $(d)$, studded with tufts $\left(d^{\prime}\right)$, surrounds the germ-vesicle, the wall of which is composed of the two primary germlayers. Between the outer (a) and the inner (i) germ-layer within the limits of the germ-area (area germinativa) the middle germ-layer (mesolerma, $m$ ) has developed. In Fig. 2, the embryo (e) is already beginning to separate from the germ-vesicle $(d s)$, and the wall of amnion-fold is beginning to rise round the embryo (in front as the head-sheath, $k s$, behind as the tail-sheath, ss.) In Fig. 3, the edges of the amnion-fold $(\mathrm{am})$ meet over the back of the embryo, thus forming the amnion-cavity $(a h)$; in consequence of the further separation of the embryo $(e)$ from the germ-vesicle $(d s)$, the intestinalcanal $(d d)$ originates, and from the hind end of this the allantois (al) grows ont. In Fig. 4, the allantois $(a l)$ is bigger; the yelk-sac $(d s)$ is smaller. In Fig. 5, the embryo already shows the gill-openings and the rudiments of the two pairs of limbs; the chorion has formed branched tufts. In all five figures, $e$ indicates embryo; $a$, onter germ-layer; $m$, middle germ-layer; $i$, inner germ-layer; $a m$, amnion; ( $k s$, head-sheath; $s s$, tail-sheath); $a h$, amnion-cavity; $a s$, amnion-sheath of the navel-cord; $k h$, intestinal germvesicle; $d s$, yelk-sac; $d g$, yelk-duct; $d f$, intestinal-fibrous layer; $d d$, intestinal-glandular layer; $a l$, allantois ; $v l=h h$, region of the heart; $d$, yelkmembrane or prochorion; $d^{\prime}$, tufts of the latter; $s h$, serous covering; $s z$, tufts of the latter; ch, tufted membrane or chorion; chz, tufts of the latter; st, terminal vein; $r$, cavity, filled with liquid, between the amnion and chorion. (After Kölliker.) (Cf. Pl. V. Fig. 14 and 15.)

higher classes, in Reptiles, Birds, and Mammals; and, secondly, because the placenta is developed from the allantois only in the higher Mammals, including Man, and not in the lower Mammals. The former are therefore called "Placental Animals" (Placentalia).

Another characteristic common to the three higher classes of Vertebrates alone, is the formation of the third appendage of the embyro, the amnion, which has already been mentioned. We have already learned something of the amnion in noticing the separation of the embryo from the intestinal germ-vesicle. We found that the walls of the latter rise in a ring-shaped fold round the embryonic body. In front, this fold appears in the form of the so-called head-cap, or head- 
sheath (Fig. 139, ${ }_{2} k s$ ); at the back, it also arches upward and forms the tail-cap, or tail-sheath (Fig. 139, ${ }_{2} s s$ ); on the right and left sides, the fold is at first lower, and is here called the side-caps, or side-sheaths (Fig. 140; Figs. 95, 96, af, p. 317). All these caps or sheaths are only parts of a con-

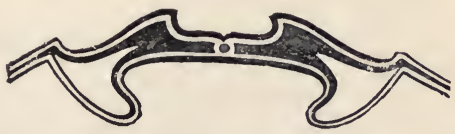

Frg. 140.-Transverse section through an embryonic Chick (a little behind the anterior opening of the intestine), at the end of the first day of incubation. The medullary furrow above and the intestinal furrow below are still wide open. At each side, the rudiment of the body-cavity (coloma) can be seen between the skin-fibrous layer and the intestinal-fibrons layer. On the right and left of it, at the outside, the side-caps of the amnion are beginning to rise. (After Remak.)

nected ring-like fold, which passes round the embryo. This grows higher and higher, rises like a great encircling wall, and finally arches over the body of the embryo, so as to form a cavern-like covering over the latter. The edges of the ringlike fold meet and, coalesce (Figs. 141, 142). The embryo, thus, at last lies in a thin membranous sac, filled with the amnion-fluid (Fig. 139, 4,5 all).

When the sac is completely closed, the inner layer of the fold, which forms the real wall of the sac, withdraws completely from the outer layer. The latter attaches itself to the inside of the outer egg-membrane ("prochorion"). It supplants this prochorion, and forms the permanent tufted membrane, the true "chorion." This arises solely from the horn-plate (Fig. 139, ${ }_{4} s l$ ). The thin wall of the amnion-sac, on the other hand, consists of two strata: of an inner stratum, the horn-plate, and of an outer stratum, the 
skin-fibrous layer-(Figs. 141;142). The latter is indeed here very thin and delicate, but yet can be distinctly shown to be a direct continuation of the leather-skin (corium), and

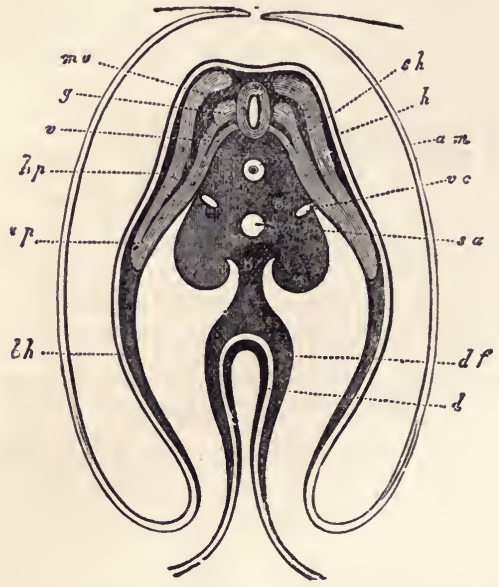

Fig. 141.-Transverse section through an embryonic Chick in the navel region (at the fifth day of incubation). The amnion-folds $(a m)$ almost meet over the back of the embryo. The intestine $(d)$, still open, passes below into the yelk-sac: $d f$, intestinal-fibrous layer; $s h$, notochord; $s a$, aorta; $v c$, principal veins; $b h$, ventral cavity, not yet closed; $v$, anterior, $g$, posterior nerve-roots of the spinal marrow; $m u$, muscle-plate; $h$, leather-plate; $h$, horn-plate. (After Remak.)

is, therefore, the outermost layer arising from the fission of the middle germ-layer (mesoderma). Thus the outer peripheric portion of the skin-fibrous layer clothes only the inner lamella of the amnion-fold (the head-sheath, tailsheath, etc.), and extends only to the edge of the fold itself. The outer lamella is formed entirely by the horn-plate, and 
it produces the tufted chorion, the hollow, branched tufts of which grow into the depressions in the mucous membrane of the maternal uterus.

Fig. 142,-Transverso section throngh an embryonic Chick in the shoulder region (at the fifth day of incubation). The section passes midway between the rudiments of the anterior limbs (or wings, E). The amnionfolds have grown completely together over the back of the embryo. (After Remak.) (Compare, as regards other points, with Figs. 139, 140, and 1.1, and Plate V. Fig. 14.)

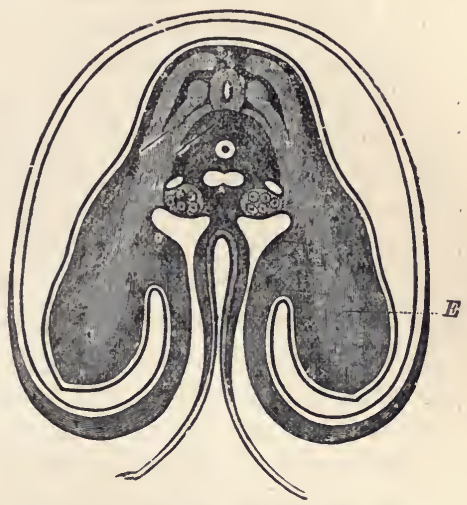

In human Phylogeny the amnion is particularly interesting, because it is a peculiar characteristic of the three higher classes of Vertebrates. Mammals, Birds, and Reptiles alone possess it, and therefore these three classes are grouped together under the name of Amnion Animals, or Amniota. All Amnion Animals, including Man, are descended from a common parent-form. All the lower Vertebrates, on the contrary, entirely want this amniotic formation.

Of the three bladder-like appendages of the embryo just mentioned, the amnion has no blood-vessels at any period of its existence. On the contrary, the two other bladders, the yelk-sac and the allantois, are provided with large bloodvessels, which accomplish the nutrition of the embryonic 
body. Here we may speak of the first circulation of blood in the embryo, and of its central organ, the heart. The first blood-vessels and the heart, as well as the first blood itself, develop from the intestinal-fibrous layer. On this account the latter was called the vascular layer by the earlier embryologists. In a certain sense this name is quite correct; only it must not be understood to imply that all the bloodvessels of the body proceed from this layer, or that the whole of the vascular layer is applied only to the formation of the blood-vessels. Neither is the case. The intestinalfibrous layer also forms, as we saw, the whole fibrous and muscular wall of the intestinal tube, and also the mesentery. We shall presently find that blood-vessels ean form independently from other parts, especially in the various parts proceeding from the skin-fibrous layer.

The heart and blood-vessiels, and the whole vaseular system, are by no means among the oldest parts of the animal organism. Aristotle assumed that the heart of the Chick was formed first; and many later authors have shared this view. This is, however, by no means the ease. On the contrary, the most important parts of the body, the four secondary germ-layers, the intestinal tube, and the notochord, are already formed before the first indication of the blood-vessel system appears. This fact, as we shall afterwards find, is in complete harmony with the Phylogeny of the animal kingdom. Our older animal ancestors possessed neither blood nor heart.

We have already examined the first blood-vessels of the mammalian embryo in transverse sections. They are, first, the two primary arteries, or "primitive aortæe," which lie in the narrow longitudinal cleft between the primitive 
spinal cords, the side-plates, and the intestinal-glandular layer (Figs. 92, $a o$, Fig. 95, 96, $a 0$ ); and, second, the two principal veins, or "cardinal veins," which appear somewhat later, outside the former, above the primitive kidney ducts (Fig. 96, vc, Fig. 141, vc). The primitive arteries seem to arise by fission from the inner parts of the intestinal-fibrous layer; the primitive veins, on the contrary, from the outer parts of the same layer.

In just the same way, and in connection with these first blood-vessels, the heart also arises from the intestinalfibrous layer, in the lower wall of the anterior intestine, near the throat, at the place where the heart remains throughout life in Fishes. Perhaps it will not seem very poetic that the heart develops directly from the intestinal wall. But the fact cannot be altered, and is also easily comprehensible phylogenetically. The Vertebrates are, at any rate, in this respect more æsthetic than the Mussels. In these the heart remains permanently lying behind on the wall of the rectum near the anus, so that the heart seems to be penetrated by the rectum.

Midway between the gill-arches of the two sides of the head, and rather further back, at the throat of the embryo, a wart-like thickening of the intestinal-fibrous layer develops on the lower wall of the intestinal head cavity (Fig. 143, df). This is the first rudiment of the heart. This swelling is spindle-shaped, at first quite solid, and is formed entirely of cells of the intestinal-fibrous layer. It afterwards, however, curves in the form of an $\mathrm{S}$ (Fig. 144, c), and a little hollow is formed in its centre, in consequence of the accumulation of a small quantity of fluid between the central cells. Some single cells of the wall separate from the rest and 
Hoat about in this fluid These cells are the first bloodcells, and the fluid is the first blood. In the same way
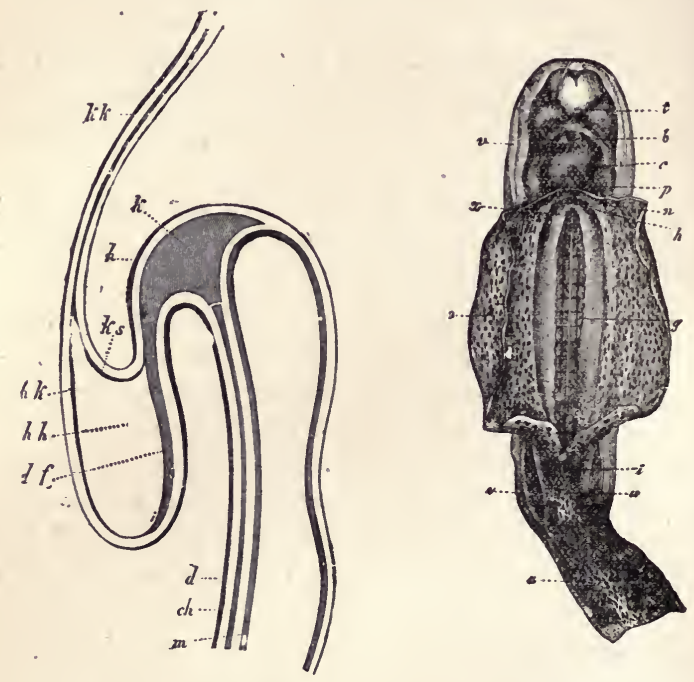

Frg. 143.-Longitudinal section through the head of an embryonic Chick (at the end of the first day of incubation): $m$, medullary tube; ch, notochord; $d$, intestinal tube (with a blind anterior end); $k$, head-plates; $d f$, first rudiment of the heart (in the intestinal-fibrons layer of the rentral wall of the head intestine); $h h$, cavity for the heart; $h k$, membrane of the heart; $k k$, head-cap of the amnion; $k s$, head-sheath; $h$, horn-plate. (After Remak.)

Fig. 144,-Hnman embryo, of 14 to 18 days, opened at the ventral side. Under the forehead-process of the head $(t)$ the heart $(c)$ appears in the lieart-cavity $(p)$ with the base of the aorta $(b)$. The greater part of the yelk-sac $(0)$ has been removed (at $x$, the opening of the anterior intestine); $g$, the primitive aorts (lying under the primitive vertebræ); $i$, terminal intestine, or large inteștine; $a$, allantois ( $u$, its stalk); $v$, amnion. (After Coste.) 
blood arises in the first rudimentary blood-vessels connected with the heart. These also, at first, are solid, cound
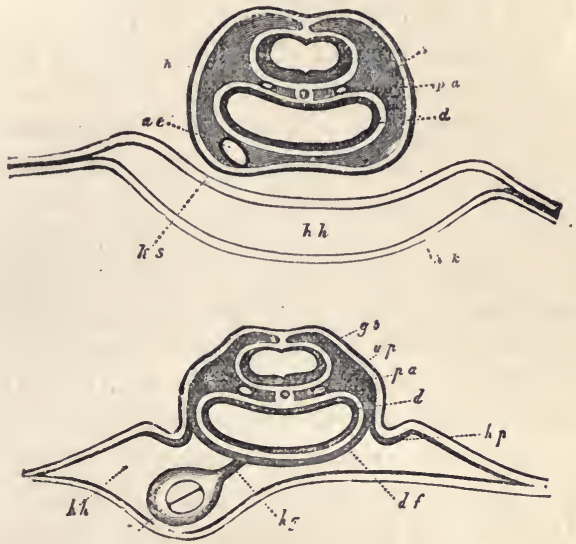

Fig. 145.-Transverse section rerough the head of an embryonic Chick of 36 hours. Below the medullary tube, the two primitive aortæ $(p a)$ are visible in the head-plates $(s)$ on both sides of the notochord. Below the throat $(d)$ can be seen the aortal.end of the heart $(a e) ; h h$, heart-cavity; $h k$, heart membrane; $k s$, head-sheath, amnion-fold; $h$, horn-plate. (After Remak.)

Fig. 146.-Transverse section throngh the heart-region of the same Chick (further back than the former). In the heart-cavity $(h h)$, the heart $(h)$ is still connected by a heart-mesentery $(h g)$ with the intestinal-fibronslayer $(d f)$ of the anterior intestine: $d$, intestinal-glandular layer; $u p$, primitive rertebral plates; $g b$, rudiment of the ear-vesicle in the hornplate; $h p$, first rising of the amnion-fold. (After Remak.)

cords of cells. They then become hollow, while a fluid separates and gathers in the centre, and single cells detach themselves from the rest and become blood-cells. This is equally true of the arteries, which earry the blood from the 
heart, and of the veins, which carry the blood back to the heart.

At first, the heart lies within the intestinal wall itself, from which it has developed, as do the first main bloodvessels proceeding from it. The heart itself is in reality only a local extension of one of these main blood-vessels. Soon, however, the heart separates from its place of origin, and now lies freely in a cavity, called the heart-cavity (Figs. 14. $, h h, 146, h h$ ). This heart-cavity is merely the anterior part of the body-cavity (coloma), which, as a horseshoe-shaped arch, connects the right and left divisions of the cœlom (Fig. 140). The wall of the heart-cavity is therefore formed, like that of the remainder of the bodycavity, partly by the intestinal-fibrous layer (Fig. 146, $d f$ ), and partly by the skin-fibrous layer $(h p)$. While the heart is separating from the anterior intestine, it remains for a short time attached to the latter by a thin plate, a heartmesentery (Fig. 146, hg). It afterwards lies quite freely in the heart-cavity, and is directly connected with the intestinal wall only by the main blood-vessels which pass from it.

The anterior extremity of this spindle-shaped heartformation, which soon assumes a curved, S-shaped form, divides into a right and a left branch. These two tubes are arched and curved upward, and represent the two first aortæ-arches. They mount up in the wall of the anterior intestine, which, in a measure, they encircle, and they there unite above at the upper wall of the intestinal head-cavity in one large single main artery, which passes backward immediately under the notochord, and which is called the main aorta (aorta principalis, Fig. 147, a). The first pair of aortæ-arches passes up on the inner wall of the first pair 
of gill-arches, and lies, therefore, between the first gill-arch $(k)$ on the outside, and the anterior intestine $(d)$ on the

Fig. 147.-Diagrammatic transverse section through the head of an embryonic Mammal : $h$, horn-plate; $m$, medullary tube (brain-bladder) ; $m r$, wall of the latter ; l, leather-plate; $s$, rudimentary skall; $c h$, notochord; $k$, gill-arch; $m p$, muscleplate; $c$, heart-cavity, anterior part of the body. cavity (coeloma); $d$, in. testinal tube; $d d$, intes. tinal-glandular layer; $d f$, intestinal-muscle plate; $h g$, heart-mesentery; $h w$, heartwall; $h k$, ventricle; $a b$, aorta-arches; $a$, transverse section through the aorta.

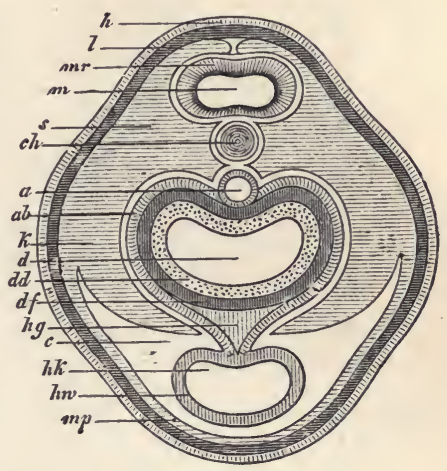

inside,-just as these vascular arches are situated in adult fishes throughout life. The single main aorta, which results from the union above of these two first vascular arches, soon again divides. into two parallel branches, which pass backward on both sides of the notochord. These are the primitive aortæ, which have been already spoken of; they are also called posterior vertebral arteries (arterice vertebrales posteriores). These two main arteries send out on each side from four to five branches at right angles, which pass from the body of the embryo into the germ-area, and are called the omphalic-mesenteric arteries (arteria omphalomesentericce), or the yelk-arteries (arterice vitellina). They represent the first rudiments of a circulation within the germ-area. The first blood-vessels, therefore, pass out from the body of the embryo and extend to the edge of 
the germ-area. Numerous blood-vessels form in the intestinal-fibrous layer of the germ-area. They are at first confined to the dark germ-area, or the so-called "vascular

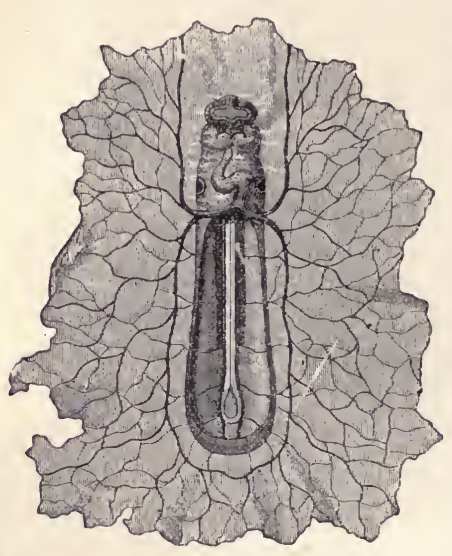

Fig.148.-Canoe-shaped germ of a Dog, from the ventral side; enlarged abont 10 times. In front, below the forehead, the first pair of gill-arches are visible; below these is the S-shaped bent heart, close by, and on either side of which lie the two ear-resicles. Posteriorly, the heart divides into the two yelkveins, which spread themselves over the germ-area (the greater part of this has been torn away). At the bottom of the open ventral cavity the primitive aortw lie between the primitive vertebræ, and from which five pairs of yelk-arteries proceed. (After Bischoff:)

area" (area opaca, or area vasculosa); but they afterwards extend over the whole outer surface of the intestinal germvesicle. The whole yelk-sac, finally, seems to be enveloped in a network of blood-vessels. It is the function of these blood-vessels to collect food-material from the contents of the yelk-sac and carry it to the body of the embryo. This is done by veins, by blood-vessels leading back, which pass in at the posterior opening of the heart, first from the germarea and later from the yelk-sac. These veins are called yelk-veins (vence vitellina); they are also often called omphalic-mesenteric veins (vena omphalo-mesentericer). 
Thus the first circulatory system of the blood in the embryo (Figs. 148-150) occurs in all the higher classes of

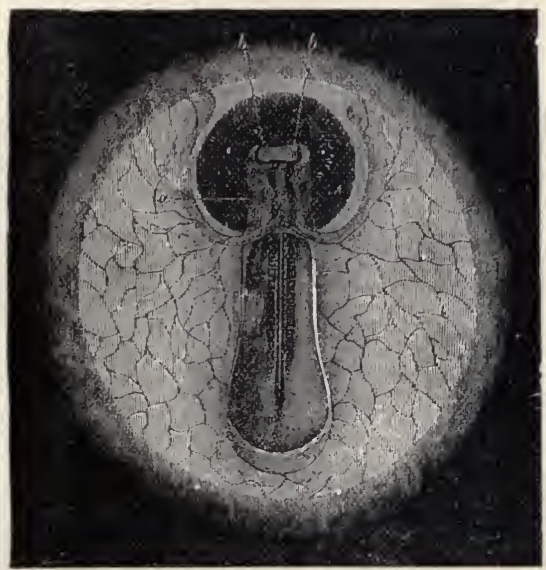

Fig. 149.-Embryo and germ-area of a Rabbit, in which the earliest rudiments of the blood-vessels appear,---seen from the ventral side (magnified abont ten times). The posterior end of the simple heart (a) divides into two large yelk-veins, which form a network of blood-vessels on the dark germ-area (which appears light on the black background). At the head extremity the fore-brain with the two eye-vesicles $(b b)$ may be seen. The dark centre of the germ is the wide-open intestinal cavity. Ten primitive vertebræ are visible on each side of the notochord. (After Bischoff.)

Vertebrates in the following simple order. The very simple pouch-shaped heart (Fig. 150, d) divides both in front and behind into two vessels. Those at the back are reins leading to the heart. They take food-material from the germ-vesicle, or yelk-sac, and carry it to the body of the 
embryo. The vessels passing from the heart in front are the gill-arch arteries, leading from the heart, and which, rising as aorta-arches, encircle the anterior end of the intestine, and unite in the main aorta (aorta principalis). The two branches, which result from the division of this main artery,

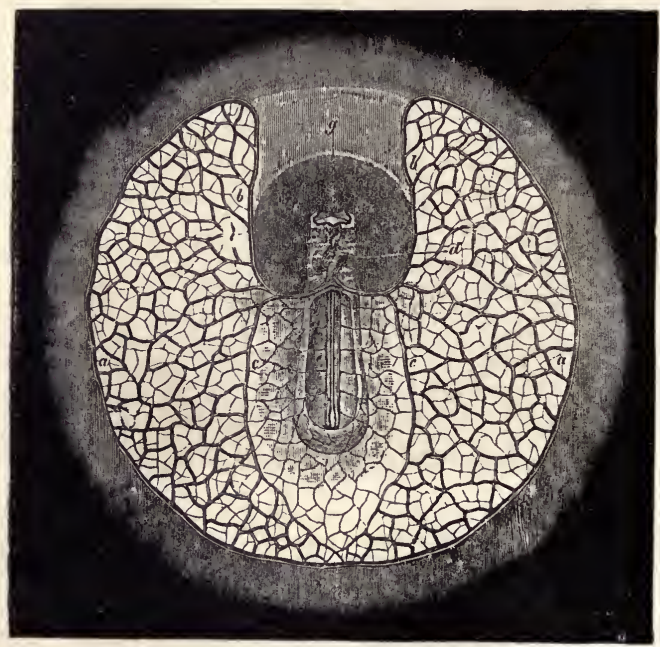

FIG. 150.-Embryo and germ-area of a Rabbit, in which the first system of blood-vessels is complete, - seen from the ventral side (magnified about five times). The posterior end of the heart $(d)$, which is curved in the form of an S, divides into two large yelk-veins, each of which sends out an anterior branch $(b)$ and a posterior branch $(c)$. The ends of these unite in the circular boundary vein, or terminal vein ( $v$.terminalis) $(a)$. In the germarea may be seen the coarser venous network (lying below), and the finer arterial network (lying nearer the surface). The yelk-arteries $(f)$ open into the two primitive aortæ $(e)$. The dark area which surrounds the head like a halo, represents the recess within the head-cap or membrane. (After Bischoff.) 
the primitive aortæ, send out right and left the yelk-arteries, which leave the body of the embryo and pass into the germarea. Here, and in the circumference of the navel-vesicle, two layers of vessels are distinguishable-the superficial arterial layer, and the lower venous layer. The two are connected together. At first this system of blood-vessels is extended only over the superficial front of the germ-area as far as the edge. Here, on the edge of the dark vascular area, all the branches unite in a large terminal vein (vena terminalis, Fig. 150,a). This vein disappears at a later period, as soon as; in the course of development, the formation of blood-vessels progresses further, and then the yelk-vessels traverse the whole yelk-sac. When the navelvesicle degenerates, these vessels, of course, also degenerate, being of importance only in the first period of embryonic life.

This first circulation in the yelk-sac is replaced, at a later period, by the second circulation of blood in the embryo, that of the allantois. Large blood-vessels are developed on the wall of the primitive urinary sac, or allantois, from the intestinal-fibrous layer. These vessels grow larger and larger, and are most intimately connected with the vessels that develop in the body of the embryo itself. This secondary allantois circulation thus gradually takes the place of the original, primary, yelk-sac circulation. When the allantois has grown to the inner wall of the chorion, and has changed itself into the placenta, its bloodvessels alone accomplish the nourishment of the embryo. They are called navel-vessels (vasa umbilicalia), and are originally in pairs : one pair of navel arteries, and one pair of navel veins. The two navel-veins (vence umbilicales, 
Figs. 123, $u, 124, u$ ), which carry blood from the placenta to the heart, open, at first, into the united yelk-veins. These last afterwards disappear, and the right navel-vein simultaneously disappears entirely, so that a single great vein, the left navel-vein, alone remains, which carries all the nutritive blood from the placenta into the heart of the embryo. The two arteries of the allantois, or the navelarteries (arterice umbilicales, Figs. 123, $n, 124, n$ ), are merely the last, posterior extremities of the two primitive aortas, which are afterwards greatly developed. It is not until the end of the nine months of embryonic life, when the human embryo is born and enters the world as an independent physiological individual, that the navel circulation loses its significance. The navel cord (Fig. 138, as), in which these larger blood-vessels pass from the embryo to the placenta, is removed with the latter at the so-called "after-birth," and an entirely"new circulation of the blood, limited to the body of the child, comes into operation simultaneously with pulmonary respiration. ${ }^{107}$

Now, if, in conclusion, we briefly review the germhistory of Man as far as we have traced it, and endeavour to comprehend the whole subject in one connected view, it seems desirable to divide it into several main sections, or periods, and these into subordinate stages, or steps. With reference to the phylogenetic significance of this history, which we shall next consider more closely, it seems to me most appropriate to make the four main divisions and ten sub-divisions as distinguished in the following pages, which correspond to the most important phylogenetic stages of development of our animal ancestors. (Cf. Table XXV. at the end of the nineteenth chapter.) This will again 
show that the germ-history of Man (according to the law of abbreviated heredity) is very rapid and compressed in the first stages of its course, but grows slower and slower in each succeeding stage. All the remarkable phenomena which we observe in the transformation of the human embryo in the whole course of our Ontogeny, are intelligible only with the help of Phylogeny, and are explicable only by reference to the historical metamorphoses of our animal ancestry. ${ }^{103}$

It is true that if the ontogenetic, and the phylogenetic stages (in Tables VIII. and XXII.) are carefully compared, a complete agreement between the two is not observable; on the contrary, there are many individual divergences. In germ-history many organs appear earlier, others later, than the probable course of tribal history leads us to expect. But an adequate explanation of these divergences is found in the various kenogenetic modifications which the germ-history of the higher Vertebrates has undergone in the long course of its evolution. This will become quite clear when we carefully compare the germ-history of Man with the Ontogeny of the lowest Vertebrate, the Amphioxus, an Ontogeny distinguished by tenacious inheritance of the original course of evolution. 


\section{TABLE VIII.}

\section{Systrmattc Survey of the Periods in Human Gebm-History.}

(Cf. Table XXII.)

\section{FIRST MAIN DIVISION OF GERM-HISTORY.}

Man as a simple Plastid.

The human embryo possesses the form-ralue of a simple individual of the first order of a single plastid.

First Stage : Monerula Stage (Fig. 36, p. 210).

The human germ is a simple cytod (the impregnated egg-cell after the loss of the germ-resicle).

Second Stage : Cytula Stage (Fig. 37, p. 210).

The human germ is a simple cell (the impregnated ovule-cell with the re-formed kernel, or the parent-cell).

\section{SECOND MAIN DIVISION OF GERM-HISTORY.}

\section{Man as a many-celled Primitive Animal.}

The human embryo consists of many cells, which, however, as yet form no organs; it therefore possesses the form-value of an individual of the second order.

Third Stage : Morula Stage (Fig. 40, p. 212, and P1. II. Fig. 14).

The human germ is a globular cell-mass, of which one hemisphere consists of animal cells, the other of vegetative cells.

Fourth Stage : Blastula Stage (Pl. II. Fig. 16).

The human germ is a vesicle, the wall of which consists of animal cells, its contents of vegetative cells. 


\section{THIRD MAIN DIVISION OF GERYI-HISTORY.}

\section{Man as an invertebrate Intestinal Animal.}

The haman embryo possesses the form-value of an individual of the third order, an unarticulated person (a single metameron). The primitive intestinal cavity is enclosed by two primary germ-layers, from the fission of which four secondary germ-layers are presently formed.

Fifth Stage : Gastrula Stage (Fig. 41, p. 213, and Pl. II. Fig. 17).

The human germ forms an Amphigastrula, consisting solely of the two primary germ-layers, the skin-layer, and the intestinal layer. The cavity of the primitive intestine is occupied by entoderm cells, which also plug the primitive month.

\section{Sixth Stage : Chordonium Stage (Fig. 90, p. 302).}

The human germ possesses, in all essential points, the organization of a worm, of which the nearest existing allied form seems to be the ascidian larva. Four secondary germ-layers have developed from the two primary germ-layers, and coalesce along the central line.

\section{FOURTH MAIN DIVISION OF GERM.HISTORY.}

\section{Man as a true Vertebrate.}

The homan embryo possesses the form-value of an articulated person, or a metameric chain. The articulation principally affects the bony system (primitive vertebræ) and the muscle-system. The skin-sensory layer is divided into the horn-plate, the medullary tube, and the primitive kidneys. The skin-fibrous layer has separated into the leather-plate, the primitive vertebrro (muscle-plate and bone-plate), and the notochord. From the intestinal-fibrous layer proceed the heart with the principal blood. vessels, and the fleshy intestinal wall. From the intestinal-glandular layer the epithelium of the intestinal tube is formed.

\section{Seventh Stage: Acranial Stage (Figs. 103, 107, pp. 342, 344).}

The human germ possesses, in essential points, the organization of a skullless vertebrate, similar to the developed Amphioxns. The body already forms a chain of metamera, as several primitive vertebro have become distinct. The head is, however, not yet distinctly separated from the trunk. The medallary tube has not yet differentiated into the brainbladders. The skull is still wanting, as are also the heart and limbs. 
Eighth Stage : Cyclostoma Stage (Fig. 132, p. 37i, Pl. VII. Fig. MI I.).

The human germ possesses, in essential points, the organization of a gillless cranial animal (like the developed Myxinoida and Petromyzonta). The number of metamera is increasing. The head is more distinctly differentiated from the trunk. The anterior extremity of the medullary tube swells in the form of a bladder, and forms the rudimentary brain, which soon divides into five brain-bladders, lying one behind the other. On the sides of these appear the rudiments of the three higher sense-organs: the nose-pit, and the eye and ear vesicles. With the first circulation of the blood the heart begins its activity. The jaws and limbs are still wanting.

Ninth Stage: Ichthyod Stage (Fig. 134, p. 378, Pl. VII. Fig. M II.).

The human germ possesses, in essential points, the organization of a fish (or a fish-like Skulled-animal). The two pairs of limbs appear in the simplest form, as fin-like processes: a pair of anterior limbs (dorsal fins) and one pair of posterior limbs (ventral fins). The gill-openings are completely formed, and between these the gill-arches form; the first pair of gill-arches differentiate into the rudiments of the upper and lower jaws. From the intestinal canal proceed lungs (swimming-bladder), liver, and pancreas.

Tenth Stage: Amniotic Stage (Pl. VII. Fig. MIII.; Pl. VIII.).

The human germ possesses, in essential points, the organization of an Amnion-animal (of a higher gill-less Vertebrate). The gill-openings disappear by concrescence. From the gill-arches develop the jaws, the tonguebone, and the bonelets (ossicles) of the ear. The allantois perfects itself, and changes into the peripheric portion of the placenta. All the organs gradnally acquire the forms peculiar to the mammals, and at last the specific human form. (Compare on these points the Phylogeny in the following chapters. ${ }^{109}$ ) 

Fig.1.

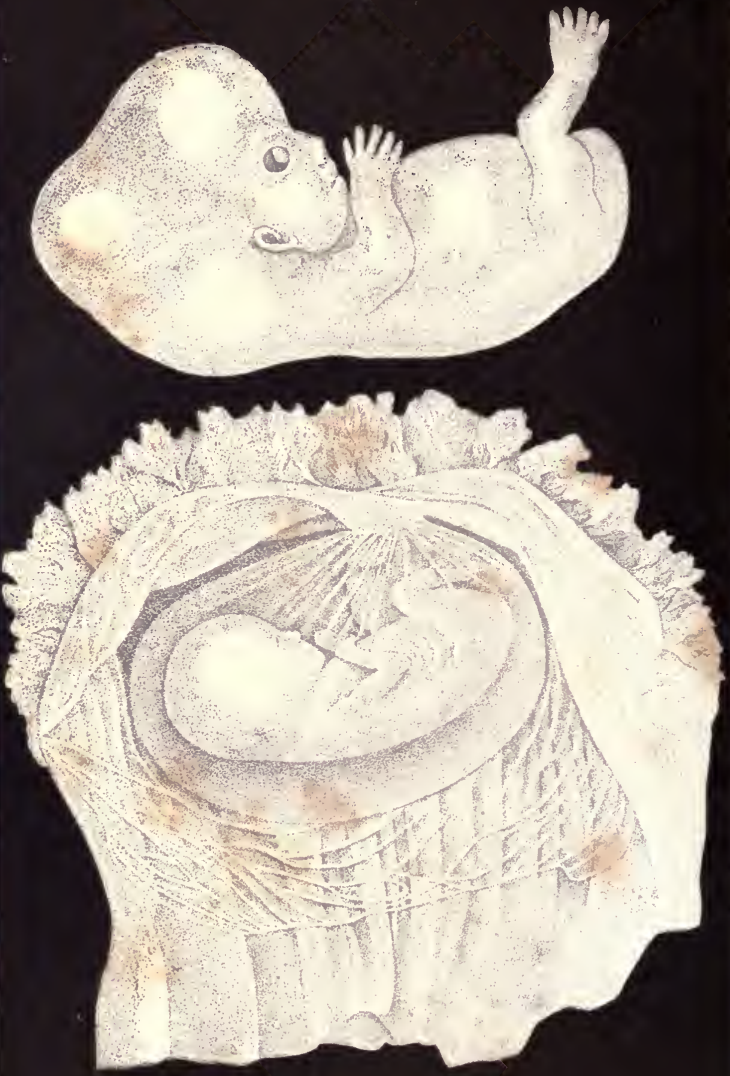

Fig: 2 . 


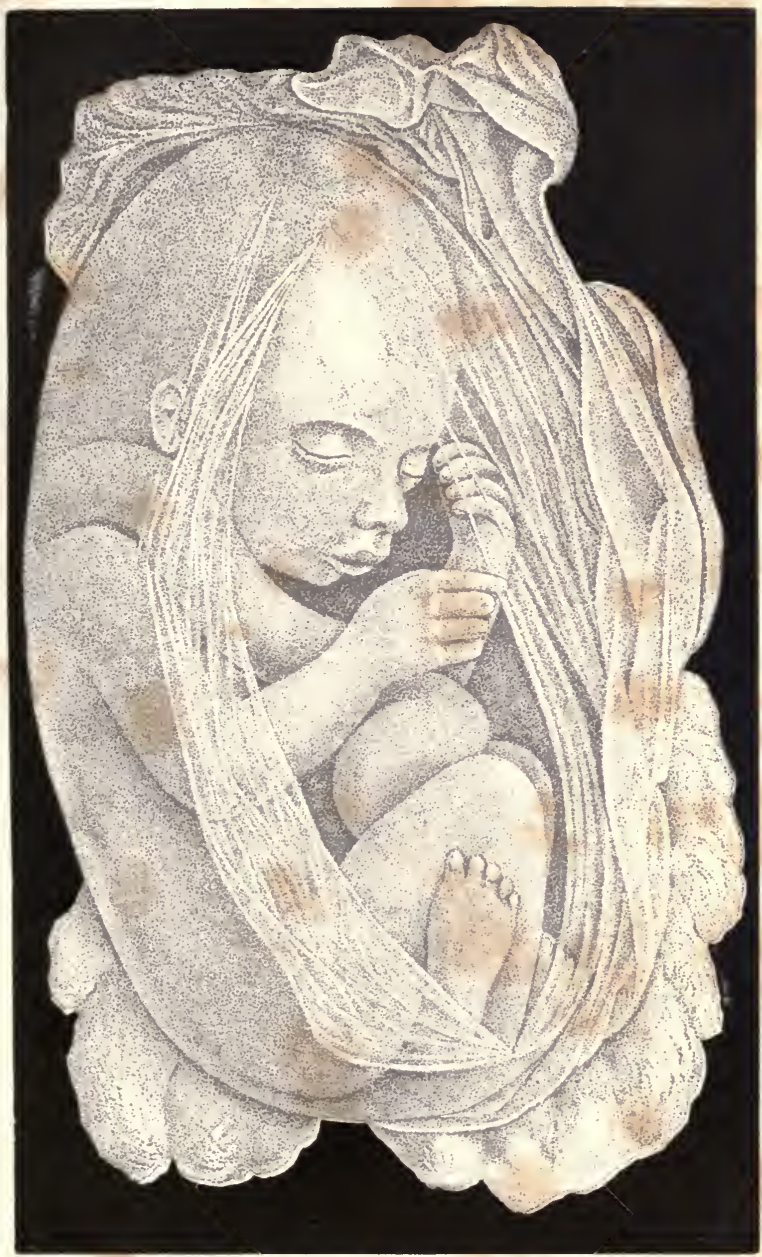





\section{(405)}

\section{EXPLANATION OF PLATES VIII. AND IX.}

\section{(Both Plates are copied from Erdl, "Entwickelung des Menschen." 110)}

Plate VIII. Fig. 1.-A human cmbryo of nine weeks, taken out from the egg-membranes and magnified three times. (Erdl, Plate XII. Fig. 1-5.) The skull is still quite transparent, so that the different divisions of the brain show through : the large mid-brain ("four-bulbs") is separated from tho scarcely larger fore-brain (cerebrum) by a shallow groove, but from the smaller hind-brain (cerebellum) by a deep indentation. The forehead is much arched in front; the nose is yet very undeveloped; the eye is still disproportionately large and wide open. The npper lip is still very short and thickly swollen; the under lip is very thin; the chin is short and very retreating. The whole face is very small in proportion to the skull. The earshell is also very small, but the outer opening of the ear very large. The neck is still very short; the trunk, only about a third longer than the head, is of nniform thickness, and, towards the tail, is produced into a blunt point. The two pairs of limbs are already completely articulated. The anterior limbs (arms) are somewhat shorter than the posterior limbs. The npper and lower parts of the arm (arm and fore-arm) are very short in proportion to the hand, and, similarly, the upper and lower parts of the leg (thigh-bone and leg-bone) are short in proportion to the foot. The fingers on the hand are almost complete; while, on the contrary, the toes on the foot are completely bound, as far as the points, in a swimming membrane, so that they form fins.

Plate VIII. Fig. 2.-A human embryo of twelve weeks, within the eggmembranes; natural size. (Erdl, Plate XI. Fig. 2.) The embryo is completely enclosed in the amnion, which is filled with the amnion fluid, as in a water-bath. The navel cord, which passes from the navel of the embryo to the chorion, is sheathed in a continuation of the amnion, which forms folds at the point where it is fastened. Above, the closely-crowded and branched chorion-tnfts form the placenta. The lower part of the chorion (cnt open and laid in many small folds) is smooth and destitute of tufts. Below it, the "decidua," which is also cut and spread out, is still hanging in deeper folds. The head and limbs of the embryo are already considerably more developed than in Fig. 1.

Pldte IX.-A human embryo of fire months; natural size. (Erdl, Plate XIV.) The embryo is enclosed in the delicate transparent amnion, which has been cut open in front, so that the face and limbs are plainly scen through the opening. The back is bent, the limbs drawn together, so that the embryo occupies the smallest possible space in the egg-cavity. The eyelids are closed. From the navel the thick navel-cord passes, in serpentine folds, over the right shoulder to the back, and from there to the spongy placenta (below, on the right). The outer, thin, mach-folded covering is the outer egg-membrane, the chorion. ${ }^{110}$ 


\section{CHAPTER XIII.}

\section{THE STRUCTURE OF THE BODY OF THE AMPHIOXUS}

\section{AND OF THE ASCIDIAN.}

Causal Significance of the Fundamental Law of Biogeny.--Influence of Shortened and Vitiated Heredity.-Kenogenetic Modification of Palingenesis.-The Method of Phylogeny based on the Method of Geology.Hypothetic Completion of the Connected Evolntionary Series by Apposition of the Actual Fragments.-Phylogenetic Hypotheses are Reliable and Justified.-Importance of the Amphioxns and the Ascidian.Natnral History and Anatomy of the Amphioxns.-External Structure of the Body.-Skin-covering.-Onter-skin (Epidermis) and Leather-skin (Corium).-Notochord.-Medullary Tnbe.-Organs of Sense.-Intestine with an Anterior Respiratory Portion (Gill-intestine) and a Posterior Digestive Portion (Stomach-intestine).-Liver.-Pulsating Blood-vessels. -Dorsal Vessel over the Intestine (Gill-rein and Aorta).-Ventral Vessel under the Intestine (Intestinal Vein and Gill-artery).-Movement of the Blood.-Lymph-vessels,-Ventral Canals and Side Canals - Body-cavity and Gill-cavity. - Gill-covering. - Kidneys. - Sexual Organs.-Testes and Ovaries.-Vertebrate Nature of Amphioxus.-Com. parison of Amphioxus and Young Lamprey (Petromyzon).-Comparison of Amphioxus and Ascidian.-Cellulose Tunic.-Gill-sac.-Intestine. -Nerve-centres.-Heart.-Sexual Organs.

"The primitive history of the species is all the more fully retained in its germ-history in proportion as the series of embryonic forms traversed is longer; and it is more accurately retained the less the mode of life of the recent forms differs from that of the earlier, and the less the peculiarities of the several embryonic states mast be regarded as transferred from a later to an earlier period of life, or as acquired independently."-Fritz MIÜLLER (1864).

Is turning from the germ-history to the tribal history of Man, we must constantly bear in mind the causal connec- 
tion which exists between these two main branches of the history of human evolution. We found that this most significant causal connection was most simply expressed in "the fundamental law of organic evolution," the meaning and significance of which was explained in detail in the first chapter. According to that first biogenetic principle, Ontogeny is a short and compressed recapitulation of Phylogeny. If this reproduction of tribal history were always complete in germ-history, it would be an easy task to re-arrange Phylogeny by using Ontogeny as a guide. When any one wanted to know from what ancestors each higher organism is descended, therefore also from what ancestors Man is descended, and from what forms the whole human race has developed, it would only be necessary to trace accurately the series of forms which occur in the evolution of the individual from the egg; each form occurring in this series might then, without further trouble, be regarded as the representative of an old and extinct ancestral form. But, as a matter of fact, this immediate translation of ontogenetic facts into phylogenetic conceptions is only directly allowable in the case of a comparatively small part of animals. There are, it is true, a number of low, Invertebrate Animals (e.g., Plant-animals, Worms, Crabs) still extant, each germ-form of which we are justified in explaining, without further trouble, as the reproduction, or the portrait, of an extinct parent-form. But in most animals, and in Man, this is impossible, because the germ-forms themselves have again been modified, and have partly lost their original nature, in consequence of the infinite variety in the conditions of existence.

During the immeasurable course of the organic history 
of the earth, during the many millions of years, in the course of which organic life has been developing on our planet, modifications in the mode of germination have occurred in most animals; this fact was first clearly recognized by Fritz Müller-Desterro, and was thus expressed in his able work, "Für Darwin." "The historical record preserved in the history of the evolution (of an individual) is gradually obliterated, in consequence of the fact that evolution continually strikes out a straighter road from the egg to the perfect animal, and the record is much vitiated by the struggle for existence which the freelyliving larvæ have to undergo." The former phenomenon, the obliteration of the ontogenetic epitome, is effected by the law of simplified or abridged heredity. The latter phenomenon, the vitiation of the ontogenetic epitome, is caused by the law of modified or vitiated heredity. In accordance with this latter law, the young forms of animals (not only freely-living larvæ, but also embryos enclosed in the mother's body) may be modified by the influence of the immediate surroundings, just as fully formed animals are modified by adaptation to the external conditions of their existence; the very species are sometimes modified during germination. In accordance with the law of shortened heredity, it is advantageous to all higher organisms (and the more so the higher their development) that the original course of development should be shortened and simplified, and, consequently, that the ancestral traditions should be obliterated. The higher the individual organism stands in the animal kingdom, the less completely does it reproduce, in its Ontogeny, the entire series of its ancestors, for reasons which are partly known, partly yet undiscovered. 
The fact is simply shown by a comparison of the various histories of individual evolution of higher and lower animals of the same tribe. ${ }^{111}$

In order to give its due weight to this significant relation, we have classed the whole series of ontogenetic phenomena, of the phenomena occuring in the evolution of an individual, in two different groups, placing the palingenetic phenomena in one group, the kenogenetic in the other. To Palingenesis, or inherited evolution, we referred those incidents in germ-history which may be regarded as accurately inherited from the history of the tribe. On the other hand, we applied the term Kenogenesis, or vitiated evolution, to such ontogenetic processes as were not directly referable to corresponding phylogenetic incidents, but were, on the contrary, to be explained as modifications, or vitiations, of the latter. In consequence of this critical separation of palingenetic from kenogenetic germinal phenomena, the fundamental law of Biogeny was more accurately defined as follows: The short and quick history of the germ (Ontogeny) is a compressed epitome of the long and slow history of the tribe; this epitome is the more correct and complete, in proportion as the inherited or epitomized evolution (Palingenesis) is retáined by heredity, and the less vitiated evolution (Kenogenesis) is introduced by adaptation. ${ }^{10}$

In order correctly to distinguish the palingenetic from the kenogenetic phenomena of germ-history, and from these rightly to infer the tribal history, we must especially apply ourselves to a comparative study of Ontogeny. It is only by comparing the germ-history of allied forms that we are able to discover the traces of their tribal history. For this 
purpose we may most advantageously apply the method which geologists have long used in determining the order of the sedimentary rocks in the crust of the earth. Most people know that the solid crust of our globe, a thin shell which surrounds the glowing and fluid main mass in its interior, consists of two chief classes of rocks : firstly, the so-called Volcanic, or Plutonic rocks, produced directly by the solidification of the molten internal mass of the earth upon the surface; and, secondly, the so-called Neptunian, or Sedimentary rocks, produced from the former by the transforming agency of water, and deposited, in stratified layers, under water, At first, each of these Neptunian layers formed a stratum of soft mud; but in the course of thousands of years they solidified into firm, hard masses of rock (sandstone, marl, chalk, etc.), at the same time permanently enclosing in their own mass such hard and imperishable bodies as had found their way into the soft mud. Among the bodies, which were in this way either actually fossilized, or left the characteristic imprints of their forms in the soft clay, the harder parts of the animals and plants which lived and died on the spot during the stratification of mud are especially frequent.

Each Neptunian rock-stratum contains its own characteristic fossils-the remains of such animals and plants as lived during that particular epoch of the earth's history. By comparing these strata, it is possible to review the whole connected series of earth-periods. All geologists are now agreed that such a positive, historical series of rock formations is demonstrable, and that the lowest of these strata were deposited in primæval times, the upper in the most recent times. But in no one place on the surface of the 
globe is the entire series of the strata-system perfect, with layer on layer in due succession; in no place is the series even approximately complete. In fact, the order of the different strata of the earth and of the corresponding periods of the earth's history, as commonly conceived by geologists, is only hypothetical, and does not actually exist; it is the result of the comparison of a number of separate observations of the sequence of strata at various points on the earth's surface.

We shall treat the Phylogeny of Man in a similar way. We will endeavour to form the various phylogenetic fragments, occurring in very different groups of the animal kingdom, into an approximately correct representation of the ancestral line of Man. We shall find, that it is really possible, by rightly grouping and comparing the germ-history of very diverse animals, to obtain an approximately perfect picture of the palrontological development of the ancestors of Man and of Mammals; a picture, such as could never be formed from the Ontogeny of the Mammals. In consequence of the kenogenetic processes to which we have alluded, in consequence of vitiated and of abridged heredity, whole series of the lower stages of evolution, especially in the most ancient periods, have fallen out from the germ-history of Man and of other Mammals, or have been vitiated by modifieation. But in the lower Vertebrates and in their Invertebrate ancestors we meet with these very low form-stages in all their original purity. Especially in the lowest of all Vertebrates, the Amphioxus, the most ancient ancestral forms have been perfectly retained in the evolution of the germ. So, too, we find strong evidence in the Fishes, which stand midway between the lower and higher Vertebrates, and which explain several other phylogenetic periods. Lastly 
come the highest Vertebrates, in which the middle and the older stages of ancestral evolution have been either falsified or abridged, but in which the later stages of the phylogenetic process are still well retained in the Ontogeny. Thus it is possible, by collating and comparing the history of individual development in the different groups of Vertebrates, to obtain an approximately complete picture of the palæontological history of the development of the ancestors of Man, within the vertebrate tribe. If we descend below the lowest Vertebrates, and compare the germ-history of these with that of the phylogenetically allied Invertebrates, we can trace the genealogical line of our animal ancestors much further, as far back as the lowest Plant-animals (Zoophytes) and Primitive-animals (Protozoa).

In now treading the obscure path of this phylogenetic labyrinth, holding fast the Ariadne's clew of the fundamental law of Biogeny and guided by the light of Comparative Anatomy, we must, in accordance with the method we have just indicated, search out from among the diverse germ-histories of very different animals, those fragments from which we may construct the tribal history of Man; and we must arrange these fragments in their proper order. Here again I would call special attention to the fact that we employ this method with the same certainty and with the same right as do geologists. No geologist has seen the actual process in which the gigantic rock-masses, composing the Carboniferous formations, the Jurassic, the Cretaceous, etc., were actually deposited by the water. Nor has any geologist actually seen that these various sedimentary rocky formations originated in a particular sequence; and yet all agree as to this sequence. The reason of this is that only 
on the hypothesis of this sedimentary stratification and of this sequence, is the nature and origin of these rock-masses intelligible. Since they are only conceivable and explicable by these "geological hypotheses," these hypotheses are universally accepted as "geological theories."

On similar grounds, our phylogenetic hypotheses can elaim precisely the same force. In proposing them we follow the same inductive and deductive methods, and with the same approximate certainty, as are followed by geologists; because only with the aid of these phylogenetic hypotheses is the nature and origin of Man and of other organisms conceivable; and because these hypotheses only can satisfy our reason in its demand for causality, therefore we hold these to be just; therefore we claim for them the rank of "biological theories." And, just as geological hypotheses, which even in the beginning of the present century were derided as speculative castles in the air, are now universally accepted; so, ton, before the close of this century will our phylogenetic hypotheses be received as valid, although they are at present ridiculed by the narrowminded majority of naturalists as "the dreams of the physio-philosophers." It is true, our task, as we shall find, is not so simple as that of the geologists. It surpasses the latter in difficulty and complexity in the same proportion as the organization of Man is higher than the structure of the rock. ${ }^{112}$

When we approach our task, we obtain very essential aid by first closely studying the comparative germ-history of two low animal forms. One of these is the Lancelet (Amphioxus), and the other is the Sea-squirt (Ascidia) (Plates $\mathrm{X}$. and $\mathrm{XI}$.). Both animals are extremely significant. 
Both stand on the borderland between the two chief divisions of the animal kingdom, which since the time of Lamarck (1801) have been distinguished as the Vertebrates and the Invertebrates. The Vertebrates embrace the already mentioned classes from the Lancelet up to Man (Acephala, Lampreys, Fishes, Double-breathers, or Dipneusta, Amphibia, Reptiles, Birds, Mammals). In contradistinction to these, all other animals have usually, in agreement with the example of Lamarck, been classed as "Invertebrates." But, as we have already had occasion to remark, the Invertebrates in turn consist of several quite distinct tribes. Of these, the Star-animals (Echinoderma), the Soft-bodied Animals (Mollusca), and the Articulated Animals (Arthropoda), do not interest us here, because they are independent main branches of the animal genealogical tree, which are quite distinct from the Vertebrates. The class of Worms is, on the other hand, extremely interesting to us. In this group a very remarkable class of animals exists which has only recently been carefully studied, and which bears most significantly on the genealogical tree of Vertebrates. This class is that of the Mantle-animals (Tunicata). One member of this class, the Sea-squirts (Ascidia), very closely resembles in its internal structure and in its germination the lowest Vertebrate, the Lancelet (Amphioxus). Till a few years ago no one suspected the close connection between these two apparently quite different animal forms, and it was a very lucky accident that just now, while the question as to the descent of the Vertebrates from Invertebrates is foremost, the germ-history of these two most closely allied animals was discovered. In order rightly to understand the germ-history of the Lancelet and the Sea- 
squirt, we must first consider these two remarkable animals in their perfect state and compare their anatomies.

We begin with the Lancelet, or Amphioxus, which, after Man, is the most important and interesting of all Vertebrates. (Cf. Fig. 151, and Plate XI. Fig. 15.) The Lancelet was first described in 1778 by a German naturalist, named Pallas. He received this little animal from the British North Sea, and, thinking that in this animal he recognized a form closely allied to the common Naked Snail (Limax), he gave it the name of Limax lanceolatus. For more than half a century, no one troubled himself about this reputed Naked Snail. Not till 1834 was this insignificant creature observed alive in the sand at Naples, by a local zoologist named Costa. He asserted that it was no snail, but a diminutive fish, and gave it the name of Branchiostoma lubricum. Just about the same time the English naturalist, Yarrell, showed that it possessed an internal axial skeleton, and called the animal Amphioxus lanceolatus. Then, in 1839, it was studied most closely by Johannes Müller of Berlin, to whom we are indebted for a very profound and thorough dissertation upon its anatomy. ${ }^{113}$ Recently our knowledge of the animal has been greatly extended, and its more delicate structure especially has become better known. ${ }^{114}$

The Amphioxus lives in flat, sandy localities on the seacoast, partly buried in the sand, and appears to be very widely distributed in various seas. It is found in the North Sea (on the British and Scandinavian coasts, and also in Heligoland), in various parts of the Mediterranean (e.g., at Nice, Naples, Messina). It also occurs on the coast of Brazil and on the distant shores of the Pacific Ocean (the coast of Peru, Borneo, China, etc.). Everywhere this remarkable little animal appears in the same simple form. ${ }^{58}$ 
Johannes Muiller referred the Lancelet to the class of Fishes, though he insisted that the differences between this lowest of the Vertebrates and the lowest Fishes are much more considerable than the difference between all Fishes and the Amphibia. But this is far from expressing the real significance of this important little animal. Indeed, we might confidently lay down the proposition that the difference between the Amphioxus and the Fishes is far greater than between the Fishes and Man and all other Vertebrates. Nay, so widely does the Amphioxus differ in its whole organization from the rest of the Vertebrates, that, according to the laws of systematic logic, we are forced to distinguish two main divisions of the vertebrate tribe: (1) the Skull-less Animals, or Acrania (the Amphioxus and the extinct allied forms); and (2) the Skulled Animals, or Craniota (Man and all other Vertebrates.) $)^{115}$

The first and lower division consists of Vertebrates without head, brain, or skull, for which reason they are called Skull-less Animals, or Acrania. Of these, the only extant representative is the Amphioxus, though in the earlier periods of the earth's history very numerous and varied forms belonging to this division must have existed. We may here lay down a universal law, which must be accepted by every adherent of the theory of evolution : viz., such entirely peculiar and isolated animal forms, as the Amphioxus-which apparently stands alone in the whole system of animals-are always the last survivors of an extinct group, numerous and diversified forms of which existed at an earlier period. As the whole Amphioxus is soft, and has no firm organs, capable of being fossilized, we may suppose that all its numerous extinct kindred were 
equally soft, and were, therefore, equally incapable of being petrified and of leaving any fossil impressions.

Contrasted with the Skull-less Animals stands the other main division of Vertebrates, embracing all the rest of that class from Fishes to Man. These all have a head, clearly marked from the trunk, with a skull and brain; they all have a centralized heart, developed kidneys, etc. They are called Skulled Animals, or Craniota. But in the earliest stages of their existence even these are skull-less. As we have seen in the Ontogeny of Man, every Mammal, in the early stages of individual development passes through a condition in which it has neither head, nor skull, nor brain, and possesses only the well-known, simple form of a lyre-shaped disc, or of a shoe-sole, without any limbs or extremities. Comparing these early embryonic forms with the developed Lancelet, we may say, that the Amphioxus is in a certain sense a persistent embryo, a permanent germ-form of Skulled-animals; it never passes beyond a certain low, early youthful condition, out of which we have long since passed.

The perfectly formed Lancelet (Fig. 151) is 5 to $6 \mathrm{~cm}$. in length (above two inches), is either colourless or slightly reddish, and is shaped like a narrow lanceolate leaf. The body is pointed at both ends, and much compressed laterally. There is no trace of limbs. The outer skin-covering is very delicate and thin, naked, translucent, and consists of two distinct strata; a simple external skin, the outer skin (epidermis; Plate X. Fig. 13, $h$ ), and a fibrous leather-skin (corium), lying below the epidermis (Fig. 13, l). The central line of the back is traversed by a narrow fin-like ridge which widens behind into an oval tail-fin, and is prolonged

vol. I. 
underneath into a short, anal fin. The fin-like ridge is supported by a great number of small and delicate quadrangular plates (Plate XI. 15, $f$ ). The delicate parallel lines under the skin, which describe an acute angle forward along the central line of each side, are the boundary lines of the numerous dorsal muscles (Fig. 15, $r$ and $b$ ).

In the centre of the body is a thin cartilaginous cord, which traverses the longitudinal axis of the entire body from front to rear, and is symmetrically sharpened at both ends (Fig. 151, i). This is the notochord (chorda dorsalis), which in this case takes the place of the backbone, or vertebral column. In the Amphioxus the notochord does not develop further, but remains permanently in this most simple original condition. It is enclosed in a firm membranous covering, the notochord-sheath. The nature of the latter, and of the formations which proceed from it, may be best seen in the transverse section of the Amphioxus (Fig. 152; Plate X. Fig. 13, cs). Immediately above the chorda the notochord-sheath forms a cylindrical tube, and in this tube the central nervous system lies enclosed, the spinal or medullary tube (Plate XI. Fig. 15, m). This important mental organ retains throughout life this most simple form, that of a cylindrical tube, the anterior and posterior ends of which are almost equally simple, and the thick wall of which encloses a narrow canal. The anterior end is, indeed, rather rounder, and contains a small, hardly noticeable, bladderlike swelling of the canal (Fig. 15, $m_{1}$ ). This may be regarded as the first indication of a real brain-bladder; as a rudimentary brain. On the foremost end there is also a little black pigment-spot, the rudiment of an eye. Near this eye-spot, on the left side, there is a little ciliated groove, 
the single organ of smell. The organ of hearing is entirely wanting. This defective evolution of the higher senseorgans is probably in great measure explicable as not original, but as a degeneration.

Below the notochord runs a very simple intestinal canal, a tube, which, on the ventral side of the little animal, opens in front in a mouth, and at the back in an anus. The mouth is oval, and surrounded by a cartilaginous circle, on which are 20 to 30 filaments of cartilage (organs of taste) (Fig. $151, a)$. By a contraction in the centre, the intestinal canal divides in the centre into two very different parts, of about equal length. The anterior division acts as a respiratory organ, the posterior end as a digestive organ. The anterior half forms a wide gill-body, the lattice-like wall of which is pierced by numerous gill-openings (Fig. 151, $d$, and Plate XI. Fig. 15, k). The delicate bars of the gill-body, between the openings, are supported by small, firm parallel staves, which are connected together in pairs by cross-staves. The water which the Amphioxus takes in through its mouth passes through these openings in the gill-body into the large gillcavity which surround the gill-body, and then passes further back and out through the breath-hole, or gill-pore (porus branchialis; Fig. 151, c). On the ventral side of the gillbody there is, along the central line, a ciliated groove (the hypobranchial groove), which also occurs in Ascidians and in the larvæ of Cyclostomi; it is of interest because from it in the higher Vertebrates is developed the thyroid cartilage on the throat (on the lower part of the so-called Adam's apple; Fig. 15, y).

Behind the breathing, or respiratory part of the intestinal canal comes, secondly, the digestive part. The small bodies 
which the Amphioxus takes up in the water it breathesInfusoria, Diatomacer, parts of decayed plants, and animal

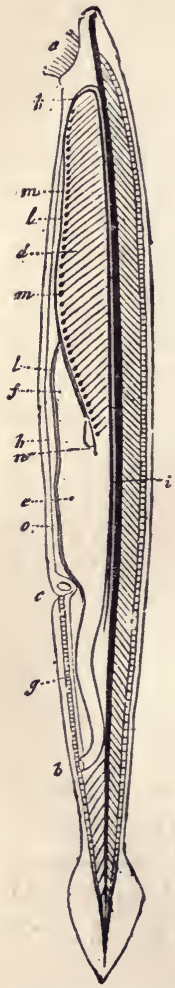

Fig. 151.-Lancelet (Amphioxus lanceolatus), twice the natural size; seen from the left side (the longitndinal axis stands apright; the month end is turned upwards, the tail end downwards, as in Plate XI. Fig. 15): $a$, mouth-opening, surrounded by hairs; $b$, anal opening; $c$, gill-pore (porus branchialis); $d$, gill-body ; $e$, stomach ; $f$, liver ; $g$, small intestine; $h$, gill-cavity; $i$, notochord (below this the aorta); $k$, aorta-arch; $l$, main trank of the gill-artery; $m$, swellings on the branches of the latter; $n$, hollow vein (vena cara); 0 , intestinal vein.

bodies, etc.-pass back from the gill-body into the digestive section of the intestinal canal, and are there taken up as food and assimilated. From a rather wider section, corresponding to the stomach (Fig. 151, e), proceeds an oblong, pouchlike blind-sac $(f)$, which passes directly. forward, and ends on the right side of the gill-body. This is the liver of the Amphioxus, the simplest form of liver that we know of in any Vertebrate. In Man also, as we shall see, the liver develops as a pouch-shaped blind-sac, which protrudes from the intestinal canal behind the stomach.

The structure of the system of bloodvessels in our little animal is not less remarkable than that of the intestine. For while all other Vertebrates have a compressed, thick, purseshaped heart, which develops at the throat from the lower 
wall of the anterior intestine, and from which the bloodvessels proceed, there is in the Amphioxus no special centralized heart, propelling the blood by its pulsations. Instead, the movement of the blood in the Amphioxus, as in the Ringed Worms (Annelida), is effected by the thin tubular blood-vessels themselves, which perform the functions of the heart, contracting and pulsating through their entire length, and thus driving the colourless blood through the whole body. This circulation is so simple and yet so remarkable, that we will briefly consider it. Let us begin in front at the lower side of the gill-body. In the central line of this lies a large main vessel, which corresponds to the heart of other Vertebrates and to the main gill-artery proceeding from its heart, and which propels the blood into the gills (Fig. 151,l). The anterior portion of this is swollen like a heart and is extended (immediately in front of the first gill-opening). Numerous little arching vessels rise on each side from this gill-artery, form little heart-like swellings (bulbs, $m$ ) at their point of departure, traverse the gillarches, between the gill-openings, round the anterior intestine, and unite as gill-veins above the gill-body in a great main vessel, which passes below the notochord. This vessel is the primitive aorta (Plate X. Fig. 13, $t$; Plate XI. Fig. 15, $t$ ). The aorta passes between the intestine and the notochord precisely as in all the higher Vertebrates. The branch-vessels which this aorta sends to all parts of the entire body, again collect into a large venous vessel, which passes to the lower side of the intestine, and which may here be called the intestinal vein (Fig. 151, o; Plate X. Fig. 15, $v$; Plate XI. Fig. 13, v). It passes on further over the pouch-like liver, there forms a kind of cystic vein, weaving 
a fine vascular network around the blind-sac of the liver, and then passes, as a liver vein, into a vessel, directed toward the front, which we may call the hollow vein (Fig. 151,n). This last passes again directly to the ventral side of the gill-body, and here directly re-enters the gillartery, which we took as a starting-point. . Like a circular closed aqueduct, this single main vascular tube passes along the intestinal tube through the whole body of the Amphioxus, pulsating throughout its entire length both above and below. Within about a minute the colourless blood is thus driven through the whole body of the little creature. When, in pulsating, the upper tube contracts, the lower fills with blood, and vice versâ. Above, the current of blood is from front to rear; below, on the contrary, it is from the rear to the front. The entire long vascular tube, which runs below along the ventral side of the intestinal tube, and which contains venous blood, probably represents the so-called ventral blood-vessel of Worms (Plate IV. Fig. 7, $v$ ). On the. other hand, the long straight vascular tube, which runs above along the dorsal line of the intestinal tube, between it and the notochord, and which contains arterial blood, is, on the one hand, evidently homologous with the aorta of other Vertebrates, and, on the other hand, with the so-called dorsal blood-vessel of Worms (Plate IV. Fig. 7, $t$ ).

Johannes Müller recognized this important similarity in the formation of the system of blood-vessels of the Lancelet and of Worms. He directed special attention to the analogies of the two, and their physiological resemblance, the blood in both being driven by the pulsating contractions of the great vascular tubes throughout their entire length, and not by a centralized heart, as in all other Vertebrates. But 
we conceive that this important resemblance is more than a mere analogy. It has the deeper significance of a true homology, and rests on a morphological resemblance of the organs compared. Thus, the Amphioxus shows us that the aorta, the single main artery of Vertebrates, running between the intestine and the notochord, represents the dorsal blood-vessel of Worms. On the other hand, the ventral blood-ressel of the latter is retained only in the single intestinal vein passing below the intestine of the Amphioxus (and its anterior continuation; cystic vein, liver vein, hollow vein ( $v$. cava), gill-artery). In the developed body of all other Vertebrates this intestinal vein (originally the main venous blood-vessel!) is far outstripped by other veins.

Together with the real blood-vessels, special absorbing lymph-vessels seem to exist in the Amphioxus. Several canals, extending under the skin, have recently been regarded in this light, especially the narrow "ventral canals" (Fig. 152, $S_{1}$ ), and wide "side canals" $(S)$. Both pass along the whole length of the ventral side and contain colourless lymph. The side canals $(S)$ must possibly be regarded as the last remnants of degenerated primitive kidney ducts. They lie in the two parallel side folds of the ventral skin $(V)$, ending blindly both in front and behind, and do not open outwards, as was supposed till recently.

The real body-cavity (coloma) in the Amphioxus (Fig. $152, L h)$ is extraordinarily narrow and small. It surrounds the intestinal tube in its narrow cavity, and is probably connected with the lymph spaces. Formerly it was confused with the large respiratory cavity or gill-cavity $(A)$, which is of entirely different morphological and physiological signifi- 


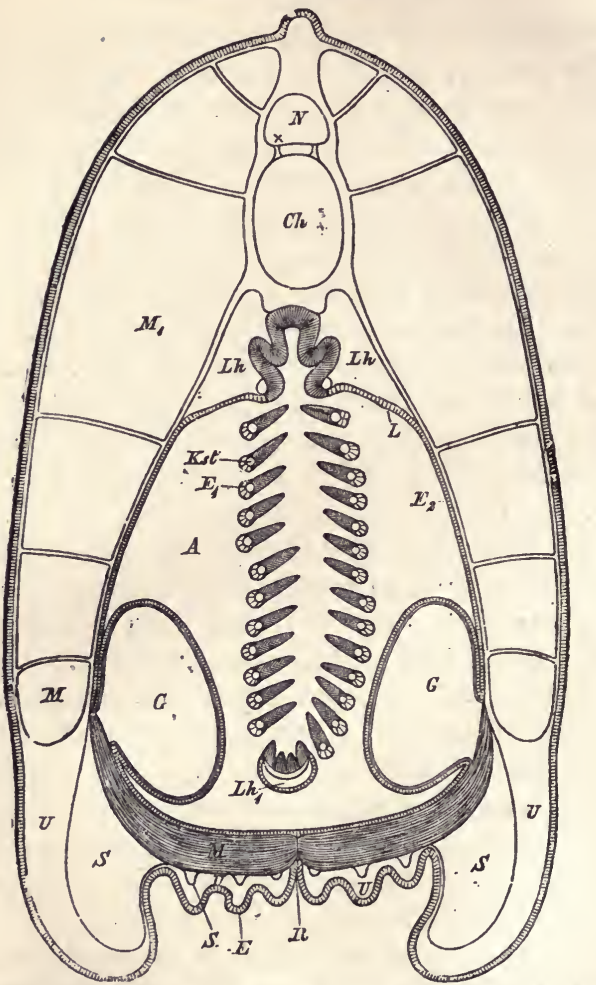

Fig. 152.-Transverse section through the anterior part of a Lancelet. (After Rolph.) The outer covering forms the single cell-stratum of the outer skin (epidermis, $E$ ). Below this lies the thin leather ekin (corium), the inner tissue of which is thickened below $(U)$; partition walls of connective tissue pass inward from it between the muscles $\left(M_{2}\right)$ and to the chordasheath; $N$, medullary tube; $c h$, notochord; $L h$, body-cavity (coloma); $A$, gill-cavity; $L$, upper wall of the latter; $E_{1}$, inner wall of the Eame; $E_{2}$, onter wall of the same; Kst, gill-rods; $M$, ventral muscles; $R$, Raphe, or seam formed by the coalescence of the ventral folds (gill-roofs); $G$, sexual glands. 
cance. The true body-cavity $(L h)$ is filled with lymph, its inner wall being clothed by the intestinal-fibrous layer, its outer wall by the skin-fibrous layer. The gill-cavity $(A)$ is, on the contrary, filled with water, and its whole wall is clothed by the skin-sensory layer. The latter envelopes the outer surface of the two large, lateral gill-roofs, the lateral processes from the body-wall, which grow together below round the original ventral side, and unite in the central line (in the ventral seam or raphe, Fig. 152, $R$ ).

On each side of this ventral seam, on the inner surface of the gill-roofs, directly in front of the gill-pore (porus branchialis), and over the ventral muscles $(M)$ and between the sexual glands $(G)$, lie the kidneys of the Amphioxus. These urinary glands are present in the simplest form, as glandular epithelial swellings of the skin-sensory layer. The epithelial cells of these are distinguished by peculiar size and nature, and contain crystalline deposits. As we regard the primitive kidneys of other Vertebrates also as originally skin-glands, and as we derive them from the skinsensory layer, it is very interesting to find these organs permanently retained in the Lancelet as skin-glands.

The sexual organs also appear in a perfectly simple form. On both sides of the gill-intestine, in the central part of the gill-cavity, lie from twenty to thirty small elliptical or roundly four-cornered sacs, which can easily be seen by the naked eye from without, through the thin transparent wall of the body. In the female, these little sacs are the ovaries, and contain numbers of simple egg-cells (Plate X. Fig. 13,e). In the male, these are replaced by the testes, heaps of smaller cells, which change into movable whip-cells (spermcells). Both kinds of sacs lie within on the inner wall of 
the gill-cavity, and have no special channels of exit. When the eggs of the female and the seed masses of the male are matured, they fall into the body-cavity, and are expelled through the gill-pore ( $p$. branchialis).

Now on trying to comprehend in one connected view the results of our anatomic study of the Amphioxus, and comparing this conception with the known organism of Man, the contrast between the two seems immense. In fact, the most perfect vertebrate organism, represented by Man, is in every respect so far above that lowest stage in which the Lancelet remains, that it seems at first almost impossible to place both organisms in the same main division of the animal kingdom. And yet this classification is based on unassailable grounds. For Man represents only a further advance of the same vertebrate type, which in all its rudimentary characters is unmistakably seen in the Amphioxus. It is only necessary to recall the representation which has been given of the ideal form of the Primitive Vertebrate (p. 256) and to compare with it the various lower stages of development of the human embryo, in order to become convinced of our near relationship to the Lancelet.

It is true that a few zoologists have recently maintained the paradoxical view that the Amphioxus is in no way allied to Vertebrates. This was asserted especially by Karl Semper and Robby Kossman, the same learned pair who discovered in Goethe a narrow-minded upholder of the constancy of species (see p. 91). But these gentlemen can only have uttered this assertion in order, in the absence of positive merits, to make their names known by negative instances. One who at the present time maintains that the Amphioxus is not allied to Vertebrates goes back a 
whole century, even beyond Pallas (1778), and only proves that his notions of Comparative Anatomy and of the history of evolution are extremely weak.

The Amphioxus does, indeed, stand very far below all other extant Vertebrates. It is, indeed, without the head containing a developed brain and skull, which distinguishes all other Vertebrates. It is without an organ of hearing, and without a centralized heart, such as all others possess; perfect kidneys are also lacking. Each organ appears in a simpler and more imperfect form than in any other Vertebrate. And yet, the rudimentary characters, the connection and relative position of all the organs, are the same as in all other Vertebrates: moreover, they all, during their embryonic development, pass, at an early period, through a stage in which their whole organization is not superior to that of the Amphioxus, but rather, agrees with it in all essential particulars. (Cf. Table IX.)

In order to be thoroughly convineed of this important fact, it is specially instructive to compare the Amphioxus with the early forms of development of those Vertebrates which are most nearly allied to it in the natural system of this tribe. This is the class of the Round-Mouths (Cyclostomi). This remarkable class, which formerly comprehended many species, contains at the present day but very few species, which are separable into two different groups. One group is formed by the Hags (Myxinoidlo), which have been made known to us by Johannes Müller's. classic work, "Vergleichende Anatomie der Myxinoiden." The other group is formed by the well-known Lampreys, or Rock-Suckers (Petromyzonta), which are eaten as a delicacy. All these Round-Mouths are usually included in the class of 
Fishes. They stand, however, far below the true Fishes, and form a very interesting connecting group between them and the Lancelet. How near they stand to the latter, is elearly seen if an immature Lamprey (Petromyzon, Plate XI. Fig. 16) is compared with the Amphioxus (Fig. 15). In both, the notochord (ch) is in the same simple form, as is also the medullary tube $(m)$, lying above the notochord, and the intestinal tube $(d)$, lying below the notochord. But in the Lamprey, the medullary tube soon swells in front into a simple pear-shaped brain-bladder $\left(m_{1}\right)$, and on each side of this appears a very simple eye (au) and a simple earvesicle $(g)$. The nose $(n)$ is still a single pit, as in the Amphioxus. The two sections of the intestine also, the anterior gill-intestine $(k)$ and the posterior stomach-intestine $(d)$, are very simple in the Lamprey, and very like those of the Amphioxus. On the other hand, there is decided progress in the organization of the heart, which appears below the gills as a centralized muscular pouch, and separates. into an auricle $(h v)$ and a ventricle $(h k)$. At a later period, the Lamprey attains to a considerably higher state of development, acquires a skull, five brain-bladders, a series of independent gill-pouches, etc. But this makes the remarkable similarity of its young larva to the developed Amphioxus all the more interesting. ${ }^{116}$

The Amphioxus, which is thus directly connected, on the one side, with the Fishes through the Round-Mouths (Cyclostomi), and thereby to the series of higher Vertebrates, is, on the other hand, very nearly allied to a lower invertebrate sea-animal, from which, at first sight, it seems very far removed. This remarkable animal is the Sea-squirt, or Ascidian, which until very recently was regarded as being 
nearly related to the Mussels, and was therefore classed with the Soft-bodied Animals (Mollusca). But since 1866, when the remarkable germ-history of these animals was first understood, there has been no doubt that they are unconnected with the Soft-bodied Animals. On the contrary, greatly to the surprise of zoologists, the entire mode of their individual development indicates that they are the nearest allies of the Vertebrates. In their matured condition the Ascidians are shapeless lumps, which at first sight certainly do not look like animals. The oblong body, often rough, or covered with uneven knobs, in which no definite outward organs are distinguishable, adheres firmly by one end to sea-weeds, stones, or to the bottom of the ocean. Some species resemble potatoes, others dried plums Many Sea-squirts form very insignificant incrustations on the surface of stones and plants. Some of the larger kinds are eaten like oysters. Fishermen, who know them well, regard them not as animals, but as sea-weeds. They are frequently offered for sale together with other low seaanimals, in the fish-markets of many Italian seaside towns, under the name of Sea-fruit (frutti di mare). There is indeed nothing outwardly indicating an animal. When they are drawn from the sea in a drag-net, all that is noticeable is that they feebly contract their bodies, thus producing a spirting of water from certain parts. Most of the Sea-squirts are very small, only a few lines, or at most a few inches long; a few species attain the length of a foot or rather more. There are a great many species, which are to be found in all seas. We find no fossil remains of this class of animals, because they have no hard parts capable of petrifaction; but they are certainly of very great an- 
tiquity, and must have existed during the primæval ages.

The whole class to which the Ascidians belong bears the name of Mantle-animals (Tunicata), because the body is enclosed in a thick and firm membrane, as in a mantle or tunic. This tunic, which is sometimes soft and jelly-like, sometimes tough and leather-like, sometimes firm and cartilaginous, is distinguished by many remarkable characteristics. Probably the most remarkable of these is, that it consists of a woody mass or cellulose, the same plant-cell material which forms the firm exterior of the cells of plants, the substance of the wood. The Mantle-animals are the only class of animals which really possess a cellulose covering, a wood-like envelope. Sometimes the cellulose tunic is variegated, at other times it is colourless. Not uncommonly it is set with spines or hairs, like a cactus. Many foreign substances, such as stones, sand, fragments of mussel-shells, and so forth, are often embedded in the tunic. The Sea-squirt has, therefore, received the name "microcosm." 117

In order correctly to understand the internal organization of the Sea-squirt, and thoroughly to compare it with the Amphioxus, we must place ourselves in the same position to it as to the latter (Plate XI. Fig. 14, on the left side; the mouth extremity is turned upward, the back to the right, the abdomen to the left). The posterior end, corresponding to the tail of the Amphioxus, is usually adherent, often by means of root-like processes. The ventral and dorsal sides are internally very different, but are often externally undistinguishable. On opening the thick tunic, in order to note the internal organization, we observe first a very consider- 
able cavity, filled with water; this is the gill-cavity, or respiratory cavity (Fig. 153, $c l$; Plate XI. Fig. 14, $c l$ ). It is also called the mantle or tunic cavity, because it receives,

Frg. 153.-Structure of an Ascidian (viewed from the left side, as in Plate XII. Fig. 14); the dorsal side is turned towards the right, the ventral side towards the left, the mouth-opening $(o)$ upwards ; at the opposite, tail extremity, the ascidian is firmly attached to some substance below. The gill-intestine $(b r)$, which is pierced by many openings, continnes below as the stomachintestine. The large intestine opens throngh the anus (a) into the gillcavity $(c l)$, from which the excrement is removed with the inhaled water throngh the mouth of tho tunic $\left(a^{\prime}\right) ; m$, tunic. (After Gegenbaur.)

not only the water for respiratory purposes, but also excrement and the sexual products. The greater.part of the respiratory eavity is occupied by the latticed gill-sac (br). The latter is in its whole position and constitution so like

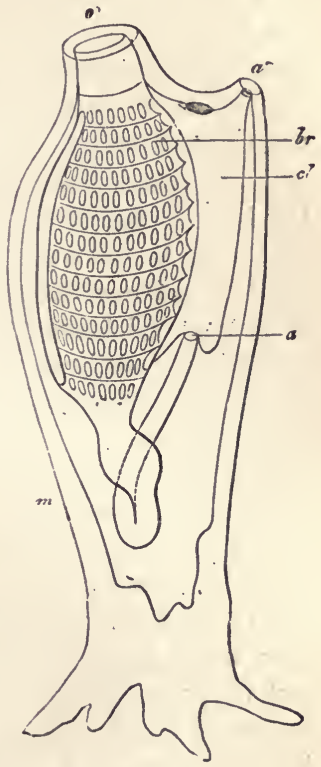
the gill-body of the Amphioxus, that many years ago, before anything was known of the real relationship of the two animals, the English naturalist, Goodsir, called attention to this striking similarity. In the Sea-squirts also the mouth-opening (o) leads directly into this gill-sac. The water breathed in passes through the openings of the 
latticed gill-sac into the gill-cavity, and is removed from there by the respiratory pore or excretory opening $\left(a^{\prime}\right)$. A ciliated groove traverses the ventral side of the gill-sac, the same "hypo-branchial groove" which we found before in the Amphioxus at the same place (Plate XI. Fig. 14, y, 15, y). The food of the Sea-squirt, like that of the Amphioxus, consists of small organisms, Infusoria, Diatomacece, parts of dismembered sea-weeds and sea-animals, etc. These pass with the inhaled water into the gill-sac, and from the end of this into the digestive part of the intestinal canal, first into an extension answering to a stomach (Fig. 14, $\mathrm{mg}$ ). The small intestine connected with it usually forms a loop, curving around toward the front, and opens in a vent (Fig. $153, a)$, not directly out, but first into the gill-cavity ; from here the excrement is removed, together with the inhaled water and the sexual products, through the common excretory opening $\left(a^{\prime}\right)$. The latter is sometimes called gillpore, or respiratory pore (porus branchialis), sometimes the cloacal opening (Plate XI. Fig. 149). In many Sea-squirts, a glandular mass, representing the liver, opens into the intestine (Fig. 14, lb). In some, there is another gland near the liver, which is supposed to be the kidney (Fig. 14, $u$ ). The real body-cavity (coeloma), which is filled with blood and surrounds the stomach, is very small in the Ascidian, as in the Amphioxus, and equally in both cases is usually confused with the gill-cavity, which is filled with water.

In the mature Sea-squirt there is no trace of a notochord, an inner bony axis. This adds interest to the fact, that the young animal, as it emerges from the egg, has a notochord (Plate X. Fig. 5, ch), above which lies a rudimentary medullary tube (Fig. $5, m$ ). In the mature Sea-squirt, 
this tube is entirely shrivelled up, and forms a little knot of nerves lying near the front above the gill-sac (Fig. 14, $n$ ). It answers to the so-called upper throat-ganglion, or the "brain" of other Worms. Special organs of sense are either entirely wanting, or exist in the very simplest form, as eye-specks and taste papillæ, which surround the mouth (Fig. 14, au, eyes). The muscular system is very feebly. and irregularly developed. Immediately below the thin leather-skin (corium) with which it is intimately connected; is a thin pouch-shaped muscular membrane, as in the lower Worms. On the other hand, the Sea-squirt has a centralized heart, and appears in this respect to be more highly organized than the Amphioxus. On the ventral side of the intestine, at a considerable distance behind the gill-sac, lies a spindle-shaped heart (Fig. 14, $h z$ ). It permanently retains that same simple pouch-shaped form which the rudimentary heart of the Vertebrate possesses for a very short time. (Cf. the heart of the human embryo, Fig. 144, c, p. 392.) This simple heart of the Ascidian, however, exhibits a remarkable peculiarity. It contracts in alternate directions. While in all other animals the pulsation of the heart takes place constantly in a given direction, usually from back to front, in the Ascidians it alternates between opposite directions. First, the heart contracts in the direction from back to front, then, after standing still a minute, it begins to pulsate in the opposite direction, driving the blood from front to back; thus the two great vessels proceeding from the opposite ends of the heart act alternately as arteries and veins. This is a peculiarity which appears only in the Mantle-Animals (Tunicata).

vOL. I. 
Of the other important organs, we have yet to mention those of reproduction, which lie at the posterior extremity of the body-cavity. All the Sea-squirts are hermaphrodites. Each individual has a male and a female gland, and is thus capable of self-fertilization. The mature eggs (Fig. 154, $o^{\prime}$ ) fall directly from the ovary $(o)$ into the gill-cavity. The male sperm, on the contrary, is carried from the testes $(t)$ into the same cavity by a special seed-duct ( $v c l$ ). Here impregnation takes place, and here in many Sea-squirts developed embryos are found (Plate XI. Fig. 14, z). These, with the water that has been inhaled, are then thrown out at the gill-pore $(q)$; they are thus "born alive."

Many Sea-squirts, especially of the smaller species.

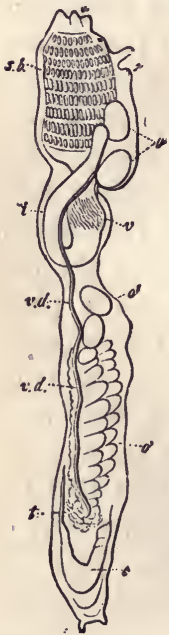

Fic. 154.-Structure of an Ascidian (observed frone the left side, as in Fig. 153, and Fig. 14, Table XI.): $s b$, gill-sac ; $v$, stomach; $i$, large intestine; $c$, heart; $t$, testes ; $v d$, seed-duct; 0 , ovary ; $o^{\prime}$, matured eggs in the gill-cavity. The two little arrows indicate the entrance and exit of the water through the two openings. of the tanic. (After Milne Edwards.)

multiply, not by sexual reproduction, but asexually by the formation of buds. Great numbers of the individuals thus produced from buds remain permanently attached to. each other, thus forming large masses, or comes like the well-known coral societies. Among these social or compound Ascidians, those species are peculiarly interesting in which the mass seems to be beautifully combined of many star-shaped groups. Each star-shaped group consists of a larger or smaller number of individuals, of which every one possesses 
its independent organization and its own mouth-opening. All the individuals together have, however, but a single common gill-pore, which is situated at the central point of the starshaped group. These star-shaped compound ascidian groups (Botryllus, Polyclinum, etc.) throw much light on the Phylogeny of one of the most remarkable races of animals, the Star-animals (Echinoderma). The parent-forms of these are the Star-fish, or Asterids, which are, like the compound Ascidians, star-shaped societies formed of Worms connected by a common central intestinal opening. ${ }^{118}$

If we now once more glance back at the entire organization of the simple Ascidians, Sea-squirts (Phallusia, Cynthia, etc.), and compare it with that of the Amphioxus, we find that the two present few points of resemblance. The developed Ascidian is indeed like the Amphioxus in some important points of internal structure, especially in the peculiar construction of the gill-sac and intestine. But it seems so far removed in most other particulars of its organization, and is so dissimilar in outward appearance, that the very near relationship of the two organisms is only revealed by study of their germ-histories. We will now consider and compare the individual development of the two animals, and shall in this way find, to our great surprise, that the same embryonic animal form develops from the egg of the Amphioxus as from the egg of the Ascidian. 


\section{EXPLANATION OF PLATES $\boldsymbol{X}$. AND XI.}

Plate X.-Germ-history of the Ascidiay and of the Amphioxts. (Priscipally accordixg to Kowalevsky.)

Fig. 1-6.-Germ-history of an Ascidian.

FIg. 1.-A parent-cell (cytula) of an Ascidian. In the bright-coloured protoplasm of the parent-cell lies eccentrically a bright spherical kernel (nncleus), and in the latter a darker nucleolus.

Fia. 2.-An Ascidian egg in the process of cleavage. The parent-cell has divided by repeated bisection into four similar cells.

Fig.3.-Membraneons germ-vesicle of an Ascidian (Blastula). The cells resulting from the cleavage of the egg form a spherical bladder filled with fluid, the wall of which consists of a single layer of cells. (Cf. Fig. 22, F, G.)

Fig. 4.-Gastrula of the Ascidian resnlting from the blastnla (Fig. 3) by inversion (invagination). The wall of the primitive intestine $(d)$, which opens at $o$ by the primitive mouth, consists of two layers of cells; the inner intestinal layer formed of larger cells, and the outer skin-layer, of smaller.

Fig. 5.-Larva of the Ascidian swimming freely. Between the medullary tube $(m)$ and the intestinal tube $(d)$ the notochord is inserted $(\mathrm{ch})$, which passes thronghout the long rudder-like tail to its point.

FIG. 6.-Transverse section through a larval Ascidian (Fig. 5), through the posterior part of the trunk just in front of the beginning of the tail. The section is just the same as that of the Amphioxus larva (Fig. 11, 12). Between the medullary tube $(m)$ and the intestinal tube $(d)$ lies the notochord $(c h)$; on both sides are the lateral muscles of the trunk $(r)$.

Fig. 7-13.-Germ-history of the Amphioxus.

Frg. 7.-Parent-cell (cytula) of the Amphioxus. (Cf. Fig. 1.)

Fig. 8.-An amphioxus-egg in the process of cleavage. (Cf. Fig. 2).

Fig. 9.-Blastula of the Amphioxns. (Cf. Fig. 3.)

Fig. 10.-Gastrala of the Amphioxus. (Cf. Fig. 4.)

Fig. 11.-Young larva of the Amphioxus. The notochord (ch) lies between the medullary tube $(m)$ and the intestinal tube $(d)$. The medullary tube has an opening at the anterior extremity of the body $(m a)$. 

ONTOgENy OF THE AScidiax (1-6) AND OF THE AMPHIOXUS (7-13).

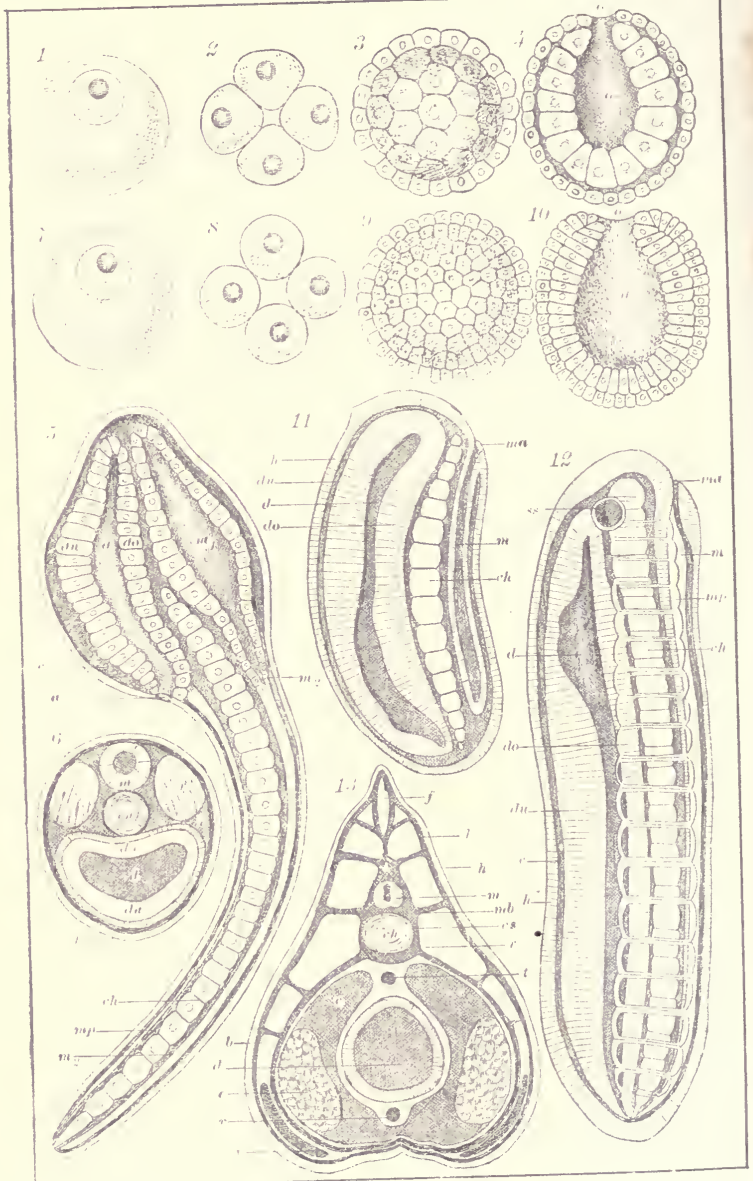


Axa Mr or he Ascidisx (14) All Aylmoxis (15).

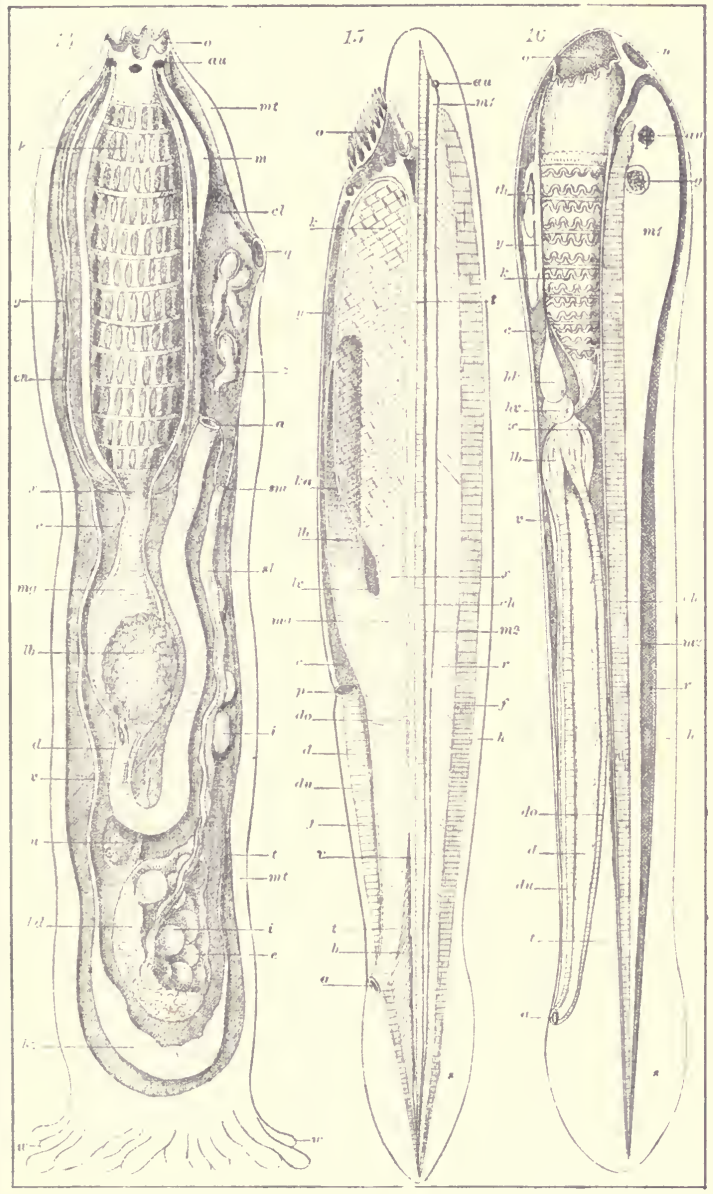



Fig. 12.-An older larva of the Amphioxus. On both sides of the mednllary tube $(\mathrm{m})$ and of the notochord $(\mathrm{ch})$ a longitudinal row of muscleplates $(m p)$ is visible; these mark the embryonic vertebræ, or metamera. An organ of sense has developed in front (ss). The wall of the intestine $(d)$ is much thicker below on the ventral side $(d u)$ than above on the dorsal side $(d o)$. The anterior part of the intestinal canal widens into the gillbody.

Fig. 13.-Transverse section through a developed Amphioxus (Fig. 15) a little behind the centre of the body. Above the intestinal tube $(d)$ is the dorsal blood-vessel, or main artery $(t)$, and below it the ventral blood-vessel, or the intestinal vein $(v)$. At the inner wall of the gill-carity $(c)$ lie the ovaries $(e)$, and outside these the side canals $(u)$. The dorsal muscles $(r)$ are divided into sereral parts by inter-muscular ligaments $(\mathrm{mb}) ; f$, dorsal fin.

Plate XI.-Strecture of the Ascidian, of the Amphioxus, ayd of the Larva oy the Petromyzon.

For the sake of comparison, all the three animals are placed in the same, position and are represented of the same size. The view is from the left side. The head extremity is turned npward, the tail downward; the dorsal side to the right, the ventral side to the left. The enveloping membrane is removed from the left side of the body, to show the inner organization with the organs in their natural position.

FIG. 14.-A simple Ascidian (Monascidia), magnified six times.

Fig. 15.-A developed Amphioxus (magnified four times).

For the sake of giving a more distinct view, the Amphioxus in Fig. 15 is drawn about twice its actual breadth. In reality, its breadth amounts to but half of the length as represented here.

Fig. 16. - Young larva of a lamprey (Petromyzon Planeri), eleven days after emerging from the egg, magnified 45 times. (After Max Schultze.) The larva of the lamprey, which nndergoes a peculiar transformation at a later period, was formerly considered as a distinct species under the name of Ammocotes.

The meaning of the letters is the same in all the figures. 


\section{ALPHABETICAL EXPLANATION}

\section{Of the Meaning of the Letters in Plates X. and XI.}

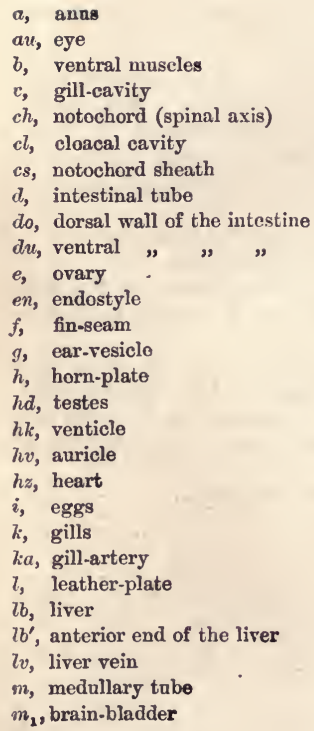

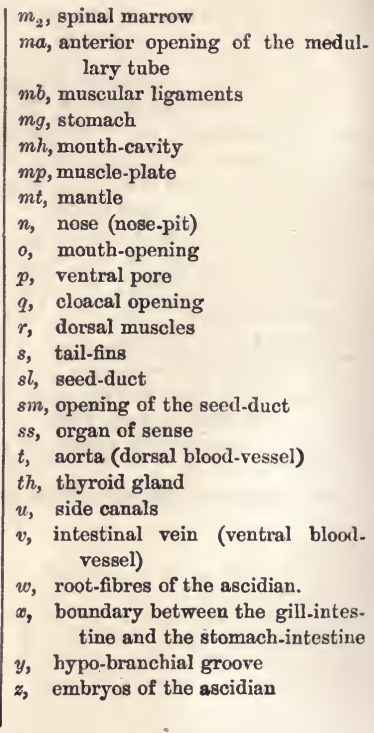




\section{CHAP'TER XIV.}

\section{GERM-HISTORY OF THE AMPHIOXUS AND OF THE ASCIDIAN.}

Relationship of the Vertebrates and Invertebrates.-Fertilization of the Amphioxus.-The Egg undergoes Total Cleavage, and changes into a Spherical Germ-membrane Vesicle (Blastula).-From this the Intestinal Larva, or Gastrula, originates by Inversion.-The Gastrala of the Amphioxus forms a Medullary Tube from a Dorsal Furrow, and between this and the Intestinal Tube, a Notochord: on both Sides the latter is a Series of Mnscle-plates; the Metamera.-Fate of the Four Secondary Germ-layers.-The Intestinal Canal divides into an Anterior Gill-intestine, and a Posterior Stomach-intestine.-Bloodvessels and an Intestinal-muscle Wall originate from the Intestinalfibrous Layer.-A Pair of Skin-folds (Gill-roofs) grow out from the Side-wall of the Body, and, by Coalescence, form the Ventral Side of the Large Gill-cavity.- The Ontogeny of the Ascidian is, at first, identical with that of the Amphioxns.-The same Gastrula is Dereloped, which forms a Notochord between the Mednllary and Intestinal Tubes. -Retrogressive Development of the same.-The Tail with the Notochord is shed.-The Ascidian attaches itself firmly, and envelopes itself in its Cellulose Tnnic.-Appendicularia, a Tunicate which remains throughout Life in the Stage of the Larval Ascidian and retains the Tail-fin with the Chorda (Chordonia).-General Comparison and Significance of the Amphioxus and the Ascidian.

"In the formation of its most important organs, the Amphioxns remains throughout life at that lowest stage of development, which all other Vertebrates pass rapidly throngh during the earliest period of their embryonic existence. We must therefore regard the Amphioxus with peculiar reverence as that animal, whioh among all existing creatures is the one alone capable 
of giving us an approximate idea of our oldest Silurian vertebrate ancestors. But the latter are descended from Worms, the nearest blood-relatives of which are the Ascidians of the present day."-The Pedigree of the Human Race (1868).

THE peculiarities in the structure of the body, which distinguish Vertebrates from Invertebrates, are so striking, that the relationship of these two main groups of the animal kingdom formerly threw great difficulties in the way of systematic classification. When, in accordance with the Theory of Descent, the relationship of the various groups of animals began to be regarded as not figurative, but as really genealogical, this question came to the front, and seemed to offer one of the greatest obstacles to the success of the theory. Even at an earlier period, when without this fundamental thought of the true genealogical connection of the relationships between the great main groups of the animal kingdom, the so-called "types" of Baer and Cuvier" were studied, investigators believed they had found, here and there among Invertebrates, points connecting these with Vertebrates; some single species of Worms, in particular, appeared to approximate in the structure of their bodies to the Vertebrates; as, for example, the oceanic Arrowworm (Sagitta). But the attempted analogy was shown, by closer investigation, to be untenable. After Darwin gave an impulse to a true tribal history of the animal kingdom, by his reform of the Theory of Descent, this very relation seemed to offer one of the greatest difficulties. When, in 1866, I attempted, in my Generelle Morphologie, to carry out the Theory of Descent in detail, and to apply it to the natural system, no part of my task demanded more care than the connection of the Vertebrates with the Invertebrates. 
But just at this time the true connection was discovered in an entirely unhoped-for and most unexpected quarter. Toward the end of the year 1866, among the treatises of the St. Petersburg academy, two works appeared by: the Russian zoologist, Kowalevsky, who had spent a long time at Naples, and had occupied himself in studying the individual evolution of some of the lower animals. A fortunate accident had led Kowalevsky to study almost simultaneously the individual evolution of the lowest Vertebrate, the Amphioxus, and that of an Invertebrate, the direct. relationship of which to the Amphioxus had not been even guessed, namely, the Ascidian. Greatly to the surprise of Darwin himself, and of all zoologists interested in that important subject, there appeared, from the very commencement of their individual development, the greatest identity in the structure of the bodies of those two wholly different animals,--between the lowest Vertebrate, the Amphioxus, on the one hand, and that misshapen lump adhering to the bottom of the sea, the Sea-squirt, or Ascidian, on the other hand. In this undeniable ontogenetic agreement, the existence of which, in an astonishing degree, can be proved, the long-sought genealogical link was, of course, directly found, according to the fundamental law of Biogeny, and that group of Invertebrates, which is most nearly allied to the Vertsbrates, was clearly recognized. There can be no longer any doubt, especially since Kupffer and several other zoologists have confirmed and continued these investigations, that of all classes of Invertebrates, the Mantle-animals (Tunicata), and of the latter, the Ascidians, are most nearly allied to the Vertebrates. We cannot say the Vertebrates are descended from the Ascidians; but we may safely assert, 
that of all Invertebrates, the Mantle-animals, and among the latter the Ascidians, are the nearest blood-relations to the primæval parent-form of Vertebrates. An extinct species of the very varied Worm tribe must be assumed as the common parent-form of both groups.

In order fully to appreciate this extraordinarily important circumstance, and especially in order to gain a secure basis for the desired genealogical tree of Vertebrates, it is indispensable to note minutely the germ-history of these two remarkable animals, and to compare the individual development of the Amphioxus stage by stage with that of the Ascidian. (Cf. Plate X., and p. 436.) We will begin with the Ontogeny of the Amphioxus (Plate X. Figs. 7-12). Kowalevsky had already spent several months in Naples with the express intention of studying the wholly unknown germ-history of the Amphioxus, before he succeeded in observing the mature eggs in the first stages of development. He says that the Lancelet begins to deposit its sexual products in the month of May, in the warm evening hours, between seven and eight o'clock. ${ }^{119}$. He noticed that at this time, the male animal first ejected a whitish fluid, the sperm, and that, somewhat later, the female, attracted by the sperm, also deposited its eggs in the water.

According to other observers the deposit of the sexual products is said to take place through the gill-pore (porus branchicalis). The eggs are simple roundish cells. They have a diameter of only $\frac{1}{10}$ of a millimetre, are, therefore, only half as large as mammalian eggs, and offer no special peculiarities (Plate X. Fig. 7). The active elementary bodies of the male seed, the pin-shaped "seed-animals," or sperm-cells, all resemble those of most other animals.

(Cf. 
Fig. 17. p. 173.) Fertilization is accomplished in this way: the moving whip-cells of the sperm approach the egg, and with their head-portion, that is, the thickened portion of the cell which encloses the nucleus, they force their way into the yelk-mass or cell-substance of the egg.

Either before or immediately after fertilization, the eggcell loses its original kernel, and appears for a time in the form of a kernel-less cytod, as a monerula. (Cf. Fig. 19, p. 179.) A new kernel soon, however, originates in the impregnated yelk; this is the parent-kernel, and the monerula thus changes into the parent-cell (cytula, Fig. 21, p. 181.) This now undergoes a regular and total cleavage, the details of which in a coral (Monoxenia) we have deseribed in detail (cf. Fig. 22). The repeated bisection of the parent-cell into $2,4,8$, $16,32,64$ cells and so on, gives rise to the globular, blackberry or mulberry-shaped body which we called the "mulberry-germ" (morula, Fig. 22, $L$ ). Fluid collects in the interior of this globular mass, composed entirely of one sort of cleavage-cells, and the result is the formation of a spherical vesicle, the wall of which is composed of a single layer of cells (Plate X. Fig. 9). We called this vesicle the membranous germ-vesicle (blastula). Its contents form a clear fluid; the wall, which consists of a single layer of cells, is the germ-membrane, or blastoderma (Fig. 22, $F, G$ ).

These processes take place so rapidly in the Amphioxus, that in from four to five hours after impregnation, that is, about midnight, the spherical blastula is complete. On one side of the latter appears a groove-like depression, by which the vesicle is turned into itself (Fig. 22, $H, \mathrm{p} .190$ ). This furrow grows constantly deeper, while the spherical form of the vesicle changes into an oval or ellipsoid shape (Fig. 155). 
At iast, the inversion is complete, so that the inner part of the wall, that which has been inverted, lies on the inside of the outer, the uninverted part. In this way an almost hemispherical hollow body is formed, the thin wall of which is composed of two layers of cells. 'The hemispherical form soon again changes into an almost spherical or oval shape, in consequence of the inner cavity becoming considerably enlarged, while its opening becomes narrower (Plate X. Fig. 10). The form which the embryo of the Amphioxus has now attained in this way is a true Gastrula or intestinal larva; is indeed a gastrula of that original and simplest form which we have already distinguished as the Bell-gastrula or Archigastrula (p. 191, Fig. 22, $I, K$ ).

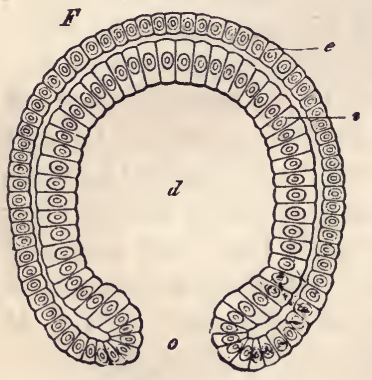

Fig. 155.-Gastrula of Amphi. oxus, in longitudinal section: $d$, primitive intestine; 0 , primitive month ; $i$, intestinal layer, or entoderm; $e$, skin-layer, or exoderm.

As in all those lowly organized animals which form a primitive Bell-gastrula of this sort, the body of the Amphioxus, which has but one axis, is merely a simple intestinal pouch; the inner cavity of this is the primitive intestine (protogaster) (Fig. 155, $d$, Fig. 156, g); its simple opening is the primitive mouth (protostoma, o). The wall is at once the intestinal wall and the body-wall. It is composed of two cell-strata, of the two well-known primary germ-layers. The inner stratum, or the inverted portion of the blastula, 
which immediately surrounds the intestinal cavity, is the entoderm, the inner or vegetative germ-layer, from which are developed the wall of the intestinal canal and all its appendages (Fig. 155, 156, $i$ ). The outer cell-stratum, the part of the blastula not inverted, is the exoderm, the outer or animal germ-layer, which furnishes the rudiment of the body-wall, the skin, the flesh, the central nervous system, etc. (e). The cells of the inner stratum, or entoderm, are considerably larger, duller, darker, and more adipose than those of the outer stratum, or exoderm, which are clearer, brighter, and less rich in fatty particles. Thus, even during the process of inversion, a differentiation takes place between the inner inverted stratum and the outer uninverted. The cells of the outer layer are soon covered with fine bright hairs; fine, short, thread-like appendages, grow from the protoplasm, which keep up a constant vibratory motion.

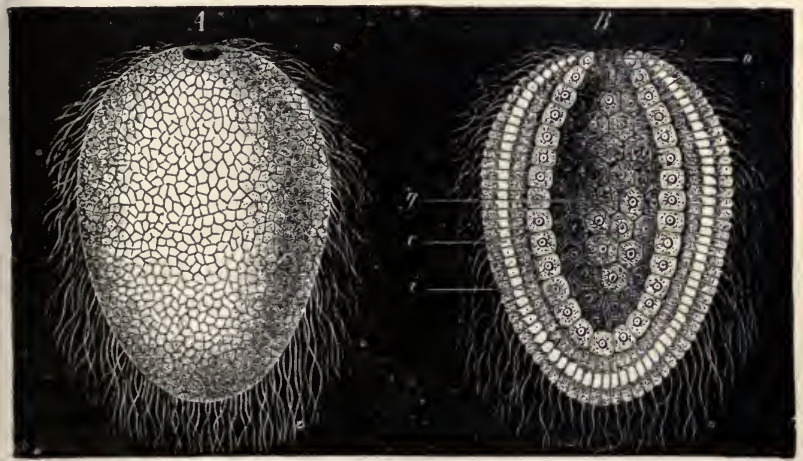

Fig. 156.-Gastrula of a Chalk-sponge (Olynthus) : $A$, from the outside ; $B$, in longitudinal section through the axis ; $g$, primitive intestine; $o$, primitive mouth; $i$, intestinal-layer, or entoderm; $e$, skin-layer, or exoderm. 
By the motions of these delicate vibratory hairs, the gastrula of the Amphioxus, like that of many other animals of low organization, after it has broken through the egg-coverings rotates and swims in the ocean (Fig. 156).

In the course of further development the roundish Bellgastrula of the Amphioxus lengthens, and at the same time it becomes rather flatter on one side parallel to the longitudinal axis. The flattened side is afterwards the dorsalside; the opposite ventral side remains roundly arched. In the middle of the dorsal surface appears a shallow longitudinal furrow or channel (Fig. 157), and on each side of this channel the surface of the body rises in the shape of two parallel ridges or longitudinal swellings. I need hardly say, that this channel is the primitive groove, or dorsal furrow, and that these swellings are the dorsal swellings or spinal swellings which form the first rudiments of the central nervous system, the medullary tube. These two swellings grow higher and higher; the groove becomes deeper and deeper. The edges of the two parallel swellings incline towards each other, and finally coalesce, and thus the medullary tube is completed (Plate X. Fig. 11, m). The formation of the medullary tube from the outer skin takcs place, therefore, on the naked dorsal surface of the independent Amphioxus larva in exactly the same way as in the embryo of Man and of other Vertebrates within the egg-envelopes. In both cases, also, the nerve-tube finally separates entirely from the horny plate. The fact is peculiar, that at that end of the body which afterwards is to be the anterior or mouth end of the Amphioxus, the medullary tube remains open at first, and has an external opening (Fig. 11, ma).

Even at the time when the first trace of the dorsal furrow 
alpears, the two primary germ-layers of the Amphioxus larva split up into the four secondary germ-layers (Fig. 157, transverse section). Round the inner vegetative layer of the intestinal tube there arises, in consequence of a fission of the cells of the latter, a second external cell-stratum, the

Fig. 157.-Tranśverse section through a larval Amphioxas (after Kowalevsky): $h s$, skin-sensory layer; $h m$, skin-fibrous layer; $c$, cœlom-fissure (rudimentary body-cavity); $d f$, intestinal-fibrous layer; $d d$, intestinal glandular layer; $a$, primitive intestine (primitive intestinal cavity). Above, the dorsal furrow is seen between the two dorsal swellings.

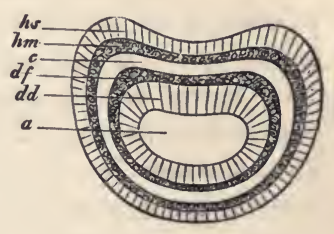

intestinal-fibrous layer $(d f)$; from this originate the muscles and the fibrous membranes of the intestinal tube, and the blood-vessels. The original inner cell-stratum must now be called the intestinal-glandular layer $(d d)$. Analogously, the outer animal germ-layer falls, in consequence of a fission in its cells, into two strata, an outer skin-sensory layer $(\mathrm{hs})$ and an inner skin-fibrous layer $(\mathrm{hm})$. The former gives rise to the outer skin (epidermis) and the medullary tube; the latter to the leather-skin (corium) and the trunk-muscles. A space forms between the skinfibrous layer and the intestinal-fibrous layer, in which a colourless liquid collects, thus forming the body-cavity (coloma, c). It is a fact of great moment for the germlayer theory that, here in the Amphioxus, the origin of the skin-fibrous layer from the animal, and that of the intestinalfibrous layer from the vegetative germ-layer is plainly demonstrable.

As soon as the four secondary germ-layers have formed 
a cylindrical cord, pointed at both ends, and composed of large, light-coloured vesicular cells, appears in the middle line of the skin-fibrous layer, directly over the intestinal tube $(d)$ and below the nerve-tube $(m$ ), (and therefore along the long axis of the body). This is the chorda dorsalis, or notochord (Plate X. Fig. 11, 12, ch). The lateral portions of the skin-fibrous layer, which lie on both sides of the notochord, and which we may in this case also call "side-layers," or "side-plates," split into two strata, a thin leather-skin (corium) and an underlying muscle-plate. The latter soon breaks up into a number of homogeneous sections, lying one behind another. These are the side muscles of the trunk, which indicate the first articulation or metameric structure of the body (Fig. 12, $m p$ ).

By these separations the gastrula of the Amphioxus has changed into a vertebrate body of the simplest form, with the characteristic disposition of the fundamental organs which belongs exclusively to Vertebrates. Directly below the skin we find, at the dorsal side of the medullary tube, on the ventral side of the intestinal tube, and between the two tubes, the firm axis of the body, the notochord; and, on either side of this, the regular series of muscle-plates. If we now look at the larva of the Amphioxus from one side (Plate X. Fig. 11, 12), we see that on the top lies the medullary tube, still open anteriorly $(m a)$; directly under this lies the strong notochord (ch), and under this the much broader intestinal tube $(d)$. The latter also has an opening at one end, the original mouth of the gastrula (o). It is, however, a very singular and important fact that this primitive mouth does not afterwards become the permanent mouth-opening of the Amphioxus. On the contrary, it soon 
closes. The future permanent mouth is formed only secondarily, from the outside, and at the opposite end of the body (near ss, Fig. 12). At this point, a groove-like depression originates in the outer skin (epidermis), and this grows inwards and breaks a way through into the closed intestine. Similarly, the anal opening forms behind (in the neighbourhood of the closed gastrula-mouth). We saw that in Man and in all higher Vertebrates mouth and anus originate as shallow grooves in the outer skin; and that these also break through inwards, thus gradually communicating with both blind ends of the intestinal tube. (Cf. p. 338.)

Between the intestinal and the nerve tubes we find the notochord as a cartilaginous cylindrical rod, traversing the entire length of the larval body. On each side of the notochord lie the muscle-plates, already broken up into a number of separate pieces, or primitive vertebral segments (10 to 20 on each side); these are separated from each other by simple oblique, parallel lines of demarcation. In the fully-formed animal each of these dividing lines describes an acute angle forwards (Plate XI. Fig. $15, r)$. The number of separate muscle-plates indicates the number of metamera of which the body consists. At first this number is small, but it afterwards increases considerably in the direction from front to rear. This is owing to that same terminal budding in virtue of which the chain of primitive vertebral segments grows in the human embryo. Here, too, the foremost metamera are the oldest, and the terminal ones the most recent. To each metameron corresponds a definite segment of the medullary tube and a pair of spinal nerves, which pass from it out to the muscles and to the skin. Of all the organic vol I. 
systems of the body, it is in the muscle-system that articulation first appears. ${ }^{120}$

While these characteristic differentiations are taking place in the two lamellæ of the animal germ-layer-while the medullary tube and the outer skin (epidermis) are separating from the skin-sensory layer, and the notochord and the muscle-plates from the skin-fibrous layer, equally important processes, characteristic of the vertebrate type, are taking place in the vegetative germ-layer. The inner lamella of this-the intestinal-glandular layer-undergoes but few modifications; it produces only the internal cellcoating, or epithelium of the intestinal tube $(d)$. But the outer lamella, the intestinal-fibrous layer, produces both the muscular covering of the intestine and the bloodvessels. Probably simultaneously, two main vessels originate from this layer: an upper, or dorsal vessel, corresponding to the aorta, situate between the intestine and the chorda dorsalis (Figs. 13, $t, 15, t$ ); and a lower, or ventral vessel, answering to the heart and the intestinal vein, on the lower edge of the intestine, and between it and the veptral skin (Figs. 13, v, 15, v). Moreover, at this time the gills, or respiratory organs, also develop in the anterior portion of the intestinal canal. The whole anterior or respiratory section of the intestine changes into a gill-body, which is pierced by numerous openings, so that it resembles a lattice-work, as in Ascidia. The cause of this is that the foremost portion of the intestinal wall adheres in places to the external skin, and that, at these points of adhesion, openings form in the wall and extend from outside into the intestine. At first these gill-openings are but very few, but soon they are numerous, appearing first in one row, 
then in two rows, one behind the other. The foremost gill-opening is the oldest. Finally, a lattice-work of fine gill-openings appears on each side.

We must call special attention to the fact that at first, in the embryo of the Amphioxus, as in that of all other Vertebrates, the side wall of the neck is perforated in such a way by openings, that there is an open passage through the latter from the external skin into the anterior intestine (Fig. 158, $K$ ). The inhaled water, which is taken in to the gill-intestine through the mouth, passes out directly through the gill-openings. While the number of these gill-openings is increasing very rapidly, over the upper row of these a longitudinal fold rises, on each side, on the side-wall of the body (Fig. 159, $U$ ). The narrow body-cavity prolongs itself in these longitudinal folds $(L h)$. Both side-folds grow downward and hang as free gill-roofs. The free edges of these then incline towards each other and coalesce in the middle line of the ventral side, thus forming the ventral seam or Raphe (Fig. 160, $R$ ). The gill-pore alone remains open (Fig 15, $p$ ). Thus originates a closed gill-cavity answering exactly to that of Fishes, and at the same time identical with that of the Ascidians. The gill-cavity of the Ascidian, the Amphioxus, the Fishes, and the larval Amphibia, are to be regarded as homologous parts. This large gill-cavity, filled with water and communicating freely with the surrounding water, must be distinguished from the small body-cavity, filled with lymph and without any external communication. The latter, the coloma (Figs. 158-160, $L h$ ), in the adult Amphioxus is very narrow and very small in size (Fig. 152, Lh). When the gill-cavity of the Amphioxus is complete, the respiratory water, 

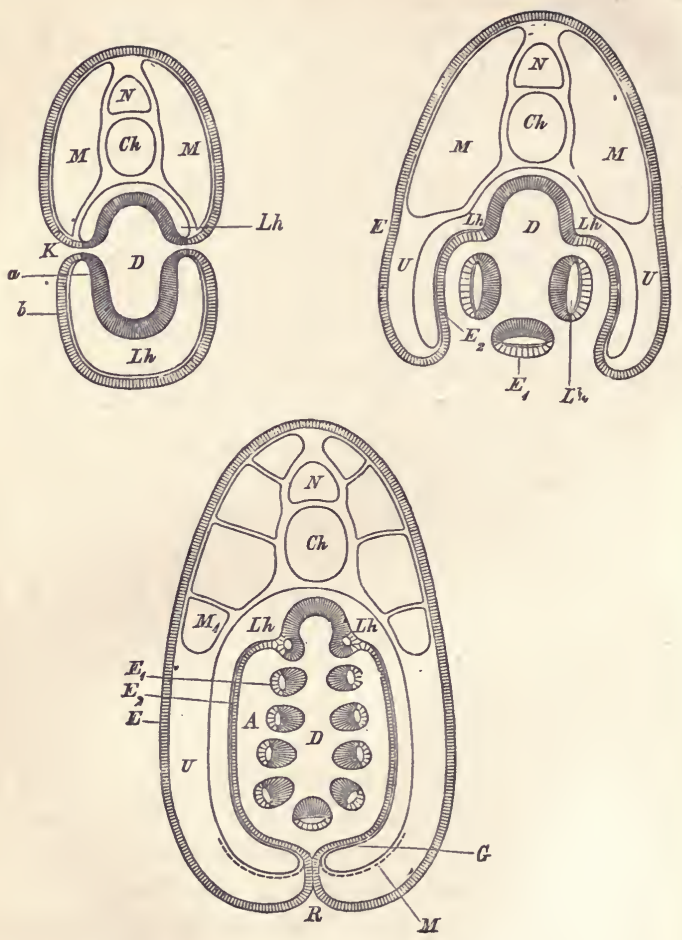

Figs, 158-160.-Transverse section through an early larval form of Amphioxus. (Diagrammatic, after Rolph.) (Cf. Fig. 152, p. 424.) In Fig. 158 there is a free passage from without into the intestinal cavity $(D)$, through the gill-openings $(K)$. In Fig. 159 the lateral longitadinal folds of the body-wall, the gill-roof, are forming, growing downwards. In Fig. 160 these side-folds have grown towards each other and their edges have 
coalesced in the middle line of the ventral side $(R)$. The respiratory water now passes from the intestinal cavity $(D)$ into the gill-cavity $(A)$. In all, the letters indicate the same parts: $N$, medullary tube; $C h$, notochord; $M$, side-muscles; $L h$, body-cavity; $G$, portion of the body-cavity in which the sexual organs afterwards form; $D$, intestinal cavity lined by the intestinal-glandular layer (a); $A$, gill-cavity ; $K$, gill-openings ; $b=E$, onter skin, or epidermis ; $E_{1}$, the same as the inner epithelium of the gill-cavity; $E_{2}$, the same as the outer epithelium of the gill-cavity.

which was taken in at the mouth, passes out, no longer directly through the gill-openings, but through the gill-pore (p. branchialis). That portion of the intestinal canal which is situated behind the gill-body becomes the stomachintestine, and forms on the right side a single purse-like protrusion, which becomes a blind liver-sac. This digestive portion of the intestinal canal is enclosed in the narrow body-cavity.

In an early stage of individual development, the structure of the body of the Amphioxus larva still corresponds essentially with our ideal "Primitive Vertebrate." The body afterwards, however, undergoes various modifications, especially in the anterior portion. These modifications are uninteresting to us at present, because they depend on special conditions of Adaptation, nor have they anything to do with the hereditary vertebrate type. Of the remaining portions of the body of the Amphioxus, we need only remark that the germ-glands, or internal sexual organs, do not develop till later, and, as it appears, directly from the inner cell-coat of the body-cavity, from the colomepithelium. Although no extension of the body-cavity is afterwards discernible in the side walls of the gill-cavity, in the gill-roofs (Fig. 152), yet such an extension does at first exist (Fig. 159, 160, Lh). In the lowest part of this 
extension, the sexual glands originate from a portion of the cœlom-epithelium (Fig. 160, G). In other respects, the farther modification of the larva into the adult form of the Amphioxus is so simple that we need not now follow it. ${ }^{121}$

We will now turn to the history of the development of the Ascidian, an animal apparently so much lower and so far simpler in its organization, which spends the greater part of its life as an unshapely mass, adhering to the bottom of the sea. It was most fortunate that Kowalevsky in his researches first fell in with those larger Ascidian forms which most clearly testify to the kinship between Vertebrates and Invertebrates, and of which the larvæ, in the first stages of development, are exactly similar to those of the Amphioxus. This agreement in all the essential characters is so great that it is really only necessary to repeat word for word what has already been said about the Ontogeny of the Amphioxus.

The egg of the larger Ascidia (Phallusia, Cynthia, etc.) is a simple globular cell $\frac{\mathrm{T}}{10}$ to $\frac{\mathrm{T}}{5} \mathrm{~mm}$. in diameter. In the cloudy, finely granular yelk a bright, globular germ-vesicle (nucleus) about $\frac{\mathrm{T}}{50} \mathrm{~mm}$. in diameter is seen, enclosing a germ-spot (nucleolus). (Fig. 1, Plate X.) Within the envelope, which surrounds the egg, the parent-cell of the Ascidian, after fertilization, passes through exactly the same changes as the cytula of the Amphioxus. The special incidents in the fertilization and egg-cleavage of the largest and most interesting of our Ascidians (Phallusia mammilata) have lately been very accurately studied and described by Edward Strasburger. The remarkable details of these processes, which do not, however, touch our present purpose, are given in the excellent work by that writer 
on "Zellbildung." ${ }^{22}$ Here, as in the Amphioxus, the germvesicle (nucleus) of the egg-cell disappears in great measure even before fertilization, while, after the latter process is accomplished, the monerula, in consequence of the re-formation of a kernel, becomes a cytula. This breaks up by primordial cleavage into $2,4,8,16,32$ cells, and so on. By continued total cleavage the morula forms the mulberry-like heap of like cells. Within this a liquid accumulates, and thus a globular germ-membrane vesicle is once more formed, the wall of which consists of a single cell-stratum, the blastoderm (Plate X. Fig. 3), just as in the case of the Amphioxus a true Gastrula, a simple Bell-gastrula (Plate X. Fig. 4), is formed from this blastula by inversion.

Up to this point in the evolution of the Ascidian there is no definite ground for assuming its near relationship to the Vertebrates; for a similar Gastrula arises in the same way in the most diverse animals of other tribes also. Now, however, comes an evolutionary process which is peculiar to Vertebrates, and which absolutely demonstrates the kinship of the Ascidia and the Vertebrates. From the outer skin (epidermis) of the Gastrula originates a medullary tube, and, between this and the primitive intestine, a notochord -organs which otherwise occur only in Vertebrates, and are peculiar to them. The formation of this highly important organ takes place in the Gastrula of the Ascidian exactly as in that of the Amphioxus. In the Ascidian also, the oblong-round or oval Gastrula-body, which has but a single axis, becomes flat on one side, on the future dorsal side. Along the central line of this flat side, a furrow or trench forms, the medullary furrow, and on either side of this two parallel ridges or swellings arise from the skin- 
layer. These two medullary swellings coalesce over the furrow, thus forming a tube; in this case also, this nerve tube or medullary tube is originally open in front, but closed behind. Again, in the Ascidian larva also, the permanent mouth-opening is a new formation, and does not originate from the primitive mouth of the Gastrula; the latter closes, and in its neighbourhood the future anal opening is formed by inversion from the outside, at the opposite end from the opening of the medullary tube (Plate $\mathrm{X}$. Fig. 5, a).

While these important changes are taking place, exactly in the same way as in the Amphioxus, a tail-like appendage grows out from the posterior end of the larval body, and the larva curls itself within the spherical egg-covering in such a way that its dorsal side projects, while the tail is bent back upon the ventral side. In this tail now develops a cylindrical cord, composed of cells, the anterior end of which extends into the body of the larva between the intestinal and the medullary tubes: this is the chorda dorsalis, an organ which, except in this one case, is found only in Vertebrates, and of which no other trace is to be seen in Invertebrates. Here, again, the notochord consists, at first, of a single row of large bright cells (Plate X. Fig. $5, c h$ ); afterwards it consists of several cell-rows. So, too, in the Ascidian larva, the notochord develops from the middle portion of a cell-stratum, the side portions of which become tail-muscles, and which can, therefore, only be the skinfibrous layer. At the same time, a cell-stratum splits off from the intestinal wall, which afterwards forms the heart, the blood and the vascular system, and also the intestinal muscles. This is the intestinal-fibrous layer. 
On making a section through the middle of the body in this stage (at the point where the tail joins the trunk), we find in the Ascidian larva precisely the same characteristic disposition of the chief organs as in the larva of the Amphioxus (Plate X. Fig. 6). In the middle, between the medullary tube and the intestinal tube, is the chorda dorsalis; and on each side of the latter, the muscle-plates of the back. The section of the Ascidian larva now differs in no essential way from that of our ideal Vertebrate (Fig. 161).

When it has reached this stage of development, the Ascidian larva begins to move within the egg-covering. This ruptures the egg-covering; the larva emerges from the latter, and swims freely about in the sea by means of its rudder-like tail (Plate X. Fig. 5). These free-swimming Ascidian larva have long been known to science. They were first observed by Darwin during his voyage round the world in 1833. In external form they resemble the larva of the frog, the tadpole, and they move about in the water

Fig. 161.-Transverse section through ideal Primitive Vertebrate (Fig. 52). The section passes through the sagittal axis and the cross axis : $n$, medullary tube; $x$, notochord; $t$, dorsal vessel; $v$, ventral vessel; $a$, intestine; $c$, body. cavity; $m_{1}$, dorsal muscles; $m_{2}$, ventral muscles; $h$, outer skin.

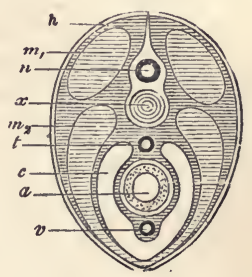

like the latter, using their tail as a rudder. This highly developed youthful condition of free movement lasts, however, only for a short time. A further progressive develop- 
ment yet occurs; two small sense-organs make their appearance in the foremost part of the medullary tube: of these the one is, according to Kowalevsky, an eye, the other an organ of hearing of the simplest structure. A heart also develops on the ventral side of the animal, on the lower wall of the intestine; and this is of the same simple form, and is situated in the same place as the heart in Man and all other Vertebrates. In the lower muscle-wall of the intestine a wart-like growth makes its appearance-a solid spindle-shaped cord of cell,-the interior of which soon becomes hollow: it begins to move by contracting in opposite directions, now backwards, and then again forwards, as in the full-grown Ascidian. In this way the blood-fluid, collected in the hollow muscular pouch, is driven in alternate directions into the blood-vessels, which develop at both ends of this tubular heart. A main vessel traverses the dorsal side of the intestine, another its ventral side; the former represents the aorta (Fig. 161, $t$ ) and the dorsal vessel of Worms. The latter represents the intestinal vein (Fig. $161, v)$ and ventral vessel of Worms.

When these organs are complete, the progressive Ontogeny of the Ascidian is at an end, and retrogression now commences. The freely-swimming Ascidian larva sinks to the bottom of the sea, relinquishes its power of free locomotion, and becomes fixed. By means of that very part of its body which was foremost in locomotion, it adheres to stones, marine plants, shells, corals, and other objects at the bottom of the sea. To secure it to these, several excrescences are employed, usually three wart-like bodies, which may be observed on the larva, even while it yet swims. The tail, which is of no further use, is now lost. 
It undergoes fatty degeneration, and is cast off together with the entire notochord. The tail-less body becomes a shapeless bag, or sac, which, by retrograde metamorphosis of its separate parts and by re-formation and modification, gradually acquires that remarkable structure which has already been described.

Fig. 162.-Appendicularia (Copelata), seen from the left side: $m$, mouth; $k$, gillintestine; 0 , œsophagus; $v$, stomach; $a$, anus; $n$, brain (upper throat ganglion); $g$, ear-vesicle; $f$, groove under the gill; $h$, heart; $t$, testes ; $e$, ovary ; $c$, notochord; s, tail.

Among the extant Mantle Animals (Tunicata) there is, however, an interesting group of small animals which retain throughout life the tailed, independent ascidian larval stage ot development, and which, by means of their permanent, broad, rudder-like tails, move actively about in the sea. These are the remarkable Appendicularice (Fig. 162). They are the only extant Invertebrates permanently possessing a notochord, and are, therefore, the nearest allies of the extinct Chorda Animals (Chordonia), of the primæval

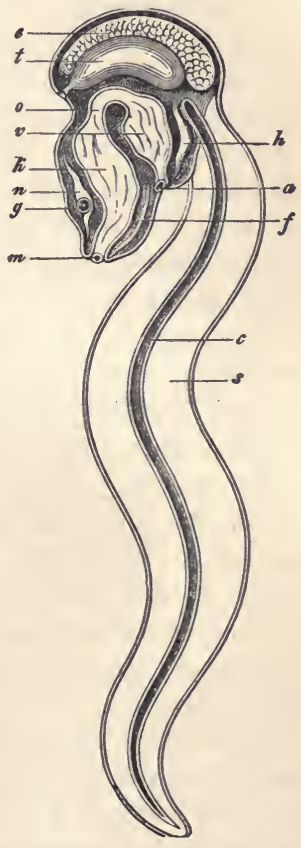
Worms which must be regarded as the common parent-form. 
of Mantle Animals (Tunicata) and of Vertebrates. The notochord of the Appendicularia is a long cylindrical cord (Fig. 162,c), which serves to connect the muscles which move the flat, rudder-like tail.

Among the various retrogressions which are undergone by the Ascidian larva after it has attached itself, the degeneration of one of the most important parts of the body, the medullary tube, is, next to the loss of the notochord, of peculiar interest. While in the Amphioxus the medulla steadily develops, that of the Ascidian larva soon shrinks to the proportions of a small, insignificant nerve ganglion, which lies over the mouth-opening, above the gill-body, and which represents the exceedingly low mental endowments of this animal (Plate XI. Fig. 14, $m$ ). This insignificant remnant of the medullary tube seems to retain no likeness to the medulla of Vertebrates, although it originated from the same rudiment as the medulla of the Amphioxus. The sense-organs, which had developed in the anterior end of the nerve-tube, are also lost; in the fullgrown Ascidian there is no trace of them. On the other hand, the intestinal canal now develops into a very capacious organ. This soon breaks up into two separate parts-a wide anterior gill-intestine for respiration, and a narrow posterior stomach-intestine for digestion. In the former the gill-openings form in exactly the same way as in the Amphioxus. At first the number of gill-openings is very small; it afterwards, however, increases considerably, and gives rise to a large, lattice-like perforated gill-body. The "hypobranchial groove" originates in the central line of the ventral side of this gill-body. The wide gill-cavity, which surrounds the gill-body, also develops in the Ascidian 
just as in the Amphioxus. The excretory opening of the former corresponds fully to the abdominal pore of the latter. In the adult Ascidian the gill-intestine and the heart resting on the ventral side of the latter, are almost the only organs that recall the original relationship to Vertebrates.

In conclusion we will glance at the development of the curious external gelatinous mantle, or cellulose sac, in which the Ascidian is afterwards entirely enclosed, and which characterizes the whole class of Mantle Animals (Tunicata). Very various and remarkable views have been entertained as to the formation of this mantle. For instance, it was the opinion of Kowalevsky, that the animal does not itself form the mantle, but that the latter is produced by special cells from the maternal body, which surround the egg. According to this the mantle would be a permanent egg-envelope. This is contrary to all analogy, and $a$ priori highly improbable. Another naturalist, Kupffer, who has confirmed and extended the researches of the former, assumed that the mantle develops from cells which, even before the impregnation of the egg-cell, form from the outer portion of the yelk, and separate entirely from the inner portion. This seems very doubtful and unlikely. Hertwig's researches, which are confirmed by my own observations, first showed that the mantle develops as a so-called "cuticula." It is an exudation from epidermic cells, which soon hardens, separates from the real body of the Ascidian, and condenses so as to form a strong envelope round the latter. The matter of these cells is chemically indistinguishable from the cellulose of plants. While the epidermic cells of the external horn-plate are secreting this mass of cellulose, some of them drop into it, continue to 
live in the exuded mass, and aid in constructing the mantle. In this way the strong external covering is at length formed, grows thicker and thicker, and in many adult Ascidia constitutes upwards of two-thirds of the entire mass of the body. ${ }^{123}$

The farther development of the individual Ascidian is of no special interest to us, and we will therefore not continue to trace it. The most important result, supplied by Ontogenesis, is its perfect agreement with that of the Amphioxus in the earliest and most important stages of its germhistory. It is only after the medullary and intestinal tubes, and, between these, the notochord with its muscles, have been formed, that their development takes different directions. The Amphioxus pursues a steadily progressive course of development, till it entirely resembles the parent-forms of the higher Vertebrates, while the Ascidian, on the contrary, enters on a course of retrograde metamorphosis, and finally, in the developed state, appears as a very imperfect nember of the Worm group.

Those who again review all the remarkable facts which we have found both in the structure and in the germhistory of the Amphioxus and Ascidian, and who then compare these with the previously ascertained facts of human germ-history, will not think that I have ascribed exaggerated importance to these highly interesting animal forms. For it is now evident that the Amphioxus as the representative of Vertebrates, and the Ascidian as the representative of Invertebrates, form the bridge which alone can span the deep gulf between these two main divisions of the animal kingdom. The fundamental agreement exhibited by the Lancelet and the Ascidian in the first and the most 
important points of their embryonic development does not only testify their close anatomical form-relationship and their connection in the system; it also testifies their true blood-relationship and their common origin from one and the same parent form; and hence it at the same time throws a flood of light upon the earliest origin of human genealogy. ${ }^{124}$

Writing in 1868 " on the origin and genealogy of the human race," I insisted upon the extraordinary importance of this circumstance, and declared that we must accordingly "regard the Amphioxus with special veneration as that animal which alone of all extant animals can enable us to form an approximate conception of our earliest Silurian vertebrate ancestors." This proposition has given very great offence, not only to unscientific theologians, but also to many others, especially such philosophers as still cherish the anthropocentric error, and who look on man as the foreordained object of "creation," and as the true final cause of all terrestrial life. The "dignity of humanity," it was said in a church newspaper, is, by such a statement as mine, "trodden underfoot, and the divine rational conscience of man grievously hurt."

This indignation at my honest and deep respect for the Amphioxus is, I am free to confess, quite incomprehensible to me. If, on entering a grove of ancient oaks, we express reverence for these venerable trees, the life of which has endured a thousand years, no one thinks this unnatural Yet how high above the oak does the Amphioxus, or even the Ascidian organization, stand in this respect! And what are the thousand years of life of a venerable oak compared with the many millions of years the history of which is told 
by the Amphioxus! But apart from all this, the Amphioxus (skull-less, brainless, and memberless as it is) deserves all respect as being of our own flesh and blood! At any rate, the Amphioxus has better right to be an object of profoundest admiration and of devoutest reverence, than any one in that worthless rabble of so-called "saints" in whose honour our "civilized and enlightened" cultured nations erect temples and decree processions.

The infinite importance of the Amphioxus and the Ascidian as explaining the development of Man, and consequently his true nature, may be clearly seen from the following summaries, in which I have stated the principal homologies of the highest and of the lowest Vertebrates (Table IX.). The table exhibits the undeniable fact that the human embryo at an early period of its development agrees in the most essential points of its organization with the Amphioxus and with the embryo of the Ascidian, while, on the other hand, it differs radically from the developed Man. It is, however, equally important that we should remember the profound gulf which separates the Amphioxus from all other Vertebrates. Even yet the Lancelet is represented in all textbooks of Zoology as a member of the Fish class. When (in 1866) I totally separated the Amphioxus from the Fishes, and divided the entire vertebrate tribe into two chief groups, the Skull-less Animals (Amphioxus) and the Skulled Animals (all other Vertebrates), my classification was regarded as a useless and unfounded innovation. ${ }^{115}$ How the matter stands is best seen in the appended table (Table X). In all essential points, Fishes are more nearly allied to Man than to the Amphioxus. 


\section{$(465)$}

\section{TAB LE IX.}

Systematic Surrey of the most important homologies between the haman embryo, the embryo of the Ascidian, and developed Amphioxus on the one hand, and on the other hand, the developed Man.

\begin{tabular}{c|c|c|c}
\hline $\begin{array}{c}\text { Embryo of } \\
\text { Ascidian. }\end{array}$ & $\begin{array}{c}\text { Developed } \\
\text { Amphioxus. }\end{array}$ & $\begin{array}{c}\text { Human } \\
\text { Embryo. }\end{array}$ & $\begin{array}{c}\text { Developed } \\
\text { Man. }\end{array}$ \\
\hline
\end{tabular}

I.-Products of the Differentiation of the Skin-layer.

\begin{tabular}{|c|c|c|c|}
\hline Naked outer skin & Naked outer skin & Naked outer skin & Hairy outer skin \\
\hline $\begin{array}{c}\text { Simple medullary } \\
\text { tube }\end{array}$ & $\begin{array}{l}\text { Simple medullary } \\
\text { tube }\end{array}$ & $\begin{array}{c}\text { Simple medullary } \\
\text { tube }\end{array}$ & $\begin{array}{l}\text { Brain and spinal } \\
\text { marrow }\end{array}$ \\
\hline $\begin{array}{r}\text { Primitivekidney(?) } \\
\text { (excretory canal?) }\end{array}$ & Primitive kidney(?) & $\begin{array}{l}\text { Primitive kidney } \\
\text { duct }\end{array}$ & $\begin{array}{l}\text { Oviduct and } \\
\text { sperm-duct }\end{array}$ \\
\hline $\begin{array}{l}\text { Simple thin leather } \\
\text { skin (Corium) }\end{array}$ & $\begin{array}{l}\text { Simplethin leather } \\
\text { skin (Corium) }\end{array}$ & $\begin{array}{l}\text { Simplethinleather } \\
\text { skin (Corium) }\end{array}$ & $\begin{array}{l}\text { Differentiated } \\
\text { thickleather skin } \\
\text { (Corium) }\end{array}$ \\
\hline $\begin{array}{l}\text { Simple skin-mus } \\
\text { cular ponch }\end{array}$ & $\begin{array}{l}\text { Simple trank- } \\
\text { muscle system }\end{array}$ & $\begin{array}{l}\text { Simple muscle- } \\
\text { plate }\end{array}$ & $\begin{array}{l}\text { Differentiated } \\
\text { trunk-muscle } \\
\text { system }\end{array}$ \\
\hline Noto & Notochord & Notochor & Vertebral column \\
\hline No skull & No skull & No skull & Bony skull \\
\hline No limbs & No limbs & No limbs & Two pair of limbs \\
\hline $\begin{array}{l}\text { Hermaphrodite } \\
\text { sexual glands }\end{array}$ & $\begin{array}{l}\text { Separated sexual } \\
\text { glands }\end{array}$ & $\begin{array}{l}\text { Hermaphrodite } \\
\text { sexual glands }\end{array}$ & $\begin{array}{c}\text { Separated sexual } \\
\text { glands }\end{array}$ \\
\hline
\end{tabular}

II.-Products of the Differentiation of the Intestinal layers.

Simple body cavity (Coeloma)

One-chambered heart

Dorsal vessel

Simple liver pouch (?)

Simple intestinal tube with gillopenings
Simplebody cavity (Ćcloma)

Simple tubalar heart Aorta

Simple liver pouch

Simple intestinal tube with gillopenings
Simple body cavity (Cceloma)

One-chambered heart

Aorta

Simple liver pouch

Simple intestinal tube with gillopenings
Distinct chest and ventral cavities Four-chambered heart Aorta

Large differentiated liver

Differentiated in. testinal tube without gill. openings 


\section{T A B L E X.}

Systematic Survey of the points of connection in form of the Ascidian and Amphioxus on the one side, and the Fishes and Men on the other, in completely developed conditions.

\begin{tabular}{|c|c|c|c|}
\hline $\begin{array}{l}\text { Developed } \\
\text { Ascidian. }\end{array}$ & $\begin{array}{l}\text { Developed } \\
\text { Amphioxus. }\end{array}$ & $\begin{array}{l}\text { Developed } \\
\text { Fish. }\end{array}$ & $\begin{array}{l}\text { Developed } \\
\text { Man. }\end{array}$ \\
\hline $\begin{array}{l}\text { Head and trunk } \\
\text { not distinct }\end{array}$ & $\begin{array}{l}\text { Head and trunk } \\
\text { not distinct }\end{array}$ & $\begin{array}{l}\text { Head and trunk } \\
\text { distinct }\end{array}$ & Head and trunk \\
\hline No limbs & No limbs & Two pair of limbs & Two pair of limbs \\
\hline No skull & No skull & Developed skull & Developed skull \\
\hline No tongue-bone & No tongue-bone & Tongue-bone & Tongue-bone \\
\hline No jaw-ap? & No jaw-apparatus & $\begin{array}{l}\text { Jaw-apparatus } \\
\text { (upper and } \\
\text { lower jaws) }\end{array}$ & $\begin{array}{l}\text { Jaw-apparatus } \\
\text { (npper and } \\
\text { lower jaws) }\end{array}$ \\
\hline $\begin{array}{l}\text { No vertebral } \\
\text { colnmn }\end{array}$ & $\begin{array}{l}\text { No vertebral } \\
\text { column }\end{array}$ & $\begin{array}{l}\text { Articulated verte- } \\
\text { bral column }\end{array}$ & $\begin{array}{l}\text { Articulated verte. } \\
\text { bral colnmn }\end{array}$ \\
\hline No ribs & No ribs & Ribs & Ribs \\
\hline $\begin{array}{l}\text { Brain undifferen- } \\
\text { tiated }\end{array}$ & $\begin{array}{l}\text { Brain undifferen- } \\
\text { tiated }\end{array}$ & $\begin{array}{l}\text { Brain differen. } \\
\text { tiated }\end{array}$ & $\begin{array}{l}\text { Brain differen- } \\
\text { tiated }\end{array}$ \\
\hline Eyes rudimentaxy & Eyes rudimentary & Eyes dereloped & Eyes developed \\
\hline No ear. & No ear-organ & $\begin{array}{l}\text { Ear - organ with } \\
\text { three semicir- } \\
\text { cular canals }\end{array}$ & $\begin{array}{l}\text { Ear-organ with } \\
\text { three semicir- } \\
\text { cular canals }\end{array}$ \\
\hline $\begin{array}{l}\text { No sympathetic } \\
\text { nerve }\end{array}$ & $\begin{array}{l}\text { No sympathetic } \\
\text { nerve }\end{array}$ & $\begin{array}{l}\text { Sympathetic } \\
\text { nerve }\end{array}$ & $\begin{array}{l}\text { Sympathetic } \\
\text { nerve }\end{array}$ \\
\hline $\begin{array}{l}\text { Intestinal epithe- } \\
\text { lium ciliated }\end{array}$ & $\begin{array}{l}\text { Intestinal epithe- } \\
\text { lium ciliated }\end{array}$ & $\begin{array}{l}\text { Intestinal epithe- } \\
\text { linm not ciliated }\end{array}$ & $\begin{array}{l}\text { Intestinal epithe. } \\
\text { linm not ciliated }\end{array}$ \\
\hline $\begin{array}{l}\text { Simple liver (or } \\
\text { none) }\end{array}$ & $\begin{array}{c}\text { Simple liver (blind } \\
\text { intestine) }\end{array}$ & $\begin{array}{l}\text { Compound liver } \\
\text { gland }\end{array}$ & $\begin{array}{l}\text { Compound liver } \\
\text { gland }\end{array}$ \\
\hline $\begin{array}{l}\text { No ventral sali- } \\
\text { vary gland }\end{array}$ & $\begin{array}{l}\text { No ventral sali- } \\
\text { vary gland }\end{array}$ & $\begin{array}{l}\text { Ventral salivary } \\
\text { gland }\end{array}$ & $\begin{array}{l}\text { Ventral salivary } \\
\text { gland }\end{array}$ \\
\hline $\begin{array}{l}\text { No ewimming } \\
\text { bladder }\end{array}$ & $\begin{array}{l}\text { No swimming } \\
\text { bladder }\end{array}$ & $\begin{array}{l}\text { Swimming blad- } \\
\text { der (rudimen- } \\
\text { tary lungs) }\end{array}$ & $\begin{array}{l}\text { Lungs (swimming } \\
\text { bladder) }\end{array}$ \\
\hline $\begin{array}{l}\text { Kidneys radimen- } \\
\text { tary (?) }\end{array}$ & $\begin{array}{l}\text { Kidneys radimen- } \\
\operatorname{tary}(?)\end{array}$ & $\begin{array}{l}\text { Kidneys deve- } \\
\text { loped }\end{array}$ & $\begin{array}{l}\text { Kidneys deve. } \\
\text { loped }\end{array}$ \\
\hline $\begin{array}{l}\text { Simple heart } \\
\text { ponch }\end{array}$ & $\underset{\text { heart }}{\text { Simple tubular }}$ & $\begin{array}{c}\text { Heart with valves } \\
\text { and chambers }\end{array}$ & $\begin{array}{c}\text { Heart with valves } \\
\text { and chambers }\end{array}$ \\
\hline Blood colourless & Blood colourless & Blood red & Blood red \\
\hline No spleen & No spleen & Spleen & Spleen \\
\hline $\begin{array}{l}\text { Hypobranchial } \\
\text { groove on gill. } \\
\text { body }\end{array}$ & $\begin{array}{l}\text { Hypobranchial } \\
\text { groove on gill. } \\
\text { body }\end{array}$ & Thyroid gland & Thyroid gland \\
\hline
\end{tabular}




\section{$(467)$}

\section{TABLE XI.}

Systematic Survey showing the derivation of the germ-layers of the Amphioxus from the parent-cell (cytula), and of the main organs from the germ-layers.

(Tree showing the ontogenetic descent of the cells in the Amphioxus).125

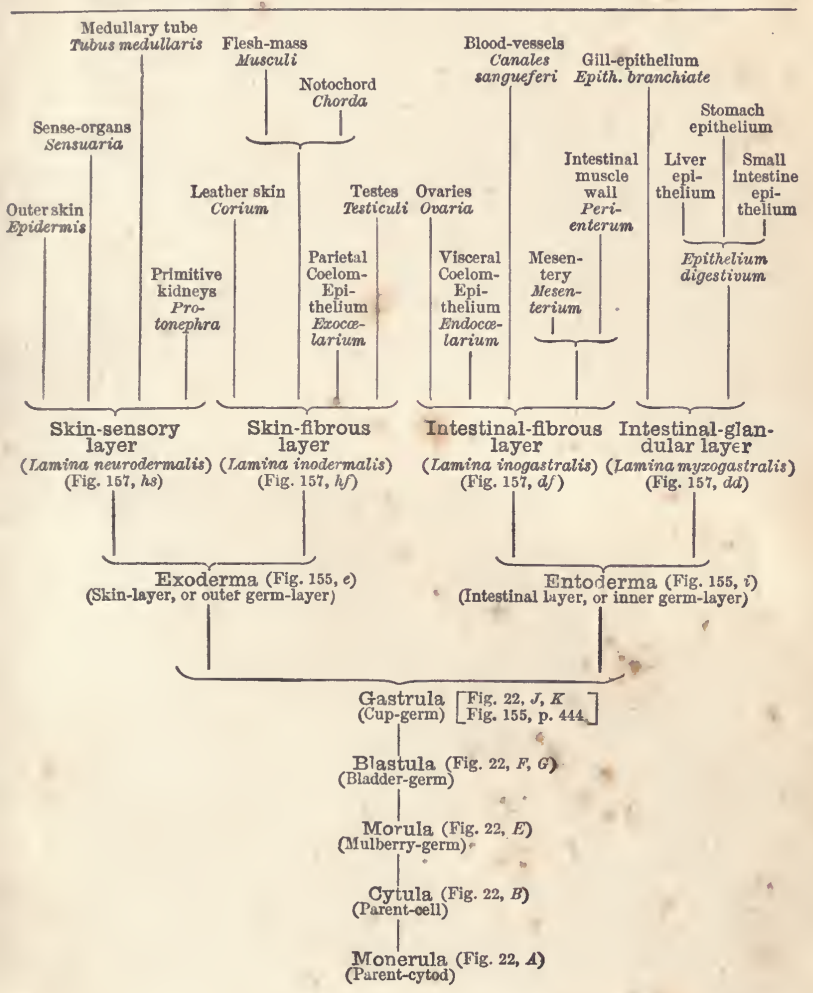


PRINTED BY WILLIAM CLOWES AND SONS, LIMITED。 LONDON AND BECCLES.
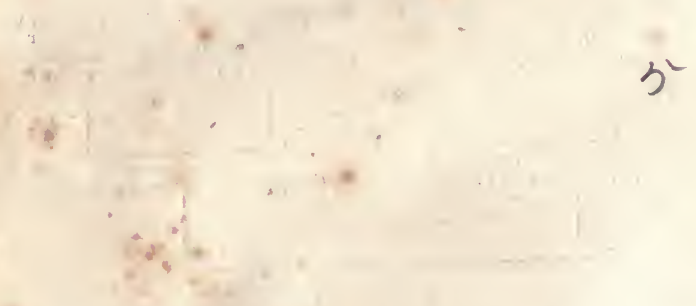


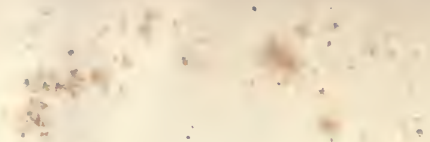

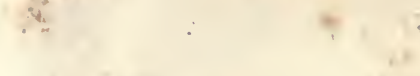

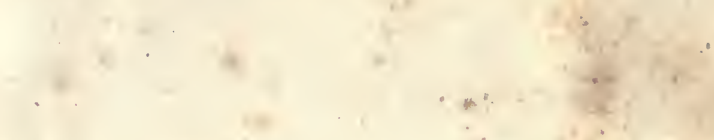

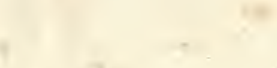

$$
\begin{aligned}
& 4 \\
& \because+2+ \\
& \text { A }
\end{aligned}
$$

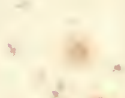

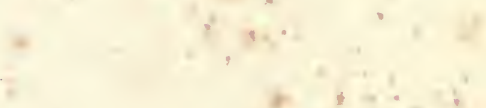

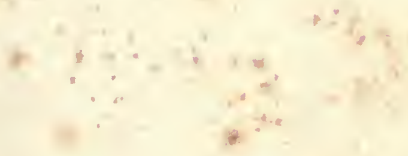

$$
\begin{aligned}
& =9 . \\
& y^{2}+0^{2} \\
& x+w^{2}+t^{2} \text {. }
\end{aligned}
$$




\section{QH 368 H21 1883 v.1}

THE LIBRARY

UNIVERSITY OF CALIFORNIA Santa Barbara

THIS BOOK IS DUE ON THE LAST DATE STAMPED BELOW. 


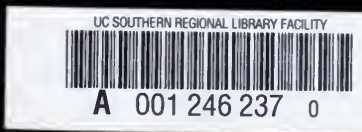



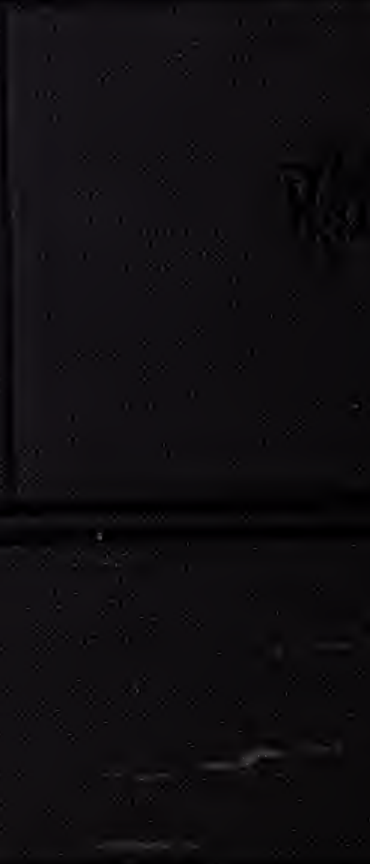